\title{
O TÉCNICO-CIENTÍFICO E O SOCIOPOLÍTICO NA GESTÃO DA ÁGUA URBANA: DRENAGEM E MANEJO DE ÁGUAS PLUVIAIS NO MUNICÍPIO DE SÃO PAULO.
}

Tese apresentada ao Programa de PósGraduação em Ciência Ambiental (PROCAM) / IEE da Universidade de São Paulo para a obtenção do título de Doutor em Ciência Ambiental.

Orientadora: Prof ${ }^{\mathrm{a}}$. $\mathrm{D}^{\mathrm{ra}}$. Monica Ferreira do Amaral Porto.

\begin{abstract}
ANEXOS
VOLUME II

Versão Corrigida

(disponível na Biblioteca do Instituto de Energia e Ambiente / USP e na Biblioteca

Digital de Teses e Dissertações da USP)
\end{abstract}

\section{SÃO PAULO}





\section{SUMÁRIO}

ANEXO 1 - INDICADORES

ANEXO 2 - QUETIONÁRIO ENVIADO A GESTORES E DEMAIS PROFISSIONAIS. .9

ANEXO 3 - QUESTIONÁRIO APLICADO NA ÁREA DA BACIA HIDROGRÁFICA DO CÓRREGO DO CORDEIRO; LOCAL E DATA DAS ENTREVISTAS REALIZADAS E AGRUPAMENTO PARA FINS DE ANÁLISE ESTATÍSTICA.

ANEXO 4 - ANÁLISE DO DISCURSO DO SUJEITO COLETIVO - RESULTADOS QUANTITATIVOS

ANEXO 5 - GESTORES E DEMAIS PROFISSIOINAIS RESULTADOS CHI-QUADRADO GRAUS DE LIBERDADE E P-VALOR

ANEXO 6 - GESTORES E DEMAIS PROFISSIONAIS, TESTES ESTATÍSTICOS .27

ANEXO 7 - GESTORES E DEMAIS PROFISSIONAIS: TENDÊNCIAS .

ANEXO 8 - MORADORES E COMERCIANTES : CONJUNTO DE TABELAS GERADAS.

ANEXO 9 - ANÁLISE ESTATÍSTICA: CATEGORIZAÇÃO DE VARIÁVEIS E REGRESSÃO LOGÍSTICA

ANEXO 10 - FLUXOGRAMA PARA A CONSTRUÇÃO DO DISCURSO DO SUJEITO COLETIVO 



\section{ANEXO 1 - INDICADORES.}

Indicadores da eficiência do programa de capacitação para o envolvimento.

$$
\begin{aligned}
& I E F I 1=\frac{\text { número de moradores inscritos na capacitação para o envolvimento }}{\text { numero total de inscritos }}(\%) \\
& I E F I 2=\frac{\text { número de comerciantes inscritos na capacitação para o envolvimento }}{\text { número total de inscritos }}(\%)
\end{aligned}
$$$$
I E F I 3=\frac{\text { número de encarregados da obra inscritos na capacitação para o envolvimento }}{\text { número total de inscritos }}
$$

$I E F I 4=\frac{\text { número de entidades locais inscritas na capacitação para o envolvimento }}{\text { número total de inscritos }}(\%)$

$$
\begin{gathered}
I E F I 5=\frac{\text { número de reuniões de capacitação previstas }}{\text { número de reuniões de capacitação realizadas }}(\%) \\
I E F I 6=\frac{\text { orçamento previsto para a capacitação para o envolvimento }}{\text { orçamento realizado }}(\%)
\end{gathered}
$$

Atendendo ao princípio da eficiência e sustentabilidade econômica

$$
\begin{gathered}
I E F I 7=\frac{\text { número de moradore que concluíram a capacitação }}{\text { número de moradores inscritos }}(\%) \\
I E F I 8=\frac{\text { número de comerciantes que concluíram a capacitação }}{\text { número de comerciantes inscritos }}(\%) \\
I E F I 9=\frac{\text { número de encarregados que concluíram a capacitação }}{\text { número de encarregados inscritos }}(\%) \\
I E F I 10=\frac{\text { número de entidades locais que concluíram a capacitação }}{\text { número de respresentantes de entidades locais inscritas }}(\%)
\end{gathered}
$$


Indicadores da eficiência do programa de envolvimento no planejamento das obras

$$
I E F I 11=\frac{\text { número de moradores inscritos nas reuniões de planejamento }}{\text { número total de inscritos }}(\%)
$$

$$
I E F I 12=\frac{\text { número de comerciantes inscritos nas reuniõe de planejamento }}{\text { número total de inscritos }}
$$

$I E F I 13=\frac{\text { número de encarregados da obra inscritos nas reuniõe de planejamento }}{\text { número total de inscritos }}(\%)$

$$
I E F I 14=\frac{\text { número de entidades locais inscritas nas reuniões de planejamento }}{\text { número total de inscritos }}(\%)
$$

$$
I E F I 15=\frac{\text { número de reuniões de planejamento previstas }}{\text { número de reuniões de planejamento realizadas }}(\%)
$$

$$
I E F I 16=\frac{\text { orçamento previsto para as reuniões de planejamento }}{\text { orçamento realizado }}(\%)
$$

$I E F I 17=\frac{\text { número de moradores que concluíram todas as reuniões de planejamento }}{\text { número de moradores inscritos }}(\%)$

$I E F I 18=\frac{\text { número de comerciantes que concluíram todas as reuniões de planejamento }}{\text { número de comerciantes inscritos }}(\%)$

$I E F I 19=\frac{\text { número de encarregados que concluíram as reuniões de planejamento }}{\text { número de encarregados inscritos }}(\%)$

$$
I E F I 20=\frac{\text { número de entidades locais que concluíram as reuniões de planejamento }}{\text { número de respresentantes de entidades locais inscritas }}(\%)
$$


$I E F I 21=\frac{\text { número de representantes locais que participam no planejamento }}{\text { número de entidades locais inscritas }}(\%)$

Indicadores da eficiência do programa de envolvimento na implantação das obras

$$
\begin{gathered}
I E F I 21=\frac{\text { número de moradores inscritos nas reuniões de implantação }}{\text { número total de inscritos }}(\%) \\
I E F I 22=\frac{\text { número de comerciantes inscritos nas reuniõe de implantação }}{\text { número total de inscritos }}(\%) \\
I E F I 23=\frac{\text { número de encarregados inscritos nas reuniõe de implantação }}{\text { número total de inscritos }}(\%)
\end{gathered}
$$$$
I E F I 24=\frac{\text { número de entidades locais inscritas nas reuniõe de implantação }}{\text { número total de inscritos }}(\%)
$$$$
I E F I 25=\frac{\text { número de reuniões de implantação previstas }}{\text { número de reuniões de implantação realizadas }}(\%)
$$$$
I E F I 26=\frac{\text { orçamento previsto para as reuniões de implantação }}{\text { orçamento realizado }}(\%)
$$

$I E F I 27=\frac{\text { número de moradores que concluíram todas as reuniões de implantação }}{\text { número de moradores inscritos }}(\%)$

IEFI28 $=\frac{\text { número de comerciantes que concluíram todas as reuniões de implantação }}{\text { número de comerciantes inscritos }}(\%)$

$I E F I 29=\frac{\text { número de encarregado que concluíram todas as reuniões de planejamento }}{\text { número de encarregados inscritos }} \%$

$I E F I 30=\frac{\text { número de entidades locais que concluíram todas as reuniões de implantação }}{\text { número de entidades locais inscritas }}(\%)$

$$
I E F I 41=\frac{\text { número de representantes locais que participam da implantação }}{\text { número de entidades locais inscritas }}(\%)
$$


Indicadores da eficiência do programa de supervisão do funcionamento das obras

$$
\begin{gathered}
I E F I 31=\frac{\text { número de moradores inscritos nas reuniões de supervisão }}{\text { número total de inscritos }}(\%) \\
I E F I 32=\frac{\text { número de comerciantes inscritos nas reuniões de supervisão }}{\text { número total de inscritos }}(\%) \\
I E F I 33=\frac{\text { número de encarregados inscritos nas reuniões de supervisão }}{\text { número total de inscritos }}(\%)
\end{gathered}
$$$$
I E F I 34=\frac{\text { número de entidades locais inscritas nas reuniões de supervisão }}{\text { número total de inscritos }}(\%)
$$$$
I E F I 35=\frac{\text { número de reuniões de supervisão previstas }}{\text { número de reuniões de supervisão realizadas }}(\%)
$$$$
I E F I 36=\frac{\text { orçamento de supervisão previsto }}{\text { orçamento de supervisão realizado }}(\%)
$$

$I E F I 37=\frac{\text { número de moradores que concluíram todas as reuniões de supervisão }}{\text { número de moradores inscritos }}(\%)$

$$
I E F I 38=\frac{\text { número de comerciantes que concluíram todas as reuniões de supervisão }}{\text { número de comerciantes inscritos }}(\%)
$$

$$
I E F I 39=\frac{\text { número de encarregados que concluíram todas as reuniões de supervisão }}{\text { número de encarregados inscritos }}(\%)
$$$$
\text { IEFI40 }=\frac{\text { número de entidades locais que concluíram todas as reuniões de supervisão }}{\text { número de entidades locais inscritas }}(\%)
$$ 
$I E F I 41=\frac{\text { número de representantes de grupos locais que participam na supervisão }}{\text { número de entidades locais inscritas nas reuniões }}(\%)$

Indicadores de eficácia para medir durabilidade da obra implantada

IEFA1 $\frac{\text { aumento de rachaduras na estrutura }}{\text { período de controle }}$ (ocorrência/mês)

$I E F A 2=\frac{\text { número de quebras verificadas na estrutura }}{\text { período de controle }}($ ocorrências $/$ mês $)$

$I E F A 3=\frac{\text { número de transbordamentos }}{\text { período de controle }}($ ocorrências $/$ mês $)$
$I E F A 4=\frac{\text { número de inspeções realizadas }}{\text { período de controle }}($ ocorrência $/ m$ ês $)$

Indicadores de eficácia para medir a sustentabilidade das obras implantadas

$I E F A 5=\frac{\text { aumento de vetores no local }}{\text { período de tempo controlado }}($ ocorrência $/$ semestre $)$

$I E F A 6=\frac{\text { número de reclamações junto a entidades oficiais }}{\text { período de tempo de controle }}($ ocorrências $/$ mês $)$

IEFA7 $=\frac{\text { número de pontos de alagamento }}{\text { período de tempo de controle }}($ ocorrências $/$ semestre $)$

IEFA8 $=\frac{\text { número de moradores no grupo de supervisão após } 3 \text { meses de concluída a obra }}{\text { número de moradores inscritos no grupo de supervisão }}(\%)$ 


$$
\begin{gathered}
I E F A 9=\frac{\text { número de comerciantes no grupo de supervisão após } 3 \text { meses de concluída a obra }}{\text { número de comerciantes inscritos no grupo de supervisão }}(\%) \\
I E F A 10=\frac{\text { número de moradores não atingidos por inundação }}{\text { número total de moradores na área de risco }}(\%)
\end{gathered}
$$

$I E F A 11=\frac{\text { atendimento em postos de saúde por doenças de veiculação hídrica }}{\text { período de tempo analisado }}($ ocorrências $/$ semestre $)$

$$
I E F A 12=\frac{\text { atendimento em postos de saúde por leptospirose }}{\text { período de tempo analisado }}(\text { ocorrências } / \text { semestre })
$$$$
\text { IEFA13 }=\frac{\text { manutenção de parques e áreas verdes }}{\text { período de tempo analisado }}(\text { ocorrências } / \text { mês })
$$$$
I E F A 14=\frac{\text { número de ruas com resíduos sólidos }}{\text { num total de } 15 \text { ruas na área da obra implantada }}(\%)
$$$$
I E F A 15=\frac{\text { número de casas alagadas }}{\text { período de tempo analisado }}(\text { ocorrência } / \text { semestre })
$$$$
I E A F 16=\frac{\text { número de comercios alagados }}{\text { período de tempo analisado }}(\text { ocorrência } / \text { semestre })
$$ 


\section{ANEXO 2 - QUETIONÁRIO ENVIADO A GESTORES E DEMAIS PROFISSIONAIS.}

Perguntas formuladas através de questionário enviado pelo programa Surveymonkey: "O técnico e o social no planejamento e implantação das intervenções em drenagem urbana”.

Assinale o grau de concordância ou discordância em relação à afirmação a seguir:

\begin{tabular}{|c|c|c|c|c|}
\hline & $\begin{array}{l}\text { Discordo } \\
\text { totalmente }\end{array}$ & $\begin{array}{l}\text { Discordo } \\
\text { parcialmente }\end{array}$ & $\begin{array}{l}\text { Concordo } \\
\text { parcialmente }\end{array}$ & $\begin{array}{l}\text { Concordo } \\
\text { totalmente }\end{array}$ \\
\hline $\begin{array}{l}\text { 1. Aspectos técnicos são tão importantes quantos aspectos sociais no } \\
\text { planejamento de obras de drenagem. }\end{array}$ & & & & \\
\hline $\begin{array}{l}\text { 2. O bom planejamento de obras de drenagem exige a participação de: } \\
\text { 2.1. Coordenadores de projetos e engenheiros. } \\
\text { 2.2. Técnicos de manutenção de obras de drenagem. } \\
\text { 2.3. Lideranças comunitárias } \\
\text { 2.4.Educadores ambientais } \\
\text { 2.5.Comerciantes instalados na área onde as obras serão implantadas } \\
\text { 2.6.Comitês de bacias hidrográficas } \\
\text { 2.7.Políticos da região } \\
\text { 2.8. Moradores na área onde as obras serão implantadas } \\
\text { 2.9. Comunicadores sociais } \\
\text { 2.10. Cientistas sociais. }\end{array}$ & & & & \\
\hline $\begin{array}{l}\text { 3. Gerentes de obras de drenagem nem sempre desejam envolver } \\
\text { moradores no planejamento das obras. }\end{array}$ & & & & \\
\hline $\begin{array}{l}\text { 4. Em geral, moradores das áreas onde obras serão implantadas não têm } \\
\text { condição de opinar sobre as mesmas para que atendam sua demanda } \\
\text { por melhorias. }\end{array}$ & & & & \\
\hline $\begin{array}{l}\text { 5. Em geral, comerciantes instalados nas áreas onde obras serão } \\
\text { implantadas não têm condição de opinar sobre as mesmas para que } \\
\text { atendam sua demanda por melhorias. }\end{array}$ & & & & \\
\hline $\begin{array}{l}\text { 6. Audiências públicas são suficientes como processo participativo da } \\
\text { população. }\end{array}$ & & & & \\
\hline $\begin{array}{l}\text { 7. Para a boa implantação de obras de drenagem é necessário que haja o } \\
\text { envolvimento de: } \\
\text { 7.1. Comunicadores sociais. } \\
\text { 7.2. Cientistas sociais. } \\
\text { 7.3. Educadores ambientais. } \\
\text { 7.4. Empresários locais. } \\
\text { 7.5. Engenheiros. } \\
\text { 7.6. Escolas da região. } \\
\text { 7.7. Lideranças comunitárias. } \\
\text { 7.8. Moradores. } \\
\text { 7.9. Políticos da região } \\
\text { 7.10. Técnicos de manutenção de obras de drenagem. }\end{array}$ & & & & \\
\hline $\begin{array}{l}\text { 8. Na implantação de obras de drenagem, é necessário que Engenheiros } \\
\text { Civis contem com suficiente: } \\
\text { 8.1 Tempo para ocupar-se com aspectos da organização sociopolítica } \\
\text { nas comunidades onde obras são implantadas. } \\
\text { 8.2 Vontade de lidar com aspectos sociopolíticos nas comunidades } \\
\text { onde implantam obras. } \\
\text { 8.3 Sensibilidade para aspectos da organização sociopilítica das } \\
\text { comunidades onde implantam obras. }\end{array}$ & & & & \\
\hline
\end{tabular}


8.4 Compreensão das interferências sociopolíticas que podem ocorrer durante a implantação das obras.

8.5 Autonomia frente às interferências políticas e dos arranjos institucionais para implantar obras já planjejadas.

9. A graduação em Engenharia Civil capacita suficientemente para a boa execução de obras de drenagem.

10. A graduação em Engenharia Civil deveria ter disciplinas obrigatórias sobre aspectos sociopolíticos.

11. Cientistas Sociais são bem-vindos para atuar em projetos de intervenções em drenagem.

12. As principais causas das inundações no Município de São Paulo são:

12.1 Insuficientes recursos financeiros por parte do Poder Público.

12.2 A impermeabilização do solo.

12.3 A fiscalização do uso e ocupação do solo em áreas de proteção de mananciais e de preservação permanente.

12.4 O envolvimento de moradores e comerciantes no planejamento das obras a fim de se obter consenso sobre as mesmas e praticar seu uso racional.

12.5 A graduação em Engenharia Civil e a formação que oferece nos aspectos sociopolíticos que as obras envolvem tendo em vista garantir sua durabilidade.

12.6 A capacitação de Profissionais de formação humanista e social para envolver moradores e comerciantes de maneira que se sintam capazes de contribuir para a redução de alagamentos e inundações.

12.7 Resíduos sólidos depositados nas vias públicas e cursos de água

12.8 A manutenção das obras de drenagem pelo Poder Público.

13. Para a durabilidade das obras em drenagem urbana e a sustentabilidade do serviço que oferecem é necessário:

13.1 Maior envolvimento de moradores e comerciantes das áreas onde as obras são implantadas para que se encontre um consenso quanto a atender o interesse público.

13.2 Capacitação de profissionais formados em áreas sociais para trabalhar junto a moradores e comerciantes tendo em vista o uso racional da obra implantada.

13.3 Projetos que focalizem trabalhar reinvidicações de moradores e comerciantes de maneira a administrar conflitos e chegar a consenso que responda ao interesse público.

13.4 Envolvimento de moradores e comerciantes no planejamento de maneira a que as decisões atendam ao interesse público.

13.5 Manutenção de obras somente pelo Poder Público para garantir sua eficácia.

13.6 Monitoramento das obras pelo Poder Público que inclua o cuidado com as mesmas também por moradores e comerciantes.

13.7 Trabalho mais eficaz pelos Educadores Ambientais e Comunicadores Sociais nas áreas onde são implantadas as obras de drenagem.

14. Relação mais estreita entre o técnico-científico (o campo de atuação e a formação do Engenheiro Civil) e o sociopolítico (a organização social e política) é fundamental para a durabilidade das obras e a sustentabilidade do serviço que oferece.

Perguntas pessoais: sexo, idade, formação, função, nível hierárquico na organização onde trabalha. 


\section{ANEXO 3 - QUESTIONÁRIO APLICADO NA ÁREA DA BACIA \\ HIDROGRÁFICA DO CÓRREGO DO CORDEIRO; LOCAL E DATA DAS \\ ENTREVISTAS REALIZADAS E AGRUPAMENTO PARA FINS DE ANÁLISE \\ ESTATÍSTICA.}

\section{Entrevistador:}

Data da entrevista:

Local *: RCO1, RCO2, RCO3, RCO4, RCO5, RCO6, CP.

\section{Dados do entrevistado:}

Se Morador: Há quanto tempo mora na região?

Proprietário do lote: $\quad$ SIM NÃO É área da Prefeitura? SIM NÃO

Se Comerciante: Há quanto tempo neste local?

Já passou problemas de inundação? N NÃO (PASSAR para identificação demográfica)

Se SIM: A cada quantos anos / meses?

Antes era PIOR ou MELHOR que agora?

Agora, que altura a água chega?

Quanto tempo leva para baixar a água?

Fora ou dentro da construção? DENTRO

FORA

Houve estragos? SIM NÃO

Você construiu alguma obra para evitar alagamento no lote? NÃO SIM - Qual?

Porque você mora em lugar com risco de inundação?

Sabia que havia este risco antes de construir? SIM NÃO

M F Faixa etária: $15-24 ; 25-34 ; 35-44 ; 45-54 ; 55-64 ;>65$

Nível de escolaridade: não dar as opções, só marcar a resposta.

$1^{\circ} \mathrm{G}$. completo ou incompleto

$2^{\circ} \mathrm{G}$. incompleto

$2^{\circ} \mathrm{G}$. completo

Curso técnico completo ou incompleto

Fundamental I

Fundamental II

Ensino Médio

Curso universitário completo ou incompleto

Outro qual?

Perguntas

1. Em sua opinião, o que mais causa inundação?

Anotar a primeira e a segunda (se houver) e o porquê.

2. Em sua opinião, quem é o maior responsável pelas inundações?

3. Quando há inundação, quem (Você acha que)
Anotar a primeira e a segunda (se houver) e o porquê.

Marcar a resposta com $1^{\circ}$. Para quem vem depois, anotar com $\mathrm{X}$ 


\begin{tabular}{|c|c|c|c|}
\hline \multicolumn{4}{|l|}{ presta socorro primeiro? } \\
\hline 3.1 Os vizinhos & & \multicolumn{2}{|r|}{ 3.5 Os técnicos da Prefeitura } \\
\hline 3.2 A família & & \multicolumn{2}{|r|}{ 3.6 Cada um por si } \\
\hline 3.3 Os amigos & & \multirow{2}{*}{\multicolumn{2}{|c|}{ 3.7 Outros: quais }} \\
\hline 3.4 Associação de moradores & & & \\
\hline $\begin{array}{l}\text { 4. Você sabe / saberia como se proteger de } \\
\text { inundação? Se SIM: como? }\end{array}$ & $\mathrm{S}$ & $\mathrm{N}$ & \\
\hline $\begin{array}{l}\text { 5. Quem você acha que deve decidir sobre as obras } \\
\text { contra inundação? }\end{array}$ & \multicolumn{3}{|c|}{ Anotar a primeira e a segunda (se houver) e o porquê. } \\
\hline
\end{tabular}

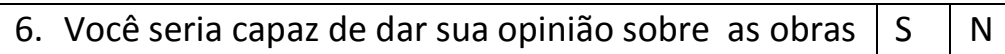
contra inundação no seu bairro? Porquê?

7. Já estiveram aqui engenheiros / técnicos para explicar tudo sobre os piscinões que vão ser construídos? Se SIM: como foi? Anotar se Não sabe.

8. Já estiveram aqui Educadores Ambientais, Comunicadores Sociais, Lideranças Comunitárias para explicar tudo sobre os piscinões que vão ser construídos? Se SIM: quem e como foi? Anotar se Não sabe.

9. Você já conversou com gente do bairro sobre as obras dos piscinões? Anotar se é informalmente na rua, ou em associação, escola, igreja,.... etc.

10. Você acha que os técnicos /Engenheiros levam os moradores e ou comerciantes a sério ou você acha que eles não ligam? Porquê?

11. Você gostaria de participar de conversas com os técnicos / Engenheiros das obras? Porquê?

\begin{tabular}{l|l}
$\mathrm{S}$ & $\mathrm{N}$
\end{tabular}
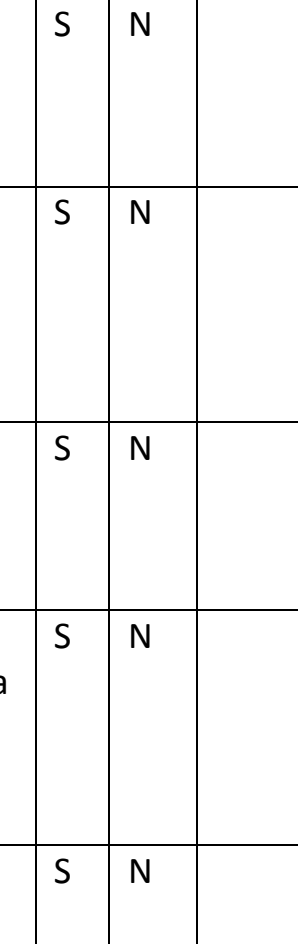

Qualquer outra anotação que considerar importante. 


\begin{tabular}{|c|c|c|c|}
\hline \multirow[t]{2}{*}{ Local de realização de entrevistas } & \multirow{2}{*}{$\begin{array}{l}\text { Característica sócio- } \\
\text { econômica da área } \\
\text { segundo o } \\
\text { empreendor das } \\
\text { obras - } \\
\text { PLANSERV. }\end{array}$} & \multicolumn{2}{|c|}{ Número de entrevistas } \\
\hline & & realizadas & consideradas \\
\hline Lugones/V.Clara/L.Stolb/Tenerem & $\begin{array}{l}\text { Entre Sebastião } \\
\text { Afonso e Álvares } \\
\text { Fagundes Região I. }\end{array}$ & 44 & 44 \\
\hline RCOI & Idem. Região 1. & 54 & 54 \\
\hline $\mathrm{RCO} 2$ & $\begin{array}{l}\text { Imediações da Praça } \\
\text { Lígia Salgado na } \\
\text { confluência com R } \\
\text { Rodrigues } \\
\text { Montemor. Área } \\
\text { considerada pela } \\
\text { pesquisadora ainda } \\
\text { dentro da Região 1, } \\
\text { apesar de } \\
\text { ligeiramente } \\
\text { melhor em termos } \\
\text { de edificações. }\end{array}$ & 48 & 48 \\
\hline $\mathrm{RCO} 3$ & $\begin{array}{l}\text { Imediações da AV. } \\
\text { Juan de La Cruz na } \\
\text { confluência com e } \\
\text { Av.João de Luca e } \\
\text { Parque do Nabuco. } \\
\text { Região } 2\end{array}$ & 35 & 30 \\
\hline $\mathrm{RCO} 4$ & $\begin{array}{l}\text { Av. Washington } \\
\text { Luiz na confluência } \\
\text { com Av. Vereador } \\
\text { João de Luca e Av. } \\
\text { Vicente Rao Região } \\
\text { 2. }\end{array}$ & 42 & 42 \\
\hline $\mathrm{RCO5}$ & $\begin{array}{l}\text { Proximidade Av. } \\
\text { Vicente Rao } \\
\text { esquina com Dr } \\
\text { Ademar de Queirós } \\
\text { / Rua Miranda } \\
\text { Guerra, até o } \\
\text { Parque do Cordeiro. } \\
\text { Região 3. }\end{array}$ & 37 & 36 \\
\hline
\end{tabular}




\begin{tabular}{|l|l|r|r|}
\hline RCO6 & $\begin{array}{l}\text { Av. Vicente Rao na } \\
\text { confluência com } \\
\text { Vereador José } \\
\text { Diniz, e rua da Prata } \\
\text { em ambos lados da } \\
\text { Av. Vicente Rao }\end{array}$ & 34 & 34 \\
\hline $\mathrm{CP}$ & $\begin{array}{l}\text { Av. Roque Petroni e } \\
\text { imediaçõs da Rua } \\
\text { Cancioneiro } \\
\text { Popular.] } \\
\text { Região 3. }\end{array}$ & 13 & 13 \\
\hline Total de entrevistas & & 307 & 301 \\
\hline
\end{tabular}

Área de entrevistas para aplicação do questionário e número de entrevistas.

Para fins do tratamento estatístico, as áreas foram agrupadas e a configuração final foi a seguinte:

Número de entrevistas

consideradas

Regiões Áreas

N

$\%$

RCO1

146

48,50

Região 1

RCO2

$72 \quad 23,92$

RCO3

Região 2

RCO4

RCO5

83

27,57

Região 3

RCO6

$\mathrm{CP}$ 


\section{ANEXO 4 - ANÁLISE DO DISCURSO DO SUJEITO COLETIVO - RESULTADOS QUANTITATIVOS}

QUALIQUANTISOFT - RESULTADOS QUANTIIATIVOS - IDÉIA CENTRAL

O técnico e o social em drenagem e manejo de águas pluviais.

1) Quem você acha que deve decidir sobre as obras contra inundação?

\begin{tabular}{lrr}
\hline A Atores sociais (Morador, proprietário, comerciante local, associaçäo de moradores, igreja, & 84 & $27,63 \%$ \\
etc.) & 137 & $45,07 \%$ \\
B Poder público (Prefeitura, vereadores, Governo do Estado, deputados estaduais, Governo & 15 & $4,93 \%$ \\
C Engeral, etc.) & 1 & $0,33 \%$ \\
D Poder público trabalhando junto com engenheiros/técnicos & 49 & $16,12 \%$ \\
E Decisäo compartilhada: Ator social é envolvido do processo de tomada de decisäo (ator & 15 & $4,93 \%$ \\
F Nocial + poder público elou engenheiro. & 3 & $0,99 \%$ \\
G Näo respondeu / vazio / em branco. & 304 \\
\hline & TOTAL DE RESPOSTAS DA PERGUNTA \\
\hline
\end{tabular}

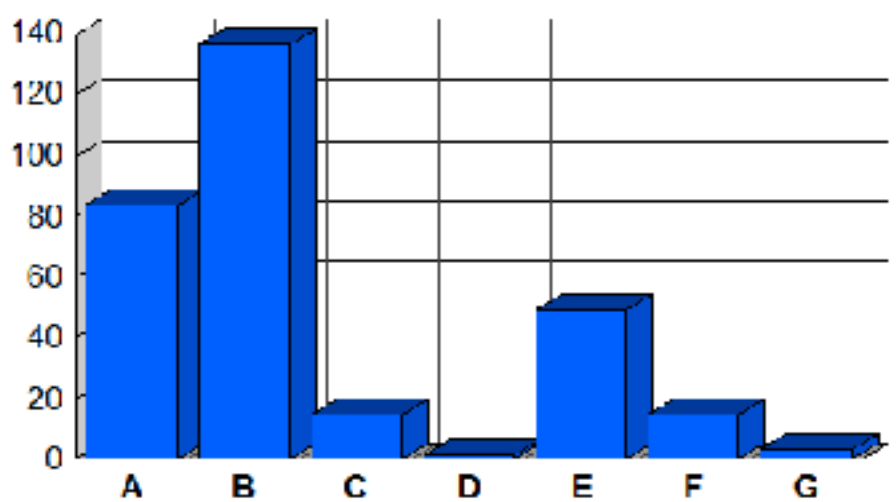


QUALIQUANTISOFTO - RESULTADOS QUANTIIATIVOS - IDÉIA CENTRAL

O técnico e o social em drenagem e manejo de águas pluviais.

2 ) Você seria capaz de dar sua opiniäo sobre as obras contra inundação no seu bairro? Por que?

A Sim, sem justificativa / sem esclarecer o porquè.

$17 \quad 5,63 \%$

B Sim, por ser morador e/ou conhecer a regäo e seus problemas.

$90 \quad 29,80 \%$

C Sim, porque a opiniäo da populaçäo deve ser compartilhada com o poder público e/ou

$5 \quad 1,66 \%$ engenheiros responsáveis.

D Sim, por ser técnico elou engenheiro, por ter conhecimento profissional e/ou acadêmico.

$13 \quad 4,30 \%$

E Sim, porque todo o cidadão tem direito de opinar, por pagar imposto, por querer participar e opinar.

F Sim, para trazer melhorias a regiäo. Tomar iniciativa para obter uma soluçäo / resolver o

20

$31 \quad 10,26 \%$ problema.

G Nä̀, sem justificativa.

$40 \quad 13,25 \%$

H Nä̀, näo entende da questäo, näo tem conhecimento (técnico). Acredita que quem deve opinar e decidir é o engenheiro elou poder público.

I Näo, pois näo convive com o problema ou não é da regiäo e nunca vivencio o problema.

$12 \quad 3,97 \%$

J Näo - e critica a atuação do Poder Público.

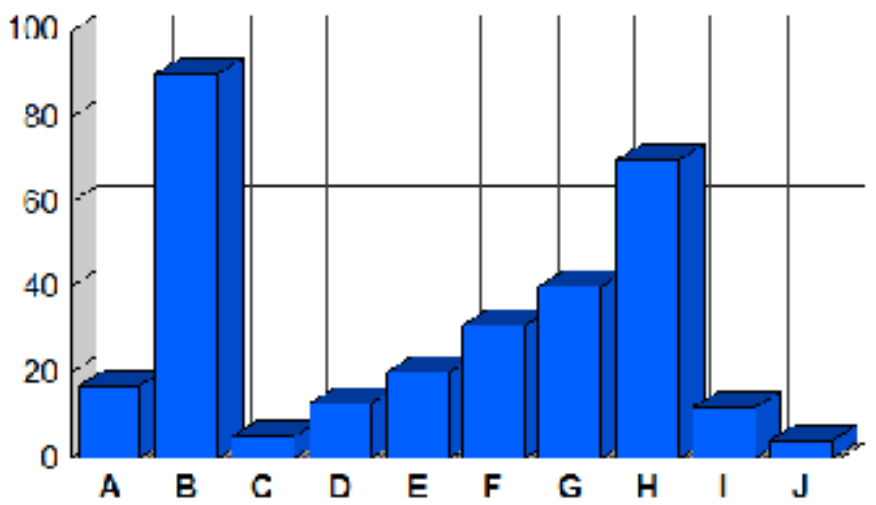


QUALIQUANTISOFTO - RESULTADOS QUANTIIATIVOS - IDÉIA CENTRAL

O técnico e o social em drenagem e manejo de águas pluviais.

3 ) Você jả conversou com gente do bairro sobre as obras dos piscinões?

A Sim, sem maiores esclarecimentos, sem justificativa elou sem especificar com quem $\quad 19 \quad 6,29 \%$ conversa.

B Sim, com vizinhos, na escola, na igreja e em outros pontos de encontro na regiäo. $\quad 46 \quad 15,23 \%$

C sim, já conversei com representantes do Poder Público. $\quad 8 \quad 2,65 \%$

D Sim, mas só conversei com gente do bairro sobre enchentes. $\quad 3 \quad 0,99 \%$

E Nä́o, sem maiores esclarecimentos ou justificativas. $\quad 148 \quad 49,01 \%$

F Näo, ninguém sabe sobre isto, nem eu estawa sabendo. $\quad 57 \quad 18,87 \%$

G Näo, só converso com gente do bairro sobre enchentes $\quad 5 \quad 1,66 \%$

H Näo, ninguem está interessado, não se conversa no bairro e/ou problema não nos afeta. $\quad 15 \quad 4,97 \%$

I Em branco.

$10,33 \%$

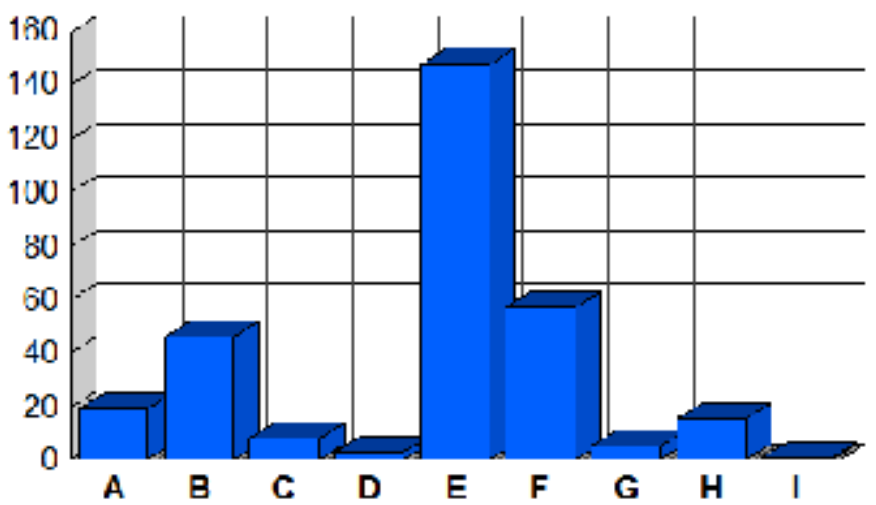


QUALIQUANTISOFTO - RESULTADOS QUANTITATIVOS - IDÉ|A CENTRAL

O técnico e o social em drenagem e manejo de águas pluviais.

4 ) Você acha que os técnicos / engenheiros levam os moradores e ou comerciantes a sério ou voce acha que eles não ligam? Por que?

\begin{tabular}{|c|c|c|c|c|}
\hline A & Sim, a opinião do morador é relevante e é levada a sério pelos técnicos e engenheiros. & 49 & 16,28 & $\%$ \\
\hline B & $\begin{array}{l}\text { Sim, o técnico / engenheiro leva a opiniäo do morador a sério, mas é o poder público que } \\
\text { decide sobre a obra. }\end{array}$ & 4 & 1,33 & $\%$ \\
\hline C & $\begin{array}{l}\text { Näo, a opiniäo do morador näo é levada a sério pelos técnicos / engenheiros. O técnico / } \\
\text { engenheiro näo interage com morador. }\end{array}$ & 156 & 51,83 & $\%$ \\
\hline D & $\begin{array}{l}\text { Näo, a opiniäo do morador näo é considerada, pois os engenheiros e técnicos executam } \\
\text { o projeto da forma como originalmente planejado. }\end{array}$ & 21 & 6,98 & $\%$ \\
\hline E & $\begin{array}{l}\text { Näo, a opinião do morador näo é levada à sério, pois quem decide sobre a obra é o poder } \\
\text { público. }\end{array}$ & 7 & 2,33 & $\%$ \\
\hline $\mathbf{F}$ & Näo, a opiniāo do morador só é considerada quando se trata de um bairro de classe alta. & 4 & 1,33 & $\%$ \\
\hline $\mathbf{G}$ & $\begin{array}{l}\text { Näo, pois os engenheiros só pensam no que é importante para eles e/ou só executam s } \\
\text { obra da forma como eles acham melhor, do ponto de vista técnico. }\end{array}$ & 33 & 10,96 & $\%$ \\
\hline $\mathbf{H}$ & $\begin{array}{l}\text { Näo, os técnicos e engenheiros não levam a opiniäo dos moradores a sério e isto está } \\
\text { correto, pois quem deve decidir sobre a obra é o técnico e näo o morador. }\end{array}$ & 7 & 2,33 & $\%$ \\
\hline $\mathbf{I}$ & Näo sabe opinar. & 19 & 6,31 & $\%$ \\
\hline J & Em branco. & 1 & 0,33 & $\%$ \\
\hline & TOTAL DE RESPOSTAS DA PERGUNTA & 301 & & \\
\hline
\end{tabular}

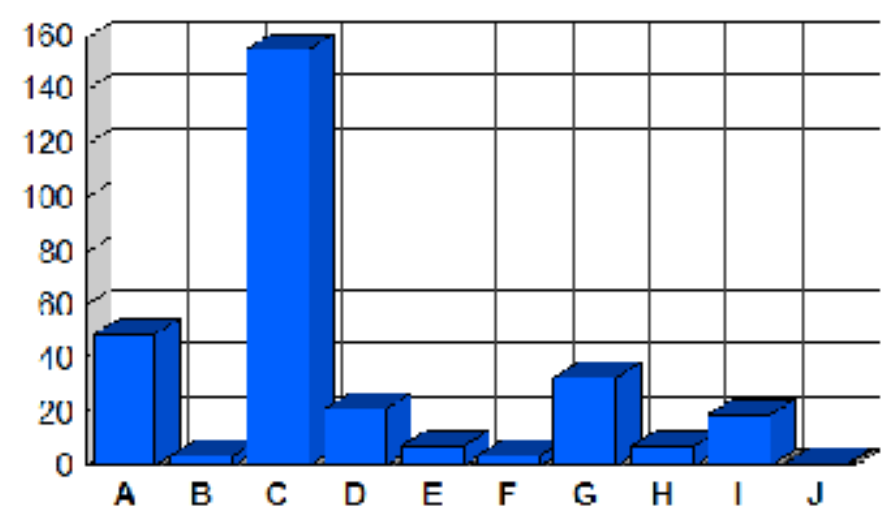


QUALIQUANTISOFT - RESULTADOS QUANTIIATIVOS - IDÉIA CENTRAL

O técnico e o social em drenagem e manejo de águas pluviais.

5 ) Você gostaria de participar de conversas com os técnicos / engenheiros das obras? Por que?

\begin{tabular}{|c|c|c|c|c|}
\hline A & Sim, gostaria de participar para conhecer mais sobre a obra e opinar a seu respeito. & 171 & 56,25 & $\%$ \\
\hline B & $\begin{array}{l}\text { Sim, gostaria de opinar sobre a obra porque conhece a regïäo (menciona que é } \\
\text { morador/da regiäo e, por isso, sua opiniäo é relevante). }\end{array}$ & 47 & 15,46 & $\%$ \\
\hline C & $\begin{array}{l}\text { Sim, gostaria de participar de conversas, pois é cidadäo, paga imposto e tem o direito de } \\
\text { opinar. }\end{array}$ & 7 & 2,30 & $\%$ \\
\hline D & Näo quer participar, pois em nada adianta / não resolve nada. & 15 & 4,93 & $\%$ \\
\hline $\mathbf{E}$ & Nä́o gostaria de participar, pois näo sofre com o problema e/ou não tem interesse. & 41 & 13,49 & $\%$ \\
\hline $\mathbf{F}$ & Näo gostaria, pois não tem tempo para participar de conversas. & 12 & 3,95 & $\%$ \\
\hline G & $\begin{array}{l}\text { Näo quer participar, pois não se sente capacitado para tanto elou acredita que pessoas } \\
\text { capacitadas (ex. engenheiros) devem decidir a respeito de obras. }\end{array}$ & 9 & 2,96 & $\%$ \\
\hline \multirow[t]{2}{*}{$\mathbf{H}$} & Nä́o sabe. & 2 & 0,66 & $\%$ \\
\hline & TOTAL DE RESPOSTAS DA PERGUNTA & 304 & & \\
\hline
\end{tabular}

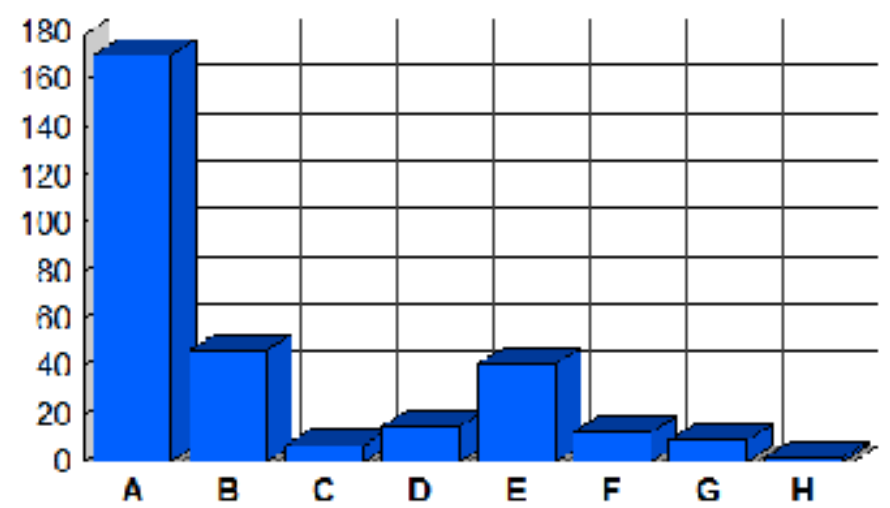




\section{ANEXO 5 - GESTORES E DEMAIS PROFISSIOINAIS RESULTADOS CHI- QUADRADO GRAUS DE LIBERDADE E P-VALOR}

\begin{tabular}{|c|c|}
\hline VAR1 & VAR2 \\
\hline FORMACAO_GRUPO & Q1_ASPTEC_SOCIAL \\
\hline FUNCAO_GRUPO & Q1_ASPTEC_SOCIAL \\
\hline IDADE & Q1_ASPTEC_SOCIAL \\
\hline NIVELHIE & Q1_ASPTEC_SOCIAL \\
\hline SEXO & Q1_ASPTEC_SOCIAL \\
\hline FORMACAO_GRUPO & Q10_GRAD_DISCIPLINA \\
\hline FUNCAO_GRUPO & Q10_GRAD_DISCIPLINA \\
\hline IDADE & Q10_GRAD_DISCIPLINA \\
\hline NIVELHIE & Q10_GRAD_DISCIPLINA \\
\hline SEXO & Q10_GRAD_DISCIPLINA \\
\hline FORMACAO_GRUPO & Q11_CIENTSOCIAIS \\
\hline FUNCAO_GRUPO & Q11_CIENTSOCIAIS \\
\hline IDADE & Q11_CIENTSOCIAIS \\
\hline NIVELHIE & Q11_CIENTSOCIAIS \\
\hline SEXO & Q11_CIENTSOCIAIS \\
\hline FORMACAO_GRUPO & Q12_CAUSA_CAPACIT \\
\hline FUNCAO_GRUPO & Q12_CAUSA_CAPACIT \\
\hline IDADE & Q12_CAUSA_CAPACIT \\
\hline NIVELHIE & Q12_CAUSA_CAPACIT \\
\hline SEXO & Q12_CAUSA_CAPACIT \\
\hline FORMACAO_GRUPO & Q12_CAUSA_CLIMA \\
\hline FUNCAO_GRUPO & Q12_CAUSA_CLIMA \\
\hline IDADE & Q12_CAUSA_CLIMA \\
\hline NIVELHIE & Q12_CAUSA_CLIMA \\
\hline SEXO & Q12_CAUSA_CLIMA \\
\hline FORMACAO_GRUPO & Q12_CAUSA_ENV \\
\hline FUNCAO_GRUPO & Q12_CAUSA_ENV \\
\hline IDADE & Q12_CAUSA_ENV \\
\hline NIVELHIE & Q12_CAUSA_ENV \\
\hline SEXO & Q12_CAUSA_ENV \\
\hline FORMACAO_GRUPO & Q12_CAUSA_FISCASOLO \\
\hline FUNCAO_GRUPO & Q12_CAUSA_FISCASOLO \\
\hline IDADE & Q12_CAUSA_FISCASOLO \\
\hline NIVELHIE & Q12_CAUSA_FISCASOLO \\
\hline SEXO & Q12_CAUSA_FISCASOLO \\
\hline FORMACAO_GRUPO & Q12_CAUSA_GRAD \\
\hline FUNCAO_GRUPO & Q12_CAUSA_GRAD \\
\hline IDADE & Q12_CAUSA_GRAD \\
\hline NIVELHIE & Q12_CAUSA_GRAD \\
\hline SEXO & Q12_CAUSA_GRAD \\
\hline FORMACAO_GRUPO & Q12_CAUSA_IMPERM \\
\hline FUNCAO_GRUPO & Q12_CAUSA_IMPERM \\
\hline IDADE & Q12_CAUSA_IMPERM \\
\hline NIVELHIE & Q12_CAUSA_IMPERM \\
\hline SEXO & Q12_CAUSA_IMPERM \\
\hline FORMACAO_GRUPO & Q12_CAUSA_INSUFREC \\
\hline FUNCAO_GRUPO & Q12_CAUSA_INSUFREC \\
\hline
\end{tabular}

\begin{tabular}{|c|c|c|}
\hline $\begin{array}{l}\text { Estatística } \\
\text { qui-quadr. }\end{array}$ & $\begin{array}{l}\text { Graus de } \\
\text { Liberdade }\end{array}$ & $\mathrm{p}$-valor \\
\hline 7,823939 & 9 & 0,5520 \\
\hline 6,061088 & 3 & 0,1087 \\
\hline 3,461911 & 12 & 0,9913 \\
\hline 15,98261 & 12 & 0,1920 \\
\hline 8,423892 & 3 & 0,0380 \\
\hline 6,414003 & 6 & 0,3784 \\
\hline 4,152221 & 2 & 0,1254 \\
\hline 6,167136 & 8 & 0,6285 \\
\hline 10,868 & 8 & 0,2093 \\
\hline 3,375079 & 2 & 0,1850 \\
\hline 11,84703 & 9 & 0,2221 \\
\hline 1,227249 & 3 & 0,7465 \\
\hline 6,317949 & 12 & 0,8992 \\
\hline 9,5 & 12 & 0,6597 \\
\hline 12,4179 & 3 & 0,0061 \\
\hline 8,274583 & 9 & 0,5067 \\
\hline 0,477869 & 3 & 0,9237 \\
\hline 9,247487 & 12 & 0,6817 \\
\hline 20,89406 & 12 & 0,0520 \\
\hline 4,405299 & 3 & 0,2209 \\
\hline 7,257789 & 9 & 0,6103 \\
\hline 0,31467 & 3 & 0,9572 \\
\hline 6,748072 & 12 & 0,8738 \\
\hline 19,31934 & 12 & 0,0811 \\
\hline 1,758531 & 3 & 0,6240 \\
\hline 13,95419 & 9 & 0,1240 \\
\hline 0,337043 & 3 & 0,9529 \\
\hline 12,66928 & 12 & 0,3935 \\
\hline 11,65013 & 12 & 0,4742 \\
\hline 0,60228 & 3 & 0,8959 \\
\hline 4,089153 & 9 & 0,9054 \\
\hline 2,366591 & 3 & 0,4999 \\
\hline 8,437263 & 12 & 0,7501 \\
\hline 7,435113 & 12 & 0,8276 \\
\hline 7,676669 & 3 & 0,0532 \\
\hline 6,117604 & 9 & 0,7281 \\
\hline 3,974559 & 3 & 0,2642 \\
\hline 34,14717 & 12 & 0,0006 \\
\hline 10,02581 & 12 & 0,6137 \\
\hline 3,811765 & 3 & 0,2825 \\
\hline 2,157433 & 6 & 0,9047 \\
\hline 2,506195 & 2 & 0,2856 \\
\hline 5,145845 & 8 & 0,7419 \\
\hline 12,69827 & 8 & 0,1227 \\
\hline 1,634052 & 2 & 0,4417 \\
\hline 12,48108 & 9 & 0,1875 \\
\hline 5,22488 & 3 & 0,1561 \\
\hline
\end{tabular}




\begin{tabular}{|c|c|}
\hline IDADE & Q12_CAUSA_INSUFREC \\
\hline NIVELHIE & Q12_CAUSA_INSUFREC \\
\hline SEXO & Q12_CAUSA_INSUFREC \\
\hline FORMACAO_GRUPO & Q12_CAUSA_MANUT \\
\hline FUNCAO_GRUPO & Q12_CAUSA_MANUT \\
\hline IDADE & Q12_CAUSA_MANUT \\
\hline NIVELHIE & Q12_CAUSA_MANUT \\
\hline SEXO & Q12_CAUSA_MANUT \\
\hline FORMACAO_GRUPO & Q12_CAUSA_RESIDUO \\
\hline FUNCAO_GRUPO & Q12_CAUSA_RESIDUO \\
\hline IDADE & Q12_CAUSA_RESIDUO \\
\hline NIVELHIE & Q12_CAUSA_RESIDUO \\
\hline SEXO & Q12_CAUSA_RESIDUO \\
\hline FORMACAO_GRUPO & Q13_DRBDE_ADMCONFL \\
\hline FUNCAO_GRUPO & Q13_DRBDE_ADMCONFL \\
\hline IDADE & Q13_DRBDE_ADMCONFL \\
\hline NIVELHIE & Q13_DRBDE_ADMCONFL \\
\hline SEXO & Q13_DRBDE_ADMCONFL \\
\hline FORMACAO_GRUPO & Q13_DRBDE_CAPACIT \\
\hline FUNCAO_GRUPO & Q13_DRBDE_CAPACIT \\
\hline IDADE & Q13_DRBDE_CAPACIT \\
\hline NIVELHIE & Q13_DRBDE_CAPACIT \\
\hline SEXO & Q13_DRBDE_CAPACIT \\
\hline FORMACAO_GRUPO & Q13_DRBDE_EDUCAMB \\
\hline FUNCAO_GRUPO & Q13_DRBDE_EDUCAMB \\
\hline IDADE & Q13_DRBDE_EDUCAMB \\
\hline NIVELHIE & Q13_DRBDE_EDUCAMB \\
\hline SEXO & Q13_DRBDE_EDUCAMB \\
\hline FORMACAO_GRUPO & Q13_DRBDE_MANUT \\
\hline FUNCAO_GRUPO & Q13_DRBDE_MANUT \\
\hline IDADE & Q13_DRBDE_MANUT \\
\hline NIVELHIE & Q13_DRBDE_MANUT \\
\hline SEXO & Q13_DRBDE_MANUT \\
\hline FORMACAO_GRUPO & Q13_DRBDE_MONITORA \\
\hline FUNCAO_GRUPO & Q13_DRBDE_MONITORA \\
\hline IDADE & Q13_DRBDE_MONITORA \\
\hline NIVELHIE & Q13_DRBDE_MONITORA \\
\hline SEXO & Q13_DRBDE_MONITORA \\
\hline FORMACAO_GRUPO & Q13_DRBDE_MORACOM \\
\hline FUNCAO_GRUPO & Q13_DRBDE_MORACOM \\
\hline IDADE & Q13_DRBDE_MORACOM \\
\hline NIVELHIE & Q13_DRBDE_MORACOM \\
\hline SEXO & Q13_DRBDE_MORACOM \\
\hline FORMACAO_GRUPO & Q13_DRBDE_MORACOMPL \\
\hline FUNCAO_GRUUPO & Q13_DRBDE_MORACOMPL \\
\hline IDADE & Q13_DRBDE_MORACOMPL \\
\hline NIVELHIE & Q13_DRBDE_MORACOMPL \\
\hline SEXO & Q13_DRBDE_MORACOMPL \\
\hline FORMACAO_GRUPO & Q14_REL_TECSOC \\
\hline FUNCAO_GRUPO & Q14_REL_TECSOC \\
\hline IDADE & Q14_REL_TECSOC \\
\hline NIVELHIE & Q14_REL_TECSOC \\
\hline SEXO & Q14_REL_TECSOC \\
\hline FORMACAO_GRUPO & Q2_PLANEJCIENT_SOCI \\
\hline
\end{tabular}

$\begin{array}{rrr}7,479422 & 12 & 0,8244 \\ 16,28154 & 12 & 0,1787 \\ 3,25124 & 3 & 0,3545 \\ 7,399822 & 9 & 0,5956 \\ 0,98205 & 3 & 0,8056 \\ 7,917528 & 12 & 0,7915 \\ 4,621565 & 12 & 0,9694 \\ 3,562012 & 3 & 0,3128 \\ 6,143529 & 9 & 0,7255 \\ 6,802484 & 3 & 0,0785 \\ 5,983768 & 12 & 0,9169 \\ 9,56799 & 12 & 0,6538 \\ 1,381715 & 3 & 0,7098 \\ 6,12819 & 9 & 0,7270 \\ 7,430126 & 3 & 0,0594 \\ 17,53762 & 12 & 0,1305 \\ 16,48357 & 12 & 0,1701 \\ 14,61472 & 3 & 0,0022 \\ 9,26384 & 9 & 0,4133 \\ 4,824254 & 3 & 0,1851 \\ 4,562386 & 12 & 0,9710 \\ 13,79897 & 12 & 0,3137 \\ 8,47274 & 3 & 0,0372 \\ 8,511052 & 6 & 0,2030 \\ 8,245781 & 2 & 0,0162 \\ 3,395365 & 8 & 0,9072 \\ 8,500409 & 8 & 0,3862 \\ 11,79574 & 2 & 0,0027 \\ 13,95987 & 9 & 0,1238 \\ 5,717338 & 3 & 0,1262 \\ 8,505623 & 12 & 0,7445 \\ 14,91129 & 12 & 0,2463 \\ 4,229132 & 3 & 0,2378 \\ 6,24187 & 9 & 0,7155 \\ 2,248677 & 3 & 0,5224 \\ 11,5283 & 12 & 0,4843 \\ 10,07412 & 12 & 0,6095 \\ 1,641644 & 3 & 0,6500 \\ 5,903982 & 9 & 0,7495 \\ 2,347343 & 3 & 0,5035 \\ 3,959032 & 12 & 0,9842 \\ 13,04292 & 12 & 0,3659 \\ 5,578653 & 3 & 0,1340 \\ 4,306861 & 9 & 0,8901 \\ 3,227149 & 3 & 0,3579 \\ 10,15668 & 12 & 0,6022 \\ 17,04825 & 12 & 0,1478 \\ 12,22538 & 3 & 0,0066 \\ 10,45681 & 9 & 0,3148 \\ 1,62117 & 3 & 0,6546 \\ 7,223294 & 12 & 0,8425 \\ 9,436816 & 3 & 0,6652 \\ 2,496006 & 9 & 0,4760 \\ 7,846973 & & 0,5496\end{array}$




\begin{tabular}{|c|c|c|c|c|}
\hline FUNCAO_GRUPO & Q2_PLANEJCIENT_SOCI & 0,168248 & 3 & 0,9825 \\
\hline IDADE & Q2_PLANEJCIENT_SOCI & 9,127667 & 12 & 0,6920 \\
\hline NIVELHIE & Q2_PLANEJCIENT_SOCI & 13,04311 & 12 & 0,3659 \\
\hline SEXO & Q2_PLANEJCIENT_SOCI & 14,91543 & 3 & 0,0019 \\
\hline FORMACAO_GRUPO & Q2_PLANEJCOMERCIANT & 7,870118 & 9 & 0,5473 \\
\hline FUNCAO_GRUPO & Q2_PLANEJCOMERCIANT & 7,585482 & 3 & 0,0554 \\
\hline IDADE & Q2_PLANEJCOMERCIANT & 14,72107 & 12 & 0,2570 \\
\hline NIVELHIE & Q2_PLANEJCOMERCIANT & 16,79902 & 12 & 0,1573 \\
\hline SEXO & Q2_PLANEJCOMERCIANT & 6,374125 & 3 & 0,0948 \\
\hline FORMACAO_GRUPO & Q2_PLANEJCOMITE_BAC & 6,741099 & 6 & 0,3455 \\
\hline FUNCAO_GRUPO & Q2_PLANEJCOMITE_BAC & 2,878095 & 2 & 0,2372 \\
\hline IDADE ${ }^{-}$ & Q2_PLANEJCOMITE_BAC & 16,35436 & 8 & 0,0376 \\
\hline NIVELHIE & Q2_PLANEJCOMITE_BAC & 3,162857 & 8 & 0,9237 \\
\hline SEXO & Q2_PLANEJCOMITE_BAC & 4,112155 & 2 & 0,1280 \\
\hline FORMACAO_GRUPO & Q2_PLANEJCOMUNIC_SO & 11,86941 & 9 & 0,2208 \\
\hline FUNCAO_GRUPO & Q2_PLANEJCOMUNIC_SO & 3,052291 & 3 & 0,3836 \\
\hline IDADE & Q2_PLANEJCOMUNIC_SO & 8,515838 & 12 & 0,7436 \\
\hline NIVELHIE & Q2_PLANEJCOMUNIC_SO & 12,78917 & 12 & 0,3845 \\
\hline SEXO & Q2_PLANEJCOMUNIC_SO & 10,7745 & 3 & 0,0130 \\
\hline FORMACAO_GRUPO & Q2_PLANEJCOMUNIT & 9,966113 & 9 & 0,3532 \\
\hline FUNCAO_GRÜPO & Q2_PLANEJCOMUNIT & 3,379076 & 3 & 0,3368 \\
\hline IDADE ${ }^{-}$ & Q2_PLANEJCOMUNIT & 5,754188 & 12 & 0,9280 \\
\hline NIVELHIE & Q2_PLANEJCOMUNIT & 14,33867 & 12 & 0,2796 \\
\hline SEXO & Q2_PLANEJCOMUNIT & 13,16228 & 3 & 0,0043 \\
\hline FORMACAO_GRUPO & Q2_PLANEJEDUCAMB & 6,495444 & 9 & 0,6895 \\
\hline FUNCAO_GRUPO & Q2_PLANEJEDUCAMB & 2,823005 & 3 & 0,4197 \\
\hline IDADE & Q2_PLANEJEDUCAMB & 5,621307 & 12 & 0,9340 \\
\hline NIVELHIE & Q2_PLANEJEDUCAMB & 11,4927 & 12 & 0,4872 \\
\hline SEXO & Q2 PLANEJEDUCAMB & 7,181466 & 3 & 0,0663 \\
\hline FORMACAO GRUPO & Q2 PLANEJENGENHEIRO & 0,477273 & 3 & 0,9239 \\
\hline FUNCAO GRUPOO & Q2 PLANEJENGENHEIRO & 0,694394 & 1 & 0,4047 \\
\hline IDADE & Q2_PLANEJENGENHEIRO & 10,32706 & 4 & 0,0353 \\
\hline NIVELHIE & Q2_PLANEJENGENHEIRO & 2,185313 & 4 & 0,7017 \\
\hline SEXO & Q2 PLANEJENGENHEIRO & 0,952921 & 1 & 0,3290 \\
\hline FORMACAO GRUPO & Q2 PLANEJMORADORES & 6,151492 & 9 & 0,7247 \\
\hline FUNCAO GRUPO & Q2 PLANEJMORADORES & 1,206318 & 3 & 0,7515 \\
\hline IDADE & Q2_PLANEJMORADORES & 6,708444 & 12 & 0,8763 \\
\hline NIVELHIE & Q2_PLANEJMORADORES & 5,786189 & 12 & 0,9265 \\
\hline SEXO & Q2_PLANEJMORADORES & 9,278143 & 3 & 0,0258 \\
\hline FORMACAO_GRUPO & Q2_PLANEJPOLITICOS & 4,544575 & 9 & 0,8721 \\
\hline FUNCAO_GRUPO & Q2_PLANEJPOLITICOS & 5,05138 & 3 & 0,1681 \\
\hline IDADE & Q2_PLANEJPOLITICOS & 10,72346 & 12 & 0,5528 \\
\hline NIVELHIE & Q2_PLANEJPOLITICOS & 15,14367 & 12 & 0,2337 \\
\hline SEXO & Q2_PLANEJPOLITICOS & 2,756386 & 3 & 0,4307 \\
\hline FORMACAO_GRUPO & Q2_PLANEJTECNICOS & 2,810097 & 6 & 0,8323 \\
\hline FUNCAO_GRUPO & Q2_PLANEJTECNICOS & 1,158522 & 2 & 0,5603 \\
\hline IDADE & Q2_PLANEJTECNICOS & 3,086861 & 8 & 0,9288 \\
\hline NIVELHIE & Q2_PLANEJTECNICOS & 6,39938 & 8 & 0,6026 \\
\hline SEXO & Q2_PLANEJTECNICOS & 3,473761 & 2 & 0,1761 \\
\hline FORMACAO_GRUPO & Q3_GERENTE_NENVOLVE & 13,31016 & 9 & 0,1491 \\
\hline FUNCAO_GRUPO & Q3_GERENTE_NENVOLVE & 3,34438 & 3 & 0,3415 \\
\hline $\mathrm{IDADE}^{-}$ & Q3_GERENTE_NENVOLVE & 7,605166 & 12 & 0,8152 \\
\hline NIVELHIE & Q3_GERENTE_NENVOLVE & 10,69811 & 12 & 0,5550 \\
\hline SEXO & Q3 GERENTE NENVOLVE & 6,919343 & 3 & 0,0745 \\
\hline
\end{tabular}




\begin{tabular}{|c|c|c|c|c|}
\hline FORMACAO_GRUPO & Q4_MORADOR_OPINAR & 4,423137 & 9 & 0,8814 \\
\hline FUNCAO_GRUPO & Q4_MORADOR_OPINAR & 3,356438 & 3 & 0,3399 \\
\hline IDADE & Q4_MORADOR_OPINAR & 9,346005 & 12 & 0,6731 \\
\hline NIVELHIE & Q4_MORADOR_OPINAR & 11,16234 & 12 & 0,5151 \\
\hline SEXO & Q4_MORADOR_OPINAR & 3,729198 & 3 & 0,2922 \\
\hline FORMACAO_GRUPO & Q5_COMERCIANTE_OPIN & 7,795243 & 9 & 0,5549 \\
\hline FUNCAO_GRUPO & Q5_COMERCIANTE_OPIN & 1,145353 & 3 & 0,7661 \\
\hline IDADE & Q5_COMERCIANTE_OPIN & 10,11659 & 12 & 0,6057 \\
\hline NIVELHIE & Q5_COMERCIANTE_OPIN & 11,78191 & 12 & 0,4634 \\
\hline SEXO & Q5_COMERCIANTE_OPIN & 5,134468 & 3 & 0,1622 \\
\hline FORMACAO_GRUPO & Q6_AUDPUB_SUF & 14,73007 & 9 & 0,0986 \\
\hline FUNCAO_GRUPO & Q6_AUDPUB_SUF & 0,560665 & 3 & 0,9054 \\
\hline IDADE & Q6_AUDPUB_SUF & 6,423654 & 12 & 0,8932 \\
\hline NIVELHIE & Q6_AUDPUB_SUF & 8,634204 & 12 & 0,7338 \\
\hline SEXO & Q6_AUDPUB_SUF & 1,854376 & 3 & 0,6032 \\
\hline FORMACAO_GRUPO & Q7_ENV_COMUNICSOC & 7,248339 & 9 & 0,6113 \\
\hline FUNCAO_GRUPO & Q7_ENV_COMUNICSOC & 1,402037 & 3 & 0,7051 \\
\hline IDADE & Q7_ENV_COMUNICSOC & 7,138869 & 12 & 0,8483 \\
\hline NIVELHIE & Q7_ENV_COMUNICSOC & 11,28678 & 12 & 0,5045 \\
\hline SEXO & Q7_ENV_COMUNICSOC & 6,964481 & 3 & 0,0730 \\
\hline FORMACAO_GRUPO & Q7_ENVCIENTSOC & 12,1978 & 9 & 0,2024 \\
\hline FUNCAO_GRUPO & Q7_ENVCIENTSOC & 0,389644 & 3 & 0,9424 \\
\hline IDADE & Q7_ENVCIENTSOC & 3,990008 & 12 & 0,9836 \\
\hline NIVELHIE & Q7_ENVCIENTSOC & 10,40746 & 12 & 0,5803 \\
\hline SEXO & Q7_ENVCIENTSOC & 14,40068 & 3 & 0,0024 \\
\hline FORMACAO_GRUPO & Q7_ENVEDUC & 8,314971 & 6 & 0,2159 \\
\hline FUNCAO_GRUPO & Q7_ENVEDUC & 1,851378 & 2 & 0,3963 \\
\hline IDADE & Q7_ENVEDUC & 4,853432 & 8 & 0,7731 \\
\hline NIVELHIE & Q7 ENVEDUC & 9,241081 & 8 & 0,3224 \\
\hline SEXO & Q7 ENVEDUC & 6,929434 & 2 & 0,0313 \\
\hline FORMACAO GRUPO & Q7 ENVEMPRESARIOS & 8,28807 & 9 & 0,5054 \\
\hline FUNCAO_GRUPO & Q7_ENVEMPRESARIOS & 1,431645 & 3 & 0,6981 \\
\hline IDADE & Q7_ENVEMPRESARIOS & 14,5867 & 12 & 0,2648 \\
\hline NIVELHIE & Q7 ENVEMPRESARIOS & 12,60123 & 12 & 0,3987 \\
\hline SEXO & Q7 ENVEMPRESARIOS & 6,545776 & 3 & 0,0879 \\
\hline FORMACAO GRUPO & Q7 ENVENGENHEIROS & 10,14413 & 6 & 0,1187 \\
\hline FUNCAO_GRUPO & Q7_ENVENGENHEIROS & 0,07514 & 2 & 0,9631 \\
\hline IDADE & Q7_ENVENGENHEIROS & 3,062411 & 8 & 0,9304 \\
\hline NIVELHIE & Q7_ENVENGENHEIROS & 11,12909 & 8 & 0,1945 \\
\hline SEXO & Q7_ENVENGENHEIROS & 2,166596 & 2 & 0,3385 \\
\hline FORMACAO_GRUPO & Q7_ENVESCOLAS & 8,495168 & 9 & 0,4851 \\
\hline FUNCAO_GRUPO & Q7_ENVESCOLAS & 0,414474 & 3 & 0,9372 \\
\hline IDADE & Q7_ENVESCOLAS & 7,006485 & 12 & 0,8572 \\
\hline NIVELHIE & Q7_ENVESCOLAS & 11,95353 & 12 & 0,4494 \\
\hline SEXO & Q7_ENVESCOLAS & 4,647848 & 3 & 0,1995 \\
\hline FORMACAO_GRUPO & Q7_ENVLIDERCOMUNI & 8,414027 & 9 & 0,4930 \\
\hline FUNCAO_GRUPO & Q7_ENVLIDERCOMUNI & 1,390492 & 3 & 0,7078 \\
\hline IDADE & Q7_ENVLIDERCOMUNI & 3,606516 & 12 & 0,9895 \\
\hline NIVELHIE & Q7_ENVLIDERCOMUNI & 15,36378 & 12 & 0,2221 \\
\hline SEXO & Q7_ENVLIDERCOMUNI & 13,30132 & 3 & 0,0040 \\
\hline FORMACAO_GRUPO & Q7_ENVMORADOR & 10,07289 & 9 & 0,3446 \\
\hline FUNCAO_GRUPO & Q7_ENVMORADOR & 0,362215 & 3 & 0,9479 \\
\hline IDADE & Q7_ENVMORADOR & 7,113304 & 12 & 0,8500 \\
\hline NIVELHIE & Q7 ENVMORADOR & 12,71923 & 12 & 0,3898 \\
\hline
\end{tabular}




\begin{tabular}{|c|c|c|c|c|}
\hline SEXO & Q7_ENVMORADOR & 3,855178 & 3 & 0,2775 \\
\hline FORMACAO_GRUPO & Q7_ENVPOLITICOS & 13,67797 & 9 & 0,1343 \\
\hline FUNCAO_GRUPO & Q7_ENVPOLITICOS & 1,386643 & 3 & 0,7087 \\
\hline IDADE & Q7_ENVPOLITICOS & 7,494901 & 12 & 0,8233 \\
\hline NIVELHIE & Q7_ENVPOLITICOS & 5,474032 & 12 & 0,9402 \\
\hline SEXO & Q7_ENVPOLITICOS & 3,162456 & 3 & 0,3672 \\
\hline FORMACAO_GRUPO & Q7_ENVTECNICO & 8,376821 & 6 & 0,2118 \\
\hline FUNCAO_GRUPO & Q7_ENVTECNICO & 2,977719 & 2 & 0,2256 \\
\hline IDADE & Q7_ENVTECNICO & 4,663722 & 8 & 0,7928 \\
\hline NIVELHIE & Q7_ENVTECNICO & 1,551243 & 8 & 0,9918 \\
\hline SEXO & Q7_ENVTECNICO & 7,610831 & 2 & 0,0222 \\
\hline FORMACAO_GRUPO & Q8_IMPLANT_AUTONOMI & 16,70688 & 9 & 0,0535 \\
\hline FUNCAO_GRUPO & Q8_IMPLANT_AUTONOMI & 4,780069 & 3 & 0,1886 \\
\hline IDADE & Q8_IMPLANT_AUTONOMI & 12,34661 & 12 & 0,4183 \\
\hline NIVELHIE & Q8_IMPLANT_AUTONOMI & 19,88132 & 12 & 0,0694 \\
\hline SEXO & Q8_IMPLANT_AUTONOMI & 2,292346 & 3 & 0,5140 \\
\hline FORMACAO_GRUPO & Q8_IMPLANT_COMPRE & 7,179167 & 6 & 0,3046 \\
\hline FUNCAO_GRUPO & Q8_IMPLANT_COMPRE & 0,525499 & 2 & 0,7689 \\
\hline IDADE & Q8_IMPLANT_COMPRE & 4,564701 & 8 & 0,8029 \\
\hline NIVELHIE & Q8_IMPLANT_COMPRE & 13,78522 & 8 & 0,0875 \\
\hline SEXO & Q8_IMPLANT_COMPRE & 5,941051 & 2 & 0,0513 \\
\hline FORMACAO_GRUPO & Q8_IMPLANT_SENS & 6,715255 & 9 & 0,6667 \\
\hline FUNCAO_GRUPO & Q8_IMPLANT_SENS & 3,068904 & 3 & 0,3811 \\
\hline IDADE & Q8_IMPLANT_SENS & 8,877067 & 12 & 0,7134 \\
\hline NIVELHIE & Q8_IMPLANT_SENS & 8,111603 & 12 & 0,7763 \\
\hline SEXO & Q8_IMPLANT_SENS & 3,80412 & 3 & 0,2834 \\
\hline FORMACAO_GRUPO & Q8_IMPLANT_TEMPO & 11,69066 & 9 & 0,2313 \\
\hline FUNCAO_GRUPO & Q8_IMPLANT_TEMPO & 3,030306 & 3 & 0,3870 \\
\hline IDADE & Q8_IMPLANT_TEMPO & 7,287379 & 12 & 0,8381 \\
\hline NIVELHIE & Q8_IMPLANT_TEMPO & 9,09912 & 12 & 0,6944 \\
\hline SEXO & Q8_IMPLANT_TEMPO & 5,705697 & 3 & 0,1268 \\
\hline FORMACAO_GRUPO & Q8_IMPLANT_VONTADE & 8,486716 & 9 & 0,4859 \\
\hline FUNCAO_GRUPO & Q8_IMPLANT_VONTADE & 4,187004 & 3 & 0,2420 \\
\hline IDADE & Q8_IMPLANT_VONTADE & 8,662957 & 12 & 0,7314 \\
\hline NIVELHIE & Q8_IMPLANT_VONTADE & 13,0829 & 12 & 0,3630 \\
\hline SEXO & Q8_IMPLANT_VONTADE & 6,50542 & 3 & 0,0894 \\
\hline FORMACAO_GRUPO & Q9_GRAD_SUFIC & 9,148846 & 9 & 0,4236 \\
\hline FUNCAO_GRUPO & Q9_GRAD_SUFIC & 2,068749 & 3 & 0,5583 \\
\hline IDADE & Q9_GRAD_SUFIC & 4,683238 & 12 & 0,9677 \\
\hline NIVELHIE & Q9_GRAD_SUFIC & 13,52593 & 12 & 0,3320 \\
\hline SEXO & Q9_GRAD_SUFIC & 6,40463 & 3 & 0,0935 \\
\hline
\end{tabular}




\section{ANEXO 6 - GESTORES E DEMAIS PROFISSIONAIS, TESTES ESTATÍSTICOS}

Programa utilizado SPSS versão 20.

Notas para tabelas gerais:

${ }_{a}$ Q2a is constant in one or more split files. It has been omitted.

b Q7g is constant in one or more split files. It has been omitted.

cUnless otherwise noted, bootstrap results are based on 1000 bootstrap samples

¿ Based on 849 samples

e Based on 960 samples

PRIMEIRA PARTE: COMPARAÇÕES POR FORMAÇÃO DOS RESPONDENTES

Questão 1 - Aspectos técnicos são tão importante quanto aspectos sociais no planejamento de obras de drenagem

\begin{tabular}{|c|c|c|c|c|c|c|c|}
\hline & & & Statistic & & Boc & $\operatorname{trap}^{\mathrm{c}}$ & \\
\hline & & & & Bias & Std. Error & $95 \%$ Confid & e Interval \\
\hline & & & & & & Lower & Upper \\
\hline & Mean & & 3.7755 & -.0014 & .0688 & 3.6327 & 3.8980 \\
\hline & $95 \%$ Confidence Interval for & Lower Bound & 3.6288 & & & & \\
\hline & Mean & Upper Bound & 3.9223 & & & & \\
\hline 04 & Median & & 4.0000 & .0000 & .0000 & 4.0000 & 4.0000 \\
\hline Q1 & Minimum & & 2.00 & & & & \\
\hline & Maximum & & 4.00 & & & & \\
\hline & Skewness & & -2.281 & .043 & .546 & -3.409 & -1.355 \\
\hline & Kurtosis & & 4.601 & -.114 & 3.046 & .307 & 12.064 \\
\hline
\end{tabular}

Comparação por formação

\begin{tabular}{|c|c|c|c|c|c|c|}
\hline \multirow[t]{3}{*}{ Formacao_num } & & & \multirow[t]{3}{*}{ Statistic } & \multicolumn{3}{|c|}{ Bootstrap $^{b}$} \\
\hline & & & & \multirow[t]{2}{*}{ Std. Error } & \multicolumn{2}{|c|}{ 95\% Confidence Interval } \\
\hline & & & & & Lower & Upper \\
\hline \multirow{5}{*}{ Arquitetura } & Mean & & 3.7500 & \multirow{5}{*}{$.0904^{\mathrm{c}}$} & $3.5500^{c}$ & $3.9000^{c}$ \\
\hline & $95 \%$ Confidence Interval for & Lower Bound & 3.5421 & & & \\
\hline & Mean & Upper Bound & 3.9579 & & & \\
\hline & Median & & 4.0000 & & $4.0000^{c}$ & $4.0000^{c}$ \\
\hline & Minimum & & 3.00 & & & \\
\hline
\end{tabular}




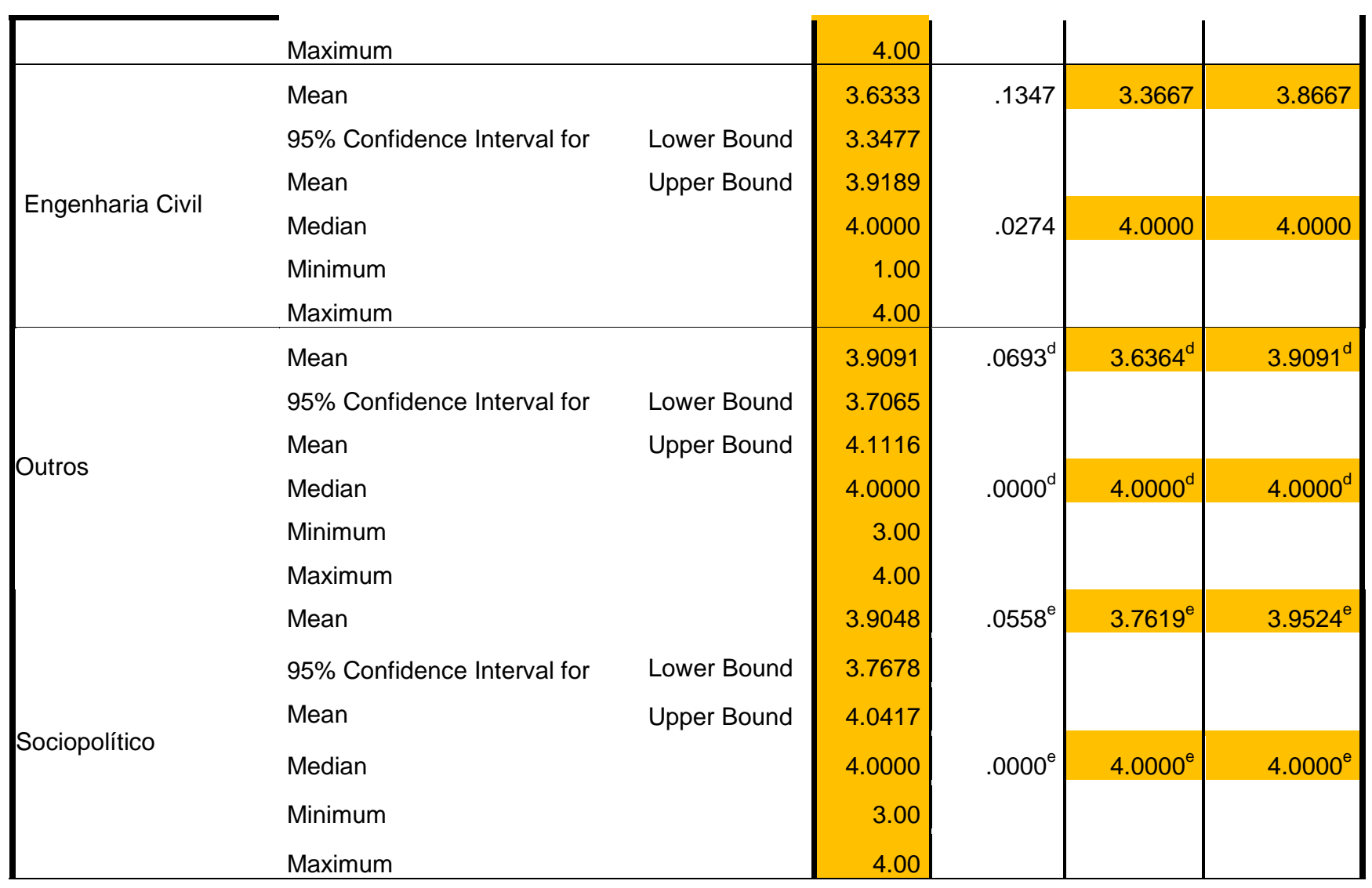

Questão 2 - 0 bom planejamento de obras de drenagem exige a participação de:

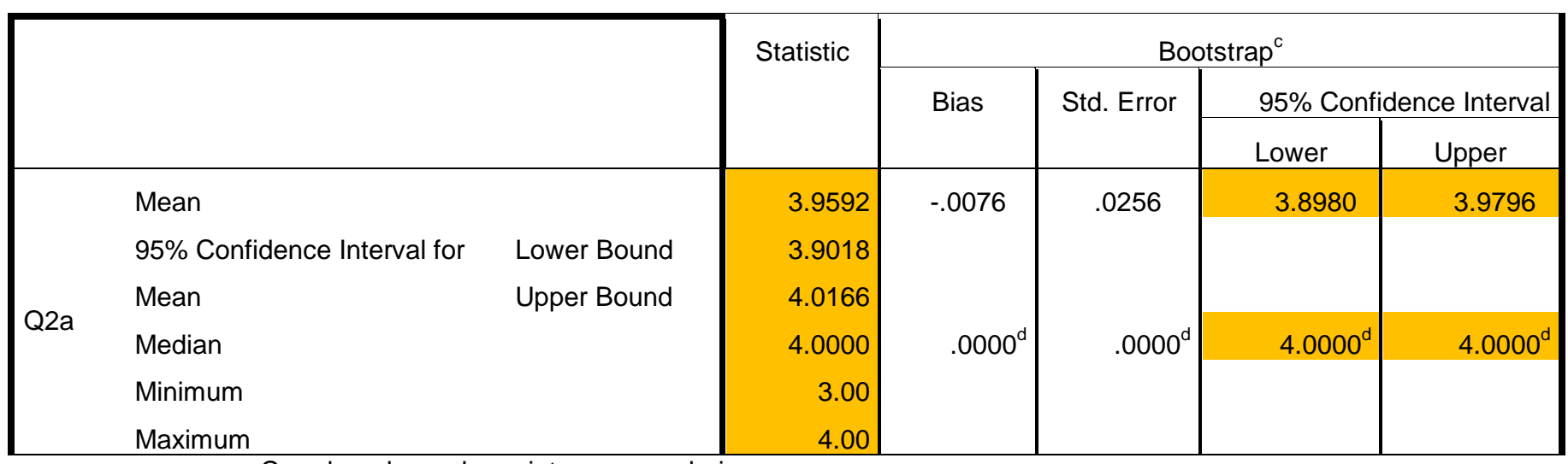

- $\quad$ Coordenadores de projetos e engenheiros

Comparação por formação

Formacao_num

(Coordenadores de projetos e engenheiros)

\begin{tabular}{|c|c|c|c|}
\hline \multirow{2}{*}{ Statistic } & \multicolumn{3}{|c|}{ Bootstrap $^{\mathrm{b}}$} \\
\cline { 2 - 3 } & \multirow{2}{*}{ Std. Error } & \multicolumn{2}{|c|}{$95 \%$ Confidence Interval } \\
\cline { 3 - 3 } & & Lower & Upper \\
\hline
\end{tabular}




\begin{tabular}{|c|c|c|c|c|c|c|}
\hline \multirow{6}{*}{ Arquitetura } & Mean & & 3.9545 & \multirow{6}{*}{$\begin{array}{l}.0367^{c} \\
.0000^{c}\end{array}$} & \multirow{6}{*}{$\begin{array}{l}3.8182^{c} \\
4.0000^{c}\end{array}$} & \multirow{6}{*}{$\begin{array}{l}3.9545^{\mathrm{c}} \\
4.0000^{\mathrm{c}}\end{array}$} \\
\hline & $95 \%$ Confidence Interval for & Lower Bound & 3.8600 & & & \\
\hline & Mean & Upper Bound & 4.0491 & & & \\
\hline & Median & & 4.0000 & & & \\
\hline & Minimum & & 3.00 & & & \\
\hline & Maximum & & 4.00 & & & \\
\hline \multirow{6}{*}{ Engenharia Civil } & Mean & \multirow{6}{*}{$\begin{array}{l}\text { Lower Bound } \\
\text { Upper Bound }\end{array}$} & 3.9667 & \multirow{6}{*}{$\begin{array}{l}.0275^{\mathrm{d}} \\
.0000^{\mathrm{d}}\end{array}$} & $3.8667^{d}$ & \multirow[t]{3}{*}{$3.9667^{d}$} \\
\hline & $95 \%$ Confidence Interval for & & 3.8985 & & & \\
\hline & Mean & & 4.0348 & & & \\
\hline & Median & & 4.0000 & & $4.0000^{d}$ & $4.0000^{d}$ \\
\hline & Minimum & & 3.00 & & & \\
\hline & Maximum & & 4.00 & & & \\
\hline \multirow{6}{*}{ Outros } & Mean & \multirow{6}{*}{$\begin{array}{l}\text { Lower Bound } \\
\text { Upper Bound }\end{array}$} & 3.9167 & \multirow[t]{3}{*}{$.0610^{\mathrm{e}}$} & $3.7500^{\mathrm{e}}$ & $3.9167^{e}$ \\
\hline & $95 \%$ Confidence Interval for & & 3.7333 & & & \\
\hline & Mean & & 4.1001 & & & \\
\hline & Median & & 4.0000 & \multirow[t]{3}{*}{$.0000^{\mathrm{e}}$} & $4.0000^{\mathrm{e}}$ & $4.0000^{e}$ \\
\hline & Minimum & & 3.00 & & & \\
\hline & Maximum & & 4.00 & & & \\
\hline \multirow{6}{*}{ Sociopolítico } & Mean & & 3.9500 & \multirow[t]{3}{*}{$.0387^{f}$} & $3.8000^{f}$ & $3.9500^{f}$ \\
\hline & 95\% Confidence Interval for & Lower Bound & 3.8453 & & & \\
\hline & Mean & Upper Bound & 4.0547 & & & \\
\hline & Median & & 4.0000 & \multirow[t]{3}{*}{$.0000^{f}$} & $4.0000^{f}$ & $4.0000^{f}$ \\
\hline & Minimum & & 3.00 & & & \\
\hline & Maximum & & 4.00 & & & \\
\hline
\end{tabular}

- Técnicos de manutenção de obras de drenagem

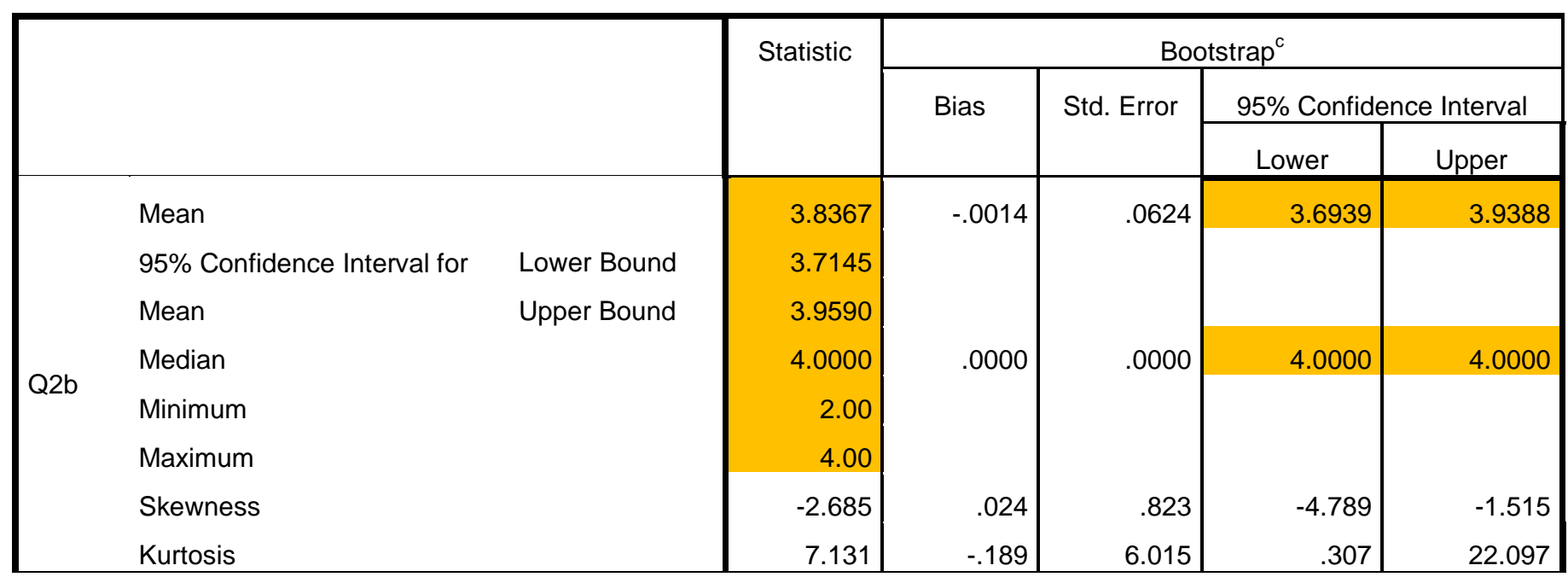


Comparação por formação

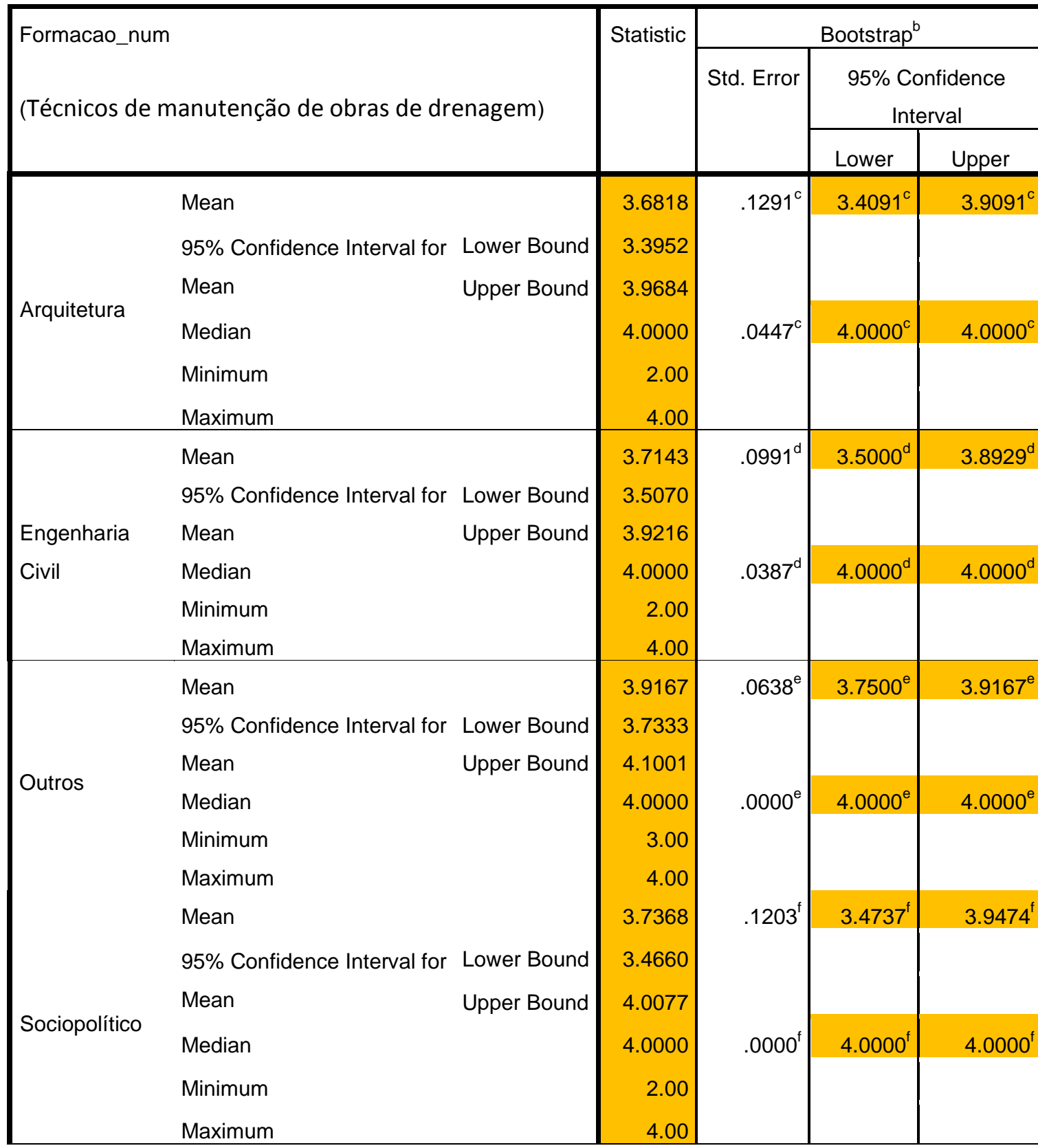

- Lideranças comunitárias 


\begin{tabular}{|c|c|c|c|c|c|c|c|}
\hline & & & & & & Lower & Upper \\
\hline \multirow{8}{*}{ Q2c } & Mean & & 3.5510 & .0003 & .0980 & 3.3469 & 3.7347 \\
\hline & 95\% Confidence Interval for & Lower Bound & 3.3560 & & & & \\
\hline & Mean & Upper Bound & 3.7460 & & & & \\
\hline & Median & & 4.0000 & -.0250 & .1562 & 3.0254 & 4.0000 \\
\hline & Minimum & & 1.00 & & & & \\
\hline & Maximum & & 4.00 & & & & \\
\hline & Skewness & & -1.650 & .203 & .459 & -2.304 & -.568 \\
\hline & Kurtosis & & 3.090 & -1.035 & 2.131 & -1.628 & 6.582 \\
\hline
\end{tabular}

Comparação por formação

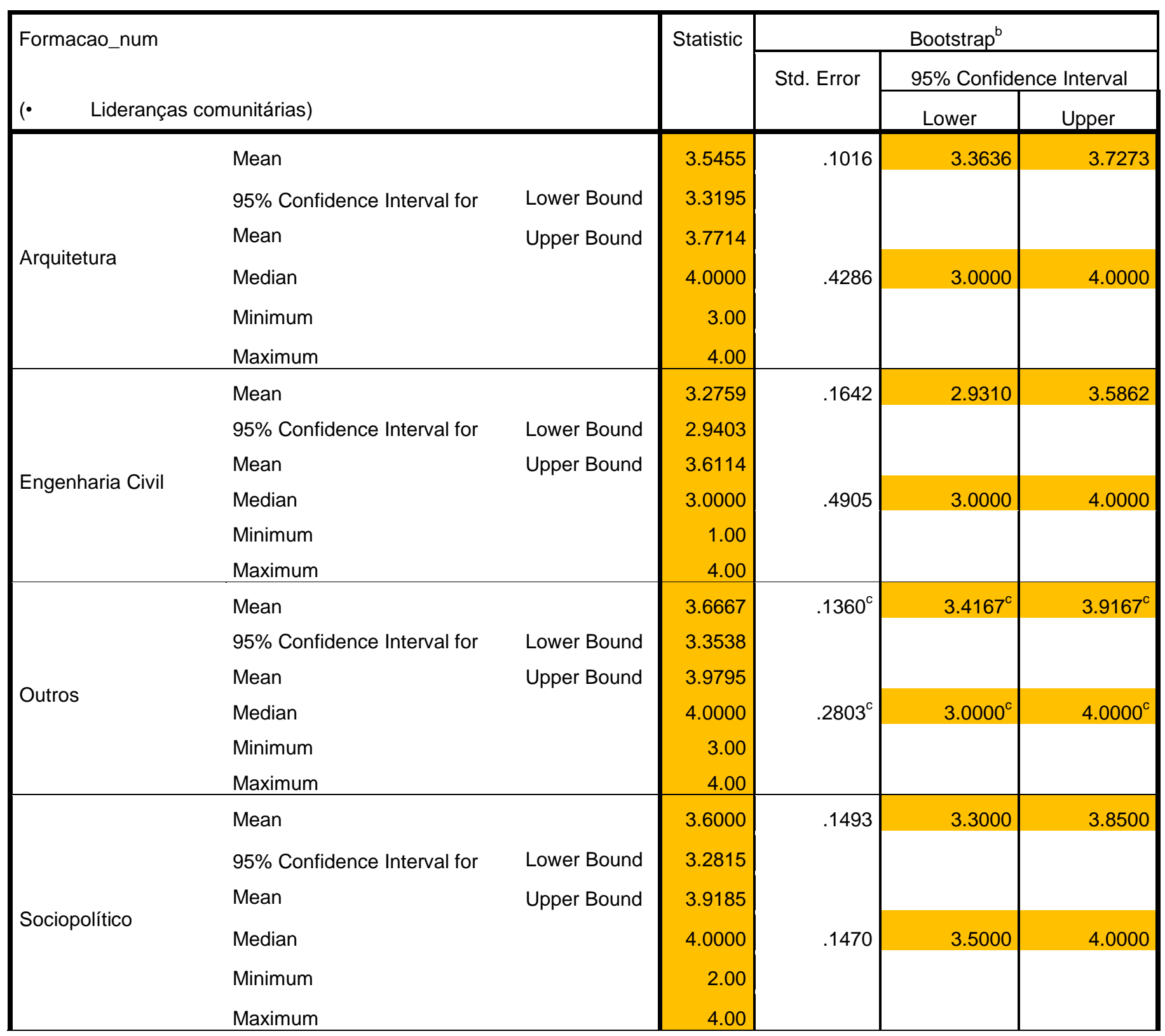


- $\quad$ Educadores ambientais

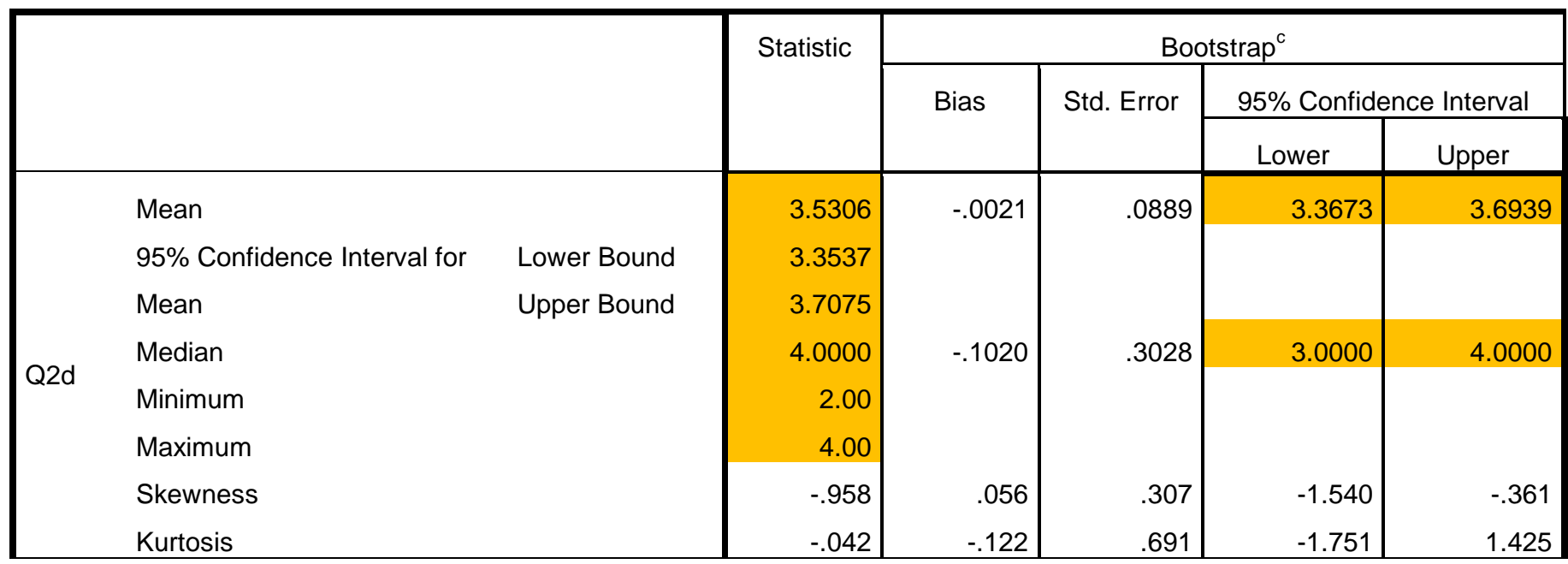

Comparação por formação

\begin{tabular}{|c|c|c|c|c|c|c|}
\hline \multicolumn{3}{|l|}{ Formacao_num } & \multirow[t]{3}{*}{ Statistic } & \multicolumn{3}{|c|}{ Bootstrap $^{b}$} \\
\hline \multirow[b]{2}{*}{ Educador } & \multirow{2}{*}{\multicolumn{2}{|c|}{ nbientais) }} & & \multirow[t]{2}{*}{ Std. Error } & \multicolumn{2}{|c|}{$95 \%$ Confidence Interval } \\
\hline & & & & & Lower & Upper \\
\hline \multirow{6}{*}{ Arquitetura } & Mean & & 3.5000 & .1386 & 3.2273 & 3.7727 \\
\hline & $95 \%$ Confidence Interval for & Lower Bound & 3.2018 & & & \\
\hline & Mean & Upper Bound & 3.7982 & & & \\
\hline & Median & & 4.0000 & .3429 & 3.0000 & 4.0000 \\
\hline & Minimum & & 2.00 & & & \\
\hline & Maximum & & 4.00 & & & \\
\hline \multirow{6}{*}{ Engenharia Civil } & Mean & & 3.2759 & .1370 & 3.0000 & 3.5172 \\
\hline & $95 \%$ Confidence Interval for & Lower Bound & 2.9902 & & & \\
\hline & Mean & Upper Bound & 3.5615 & & & \\
\hline & Median & & 3.0000 & .3758 & 3.0000 & 4.0000 \\
\hline & Minimum & & 1.00 & & & \\
\hline & Maximum & & 4.00 & & & \\
\hline \multirow{6}{*}{ Outros } & Mean & & 3.6667 & $.1744^{\mathrm{c}}$ & $3.2500^{c}$ & $3.9167^{c}$ \\
\hline & $95 \%$ Confidence Interval for & Lower Bound & 3.2528 & & & \\
\hline & Mean & Upper Bound & 4.0805 & & & \\
\hline & Median & & 4.0000 & $.1587^{c}$ & $3.5000^{c}$ & $4.0000^{c}$ \\
\hline & Minimum & & 2.00 & & & \\
\hline & Maximum & & 4.00 & & & \\
\hline Sociopolítico & Mean & & 3.4211 & .1536 & 3.1053 & 3.7368 \\
\hline
\end{tabular}




\begin{tabular}{|c|c|c|c|c|c|}
\hline 95\% Confidence Interval for & Lower Bound & 3.0873 & \multirow{5}{*}{.4884} & \multirow{5}{*}{3.0000} & \multirow{5}{*}{4.0000} \\
\hline Mean & Upper Bound & 3.7548 & & & \\
\hline Median & & 4.0000 & & & \\
\hline Minimum & & 2.00 & & & \\
\hline Maximum & & 4.00 & & & \\
\hline
\end{tabular}

- Comerciantes instalados na área onde as obras serão implantadas

\begin{tabular}{|c|c|c|c|c|c|c|c|}
\hline & & & Statistic & & Boc & $\operatorname{trap}^{c}$ & \\
\hline & & & & Bias & Std. Error & 95\% Confide & Interval \\
\hline & & & & & & Lower & Upper \\
\hline & Mean & & 3.1837 & .0026 & 1208 & 2.9388 & 3.4286 \\
\hline & $95 \%$ Confidence Interval for & Lower Bound & 2.9443 & & & & \\
\hline & Mean & Upper Bound & 3.4231 & & & & \\
\hline Q2e & Median & & 3.0000 & .1540 & .3611 & 3.0000 & 4.0000 \\
\hline & Minimum & & 1.00 & & & & \\
\hline & Maximum & & 4.00 & & & & \\
\hline & Skewness & & -.588 & .033 & .258 & -1.089 & -.077 \\
\hline & Kurtosis & & -.668 & -.055 & .563 & -1.540 & .588 \\
\hline
\end{tabular}

Comparação por formação

\begin{tabular}{|c|c|c|c|c|c|c|}
\hline \multicolumn{3}{|l|}{ Formacao_num } & \multirow[t]{3}{*}{ Statistic } & \multicolumn{3}{|c|}{ Bootstrap $^{a}$} \\
\hline \multirow{2}{*}{\multicolumn{3}{|c|}{ (Comerciantes instalados na área onde as obras serão implantadas) }} & & \multirow[t]{2}{*}{ Std. Error } & \multicolumn{2}{|c|}{ 95\% Confidence Interval } \\
\hline & & & & & Lower & Upper \\
\hline \multirow{6}{*}{ Arquitetura } & Mean & & 3.2273 & .1597 & 2.9091 & 3.5455 \\
\hline & 95\% Confidence Interval for & Lower Bound & 2.8940 & & & \\
\hline & Mean & Upper Bound & 3.5605 & & & \\
\hline & Median & & 3.0000 & .3678 & 3.0000 & 4.0000 \\
\hline & Minimum & & 2.00 & & & \\
\hline & Maximum & & 4.00 & & & \\
\hline \multirow{6}{*}{ Engenharia Civil } & Mean & & 2.9667 & 1717 & 2.6333 & 3.3000 \\
\hline & 95\% Confidence Interval for & Lower Bound & 2.6202 & & & \\
\hline & Mean & Upper Bound & 3.3131 & & & \\
\hline & Median & & 3.0000 & .0979 & 3.0000 & 3.0000 \\
\hline & Minimum & & 1.00 & & & \\
\hline & Maximum & & 4.00 & & & \\
\hline \multirow{3}{*}{ Outros } & Mean & & 3.2500 & .2103 & 2.8333 & 3.6667 \\
\hline & 95\% Confidence Interval for & Lower Bound & 2.7711 & & & \\
\hline & Mean & Upper Bound & 3.7289 & & & \\
\hline
\end{tabular}




\begin{tabular}{|c|c|c|c|c|c|c|}
\hline & Median & & 3.0000 & .4079 & 3.0000 & 4.0000 \\
\hline & Minimum & & 2.00 & & & \\
\hline & Maximum & & 4.00 & & & \\
\hline & Mean & & 3.3000 & 1697 & 2.9500 & 3.6000 \\
\hline & $95 \%$ Confidence Interval for & Lower Bound & 2.9250 & & & \\
\hline & Mean & Upper Bound & 3.6750 & & & \\
\hline 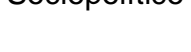 & Median & & 3.5000 & 4531 & 3.0000 & 4.0000 \\
\hline & Minimum & & 2.00 & & & \\
\hline & Maximum & & 4.00 & & & \\
\hline
\end{tabular}

Comitês de bacias hidrográficas

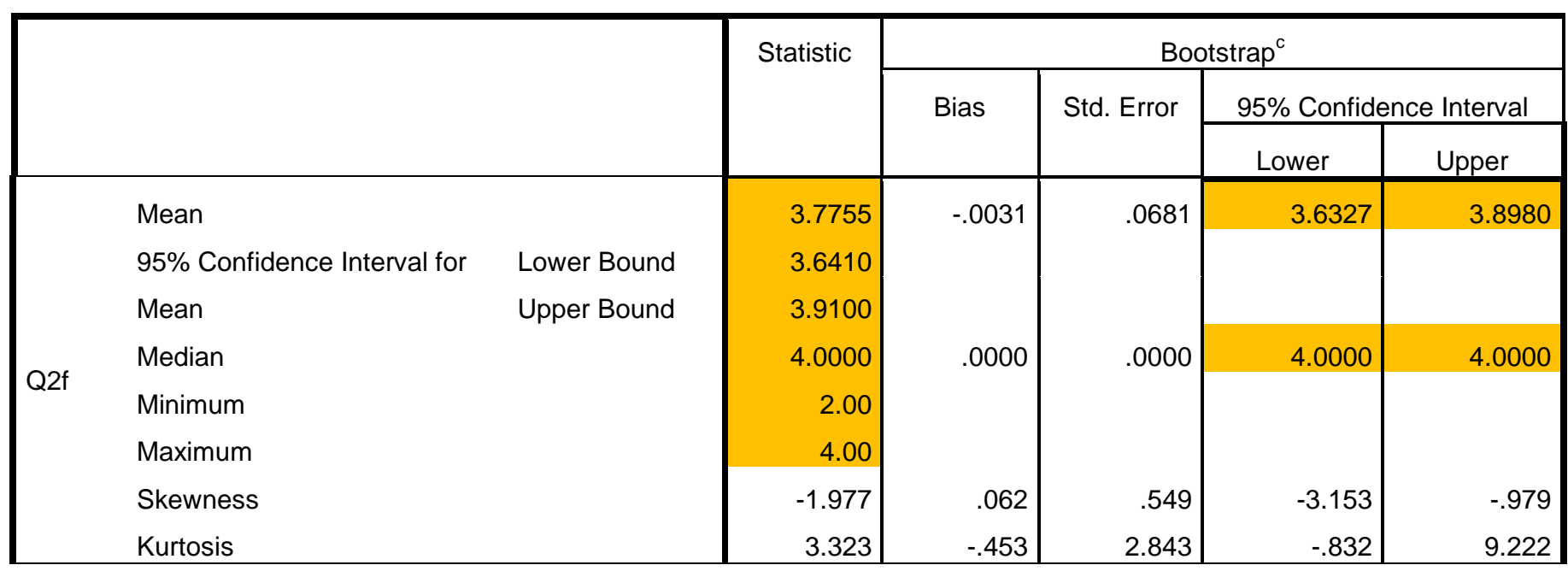

Comparação por formação

\begin{tabular}{|c|c|c|c|c|c|c|}
\hline \multirow{3}{*}{\multicolumn{2}{|c|}{$\begin{array}{l}\text { Formacao_num } \\
\text { (Comitês de bacias hidrográficas) }\end{array}$}} & & \multirow[t]{3}{*}{ Statistic } & \multicolumn{3}{|c|}{ Bootstrap $^{b}$} \\
\hline & & & & \multirow[t]{2}{*}{ Std. Error } & \multicolumn{2}{|c|}{ 95\% Confidence Interval } \\
\hline & & & & & Lower & Upper \\
\hline \multirow{6}{*}{ Arquitetura } & Mean & & 3.9524 & $.0362^{\mathrm{c}}$ & $3.8571^{\mathrm{C}}$ & $3.9524^{\mathrm{C}}$ \\
\hline & 95\% Confidence Interval for & Lower Bound & 3.8530 & & & \\
\hline & Mean & Upper Bound & 4.0517 & & & \\
\hline & Median & & 4.0000 & $.0000^{c}$ & $4.0000^{\mathrm{C}}$ & $4.0000^{c}$ \\
\hline & Minimum & & 3.00 & & & \\
\hline & Maximum & & 4.00 & & & \\
\hline \multirow{3}{*}{ Engenharia Civil } & Mean & & 3.7000 & \multirow[t]{3}{*}{0952} & \multirow[t]{3}{*}{3.5000} & \multirow[t]{3}{*}{3.8667} \\
\hline & $95 \%$ Confidence Interval for & Lower Bound & 3.5002 & & & \\
\hline & Mean & Upper Bound & 3.8998 & & & \\
\hline
\end{tabular}




\begin{tabular}{|c|c|c|c|c|c|c|}
\hline & $\begin{array}{l}\text { Median } \\
\text { Minimum } \\
\text { Maximum }\end{array}$ & & $\begin{array}{r}4.0000 \\
2.00 \\
4.00 \\
\end{array}$ & .0668 & 4.0000 & 4.0000 \\
\hline \multirow{6}{*}{ Outros } & Mean & & 3.6667 & $.1344^{\mathrm{d}}$ & $3.4167^{d}$ & $3.9167^{d}$ \\
\hline & 95\% Confidence Interval for & Lower Bound & 3.3538 & & & \\
\hline & Mean & Upper Bound & 3.9795 & & & \\
\hline & Median & & 4.0000 & $.2894^{d}$ & $3.0000^{d}$ & $4.0000^{d}$ \\
\hline & Minimum & & 3.00 & & & \\
\hline & Maximum & & 4.00 & & & \\
\hline \multirow{6}{*}{ Sociopolítico } & Mean & & 3.8333 & \multirow[t]{3}{*}{$.0815^{\mathrm{e}}$} & \multirow[t]{3}{*}{$3.6667^{\mathrm{e}}$} & \multirow[t]{3}{*}{$3.9444^{\mathrm{e}}$} \\
\hline & $95 \%$ Confidence Interval for & Lower Bound & 3.6426 & & & \\
\hline & Mean & Upper Bound & 4.0240 & & & \\
\hline & Median & & 4.0000 & \multirow[t]{3}{*}{$.0162^{\mathrm{e}}$} & \multirow[t]{3}{*}{$4.0000^{\mathrm{e}}$} & \multirow[t]{3}{*}{$4.0000^{\circ}$} \\
\hline & Minimum & & 3.00 & & & \\
\hline & Maximum & & 4.00 & & & \\
\hline
\end{tabular}

- Políticos da região

\begin{tabular}{|c|c|c|c|c|c|c|c|}
\hline & & & \multirow[t]{3}{*}{ Statistic } & \multicolumn{4}{|c|}{ Bootstrap ${ }^{c}$} \\
\hline & & & & \multirow[t]{2}{*}{ Bias } & \multirow[t]{2}{*}{ Std. Error } & \multicolumn{2}{|c|}{ 95\% Confidence Interval } \\
\hline & & & & & & Lower & Upper \\
\hline \multirow{8}{*}{ Q2g } & Mean & & 2.9184 & -.0087 & .1456 & 2.6327 & 3.1837 \\
\hline & $95 \%$ Confidence Interval for & Lower Bound & 2.6203 & & & & \\
\hline & Mean & Upper Bound & 3.2164 & & & & \\
\hline & Median & & 3.0000 & .0110 & .1044 & 3.0000 & 3.0000 \\
\hline & Minimum & & 1.00 & & & & \\
\hline & Maximum & & 4.00 & & & & \\
\hline & Skewness & & -.648 & .011 & .215 & -1.091 & -.233 \\
\hline & Kurtosis & & -.690 & .062 & .500 & -1.370 & .608 \\
\hline
\end{tabular}

Comparação por formação

\begin{tabular}{|c|c|c|c|c|c|c|}
\hline \multirow{3}{*}{\multicolumn{2}{|c|}{$\begin{array}{l}\text { Formacao_num } \\
\text { - (Políticos da região) }\end{array}$}} & & \multirow[t]{3}{*}{ Statistic } & \multicolumn{3}{|c|}{ Bootstrap $^{a}$} \\
\hline & & & & \multirow[t]{2}{*}{ Std. Error } & \multicolumn{2}{|c|}{ 95\% Confidence Interval } \\
\hline & & & & & Lower & Upper \\
\hline \multirow{3}{*}{ Arquitetura } & Mean & & 2.8500 & \multirow[t]{3}{*}{.2402} & \multirow[t]{3}{*}{2.3513} & \multirow[t]{3}{*}{3.3000} \\
\hline & 95\% Confidence Interval for & Lower Bound & 2.3401 & & & \\
\hline & Mean & Upper Bound & 3.3599 & & & \\
\hline
\end{tabular}




\begin{tabular}{|c|c|c|c|c|c|c|}
\hline & $\begin{array}{l}\text { Median } \\
\text { Minimum } \\
\text { Maximum }\end{array}$ & & $\begin{array}{r}3.0000 \\
1.00 \\
4.00 \\
\end{array}$ & .3853 & 2.0000 & 4.0000 \\
\hline \multirow{6}{*}{ Engenharia Civil } & Mean & \multirow{6}{*}{$\begin{array}{l}\text { Lower Bound } \\
\text { Upper Bound }\end{array}$} & 2.6897 & \multirow[t]{3}{*}{.1800} & \multirow[t]{3}{*}{2.3448} & \multirow[t]{3}{*}{3.0690} \\
\hline & 95\% Confidence Interval for & & 2.3079 & & & \\
\hline & Mean & & 3.0714 & & & \\
\hline & Median & & 3.0000 & \multirow[t]{3}{*}{.3600} & \multirow[t]{3}{*}{2.0000} & \multirow[t]{3}{*}{3.0000} \\
\hline & Minimum & & 1.00 & & & \\
\hline & Maximum & & 4.00 & & & \\
\hline \multirow{6}{*}{ Outros } & Mean & & 2.6667 & \multirow[t]{3}{*}{.2435} & \multirow[t]{3}{*}{2.1667} & \multirow[t]{3}{*}{3.1667} \\
\hline & 95\% Confidence Interval for & Lower Bound & 2.1027 & & & \\
\hline & Mean & Upper Bound & 3.2306 & & & \\
\hline & Median & & 3.0000 & \multirow[t]{3}{*}{.4101} & \multirow[t]{3}{*}{2.0000} & \multirow[t]{3}{*}{3.0000} \\
\hline & Minimum & & 1.00 & & & \\
\hline & Maximum & & 4.00 & & & \\
\hline \multirow{6}{*}{ Sociopolítico } & Mean & & 2.7895 & \multirow[t]{3}{*}{.2611} & \multirow[t]{3}{*}{2.3158} & \multirow[t]{3}{*}{3.3158} \\
\hline & 95\% Confidence Interval for & Lower Bound & 2.2428 & & & \\
\hline & Mean & Upper Bound & 3.3362 & & & \\
\hline & Median & & 3.0000 & \multirow[t]{3}{*}{.3116} & \multirow[t]{3}{*}{2.0000} & \multirow[t]{3}{*}{4.0000} \\
\hline & Minimum & & 1.00 & & & \\
\hline & Maximum & & 4.00 & & & \\
\hline
\end{tabular}

- Moradores na área onde as obras serão implantadas

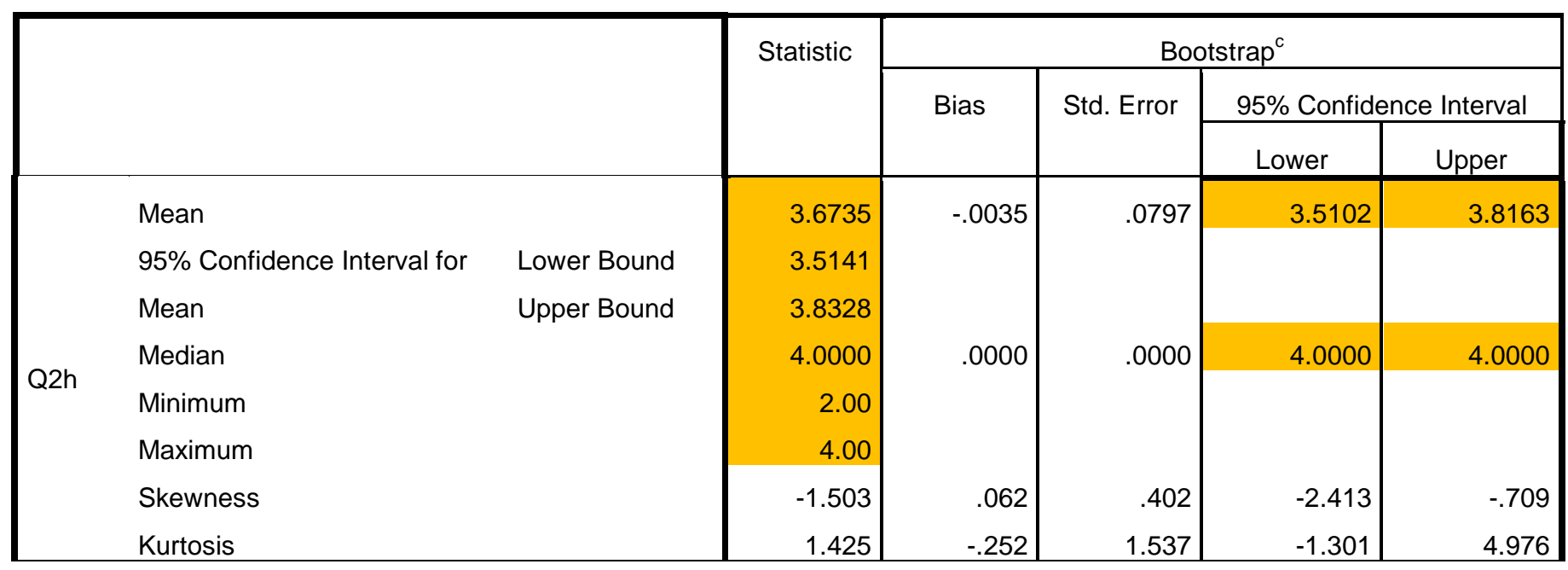

Comparação por formação 


\begin{tabular}{|c|c|c|c|c|c|c|}
\hline \multirow{2}{*}{\multicolumn{3}{|c|}{ - (Moradores na área onde as obras serão implantadas) }} & & \multirow[t]{2}{*}{ Std. Error } & \multicolumn{2}{|c|}{ 95\% Confidence Interval } \\
\hline & & & & & Lower & Upper \\
\hline \multirow{6}{*}{ Arquitetura } & Mean & & 3.5238 & \multirow[t]{6}{*}{.1311} & \multirow[t]{6}{*}{3.2857} & \multirow[t]{6}{*}{3.7619} \\
\hline & 95\% Confidence Interval for & Lower Bound & 3.2500 & & & \\
\hline & Mean & Upper Bound & 3.7976 & & & \\
\hline & Median & & 4.0000 & & & \\
\hline & Minimum & & 2.00 & & & \\
\hline & Maximum & & 4.00 & & & \\
\hline \multirow{6}{*}{ Engenharia Civil } & Mean & & 3.4138 & \multirow[t]{6}{*}{.1394} & \multirow[t]{6}{*}{3.1379} & \multirow[t]{6}{*}{3.6897} \\
\hline & 95\% Confidence Interval for & Lower Bound & 3.1171 & & & \\
\hline & Mean & Upper Bound & 3.7105 & & & \\
\hline & Median & & 4.0000 & & & \\
\hline & Minimum & & 1.00 & & & \\
\hline & Maximum & & 4.00 & & & \\
\hline \multirow{6}{*}{ Outros } & Mean & & 3.7500 & \multirow[t]{6}{*}{$.1165^{c}$} & \multirow[t]{6}{*}{$3.5000^{c}$} & \multirow[t]{3}{*}{$3.9167^{\mathrm{C}}$} \\
\hline & 95\% Confidence Interval for & Lower Bound & 3.4626 & & & \\
\hline & Mean & Upper Bound & 4.0374 & & & \\
\hline & Median & & 4.0000 & & & $4.0000^{\mathrm{C}}$ \\
\hline & Minimum & & 3.00 & & & \\
\hline & Maximum & & 4.00 & & & \\
\hline \multirow{6}{*}{ Sociopolítico } & Mean & & 3.7619 & \multirow[t]{6}{*}{$.0921^{d}$} & \multirow[t]{6}{*}{$3.5714^{d}$} & \multirow[t]{6}{*}{$3.9048^{d}$} \\
\hline & 95\% Confidence Interval for & Lower Bound & 3.5632 & & & \\
\hline & Mean & Upper Bound & 3.9606 & & & \\
\hline & Median & & 4.0000 & & & \\
\hline & Minimum & & 3.00 & & & \\
\hline & Maximum & & 4.00 & & & \\
\hline
\end{tabular}

- Comunicadores sociais

\begin{tabular}{|c|c|c|c|c|c|c|c|}
\hline & & & \multirow[t]{3}{*}{ Statistic } & \multicolumn{4}{|c|}{ Bootstrap $^{c}$} \\
\hline & & & & \multirow[t]{2}{*}{ Bias } & \multirow[t]{2}{*}{ Std. Error } & \multicolumn{2}{|c|}{ 95\% Confidence Interval } \\
\hline & & & & & & Lower & Upper \\
\hline \multirow{7}{*}{ Q2i } & Mean & & 3.4898 & \multirow[t]{3}{*}{.0001} & \multirow[t]{3}{*}{.0959} & 3.3061 & 3.6735 \\
\hline & 95\% Confidence Interval for & Lower Bound & 3.2943 & & & & \\
\hline & Mean & Upper Bound & 3.6853 & & & & \\
\hline & Median & & 4.0000 & \multirow[t]{3}{*}{-.1150} & \multirow[t]{3}{*}{.3192} & 3.0000 & 4.0000 \\
\hline & Minimum & & 2.00 & & & & \\
\hline & Maximum & & 4.00 & & & & \\
\hline & Skewness & & -.994 & .019 & .277 & -1.633 & -.496 \\
\hline
\end{tabular}


Kurtosis

$-.179$

.048

.649

$-1.060$

Comparação por formação

\begin{tabular}{|c|c|c|c|c|c|c|}
\hline \multicolumn{3}{|l|}{ Formacao_num } & \multirow[t]{3}{*}{ Statistic } & \multicolumn{3}{|c|}{ Bootstrap $^{\mathrm{b}}$} \\
\hline \multirow{2}{*}{\multicolumn{3}{|c|}{ - (Comunicadores sociais) }} & & \multirow[t]{2}{*}{ Std. Error } & \multicolumn{2}{|c|}{$95 \%$ Confidence Interval } \\
\hline & & & & & Lower & Upper \\
\hline \multirow{6}{*}{ Arquitetura } & Mean & & 3.6190 & \multirow[t]{6}{*}{.1219} & \multirow[t]{6}{*}{3.3810} & \multirow[t]{6}{*}{3.8571} \\
\hline & $95 \%$ Confidence Interval for & Lower Bound & 3.3507 & & & \\
\hline & Mean & Upper Bound & 3.8874 & & & \\
\hline & Median & & 4.0000 & & & \\
\hline & Minimum & & 2.00 & & & \\
\hline & Maximum & & 4.00 & & & \\
\hline \multirow{6}{*}{ Engenharia Civil } & Mean & & 3.1034 & \multirow[t]{6}{*}{.1490} & \multirow[t]{6}{*}{2.8276} & \multirow[t]{6}{*}{3.3793} \\
\hline & 95\% Confidence Interval for & Lower Bound & 2.7927 & & & \\
\hline & Mean & Upper Bound & 3.4142 & & & \\
\hline & Median & & 3.0000 & & & \\
\hline & Minimum & & 1.00 & & & \\
\hline & Maximum & & 4.00 & & & \\
\hline \multirow{6}{*}{ Outros } & Mean & & 3.4167 & \multirow[t]{6}{*}{$.2451^{\mathrm{c}}$} & \multirow[t]{6}{*}{$2.9105^{c}$} & \multirow[t]{6}{*}{$3.8333^{\mathrm{c}}$} \\
\hline & 95\% Confidence Interval for & Lower Bound & 2.8446 & & & \\
\hline & Mean & Upper Bound & 3.9887 & & & \\
\hline & Median & & 4.0000 & & & \\
\hline & Minimum & & 1.00 & & & \\
\hline & Maximum & & 4.00 & & & \\
\hline \multirow{6}{*}{ Sociopolítico } & Mean & & 3.6190 & \multirow[t]{6}{*}{.1250} & \multirow[t]{6}{*}{3.3333} & \multirow{6}{*}{4.0000} \\
\hline & $95 \%$ Confidence Interval for & Lower Bound & 3.3507 & & & \\
\hline & Mean & Upper Bound & 3.8874 & & & \\
\hline & Median & & 4.0000 & & & \\
\hline & Minimum & & 2.00 & & & \\
\hline & Maximum & & 4.00 & & & \\
\hline
\end{tabular}

Cientistas sociais 


\begin{tabular}{|lll|r|r|r|r|r|}
\hline & & & & & Lower & \multicolumn{1}{c|}{ Upper } \\
\hline Mean & & 3.1224 & -.0065 & .1262 & 2.8571 & 3.3673 \\
95\% Confidence Interval for & Lower Bound & 2.8627 & & & & \\
Mean & Upper Bound & 3.3822 & & & & \\
Q2j & & 3.0000 & .1390 & .3490 & 3.0000 & 4.0000 \\
Median & & 1.00 & & & & \\
& Minimum & 4.00 & & & & \\
Maximum & & -.602 & .028 & .252 & -1.129 & -.099 \\
Skewness & -.710 & -.001 & .501 & -1.521 & .442 \\
\hline
\end{tabular}

Comparação por formação

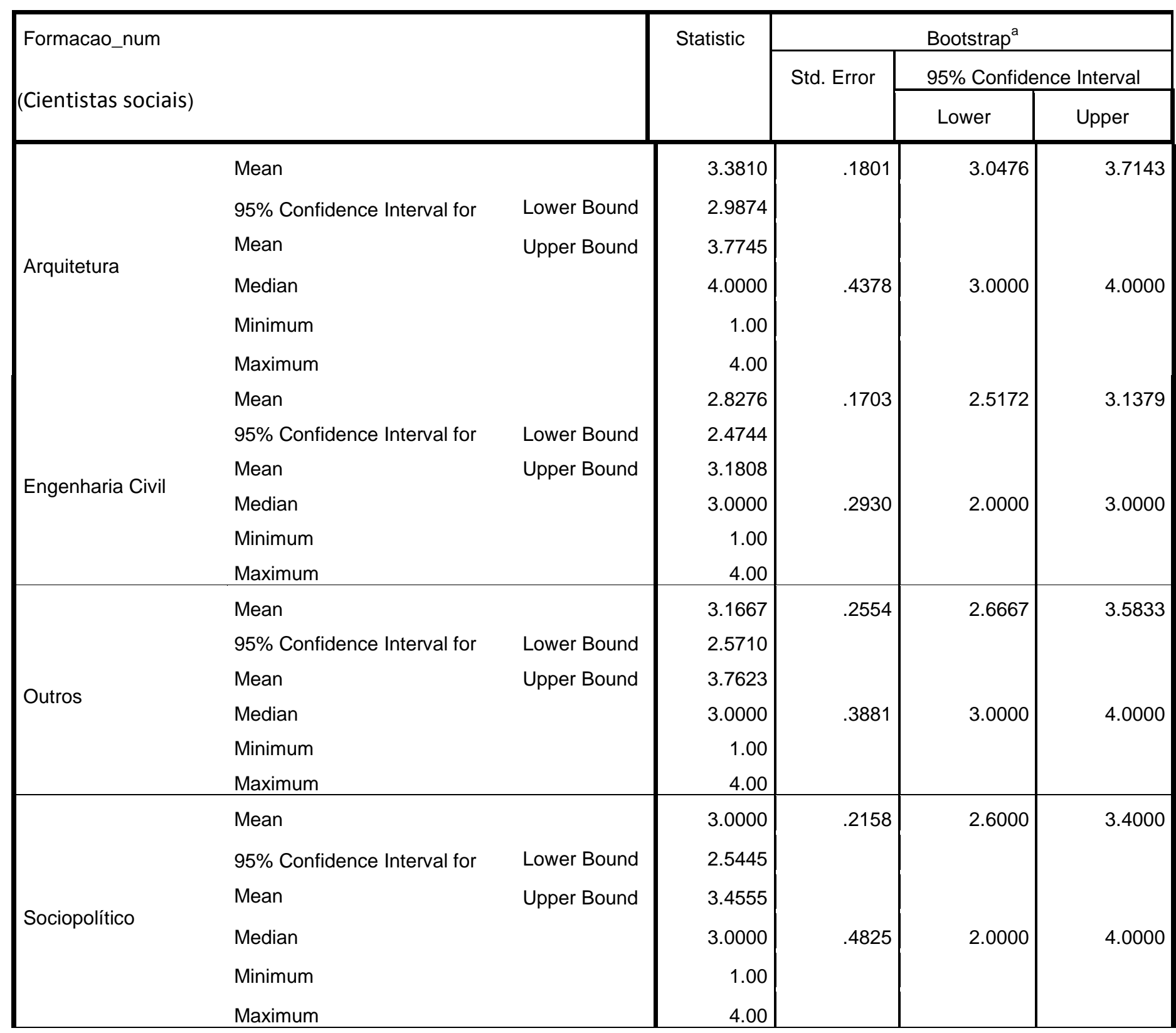


Questão 3 - Gerentes de obras de drenagem nem sempre desejam envolver moradores no planejamento das obras

\begin{tabular}{|c|c|c|c|c|c|c|c|}
\hline & & & \multirow[t]{3}{*}{ Statistic } & \multicolumn{4}{|c|}{ Bootstrap $^{c}$} \\
\hline & & & & \multirow[t]{2}{*}{ Bias } & \multirow[t]{2}{*}{ Std. Error } & \multicolumn{2}{|c|}{$95 \%$ Confidence Interval } \\
\hline & & & & & & Lower & Upper \\
\hline \multirow{8}{*}{ Q3 } & Mean & & 3.4490 & .0000 & .0864 & 3.2653 & 3.6122 \\
\hline & $95 \%$ Confidence Interval for & Lower Bound & 3.2725 & & & & \\
\hline & Mean & Upper Bound & 3.6255 & & & & \\
\hline & Median & & 4.0000 & -.4520 & .4979 & 3.0000 & 4.0000 \\
\hline & Minimum & & 2.00 & & & & \\
\hline & Maximum & & 4.00 & & & & \\
\hline & Skewness & & -.641 & .063 & .278 & -1.135 & .039 \\
\hline & Kurtosis & & -.484 & -.123 & .445 & -2.040 & .254 \\
\hline
\end{tabular}

Comparação por formação

Nota: quando a base de dados é separada por formação, essa pergunta torna-se uma constante. Há que se ter cuidado ao interpretar esses intervalos de confiança porque na verdade a variância de respostas é muito pequena.

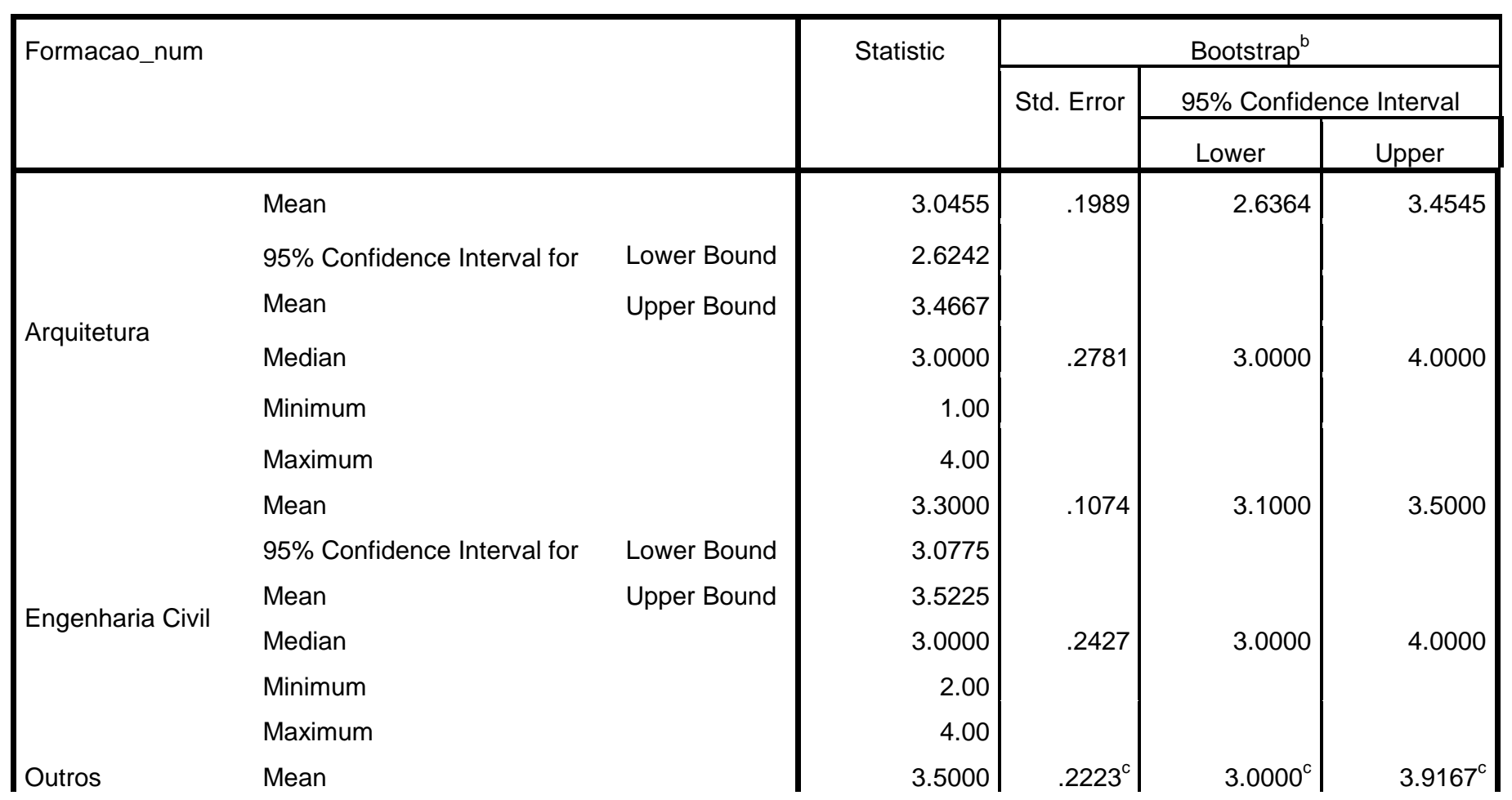




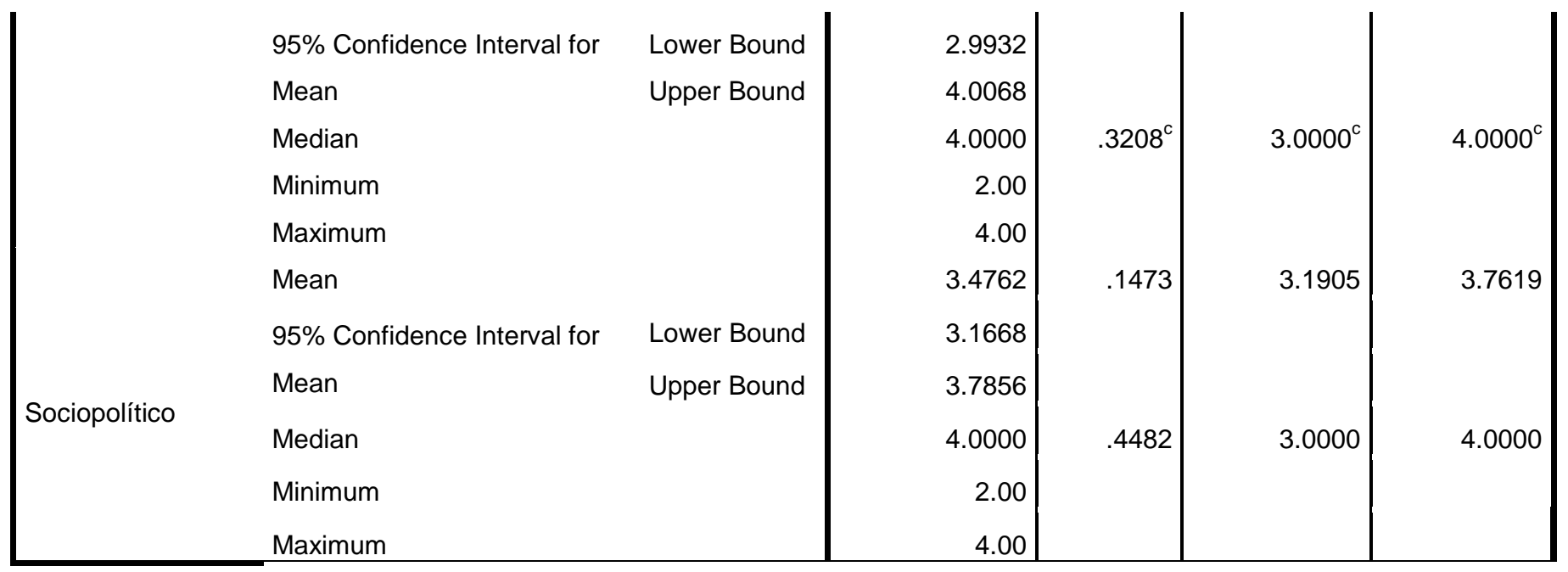

Questão 4 - Em geral, moradores das áreas onde obras serão implantadas não têm condição de opinar sobre as mesmas para que atendam sua demanda por melhorias

\begin{tabular}{|c|c|c|c|c|c|c|c|}
\hline & & & \multirow[t]{3}{*}{ Statistic } & \multicolumn{4}{|c|}{ Bootstrap $^{c}$} \\
\hline & & & & \multirow[t]{2}{*}{ Bias } & \multirow[t]{2}{*}{ Std. Error } & \multicolumn{2}{|c|}{$95 \%$ Confidence Interval } \\
\hline & & & & & & Lower & Upper \\
\hline \multirow{8}{*}{ Q4 } & Mean & & 1.9592 & -.0030 & .1399 & 1.6735 & 2.2444 \\
\hline & $95 \%$ Confidence Interval for & Lower Bound & 1.6722 & & & & \\
\hline & Mean & Upper Bound & 2.2462 & & & & \\
\hline & Median & & 2.0000 & -.1570 & .3667 & 1.0000 & 2.0000 \\
\hline & Minimum & & 1.00 & & & & \\
\hline & Maximum & & 4.00 & & & & \\
\hline & Skewness & & .607 & -.007 & .243 & .124 & 1.086 \\
\hline & Kurtosis & & -.826 & .047 & .425 & -1.382 & .238 \\
\hline
\end{tabular}

Comparação por formação

\begin{tabular}{|c|c|c|c|c|c|c|}
\hline \multicolumn{3}{|c|}{ Formacao_num } & \multirow[t]{3}{*}{ Statistic } & \multicolumn{3}{|c|}{ Bootstrap $^{a}$} \\
\hline & & & & \multirow[t]{2}{*}{ Std. Error } & \multicolumn{2}{|c|}{ 95\% Confidence Interval } \\
\hline & & & & & Lower & Upper \\
\hline \multirow{5}{*}{ Arquitetura } & Mean & & 2.1818 & .2063 & 1.7727 & 2.5909 \\
\hline & 95\% Confidence Interval for & Lower Bound & 1.7356 & & & \\
\hline & Mean & Upper Bound & 2.6281 & & & \\
\hline & Median & & 2.0000 & .4056 & 1.5000 & 3.0000 \\
\hline & Minimum & & 1.00 & & & \\
\hline
\end{tabular}




\begin{tabular}{|c|c|c|c|c|c|c|}
\hline \multirow{9}{*}{ Engenharia Civil } & Maximum & & 4.00 & \multirow{4}{*}{.1851} & \multirow[b]{2}{*}{1.7667} & \multirow{3}{*}{2.5000} \\
\hline & Mean & & 2.1333 & & & \\
\hline & $95 \%$ Confidence Interval for & Lower Bound & 1.7444 & & & \\
\hline & Mean & Upper Bound & 2.5223 & & & \\
\hline & Median & & 2.0000 & .4165 & 1.0000 & 3.0000 \\
\hline & Minimum & & 1.00 & & & \\
\hline & Maximum & & 4.00 & & & \\
\hline & Mean & & 2.0833 & 2958 & 1.5000 & 2.6667 \\
\hline & 95\% Confidence Interval for & Lower Bound & 1.3948 & & & \\
\hline \multirow{5}{*}{ Outros } & Mean & Upper Bound & 2.7718 & & & \\
\hline & Median & & 2.0000 & .6780 & 1.0000 & 3.0000 \\
\hline & Minimum & & 1.00 & & & \\
\hline & Maximum & & 4.00 & & & \\
\hline & Mean & & 2.0000 & 2058 & 1.6190 & 2.4750 \\
\hline \multirow{5}{*}{ Sociopolítico } & 95\% Confidence Interval for & Lower Bound & 1.5682 & & & \\
\hline & Mean & Upper Bound & 2.4318 & & & \\
\hline & Median & & 2.0000 & .2534 & 1.0000 & 2.0000 \\
\hline & Minimum & & 1.00 & & & \\
\hline & Maximum & & 4.00 & & & \\
\hline
\end{tabular}

Questão 5 - Em geral, comerciantes instalados nas áreas onde obras serão implantadas não têm condição de opinar sobre as mesmas para que atendam sua demanda por melhorias

\begin{tabular}{|c|c|c|c|c|c|c|c|}
\hline & & & \multirow[t]{3}{*}{ Statistic } & \multicolumn{4}{|c|}{ Bootstrap $^{c}$} \\
\hline & & & & \multirow[t]{2}{*}{ Bias } & \multirow[t]{2}{*}{ Std. Error } & \multicolumn{2}{|c|}{ 95\% Confidence Interval } \\
\hline & & & & & & Lower & Upper \\
\hline \multirow{8}{*}{ Q5 } & Mean & & 2.0408 & -.0049 & .1357 & 1.7755 & 2.3061 \\
\hline & 95\% Confidence Interval for & Lower Bound & 1.7724 & & & & \\
\hline & Mean & Upper Bound & 2.3092 & & & & \\
\hline & Median & & 2.0000 & -.0110 & .1375 & 2.0000 & 2.0000 \\
\hline & Minimum & & 1.00 & & & & \\
\hline & Maximum & & 4.00 & & & & \\
\hline & Skewness & & .396 & -.018 & .235 & -.063 & .823 \\
\hline & Kurtosis & & -.871 & .012 & .346 & -1.452 & -.060 \\
\hline
\end{tabular}

Comparação por formação

\begin{tabular}{|l|c|c|c|}
\hline \multirow{3}{*}{ Statistic } & \multicolumn{3}{|c|}{ Bootstrap $^{\mathrm{a}}$} \\
\cline { 2 - 3 } & \multirow{2}{*}{ Std. Error } & \multicolumn{2}{|c|}{$95 \%$ Confidence Interval } \\
\cline { 3 - 4 } & & Lower & Upper \\
\hline
\end{tabular}




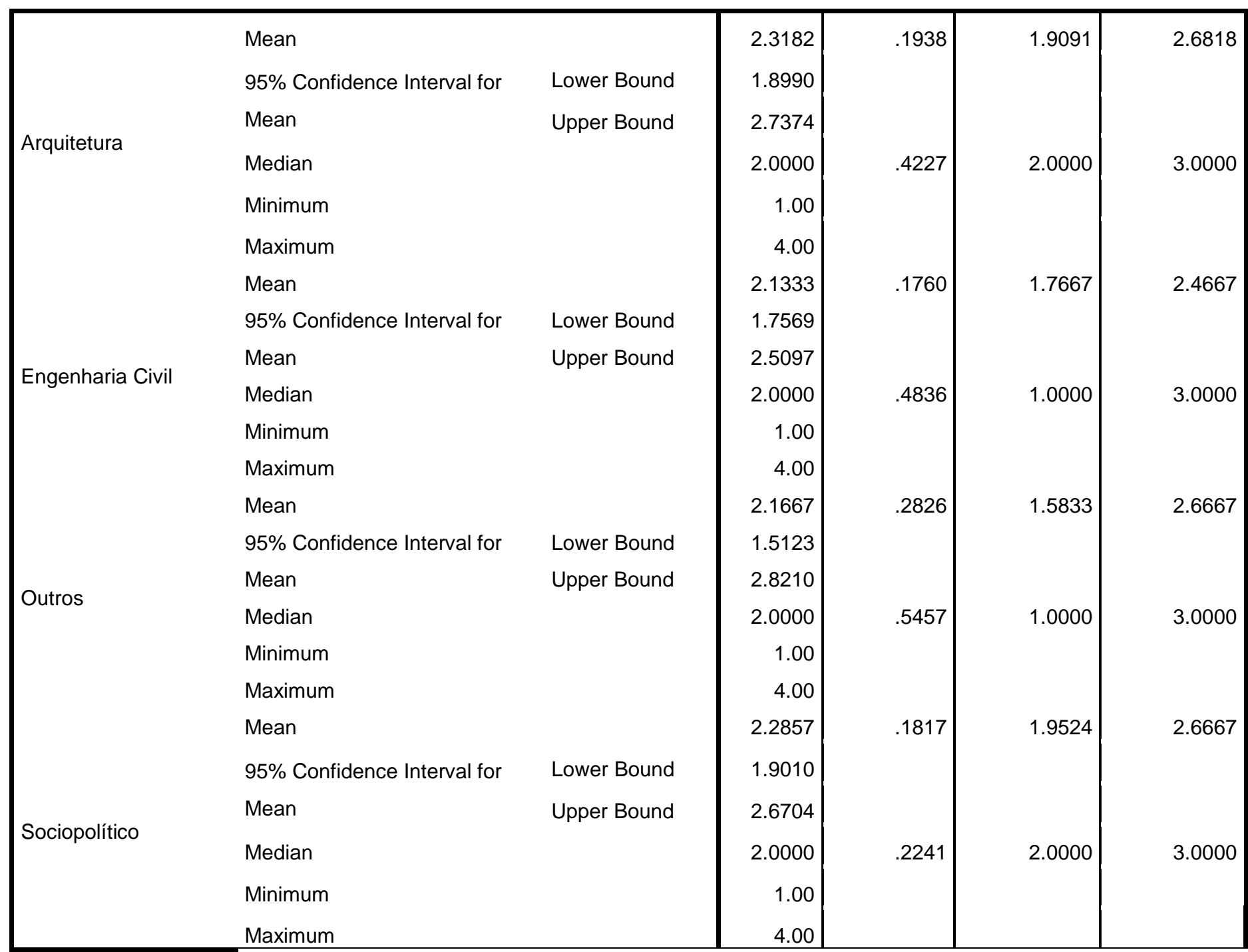

Questão 6 - Audiências públicas são suficientes como processo participativo da população

\begin{tabular}{|c|c|c|c|c|c|c|c|}
\hline & & & \multirow[t]{3}{*}{ Statistic } & \multicolumn{4}{|c|}{ Bootstrap $^{c}$} \\
\hline & & & & \multirow[t]{2}{*}{ Bias } & \multirow[t]{2}{*}{ Std. Error } & \multicolumn{2}{|c|}{ 95\% Confidence Interval } \\
\hline & & & & & & Lower & Upper \\
\hline \multirow{8}{*}{ Q6 } & Mean & & 1.8980 & -.0009 & . 1285 & 1.6536 & 2.1633 \\
\hline & $95 \%$ Confidence Interval for & Lower Bound & 1.6342 & & & & \\
\hline & Mean & Upper Bound & 2.1618 & & & & \\
\hline & Median & & 2.0000 & -.1500 & .3656 & 1.0000 & 2.0000 \\
\hline & Minimum & & 1.00 & & & & \\
\hline & Maximum & & 4.00 & & & & \\
\hline & Skewness & & .545 & -.016 & .254 & .023 & 1.013 \\
\hline & Kurtosis & & -.861 & .010 & .453 & -1.564 & .128 \\
\hline
\end{tabular}


Comparação por formação

\begin{tabular}{|c|c|c|c|c|c|c|}
\hline \multirow[t]{3}{*}{ Formacao_num } & & & \multirow[t]{3}{*}{ Statistic } & \multicolumn{3}{|c|}{ Bootstrap $^{a}$} \\
\hline & & & & \multirow[t]{2}{*}{ Std. Error } & \multicolumn{2}{|c|}{ 95\% Confidence Interval } \\
\hline & & & & & Lower & Upper \\
\hline \multirow{8}{*}{ Arquitetura } & Mean & & 2.0909 & 1430 & 1.8182 & 2.3636 \\
\hline & $95 \%$ Confidence Interval for & Lower Bound & 1.7877 & & & \\
\hline & Mean & Upper Bound & 2.3941 & & & \\
\hline & Median & & 2.0000 & .1138 & 2.0000 & 2.5000 \\
\hline & Minimum & & 1.00 & & & \\
\hline & Maximum & & 3.00 & & & \\
\hline & Mean & & 2.1000 & 1686 & 1.7667 & 2.4000 \\
\hline & 95\% Confidence Interval for & Lower Bound & 1.7417 & & & \\
\hline \multirow{6}{*}{ Engenharia Civil } & Mean & Upper Bound & 2.4583 & & & \\
\hline & Median & & 2.0000 & .2717 & 1.5000 & 3.0000 \\
\hline & Minimum & & 1.00 & & & \\
\hline & Maximum & & 4.00 & & & \\
\hline & Mean & & 2.0833 & .3202 & 1.5000 & 2.7479 \\
\hline & 95\% Confidence Interval for & Lower Bound & 1.3434 & & & \\
\hline \multirow{7}{*}{ Outros } & Mean & Upper Bound & 2.8232 & & & \\
\hline & Median & & 2.0000 & .8779 & 1.0000 & 3.0000 \\
\hline & Minimum & & 1.00 & & & \\
\hline & Maximum & & 4.00 & & & \\
\hline & Mean & & 1.9048 & 2181 & 1.4762 & 2.3333 \\
\hline & $95 \%$ Confidence Interval for & Lower Bound & 1.4517 & & & \\
\hline & Mean & Upper Bound & 2.3578 & & & \\
\hline \multirow{3}{*}{ Sociopolítico } & Median & & 2.0000 & .5848 & 1.0000 & 3.0000 \\
\hline & Minimum & & 1.00 & & & \\
\hline & Maximum & & 4.00 & & & \\
\hline
\end{tabular}

Questão 7 - Para a boa implantação de obras de drenagem é necessário que haja o envolvimento de:

- Comunicadores sociais. 


\begin{tabular}{|lll|r|r|r|r|r|}
\hline & & & & & Lower & \multicolumn{1}{c|}{ Upper } \\
\hline \multirow{2}{*}{ Mean } & & 3.5306 & -.0005 & .1009 & 3.3061 & 3.7143 \\
95\% Confidence Interval for & Lower Bound & 3.3266 & & & & \\
Mean & Upper Bound & 3.7346 & & & & \\
Q7a & Median & 4.0000 & -.0340 & .1813 & 3.0000 & 4.0000 \\
& Minimum & 1.00 & & & & \\
& Maximum & 4.00 & & & & \\
& Skewness & -1.568 & .118 & .415 & -2.300 & -.709 \\
Kurtosis & & 2.382 & -.564 & 1.908 & -.648 & 6.114 \\
\hline
\end{tabular}

Comparação por formação

\begin{tabular}{|c|c|c|c|c|c|c|}
\hline \multicolumn{3}{|l|}{ Formacao_num } & \multirow[t]{3}{*}{ Statistic } & \multicolumn{3}{|c|}{ Bootstrap ${ }^{b}$} \\
\hline \multirow{2}{*}{\multicolumn{3}{|c|}{ - Comunicadores sociais. }} & & \multirow[t]{2}{*}{ Std. Error } & \multicolumn{2}{|c|}{ 95\% Confidence Interval } \\
\hline & & & & & Lower & Upper \\
\hline \multirow{8}{*}{ Arquitetura } & Mean & & 3.5714 & 1447 & 3.2381 & 3.8095 \\
\hline & 95\% Confidence Interval for & Lower Bound & 3.2637 & & & \\
\hline & Mean & Upper Bound & 3.8792 & & & \\
\hline & Median & & 4.0000 & 2261 & 3.0000 & 4.0000 \\
\hline & Minimum & & 2.00 & & & \\
\hline & Maximum & & 4.00 & & & \\
\hline & Mean & & 3.3000 & 1444 & 3.0000 & 3.5667 \\
\hline & 95\% Confidence Interval for & Lower Bound & 3.0034 & & & \\
\hline \multirow{5}{*}{ Engenharia Civil } & Mean & Upper Bound & 3.5966 & & & \\
\hline & Median & & 3.0000 & 4425 & 3.0000 & 4.0000 \\
\hline & Minimum & & 1.00 & & & \\
\hline & Maximum & & 4.00 & & & \\
\hline & Mean & & 3.3333 & 1753 & 3.0000 & 3.6667 \\
\hline \multirow{6}{*}{ Outros } & 95\% Confidence Interval for & Lower Bound & 2.9195 & & & \\
\hline & Mean & Upper Bound & 3.7472 & & & \\
\hline & Median & & 3.0000 & .3852 & 3.0000 & 4.0000 \\
\hline & Minimum & & 2.00 & & & \\
\hline & Maximum & & 4.00 & & & \\
\hline & Mean & & 3.6842 & $.1225^{\mathrm{c}}$ & $3.4211^{\mathrm{C}}$ & $3.8947^{c}$ \\
\hline \multirow{5}{*}{ Sociopolítico } & 95\% Confidence Interval for & Lower Bound & 3.4035 & & & \\
\hline & Mean & Upper Bound & 3.9649 & & & \\
\hline & Median & & 4.0000 & $.0893^{\mathrm{C}}$ & $4.0000^{\mathrm{C}}$ & $4.0000^{c}$ \\
\hline & Minimum & & 2.00 & & & \\
\hline & Maximum & & 4.00 & & & \\
\hline
\end{tabular}


- Lideranças comunitárias.

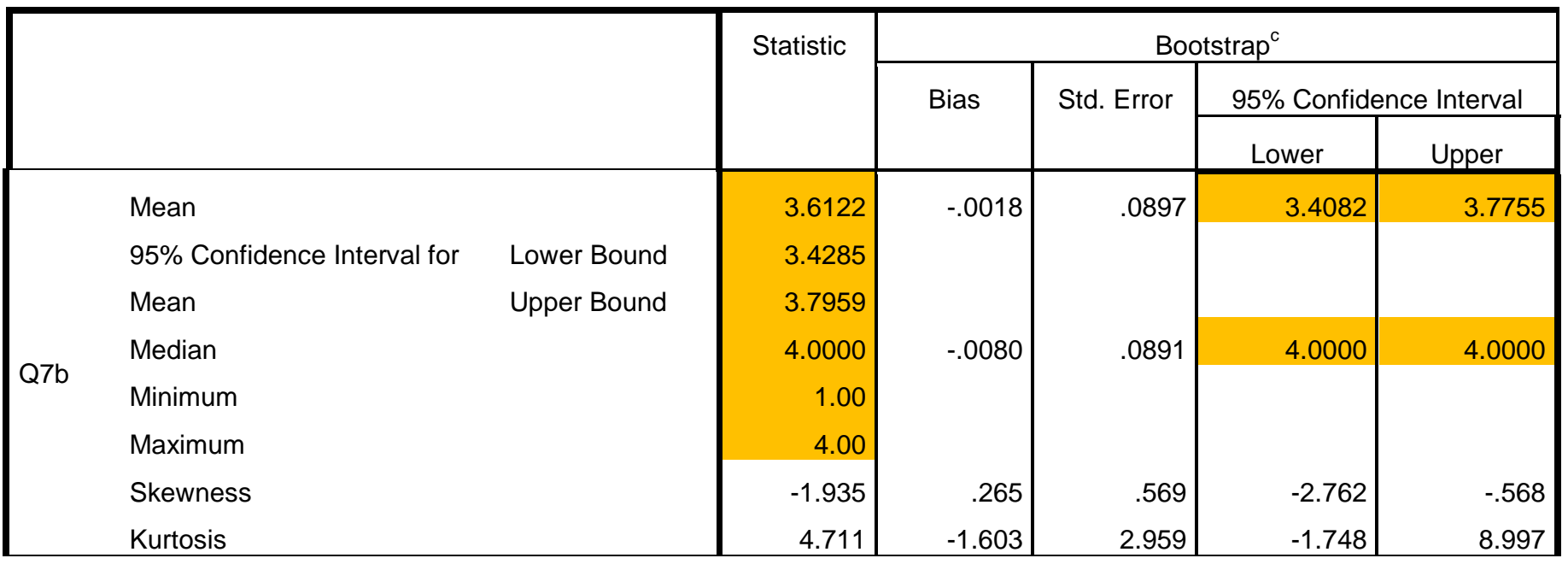

Comparação por formação

\begin{tabular}{|c|c|c|c|c|c|c|}
\hline \multicolumn{3}{|l|}{ Formacao_num } & \multirow[t]{3}{*}{ Statistic } & \multicolumn{3}{|c|}{ Bootstrap $^{b}$} \\
\hline \multirow{2}{*}{\multicolumn{3}{|c|}{ - Lideranças comunitárias }} & & \multirow[t]{2}{*}{ Std. Error } & \multicolumn{2}{|c|}{ 95\% Confidence Interval } \\
\hline & & & & & Lower & Upper \\
\hline \multirow{7}{*}{ Arquitetura } & Mean & & 3.4545 & .1437 & 3.1818 & 3.7273 \\
\hline & $95 \%$ Confidence Interval for & Lower Bound & 3.1570 & & & \\
\hline & Mean & Upper Bound & 3.7520 & & & \\
\hline & Median & & 4.0000 & .4231 & 3.0000 & 4.0000 \\
\hline & Minimum & & 2.00 & & & \\
\hline & Maximum & & 4.00 & & & \\
\hline & Mean & & 3.4000 & .1199 & 3.1342 & 3.6333 \\
\hline \multirow{6}{*}{ Engenharia Civil } & $95 \%$ Confidence Interval for & Lower Bound & 3.1481 & & & \\
\hline & Mean & Upper Bound & 3.6519 & & & \\
\hline & Median & & 3.0000 & .4456 & 3.0000 & 4.0000 \\
\hline & Minimum & & 1.00 & & & \\
\hline & Maximum & & 4.00 & & & \\
\hline & Mean & & 3.5833 & $.1845^{\circ}$ & $3.1667^{\mathrm{C}}$ & $3.9167^{c}$ \\
\hline \multirow{5}{*}{ Outros } & $95 \%$ Confidence Interval for & Lower Bound & 3.1586 & & & \\
\hline & Mean & Upper Bound & 4.0081 & & & \\
\hline & Median & & 4.0000 & $.2747^{\circ}$ & $3.0000^{\mathrm{c}}$ & $4.0000^{c}$ \\
\hline & Minimum & & 2.00 & & & \\
\hline & Maximum & & 4.00 & & & \\
\hline \multirow{2}{*}{ Sociopolítico } & Mean & & 3.6500 & $.1248^{\mathrm{d}}$ & $3.4000^{d}$ & $3.9000^{d}$ \\
\hline & $95 \%$ Confidence Interval for & Lower Bound & 3.3752 & & & \\
\hline
\end{tabular}




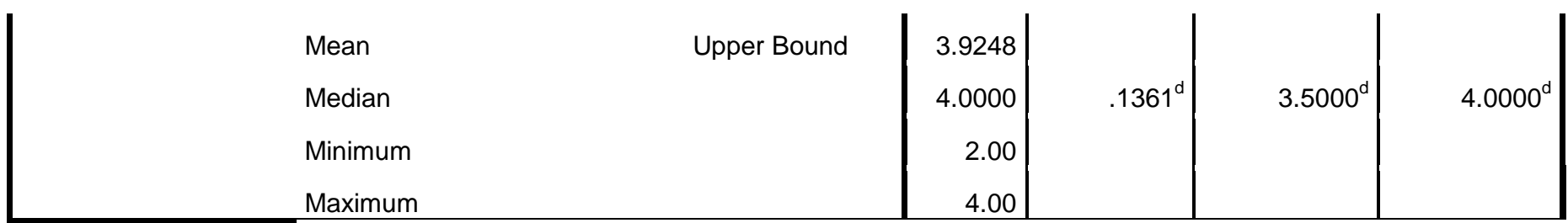

- Escolas da região.

\begin{tabular}{|c|c|c|c|c|c|c|c|}
\hline & & & \multirow[t]{3}{*}{ Statistic } & \multicolumn{4}{|c|}{ Bootstrap ${ }^{c}$} \\
\hline & & & & \multirow[t]{2}{*}{ Bias } & \multirow[t]{2}{*}{ Std. Error } & \multicolumn{2}{|c|}{ 95\% Confidence Interval } \\
\hline & & & & & & Lower & Upper \\
\hline \multirow{8}{*}{ Q7c } & Mean & & 3.2041 & .0008 & .1295 & 2.9592 & 3.4490 \\
\hline & $95 \%$ Confidence Interval for & Lower Bound & 2.9420 & & & & \\
\hline & Mean & Upper Bound & 3.4662 & & & & \\
\hline & Median & & 3.0000 & .2340 & .4236 & 3.0000 & 4.0000 \\
\hline & Minimum & & 1.00 & & & & \\
\hline & Maximum & & 4.00 & & & & \\
\hline & Skewness & & -1.112 & .037 & .237 & -1.522 & -.618 \\
\hline & Kurtosis & & .607 & .046 & .860 & -.717 & 2.450 \\
\hline
\end{tabular}

Comparação por formação

\begin{tabular}{|c|c|c|c|c|c|c|}
\hline \multicolumn{3}{|l|}{ Formacao_num } & \multirow[t]{3}{*}{ Statistic } & \multicolumn{3}{|c|}{ Bootstrap $^{a}$} \\
\hline \multirow{2}{*}{\multicolumn{3}{|c|}{ - Escolas da região. }} & & \multirow[t]{2}{*}{ Std. Error } & \multicolumn{2}{|c|}{ 95\% Confidence Interval } \\
\hline & & & & & Lower & Upper \\
\hline \multirow{8}{*}{ Arquitetura } & Mean & & 3.2727 & .1882 & 2.8636 & 3.6364 \\
\hline & $95 \%$ Confidence Interval for & Lower Bound & 2.8813 & & & \\
\hline & Mean & Upper Bound & 3.6641 & & & \\
\hline & Median & & 3.5000 & .4619 & 3.0000 & 4.0000 \\
\hline & Minimum & & 1.00 & & & \\
\hline & Maximum & & 4.00 & & & \\
\hline & Mean & & 2.9000 & .1694 & 2.5342 & 3.2000 \\
\hline & $95 \%$ Confidence Interval for & Lower Bound & 2.5417 & & & \\
\hline \multirow{4}{*}{ Engenharia Civil } & Mean & Upper Bound & 3.2583 & & & \\
\hline & Median & & 3.0000 & .0569 & 3.0000 & 3.0000 \\
\hline & Minimum & & 1.00 & & & \\
\hline & Maximum & & 4.00 & & & \\
\hline \multirow{2}{*}{ Outros } & Mean & & 3.0000 & .3129 & 2.4167 & 3.5833 \\
\hline & $95 \%$ Confidence Interval for & Lower Bound & 2.2832 & & & \\
\hline
\end{tabular}




\begin{tabular}{|c|c|c|c|c|c|c|}
\hline & Mean & Upper Bound & 3.7168 & & & \\
\hline & Median & & 3.0000 & .4332 & 2.5000 & 4.0000 \\
\hline & Minimum & & 1.00 & & & \\
\hline & Maximum & & 4.00 & & & \\
\hline & Mean & & 3.3684 & 1677 & 3.0000 & 3.6842 \\
\hline & 95\% Confidence Interval for & Lower Bound & 3.0017 & & & \\
\hline & Mean & Upper Bound & 3.7352 & & & \\
\hline & Median & & 4.0000 & 4919 & 3.0000 & 4.0000 \\
\hline & Minimum & & 2.00 & & & \\
\hline & Maximum & & 4.00 & & & \\
\hline
\end{tabular}

- Moradores.

\begin{tabular}{|c|c|c|c|c|c|c|c|}
\hline & & & \multirow[t]{3}{*}{ Statistic } & \multicolumn{4}{|c|}{ Bootstrap ${ }^{c}$} \\
\hline & & & & \multirow[t]{2}{*}{ Bias } & \multirow[t]{2}{*}{ Std. Error } & \multicolumn{2}{|c|}{$95 \%$ Confidence Interval } \\
\hline & & & & & & Lower & Upper \\
\hline \multirow{8}{*}{ Q7d } & Mean & & 3.5102 & -.0014 & .0932 & 3.3265 & 3.6939 \\
\hline & 95\% Confidence Interval for & Lower Bound & 3.3237 & & & & \\
\hline & Mean & Upper Bound & 3.6967 & & & & \\
\hline & Median & & 4.0000 & -.1810 & .3852 & 3.0000 & 4.0000 \\
\hline & Minimum & & 1.00 & & & & \\
\hline & Maximum & & 4.00 & & & & \\
\hline & Skewness & & -1.467 & .256 & .552 & -2.062 & -.118 \\
\hline & Kurtosis & & 3.147 & -1.337 & 2.323 & -2.069 & 5.986 \\
\hline
\end{tabular}

Comparação por formação

\begin{tabular}{|c|c|c|c|c|c|c|}
\hline \multicolumn{3}{|c|}{ Formacao_num } & \multirow[t]{3}{*}{ Statistic } & \multicolumn{3}{|c|}{ Bootstrap $^{b}$} \\
\hline \multirow{2}{*}{\multicolumn{3}{|c|}{ - Moradores. }} & & \multirow[t]{2}{*}{ Std. Error } & \multicolumn{2}{|c|}{$95 \%$ Confidence Interval } \\
\hline & & & & & Lower & Upper \\
\hline \multirow{6}{*}{ Arquitetura } & Mean & & 3.5909 & .1284 & 3.3182 & 3.8182 \\
\hline & $95 \%$ Confidence Interval for & Lower Bound & 3.3292 & & & \\
\hline & Mean & Upper Bound & 3.8526 & & & \\
\hline & Median & & 4.0000 & .2777 & 3.0000 & 4.0000 \\
\hline & Minimum & & 2.00 & & & \\
\hline & Maximum & & 4.00 & & & \\
\hline
\end{tabular}




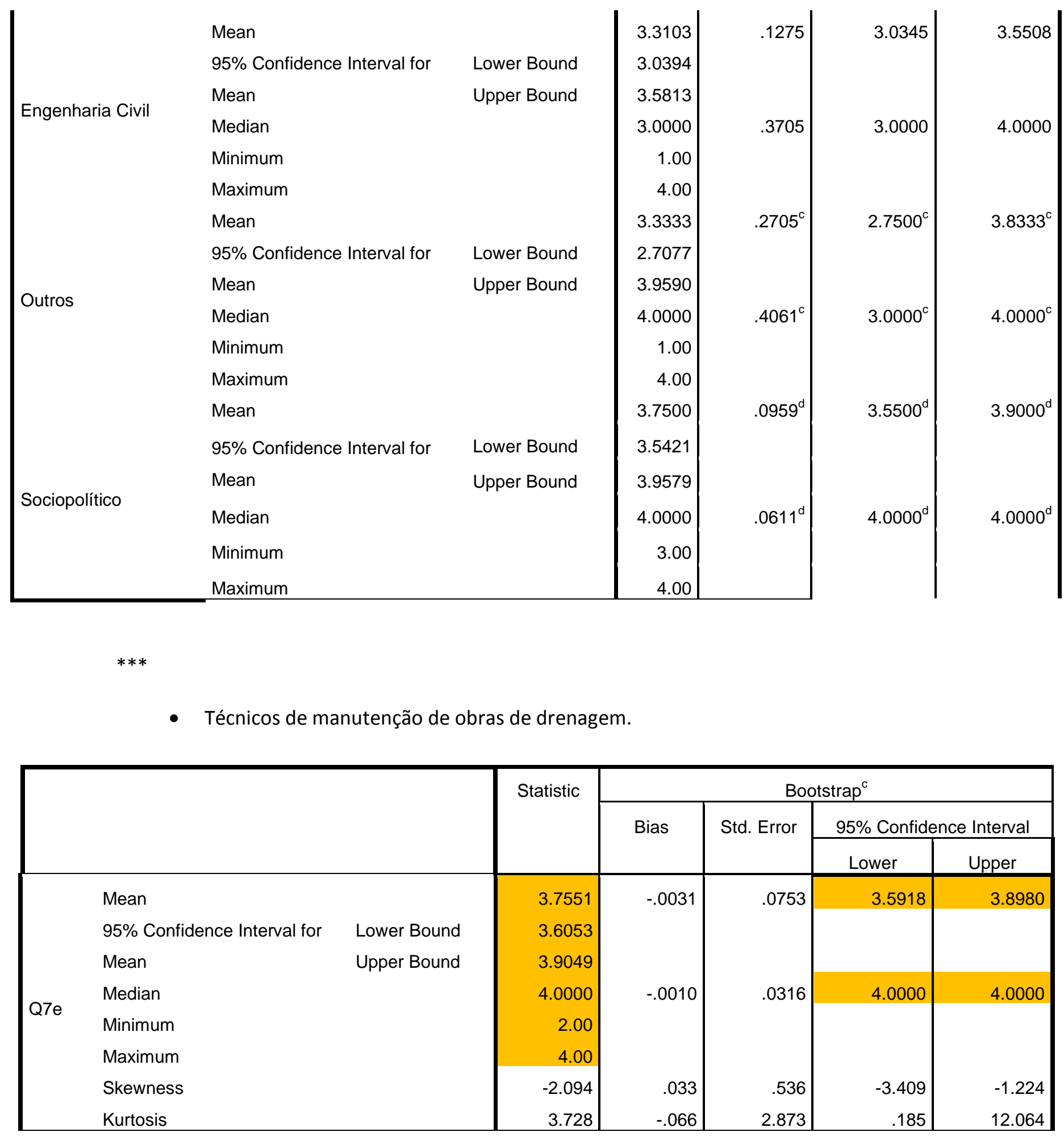

Comparação por formação

Formacao_num

- Técnicos de manutenção de obras de drenagem.

\begin{tabular}{|l|l|l|l|}
\hline \multirow{2}{*}{ Statistic } & \multicolumn{3}{|c|}{ Bootstrap $^{\mathrm{b}}$} \\
\cline { 2 - 3 } & \multirow{2}{*}{ Std. Error } & \multicolumn{2}{|c|}{$95 \%$ Confidence Interval } \\
\cline { 3 - 4 } & & Lower & Upper \\
\hline
\end{tabular}




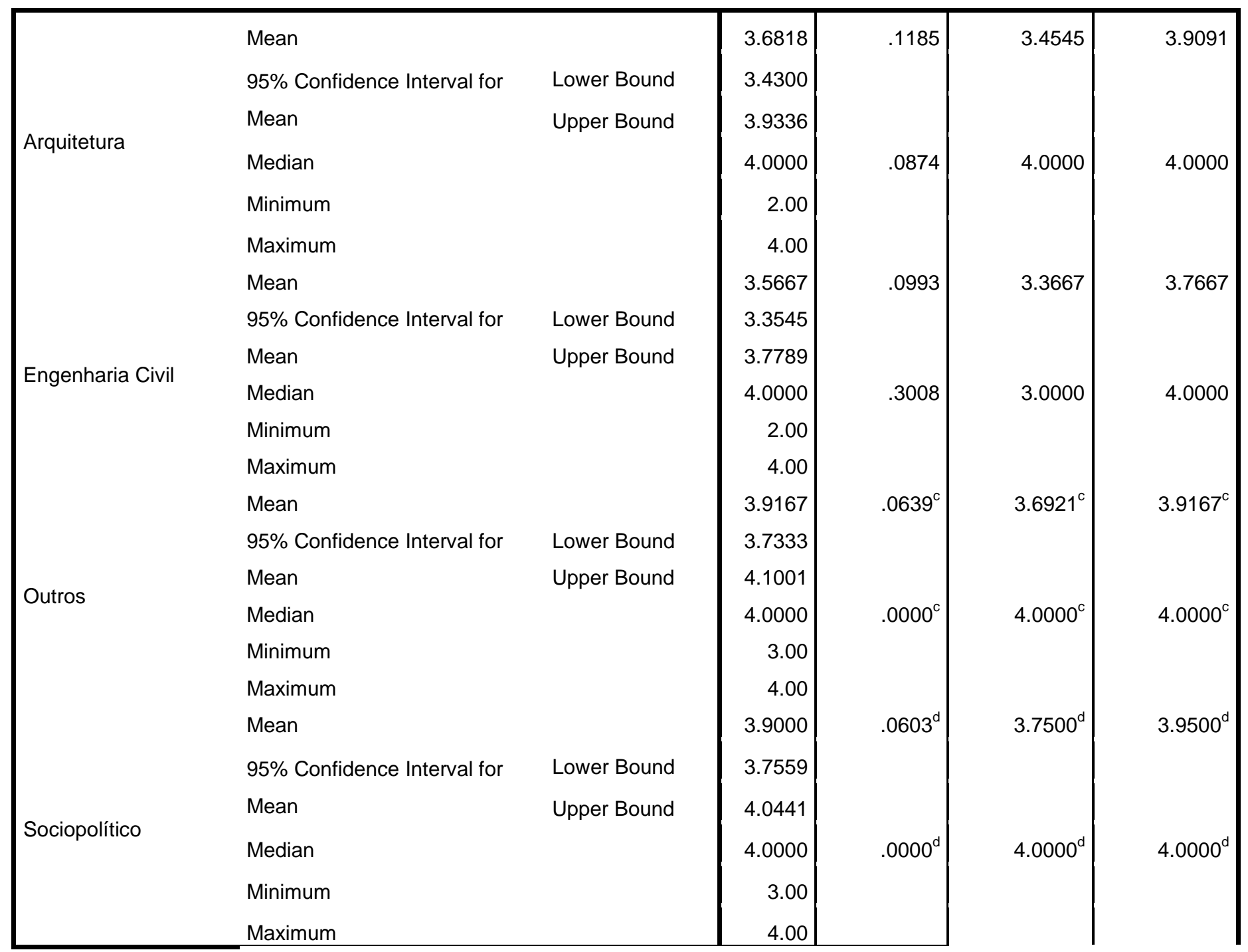

- Empresários locais.

\begin{tabular}{|c|c|c|c|c|c|c|c|}
\hline \multicolumn{8}{|c|}{ Bootstrap $^{c}$} \\
\hline & & & & \multirow[t]{2}{*}{ Bias } & \multirow[t]{2}{*}{ Std. Error } & \multicolumn{2}{|c|}{ 95\% Confidence Interval } \\
\hline & & & & & & Lower & Upper \\
\hline \multirow{8}{*}{ Q7f } & Mean & & 3.1633 & -.0012 & 1296 & 2.9184 & 3.4082 \\
\hline & $95 \%$ Confidence Interval for & Lower Bound & 2.9121 & & & & \\
\hline & Mean & Upper Bound & 3.4144 & & & & \\
\hline & Median & & 3.0000 & .0960 & .2947 & 3.0000 & 4.0000 \\
\hline & Minimum & & 1.00 & & & & \\
\hline & Maximum & & 4.00 & & & & \\
\hline & Skewness & & -.916 & .055 & .248 & -1.378 & -.390 \\
\hline & Kurtosis & & .298 & -.056 & .727 & -.855 & 1.941 \\
\hline
\end{tabular}


Comparação por formação

\begin{tabular}{|c|c|c|c|c|c|c|}
\hline \multicolumn{3}{|l|}{ Formacao_num } & \multirow[t]{3}{*}{ Statistic } & \multicolumn{3}{|c|}{ Bootstrap $^{a}$} \\
\hline \multirow{2}{*}{\multicolumn{3}{|c|}{ - Empresários locais. }} & & \multirow[t]{2}{*}{ Std. Error } & \multicolumn{2}{|c|}{ 95\% Confidence Interval } \\
\hline & & & & & Lower & Upper \\
\hline \multirow{8}{*}{ Arquitetura } & Mean & & 3.4286 & .1661 & 3.0952 & 3.7607 \\
\hline & 95\% Confidence Interval for & Lower Bound & 3.0596 & & & \\
\hline & Mean & Upper Bound & 3.7976 & & & \\
\hline & Median & & 4.0000 & .4344 & 3.0000 & 4.0000 \\
\hline & Minimum & & 1.00 & & & \\
\hline & Maximum & & 4.00 & & & \\
\hline & Mean & & 3.0333 & .1605 & 2.7000 & 3.3333 \\
\hline & $95 \%$ Confidence Interval for & Lower Bound & 2.7010 & & & \\
\hline \multirow{5}{*}{ Engenharia Civil } & Mean & Upper Bound & 3.3656 & & & \\
\hline & Median & & 3.0000 & .1567 & 3.0000 & 3.5000 \\
\hline & Minimum & & 1.00 & & & \\
\hline & Maximum & & 4.00 & & & \\
\hline & Mean & & 3.1667 & .2899 & 2.5021 & 3.6667 \\
\hline \multirow{6}{*}{ Outros } & $95 \%$ Confidence Interval for & Lower Bound & 2.5123 & & & \\
\hline & Mean & Upper Bound & 3.8210 & & & \\
\hline & Median & & 3.5000 & .5097 & 2.5000 & 4.0000 \\
\hline & Minimum & & 1.00 & & & \\
\hline & Maximum & & 4.00 & & & \\
\hline & Mean & & 3.3158 & .1304 & 3.0526 & 3.5789 \\
\hline \multirow{5}{*}{ Sociopolítico } & $95 \%$ Confidence Interval for & Lower Bound & 3.0351 & & & \\
\hline & Mean & Upper Bound & 3.5965 & & & \\
\hline & Median & & 3.0000 & .3080 & 3.0000 & 4.0000 \\
\hline & Minimum & & 2.00 & & & \\
\hline & Maximum & & 4.00 & & & \\
\hline
\end{tabular}

- Engenheiros.

\begin{tabular}{|l|c|c|c|c|}
\hline \multirow{3}{*}{ Statistic } & \multicolumn{4}{|c|}{ Bootstrap $^{c}$} \\
\cline { 2 - 4 } & \multirow{2}{*}{ Bias } & \multirow{2}{*}{ Std. Error } & $95 \%$ Confidence Interval \\
\cline { 4 - 5 } & & & Lower & Upper \\
\hline
\end{tabular}




\begin{tabular}{|c|c|c|c|c|c|c|c|}
\hline \multirow{8}{*}{ Q7g } & \multicolumn{2}{|l|}{ Mean } & \multirow{3}{*}{$\begin{array}{l}3.9184 \\
3.8196 \\
4.0171\end{array}$} & \multirow[t]{3}{*}{$-.0037^{\mathrm{e}}$} & \multirow[t]{3}{*}{$.0464^{\mathrm{e}}$} & \multirow[t]{3}{*}{$3.8163^{\mathrm{e}}$} & \multirow[t]{3}{*}{$3.9796^{\epsilon}$} \\
\hline & $95 \%$ Confidence Interval for & Lower Bound & & & & & \\
\hline & Mean & Upper Bound & & & & & \\
\hline & Median & & 4.0000 & $.0000^{\mathrm{e}}$ & $.0000^{\mathrm{e}}$ & $4.0000^{\mathrm{e}}$ & $4.0000^{\mathrm{e}}$ \\
\hline & Minimum & & 2.00 & & & & \\
\hline & Maximum & & 4.00 & & & & \\
\hline & Skewness & & -4.588 & $.043^{\mathrm{e}}$ & $1.327^{\mathrm{e}}$ & $-7.000^{\mathrm{e}}$ & $-2.637^{\mathrm{e}}$ \\
\hline & Kurtosis & & 22.097 & $.084^{\mathrm{e}}$ & $13.619^{\mathrm{e}}$ & $5.588^{\mathrm{e}}$ & $49.000^{\mathrm{e}}$ \\
\hline
\end{tabular}

Comparação por formação

\begin{tabular}{|c|c|c|c|c|c|c|}
\hline \multicolumn{3}{|l|}{ Formacao_num } & \multirow[t]{3}{*}{ Statistic } & \multicolumn{3}{|c|}{ Bootstrap $^{b}$} \\
\hline \multirow{2}{*}{\multicolumn{3}{|c|}{ - Engenheiros. }} & & \multirow[t]{2}{*}{ Std. Error } & \multicolumn{2}{|c|}{ 95\% Confidence Interval } \\
\hline & & & & & Lower & Upper \\
\hline \multirow{8}{*}{ Arquitetura } & Mean & & 3.9545 & $.0364^{\mathrm{c}}$ & $3.8286^{c}$ & $3.9545^{\mathrm{c}}$ \\
\hline & $95 \%$ Confidence Interval for & Lower Bound & 3.8600 & & & \\
\hline & Mean & Upper Bound & 4.0491 & & & \\
\hline & Median & & 4.0000 & $.0000^{\mathrm{c}}$ & $4.0000^{\mathrm{C}}$ & $4.0000^{c}$ \\
\hline & Minimum & & 3.00 & & & \\
\hline & Maximum & & 4.00 & & & \\
\hline & Mean & & 3.9333 & $.0422^{d}$ & $3.8333^{d}$ & $3.9667^{d}$ \\
\hline & $95 \%$ Confidence Interval for & Lower Bound & 3.8386 & & & \\
\hline \multirow{6}{*}{ Engenharia Civil } & Mean & Upper Bound & 4.0281 & & & \\
\hline & Median & & 4.0000 & $.0000^{d}$ & $4.0000^{d}$ & $4.0000^{d}$ \\
\hline & Minimum & & 3.00 & & & \\
\hline & Maximum & & 4.00 & & & \\
\hline & Mean & & 3.8333 & $.0908^{\mathrm{e}}$ & $3.5833^{\mathrm{e}}$ & $3.9167^{\mathrm{e}}$ \\
\hline & $95 \%$ Confidence Interval for & Lower Bound & 3.5860 & & & \\
\hline \multirow{7}{*}{ Outros } & Mean & Upper Bound & 4.0807 & & & \\
\hline & Median & & 4.0000 & $.0237^{\mathrm{e}}$ & $4.0000^{\mathrm{e}}$ & $4.0000^{\mathrm{e}}$ \\
\hline & Minimum & & 3.00 & & & \\
\hline & Maximum & & 4.00 & & & \\
\hline & Mean & & 3.8000 & $.1145^{f}$ & $3.5000^{f}$ & $3.9000^{f}$ \\
\hline & 95\% Confidence Interval for & Lower Bound & 3.5119 & & & \\
\hline & Mean & Upper Bound & 4.0881 & & & \\
\hline \multirow{3}{*}{ Sociopolítico } & Median & & 4.0000 & $.0000^{f}$ & $4.0000^{f}$ & $4.0000^{f}$ \\
\hline & Minimum & & 2.00 & & & \\
\hline & Maximum & & 4.00 & & & \\
\hline
\end{tabular}


- Políticos da região.

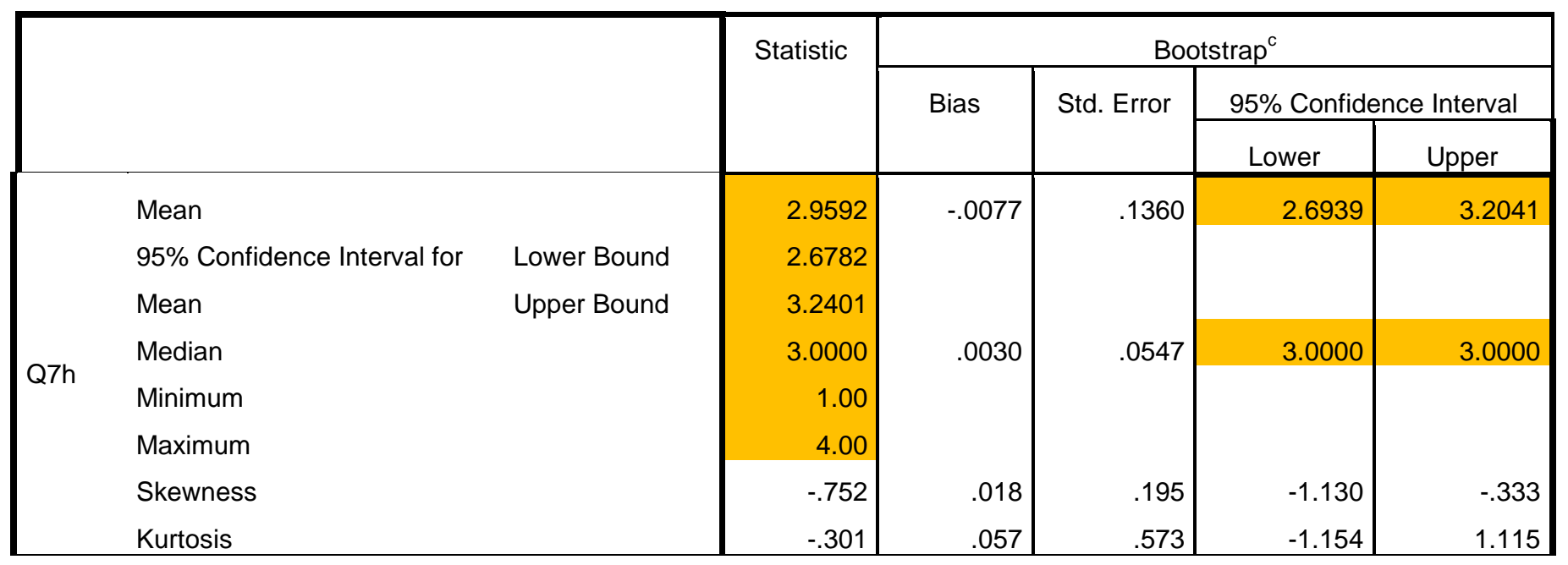

Comparação por formação

\begin{tabular}{|c|c|c|c|c|c|c|}
\hline \multirow{3}{*}{\multicolumn{2}{|c|}{$\begin{array}{l}\text { Formacao_num } \\
\text { • Políticos da região. }\end{array}$}} & & \multirow[t]{3}{*}{ Statistic } & \multicolumn{3}{|c|}{ Bootstrap $^{a}$} \\
\hline & & & & \multirow{2}{*}{$\begin{array}{l}\text { Std. } \\
\text { Error }\end{array}$} & \multicolumn{2}{|c|}{$95 \%$ Confidence Interval } \\
\hline & & & & & Lower & Upper \\
\hline \multirow{7}{*}{ Arquitetura } & Mean & & 3.0476 & .2335 & 2.5726 & 3.5238 \\
\hline & $95 \%$ Confidence Interval for & Lower Bound & 2.5392 & & & \\
\hline & Mean & Upper Bound & 3.5561 & & & \\
\hline & Median & & 3.0000 & .5182 & 3.0000 & 4.0000 \\
\hline & Minimum & & 1.00 & & & \\
\hline & Maximum & & 4.00 & & & \\
\hline & Mean & & 2.8000 & 1737 & 2.5000 & 3.1667 \\
\hline \multirow{5}{*}{ Engenharia Civil } & $95 \%$ Confidence Interval for & Lower Bound & 2.4410 & & & \\
\hline & Mean & Upper Bound & 3.1590 & & & \\
\hline & Median & & 3.0000 & .2322 & 2.0000 & 3.0000 \\
\hline & Minimum & & 1.00 & & & \\
\hline & Maximum & & 4.00 & & & \\
\hline \multirow{6}{*}{ Outros } & Mean & & 2.2727 & .3423 & 1.6364 & 2.9091 \\
\hline & 95\% Confidence Interval for & Lower Bound & 1.4727 & & & \\
\hline & Mean & Upper Bound & 3.0728 & & & \\
\hline & Median & & 2.0000 & .7232 & 1.0000 & 3.0000 \\
\hline & Minimum & & 1.00 & & & \\
\hline & Maximum & & 4.00 & & & \\
\hline \multirow{2}{*}{ Sociopolítico } & Mean & & 3.0000 & 1959 & 2.6316 & 3.3684 \\
\hline & $95 \%$ Confidence Interval for & Lower Bound & 2.5749 & & & \\
\hline
\end{tabular}




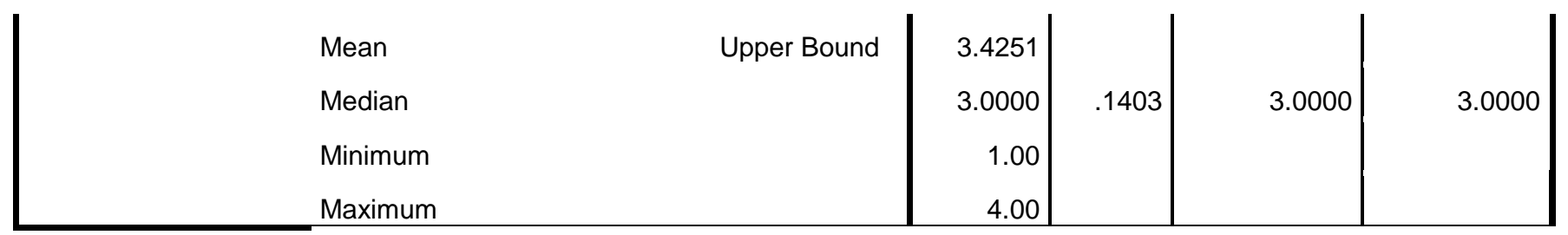

- Educadores ambientais.

\begin{tabular}{|c|c|c|c|c|c|c|c|}
\hline & & & \multirow[t]{3}{*}{ Statistic } & \multicolumn{4}{|c|}{ Bootstrap $^{c}$} \\
\hline & & & & \multirow[t]{2}{*}{ Bias } & \multirow[t]{2}{*}{ Std. Error } & \multicolumn{2}{|c|}{ 95\% Confidence Interval } \\
\hline & & & & & & Lower & Upper \\
\hline \multirow{8}{*}{ Q7i } & Mean & & 3.5306 & \multirow[t]{3}{*}{-.0006} & \multirow[t]{3}{*}{.0857} & 3.3673 & 3.6735 \\
\hline & $95 \%$ Confidence Interval for & Lower Bound & 3.3537 & & & & \\
\hline & Mean & Upper Bound & 3.7075 & & & & \\
\hline & Median & & 4.0000 & \multirow[t]{3}{*}{-.1030} & \multirow[t]{3}{*}{.3041} & 3.0000 & 4.0000 \\
\hline & Minimum & & 2.00 & & & & \\
\hline & Maximum & & 4.00 & & & & \\
\hline & Skewness & & -.958 & .035 & .293 & -1.540 & -.361 \\
\hline & Kurtosis & & -.042 & -.085 & .659 & -1.628 & 1.425 \\
\hline
\end{tabular}

Comparação por formação

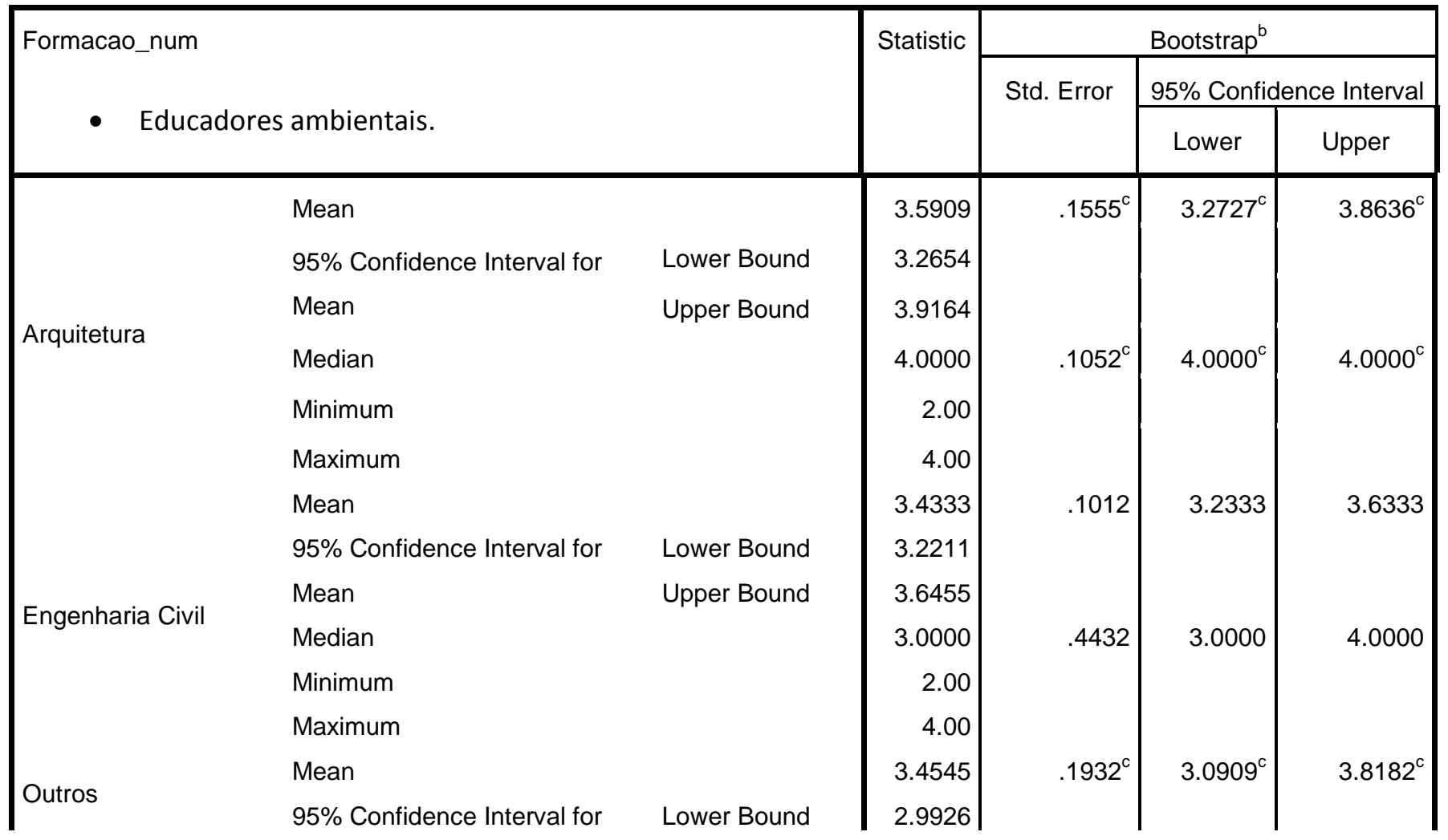




\begin{tabular}{|c|c|c|c|c|c|c|}
\hline & Mean & Upper Bound & 3.9164 & & & \\
\hline & Median & & 4.0000 & $.4890^{\circ}$ & $3.0000^{c}$ & $4.0000^{c}$ \\
\hline & Minimum & & 2.00 & & & \\
\hline & Maximum & & 4.00 & & & \\
\hline & Mean & & 3.5000 & .1524 & 3.1513 & 3.8000 \\
\hline & $95 \%$ Confidence Interval for & Lower Bound & 3.1779 & & & \\
\hline ingolític & Mean & Upper Bound & 3.8221 & & & \\
\hline Sосіороіпісо & Median & & 4.0000 & .3366 & 3.0000 & 4.0000 \\
\hline & Minimum & & 2.00 & & & \\
\hline & Maximum & & 4.00 & & & \\
\hline
\end{tabular}

- Cientistas sociais.

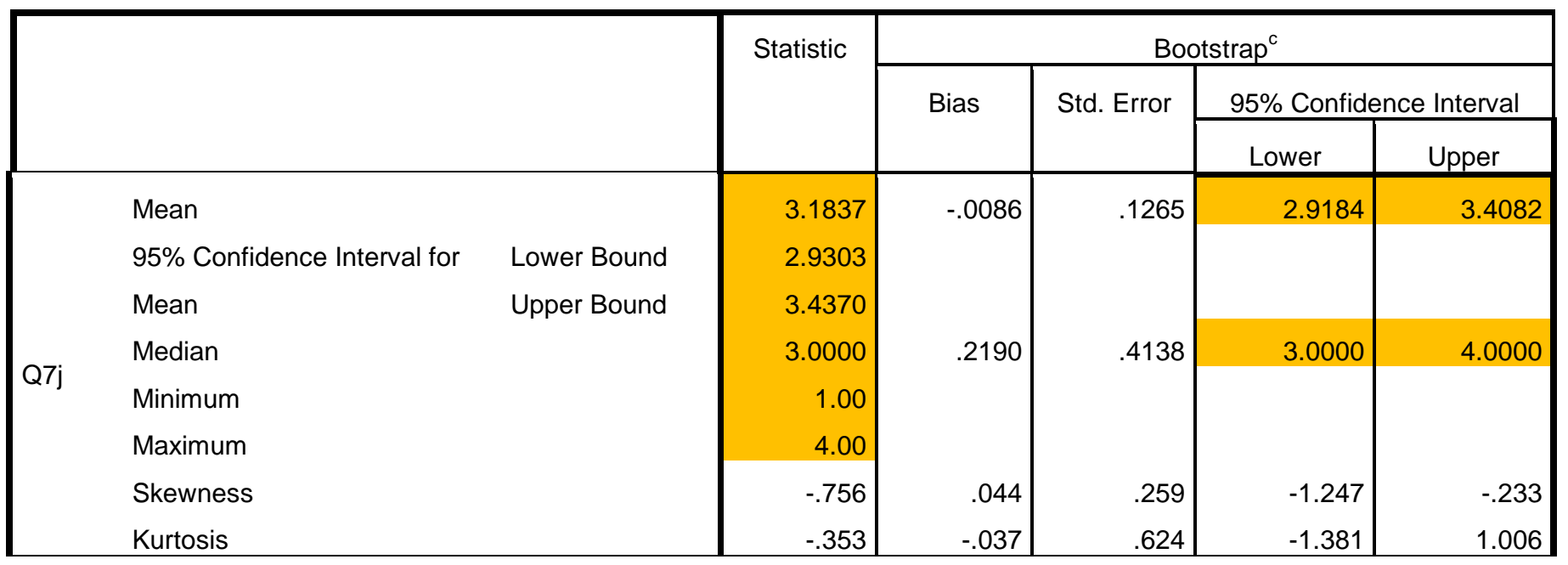

Comparação por formação

\begin{tabular}{|c|c|c|c|c|c|c|}
\hline \multirow[t]{3}{*}{ Formacao_num } & & & \multirow[t]{3}{*}{ Statistic } & \multicolumn{3}{|c|}{ Bootstrap $^{a}$} \\
\hline & & & & \multirow{2}{*}{$\begin{array}{l}\text { Std. } \\
\text { Error }\end{array}$} & \multicolumn{2}{|c|}{ 95\% Confidence Interval } \\
\hline & & & & & Lower & Upper \\
\hline \multirow{6}{*}{ Arquitetura } & Mean & & 3.4091 & .1681 & 3.0909 & 3.7273 \\
\hline & $95 \%$ Confidence Interval for & Lower Bound & 3.0560 & & & \\
\hline & Mean & Upper Bound & 3.7622 & & & \\
\hline & Median & & 4.0000 & .3621 & 3.0000 & 4.0000 \\
\hline & Minimum & & 2.00 & & & \\
\hline & Maximum & & 4.00 & & & \\
\hline \multirow{2}{*}{2 Engenharia Civil } & Mean & & 3.0000 & .1370 & 2.7333 & 3.2667 \\
\hline & 95\% Confidence Interval for & Lower Bound & 2.7058 & & & \\
\hline
\end{tabular}




\begin{tabular}{|c|c|c|c|c|c|c|}
\hline & Mean & Upper Bound & 3.2942 & & & \\
\hline & Median & & 3.0000 & .0631 & 3.0000 & 3.0000 \\
\hline & Minimum & & 1.00 & & & \\
\hline & Maximum & & 4.00 & & & \\
\hline & Mean & & 2.9167 & .2944 & 2.2500 & 3.4167 \\
\hline & $95 \%$ Confidence Interval for & Lower Bound & 2.2282 & & & \\
\hline & Mean & Upper Bound & 3.6052 & & & \\
\hline Sultus & Median & & 3.0000 & .3623 & 2.5000 & 4.0000 \\
\hline & Minimum & & 1.00 & & & \\
\hline & Maximum & & 4.00 & & & \\
\hline & Mean & & 3.2222 & .2206 & 2.7778 & 3.6111 \\
\hline & $95 \%$ Confidence Interval for & Lower Bound & 2.7534 & & & \\
\hline Croinonl'tion & Mean & Upper Bound & 3.6911 & & & \\
\hline Soclopoiltico & Median & & 3.5000 & .4619 & 3.0000 & 4.0000 \\
\hline & Minimum & & 1.00 & & & \\
\hline & Maximum & & 4.00 & & & \\
\hline
\end{tabular}

Questão 8 - Na implantação de obras de drenagem, é necessário que Engenheiros Civis contem com suficiente:

- Tempo para ocupar-se com aspectos da organização sociopolítica nas comunidades onde obras são implantadas

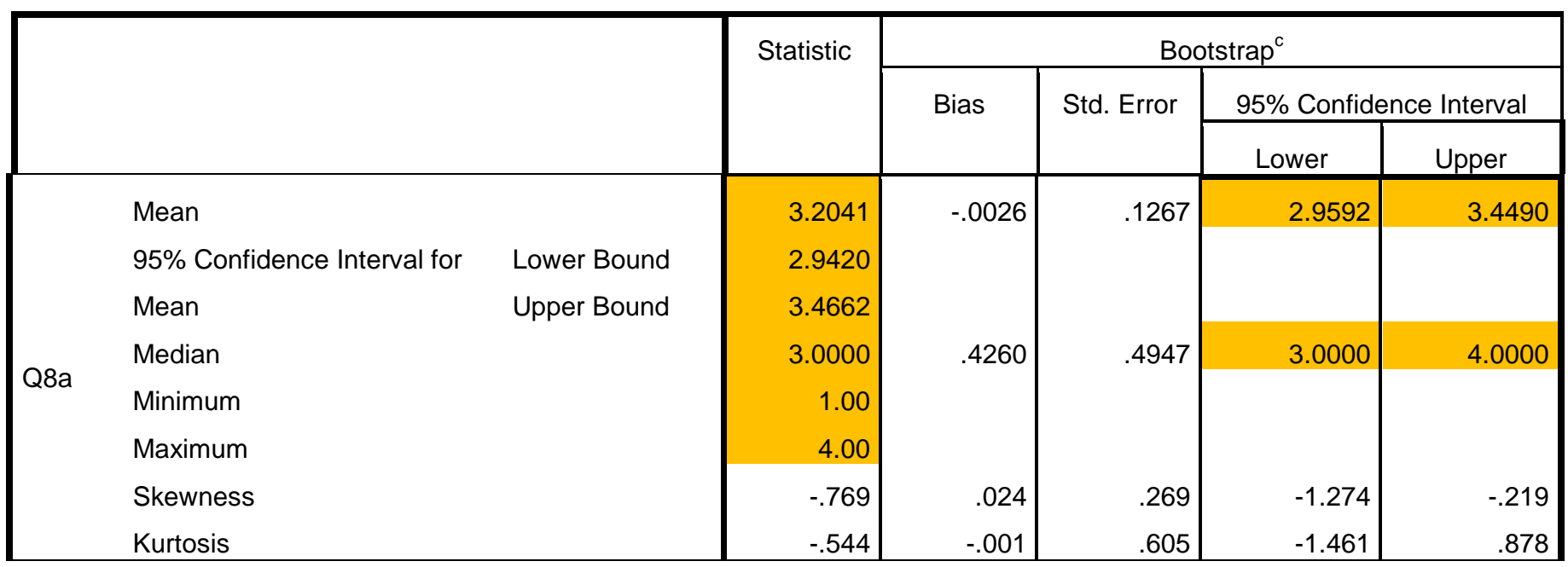

Comparação por formação

Formacao_num

- Tempo para ocupar-se com aspectos da organização
Statistic Bootstrap $^{b}$

95\% Confidence Interval 


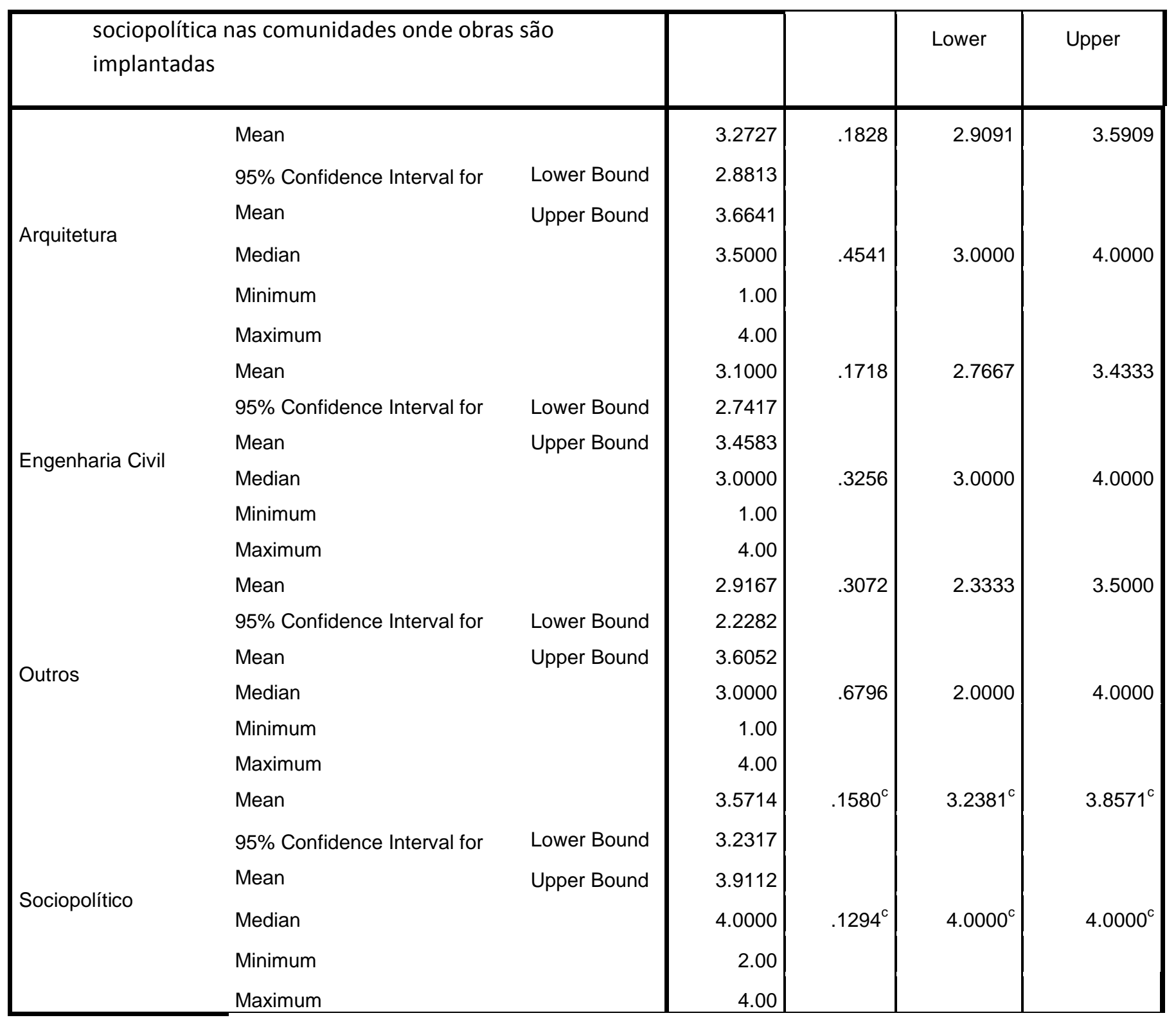

- Vontade de lidar com aspectos sociopolíticos nas comunidades onde implantam obras.

\begin{tabular}{|c|c|c|c|c|c|c|c|}
\hline & & & \multirow[t]{3}{*}{ Statistic } & \multicolumn{4}{|c|}{ Bootstrap $^{c}$} \\
\hline & & & & \multirow[t]{2}{*}{ Bias } & \multirow[t]{2}{*}{ Std. Error } & \multicolumn{2}{|c|}{ 95\% Confidence Interval } \\
\hline & & & & & & Lower & Upper \\
\hline \multirow{5}{*}{ Q8b } & Mean & & 3.5714 & \multirow[t]{3}{*}{-.0018} & \multirow[t]{3}{*}{.0806} & 3.4082 & 3.7143 \\
\hline & $95 \%$ Confidence Interval for & Lower Bound & 3.4056 & & & & \\
\hline & Mean & Upper Bound & 3.7373 & & & & \\
\hline & Median & & 4.0000 & \multirow[t]{2}{*}{-.0560} & \multirow[t]{2}{*}{.2300} & 3.0000 & 4.0000 \\
\hline & Minimum & & 2.00 & & & & \\
\hline
\end{tabular}




\begin{tabular}{|c|c|c|c|c|c|}
\hline Maximum & 4.00 & & & & \\
\hline Skewness & -.967 & .059 & .344 & -1.633 & -.212 \\
\hline Kurtosis & -.006 & -.199 & .879 & -1.994 & 1.868 \\
\hline
\end{tabular}

Comparação por formação

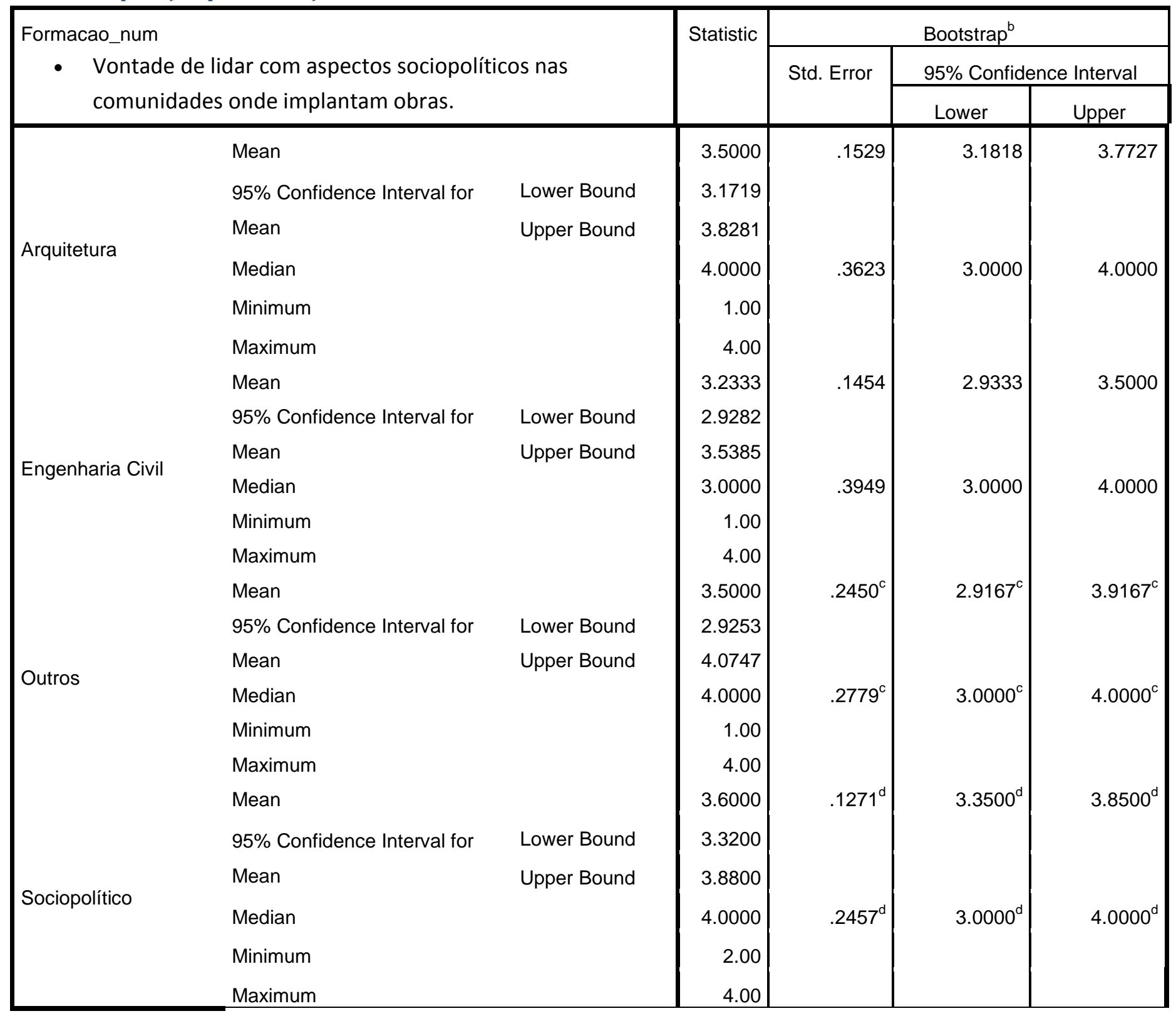

- Sensibilidade para aspectos da organização sociopilítica das comunidades onde implantam obras.

\begin{tabular}{|l|c|c|c|c|c|}
\hline \multirow{2}{*}{ Statistic } & \multicolumn{3}{|c|}{ Bootstrap $^{c}$} \\
\cline { 4 - 6 } & & \multirow{2}{*}{ Bias } & \multirow{2}{*}{ Std. Error } & \multicolumn{2}{|c|}{$95 \%$ Confidence Interval } \\
\cline { 4 - 6 } & & & & Lower & Upper \\
\hline
\end{tabular}




\begin{tabular}{|c|c|c|c|c|c|c|c|}
\hline \multicolumn{3}{|c|}{ Mean } & 3.6531 & -.0038 & .0893 & 3.4694 & 3.8163 \\
\hline \multirow{7}{*}{ Q8c } & 95\% Confidence Interval for & Lower Bound & 3.4719 & & & & \\
\hline & Mean & Upper Bound & 3.8343 & & & & \\
\hline & Median & & 4.0000 & -.0010 & .0316 & 4.0000 & 4.0000 \\
\hline & Minimum & & 2.00 & & & & \\
\hline & Maximum & & 4.00 & & & & \\
\hline & Skewness & & -1.650 & -.002 & .401 & -2.491 & -.958 \\
\hline & Kurtosis & & 1.577 & .184 & 1.659 & -.446 & 5.658 \\
\hline
\end{tabular}

Comparação por formação

\begin{tabular}{|c|c|c|c|c|c|c|}
\hline \multirow{3}{*}{\multicolumn{3}{|c|}{$\begin{array}{l}\text { Formacao_num } \\
\text { - Sensibilidade para aspectos da organização sociopilítica das } \\
\text { comunidades onde implantam obras. }\end{array}$}} & \multirow[t]{3}{*}{ Statistic } & \multicolumn{3}{|c|}{ Bootstrap $^{b}$} \\
\hline & & & & \multirow{2}{*}{$\begin{array}{l}\text { Std. } \\
\text { Error }\end{array}$} & \multicolumn{2}{|c|}{ 95\% Confidence Interval } \\
\hline & & & & & Lower & Upper \\
\hline \multirow{7}{*}{ Arquitetura } & Mean & & 3.7273 & $.1138^{\mathrm{c}}$ & $3.4545^{\mathrm{c}}$ & $3.9091^{\mathrm{C}}$ \\
\hline & 95\% Confidence Interval for & Lower Bound & 3.4832 & & & \\
\hline & Mean & Upper Bound & 3.9713 & & & \\
\hline & Median & & 4.0000 & $.0474^{\mathrm{C}}$ & $4.0000^{\circ}$ & $4.0000^{\circ}$ \\
\hline & Minimum & & 2.00 & & & \\
\hline & Maximum & & 4.00 & & & \\
\hline & Mean & & 3.5000 & .1220 & 3.2667 & 3.7333 \\
\hline \multirow{6}{*}{ Engenharia Civil } & $95 \%$ Confidence Interval for & Lower Bound & 3.2452 & & & \\
\hline & Mean & Upper Bound & 3.7548 & & & \\
\hline & Median & & 4.0000 & .3094 & 3.0000 & 4.0000 \\
\hline & Minimum & & 2.00 & & & \\
\hline & Maximum & & 4.00 & & & \\
\hline & Mean & & 3.5000 & $.2544^{d}$ & $2.9167^{d}$ & $3.9167^{d}$ \\
\hline \multirow{5}{*}{ Outros } & $95 \%$ Confidence Interval for & Lower Bound & 2.9253 & & & \\
\hline & Mean & Upper Bound & 4.0747 & & & \\
\hline & Median & & 4.0000 & $.2976^{d}$ & $3.0000^{d}$ & $4.0000^{\mathrm{d}}$ \\
\hline & Minimum & & 1.00 & & & \\
\hline & Maximum & & 4.00 & & & \\
\hline \multirow{6}{*}{ Sociopolítico } & Mean & & 3.4762 & .1880 & 3.0488 & 3.8095 \\
\hline & $95 \%$ Confidence Interval for & Lower Bound & 3.0789 & & & \\
\hline & Mean & Upper Bound & 3.8735 & & & \\
\hline & Median & & 4.0000 & .2431 & 3.0000 & 4.0000 \\
\hline & Minimum & & 1.00 & & & \\
\hline & Maximum & & 4.00 & & & \\
\hline
\end{tabular}


- Compreensão das interferências sociopolíticas que podem ocorrer durante a implantação das obras.

\begin{tabular}{|c|c|c|c|c|c|c|c|}
\hline & & & Statistic & & Boo & $\operatorname{trap}^{c}$ & \\
\hline & & & & Bias & Std. Error & $95 \%$ Confide & e Interval \\
\hline & & & & & & Lower & Upper \\
\hline & Mean & & 3.8571 & -.0029 & .0492 & 3.7551 & 3.9388 \\
\hline & 95\% Confidence Interval for & Lower Bound & 3.7556 & & & & \\
\hline & Mean & Upper Bound & 3.9587 & & & & \\
\hline 0 & Median & & 4.0000 & .0000 & .0000 & 4.0000 & 4.0000 \\
\hline Q 80 & Minimum & & 3.00 & & & & \\
\hline & Maximum & & 4.00 & & & & \\
\hline & Skewness & & -2.106 & -.113 & .719 & -3.777 & -1.224 \\
\hline & Kurtosis & & 2.538 & 1.046 & 4.513 & -.524 & 12.787 \\
\hline
\end{tabular}

Comparação por formação

\begin{tabular}{|c|c|c|c|c|c|c|}
\hline \multirow{3}{*}{\multicolumn{3}{|c|}{$\begin{array}{l}\text { Formacao_num } \\
\text { - Compreensão das interferências sociopolíticas que podem } \\
\text { ocorrer durante a implantação das obras. }\end{array}$}} & \multirow[t]{3}{*}{ Statistic } & \multicolumn{3}{|c|}{ Bootstrap $^{\mathrm{b}}$} \\
\hline & & & & \multirow[t]{2}{*}{ Std. Error } & \multicolumn{2}{|c|}{ 95\% Confidence Interval } \\
\hline & & & & & Lower & Upper \\
\hline \multirow{7}{*}{ Arquitetura } & Mean & & 3.7619 & $.0904^{\mathrm{c}}$ & $3.5714^{\mathrm{C}}$ & $3.9524^{\mathrm{C}}$ \\
\hline & $95 \%$ Confidence Interval for & Lower Bound & 3.5632 & & & \\
\hline & Mean & Upper Bound & 3.9606 & & & \\
\hline & Median & & 4.0000 & $.0632^{\mathrm{c}}$ & $4.0000^{\mathrm{C}}$ & $4.0000^{\circ}$ \\
\hline & Minimum & & 3.00 & & & \\
\hline & Maximum & & 4.00 & & & \\
\hline & Mean & & 3.7333 & .0792 & 3.5667 & 3.8992 \\
\hline \multirow{5}{*}{ Engenharia Civil } & $95 \%$ Confidence Interval for & Lower Bound & 3.5654 & & & \\
\hline & Mean & Upper Bound & 3.9013 & & & \\
\hline & Median & & 4.0000 & .0316 & 4.0000 & 4.0000 \\
\hline & Minimum & & 3.00 & & & \\
\hline & Maximum & & 4.00 & & & \\
\hline \multirow{6}{*}{ Outros } & Mean & & 3.8333 & $.0972^{d}$ & $3.5833^{d}$ & $3.9167^{d}$ \\
\hline & $95 \%$ Confidence Interval for & Lower Bound & 3.5860 & & & \\
\hline & Mean & Upper Bound & 4.0807 & & & \\
\hline & Median & & 4.0000 & $.0602^{d}$ & $4.0000^{d}$ & $4.0000^{d}$ \\
\hline & Minimum & & 3.00 & & & \\
\hline & Maximum & & 4.00 & & & \\
\hline Sociopolítico & Mean & & 3.6667 & .1300 & 3.3810 & 3.9048 \\
\hline
\end{tabular}




\begin{tabular}{|lr|r|r|r|r|}
$95 \%$ Confidence Interval for & Lower Bound & 3.3670 & & & \\
Mean & Upper Bound & 3.9663 & & & \\
Median & & 4.0000 & .0447 & 4.0000 & 4.0000 \\
Minimum & & & & \\
Maximum & & & & \\
\hline
\end{tabular}

- Autonomia frente às interferências políticas e dos arranjos institucionais para implantar obras já planejadas.

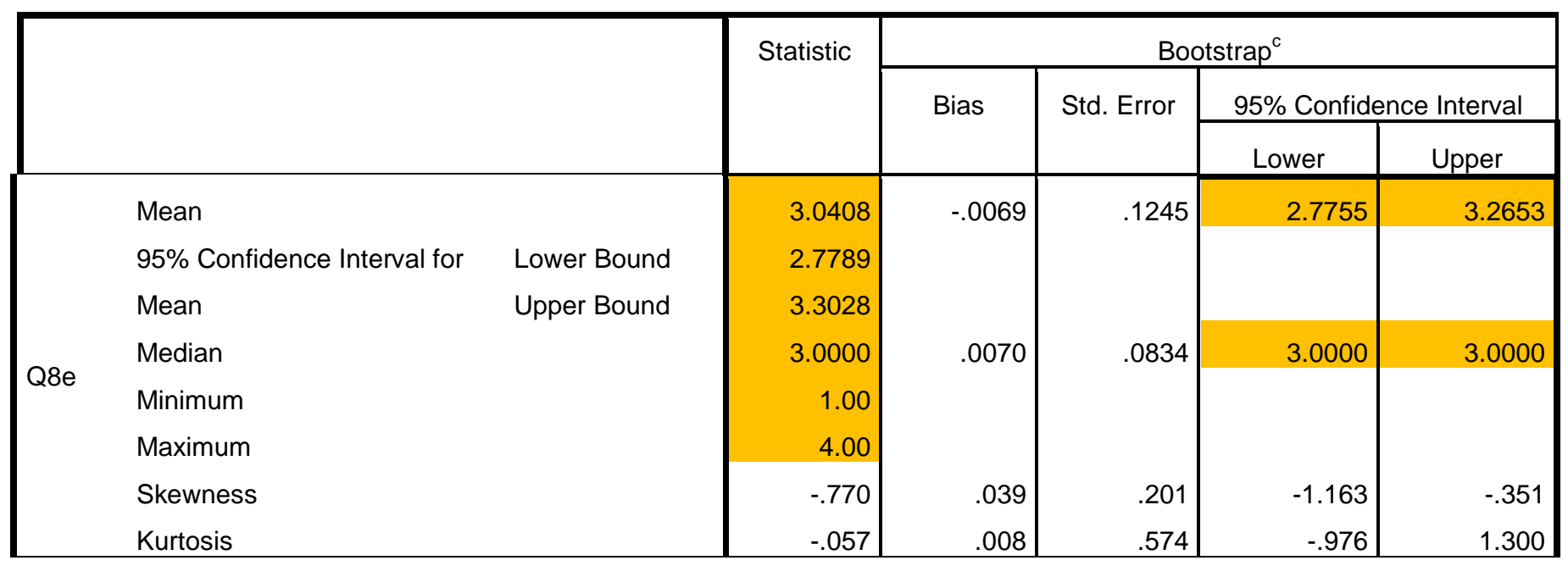

Comparação por formação

\begin{tabular}{|c|c|c|c|c|c|c|}
\hline \multirow{3}{*}{\multicolumn{3}{|c|}{$\begin{array}{l}\text { Formacao_num } \\
\text { - Autonomia frente às interferências políticas e dos } \\
\text { arranjos institucionais para implantar obras já } \\
\text { planejadas. }\end{array}$}} & \multirow[t]{3}{*}{ Statistic } & \multicolumn{3}{|c|}{ Bootstrap ${ }^{b}$} \\
\hline & & & & \multirow[t]{2}{*}{ Std. Error } & \multicolumn{2}{|c|}{ 95\% Confidence Interval } \\
\hline & & & & & Lower & Upper \\
\hline \multirow{8}{*}{ Arquitetura } & Mean & & 3.0455 & 1841 & 2.6364 & 3.4091 \\
\hline & $95 \%$ Confidence Interval for & Lower Bound & 2.6471 & & & \\
\hline & Mean & Upper Bound & 3.4438 & & & \\
\hline & Median & & 3.0000 & .1734 & 3.0000 & 3.5000 \\
\hline & Minimum & & 1.00 & & & \\
\hline & Maximum & & 4.00 & & & \\
\hline & Mean & & 3.0000 & .1520 & 2.7000 & 3.2667 \\
\hline & $95 \%$ Confidence Interval for & Lower Bound & 2.6748 & & & \\
\hline \multirow[t]{3}{*}{ Engenharia Civil } & Mean & Upper Bound & 3.3252 & & & \\
\hline & Median & & 3.0000 & 1746 & 3.0000 & 3.5000 \\
\hline & Minimum & & 1.00 & & & \\
\hline
\end{tabular}




\begin{tabular}{|lll} 
& Maximum & \\
& Mean & \\
& $95 \%$ Confidence Interval for & Lower Bound \\
Outros & Mean & Upper Bound \\
& Median & \\
& Minimum & \\
& Maximum & \\
& Mean & \\
& $95 \%$ Confidence Interval for & Lower Bound \\
& Mean & Upper Bound \\
& Median & \\
Sociopolítico & Minimum & \\
& Maximum &
\end{tabular}

\begin{tabular}{r|r|r|r|}
4.00 & & & \\
3.5000 & $.2417^{\mathrm{c}}$ & $2.9167^{\mathrm{c}}$ & $3.9167^{\mathrm{c}}$ \\
2.9253 & & & \\
4.0747 & & & \\
4.0000 & $.2726^{\mathrm{c}}$ & $3.0000^{\mathrm{c}}$ & $4.0000^{\mathrm{c}}$ \\
1.00 & & & \\
4.00 & & & \\
3.2500 & .2340 & 2.7500 & 3.7000 \\
2.7493 & & & \\
3.7507 & & & \\
4.0000 & .4209 & 3.0000 & 4.0000 \\
1.00 & & & \\
4.00 & & &
\end{tabular}

Questão 9 - A graduação em Engenharia Civil capacita suficientemente para a boa execução de obras de drenagem.

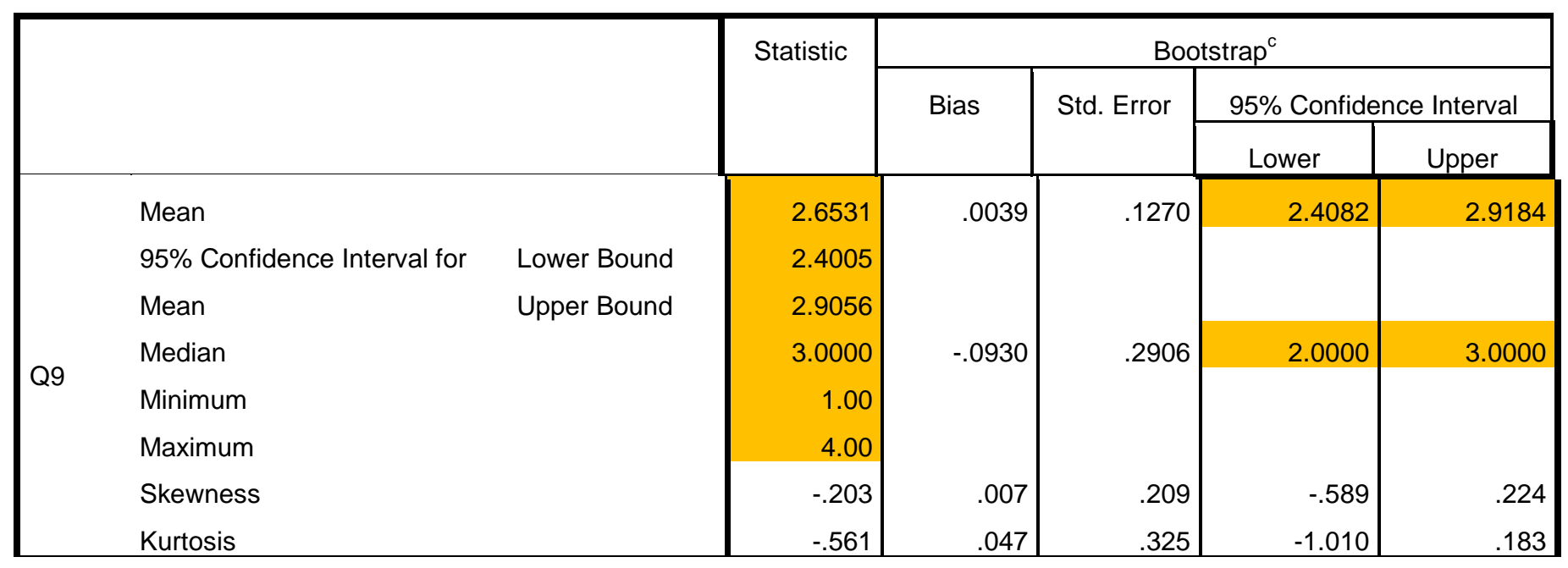

Comparação por formação

\begin{tabular}{|c|c|c|c|c|c|c|}
\hline \multirow[t]{3}{*}{ Formacao_nu } & & & \multirow[t]{3}{*}{ Statistic } & \multicolumn{3}{|c|}{ Bootstrap $^{a}$} \\
\hline & & & & \multirow[t]{2}{*}{ Std. Error } & \multicolumn{2}{|c|}{ 95\% Confidence Interval } \\
\hline & & & & & Lower & Upper \\
\hline \multirow{5}{*}{ Arquitetura } & Mean & & 2.5455 & \multirow[t]{3}{*}{.1785} & \multirow[t]{3}{*}{2.1364} & \multirow[t]{3}{*}{2.8636} \\
\hline & $95 \%$ Confidence Interval for & Lower Bound & 2.1651 & & & \\
\hline & Mean & Upper Bound & 2.9258 & & & \\
\hline & Median & & 3.0000 & \multirow[t]{2}{*}{.3601} & \multirow[t]{2}{*}{2.0000} & \multirow[t]{2}{*}{3.0000} \\
\hline & Minimum & & 1.00 & & & \\
\hline
\end{tabular}




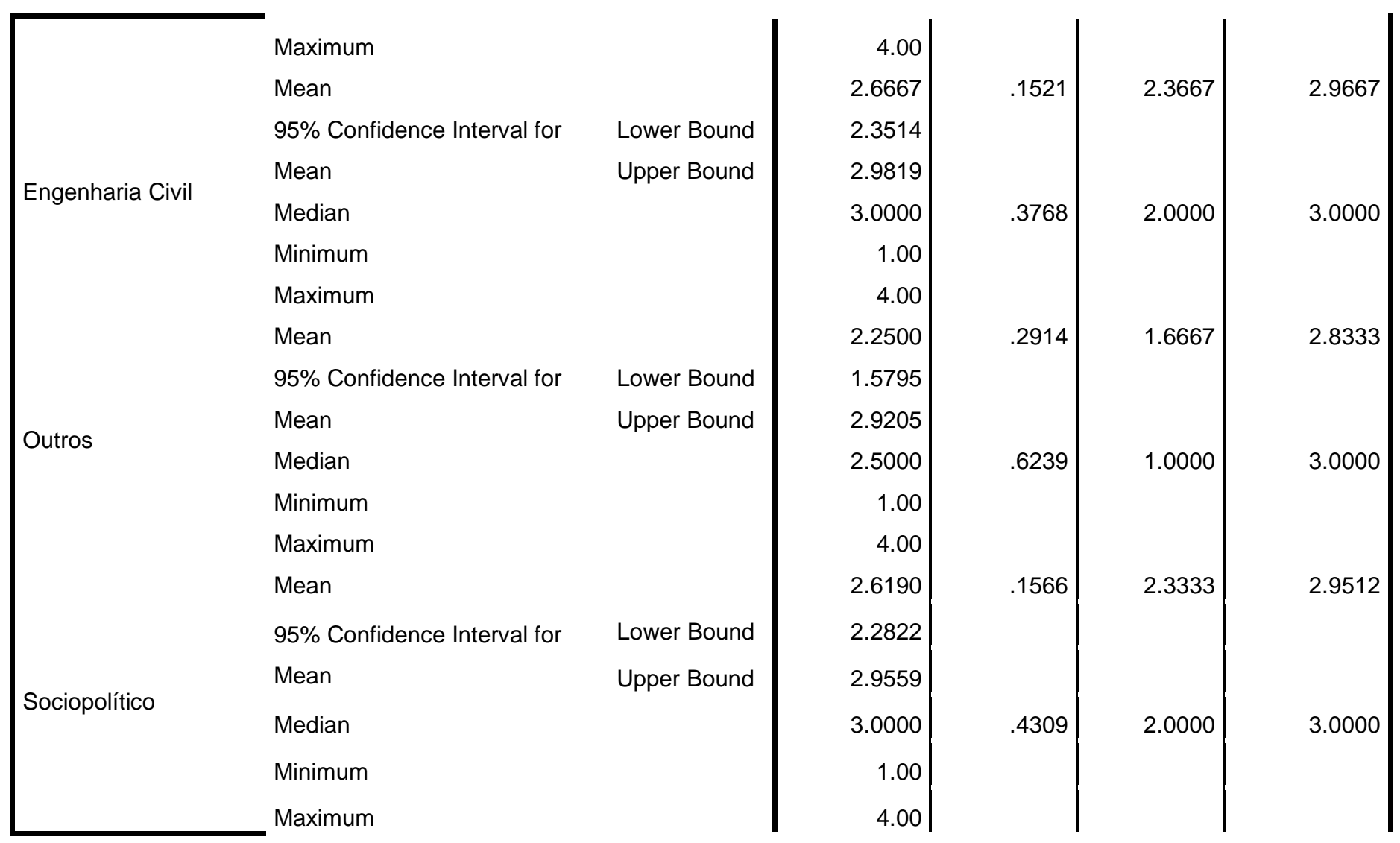

Questão 10 - A graduação em Engenharia Civil deveria ter disciplinas obrigatórias sobre aspectos sociopolíticos.

\begin{tabular}{|c|c|c|c|c|c|c|c|}
\hline & & & \multirow[t]{3}{*}{ Statistic } & \multicolumn{4}{|c|}{ Bootstrap $^{c}$} \\
\hline & & & & \multirow[t]{2}{*}{ Bias } & \multirow[t]{2}{*}{ Std. Error } & \multicolumn{2}{|c|}{ 95\% Confidence Interval } \\
\hline & & & & & & Lower & Upper \\
\hline \multirow{8}{*}{ Q10 } & Mean & & 3.6531 & -.0012 & .0812 & 3.4898 & 3.7959 \\
\hline & $95 \%$ Confidence Interval for & Lower Bound & 3.4919 & & & & \\
\hline & Mean & Upper Bound & 3.8142 & & & & \\
\hline & Median & & 4.0000 & -.0010 & .0316 & 4.0000 & 4.0000 \\
\hline & Minimum & & 2.00 & & & & \\
\hline & Maximum & & 4.00 & & & & \\
\hline & Skewness & & -1.383 & .046 & .377 & -2.094 & -.664 \\
\hline & Kurtosis & & 1.046 & -.192 & 1.299 & -1.479 & 3.728 \\
\hline
\end{tabular}

Comparação por formação

\begin{tabular}{|l|l|}
\hline \multicolumn{2}{|c|}{ Bootstrap $^{\mathrm{b}}$} \\
\hline Std. Error & $95 \%$ Confidence Interval \\
\hline
\end{tabular}




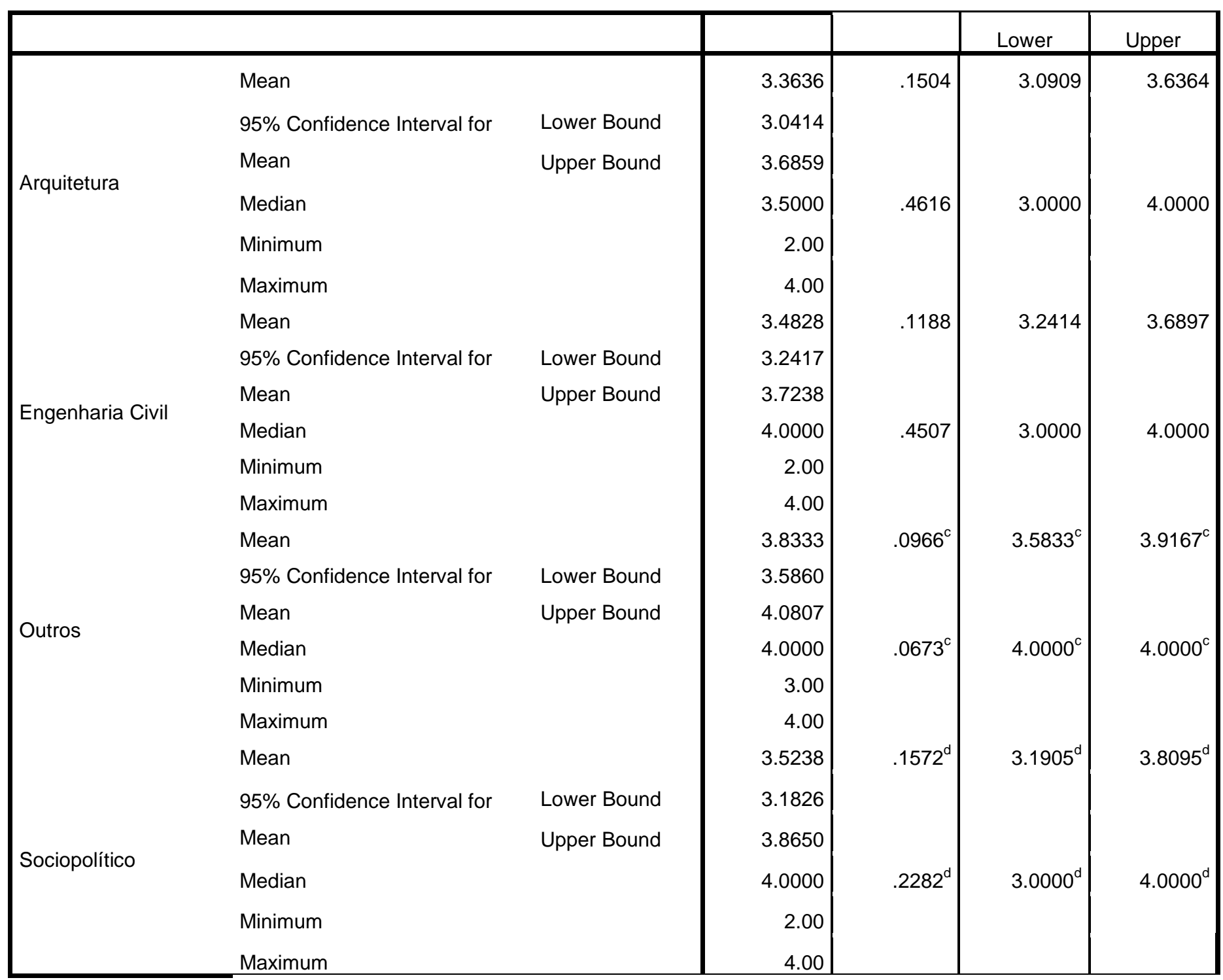

Questão 11 - Cientistas Sociais são bem-vindos para atuar em projetos de intervenções em drenagem.

\begin{tabular}{|c|c|c|c|c|c|c|c|}
\hline & & & \multirow[t]{3}{*}{ Statistic } & \multicolumn{4}{|c|}{ Bootstrap ${ }^{c}$} \\
\hline & & & & \multirow[t]{2}{*}{ Bias } & \multirow[t]{2}{*}{ Std. Error } & \multicolumn{2}{|c|}{ 95\% Confidence Interval } \\
\hline & & & & & & Lower & Upper \\
\hline \multirow{7}{*}{ Q11 } & Mean & & 3.3265 & -.0050 & .1023 & 3.1020 & 3.5306 \\
\hline & $95 \%$ Confidence Interval for & Lower Bound & 3.1202 & & & & \\
\hline & Mean & Upper Bound & 3.5329 & & & & \\
\hline & Median & & 3.0000 & .2940 & .4558 & 3.0000 & 4.0000 \\
\hline & Minimum & & 2.00 & & & & \\
\hline & Maximum & & 4.00 & & & & \\
\hline & Skewness & & -.584 & .026 & .214 & -1.044 & -.158 \\
\hline
\end{tabular}


Comparação por formação

\begin{tabular}{|c|c|c|c|c|c|c|}
\hline \multirow[t]{2}{*}{ Formacao_num } & & & \multirow[t]{2}{*}{ Statistic } & \multicolumn{3}{|c|}{ Bootstrap $^{a}$} \\
\hline & & & & Std. Error & Lower & Upper \\
\hline \multirow{6}{*}{ Arquitetura } & Mean & & 3.4762 & .1340 & 3.1905 & 3.7143 \\
\hline & $95 \%$ Confidence Interval for & Lower Bound & 3.2024 & & & \\
\hline & Median & & 4.0000 & .4941 & 3.0000 & 4.0000 \\
\hline & Minimum & & 2.00 & & & \\
\hline & Maximum & & 4.00 & & & \\
\hline & Mean & & 3.1000 & .1279 & 2.8667 & 3.3667 \\
\hline \multirow{3}{*}{ Engenharia Civil } & Minimum & & 2.00 & & & \\
\hline & Maximum & & 4.00 & & & \\
\hline & Mean & & 3.0000 & .2675 & 2.4167 & 3.5000 \\
\hline \multirow{5}{*}{ Outros } & $95 \%$ Confidence Interval for & Lower Bound & 2.3942 & & & \\
\hline & Mean & Upper Bound & 3.6058 & & & \\
\hline & Median & & 3.0000 & .3342 & 2.5000 & 4.0000 \\
\hline & Minimum & & 1.00 & & & \\
\hline & Maximum & & 4.00 & & & \\
\hline Sociopolítico & Maximum & & 4.00 & & & \\
\hline
\end{tabular}

Questão 12 - As principais causas das inundações no Município de São Paulo são:

- Insuficientes recursos financeiros por parte do Poder Público.

\begin{tabular}{|l|r|r|r|r|r|}
\hline & \multirow{2}{*}{ Statistic } & \multicolumn{3}{|c|}{ Bootstrap $^{c}$} \\
\cline { 4 - 6 } & & & \multirow{2}{*}{ Bias } & \multirow{2}{*}{ Std. Error } & 95\% Confidence Interval \\
\cline { 4 - 6 } & & & & & Lower Upper \\
\hline Q12a Mean & & 2.5306 & -.0015 & .1404 & 2.2449
\end{tabular}




\begin{tabular}{|ll} 
95\% Confidence Interval for & Lower Bound \\
Mean & Upper Bound \\
Median & \\
Minimum & \\
Maximum & \\
Skewness & \\
Kurtosis &
\end{tabular}
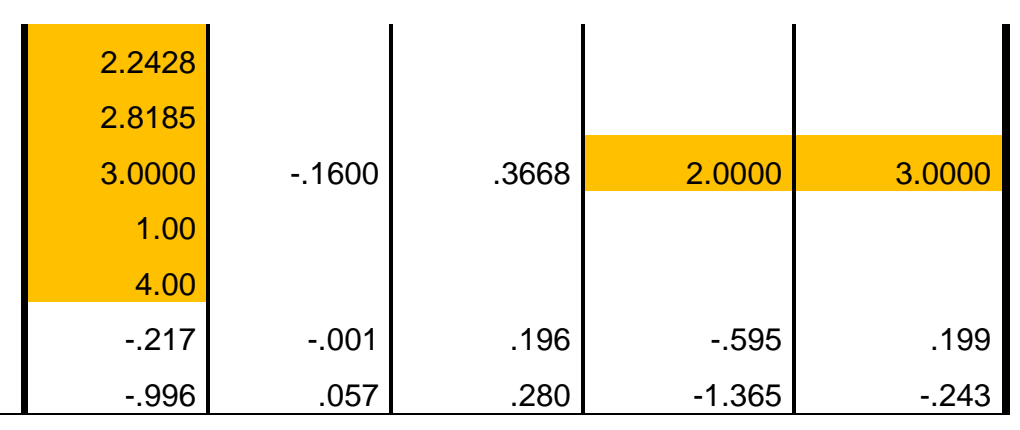

Comparação por formação

\begin{tabular}{|c|c|c|c|c|c|c|}
\hline \multicolumn{3}{|l|}{ Formacao_num } & \multirow[t]{3}{*}{ Statistic } & \multicolumn{3}{|c|}{ Bootstrap $^{a}$} \\
\hline \multirow{2}{*}{\multicolumn{3}{|c|}{ - Insuficientes recursos financeiros por parte do Poder Público. }} & & \multirow[t]{2}{*}{ Std. Error } & \multicolumn{2}{|c|}{ 95\% Confidence Interval } \\
\hline & & & & & Lower & Upper \\
\hline \multirow{7}{*}{ Arquitetura } & Mean & & 2.1364 & .2036 & 1.7273 & 2.5000 \\
\hline & $95 \%$ Confidence Interval for & Lower Bound & 1.6973 & & & \\
\hline & Mean & Upper Bound & 2.5754 & & & \\
\hline & Median & & 2.0000 & .3229 & 1.5000 & 3.0000 \\
\hline & Minimum & & 1.00 & & & \\
\hline & Maximum & & 4.00 & & & \\
\hline & Mean & & 2.7333 & .1743 & 2.4000 & 3.1000 \\
\hline \multirow{5}{*}{ Engenharia Civil } & $95 \%$ Confidence Interval for & Lower Bound & 2.3673 & & & \\
\hline & Mean & Upper Bound & 3.0994 & & & \\
\hline & Median & & 3.0000 & .2221 & 2.0000 & 3.0000 \\
\hline & Minimum & & 1.00 & & & \\
\hline & Maximum & & 4.00 & & & \\
\hline \multirow{6}{*}{ Outros } & Mean & & 2.0833 & .2916 & 1.5000 & 2.6667 \\
\hline & $95 \%$ Confidence Interval for & Lower Bound & 1.3948 & & & \\
\hline & Mean & Upper Bound & 2.7718 & & & \\
\hline & Median & & 2.0000 & .6674 & 1.0000 & 3.0000 \\
\hline & Minimum & & 1.00 & & & \\
\hline & Maximum & & 4.00 & & & \\
\hline \multirow{6}{*}{ Sociopolítico } & Mean & & 2.5500 & .1652 & 2.2000 & 2.8500 \\
\hline & 95\% Confidence Interval for & Lower Bound & 2.1947 & & & \\
\hline & Mean & Upper Bound & 2.9053 & & & \\
\hline & Median & & 3.0000 & .3567 & 2.0000 & 3.0000 \\
\hline & Minimum & & 1.00 & & & \\
\hline & Maximum & & 4.00 & & & \\
\hline
\end{tabular}


- Clima

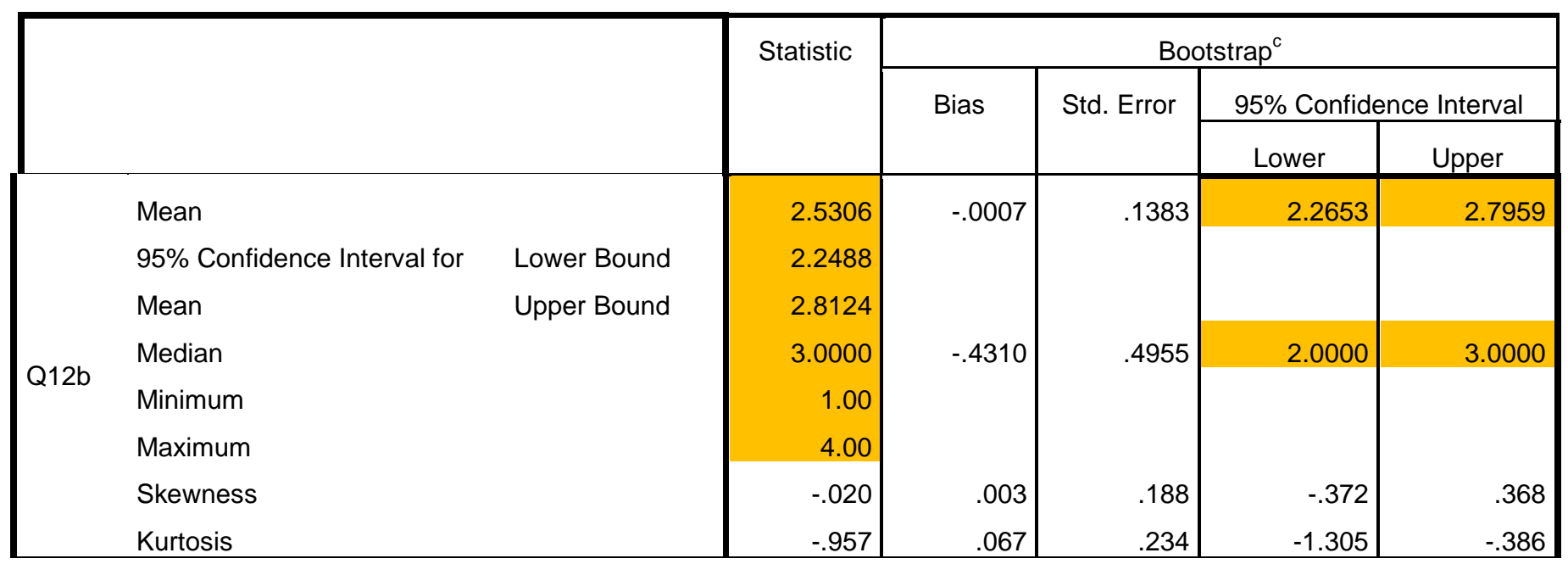

Comparação por formação

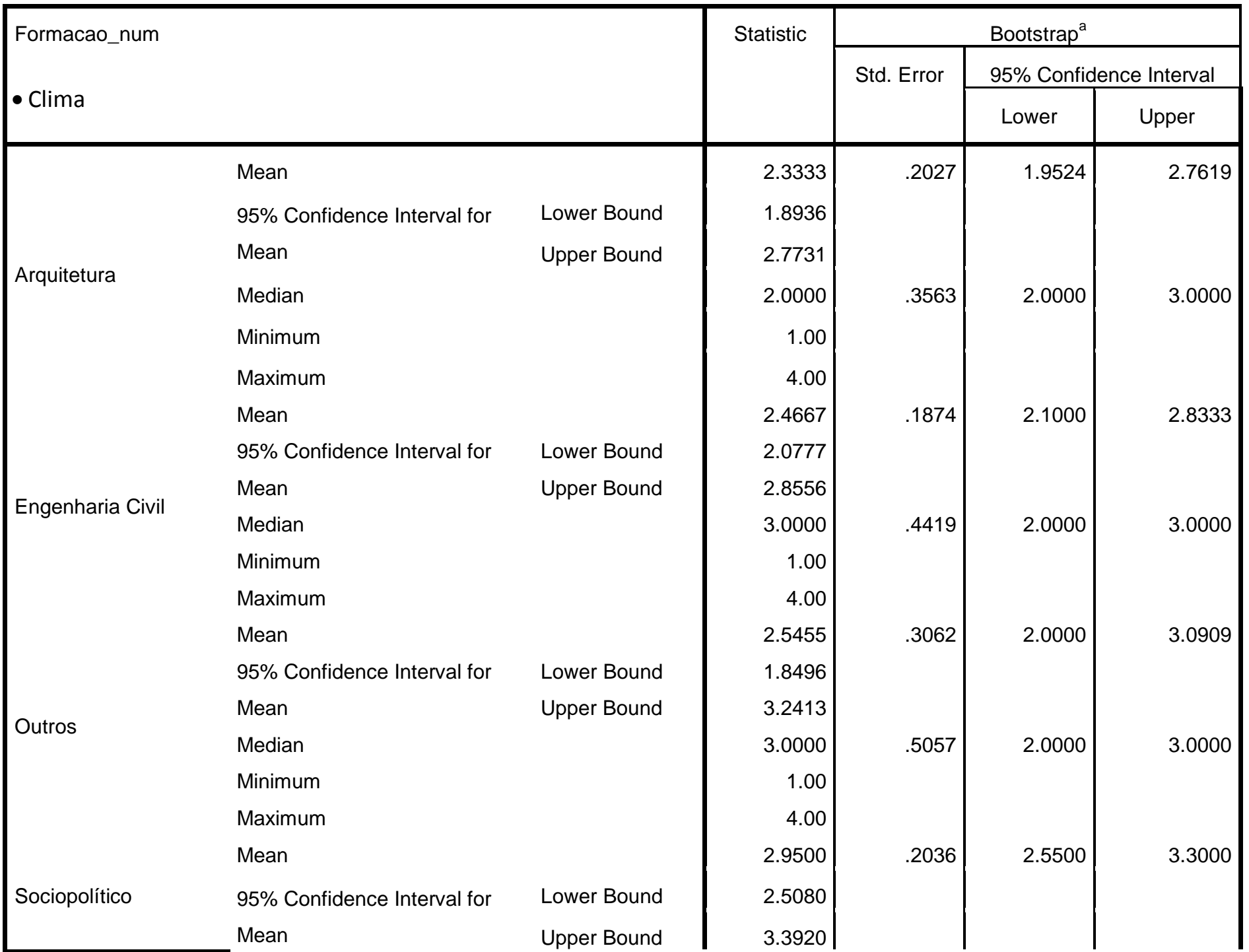


Median

$$
\begin{array}{r}
3.0000 \\
1.00
\end{array}
$$

\begin{tabular}{|c|c|c|c|c|c|c|c|}
\hline & & & \multirow[t]{3}{*}{ Statistic } & \multicolumn{4}{|c|}{ Bootstrap $^{c}$} \\
\hline & & & & \multirow[t]{2}{*}{ Bias } & \multirow[t]{2}{*}{ Std. Error } & \multicolumn{2}{|c|}{$95 \%$ Confidence Interval } \\
\hline & & & & & & Lower & Upper \\
\hline \multirow{8}{*}{ Q12c } & Mean & & 3.7551 & .0008 & .0608 & 3.6327 & 3.8776 \\
\hline & $95 \%$ Confidence Interval for & Lower Bound & 3.6303 & & & & \\
\hline & Mean & Upper Bound & 3.8799 & & & & \\
\hline & Median & & 4.0000 & .0000 & .0000 & 4.0000 & 4.0000 \\
\hline & Minimum & & 3.00 & & & & \\
\hline & Maximum & & 4.00 & & & & \\
\hline & Skewness & & -1.224 & -.060 & .432 & -2.377 & -.568 \\
\hline & Kurtosis & & -.524 & .352 & 1.357 & -1.751 & 3.803 \\
\hline
\end{tabular}

- A impermeabilização do solo.

\begin{tabular}{|c|c|c|c|c|c|c|}
\hline \multirow{3}{*}{\multicolumn{2}{|c|}{$\begin{array}{l}\text { Formacao_num } \\
\text { • A impermeabilização do solo. }\end{array}$}} & & \multirow[t]{3}{*}{ Statistic } & \multicolumn{3}{|c|}{ Bootstrap $^{b}$} \\
\hline & & & & \multirow[t]{2}{*}{ Std. Error } & \multicolumn{2}{|c|}{ 95\% Confidence Interval } \\
\hline & & & & & Lower & Upper \\
\hline \multirow{7}{*}{ Arquitetura } & Mean & & 3.5909 & .1452 & 3.2727 & 3.8636 \\
\hline & 95\% Confidence Interval for & Lower Bound & 3.2956 & & & \\
\hline & Mean & Upper Bound & 3.8863 & & & \\
\hline & Median & & 4.0000 & .1968 & 3.0000 & 4.0000 \\
\hline & Minimum & & 2.00 & & & \\
\hline & Maximum & & 4.00 & & & \\
\hline & Mean & & 3.7000 & .0961 & 3.5000 & 3.8667 \\
\hline \multirow{5}{*}{ Engenharia Civil } & $95 \%$ Confidence Interval for & Lower Bound & 3.5002 & & & \\
\hline & Mean & Upper Bound & 3.8998 & & & \\
\hline & Median & & 4.0000 & .0274 & 4.0000 & 4.0000 \\
\hline & Minimum & & 2.00 & & & \\
\hline & Maximum & & 4.00 & & & \\
\hline \multirow{3}{*}{ Outros } & Mean & & 3.8333 & $.0935^{\mathrm{C}}$ & $3.5833^{\mathrm{C}}$ & $3.9167^{\mathrm{C}}$ \\
\hline & $95 \%$ Confidence Interval for & Lower Bound & 3.5860 & & & \\
\hline & Mean & Upper Bound & 4.0807 & & & \\
\hline
\end{tabular}

Comparação por formação 


\begin{tabular}{|c|c|c|c|c|c|c|}
\hline & Median & & 4.0000 & $.0528^{c}$ & $4.0000^{c}$ & $4.0000^{\mathrm{C}}$ \\
\hline & Std. Deviation & & .38925 & $.07577^{\mathrm{C}}$ & $.28868^{c}$ & $.51493^{c}$ \\
\hline & Minimum & & 3.00 & & & \\
\hline & Maximum & & 4.00 & & & \\
\hline & Mean & & 3.6316 & $.1306^{d}$ & $3.3684^{d}$ & $3.8947^{d}$ \\
\hline & Mean & Upper Bound & 3.9195 & & & \\
\hline SOCIOpOIIICO & Median & & & $.1938^{d}$ & $3.0000^{d}$ & $4.0000^{d}$ \\
\hline & Minimum & & 2.00 & & & \\
\hline
\end{tabular}

- A fiscalização do uso e ocupação do solo em áreas de proteção de mananciais e de preservação permanente.

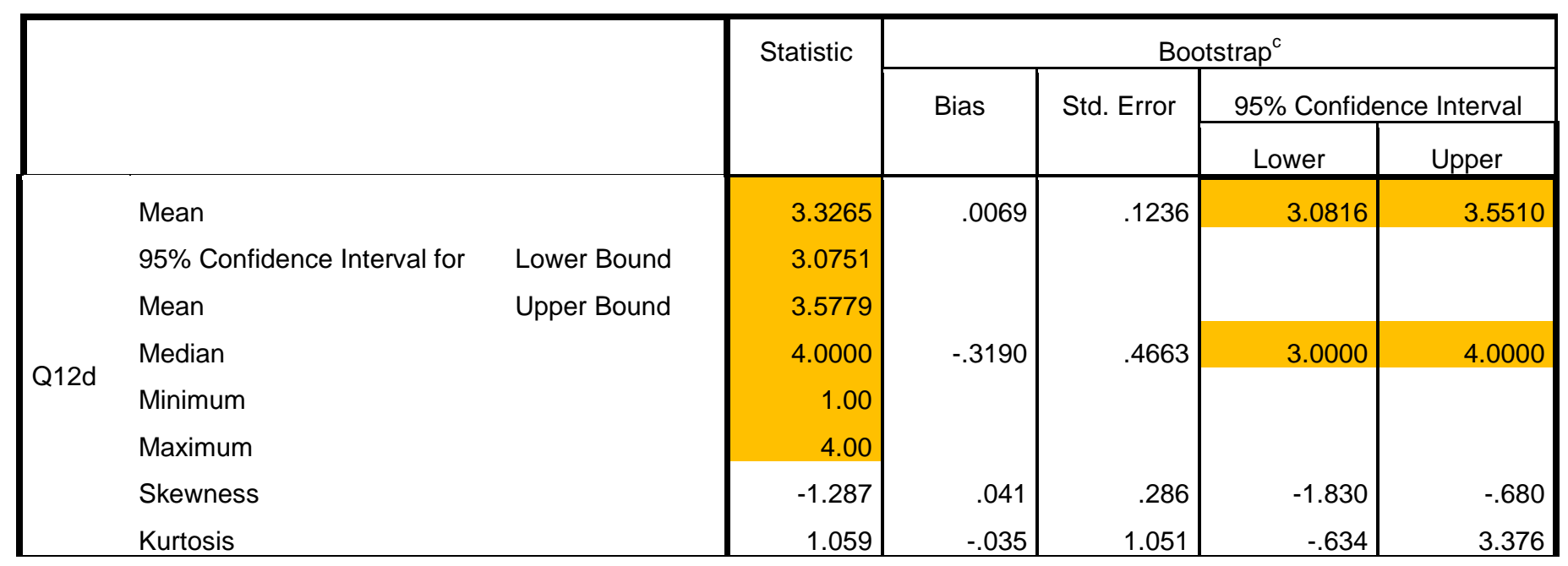

Comparação por formação

\begin{tabular}{|c|c|c|c|c|c|c|}
\hline \multirow{3}{*}{\multicolumn{3}{|c|}{$\begin{array}{l}\text { Formacao_num } \\
\text { - A fiscalização do uso e ocupação do solo em áreas de proteção de } \\
\text { mananciais e de preservação permanente. }\end{array}$}} & \multirow[t]{3}{*}{ Statistic } & \multicolumn{3}{|c|}{ Bootstrap $^{b}$} \\
\hline & & & & \multirow[t]{2}{*}{ Std. Error } & \multicolumn{2}{|c|}{ 95\% Confidence Interval } \\
\hline & & & & & Lower & Upper \\
\hline \multirow{4}{*}{ Arquitetura } & Mean & & 3.3636 & .1811 & 3.0000 & 3.6818 \\
\hline & $95 \%$ Confidence Interval for & Lower Bound & 2.9878 & & & \multirow{3}{*}{4.0000} \\
\hline & Median & & 4.0000 & \multirow[t]{2}{*}{.4327} & \multirow[t]{2}{*}{3.0000} & \\
\hline & Minimum & & 1.00 & & & \\
\hline
\end{tabular}




\begin{tabular}{|c|c|c|c|c|c|c|}
\hline \multirow{9}{*}{ Engenharia Civil } & Maximum & & 4.00 & \multirow{4}{*}{.1111} & \multirow{4}{*}{3.2333} & \multirow{3}{*}{3.6667} \\
\hline & Mean & & 3.4667 & & & \\
\hline & 95\% Confidence Interval for & Lower Bound & 3.2319 & & & \\
\hline & Mean & Upper Bound & 3.7015 & & & \multirow{4}{*}{4.0000} \\
\hline & Median & & 4.0000 & \multirow[t]{3}{*}{.4488} & \multirow[t]{3}{*}{3.0000} & \\
\hline & Minimum & & 2.00 & & & \\
\hline & Maximum & & 4.00 & & & \\
\hline & Mean & & 3.5000 & $.2424^{\circ}$ & $2.9167^{\mathrm{C}}$ & $3.9167^{\circ}$ \\
\hline & $95 \%$ Confidence Interval for & Lower Bound & 2.9253 & & & \\
\hline \multirow{7}{*}{ Outros } & Mean & Upper Bound & 4.0747 & \multirow{4}{*}{$.2830^{\circ}$} & \multirow{4}{*}{$3.0000^{c}$} & \multirow{4}{*}{$4.0000^{c}$} \\
\hline & Median & & 4.0000 & & & \\
\hline & Minimum & & 1.00 & & & \\
\hline & Maximum & & 4.00 & & & \\
\hline & Mean & & 3.4286 & .1716 & 3.0952 & 3.7143 \\
\hline & $95 \%$ Confidence Interval for & Lower Bound & 3.0596 & & & \multirow{5}{*}{4.0000} \\
\hline & Mean & Upper Bound & 3.7976 & \multirow{4}{*}{.4366} & \multirow{4}{*}{3.0000} & \\
\hline \multirow{3}{*}{ Sociopolítico } & Median & & 4.0000 & & & \\
\hline & Minimum & & 1.00 & & & \\
\hline & Maximum & & 4.00 & & & \\
\hline
\end{tabular}

- O envolvimento de moradores e comerciantes no planejamento das obras a fim de se obter consenso sobre as mesmas e praticar seu uso racional.

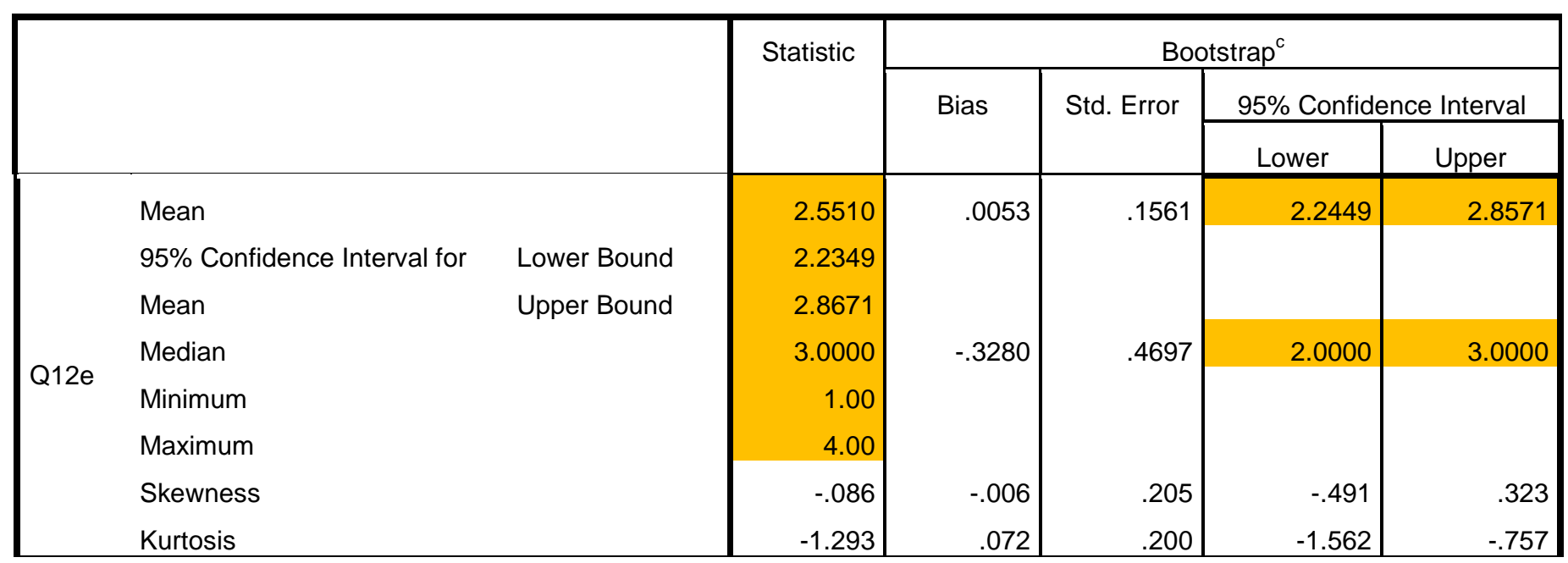

Comparação por formação 


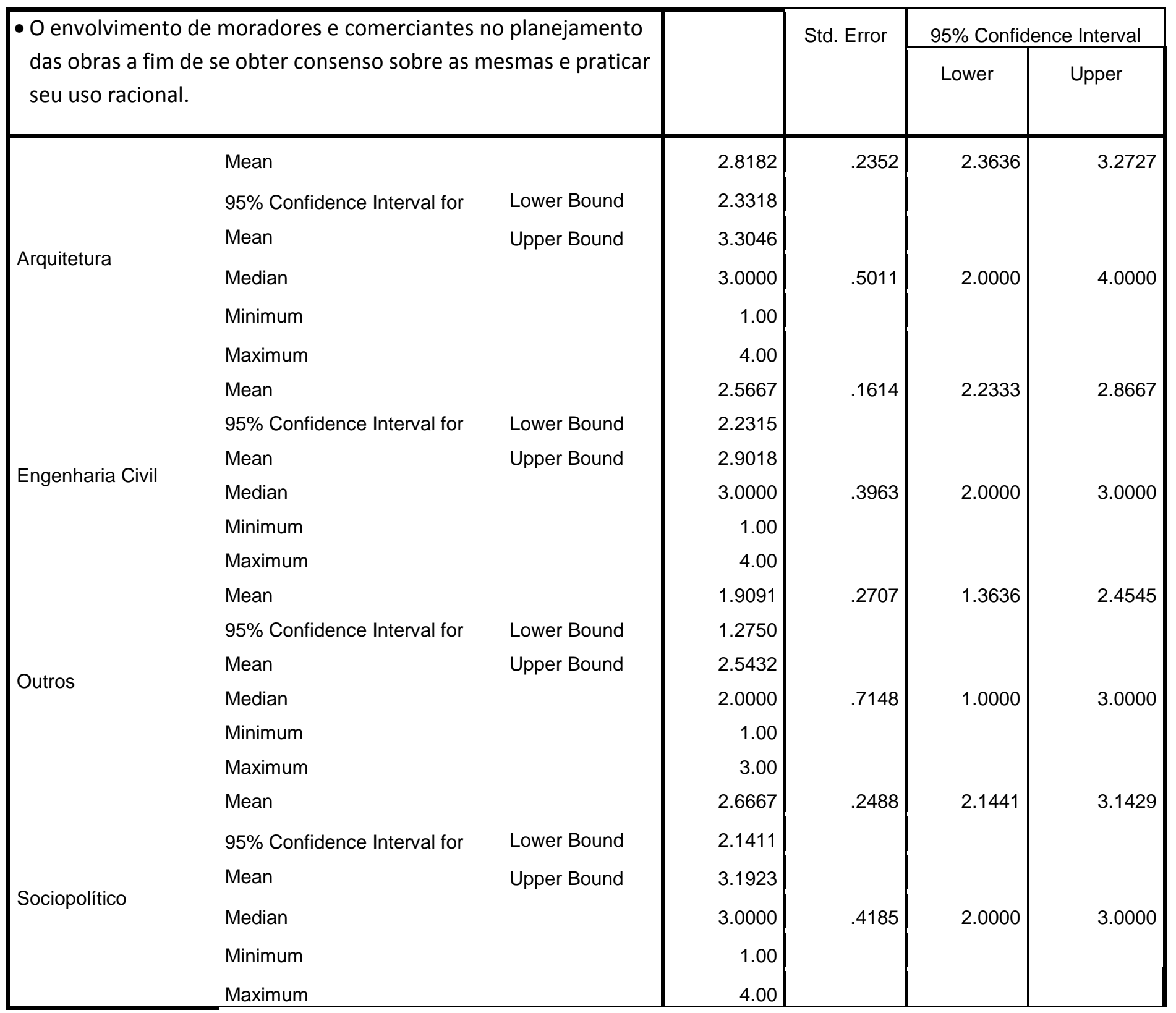

- A graduação em Engenharia Civil e a formação que oferece nos aspectos sociopolíticos que as obras envolvem tendo em vista garantir sua durabilidade.

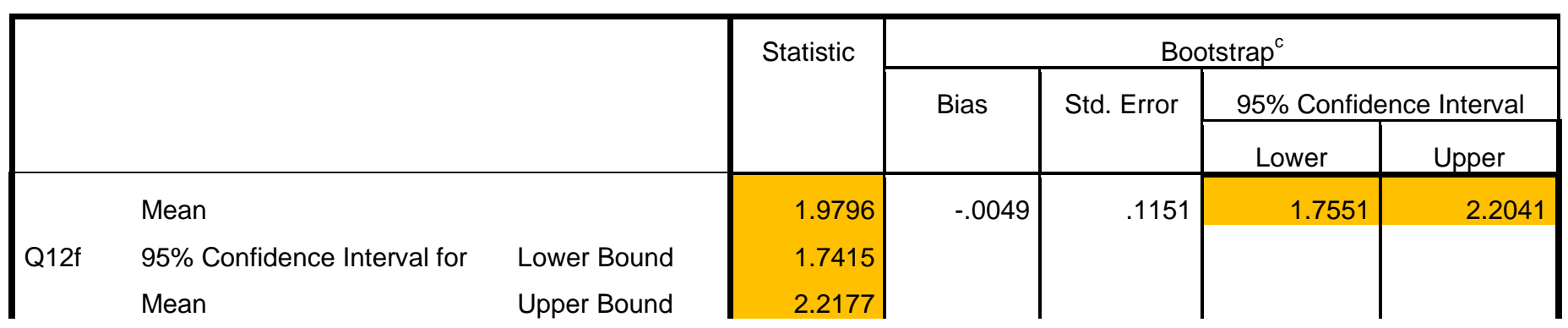




\begin{tabular}{|c|c|c|c|c|c|}
\hline Median & 2.0000 & -.0010 & .0316 & 2.0000 & 2.0000 \\
\hline Minimum & 1.00 & & & & \\
\hline Maximum & 4.00 & & & & \\
\hline Skewness & .497 & -.053 & .243 & .000 & .928 \\
\hline Kurtosis & -.297 & -.053 & .561 & -1.270 & 1.005 \\
\hline
\end{tabular}

Comparação por formação

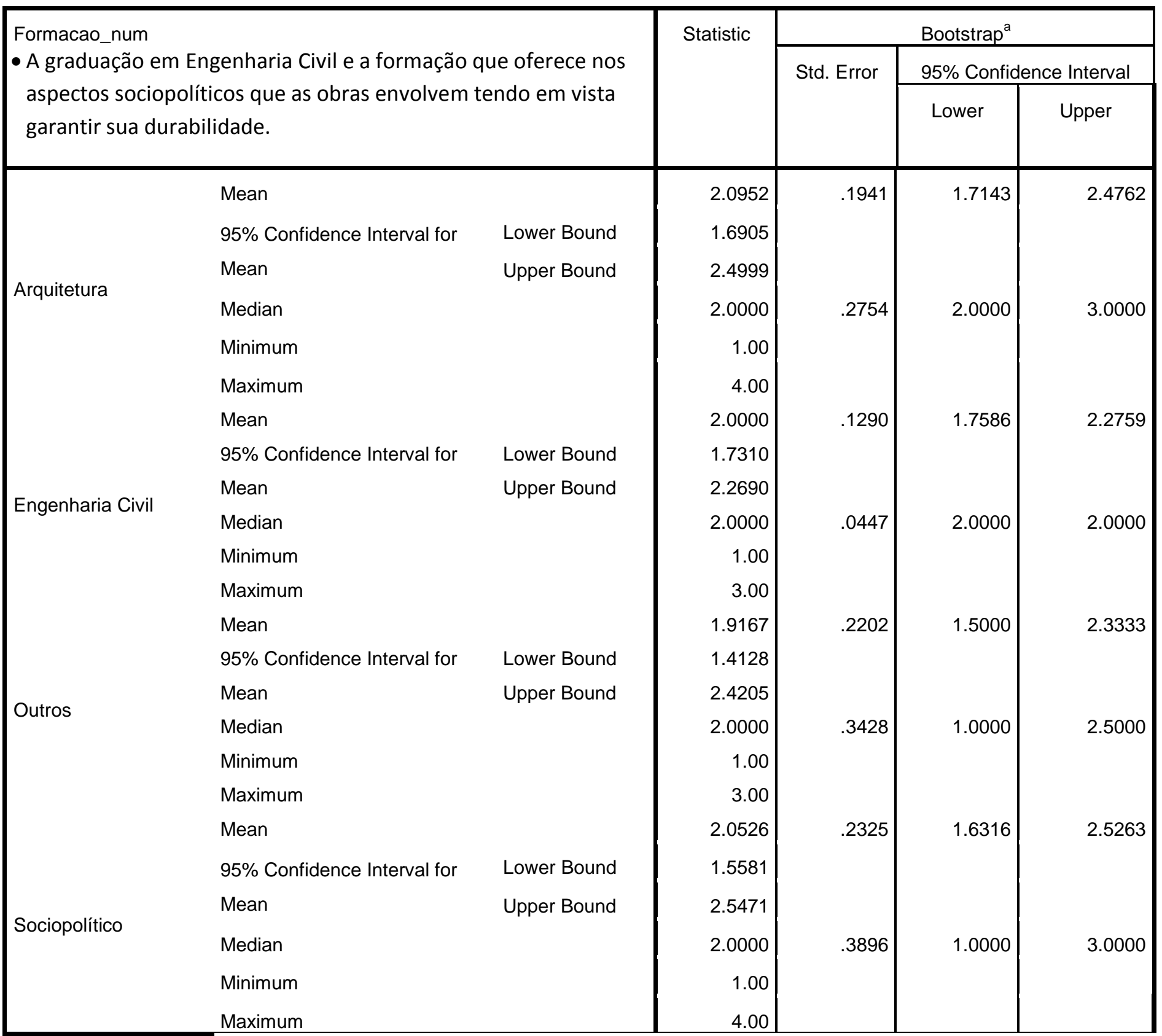


- A capacitação de Profissionais de formação humanista e social para envolver moradores e comerciantes de maneira que se sintam capazes de contribuir para a redução de alagamentos e inundações.

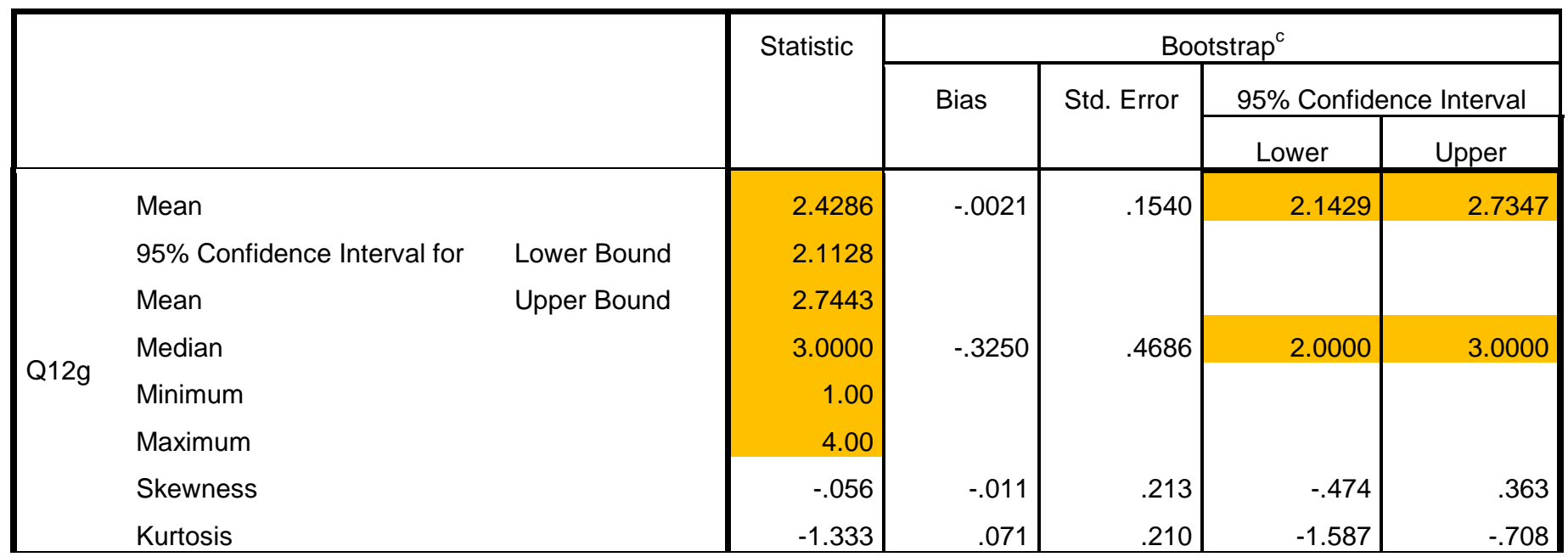

Comparação por formação

Formacao_num

- A capacitação de Profissionais de formação humanista e social para envolver moradores e comerciantes de maneira que se sintam capazes de contribuir para a redução de alagamentos e inundações.

Engenharia Civil

Arquitetura

$\begin{array}{ll}\text { Engenharia Civil } & \text { Minimum } \\ & \text { Maximum } \\ & \text { Mean } \\ & 95 \% \text { Confidence Interval for } \\ & \text { Mean } \\ \text { Outros } & \text { Median } \\ & \text { Minimum } \\ & \text { Maximum }\end{array}$

Mean

95\% Confidence Interval for

Mean

Median

Minimum

Maximum

Mean

95\% Confidence Interval for

Mean

Maximum
Lower Bound

Upper Bound

Lower Bound

Upper Bound

Lower Bound
Upper Bound

\begin{tabular}{|c|c|c|c|}
\hline \multirow[t]{3}{*}{ Statistic } & \multicolumn{3}{|c|}{ Bootstrap $^{a}$} \\
\hline & \multirow[t]{2}{*}{ Std. Error } & \multicolumn{2}{|c|}{ 95\% Confidence Interval } \\
\hline & & Lower & Upper \\
\hline 2.7273 & .2144 & 2.3182 & 3.1364 \\
\hline 2.2697 & & & \\
\hline 3.1848 & & & \\
\hline 3.0000 & .1911 & 2.5000 & 3.0000 \\
\hline 1.00 & & & \\
\hline 4.00 & & & \\
\hline 2.5333 & .1920 & 2.2000 & 2.9333 \\
\hline 2.1444 & & & \\
\hline 2.9223 & & & \\
\hline 3.0000 & .3229 & 2.0000 & 3.0000 \\
\hline 1.00 & & & \\
\hline 4.00 & & & \\
\hline 2.0833 & .3280 & 1.5000 & 2.8312 \\
\hline 1.3434 & & & \\
\hline 2.8232 & & & \\
\hline 2.0000 & .5771 & 1.0000 & 3.0000 \\
\hline 1.00 & & & \\
\hline 4.00 & & & \\
\hline
\end{tabular}




\begin{tabular}{|c|c|c|c|c|c|c|}
\hline \multirow{6}{*}{ Sociopolítico } & Mean & & 2.6000 & .2763 & 2.0500 & 3.1500 \\
\hline & $95 \%$ Confidence Interval for & Lower Bound & 2.0041 & & & \\
\hline & Mean & Upper Bound & 3.1959 & & & \\
\hline & Median & & 3.0000 & .5993 & 1.5000 & 4.0000 \\
\hline & Minimum & & 1.00 & & & \\
\hline & Maximum & & 4.00 & & & \\
\hline
\end{tabular}

- Resíduos sólidos depositados nas vias públicas e cursos de água

\begin{tabular}{|c|c|c|c|c|c|c|c|}
\hline & & & \multirow[t]{3}{*}{ Statistic } & \multicolumn{4}{|c|}{ Bootstrap ${ }^{c}$} \\
\hline & & & & \multirow[t]{2}{*}{ Bias } & \multirow[t]{2}{*}{ Std. Error } & \multicolumn{2}{|c|}{ 95\% Confidence Interval } \\
\hline & & & & & & Lower & Upper \\
\hline \multirow{8}{*}{ Q12h } & Mean & & 3.6735 & .0030 & .0734 & 3.5306 & 3.8163 \\
\hline & 95\% Confidence Interval for & Lower Bound & 3.5253 & & & & \\
\hline & Mean & Upper Bound & 3.8217 & & & & \\
\hline & Median & & 4.0000 & -.0010 & .0316 & 4.0000 & 4.0000 \\
\hline & Minimum & & 2.00 & & & & \\
\hline & Maximum & & 4.00 & & & & \\
\hline & Skewness & & -1.231 & .026 & .402 & -2.086 & -.475 \\
\hline & Kurtosis & & .505 & -.223 & 1.415 & -1.851 & 3.323 \\
\hline
\end{tabular}

Comparação por formação

\begin{tabular}{|c|c|c|c|c|c|c|}
\hline \multicolumn{3}{|l|}{ Formacao_num } & \multirow[t]{2}{*}{ Statistic } & \multicolumn{3}{|c|}{ Bootstrap $^{b}$} \\
\hline \multicolumn{3}{|c|}{$\begin{array}{l}\text { - Resíduos sólidos depositados nas vias públicas e cursos de } \\
\text { água }\end{array}$} & & Std. Error & Lower & Upper \\
\hline \multirow{4}{*}{ Arquitetura } & Mean & & 3.5000 & .1655 & 3.1364 & 3.8182 \\
\hline & Mean & Upper Bound & 3.8555 & & & \\
\hline & Median & & 4.0000 & .2609 & 3.0000 & 4.0000 \\
\hline & Minimum & & 1.00 & & & \\
\hline \multirow{2}{*}{ Engenharia Civil } & Mean & Upper Bound & 3.8321 & & & \\
\hline & Median & & 4.0000 & .1761 & 3.0000 & 4.0000 \\
\hline
\end{tabular}




\begin{tabular}{|c|c|c|c|c|c|c|}
\hline & Minimum & & 2.00 & & & \\
\hline & Maximum & & 4.00 & & & \\
\hline & Mean & & 3.6667 & $.1273^{\mathrm{C}}$ & $3.4167^{\mathrm{c}}$ & $3.9167^{c}$ \\
\hline & $95 \%$ Confidence Interval for & Lower Bound & 3.3538 & & & \\
\hline Outroc & Mean & Upper Bound & 3.9795 & & & \\
\hline Sultos & Median & & 4.0000 & $.2600^{\circ}$ & $3.0000^{c}$ & $4.0000^{\mathrm{C}}$ \\
\hline & Minimum & & 3.00 & & & \\
\hline & Maximum & & 4.00 & & & \\
\hline & Mean & & 3.8095 & $.0846^{\mathrm{d}}$ & $3.6190^{d}$ & $3.9524^{d}$ \\
\hline & $95 \%$ Confidence Interval for & Lower Bound & 3.6264 & & & \\
\hline & Mean & Upper Bound & 3.9927 & & & \\
\hline outiopomitico & Median & & 4.0000 & $.0550^{\mathrm{d}}$ & $4.0000^{d}$ & $4.0000^{d}$ \\
\hline & Minimum & & 3.00 & & & \\
\hline & Maximum & & 4.00 & & & \\
\hline
\end{tabular}

- A manutenção das obras de drenagem pelo Poder Público.

\begin{tabular}{|c|c|c|c|c|c|c|c|}
\hline & & & Statistic & & Boc & $\operatorname{trap}^{c}$ & \\
\hline & & & & Bias & Std. Error & $95 \%$ Confid & Interval \\
\hline & & & & & & Lower & Upper \\
\hline & Mean & & 3.2857 & .0045 & .1235 & 3.0408 & 3.5102 \\
\hline & $95 \%$ Confidence Interval for & Lower Bound & 3.0370 & & & & \\
\hline & Mean & Upper Bound & 3.5345 & & & & \\
\hline (1) & Median & & 3.0000 & .3340 & .4719 & 3.0000 & 4.0000 \\
\hline रा & Minimum & & 1.00 & & & & \\
\hline & Maximum & & 4.00 & & & & \\
\hline & Skewness & & -1.404 & .058 & .263 & -1.854 & -.804 \\
\hline & Kurtosis & & 1.757 & .038 & 1.149 & -.453 & 3.997 \\
\hline
\end{tabular}

Comparação por formação

\begin{tabular}{|c|c|c|c|c|c|c|}
\hline \multirow{3}{*}{\multicolumn{3}{|c|}{$\begin{array}{l}\text { Formacao_num } \\
\text { - A manutenção das obras de drenagem pelo Poder Público. }\end{array}$}} & \multirow[t]{3}{*}{ Statistic } & \multicolumn{3}{|c|}{ Bootstrap $^{a}$} \\
\hline & & & & \multirow[t]{2}{*}{ Std. Error } & \multicolumn{2}{|c|}{ 95\% Confidence Interval } \\
\hline & & & & & Lower & Upper \\
\hline \multirow{3}{*}{ Arquitetura } & Mean & & 3.3810 & \multirow[t]{3}{*}{.1935} & \multirow[t]{3}{*}{3.0000} & \multirow[t]{3}{*}{3.7143} \\
\hline & $95 \%$ Confidence Interval for & Lower Bound & 2.9619 & & & \\
\hline & Mean & Upper Bound & 3.8000 & & & \\
\hline
\end{tabular}




\begin{tabular}{|c|c|c|c|c|c|c|}
\hline & Median & & 4.0000 & .4394 & 3.0000 & 4.0000 \\
\hline & Minimum & & 1.00 & & & \\
\hline & Maximum & & 4.00 & & & \\
\hline & Mean & & 3.4667 & .0992 & 3.2667 & 3.6667 \\
\hline & $95 \%$ Confidence Interval for & Lower Bound & 3.2533 & & & \\
\hline & Mean & Upper Bound & 3.6800 & & & \\
\hline Ligomianca & Median & & 3.5000 & .4663 & 3.0000 & 4.0000 \\
\hline & Minimum & & 2.00 & & & \\
\hline & Maximum & & 4.00 & & & \\
\hline & Mean & & 3.2727 & .2628 & 2.7273 & 3.7273 \\
\hline & $95 \%$ Confidence Interval for & Lower Bound & 2.6651 & & & \\
\hline Outrac & Mean & Upper Bound & 3.8804 & & & \\
\hline Sutios & Median & & 3.0000 & 4825 & 3.0000 & 4.0000 \\
\hline & Minimum & & 1.00 & & & \\
\hline & Maximum & & 4.00 & & & \\
\hline & Mean & & 3.1500 & .2165 & 2.7013 & 3.5500 \\
\hline & $95 \%$ Confidence Interval for & Lower Bound & 2.6876 & & & \\
\hline Coninnolíting & Mean & Upper Bound & 3.6124 & & & \\
\hline & Median & & 3.0000 & .4292 & 3.0000 & 4.0000 \\
\hline & Minimum & & 1.00 & & & \\
\hline & Maximum & & 4.00 & & & \\
\hline
\end{tabular}

Questão 13 - Para a durabilidade das obras em drenagem urbana e a sustentabilidade do serviço que oferecem é necessário:

- Maior envolvimento de moradores e comerciantes das áreas onde as obras são implantadas para que se encontre um consenso quanto a atender o interesse público.

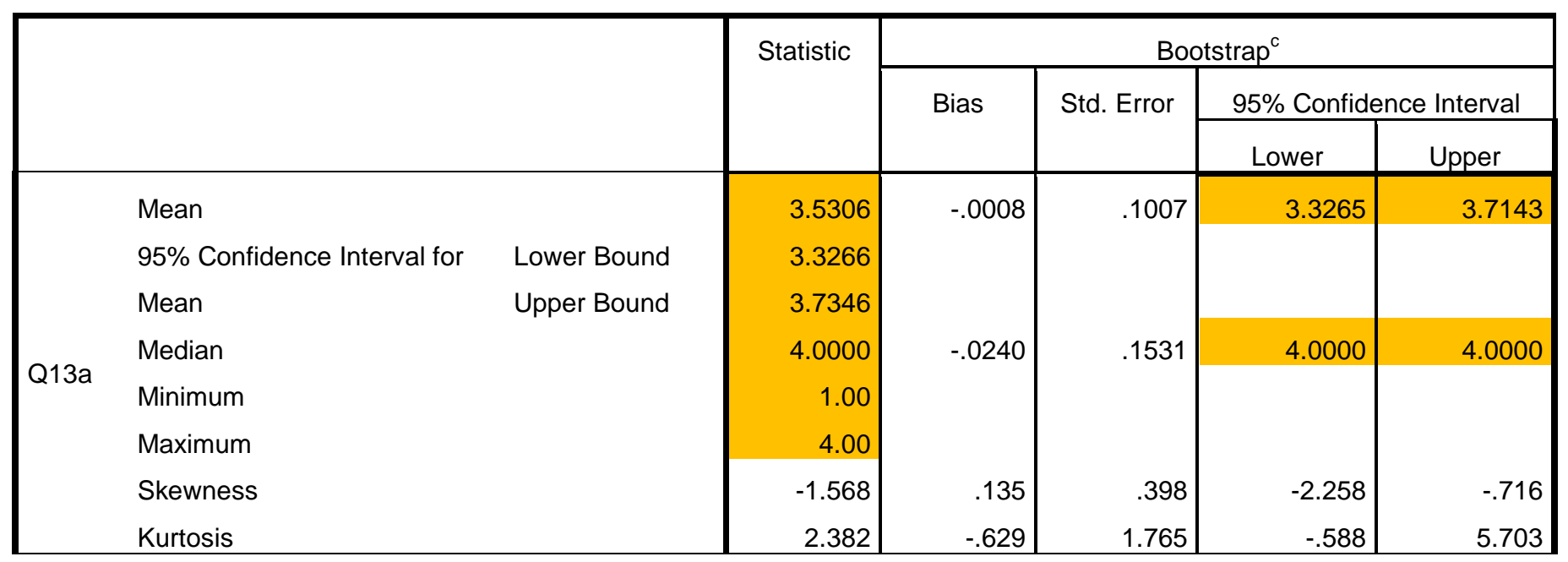


Comparação por formação

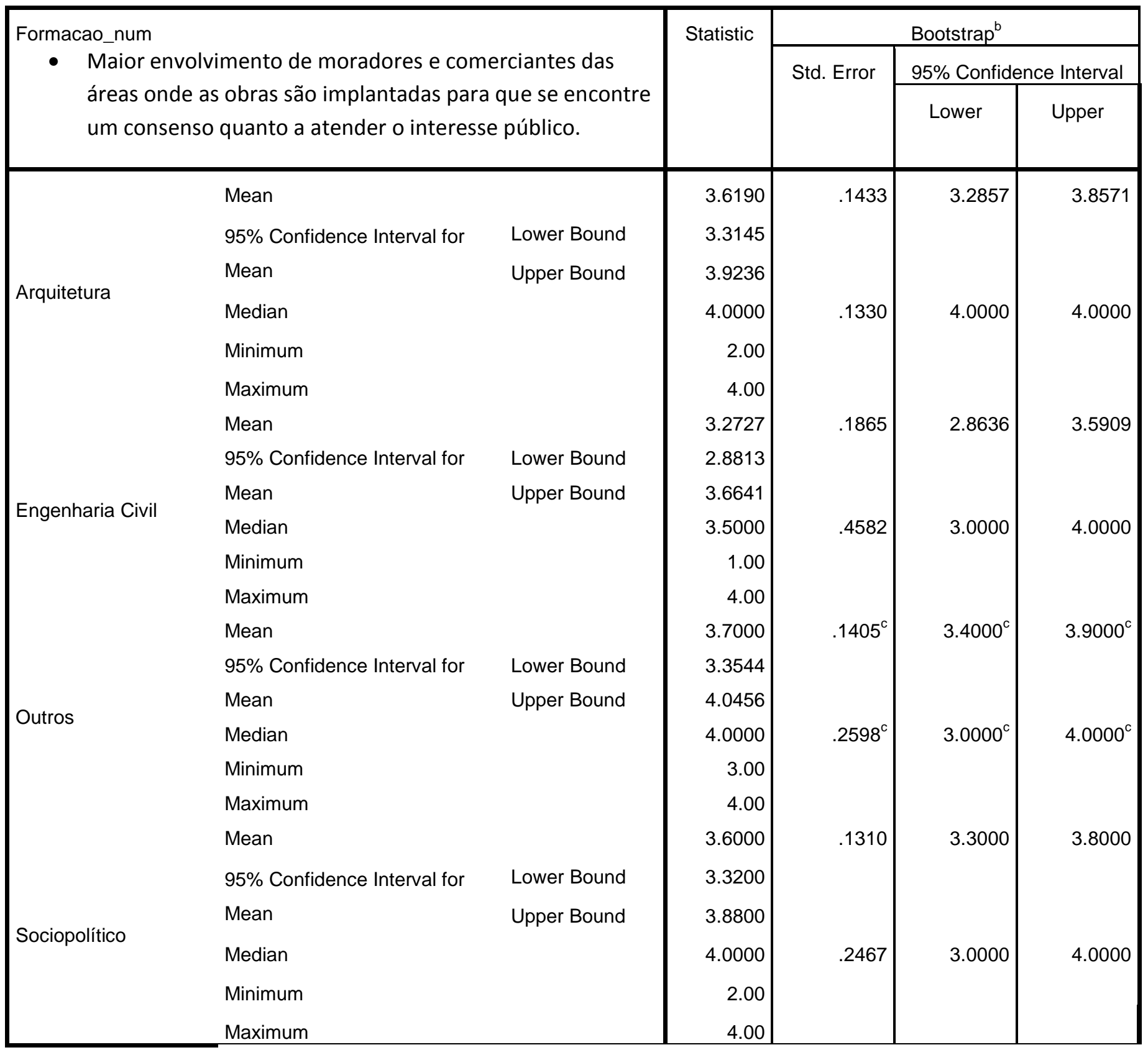

- Capacitação de profissionais formados em áreas sociais para trabalhar junto a moradores e comerciantes tendo em vista o uso racional da obra implantada.

\begin{tabular}{|l|l|l|l|c|c|}
\hline \multirow{2}{*}{$*$} & \multirow{2}{*}{ Statistic } & \multicolumn{3}{|c|}{ Bootstrap $^{c}$} \\
\cline { 4 - 6 } & & \multirow{2}{*}{ Bias } & \multirow{2}{*}{ Std. Error } & \multicolumn{2}{|c|}{$95 \%$ Confidence Interval } \\
\cline { 4 - 6 } & & & & Lower & Upper \\
\hline
\end{tabular}




\begin{tabular}{|c|c|c|c|c|c|c|c|}
\hline \multirow{8}{*}{ Q13b } & Mean & \multirow{3}{*}{$\begin{array}{l}\text { Lower Bound } \\
\text { Upper Bound }\end{array}$} & 3.5918 & \multirow[t]{3}{*}{-.0006} & \multirow[t]{3}{*}{.0903} & 3.4082 & 3.7551 \\
\hline & $95 \%$ Confidence Interval for & & 3.4072 & & & & \\
\hline & Mean & & 3.7765 & & & & \\
\hline & Median & & 4.0000 & -.0130 & .1133 & 4.0000 & 4.0000 \\
\hline & Minimum & & 1.00 & & & & \\
\hline & Maximum & & 4.00 & & & & \\
\hline & Skewness & & -1.830 & .271 & .538 & -2.448 & -.541 \\
\hline & Kurtosis & & 4.306 & -1.617 & 2.678 & -1.751 & 7.271 \\
\hline
\end{tabular}

Comparação por formação

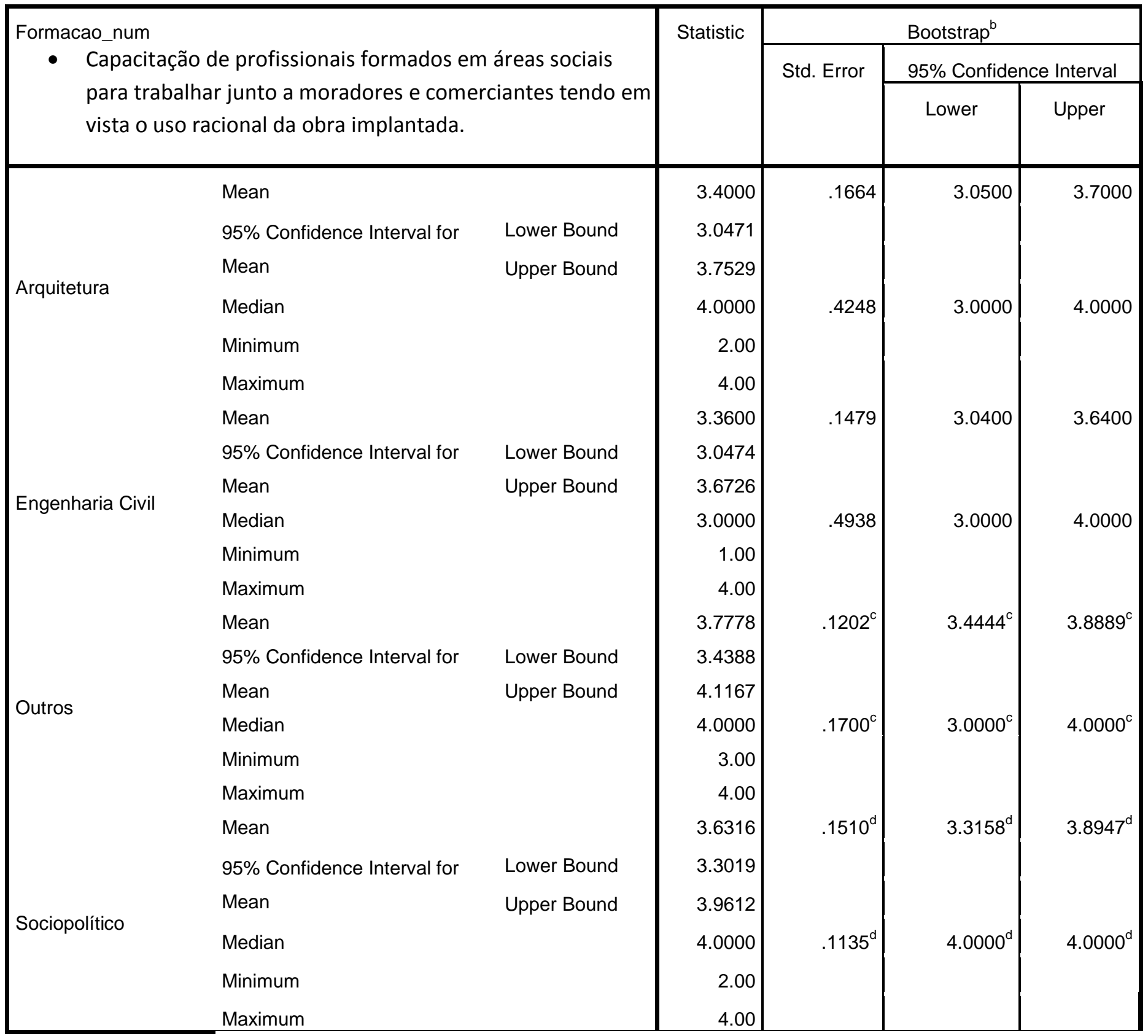


- Projetos que focalizem trabalhar reinvidicações de moradores e comerciantes de maneira a administrar conflitos e chegar a consenso que responda ao interesse público.

\begin{tabular}{|c|c|c|c|c|c|c|c|}
\hline & & & Statistic & & Boo & $\operatorname{trap}^{c}$ & \\
\hline & & & & Bias & Std. Error & $95 \%$ Confid & Interval \\
\hline & & & & & & Lower & Upper \\
\hline & Mean & & 3.4490 & .0005 & .0984 & 3.2653 & 3.6327 \\
\hline & 95\% Confidence Interval for & Lower Bound & 3.2454 & & & & \\
\hline & Mean & Upper Bound & 3.6526 & & & & \\
\hline 013 & Median & & 4.0000 & -.2470 & .4315 & 3.0000 & 4.0000 \\
\hline 4100 & Minimum & & 1.00 & & & & \\
\hline & Maximum & & 4.00 & & & & \\
\hline & Skewness & & -1.276 & .144 & .382 & -1.843 & -.387 \\
\hline & Kurtosis & & 1.703 & -.622 & 1.478 & -.915 & 4.192 \\
\hline
\end{tabular}

Comparação por formação

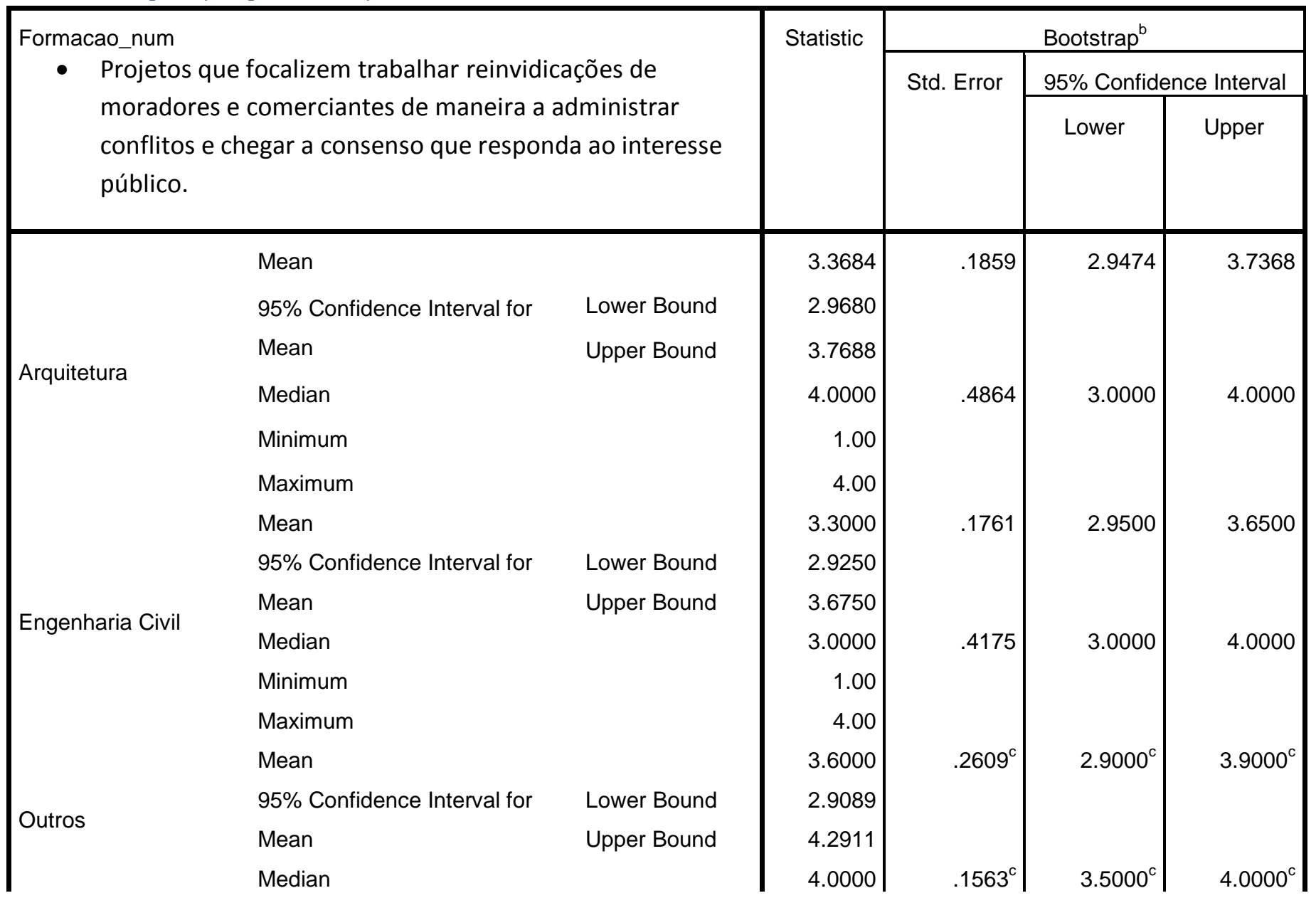




\begin{tabular}{|lll|r|r|r|r|} 
& Minimum & & 1.00 \\
& Maximum & 4.00 & & & \\
& Mean & & 3.4737 & .1340 & 3.2105 & 3.7368 \\
& $95 \%$ Confidence Interval for & Lower Bound & 3.1788 & & \\
Sociopolítico & Mean & Upper Bound & 3.7686 & & & \\
& Median & & 4.0000 & .4891 & 3.0000 & 4.0000 \\
& Minimum & & & \\
& Maximum & & & & \\
& & & & & \\
\end{tabular}

- Envolvimento de moradores e comerciantes no planejamento de maneira a que as decisões atendam ao interesse público.

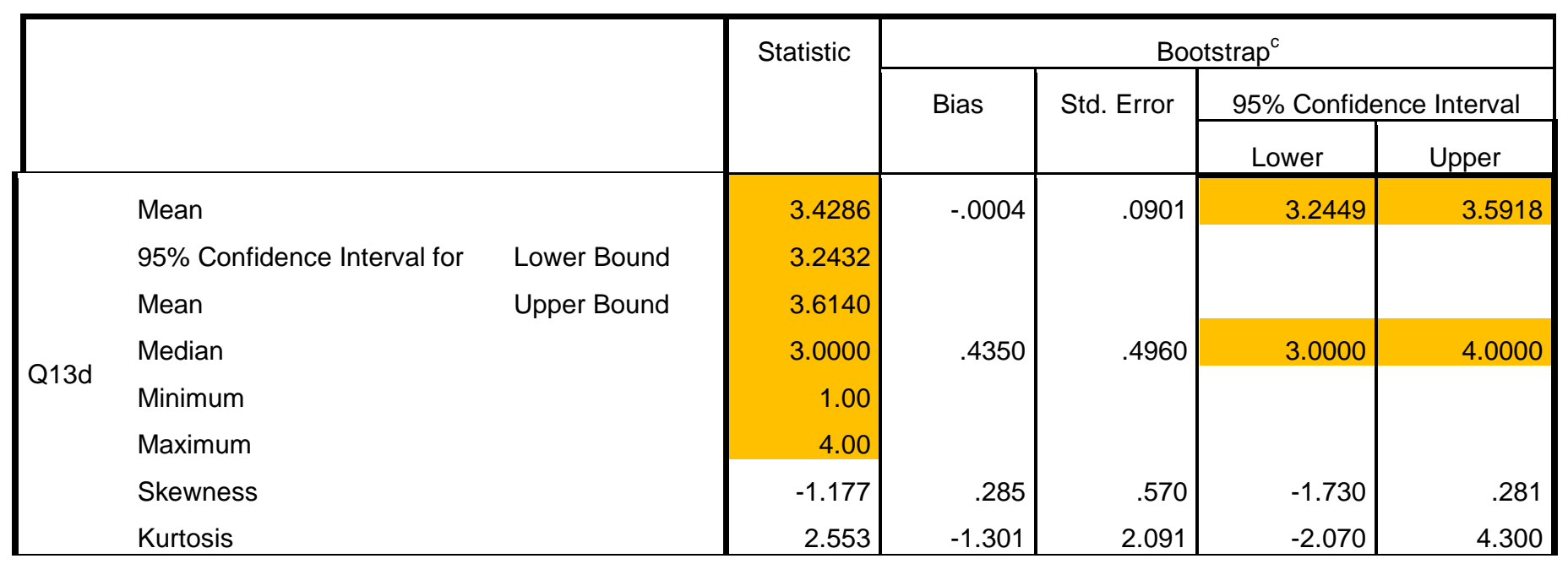

Comparação por formação

\begin{tabular}{|c|c|c|c|c|c|c|}
\hline \multirow{3}{*}{\multicolumn{3}{|c|}{$\begin{array}{l}\text { Formacao_num } \\
\text { - Envolvimento de moradores e comerciantes no } \\
\text { planejamento de maneira a que as decisões atendam ao } \\
\text { interesse público. }\end{array}$}} & \multirow[t]{3}{*}{ Statistic } & \multicolumn{3}{|c|}{ Bootstrap $^{b}$} \\
\hline & & & & \multirow[t]{2}{*}{ Std. Error } & \multicolumn{2}{|c|}{ 95\% Confidence Interval } \\
\hline & & & & & Lower & Upper \\
\hline \multirow{7}{*}{ Arquitetura } & Mean & & 3.3889 & .1980 & 2.9444 & 3.7222 \\
\hline & 95\% Confidence Interval for & Lower Bound & 2.9663 & & & \\
\hline & Mean & Upper Bound & 3.8115 & & & \\
\hline & Median & & 4.0000 & .4201 & 3.0000 & 4.0000 \\
\hline & Minimum & & 1.00 & & & \\
\hline & Maximum & & 4.00 & & & \\
\hline & Mean & & 3.2308 & .1714 & 2.8471 & 3.5385 \\
\hline Engenharia Civil & $95 \%$ Confidence Interval for & Lower Bound & 2.8822 & & & \\
\hline
\end{tabular}




$\begin{array}{|lll|} & \text { Mean } & \text { Upper Bound } \\ & \text { Median } & \\ & \text { Minimum } & \\ & \text { Maximum } & \\ & \text { Mean } & \\ & 95 \% \text { Confidence Interval for } & \text { Lower Bound } \\ \text { Outros } & \text { Mean } & \text { Upper Bound } \\ & \text { Median } & \\ & \text { Minimum } & \\ & \text { Maximum } & \\ & \text { Mean } & \\ & 95 \% \text { Confidence Interval for } & \text { Lower Bound } \\ & \text { Mean } & \text { Upper Bound } \\ \text { Sociopolítico } & \text { Median } & \\ & \text { Minimum } & \\ & \text { Maximum } & \end{array}$

\begin{tabular}{r|r|r|r|}
3.5793 & & & \\
3.0000 & .3743 & 3.0000 & 4.0000 \\
1.00 & & & \\
4.00 & & & \\
3.4444 & $.2200^{\mathrm{C}}$ & $3.0000^{\mathrm{c}}$ & $3.8889^{\mathrm{c}}$ \\
2.8860 & & & \\
4.0029 & & & \\
4.0000 & $.4849^{\mathrm{c}}$ & $3.0000^{\mathrm{c}}$ & $4.0000^{\mathrm{c}}$ \\
2.00 & & & \\
4.00 & & & \\
3.4444 & .1636 & 3.1111 & 3.7222 \\
3.0940 & & & \\
3.7949 & & & \\
4.0000 & .4174 & 3.0000 & \\
2.00 & & & \\
4.00 & & &
\end{tabular}

- Manutenção de obras somente pelo Poder Público para garantir sua eficácia.

\begin{tabular}{|c|c|c|c|c|c|c|c|}
\hline & & & Statistic & & Boc & $\operatorname{trap}^{c}$ & \\
\hline & & & & Bias & Std. Error & $95 \%$ Confid & e Interval \\
\hline & & & & & & Lower & Upper \\
\hline & Mean & & 2.3469 & -.0002 & .1391 & 2.0816 & 2.5918 \\
\hline & $95 \%$ Confidence Interval for & Lower Bound & 2.0685 & & & & \\
\hline & Mean & Upper Bound & 2.6254 & & & & \\
\hline 013 & Median & & 2.0000 & .4480 & .4975 & 2.0000 & 3.0000 \\
\hline Q13e & Minimum & & 1.00 & & & & \\
\hline & Maximum & & 4.00 & & & & \\
\hline & Skewness & & -.047 & -.013 & .218 & -.498 & .382 \\
\hline & Kurtosis & & -1.045 & .049 & .234 & -1.379 & -.491 \\
\hline
\end{tabular}

Comparação por formação

\begin{tabular}{|c|c|c|c|c|}
\hline \multirow{3}{*}{$\begin{array}{l}\text { Formacao_num } \\
\text { - Manutenção de obras somente pelo Poder Público para } \\
\text { garantir sua eficácia. }\end{array}$} & \multirow[t]{3}{*}{ Statistic } & \multicolumn{3}{|c|}{ Bootstrap $^{b}$} \\
\hline & & \multirow[t]{2}{*}{ Std. Error } & \multicolumn{2}{|c|}{$95 \%$ Confidence Interval } \\
\hline & & & Lower & Upper \\
\hline Arquitetura & 2.5263 & .1974 & 2.1053 & 2.9474 \\
\hline
\end{tabular}




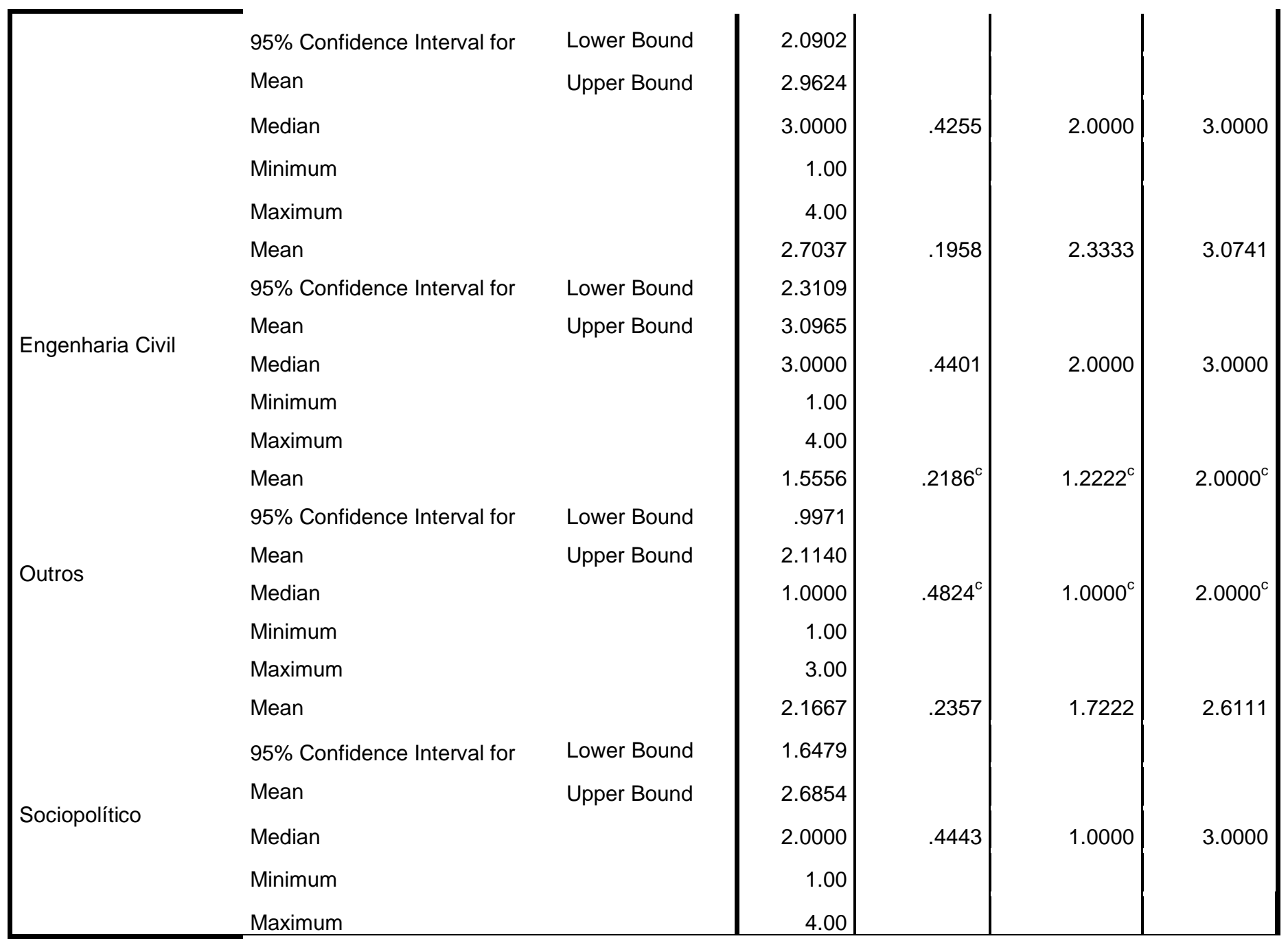

- Monitoramento das obras pelo Poder Público que inclua o cuidado com as mesmas também por moradores e comerciantes.

\begin{tabular}{|c|c|c|c|c|c|c|c|}
\hline & & & Statistic & & Boo & $\operatorname{trap}^{c}$ & \\
\hline & & & & Bias & Std. Error & $95 \%$ Confide & Interval \\
\hline & & & & & & Lower & Upper \\
\hline & Mean & & 3.6939 & -.0026 & .0845 & 3.5306 & 3.8571 \\
\hline & $95 \%$ Confidence Interval for & Lower Bound & 3.5259 & & & & \\
\hline & Mean & Upper Bound & 3.8618 & & & & \\
\hline $013 f$ & Median & & 4.0000 & .0000 & .0000 & 4.0000 & 4.0000 \\
\hline 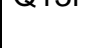 & Minimum & & 2.00 & & & & \\
\hline & Maximum & & 4.00 & & & & \\
\hline & Skewness & & -1.796 & .016 & .451 & -2.730 & -1.072 \\
\hline & Kurtosis & & 2.280 & .077 & 2.082 & -.193 & 7.131 \\
\hline
\end{tabular}


Comparação por formação

\begin{tabular}{|c|c|c|c|c|c|c|}
\hline \multirow{3}{*}{\multicolumn{3}{|c|}{$\begin{array}{l}\text { Formacao_num } \\
\text { - Monitoramento das obras pelo Poder Público que inclua o } \\
\text { cuidado com as mesmas também por moradores e } \\
\text { comerciantes. }\end{array}$}} & \multirow[t]{3}{*}{ Statistic } & \multicolumn{3}{|c|}{ Bootstrap $^{b}$} \\
\hline & & & & \multirow[t]{2}{*}{ Std. Error } & \multicolumn{2}{|c|}{ 95\% Confidence Interval } \\
\hline & & & & & Lower & Upper \\
\hline \multirow{8}{*}{ Arquitetura } & Mean & & 3.6000 & $.1492^{c}$ & $3.3000^{c}$ & $3.8500^{\mathrm{C}}$ \\
\hline & $95 \%$ Confidence Interval for & Lower Bound & 3.2815 & & & \\
\hline & Mean & Upper Bound & 3.9185 & & & \\
\hline & Median & & 4.0000 & $.1493^{\mathrm{c}}$ & $3.5000^{c}$ & $4.0000^{\mathrm{C}}$ \\
\hline & Minimum & & 2.00 & & & \\
\hline & Maximum & & 4.00 & & & \\
\hline & Mean & & 3.6364 & $.1650^{d}$ & $3.2727^{d}$ & $3.9091^{d}$ \\
\hline & 95\% Confidence Interval for & Lower Bound & 3.2863 & & & \\
\hline \multirow{6}{*}{ Engenharia Civil } & Mean & Upper Bound & 3.9864 & & & \\
\hline & Median & & 4.0000 & $.0419^{d}$ & $4.0000^{d}$ & $4.0000^{d}$ \\
\hline & Minimum & & 1.00 & & & \\
\hline & Maximum & & 4.00 & & & \\
\hline & Mean & & 3.8000 & $.1109^{\mathrm{e}}$ & $3.5000^{\mathrm{e}}$ & $3.9000^{\mathrm{e}}$ \\
\hline & $95 \%$ Confidence Interval for & Lower Bound & 3.4984 & & & \\
\hline \multirow{7}{*}{ Outros } & Mean & Upper Bound & 4.1016 & & & \\
\hline & Median & & 4.0000 & $.1190^{\mathrm{e}}$ & $3.5000^{\mathrm{e}}$ & $4.0000^{\mathrm{e}}$ \\
\hline & Minimum & & 3.00 & & & \\
\hline & Maximum & & 4.00 & & & \\
\hline & Mean & & 3.6875 & $.1139^{d}$ & $3.4375^{d}$ & $3.8750^{d}$ \\
\hline & $95 \%$ Confidence Interval for & Lower Bound & 3.4324 & & & \\
\hline & Mean & Upper Bound & 3.9426 & & & \\
\hline \multirow{3}{*}{ Sociopolítico } & Median & & 4.0000 & $.1998^{d}$ & $3.0000^{d}$ & $4.0000^{d}$ \\
\hline & Minimum & & 3.00 & & & \\
\hline & Maximum & & 4.00 & & & \\
\hline
\end{tabular}

- Trabalho mais eficaz pelos Educadores Ambientais e Comunicadores Sociais nas áreas onde são implantadas as obras de drenagem. 


\begin{tabular}{|c|c|c|c|c|c|c|c|}
\hline & & & & Bias & Std. Error & $95 \%$ Confid & Interval \\
\hline & & & & & & Lower & Upper \\
\hline & Mean & & 3.6122 & -.0012 & .0807 & 3.4490 & 3.7551 \\
\hline & $95 \%$ Confidence Interval for & Lower Bound & 3.4483 & & & & \\
\hline & Mean & Upper Bound & 3.7762 & & & & \\
\hline & Median & & 4.0000 & -.0130 & .1133 & 4.0000 & 4.0000 \\
\hline QIJg & Minimum & & 2.00 & & & & \\
\hline & Maximum & & 4.00 & & & & \\
\hline & Skewness & & -1.164 & .046 & .344 & -1.878 & -.475 \\
\hline & Kurtosis & & .441 & -.183 & 1.030 & -1.751 & 2.528 \\
\hline
\end{tabular}

Comparação por formação

\begin{tabular}{|c|c|c|c|c|c|c|}
\hline \multirow{3}{*}{\multicolumn{3}{|c|}{$\begin{array}{l}\text { Formacao_num } \\
\text { - Trabalho mais eficaz pelos Educadores Ambientais e } \\
\text { Comunicadores Sociais nas áreas onde são implantadas as } \\
\text { obras de drenagem. }\end{array}$}} & \multirow[t]{3}{*}{ Statistic } & \multicolumn{3}{|c|}{ Bootstrap $^{b}$} \\
\hline & & & & \multirow[t]{2}{*}{ Std. Error } & \multicolumn{2}{|c|}{$95 \%$ Confidence Interval } \\
\hline & & & & & Lower & Upper \\
\hline \multirow{8}{*}{ Arquitetura } & Mean & & 3.6667 & .1094 & 3.4444 & 3.8889 \\
\hline & $95 \%$ Confidence Interval for & Lower Bound & 3.4254 & & & \\
\hline & Mean & Upper Bound & 3.9079 & & & \\
\hline & Median & & 4.0000 & .2215 & 3.0000 & 4.0000 \\
\hline & Minimum & & 3.00 & & & \\
\hline & Maximum & & 4.00 & & & \\
\hline & Mean & & 3.4615 & .1210 & 3.2308 & 3.6923 \\
\hline & $95 \%$ Confidence Interval for & Lower Bound & 3.2003 & & & \\
\hline \multirow{7}{*}{ Engenharia Civil } & Mean & Upper Bound & 3.7228 & & & \\
\hline & Median & & 4.0000 & .4408 & 3.0000 & 4.0000 \\
\hline & Minimum & & 2.00 & & & \\
\hline & Maximum & & 4.00 & & & \\
\hline & Mean & & 3.8889 & $.0824^{\mathrm{c}}$ & $3.6667^{\mathrm{c}}$ & $3.8889^{c}$ \\
\hline & $95 \%$ Confidence Interval for & Lower Bound & 3.6327 & & & \\
\hline & Mean & Upper Bound & 4.1451 & & & \\
\hline \multirow{5}{*}{ Outros } & Median & & 4.0000 & $.0000^{c}$ & $4.0000^{c}$ & $4.0000^{\mathrm{C}}$ \\
\hline & Minimum & & 3.00 & & & \\
\hline & Maximum & & 4.00 & & & \\
\hline & Mean & & 3.5263 & .1729 & 3.1579 & 3.8421 \\
\hline & $95 \%$ Confidence Interval for & Lower Bound & 3.1541 & & & \\
\hline \multirow[t]{3}{*}{ Sociopolítico } & Mean & Upper Bound & 3.8986 & & & \\
\hline & Median & & 4.0000 & .2143 & 3.0000 & 4.0000 \\
\hline & Minimum & & 2.00 & & & \\
\hline
\end{tabular}


Questão 14 - Relação mais estreita entre o técnico-científico (o campo de atuação e a

formação do Engenheiro Civil) e o sociopolítico (a organização social e política) é fundamental para a durabilidade das obras e a sustentabilidade do serviço que oferece.

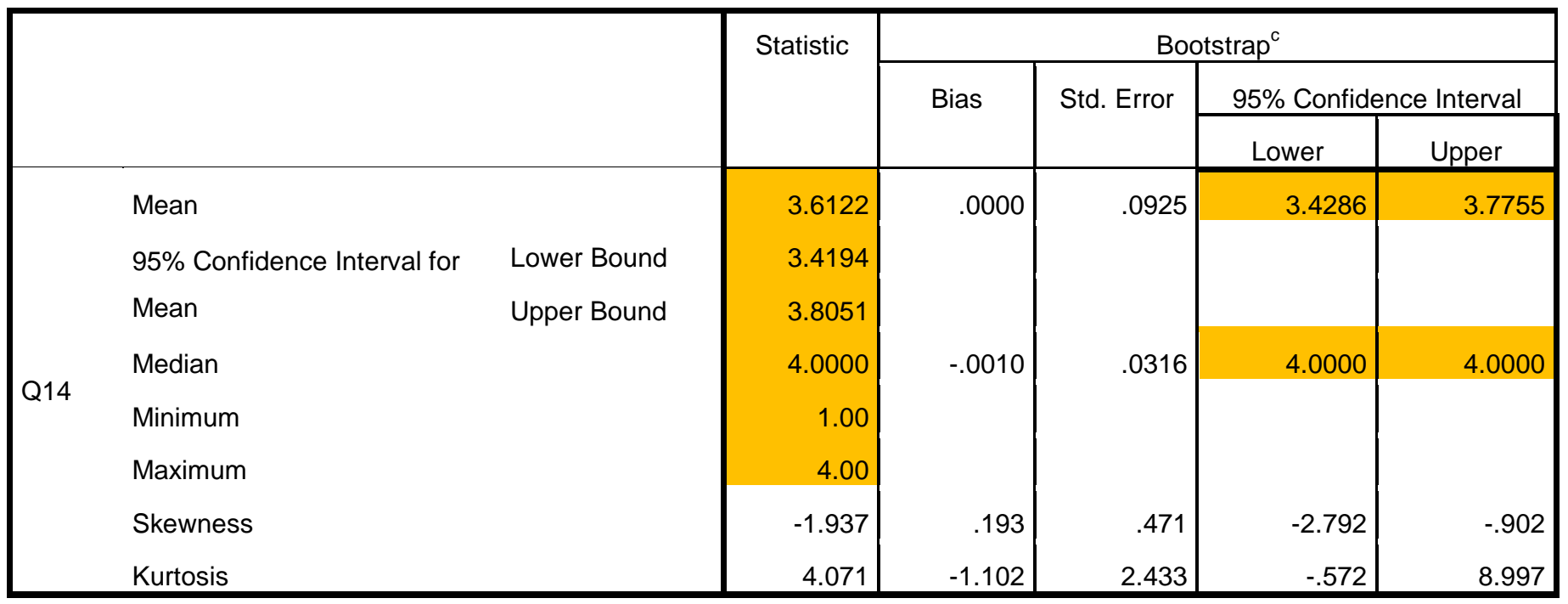

Comparação por formação

\begin{tabular}{|c|c|c|c|c|c|c|}
\hline \multirow[t]{3}{*}{ Formacao_num } & & & \multirow[t]{3}{*}{ Statistic } & \multicolumn{3}{|c|}{ Bootstrap $^{b}$} \\
\hline & & & & \multirow[t]{2}{*}{ Std. Error } & \multicolumn{2}{|c|}{ 95\% Confidence Interval } \\
\hline & & & & & Lower & Upper \\
\hline \multirow{8}{*}{ Arquitetura } & Mean & & 3.4091 & .1390 & 3.0921 & 3.6364 \\
\hline & $95 \%$ Confidence Interval for & Lower Bound & 3.1137 & & & \\
\hline & Mean & Upper Bound & 3.7044 & & & \\
\hline & Median & & 3.5000 & .4567 & 3.0000 & 4.0000 \\
\hline & Minimum & & 2.00 & & & \\
\hline & Maximum & & 4.00 & & & \\
\hline & Mean & & 3.3793 & .1428 & 3.1034 & 3.6552 \\
\hline & $95 \%$ Confidence Interval for & Lower Bound & 3.0844 & & & \\
\hline \multirow{4}{*}{ Engenharia Civil } & Mean & Upper Bound & 3.6742 & & & \\
\hline & Median & & 4.0000 & .4970 & 3.0000 & 4.0000 \\
\hline & Minimum & & 1.00 & & & \\
\hline & Maximum & & 4.00 & & & \\
\hline \multirow{2}{*}{ Outros } & Mean & & 3.7500 & $.1555^{\mathrm{c}}$ & $3.3333^{c}$ & $3.9167^{c}$ \\
\hline & $95 \%$ Confidence Interval for & Lower Bound & 3.3551 & & & \\
\hline
\end{tabular}




\begin{tabular}{|c|c|c|c|c|c|c|}
\hline & Mean & Upper Bound & 4.1449 & & & \\
\hline & Median & & 4.0000 & $.0526^{\circ}$ & $4.0000^{c}$ & $4.0000^{\circ}$ \\
\hline & Minimum & & 2.00 & & & \\
\hline & Maximum & & 4.00 & & & \\
\hline & Mean & & 3.8000 & $.0895^{\circ}$ & $3.6000^{d}$ & $3.9500^{\circ}$ \\
\hline & $95 \%$ Confidence Interval for & Lower Bound & 3.6079 & & & \\
\hline & Mean & Upper Bound & 3.9921 & & & \\
\hline 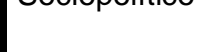 & Median & & 4.0000 & $.0356^{\circ}$ & $4.0000^{d}$ & $4.0000^{\circ}$ \\
\hline & Minimum & & 3.00 & & & \\
\hline & Maximum & & 4.00 & & & \\
\hline
\end{tabular}

SEGUNDA PARTE: COMPARAÇÕES POR FUNÇÃO DOS RESPONDENTES

Questão 1 - Aspectos técnicos são tão importantes quantos aspectos sociais no planejamento de obras de drenagem

\begin{tabular}{|c|c|c|c|c|c|c|}
\hline \multirow[t]{3}{*}{ Funcao_num } & & & \multirow[t]{3}{*}{ Statistic } & \multicolumn{3}{|c|}{ Bootstrap $^{b}$} \\
\hline & & & & \multirow[t]{2}{*}{ Std. Error } & \multicolumn{2}{|c|}{ 95\% Confidence Interval } \\
\hline & & & & & Lower & Upper \\
\hline \multirow{8}{*}{$\begin{array}{l}\text { Assessoria- Consultoria e } \\
\text { Docência }\end{array}$} & Mean & & 3.6591 & \multirow[t]{3}{*}{.0976} & \multirow[t]{3}{*}{3.4545} & \multirow[t]{3}{*}{3.8409} \\
\hline & $95 \%$ Confidence Interval for & Lower Bound & 3.4630 & & & \\
\hline & Mean & Upper Bound & 3.8552 & & & \\
\hline & Median & & 4.0000 & \multirow[t]{3}{*}{.0000} & \multirow[t]{3}{*}{4.0000} & \multirow[t]{3}{*}{4.0000} \\
\hline & Minimum & & 1.00 & & & \\
\hline & Maximum & & 4.00 & & & \\
\hline & Mean & & 3.8947 & \multirow[t]{3}{*}{$.0575^{\mathrm{C}}$} & \multirow[t]{3}{*}{$3.7632^{c}$} & \multirow[t]{3}{*}{$3.9737^{\mathrm{C}}$} \\
\hline & $95 \%$ Confidence Interval for & Lower Bound & 3.7671 & & & \\
\hline Coordenação- Gestão- & Mean & Upper Bound & 4.0224 & & & \\
\hline \multirow[t]{3}{*}{ Supervisão } & Median & & 4.0000 & \multirow[t]{3}{*}{$.0000^{\circ}$} & \multirow[t]{3}{*}{$4.0000^{\mathrm{c}}$} & \multirow[t]{3}{*}{$4.0000^{\mathrm{c}}$} \\
\hline & Minimum & & 2.00 & & & \\
\hline & Maximum & & 4.00 & & & \\
\hline
\end{tabular}

Questão 2 - 0 bom planejamento de obras de drenagem exige a participação de:

- Coordenadores de projetos e engenheiros 


\begin{tabular}{|c|c|c|c|c|c|c|}
\hline \multirow[t]{3}{*}{ Funcao_num } & & & \multirow[t]{3}{*}{ Statistic } & \multicolumn{3}{|c|}{ Bootstrap $^{b}$} \\
\hline & & & & \multirow[t]{2}{*}{ Std. Error } & \multicolumn{2}{|c|}{ 95\% Confidence Interval } \\
\hline & & & & & Lower & Upper \\
\hline \multirow{7}{*}{$\begin{array}{l}\text { Assessoria- Consultoria e } \\
\text { Docência }\end{array}$} & Mean & & 3.9348 & $.0350^{\mathrm{c}}$ & $3.8478^{c}$ & $3.9783^{\mathrm{C}}$ \\
\hline & 95\% Confidence Interval for & Lower Bound & 3.8606 & & & \\
\hline & Mean & Upper Bound & 4.0089 & & & \\
\hline & Median & & 4.0000 & $.0000^{\mathrm{c}}$ & $4.0000^{\mathrm{C}}$ & $4.0000^{\mathrm{C}}$ \\
\hline & Minimum & & 3.00 & & & \\
\hline & Maximum & & 4.00 & & & \\
\hline & Mean & & 3.9737 & $.0209^{d}$ & $3.8947^{d}$ & $3.9737^{d}$ \\
\hline \multirow{5}{*}{$\begin{array}{l}\text { Coordenação- Gestão- } \\
\text { Supervisão }\end{array}$} & 95\% Confidence Interval for & Lower Bound & 3.9204 & & & \\
\hline & Mean & Upper Bound & 4.0270 & & & \\
\hline & Median & & 4.0000 & $.0000^{\mathrm{d}}$ & $4.0000^{d}$ & $4.0000^{d}$ \\
\hline & Minimum & & 3.00 & & & \\
\hline & Maximum & & 4.00 & & & \\
\hline
\end{tabular}

- Técnicos de manutenção de obras de drenagem

\begin{tabular}{|c|c|c|c|c|c|c|}
\hline \multirow[t]{3}{*}{ Funcao_num } & & & \multirow[t]{3}{*}{ Statistic } & \multicolumn{3}{|c|}{ Bootstrap $^{b}$} \\
\hline & & & & \multirow[t]{2}{*}{ Std. Error } & \multicolumn{2}{|c|}{$95 \%$ Confidence Interval } \\
\hline & & & & & Lower & Upper \\
\hline \multirow{8}{*}{$\begin{array}{l}\text { Assessoria- Consultoria e } \\
\text { Docência }\end{array}$} & Mean & & 3.6818 & \multirow[t]{3}{*}{.0932} & \multirow[t]{3}{*}{3.4773} & \multirow[t]{3}{*}{3.8409} \\
\hline & $95 \%$ Confidence Interval for & Lower Bound & 3.4990 & & & \\
\hline & Mean & Upper Bound & 3.8646 & & & \\
\hline & Median & & 4.0000 & \multirow[t]{3}{*}{.0000} & \multirow[t]{3}{*}{4.0000} & \multirow[t]{3}{*}{4.0000} \\
\hline & Minimum & & 2.00 & & & \\
\hline & Maximum & & 4.00 & & & \\
\hline & Mean & & 3.8108 & $.0721^{\mathrm{C}}$ & $3.6486^{c}$ & $3.9459^{\mathrm{c}}$ \\
\hline & $95 \%$ Confidence Interval for & Lower Bound & 3.6569 & \multirow{5}{*}{$.0000^{\circ}$} & \multirow{5}{*}{$4.0000^{c}$} & \multirow{5}{*}{$4.0000^{\mathrm{C}}$} \\
\hline \multirow{4}{*}{$\begin{array}{l}\text { Coordenação- Gestão- } \\
\text { Supervisão }\end{array}$} & Mean & Upper Bound & 3.9648 & & & \\
\hline & Median & & 4.0000 & & & \\
\hline & Minimum & & 2.00 & & & \\
\hline & Maximum & & 4.00 & & & \\
\hline
\end{tabular}

- $\quad$ Lideranças comunitárias 


\begin{tabular}{|c|c|c|c|c|c|c|}
\hline \multirow[t]{3}{*}{ Funcao_num } & & & \multirow[t]{3}{*}{ Statistic } & \multicolumn{3}{|c|}{ Bootstrap $^{a}$} \\
\hline & & & & \multirow{2}{*}{$\begin{array}{l}\text { Std. } \\
\text { Error }\end{array}$} & \multicolumn{2}{|c|}{ 95\% Confidence Interval } \\
\hline & & & & & Lower & Upper \\
\hline \multirow{8}{*}{$\begin{array}{l}\text { Assessoria- Consultoria e } \\
\text { Docência }\end{array}$} & Mean & & 3.4444 & .1076 & 3.2222 & 3.6444 \\
\hline & $95 \%$ Confidence Interval & Lower Bound & 3.2175 & & & \\
\hline & for Mean & Upper Bound & 3.6714 & & & \\
\hline & Median & & 4.0000 & .4204 & 3.0000 & 4.0000 \\
\hline & Minimum & & 1.00 & & & \\
\hline & Maximum & & 4.00 & & & \\
\hline & Mean & & 3.5263 & .1023 & 3.3158 & 3.7105 \\
\hline & $95 \%$ Confidence Interval & Lower Bound & 3.3138 & & & \\
\hline \multirow{4}{*}{$\begin{array}{l}\text { Coordenação- Gestão- } \\
\text { Supervisão }\end{array}$} & for Mean & Upper Bound & 3.7389 & & & \\
\hline & Median & & 4.0000 & .2523 & 3.0000 & 4.0000 \\
\hline & Minimum & & 2.00 & & & \\
\hline & Maximum & & 4.00 & & & \\
\hline
\end{tabular}

\section{- $\quad$ Educadores ambientais}

\begin{tabular}{|c|c|c|c|c|c|c|}
\hline \multirow[t]{3}{*}{ Funcao_num } & & & \multirow[t]{3}{*}{ Statistic } & \multicolumn{3}{|c|}{ Bootstrap $^{a}$} \\
\hline & & & & \multirow[t]{2}{*}{ Std. Error } & \multicolumn{2}{|c|}{ 95\% Confidence Interval } \\
\hline & & & & & Lower & Upper \\
\hline \multirow{8}{*}{$\begin{array}{l}\text { Assessoria- Consultoria e } \\
\text { Docência }\end{array}$} & Mean & & 3.3111 & .1157 & 3.0889 & 3.5333 \\
\hline & $95 \%$ Confidence Interval & Lower Bound & 3.0818 & & & \\
\hline & for Mean & Upper Bound & 3.5405 & & & \\
\hline & Median & & 3.0000 & .4736 & 3.0000 & 4.0000 \\
\hline & Minimum & & 1.00 & & & \\
\hline & Maximum & & 4.00 & & & \\
\hline & Mean & & 3.5676 & .0926 & 3.3784 & 3.7297 \\
\hline & $95 \%$ Confidence Interval & Lower Bound & 3.3666 & & & \\
\hline \multirow{4}{*}{$\begin{array}{l}\text { Coordenação- Gestão- } \\
\text { Supervisão }\end{array}$} & for Mean & Upper Bound & 3.7685 & & & \\
\hline & Median & & 4.0000 & .2395 & 3.0000 & 4.0000 \\
\hline & Minimum & & 2.00 & & & \\
\hline & Maximum & & 4.00 & & & \\
\hline
\end{tabular}

- Comerciantes instalados na área onde as obras serão implantadas 


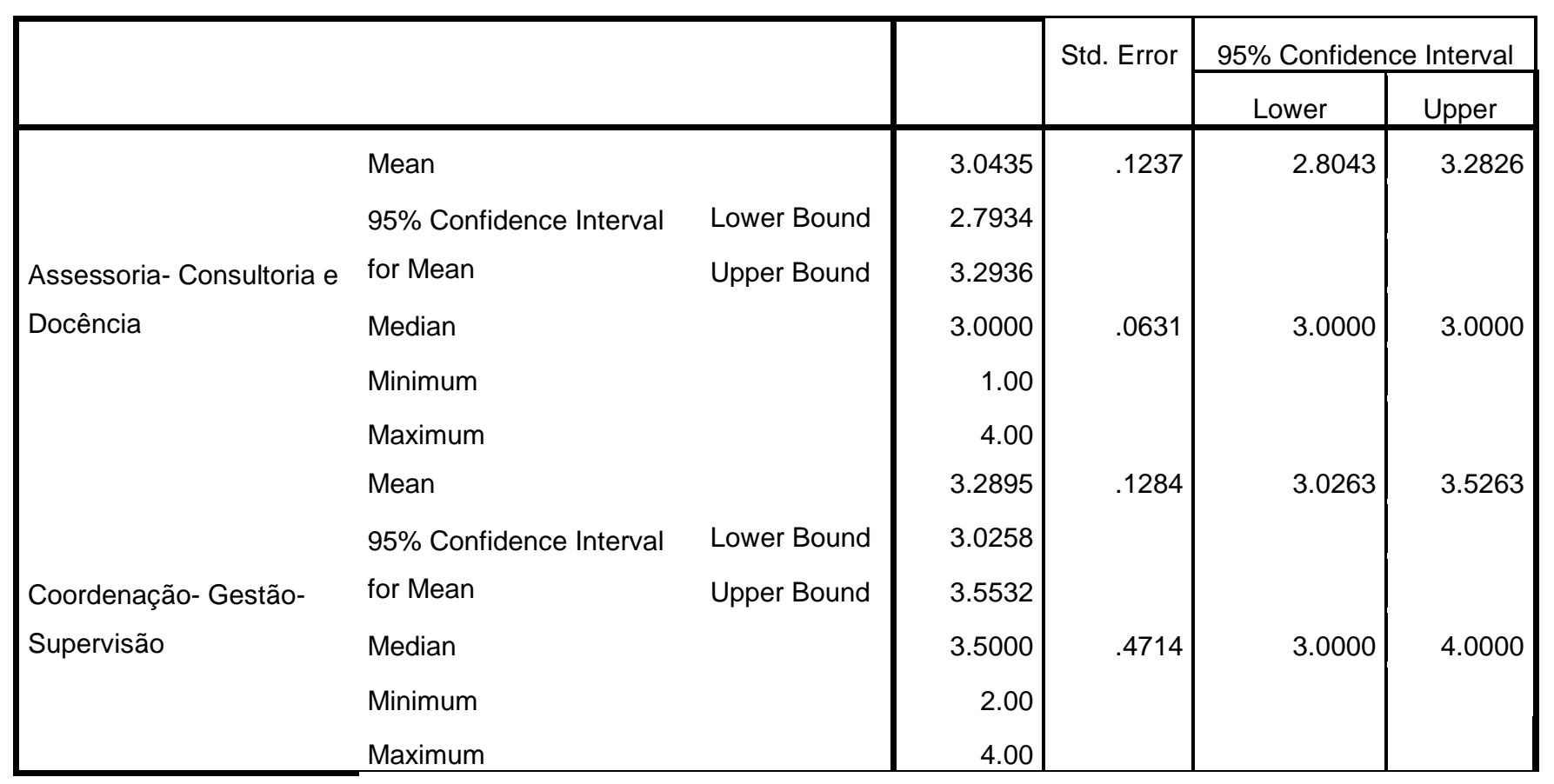

Comitês de bacias hidrográficas

\begin{tabular}{|c|c|c|c|c|c|c|}
\hline \multirow[t]{3}{*}{ Funcao_num } & & & \multirow[t]{3}{*}{ Statistic } & \multicolumn{3}{|c|}{ Bootstrap $^{b}$} \\
\hline & & & & \multirow[t]{2}{*}{ Std. Error } & \multicolumn{2}{|c|}{$95 \%$ Confidence Interval } \\
\hline & & & & & Lower & Upper \\
\hline \multirow{8}{*}{$\begin{array}{l}\text { Assessoria- Consultoria e } \\
\text { Docência }\end{array}$} & Mean & & 3.8636 & \multirow[t]{3}{*}{$.0515^{\mathrm{c}}$} & \multirow[t]{3}{*}{$3.7500^{c}$} & \multirow[t]{3}{*}{$3.9545^{\circ}$} \\
\hline & 95\% Confidence Interval & Lower Bound & 3.7581 & & & \\
\hline & for Mean & Upper Bound & 3.9692 & & & \\
\hline & Median & & 4.0000 & $.0000^{\mathrm{C}}$ & $4.0000^{\circ}$ & $4.0000^{\circ}$ \\
\hline & Minimum & & 3.00 & & & \\
\hline & Maximum & & 4.00 & & & \\
\hline & Mean & & 3.7027 & .0878 & 3.5135 & 3.8649 \\
\hline & $95 \%$ Confidence Interval & Lower Bound & 3.5294 & \multirow{5}{*}{.0632} & \multirow{5}{*}{4.0000} & \multirow{5}{*}{4.0000} \\
\hline \multirow{4}{*}{$\begin{array}{l}\text { Coordenação- Gestão- } \\
\text { Supervisão }\end{array}$} & for Mean & Upper Bound & 3.8760 & & & \\
\hline & Median & & 4.0000 & & & \\
\hline & Minimum & & 2.00 & & & \\
\hline & Maximum & & 4.00 & & & \\
\hline
\end{tabular}

- Políticos da região 


\begin{tabular}{|c|c|c|c|c|c|c|}
\hline & & & & \multirow[t]{2}{*}{ Std. Error } & \multicolumn{2}{|c|}{ 95\% Confidence Interval } \\
\hline & & & & & Lower & Upper \\
\hline \multirow{8}{*}{$\begin{array}{l}\text { Assessoria- Consultoria } \\
\text { e Docência }\end{array}$} & Mean & & 2.7727 & .1342 & 2.5227 & 3.0227 \\
\hline & $95 \%$ Confidence Interval & Lower Bound & 2.4956 & & & \\
\hline & for Mean & Upper Bound & 3.0499 & & & \\
\hline & Median & & 3.0000 & .1678 & 2.0127 & 3.0000 \\
\hline & Minimum & & 1.00 & & & \\
\hline & Maximum & & 4.00 & & & \\
\hline & Mean & & 2.7222 & .1868 & 2.3333 & 3.0826 \\
\hline & 95\% Confidence Interval & Lower Bound & 2.3292 & & & \\
\hline \multirow{4}{*}{$\begin{array}{l}\text { Coordenação- Gestão- } \\
\text { Supervisão }\end{array}$} & for Mean & Upper Bound & 3.1152 & & & \\
\hline & Median & & 3.0000 & .2903 & 2.0000 & 3.0000 \\
\hline & Minimum & & 1.00 & & & \\
\hline & Maximum & & 4.00 & & & \\
\hline
\end{tabular}

- Moradores na área onde as obras serão implantadas

\begin{tabular}{|c|c|c|c|c|c|c|}
\hline \multirow[t]{3}{*}{ Funcao_num } & & & \multirow[t]{3}{*}{ Statistic } & \multicolumn{3}{|c|}{ Bootstrap $^{a}$} \\
\hline & & & & \multirow[t]{2}{*}{ Std. Error } & \multicolumn{2}{|c|}{ 95\% Confidence Interval } \\
\hline & & & & & Lower & Upper \\
\hline \multirow{8}{*}{$\begin{array}{l}\text { Assessoria- Consultoria } \\
\text { e Docência }\end{array}$} & Mean & & 3.5455 & \multirow[t]{3}{*}{.1071} & \multirow[t]{3}{*}{3.3182} & \multirow[t]{3}{*}{3.7273} \\
\hline & 95\% Confidence Interval & Lower Bound & 3.3334 & & & \\
\hline & for Mean & Upper Bound & 3.7575 & & & \\
\hline & Median & & 4.0000 & \multirow[t]{3}{*}{.1911} & \multirow[t]{3}{*}{3.0000} & \multirow[t]{3}{*}{4.0000} \\
\hline & Minimum & & 1.00 & & & \\
\hline & Maximum & & 4.00 & & & \\
\hline & Mean & & 3.6154 & \multirow[t]{3}{*}{.0860} & \multirow[t]{3}{*}{3.4359} & \multirow[t]{3}{*}{3.7692} \\
\hline & 95\% Confidence Interval & Lower Bound & 3.4392 & & & \\
\hline Coordenação- Gestão- & for Mean & Upper Bound & 3.7916 & & & \\
\hline \multirow[t]{3}{*}{ Supervisão } & Median & & 4.0000 & \multirow[t]{3}{*}{.1761} & \multirow[t]{3}{*}{3.0000} & \multirow[t]{3}{*}{4.0000} \\
\hline & Minimum & & 2.00 & & & \\
\hline & Maximum & & 4.00 & & & \\
\hline
\end{tabular}

- Comunicadores sociais 


\begin{tabular}{|c|c|c|c|c|c|c|}
\hline \multirow[t]{3}{*}{ Funcao_num } & & & \multirow[t]{3}{*}{ Statistic } & \multicolumn{3}{|c|}{ Bootstrap $^{a}$} \\
\hline & & & & \multirow[t]{2}{*}{ Std. Error } & \multicolumn{2}{|c|}{$95 \%$ Confidence Interval } \\
\hline & & & & & Lower & Upper \\
\hline \multirow{8}{*}{$\begin{array}{l}\text { Assessoria- Consultoria } \\
\text { e Docência }\end{array}$} & Mean & & 3.2955 & .1273 & 3.0455 & 3.5455 \\
\hline & $95 \%$ Confidence Interval & Lower Bound & 3.0367 & & & \\
\hline & for Mean & Upper Bound & 3.5543 & & & \\
\hline & Median & & 3.5000 & .4716 & 3.0000 & 4.0000 \\
\hline & Minimum & & 1.00 & & & \\
\hline & Maximum & & 4.00 & & & \\
\hline & Mean & & 3.5385 & .0953 & 3.3590 & 3.7179 \\
\hline & 95\% Confidence Interval & Lower Bound & 3.3439 & & & \\
\hline Coordenação- Gestão- & for Mean & Upper Bound & 3.7330 & & & \\
\hline \multirow[t]{3}{*}{ Supervisão } & Median & & 4.0000 & .3430 & 3.0000 & 4.0000 \\
\hline & Minimum & & 2.00 & & & \\
\hline & Maximum & & 4.00 & & & \\
\hline
\end{tabular}

- Cientistas sociais

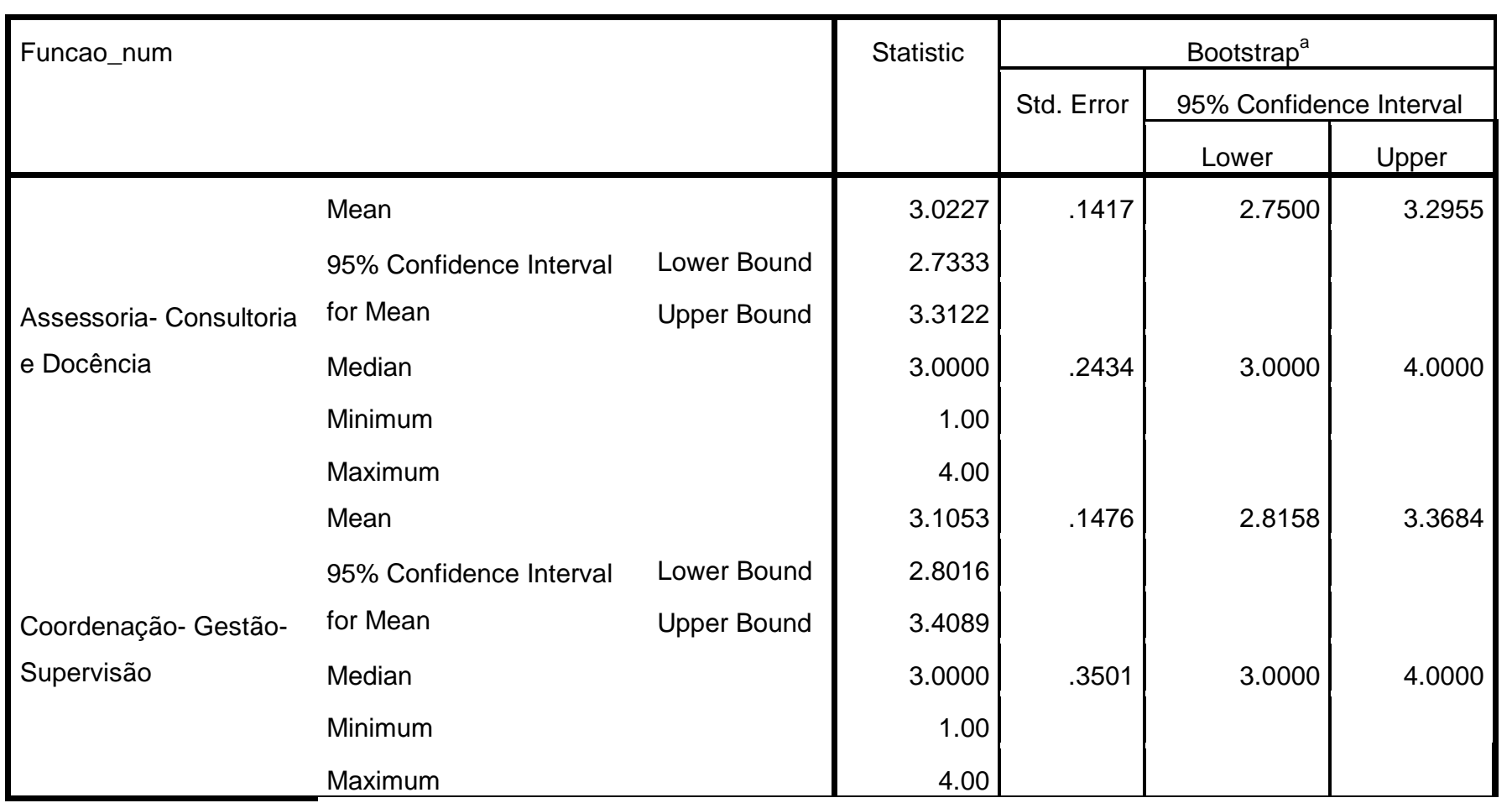

Questão 3 - Gerentes de obras de drenagem nem sempre desejam envolver moradores no planejamento das obras 


\begin{tabular}{|c|c|c|c|c|c|c|}
\hline \multirow[t]{3}{*}{ Funcao_num } & & & \multirow[t]{3}{*}{ Statistic } & \multicolumn{3}{|c|}{ Bootstrap $^{a}$} \\
\hline & & & & \multirow[t]{2}{*}{ Std. Error } & \multicolumn{2}{|c|}{ 95\% Confidence Interval } \\
\hline & & & & & Lower & Upper \\
\hline \multirow{8}{*}{$\begin{array}{l}\text { Assessoria- Consultoria } \\
\text { e Docência }\end{array}$} & Mean & & 3.3261 & .1171 & 3.0870 & 3.5647 \\
\hline & $95 \%$ Confidence Interval & Lower Bound & 3.0914 & & & \\
\hline & for Mean & Upper Bound & 3.5608 & & & \\
\hline & Median & & 3.0000 & .4595 & 3.0000 & 4.0000 \\
\hline & Minimum & & 1.00 & & & \\
\hline & Maximum & & 4.00 & & & \\
\hline & Mean & & 3.2821 & .1140 & 3.0513 & 3.5122 \\
\hline & $95 \%$ Confidence Interval & Lower Bound & 3.0475 & & & \\
\hline \multirow{4}{*}{$\begin{array}{l}\text { Coordenação- Gestão- } \\
\text { Supervisão }\end{array}$} & for Mean & Upper Bound & 3.5166 & & & \\
\hline & Median & & 3.0000 & .4039 & 3.0000 & 4.0000 \\
\hline & Minimum & & 2.00 & & & \\
\hline & Maximum & & 4.00 & & & \\
\hline
\end{tabular}

Questão 4 - Em geral, moradores das áreas onde obras serão implantadas não têm condição de opinar sobre as mesmas para que atendam sua demanda por melhorias

\begin{tabular}{|c|c|c|c|c|c|c|}
\hline \multirow[t]{3}{*}{ Funcao_num } & & & \multirow[t]{3}{*}{ Statistic } & \multicolumn{3}{|c|}{ Bootstrap $^{a}$} \\
\hline & & & & \multirow[t]{2}{*}{ Std. Error } & \multicolumn{2}{|c|}{$95 \%$ Confidence Interval } \\
\hline & & & & & Lower & Upper \\
\hline \multirow{8}{*}{$\begin{array}{l}\text { Assessoria- Consultoria } \\
\text { e Docência }\end{array}$} & Mean & & 2.1304 & \multirow[t]{3}{*}{.1620} & \multirow[t]{3}{*}{1.8043} & \multirow[t]{3}{*}{2.4565} \\
\hline & $95 \%$ Confidence Interval & Lower Bound & 1.8075 & & & \\
\hline & for Mean & Upper Bound & 2.4534 & & & \\
\hline & Median & & 2.0000 & \multirow[t]{3}{*}{.3572} & \multirow[t]{3}{*}{1.0000} & \multirow[t]{3}{*}{3.0000} \\
\hline & Minimum & & 1.00 & & & \\
\hline & Maximum & & 4.00 & & & \\
\hline & Mean & & 2.0769 & \multirow[t]{3}{*}{.1463} & \multirow[t]{3}{*}{1.7949} & \multirow[t]{3}{*}{2.3846} \\
\hline & 95\% Confidence Interval & Lower Bound & 1.7852 & & & \\
\hline Coordenação- Gestão- & for Mean & Upper Bound & 2.3686 & & & \\
\hline \multirow[t]{3}{*}{ Supervisão } & Median & & 2.0000 & \multirow[t]{3}{*}{.1721} & \multirow[t]{3}{*}{2.0000} & \multirow[t]{3}{*}{2.9746} \\
\hline & Minimum & & 1.00 & & & \\
\hline & Maximum & & 4.00 & & & \\
\hline
\end{tabular}

Questão 5 - Em geral, comerciantes instalados nas áreas onde obras serão implantadas não têm condição de opinar sobre as mesmas para que atendam sua demanda por melhorias 


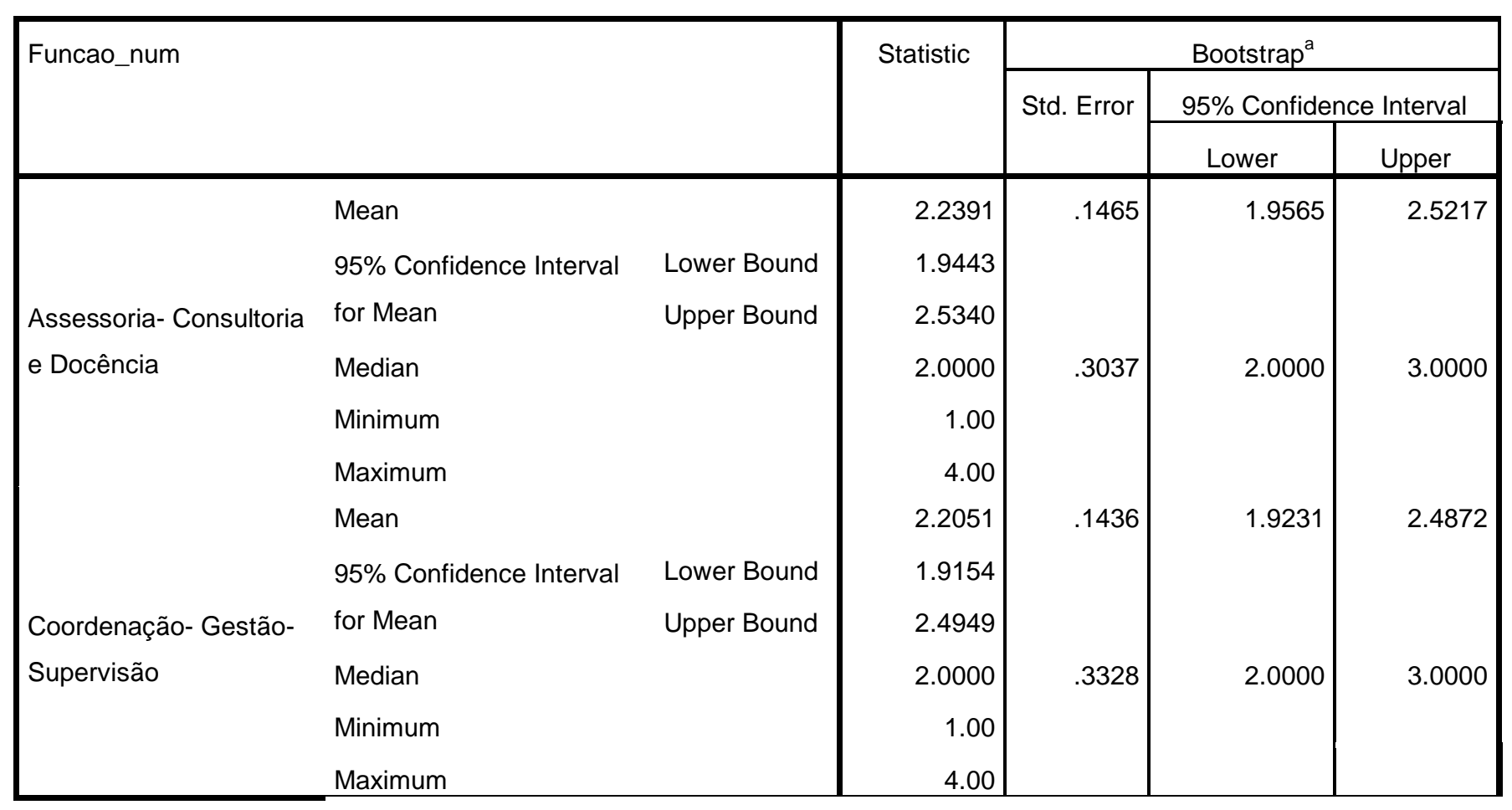

Questão 6 - Audiências públicas são suficientes como processo participativo da população

\begin{tabular}{|c|c|c|c|c|c|c|}
\hline \multirow[t]{3}{*}{ Funcao_num } & & & \multirow[t]{3}{*}{ Statistic } & \multicolumn{3}{|c|}{ Bootstrap $^{a}$} \\
\hline & & & & \multirow[t]{2}{*}{ Std. Error } & \multicolumn{2}{|c|}{$95 \%$ Confidence Interval } \\
\hline & & & & & Lower & Upper \\
\hline \multirow{8}{*}{$\begin{array}{l}\text { Assessoria- Consultoria } \\
\text { e Docência }\end{array}$} & Mean & & 2.0217 & .1371 & 1.7609 & 2.3043 \\
\hline & 95\% Confidence Interval & Lower Bound & 1.7525 & & & \\
\hline & for Mean & Upper Bound & 2.2909 & & & \\
\hline & Median & & 2.0000 & .1542 & 1.5000 & 2.0000 \\
\hline & Minimum & & 1.00 & & & \\
\hline & Maximum & & 4.00 & & & \\
\hline & Mean & & 2.0769 & .1498 & 1.7949 & 2.3590 \\
\hline & $95 \%$ Confidence Interval & Lower Bound & 1.7668 & & & \\
\hline Coordenação- Gestão- & for Mean & Upper Bound & 2.3870 & & & \\
\hline \multirow[t]{3}{*}{ Supervisão } & Median & & 2.0000 & .3069 & 1.0000 & 3.0000 \\
\hline & Minimum & & 1.00 & & & \\
\hline & Maximum & & 4.00 & & & \\
\hline
\end{tabular}


Questão 7 - Para a boa implantação de obras de drenagem é necessário que haja o envolvimento de:

- Comunicadores sociais.

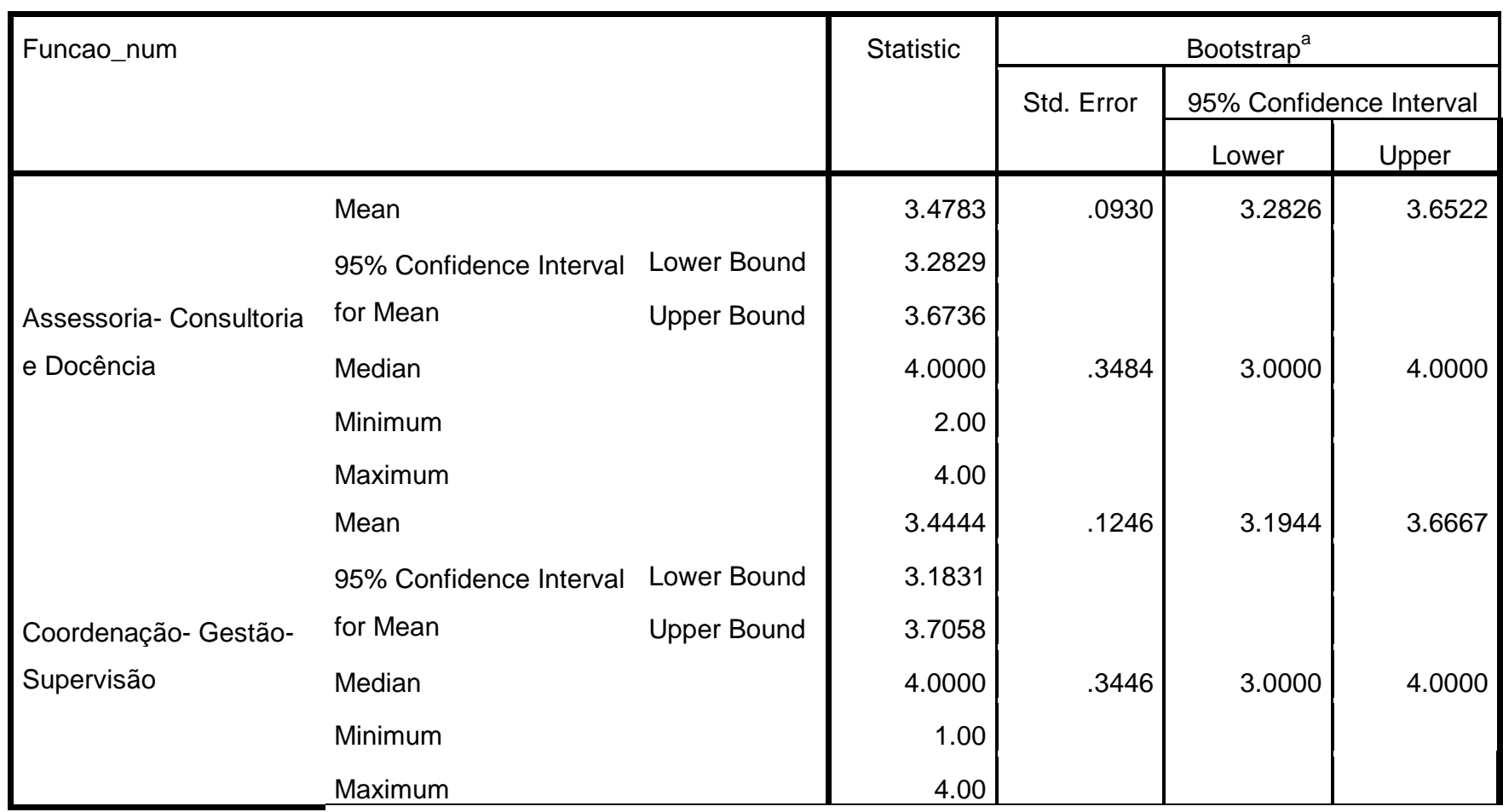

$* * *$

- Lideranças comunitárias.

\begin{tabular}{|c|c|c|c|c|c|c|}
\hline \multirow[t]{3}{*}{ Funcao_num } & & & \multirow[t]{3}{*}{ Statistic } & \multicolumn{3}{|c|}{ Bootstrap $^{a}$} \\
\hline & & & & \multirow[t]{2}{*}{ Std. Error } & \multicolumn{2}{|c|}{$95 \%$ Confidence Interval } \\
\hline & & & & & Lower & Upper \\
\hline \multirow{7}{*}{$\begin{array}{l}\text { Assessoria- Consultoria } \\
\text { e Docência }\end{array}$} & Mean & & 3.5217 & .0857 & 3.3696 & 3.6739 \\
\hline & $95 \%$ Confidence Interval & Lower Bound & 3.3476 & & & \\
\hline & for Mean & Upper Bound & 3.6959 & & & \\
\hline & Median & & 4.0000 & .3586 & 3.0000 & 4.0000 \\
\hline & Minimum & & 2.00 & & & \\
\hline & Maximum & & 4.00 & & & \\
\hline & Mean & & 3.4737 & .1168 & 3.2368 & 3.6842 \\
\hline \multirow{3}{*}{$\begin{array}{l}\text { Coordenação- Gestão- } \\
\text { Supervisão }\end{array}$} & $95 \%$ Confidence Interval & Lower Bound & 3.2352 & & & \\
\hline & for Mean & Upper Bound & 3.7121 & & & \\
\hline & Median & & 4.0000 & .3461 & 3.0000 & 4.0000 \\
\hline
\end{tabular}


Minimum

- Escolas da região

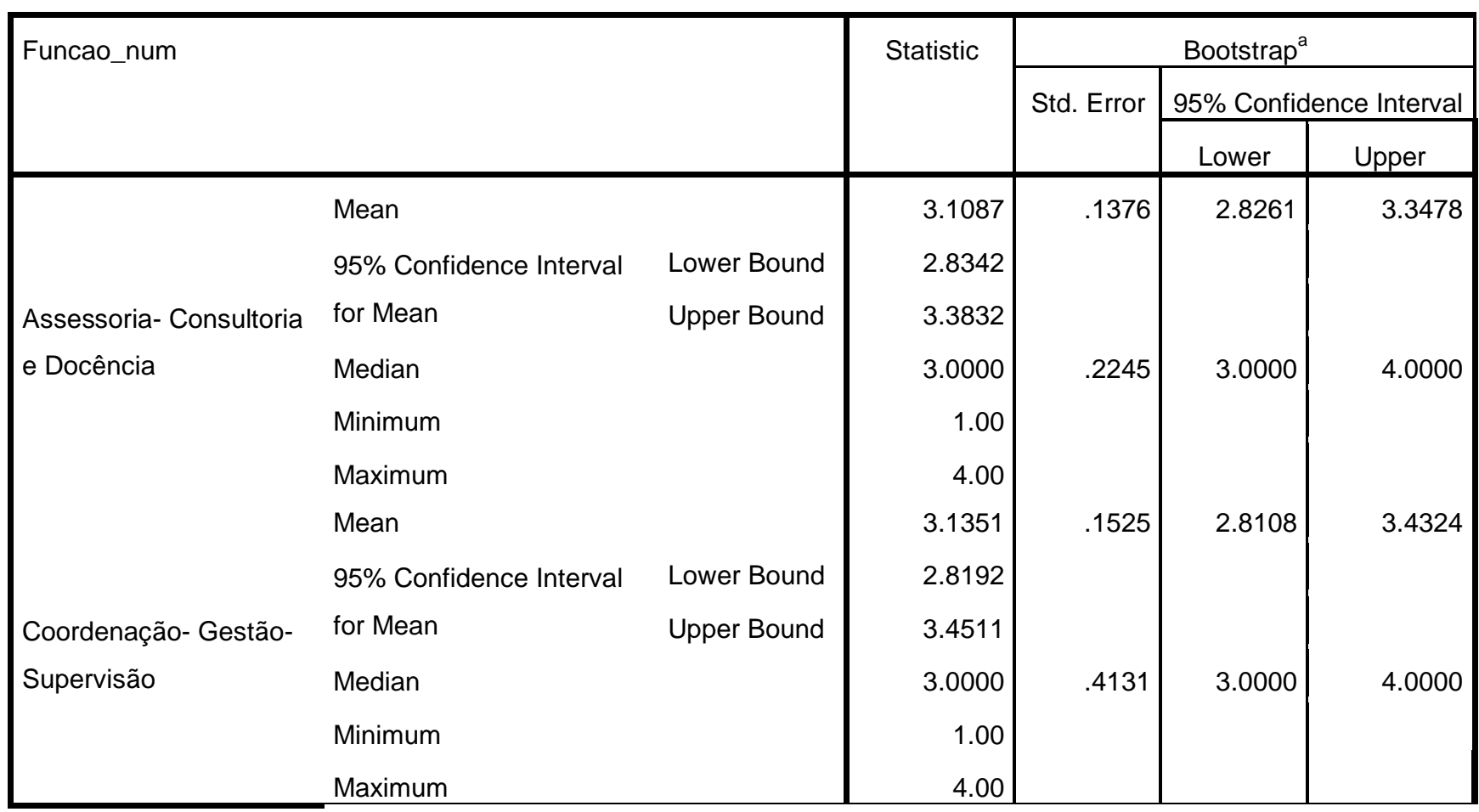

- Moradores.

\begin{tabular}{|c|c|c|c|c|c|c|}
\hline \multicolumn{3}{|l|}{ Funcao_num } & \multirow[t]{3}{*}{ Statistic } & \multicolumn{3}{|c|}{ Bootstrap $^{a}$} \\
\hline & & & & \multirow[t]{2}{*}{ Std. Error } & \multicolumn{2}{|c|}{ 95\% Confidence Interval } \\
\hline & & & & & Lower & Upper \\
\hline \multirow{6}{*}{$\begin{array}{l}\text { Assessoria- Consultoria } \\
\text { e Docência }\end{array}$} & Mean & & 3.4667 & .1074 & 3.2444 & 3.6667 \\
\hline & $95 \%$ Confidence Interval & Lower Bound & 3.2581 & & & \\
\hline & for Mean & Upper Bound & 3.6752 & & & \\
\hline & Median & & 4.0000 & .4217 & 3.0000 & 4.0000 \\
\hline & Minimum & & 1.00 & & & \\
\hline & Maximum & & 4.00 & & & \\
\hline \multirow{3}{*}{$\begin{array}{l}\text { Coordenação- Gestão- } \\
\text { Supervisão }\end{array}$} & Mean & & 3.5263 & .1087 & 3.3158 & 3.7368 \\
\hline & $95 \%$ Confidence Interval & Lower Bound & 3.3004 & & & \\
\hline & for Mean & Upper Bound & 3.7522 & & & \\
\hline
\end{tabular}




\begin{tabular}{|c|c|c|c|c|}
\hline Median & 4.0000 & .2678 & 3.0000 & 4.0000 \\
\hline Minimum & 1.00 & & & \\
\hline Maximum & 4.00 & & & \\
\hline
\end{tabular}

- Técnicos de manutenção de obras de drenagem.

\begin{tabular}{|c|c|c|c|c|c|c|}
\hline \multirow[t]{3}{*}{ Funcao_num } & & & \multirow[t]{3}{*}{ Statistic } & \multicolumn{3}{|c|}{ Bootstrap $^{a}$} \\
\hline & & & & \multirow[t]{2}{*}{ Std. Error } & \multicolumn{2}{|c|}{ 95\% Confidence Interval } \\
\hline & & & & & Lower & Upper \\
\hline \multirow{8}{*}{$\begin{array}{l}\text { Assessoria- Consultoria } \\
\text { e Docência }\end{array}$} & Mean & & 3.7391 & .0652 & 3.6087 & 3.8696 \\
\hline & $95 \%$ Confidence Interval & Lower Bound & 3.6073 & & & \\
\hline & for Mean & Upper Bound & 3.8710 & & & \\
\hline & Median & & 4.0000 & .0000 & 4.0000 & 4.0000 \\
\hline & Minimum & & 3.00 & & & \\
\hline & Maximum & & 4.00 & & & \\
\hline & Mean & & 3.7105 & .0920 & 3.5263 & 3.8684 \\
\hline & 95\% Confidence Interval & Lower Bound & 3.5248 & & & \\
\hline \multirow{4}{*}{$\begin{array}{l}\text { Coordenação- Gestão- } \\
\text { Supervisão }\end{array}$} & for Mean & Upper Bound & 3.8963 & & & \\
\hline & Median & & 4.0000 & .0158 & 4.0000 & 4.0000 \\
\hline & Minimum & & 2.00 & & & \\
\hline & Maximum & & 4.00 & & & \\
\hline
\end{tabular}

- Empresários locais.

\begin{tabular}{|c|c|c|c|c|c|c|}
\hline \multirow[t]{3}{*}{ Funcao_num } & & & \multirow[t]{3}{*}{ Statistic } & \multicolumn{3}{|c|}{ Bootstrap $^{a}$} \\
\hline & & & & \multirow[t]{2}{*}{ Std. Error } & \multicolumn{2}{|c|}{$95 \%$ Confidence Interval } \\
\hline & & & & & Lower & Upper \\
\hline \multirow{7}{*}{$\begin{array}{l}\text { Assessoria- Consultoria } \\
\text { e Docência }\end{array}$} & Mean & & 3.1778 & .1326 & 2.9111 & 3.4439 \\
\hline & $95 \%$ Confidence Interval & Lower Bound & 2.9193 & & & \\
\hline & for Mean & Upper Bound & 3.4363 & & & \\
\hline & Median & & 3.0000 & .2805 & 3.0000 & 4.0000 \\
\hline & Minimum & & 1.00 & & & \\
\hline & Maximum & & 4.00 & & & \\
\hline & Mean & & 3.2703 & .1307 & 3.0007 & 3.5135 \\
\hline \multirow{2}{*}{$\begin{array}{l}\text { Coordenação- Gestão- } \\
\text { Supervisão }\end{array}$} & $95 \%$ Confidence Interval & Lower Bound & 3.0021 & & & \\
\hline & for Mean & Upper Bound & 3.5385 & & & \\
\hline
\end{tabular}




\begin{tabular}{|c|c|c|c|c|}
\hline Median & 3.0000 & 4639 & 3.0000 & 4.0000 \\
\hline Minimum & 1.00 & & & \\
\hline Maximum & 4.00 & & & \\
\hline
\end{tabular}

- Engenheiros.

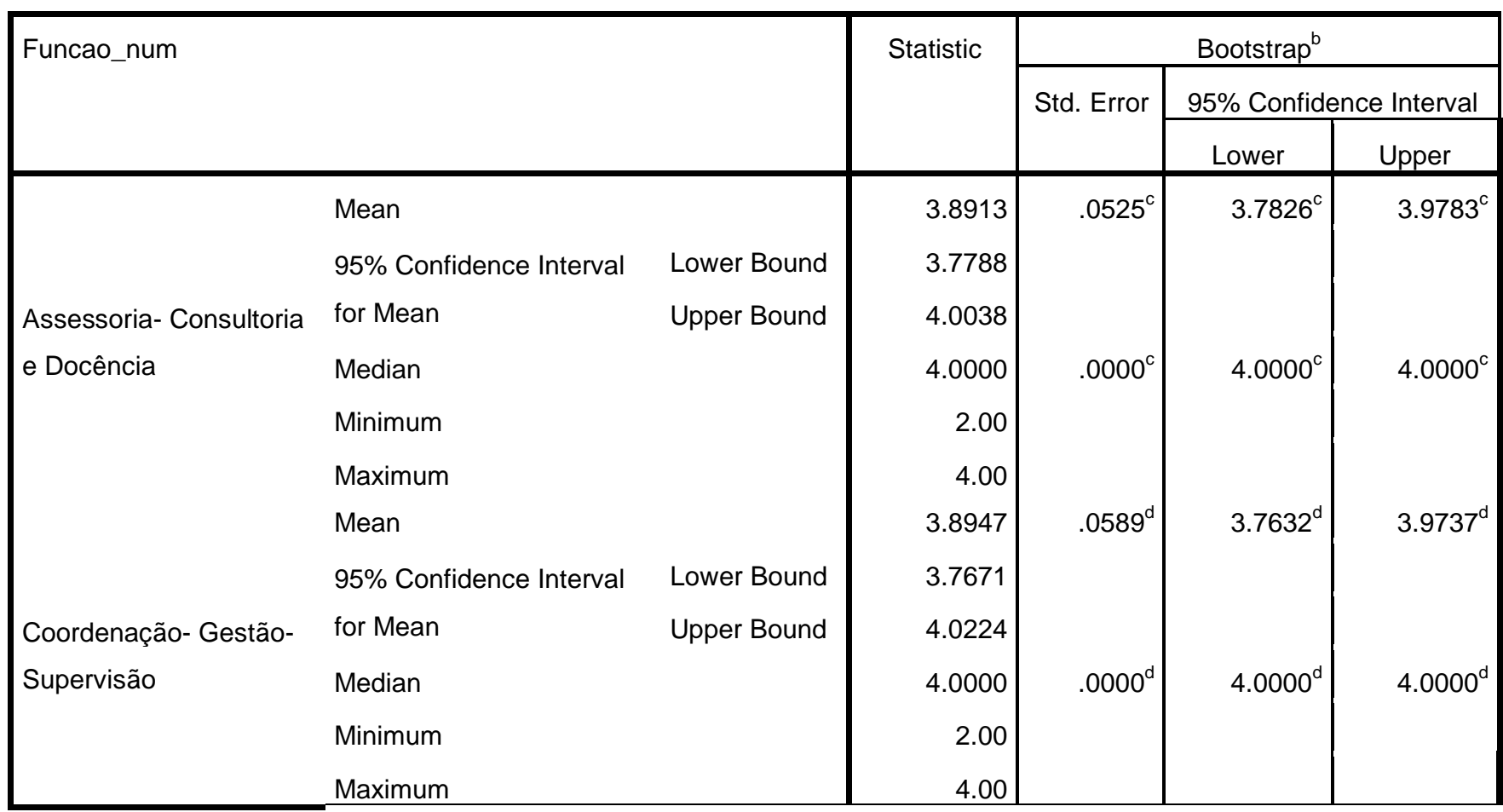

- Políticos da região.

\begin{tabular}{|c|c|c|c|c|c|c|}
\hline \multirow[t]{3}{*}{ Funcao_num } & & & \multirow[t]{3}{*}{ Statistic } & \multicolumn{3}{|c|}{ Bootstrap $^{a}$} \\
\hline & & & & \multirow[t]{2}{*}{ Std. Error } & \multicolumn{2}{|c|}{$95 \%$ Confidence Interval } \\
\hline & & & & & Lower & Upper \\
\hline \multirow{6}{*}{$\begin{array}{l}\text { Assessoria- Consultoria } \\
\text { e Docência }\end{array}$} & Mean & & 2.8889 & .1444 & 2.6000 & 3.1556 \\
\hline & $95 \%$ Confidence Interval & Lower Bound & 2.5938 & & & \\
\hline & for Mean & Upper Bound & 3.1840 & & & \\
\hline & Median & & 3.0000 & .0707 & 3.0000 & 3.0000 \\
\hline & Minimum & & 1.00 & & & \\
\hline & Maximum & & 4.00 & & & \\
\hline \multirow{3}{*}{$\begin{array}{l}\text { Coordenação- Gestão- } \\
\text { Supervisão }\end{array}$} & Mean & & 2.7778 & .1878 & 2.3611 & 3.1111 \\
\hline & $95 \%$ Confidence Interval & Lower Bound & 2.4062 & & & \\
\hline & for Mean & Upper Bound & 3.1494 & & & \\
\hline
\end{tabular}




\begin{tabular}{l|r|r|r|r|} 
Median & 3.0000 & .1804 & 2.5000 & 3.0000 \\
Minimum & 1.00 & & & \\
Maximum & 4.00 & & & \\
\hline
\end{tabular}

- Educadores ambientais.

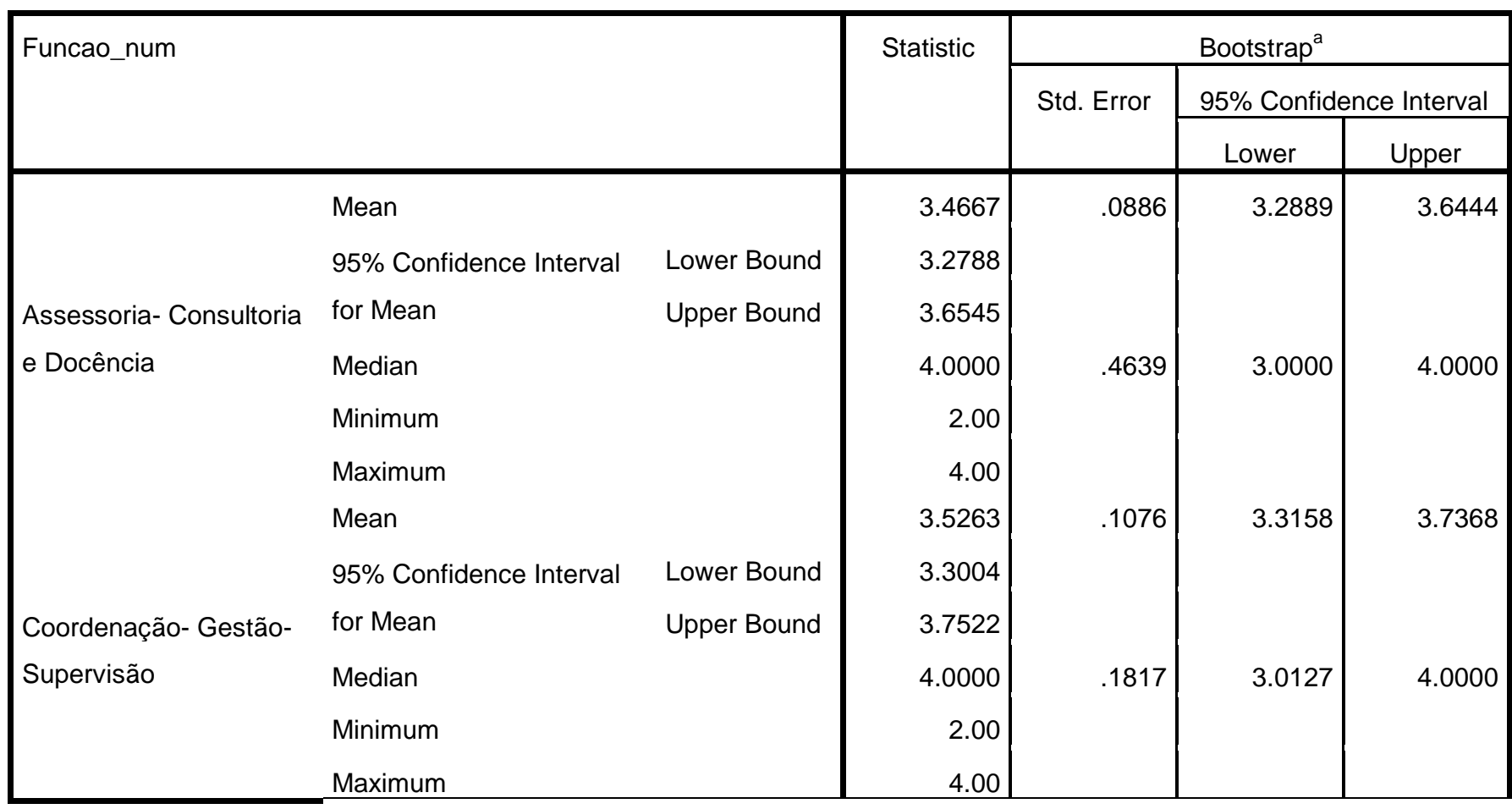

- Cientistas sociais.

\begin{tabular}{|c|c|c|c|c|c|c|}
\hline \multirow[t]{3}{*}{ Funcao_num } & & & \multirow[t]{3}{*}{ Statistic } & \multicolumn{3}{|c|}{ Bootstrap $^{a}$} \\
\hline & & & & \multirow[t]{2}{*}{ Std. Error } & \multicolumn{2}{|c|}{ 95\% Confidence Interval } \\
\hline & & & & & Lower & Upper \\
\hline \multirow{6}{*}{$\begin{array}{l}\text { Assessoria- Consultoria } \\
\text { e Docência }\end{array}$} & Mean & & 3.1304 & .1260 & 2.8696 & 3.3696 \\
\hline & 95\% Confidence Interval & Lower Bound & 2.8753 & & & \\
\hline & for Mean & Upper Bound & 3.3856 & & & \\
\hline & Median & & 3.0000 & .2272 & 3.0000 & 4.0000 \\
\hline & Minimum & & 1.00 & & & \\
\hline & Maximum & & 4.00 & & & \\
\hline \multirow{3}{*}{$\begin{array}{l}\text { Coordenação- Gestão- } \\
\text { Supervisão }\end{array}$} & Mean & & 3.1667 & .1462 & 2.8611 & 3.4444 \\
\hline & $95 \%$ Confidence Interval & Lower Bound & 2.8587 & & & \\
\hline & for Mean & Upper Bound & 3.4747 & & & \\
\hline
\end{tabular}


Median

3.0000
1.00
4.00

Maximum

\section{Questão 8 - Na implantação de obras de drenagem, é necessário que Engenheiros Civis contem com suficiente:}

- Tempo para ocupar-se com aspectos da organização sociopolítica nas comunidades onde obras são implantadas

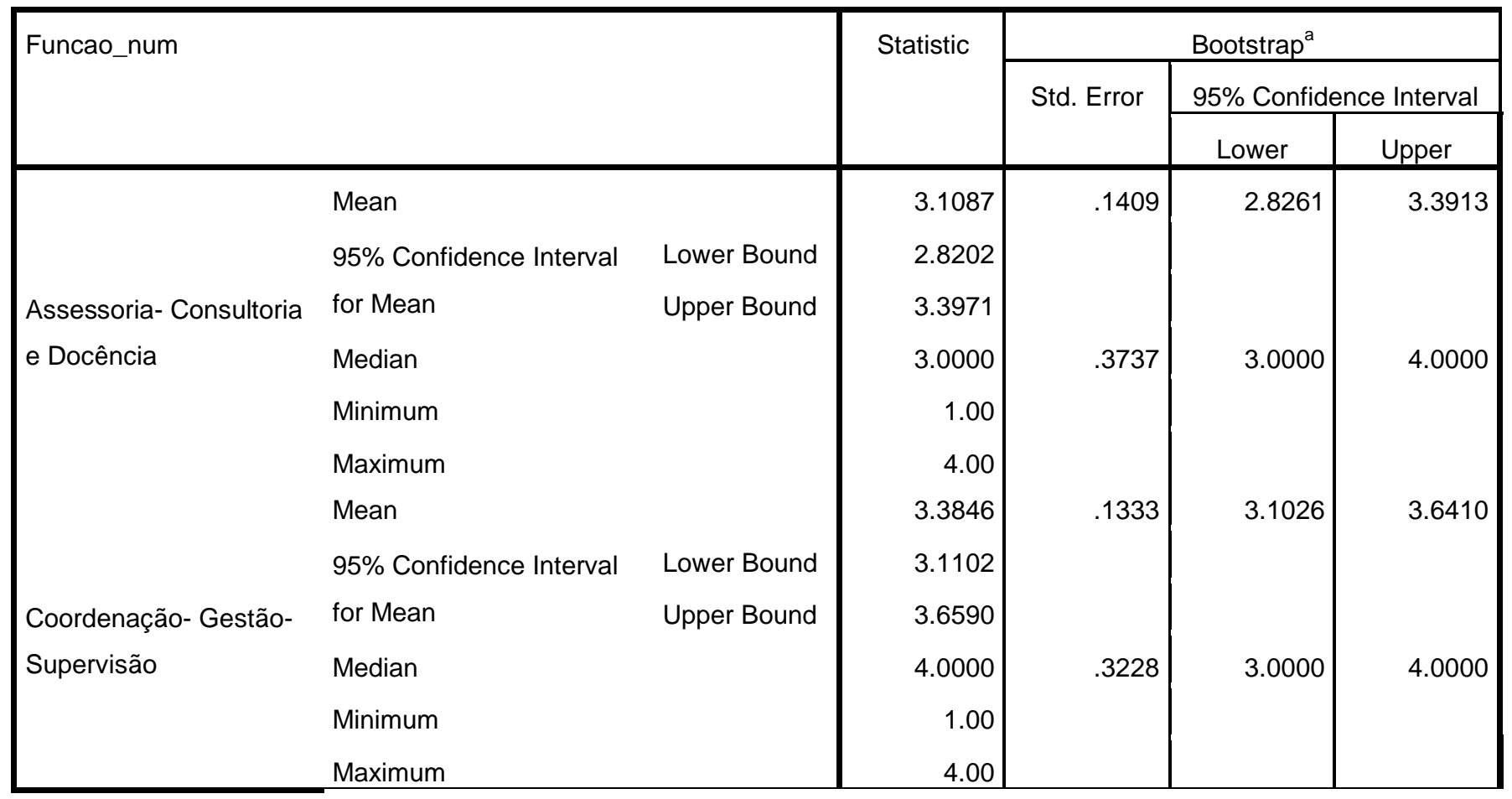

- Vontade de lidar com aspectos sociopolíticos nas comunidades onde implantam obras.

\begin{tabular}{|c|c|c|c|c|c|c|}
\hline \multirow[t]{3}{*}{ Funcao_num } & & & \multirow[t]{3}{*}{ Statistic } & \multicolumn{3}{|c|}{ Bootstrap $^{a}$} \\
\hline & & & & \multirow[t]{2}{*}{ Std. Error } & \multicolumn{2}{|c|}{$95 \%$ Confidence Interval } \\
\hline & & & & & Lower & Upper \\
\hline \multirow{6}{*}{$\begin{array}{l}\text { Assessoria- Consultoria } \\
\text { e Docência }\end{array}$} & Mean & & 3.3261 & .1236 & 3.0870 & 3.5652 \\
\hline & $95 \%$ Confidence Interval & Lower Bound & 3.0752 & & & \\
\hline & for Mean & Upper Bound & 3.5769 & & & \\
\hline & Median & & 3.5000 & .4717 & 3.0000 & 4.0000 \\
\hline & Minimum & & 1.00 & & & \\
\hline & Maximum & & 4.00 & & & \\
\hline
\end{tabular}




\begin{tabular}{|c|c|c|c|c|c|c|}
\hline & Mean & & 3.5526 & .1031 & 3.3421 & 3.7368 \\
\hline & 95\% Confidence Interval & Lower Bound & 3.3406 & & & \\
\hline Coordenação- Gestão- & for Mean & Upper Bound & 3.7647 & & & \\
\hline Supervisão & Median & & 4.0000 & 2078 & 3.0000 & 4.0000 \\
\hline & Minimum & & 2.00 & & & \\
\hline & Maximum & & 4.00 & & & \\
\hline
\end{tabular}

- Sensibilidade para aspectos da organização sociopilítica das comunidades onde implantam obras.

\begin{tabular}{|c|c|c|c|c|c|c|}
\hline \multicolumn{3}{|l|}{ Funcao_num } & \multirow[t]{3}{*}{ Statistic } & \multicolumn{3}{|c|}{ Bootstrap $^{a}$} \\
\hline & & & & \multirow[t]{2}{*}{ Std. Error } & \multicolumn{2}{|c|}{$95 \%$ Confidence Interval } \\
\hline & & & & & Lower & Upper \\
\hline \multirow{7}{*}{$\begin{array}{l}\text { Assessoria- Consultoria } \\
\text { e Docência }\end{array}$} & Mean & & 3.5217 & .1160 & 3.2826 & 3.7391 \\
\hline & $95 \%$ Confidence Interval & Lower Bound & 3.2897 & & & \\
\hline & for Mean & Upper Bound & 3.7538 & & & \\
\hline & Median & & 4.0000 & .0993 & 4.0000 & 4.0000 \\
\hline & Minimum & & 1.00 & & & \\
\hline & Maximum & & 4.00 & & & \\
\hline & Mean & & 3.5897 & .1086 & 3.3590 & 3.7949 \\
\hline \multirow{5}{*}{$\begin{array}{l}\text { Coordenação- Gestão- } \\
\text { Supervisão }\end{array}$} & 95\% Confidence Interval & Lower Bound & 3.3702 & & & \\
\hline & for Mean & Upper Bound & 3.8093 & & & \\
\hline & Median & & 4.0000 & .0447 & 4.0000 & 4.0000 \\
\hline & Minimum & & 2.00 & & & \\
\hline & Maximum & & 4.00 & & & \\
\hline
\end{tabular}

- Compreensão das interferências sociopolíticas que podem ocorrer durante a implantação das obras.

\begin{tabular}{|c|c|c|c|c|c|c|}
\hline \multicolumn{3}{|l|}{ Funcao_num } & \multirow[t]{3}{*}{ Statistic } & \multicolumn{3}{|c|}{ Bootstrap $^{a}$} \\
\hline & & & & \multirow[t]{2}{*}{ Std. Error } & \multicolumn{2}{|c|}{$95 \%$ Confidence Interval } \\
\hline & & & & & Lower & Upper \\
\hline \multirow{4}{*}{$\begin{array}{l}\text { Assessoria- Consultoria } \\
\text { e Docência }\end{array}$} & Mean & & 3.7111 & .0734 & 3.5556 & 3.8444 \\
\hline & 95\% Confidence Interval & Lower Bound & 3.5592 & & & \\
\hline & for Mean & Upper Bound & 3.8630 & & & \\
\hline & Median & & 4.0000 & .0000 & 4.0000 & 4.0000 \\
\hline
\end{tabular}




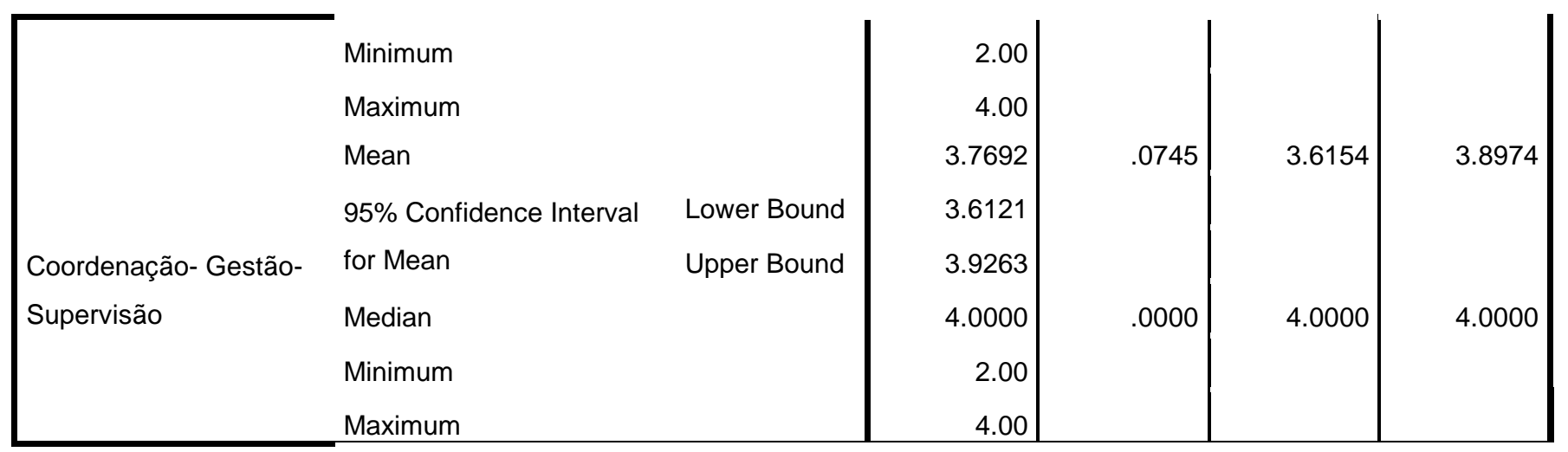

- Autonomia frente às interferências políticas e dos arranjos institucionais para implantar obras já planejadas.

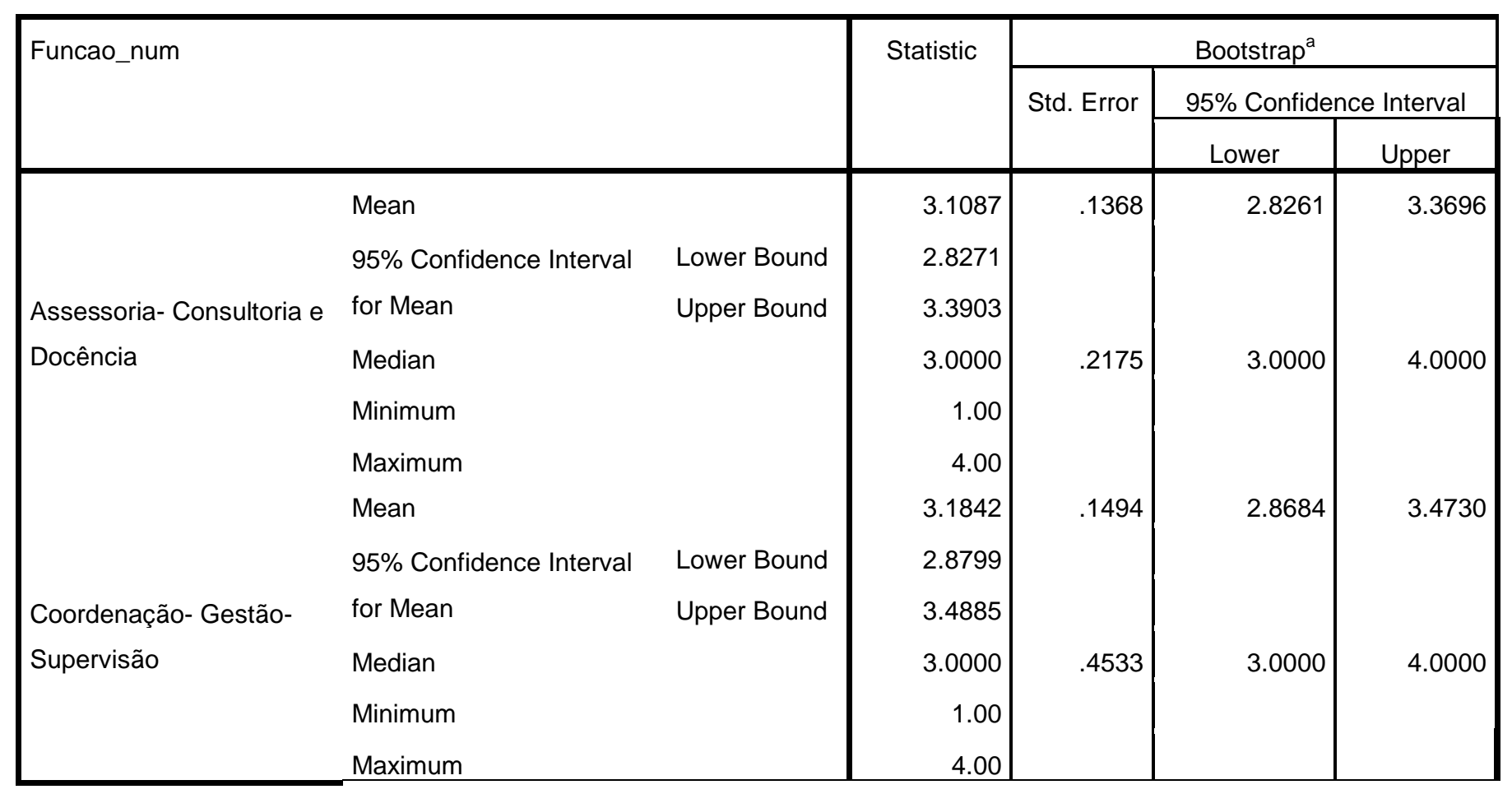

Questão 9 - A graduação em Engenharia Civil capacita suficientemente para a boa execução de obras de drenagem.

\begin{tabular}{|ll|r|r|r|r|}
\hline Funcao_num & \multirow{2}{*}{ Statistic } & \multicolumn{3}{|c|}{ Bootstrap $^{\mathrm{a}}$} \\
\cline { 4 - 6 } & & Std. Error & \multicolumn{2}{|c|}{$95 \%$ Confidence Interval } \\
\cline { 4 - 6 } & & & .1286 & 2.1962 \\
\hline $\begin{array}{l}\text { Assessoria- Consultoria } \\
\text { e Docência }\end{array}$ & $\begin{array}{l}\text { Mean } \\
\text { 95\% Confidence Interval Lower Bound }\end{array}$ & 2.1931 & & & \\
\end{tabular}




\begin{tabular}{|c|c|c|c|c|c|c|}
\hline & for Mean & Upper Bound & 2.7200 & & & \\
\hline & Median & & 2.5000 & 4677 & 2.0000 & 3.0000 \\
\hline & Minimum & & 1.00 & & & \\
\hline & Maximum & & 4.00 & & & \\
\hline & Mean & & 2.6923 & .1237 & 2.4359 & 2.9481 \\
\hline & 95\% Confidence Interval & Lower Bound & 2.4330 & & & \\
\hline Coordenação- Gestão- & for Mean & Upper Bound & 2.9516 & & & \\
\hline Supervisão & Median & & 3.0000 & 1679 & 2.0000 & 3.0000 \\
\hline & Minimum & & 1.00 & & & \\
\hline & Maximum & & 4.00 & & & \\
\hline
\end{tabular}

\section{Questão 10 - A graduação em Engenharia Civil deveria ter disciplinas obrigatórias sobre aspectos sociopolíticos.}

\begin{tabular}{|c|c|c|c|c|c|c|}
\hline \multirow[t]{3}{*}{ Funcao_num } & & & \multirow[t]{3}{*}{ Statistic } & \multicolumn{3}{|c|}{ Bootstrap $^{a}$} \\
\hline & & & & \multirow[t]{2}{*}{ Std. Error } & \multicolumn{2}{|c|}{ 95\% Confidence Interval } \\
\hline & & & & & Lower & Upper \\
\hline \multirow{8}{*}{$\begin{array}{l}\text { Assessoria- Consultoria } \\
\text { e Docência }\end{array}$} & Mean & & 3.4000 & .1059 & 3.2000 & 3.6000 \\
\hline & 95\% Confidence Interval & Lower Bound & 3.1744 & & & \\
\hline & for Mean & Upper Bound & 3.6256 & & & \\
\hline & Median & & 4.0000 & 4217 & 3.0000 & 4.0000 \\
\hline & Minimum & & 2.00 & & & \\
\hline & Maximum & & 4.00 & & & \\
\hline & Mean & & 3.6410 & .0880 & 3.4615 & 3.7949 \\
\hline & 95\% Confidence Interval & Lower Bound & 3.4668 & & & \\
\hline \multirow{4}{*}{$\begin{array}{l}\text { Coordenação- Gestão- } \\
\text { Supervisão }\end{array}$} & for Mean & Upper Bound & 3.8152 & & & \\
\hline & Median & & 4.0000 & .1401 & 4.0000 & 4.0000 \\
\hline & Minimum & & 2.00 & & & \\
\hline & Maximum & & 4.00 & & & \\
\hline
\end{tabular}

Questão 11 - Cientistas Sociais são bem-vindos para atuar em projetos de intervenções em drenagem.

Funcao_num

\begin{tabular}{|l|c|c|c|}
\hline \multirow{3}{*}{ Statistic } & \multicolumn{3}{|c|}{ Bootstrap $^{\mathrm{a}}$} \\
\cline { 2 - 4 } & \multirow{2}{*}{ Std. Error } & \multicolumn{2}{|c|}{$95 \%$ Confidence Interval } \\
\cline { 3 - 4 } & & Lower & Upper \\
\hline
\end{tabular}




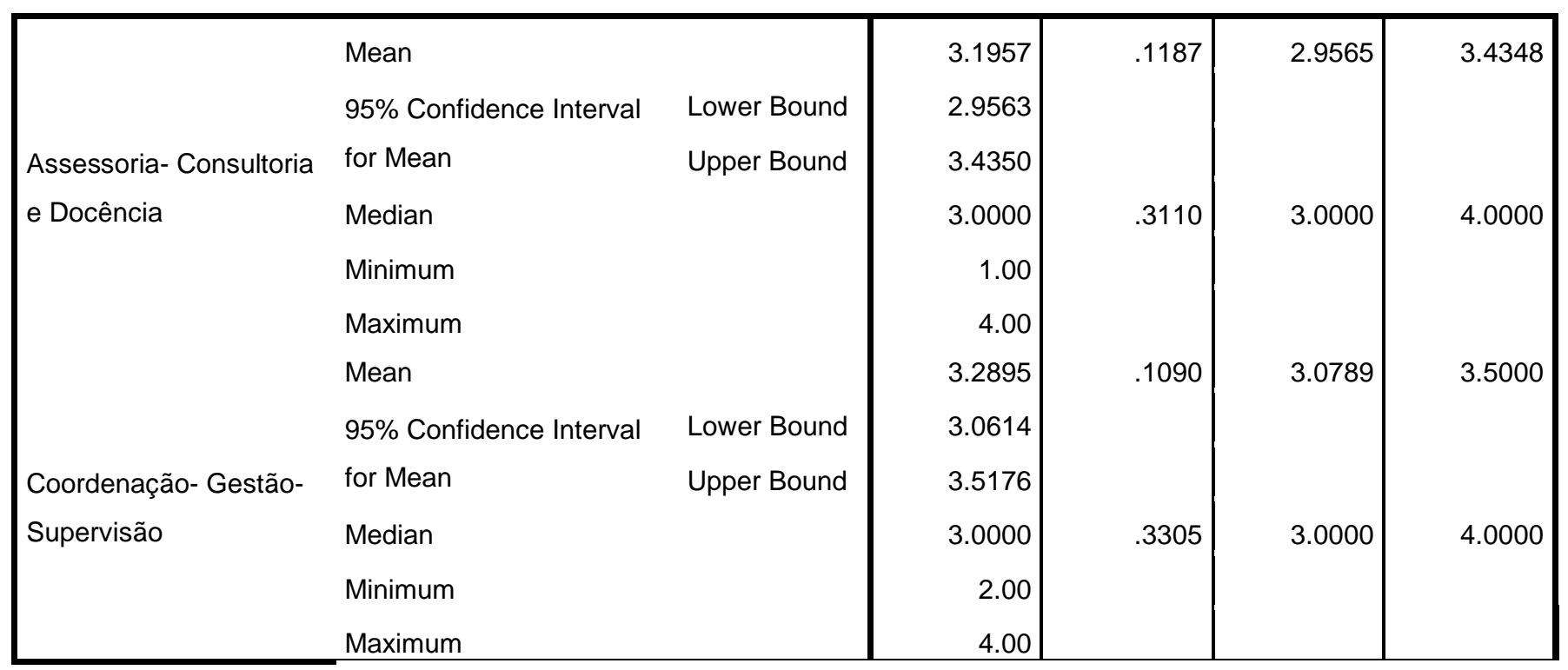

Questão 12 - As principais causas das inundações no Município de São Paulo são:

- Insuficientes recursos financeiros por parte do Poder Público.

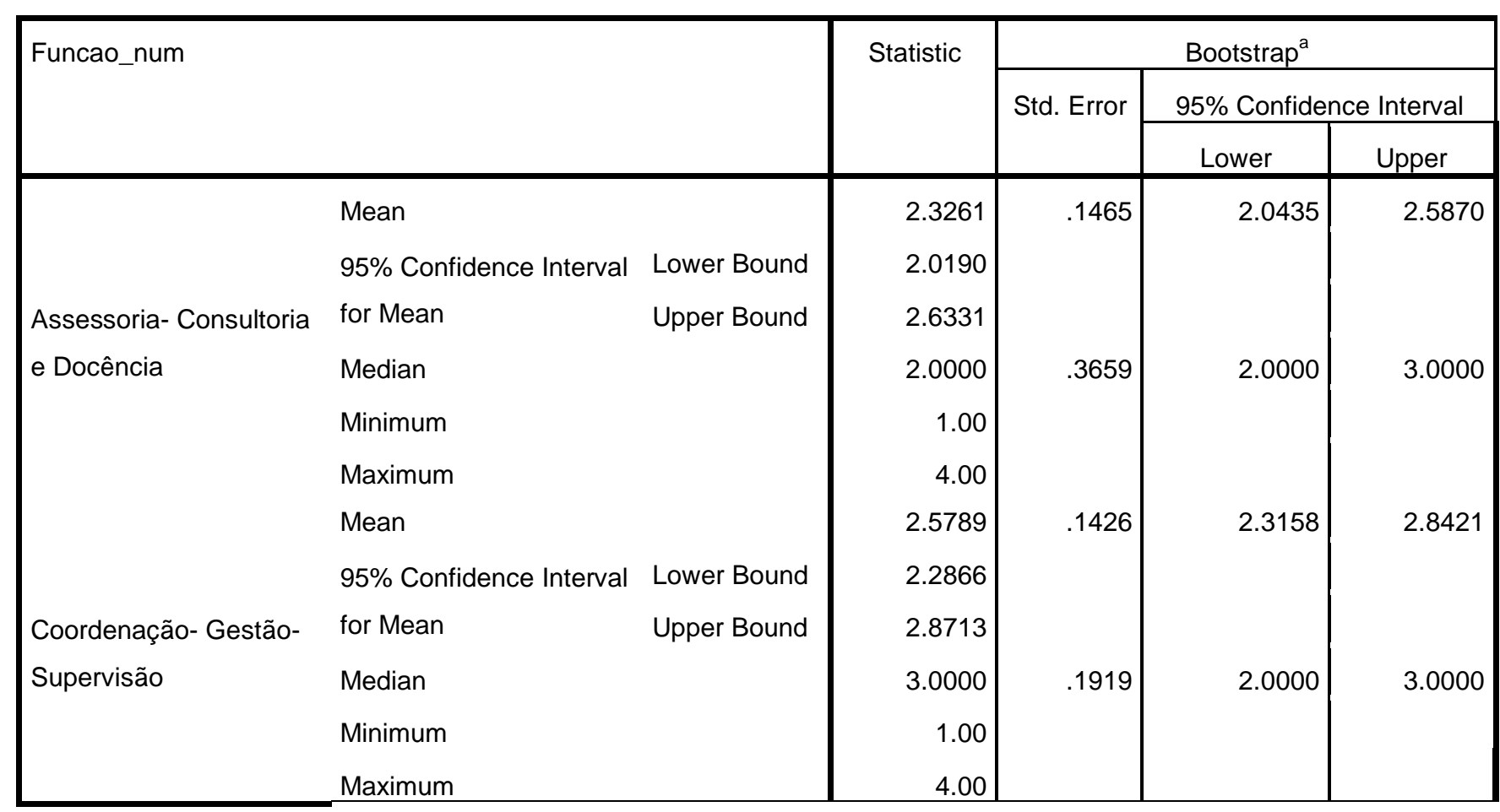

- Clima 


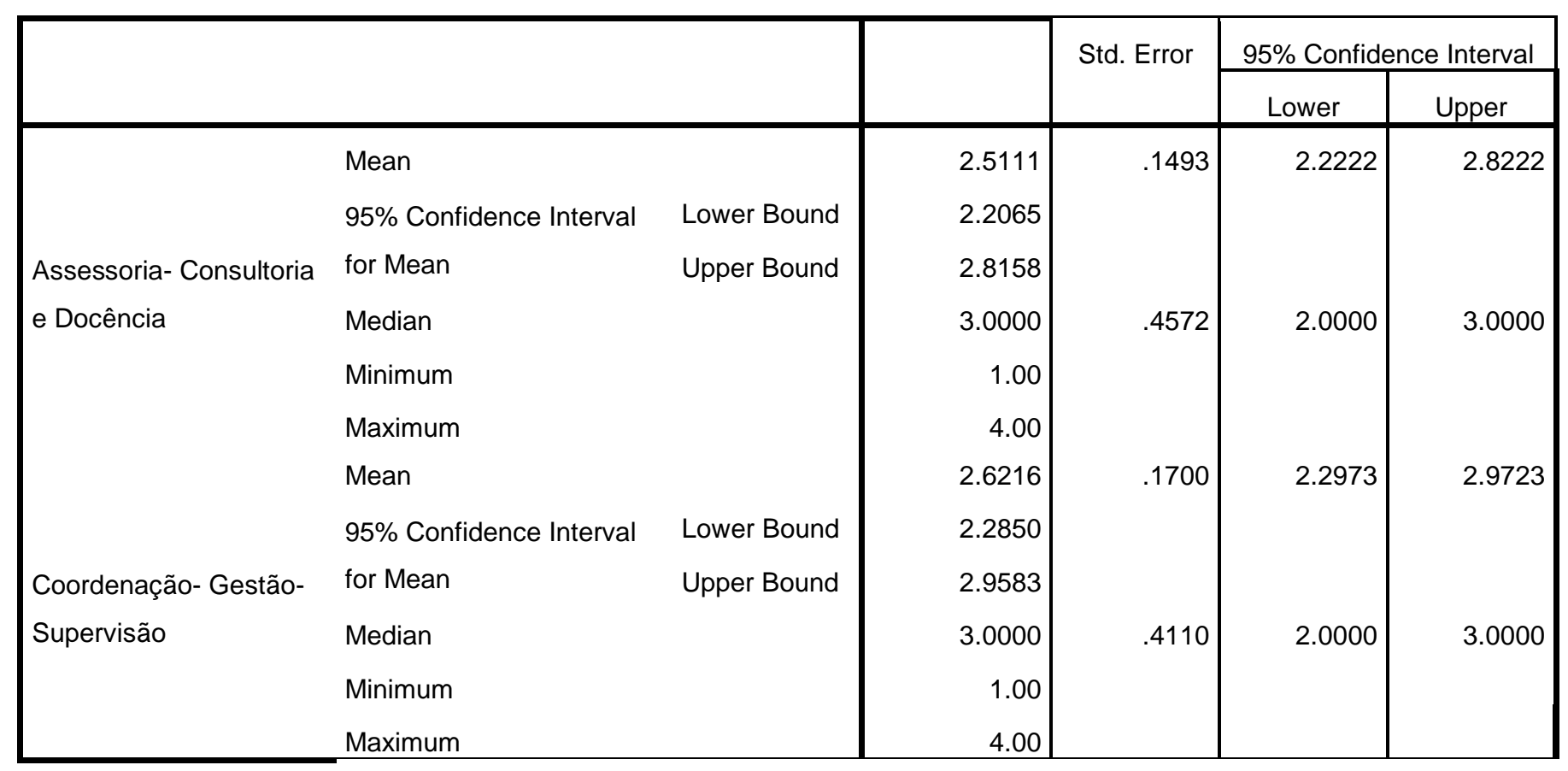

$* * *$

- A impermeabilização do solo.

\begin{tabular}{|c|c|c|c|c|c|c|}
\hline \multirow[t]{3}{*}{ Funcao_num } & & & \multirow[t]{3}{*}{ Statistic } & \multicolumn{3}{|c|}{ Bootstrap $^{a}$} \\
\hline & & & & \multirow[t]{2}{*}{ Std. Error } & \multicolumn{2}{|c|}{$95 \%$ Confidence Interval } \\
\hline & & & & & Lower & Upper \\
\hline \multirow{8}{*}{$\begin{array}{l}\text { Assessoria- Consultoria } \\
\text { e Docência }\end{array}$} & Mean & & 3.7609 & \multirow[t]{3}{*}{.0686} & \multirow[t]{3}{*}{3.6087} & \multirow[t]{3}{*}{3.891} \\
\hline & 95\% Confidence Interval & Lower Bound & 3.6183 & & & \\
\hline & for Mean & Upper Bound & 3.9034 & & & \\
\hline & Median & & 4.0000 & .0000 & 4.0000 & 4.0000 \\
\hline & Minimum & & 2.00 & & & \\
\hline & Maximum & & 4.00 & & & \\
\hline & Mean & & 3.5676 & .1093 & 3.3243 & 3.7838 \\
\hline & $95 \%$ Confidence Interval & Lower Bound & 3.3518 & \multirow{5}{*}{.2052} & \multirow{5}{*}{3.0000} & \multirow{5}{*}{4.0000} \\
\hline \multirow{4}{*}{$\begin{array}{l}\text { Coordenação- Gestão- } \\
\text { Supervisão }\end{array}$} & for Mean & Upper Bound & 3.7834 & & & \\
\hline & Median & & 4.0000 & & & \\
\hline & Minimum & & 2.00 & & & \\
\hline & Maximum & & 4.00 & & & \\
\hline
\end{tabular}

- A fiscalização do uso e ocupação do solo em áreas de proteção de mananciais e de preservação permanente. 


\begin{tabular}{|c|c|c|c|c|c|c|}
\hline \multirow[t]{3}{*}{ Funcao_num } & & & \multirow[t]{3}{*}{ Statistic } & \multicolumn{3}{|c|}{ Bootstrap ${ }^{a}$} \\
\hline & & & & \multirow[t]{2}{*}{ Std. Error } & \multicolumn{2}{|c|}{$95 \%$ Confidence Interval } \\
\hline & & & & & Lower & Upper \\
\hline \multirow{8}{*}{$\begin{array}{l}\text { Assessoria- Consultoria } \\
\text { e Docência }\end{array}$} & Mean & & 3.5217 & \multirow[t]{3}{*}{.1060} & \multirow[t]{3}{*}{3.3043} & \multirow[t]{3}{*}{3.7174} \\
\hline & $95 \%$ Confidence Interval & Lower Bound & 3.3072 & & & \\
\hline & for Mean & Upper Bound & 3.7362 & & & \\
\hline & Median & & 4.0000 & \multirow[t]{3}{*}{.2043} & \multirow[t]{3}{*}{3.0000} & \multirow[t]{3}{*}{4.0000} \\
\hline & Minimum & & 1.00 & & & \\
\hline & Maximum & & 4.00 & & & \\
\hline & Mean & & 3.3333 & \multirow[t]{3}{*}{.1258} & \multirow[t]{3}{*}{3.0519} & \multirow[t]{3}{*}{3.5385} \\
\hline & $95 \%$ Confidence Interval & Lower Bound & 3.0722 & & & \\
\hline Coordenação- Gestão- & for Mean & Upper Bound & 3.5945 & & & \\
\hline \multirow[t]{3}{*}{ Supervisão } & Median & & 3.0000 & \multirow[t]{3}{*}{.4961} & \multirow[t]{3}{*}{3.0000} & \multirow[t]{3}{*}{4.0000} \\
\hline & Minimum & & 1.00 & & & \\
\hline & Maximum & & 4.00 & & & \\
\hline
\end{tabular}

- O envolvimento de moradores e comerciantes no planejamento das obras a fim de se obter consenso sobre as mesmas e praticar seu uso racional.

\begin{tabular}{|c|c|c|c|c|c|c|}
\hline \multirow[t]{3}{*}{ Funcao_num } & & & \multirow[t]{3}{*}{ Statistic } & \multicolumn{3}{|c|}{ Bootstrap $^{a}$} \\
\hline & & & & \multirow[t]{2}{*}{ Std. Error } & \multicolumn{2}{|c|}{ 95\% Confidence Interval } \\
\hline & & & & & Lower & Upper \\
\hline \multirow{8}{*}{$\begin{array}{l}\text { Assessoria- Consultoria } \\
\text { e Docência }\end{array}$} & Mean & & 2.5111 & .1547 & 2.2000 & 2.8000 \\
\hline & $95 \%$ Confidence Interval & Lower Bound & 2.1933 & & & \\
\hline & for Mean & Upper Bound & 2.8289 & & & \\
\hline & Median & & 3.0000 & .4749 & 2.0000 & 3.0000 \\
\hline & Minimum & & 1.00 & & & \\
\hline & Maximum & & 4.00 & & & \\
\hline & Mean & & 2.6410 & .1644 & 2.3077 & 2.9487 \\
\hline & $95 \%$ Confidence Interval & Lower Bound & 2.3044 & & & \\
\hline \multirow{4}{*}{$\begin{array}{l}\text { Coordenação- Gestão- } \\
\text { Supervisão }\end{array}$} & for Mean & Upper Bound & 2.9776 & & & \\
\hline & Median & & 3.0000 & .3105 & 2.0000 & 3.0000 \\
\hline & Minimum & & 1.00 & & & \\
\hline & Maximum & & 4.00 & & & \\
\hline
\end{tabular}


- A graduação em Engenharia Civil e a formação que oferece nos aspectos sociopolíticos que as obras envolvem tendo em vista garantir sua durabilidade.

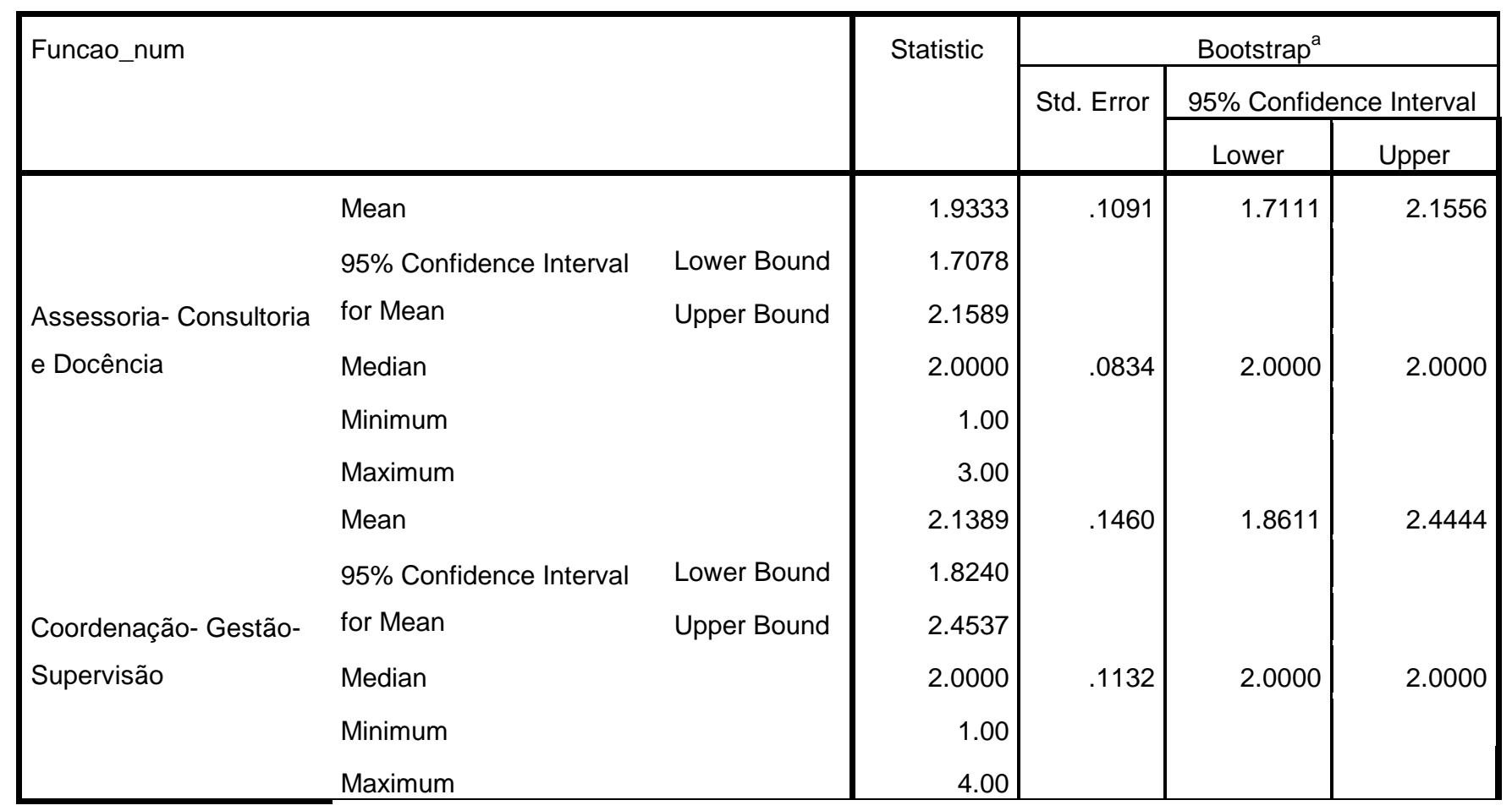

- A capacitação de Profissionais de formação humanista e social para envolver moradores e comerciantes de maneira que se sintam capazes de contribuir para a redução de alagamentos e inundações.

\begin{tabular}{|c|c|c|c|c|c|c|}
\hline \multirow[t]{3}{*}{ Funcao_num } & & & \multirow[t]{3}{*}{ Statistic } & \multicolumn{3}{|c|}{ Bootstrap $^{a}$} \\
\hline & & & & \multirow[t]{2}{*}{ Std. Error } & \multicolumn{2}{|c|}{$95 \%$ Confidence Interval } \\
\hline & & & & & Lower & Upper \\
\hline \multirow{8}{*}{$\begin{array}{l}\text { Assessoria- Consultoria } \\
\text { e Docência }\end{array}$} & Mean & & 2.5217 & \multirow[t]{3}{*}{.1633} & \multirow[t]{2}{*}{2.1957} & \multirow[t]{2}{*}{2.8473} \\
\hline & 95\% Confidence Interval for & Lower Bound & 2.1803 & & & \\
\hline & Mean & Upper Bound & 2.8631 & & & \\
\hline & Median & & 3.0000 & .3661 & 2.0000 & 3.0000 \\
\hline & Minimum & & 1.00 & & & \\
\hline & Maximum & & 4.00 & & & \\
\hline & Mean & & 2.5526 & .1748 & 2.2112 & 2.8947 \\
\hline & 95\% Confidence Interval for & Lower Bound & 2.1967 & \multirow{5}{*}{.3276} & \multirow{5}{*}{2.0000} & \multirow{5}{*}{3.0000} \\
\hline \multirow{4}{*}{$\begin{array}{l}\text { Coordenação- Gestão- } \\
\text { Supervisão }\end{array}$} & Mean & Upper Bound & 2.9086 & & & \\
\hline & Median & & 3.0000 & & & \\
\hline & Minimum & & 1.00 & & & \\
\hline & Maximum & & 4.00 & & & \\
\hline
\end{tabular}


- Resíduos sólidos depositados nas vias públicas e cursos de água

\begin{tabular}{|c|c|c|c|c|c|c|}
\hline \multirow[t]{3}{*}{ Funcao_num } & & & \multirow[t]{3}{*}{ Statistic } & \multicolumn{3}{|c|}{ Bootstrap $^{a}$} \\
\hline & & & & \multirow[t]{2}{*}{ Std. Error } & \multicolumn{2}{|c|}{$95 \%$ Confidence Interval } \\
\hline & & & & & Lower & Upper \\
\hline \multirow[t]{3}{*}{ Funcao_num } & Mean & & 3.4783 & .1063 & 3.2609 & 3.6739 \\
\hline & 95\% Confidence Interval & Lower Bound & 3.2638 & & & \\
\hline & for Mean & Upper Bound & 3.6928 & & & \\
\hline & Median & & 4.0000 & 2851 & 3.0000 & 4.0000 \\
\hline & Minimum & & 1.00 & & & \\
\hline \multirow{2}{*}{\multicolumn{7}{|c|}{$\begin{array}{l}\text { Assessoria- Consultoria } \\
\text { e Docência }\end{array}$}} \\
\hline & & & & & & \\
\hline \multicolumn{7}{|l|}{$\begin{array}{l}\text { Coordenação- Gestão- } \\
\text { Supervisão }\end{array}$} \\
\hline \multirow{2}{*}{\multicolumn{7}{|c|}{$\begin{array}{l}\text { Assessoria- Consultoria } \\
\text { e Docência }\end{array}$}} \\
\hline & & & & & & \\
\hline & Mean & & 3.8205 & .0636 & 3.6923 & 3.9231 \\
\hline & 95\% Confidence Interval & Lower Bound & 3.6945 & & & \\
\hline Coordenação- Gestão- & for Mean & Upper Bound & 3.9465 & & & \\
\hline Supervisão & Median & & 4.0000 & .0000 & 4.0000 & 4.0000 \\
\hline & Minimum & & 3.00 & & & \\
\hline & Maximum & & 4.00 & & & \\
\hline
\end{tabular}

- A manutenção das obras de drenagem pelo Poder Público.

Questão 13 - Para a durabilidade das obras em drenagem urbana e a sustentabilidade do serviço que oferecem é necessário: 
- Maior envolvimento de moradores e comerciantes das áreas onde as obras são implantadas para que se encontre um consenso quanto a atender o interesse público.

\begin{tabular}{|c|c|c|c|c|c|c|}
\hline \multirow[t]{3}{*}{ Funcao_num } & & & \multirow[t]{3}{*}{ Statistic } & \multicolumn{3}{|c|}{ Bootstrap $^{a}$} \\
\hline & & & & \multirow[t]{2}{*}{ Std. Error } & \multicolumn{2}{|c|}{$95 \%$ Confidence Interval } \\
\hline & & & & & Lower & Upper \\
\hline \multirow{8}{*}{$\begin{array}{l}\text { Assessoria- Consultoria } \\
\text { e Docência }\end{array}$} & Mean & & 3.5000 & .1196 & 3.2632 & 3.7105 \\
\hline & $95 \%$ Confidence Interval & Lower Bound & 3.2614 & & & \\
\hline & for Mean & Upper Bound & 3.7386 & & & \\
\hline & Median & & 4.0000 & .2684 & 3.0000 & 4.0000 \\
\hline & Minimum & & 1.00 & & & \\
\hline & Maximum & & 4.00 & & & \\
\hline & Mean & & 3.5429 & .1147 & 3.3143 & 3.7429 \\
\hline & 95\% Confidence Interval & Lower Bound & 3.3022 & & & \\
\hline \multirow{4}{*}{$\begin{array}{l}\text { Coordenação- Gestão- } \\
\text { Supervisão }\end{array}$} & for Mean & Upper Bound & 3.7835 & & & \\
\hline & Median & & 4.0000 & .1468 & 4.0000 & 4.0000 \\
\hline & Minimum & & 2.00 & & & \\
\hline & Maximum & & 4.00 & & & \\
\hline
\end{tabular}

- Capacitação de profissionais formados em áreas sociais para trabalhar junto a moradores e comerciantes tendo em vista o uso racional da obra implantada.

\begin{tabular}{|c|c|c|c|c|c|c|}
\hline \multirow[t]{3}{*}{ Funcao_num } & & & \multirow[t]{3}{*}{ Statistic } & \multicolumn{3}{|c|}{ Bootstrap $^{a}$} \\
\hline & & & & \multirow[t]{2}{*}{ Std. Error } & \multicolumn{2}{|c|}{$95 \%$ Confidence Interval } \\
\hline & & & & & Lower & Upper \\
\hline \multirow{8}{*}{$\begin{array}{l}\text { Assessoria- Consultoria } \\
\text { e Docência }\end{array}$} & Mean & & 3.4211 & .1162 & 3.1579 & 3.6316 \\
\hline & $95 \%$ Confidence Interval & Lower Bound & 3.1839 & & & \\
\hline & for Mean & Upper Bound & 3.6582 & & & \\
\hline & Median & & 4.0000 & .4498 & 3.0000 & 4.0000 \\
\hline & Minimum & & 1.00 & & & \\
\hline & Maximum & & 4.00 & & & \\
\hline & Mean & & 3.5714 & .1190 & 3.3429 & 3.8000 \\
\hline & $95 \%$ Confidence Interval & Lower Bound & 3.3316 & & & \\
\hline \multirow{4}{*}{$\begin{array}{l}\text { Coordenação- Gestão- } \\
\text { Supervisão }\end{array}$} & for Mean & Upper Bound & 3.8112 & & & \\
\hline & Median & & 4.0000 & .1044 & 4.0000 & 4.0000 \\
\hline & Minimum & & 2.00 & & & \\
\hline & Maximum & & 4.00 & & & \\
\hline
\end{tabular}


- Projetos que focalizem trabalhar reinvidicações de moradores e comerciantes de maneira a administrar conflitos e chegar a consenso que responda ao interesse público.

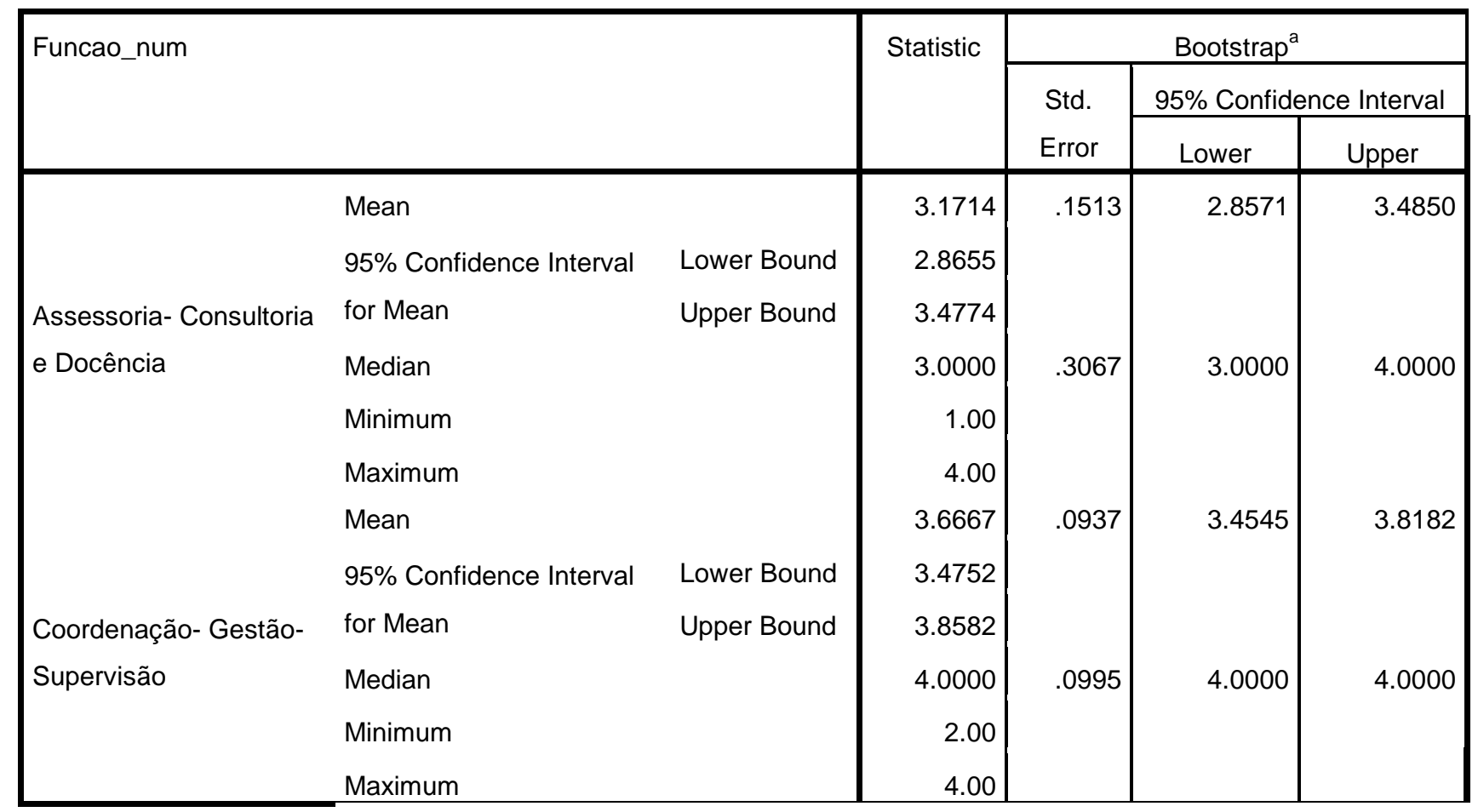

- Envolvimento de moradores e comerciantes no planejamento de maneira a que as decisões atendam ao interesse público.

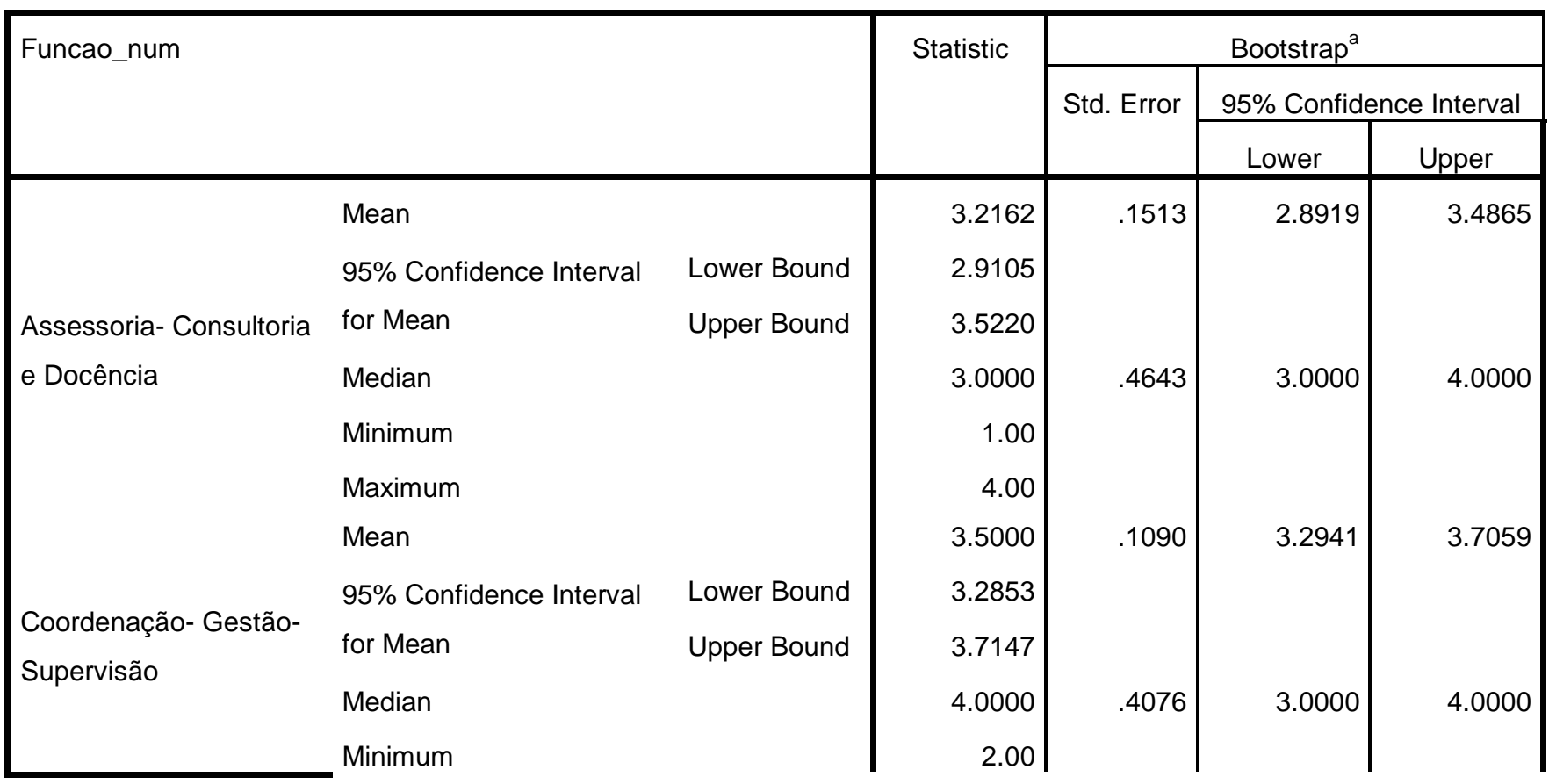


- Manutenção de obras somente pelo Poder Público para garantir sua eficácia.

\begin{tabular}{|c|c|c|c|c|c|c|}
\hline \multirow[t]{3}{*}{ Funcao_num } & & & \multirow[t]{3}{*}{ Statistic } & \multicolumn{3}{|c|}{ Bootstrap $^{a}$} \\
\hline & & & & \multirow[t]{2}{*}{ Std. Error } & \multicolumn{2}{|c|}{ 95\% Confidence Interval } \\
\hline & & & & & Lower & Upper \\
\hline \multirow{8}{*}{$\begin{array}{l}\text { Assessoria- Consultoria } \\
\text { e Docência }\end{array}$} & Mean & & 2.5263 & 1426 & 2.2368 & 2.8151 \\
\hline & $95 \%$ Confidence Interval & Lower Bound & 2.2330 & & & \\
\hline & for Mean & Upper Bound & 2.8197 & & & \\
\hline & Median & & 3.0000 & .4520 & 2.0000 & 3.0000 \\
\hline & Minimum & & 1.00 & & & \\
\hline & Maximum & & 4.00 & & & \\
\hline & Mean & & 2.2286 & 1926 & 1.8286 & 2.5993 \\
\hline & 95\% Confidence Interval & Lower Bound & 1.8460 & & & \\
\hline \multirow{4}{*}{$\begin{array}{l}\text { Coordenação- Gestão- } \\
\text { Supervisão }\end{array}$} & for Mean & Upper Bound & 2.6111 & & & \\
\hline & Median & & 2.0000 & 3796 & 1.0000 & 3.0000 \\
\hline & Minimum & & 1.00 & & & \\
\hline & Maximum & & 4.00 & & & \\
\hline
\end{tabular}

\begin{tabular}{|c|c|c|c|c|c|c|}
\hline \multirow[t]{3}{*}{ Funcao_num } & & & \multirow[t]{3}{*}{ Statistic } & \multicolumn{3}{|c|}{ Bootstrap $^{b}$} \\
\hline & & & & \multirow[t]{2}{*}{ Std. Error } & \multicolumn{2}{|c|}{ 95\% Confidence Interval } \\
\hline & & & & & Lower & Upper \\
\hline \multirow{7}{*}{$\begin{array}{l}\text { Assessoria- Consultoria } \\
\text { e Docência }\end{array}$} & Mean & & 3.6111 & .1125 & 3.3889 & 3.8056 \\
\hline & $95 \%$ Confidence Interval & Lower Bound & 3.3784 & & & \\
\hline & for Mean & Upper Bound & 3.8438 & & & \\
\hline & Median & & 4.0000 & .0631 & 4.0000 & 4.0000 \\
\hline & Minimum & & 1.00 & & & \\
\hline & Maximum & & 4.00 & & & \\
\hline & Mean & & 3.7188 & $.1014^{\mathrm{C}}$ & $3.5000^{c}$ & $3.9063^{\mathrm{c}}$ \\
\hline \multirow{3}{*}{$\begin{array}{l}\text { Coordenação- Gestão- } \\
\text { Supervisão }\end{array}$} & 95\% Confidence Interval & Lower Bound & 3.5092 & & & \\
\hline & for Mean & Upper Bound & 3.9283 & & & \\
\hline & Median & & 4.0000 & $.0000^{\mathrm{C}}$ & $4.0000^{c}$ & $4.0000^{c}$ \\
\hline
\end{tabular}




\begin{tabular}{l|l|} 
Minimum & 2.00 \\
4.00
\end{tabular} \mid

- Monitoramento das obras pelo Poder Público que inclua o cuidado com as mesmas também por moradores e comerciantes.

- Trabalho mais eficaz pelos Educadores Ambientais e Comunicadores Sociais nas áreas

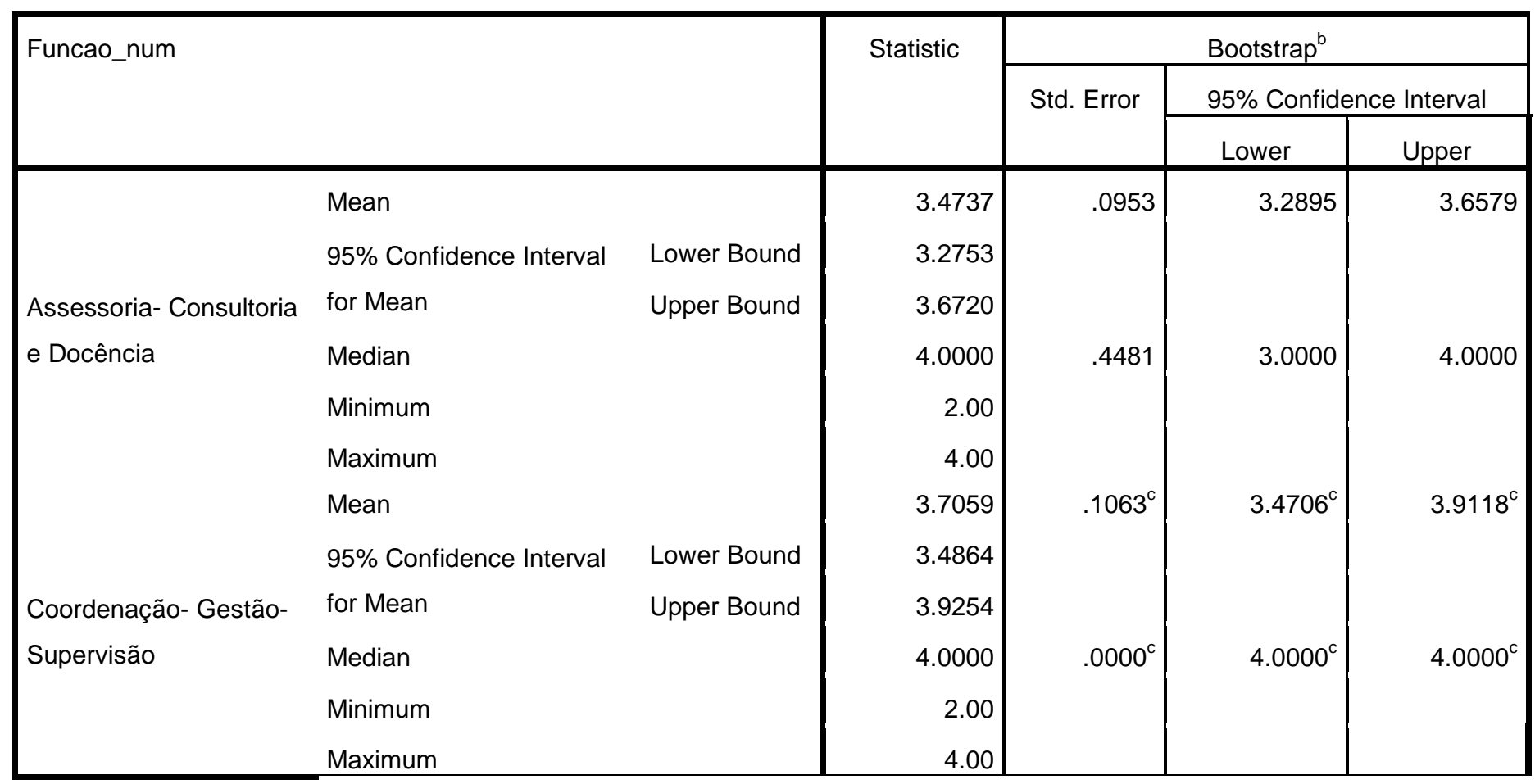

onde são implantadas as obras de drenagem.

Questão 14 - Relação mais estreita entre o técnico-científico (o campo de atuação e a formação do Engenheiro Civil) e o sociopolítico (a organização social e política) é fundamental para a durabilidade das obras e a sustentabilidade do serviço que oferece.

\begin{tabular}{|c|c|c|c|c|c|c|}
\hline \multirow[t]{3}{*}{ Funcao_num } & & & \multirow[t]{3}{*}{ Statistic } & \multicolumn{3}{|c|}{ Bootstrap ${ }^{a}$} \\
\hline & & & & \multirow[t]{2}{*}{ Std. Error } & \multicolumn{2}{|c|}{ 95\% Confidence Interval } \\
\hline & & & & & Lower & Upper \\
\hline \multirow{4}{*}{$\begin{array}{l}\text { Assessoria- Consultoria } \\
\text { e Docência }\end{array}$} & Mean & & 3.4667 & .1063 & 3.2667 & 3.6667 \\
\hline & 95\% Confidence Interval & Lower Bound & 3.2485 & & & \\
\hline & for Mean & Upper Bound & 3.6848 & & & \\
\hline & Median & & 4.0000 & .3523 & 3.0000 & 4.0000 \\
\hline
\end{tabular}




\begin{tabular}{|c|c|c|c|c|c|c|}
\hline & Minimum & & 1.00 & & & \\
\hline & Maximum & & 4.00 & & & \\
\hline & Mean & & 3.6316 & .0937 & 3.4474 & 3.8158 \\
\hline & 95\% Confidence Interval & Lower Bound & 3.4379 & & & \\
\hline Coordenação- Gestão- & for Mean & Upper Bound & 3.8252 & & & \\
\hline Supervisão & Median & & 4.0000 & .0630 & 4.0000 & 4.0000 \\
\hline & Minimum & & 2.00 & & & \\
\hline & Maximum & & 4.00 & & & \\
\hline
\end{tabular}


ANEXO 7 - GESTORES E DEMAIS PROFISSIONAIS: TENDÊNCIAS

\begin{tabular}{|c|c|c|c|c|c|}
\hline \multicolumn{6}{|c|}{$\begin{array}{l}\text { Pergunta } 1 \text { - Aspectos técnicos são tão importantes quantos aspectos sociais no planejamento de obras de } \\
\text { drenagem }\end{array}$} \\
\hline & & \multirow{3}{*}{ discordo } & \multirow{3}{*}{ concordo } & \multirow{3}{*}{ sem } & \multirow{3}{*}{ total } \\
\hline & \multirow[b]{2}{*}{ Atributo } & & & & \\
\hline Variável & & & & & \\
\hline \multirow{10}{*}{ Formação } & Arquitetura & 0 & 20 & 2 & 22 \\
\hline & $\%$ na linha & $0,00 \%$ & $90,91 \%$ & $9,09 \%$ & $100,00 \%$ \\
\hline & Engenharia Civil & 3 & 27 & $\mathbf{0}$ & 30 \\
\hline & \% na linha & $10,00 \%$ & $90,00 \%$ & $0,00 \%$ & $100,00 \%$ \\
\hline & Outros & 0 & 11 & 1 & 12 \\
\hline & $\%$ na linha & $0,00 \%$ & $91,67 \%$ & $8,33 \%$ & $100,00 \%$ \\
\hline & Sociopolítico & 0 & 21 & 0 & 21 \\
\hline & $\%$ na linha & $0 \%$ & $100 \%$ & $0 \%$ & $100 \%$ \\
\hline & Total & 3 & 79 & 3 & 85 \\
\hline & Referência para comparações em \% & $3,53 \%$ & $92,94 \%$ & $3,53 \%$ & $100,00 \%$ \\
\hline \multirow{6}{*}{ Função } & Assessoria - Consultoria - Docência & 2 & 42 & 2 & 46 \\
\hline & $\%$ na linha & $4,35 \%$ & $91,30 \%$ & $4,35 \%$ & $100,00 \%$ \\
\hline & Coordenação - Gestão - Supervisão & 1 & 37 & 1 & 39 \\
\hline & $\%$ na linha & $2,56 \%$ & $94,87 \%$ & $2,56 \%$ & $100,00 \%$ \\
\hline & Total & 3 & 79 & 3 & 85 \\
\hline & Referência para comparações em \% & $3,53 \%$ & $92,94 \%$ & $3,53 \%$ & $100,00 \%$ \\
\hline \multirow{10}{*}{ Idade } & 30a39anos & 1 & 16 & 1 & 18 \\
\hline & $\%$ na linha & $5,56 \%$ & $88,89 \%$ & $5,56 \%$ & $100,00 \%$ \\
\hline & 40a49anos & 0 & 15 & 0 & 15 \\
\hline & $\%$ na linha & $0,00 \%$ & $100,00 \%$ & $0,00 \%$ & $100,00 \%$ \\
\hline & 50a59anos & 2 & 35 & 0 & 37 \\
\hline & \% na linha & $5,41 \%$ & $94,59 \%$ & $0,00 \%$ & $100,00 \%$ \\
\hline & 60anos a mais & 0 & 13 & 2 & 15 \\
\hline & $\%$ na linha & $0,00 \%$ & $86,67 \%$ & $13,33 \%$ & $100,00 \%$ \\
\hline & Total & 3 & 79 & 3 & 85 \\
\hline & Referência para comparações em \% & $3,53 \%$ & $92,94 \%$ & $3,53 \%$ & $100,00 \%$ \\
\hline \multirow{10}{*}{ Nível } & Outro(especifique) & 0 & 4 & 0 & 4 \\
\hline & $\%$ na linha & $0,00 \%$ & $100,00 \%$ & $0,00 \%$ & $100,00 \%$ \\
\hline & Primeiro(mais alto) & 0 & 10 & 0 & 10 \\
\hline & $\%$ na linha & $0,00 \%$ & $100,00 \%$ & $0,00 \%$ & $100,00 \%$ \\
\hline & Quarto & 0 & 7 & 1 & 8 \\
\hline & $\%$ na linha & $0,00 \%$ & $87,50 \%$ & $12,50 \%$ & $100,00 \%$ \\
\hline & Segundo & 1 & 29 & 0 & 30 \\
\hline & $\%$ na linha & $3,33 \%$ & $96,67 \%$ & $0,00 \%$ & $100,00 \%$ \\
\hline & Terceiro & 2 & 29 & 2 & 33 \\
\hline & $\%$ na linha & $6,06 \%$ & $87,88 \%$ & $6,06 \%$ & $100,00 \%$ \\
\hline
\end{tabular}




\begin{tabular}{|c|c|c|c|c|c|}
\hline & Total & 3 & 79 & 3 & 85 \\
\hline & Referência para comparações em \% & $3,53 \%$ & $92,94 \%$ & $3,53 \%$ & $100,00 \%$ \\
\hline \multirow{3}{*}{ Sexo } & Sexo feminino. & & & & \\
\cline { 2 - 6 } & \% na linha & $\mathbf{3}$ & 37 & 1 & 41 \\
\hline \multirow{3}{*}{} & Sexo masculino & $\mathbf{7 , 3 2 \%}$ & $90,24 \%$ & $2,44 \%$ & $100,00 \%$ \\
\hline & \% na linha & $0,00 \%$ & $95,45 \%$ & $4,55 \%$ & $100,00 \%$ \\
\hline & Total & 3 & 79 & 3 & 85 \\
\hline & Referência para comparações em \% & $\mathbf{3 , 5 3 \%}$ & $\mathbf{9 2 , 9 4 \%}$ & $\mathbf{3 , 5 3 \%}$ & $\mathbf{1 0 0 , 0 0 \%}$ \\
\hline
\end{tabular}

A grande maioria dos respondentes concorda em que os aspectos técnicos sejam tão importantes quanto os aspectos sociais no planejamento de obras de drenagem, havendo consenso entre os grupos com relação a esta afirmação. Entretanto, é interessante notar que o grupo que apresenta maior divergência, ainda que em pequena proporção, é o grupo formado por aqueles com formação em Engenharia Civil. Por outro lado, ainda que com diferença mínima, chama atenção o fato de serem os engenheiros civis os únicos que discordam desta afirmação, situando-se o percentual de sua discordância notoriamente acima do percentual de referência para esta resposta Já o grupo com formação relacionada ao sociopolítico, tal como aqui descrito, foram unânimes em aceitar este princípio. Outro dado que chama a atenção relativamente a esta pergunta é o grupo daqueles situados em nível hierárquico de primeiro escalão, onde há unanimidade com relação à concordância à esta afirmação. Estes são seguidos por aqueles que se situação no segundo escalão. Essa concordância representa um ganho considerável para a incorporação de aspectos sociais em políticas e estratégias que afetam o planejamento de obras de drenagem, dada a sua condição de tomada de decisões quanto a estratégias a serem seguidas e mesmo na formulação de políticas públicas. É digno de nota que o percentual de mulheres que discordam dessa afirmação se situa bastante acima do percentual de referência.

\begin{tabular}{|c|c|c|c|c|c|}
\hline \multicolumn{6}{|c|}{ Pergunta 2.1 - O bom planejamento de obras de drenagem exige a participação de Cientistas Sociais } \\
\hline & & \multirow{3}{*}{ discordo } & \multirow{3}{*}{ concordo } & \multirow{3}{*}{$\begin{array}{c}\text { sem } \\
\text { resposta }\end{array}$} & \multirow{3}{*}{ total } \\
\hline & \multirow[b]{2}{*}{ Atributo } & & & & \\
\hline Variável & & & & & \\
\hline \multirow{10}{*}{ Formação } & Arquitetura & 3 & 18 & 1 & 22 \\
\hline & $\%$ na linha & $13,64 \%$ & $81,82 \%$ & $4,55 \%$ & $100,00 \%$ \\
\hline & Engenharia Civil & 11 & 18 & 1 & 30 \\
\hline & $\%$ na linha & $36,67 \%$ & $60,00 \%$ & $3,33 \%$ & $100,00 \%$ \\
\hline & Outros & 2 & 10 & 0 & 12 \\
\hline & $\%$ na linha & $16,67 \%$ & $83,33 \%$ & $0,00 \%$ & $100,00 \%$ \\
\hline & Sociopolítico & 7 & 13 & 1 & 21 \\
\hline & $\%$ na linha & $33,33 \%$ & $61,90 \%$ & $4,76 \%$ & $100,00 \%$ \\
\hline & Total & 23 & 59 & 3 & 85 \\
\hline & Referência para comparações em \% & $27,06 \%$ & $69,41 \%$ & $3,53 \%$ & $100,00 \%$ \\
\hline
\end{tabular}




\begin{tabular}{|c|c|c|c|c|c|}
\hline \multirow{6}{*}{ Função } & Assessoria - Consultoria - Docência & 13 & 31 & 2 & 46 \\
\hline & $\%$ na linha & $28,26 \%$ & $67,39 \%$ & $4,35 \%$ & $100,00 \%$ \\
\hline & Coordenação - Gestão - Supervisão & 10 & 28 & 1 & 39 \\
\hline & $\%$ na linha & $25,64 \%$ & $71,79 \%$ & $2,56 \%$ & $100,00 \%$ \\
\hline & Total & 23 & 59 & 3 & 85 \\
\hline & Referência para comparações em \% & $27,06 \%$ & $69,41 \%$ & $3,53 \%$ & $100,00 \%$ \\
\hline \multirow{10}{*}{ Idade } & 30a39anos & 4 & 14 & 0 & 18 \\
\hline & $\%$ na linha & $22,22 \%$ & $77,78 \%$ & $0,00 \%$ & $100,00 \%$ \\
\hline & 40a49anos & 6 & 9 & 0 & 15 \\
\hline & $\%$ na linha & $40,00 \%$ & $60,00 \%$ & $0,00 \%$ & $100,00 \%$ \\
\hline & 50a59anos & 9 & 27 & 1 & 37 \\
\hline & $\%$ na linha & $24,32 \%$ & $72,97 \%$ & $2,70 \%$ & $100,00 \%$ \\
\hline & 60anos a mais & 4 & 9 & 2 & 15 \\
\hline & $\%$ na linha & $26,67 \%$ & $60,00 \%$ & $13,33 \%$ & $100,00 \%$ \\
\hline & Total & 23 & 59 & 3 & 85 \\
\hline & Referência para comparações em \% & $27,06 \%$ & $69,41 \%$ & $3,53 \%$ & $100,00 \%$ \\
\hline \multirow{12}{*}{ Nível } & Outro(especifique) & 1 & 3 & 0 & 4 \\
\hline & $\%$ na linha & $25,00 \%$ & $75,00 \%$ & $0,00 \%$ & $100,00 \%$ \\
\hline & Primeiro(mais alto) & 2 & 7 & 1 & 10 \\
\hline & $\%$ na linha & $20,00 \%$ & $70,00 \%$ & $10,00 \%$ & $100,00 \%$ \\
\hline & Quarto & 0 & 7 & 1 & 8 \\
\hline & $\%$ na linha & $0,00 \%$ & $87,50 \%$ & $12,50 \%$ & $100,00 \%$ \\
\hline & Segundo & 9 & 20 & 1 & 30 \\
\hline & $\%$ na linha & $30,00 \%$ & $66,67 \%$ & $3,33 \%$ & $100,00 \%$ \\
\hline & Terceiro & 11 & 22 & 0 & 33 \\
\hline & $\%$ na linha & $33,33 \%$ & $66,67 \%$ & $0,00 \%$ & $100,00 \%$ \\
\hline & Total & 23 & 59 & 3 & 85 \\
\hline & Referência para comparações em \% & $27,06 \%$ & $69,41 \%$ & $3,53 \%$ & $100,00 \%$ \\
\hline \multirow{6}{*}{ Sexo } & Sexo feminino. & 4 & 35 & 2 & 41 \\
\hline & \% na linha & $9,76 \%$ & $85,37 \%$ & $4,88 \%$ & $100,00 \%$ \\
\hline & Sexo masculino & 19 & 24 & 1 & 44 \\
\hline & \% na linha & $43,18 \%$ & $54,55 \%$ & $2,27 \%$ & $100,00 \%$ \\
\hline & Total & 23 & 59 & 3 & 85 \\
\hline & Referência para comparações em \% & $27,06 \%$ & $69,41 \%$ & $3,53 \%$ & $100,00 \%$ \\
\hline
\end{tabular}

Para esta resposta, chama atenção o fato daqueles que formam o 'sociopolítico' apresentarem percentual de discordância quanto a esta afirmação bastante acima da referência Esse dado é interessante, pois este grupo é composto por Cientistas Sociais e demais profissionais com formação voltada para o social, tal como indicado na Tabela 1. Assim também se encontra o grupo formado por engenheiros civis: seu nível de discordância com esta afirmação é o mais elevado. Já os arquitetos acolhem esta 
afirmação, ou seja, aceitam como importante a participação de cientistas sociais no planejamento de obras de drenagem. O grupo formado por 'outros', composto por aqueles com formação em Engenharia Elétrica, Química, Mecânica, Agrimensura e cartografia, Engenharia Ambiental, Geografia e Geologia é o grupo com maior concordância quanto a esta questão. Por tratar-se de grupo heterogêneo, não se pode chegar a qualquer interpretação.

Ainda que quase $70 \%$ dos indivíduos que compõem a amostra concordem com a importância desta afirmação, existem diferenças de opinião entre os grupos, sobretudo daqueles que compõe o grupo de formação 'sociopolítica', os mais velhos, e os homens. E a maior diferença se apresenta entre homens e mulheres, onde os homens têm uma rejeição bastante notória com relação à participação de cientistas sociais no planejamento de obras de drenagem. Essa rejeição se nota pelo percentual de discordância muito acima do percentual de referência. O teste do 'chi-quadrado' mostrou uma associação entre a variável sexo e esta pergunta.

\begin{tabular}{|c|c|c|c|c|c|}
\hline \multicolumn{6}{|c|}{$\begin{array}{l}\text { Pergunta } 2.2 \text { - } 0 \text { bom planejamento de obras de drenagem exige a participação de comerciantes instalados } \\
\text { na área }\end{array}$} \\
\hline & & \multirow{3}{*}{ Discordo } & \multirow{3}{*}{ concordo } & \multirow{3}{*}{$\begin{array}{c}\text { sem } \\
\text { resposta }\end{array}$} & \multirow{3}{*}{ total } \\
\hline & \multirow[b]{2}{*}{ Atributo } & & & & \\
\hline Variável & & & & & \\
\hline \multirow{10}{*}{ Formação } & Arquitetura & 4 & 18 & 0 & 22 \\
\hline & $\%$ na linha & $18,18 \%$ & $81,82 \%$ & $0,00 \%$ & $100,00 \%$ \\
\hline & Engenharia Civil & 7 & 23 & 0 & 30 \\
\hline & $\%$ na linha & $23,33 \%$ & $76,67 \%$ & $0,00 \%$ & $100,00 \%$ \\
\hline & Outros & 2 & 10 & 0 & 12 \\
\hline & $\%$ na linha & $16,67 \%$ & $83,33 \%$ & $0,00 \%$ & $100,00 \%$ \\
\hline & Sociopolítico & 4 & 16 & 1 & 21 \\
\hline & $\%$ na linha & $19,05 \%$ & $76,19 \%$ & $4,76 \%$ & $100,00 \%$ \\
\hline & Total & 17 & 67 & 1 & 85 \\
\hline & Referência para comparações em \% & $20,00 \%$ & $78,82 \%$ & $1,18 \%$ & $100,00 \%$ \\
\hline \multirow{6}{*}{ Função } & Assessoria - Consultoria - Docência & 9 & 37 & 0 & 46 \\
\hline & $\%$ na linha & $19,57 \%$ & $80,43 \%$ & $0,00 \%$ & $100,00 \%$ \\
\hline & Coordenação - Gestão - Supervisão & 8 & 30 & 1 & 39 \\
\hline & $\%$ na linha & $20,51 \%$ & $76,92 \%$ & $2,56 \%$ & $100,00 \%$ \\
\hline & Total & 17 & 67 & 1 & 85 \\
\hline & Referência para comparações em \% & $20,00 \%$ & $78,82 \%$ & $1,18 \%$ & $100,00 \%$ \\
\hline \multirow{7}{*}{ Idade } & 30a39anos & 3 & 15 & 0 & 18 \\
\hline & $\%$ na linha & $16,67 \%$ & $83,33 \%$ & $0,00 \%$ & $100,00 \%$ \\
\hline & 40a49anos & 5 & 9 & 1 & 15 \\
\hline & $\%$ na linha & $33,33 \%$ & $60,00 \%$ & $6,67 \%$ & $100,00 \%$ \\
\hline & 50a59anos & 5 & 32 & 0 & 37 \\
\hline & $\%$ na linha & $13,51 \%$ & $86,49 \%$ & $0,00 \%$ & $100,00 \%$ \\
\hline & 60anos a mais & 4 & 11 & 0 & 15 \\
\hline
\end{tabular}




\begin{tabular}{|c|c|c|c|c|c|}
\hline & $\%$ na linha & $26,67 \%$ & $73,33 \%$ & $0,00 \%$ & $100,00 \%$ \\
\hline & Total & 17 & 67 & 1 & 85 \\
\hline & Referência para comparações em \% & $20,00 \%$ & $78,82 \%$ & $1,18 \%$ & $100,00 \%$ \\
\hline \multirow{12}{*}{ Nível } & Outro(especifique) & 1 & 3 & 0 & 4 \\
\hline & $\%$ na linha & $25,00 \%$ & $75,00 \%$ & $0,00 \%$ & $100,00 \%$ \\
\hline & Primeiro(mais alto) & 2 & 8 & 0 & 10 \\
\hline & $\%$ na linha & $20,00 \%$ & $80,00 \%$ & $0,00 \%$ & $100,00 \%$ \\
\hline & Quarto & 0 & 8 & 0 & 8 \\
\hline & $\%$ na linha & $0,00 \%$ & $100,00 \%$ & $0,00 \%$ & $100,00 \%$ \\
\hline & Segundo & 4 & 26 & 0 & 30 \\
\hline & $\%$ na linha & $13,33 \%$ & $86,67 \%$ & $0,00 \%$ & $100,00 \%$ \\
\hline & Terceiro & 10 & 22 & 1 & 33 \\
\hline & $\%$ na linha & $30,30 \%$ & $66,67 \%$ & $3,03 \%$ & $100,00 \%$ \\
\hline & Total & 17 & 67 & 1 & 85 \\
\hline & Referência para comparações em \% & $20,00 \%$ & $78,82 \%$ & $1,18 \%$ & $100,00 \%$ \\
\hline \multirow{6}{*}{ Sexo } & Sexo feminino. & 6 & 35 & 0 & 41 \\
\hline & \% na linha & $14,63 \%$ & $85,37 \%$ & $0,00 \%$ & $100,00 \%$ \\
\hline & Sexo masculino & 11 & 32 & 1 & 44 \\
\hline & $\%$ na linha & $25,00 \%$ & $72,73 \%$ & $2,27 \%$ & $100,00 \%$ \\
\hline & Total & 17 & 67 & 1 & 85 \\
\hline & Referência para comparações em \% & $20,00 \%$ & $78,82 \%$ & $1,18 \%$ & $100,00 \%$ \\
\hline
\end{tabular}

Nota-se que não há diferenças significativas entre a opinião dos grupos com relação à esta pergunta. É interessante notar que, ao comparar as respostas a esta pergunta com as respostas à pergunta anterior, vê-se que, em geral (quase 80\%), os grupos de respondentes concordam em maior grau com a participação de comerciantes instalados na área do que com a participação de cientistas sociais no planejamento de obras de drenagem por parte Esse dado é significativo, pois revela a aceitação da participação daqueles atores sociais presentes na região, acreditando que conhecem melhor a situação concreta do lugar.

\begin{tabular}{|c|c|c|c|c|c|}
\hline \multicolumn{6}{|c|}{ Pergunta 2.3: O bom planejamento de obras de drenagem exige a participação de Comitês de Bacia } \\
\hline & & \multirow[b]{2}{*}{ discordo } & \multirow[b]{2}{*}{ concordo } & \multirow{2}{*}{ sem } & \multirow[b]{2}{*}{ total } \\
\hline & \multirow[b]{2}{*}{ Atributo } & & & & \\
\hline Variável & & & & & \\
\hline \multirow{8}{*}{ Formação } & Arquitetura & 0 & 21 & 1 & 22 \\
\hline & $\%$ na linha & $0,00 \%$ & $95,45 \%$ & $4,55 \%$ & $100,00 \%$ \\
\hline & Engenharia Civil & 1 & 29 & 0 & 30 \\
\hline & $\%$ na linha & $3,33 \%$ & $96,67 \%$ & $0,00 \%$ & $100,00 \%$ \\
\hline & Outros & 0 & 12 & 0 & 12 \\
\hline & $\%$ na linha & $0,00 \%$ & $100,00 \%$ & $0,00 \%$ & $100,00 \%$ \\
\hline & Sociopolítico & 0 & 18 & 3 & 21 \\
\hline & $\%$ na linha & $0,00 \%$ & $85,71 \%$ & $14,29 \%$ & $100,00 \%$ \\
\hline
\end{tabular}




\begin{tabular}{|c|c|c|c|c|c|}
\hline & Total & 1 & 80 & 4 & 85 \\
\hline & Referência para comparações em \% & $1,18 \%$ & $94,12 \%$ & $4,71 \%$ & $100,00 \%$ \\
\hline \multirow{6}{*}{ Função } & Assessoria - Consultoria - Docência & 0 & 44 & 2 & 46 \\
\hline & $\%$ na linha & $0,00 \%$ & $95,65 \%$ & $4,35 \%$ & $100,00 \%$ \\
\hline & Coordenação - Gestão - Supervisão & 1 & 36 & 2 & 39 \\
\hline & $\%$ na linha & $2,56 \%$ & $92,31 \%$ & $5,13 \%$ & $100,00 \%$ \\
\hline & Total & 1 & 80 & 4 & 85 \\
\hline & Referência para comparações em \% & $1,18 \%$ & $94,12 \%$ & $4,71 \%$ & $100,00 \%$ \\
\hline \multirow{10}{*}{ Idade } & 30a39anos & 0 & 18 & 0 & 18 \\
\hline & $\%$ na linha & $0,00 \%$ & $100,00 \%$ & $0,00 \%$ & $100,00 \%$ \\
\hline & 40a49anos & 0 & 13 & 2 & 15 \\
\hline & $\%$ na linha & $0,00 \%$ & $86,67 \%$ & $13,33 \%$ & $100,00 \%$ \\
\hline & 50a59anos & 0 & 36 & 1 & 37 \\
\hline & $\%$ na linha & $0,00 \%$ & $97,30 \%$ & $2,70 \%$ & $100,00 \%$ \\
\hline & 60anos a mais & 1 & 13 & 1 & 15 \\
\hline & \% na linha & $6,67 \%$ & $86,67 \%$ & $6,67 \%$ & $100,00 \%$ \\
\hline & Total & 1 & 80 & 4 & 85 \\
\hline & Referência para comparações em \% & $1,18 \%$ & $94,12 \%$ & $4,71 \%$ & $100,00 \%$ \\
\hline \multirow{12}{*}{ Nível } & Outro(especifique) & 0 & 4 & 0 & 4 \\
\hline & $\%$ na linha & $0,00 \%$ & $100,00 \%$ & $0,00 \%$ & $100,00 \%$ \\
\hline & Primeiro(mais alto) & 0 & 10 & 0 & 10 \\
\hline & $\%$ na linha & $0,00 \%$ & $100,00 \%$ & $0,00 \%$ & $100,00 \%$ \\
\hline & Quarto & 0 & 7 & 1 & 8 \\
\hline & $\%$ na linha & $0,00 \%$ & $87,50 \%$ & $12,50 \%$ & $100,00 \%$ \\
\hline & Segundo & 1 & 27 & 2 & 30 \\
\hline & $\%$ na linha & $3,33 \%$ & $90,00 \%$ & $6,67 \%$ & $100,00 \%$ \\
\hline & Terceiro & 0 & 32 & 1 & 33 \\
\hline & $\%$ na linha & $0,00 \%$ & $96,97 \%$ & $3,03 \%$ & $100,00 \%$ \\
\hline & Total & 1 & 80 & 4 & 85 \\
\hline & Referência para comparações em \% & $1,18 \%$ & $94,12 \%$ & $4,71 \%$ & $100,00 \%$ \\
\hline \multirow{6}{*}{ Sexo } & Sexo feminino. & 0 & 38 & 3 & 41 \\
\hline & $\%$ na linha & $0,00 \%$ & $92,68 \%$ & $7,32 \%$ & $100,00 \%$ \\
\hline & Sexo masculino & 1 & 42 & 1 & 44 \\
\hline & $\%$ na linha & $2,27 \%$ & $95,45 \%$ & $2,27 \%$ & $100,00 \%$ \\
\hline & Total & 1 & 80 & 4 & 85 \\
\hline & Referência para comparações em \% & $1,18 \%$ & $94,12 \%$ & $4,71 \%$ & $100,00 \%$ \\
\hline
\end{tabular}

Novamente vê-se o consenso entre os grupos quanto à essa questão. A única maior divergência é o fato dos mais velhos situarem sua discordância bastante acima do percentual de referência do que os demais grupos. 


\begin{tabular}{|c|c|c|c|c|c|}
\hline \multicolumn{6}{|c|}{ Pergunta 2.4 - O bom planejamento de obras de drenagem exige a participação de Comunicadores Sociais. } \\
\hline & & \multirow{3}{*}{ discordo } & \multirow{3}{*}{ concordo } & \multirow{3}{*}{$\begin{array}{c}\text { sem } \\
\text { resposta }\end{array}$} & \multirow{3}{*}{ total } \\
\hline & \multirow[b]{2}{*}{ Atributo } & & & & \\
\hline Variável & & & & & \\
\hline \multirow{10}{*}{ Formação } & Arquitetura & 1 & 20 & 1 & 22 \\
\hline & $\%$ na linha & $4,55 \%$ & $90,91 \%$ & $4,55 \%$ & $100,00 \%$ \\
\hline & Engenharia Civil & 6 & 23 & 1 & 30 \\
\hline & \% na linha & $20,00 \%$ & $76,67 \%$ & $3,33 \%$ & $100,00 \%$ \\
\hline & Outros & 1 & 11 & 0 & 12 \\
\hline & $\%$ na linha & $8,33 \%$ & $91,67 \%$ & $0,00 \%$ & $100,00 \%$ \\
\hline & Sociopolítico & 1 & 20 & 0 & 21 \\
\hline & $\%$ na linha & $4,76 \%$ & $95,24 \%$ & $0,00 \%$ & $100,00 \%$ \\
\hline & Total & 9 & 74 & 2 & 85 \\
\hline & Referência para comparações em \% & $10,59 \%$ & $87,06 \%$ & $2,35 \%$ & $100,00 \%$ \\
\hline \multirow{6}{*}{ Função } & Assessoria - Consultoria - Docência & 7 & 37 & 2 & 46 \\
\hline & $\%$ na linha & $15,22 \%$ & $80,43 \%$ & $4,35 \%$ & $100,00 \%$ \\
\hline & Coordenação - Gestão - Supervisão & 2 & 37 & 0 & 39 \\
\hline & $\%$ na linha & $5,13 \%$ & $94,87 \%$ & $0,00 \%$ & $100,00 \%$ \\
\hline & Total & 9 & 74 & 2 & 85 \\
\hline & Referência para comparações em \% & $10,59 \%$ & $87,06 \%$ & $2,35 \%$ & $100,00 \%$ \\
\hline \multirow{10}{*}{ Idade } & 30a39anos & 1 & 17 & 0 & 18 \\
\hline & $\%$ na linha & $5,56 \%$ & $94,44 \%$ & $0,00 \%$ & $100,00 \%$ \\
\hline & 40a49anos & 2 & 13 & 0 & 15 \\
\hline & $\%$ na linha & $13,33 \%$ & $86,67 \%$ & $0,00 \%$ & $100,00 \%$ \\
\hline & 50a59anos & 5 & 32 & 0 & 37 \\
\hline & $\%$ na linha & $13,51 \%$ & $86,49 \%$ & $0,00 \%$ & $100,00 \%$ \\
\hline & 60anos a mais & 1 & 9 & 2 & 15 \\
\hline & $\%$ na linha & $6,67 \%$ & $60,00 \%$ & $13,33 \%$ & $100,00 \%$ \\
\hline & Total & 9 & 74 & 2 & 85 \\
\hline & Referência para comparações em \% & $10,59 \%$ & $87,06 \%$ & $2,35 \%$ & $100,00 \%$ \\
\hline \multirow{12}{*}{ Nível } & Outro(especifique) & 0 & 4 & 0 & 4 \\
\hline & $\%$ na linha & $0,00 \%$ & $100,00 \%$ & $0,00 \%$ & $100,00 \%$ \\
\hline & Primeiro(mais alto) & 1 & 8 & 1 & 10 \\
\hline & $\%$ na linha & $10,00 \%$ & $80,00 \%$ & $10,00 \%$ & $100,00 \%$ \\
\hline & Quarto & 0 & 8 & 0 & 8 \\
\hline & $\%$ na linha & $0,00 \%$ & $100,00 \%$ & $0,00 \%$ & $100,00 \%$ \\
\hline & Segundo & 1 & 28 & 1 & 30 \\
\hline & $\%$ na linha & $3,33 \%$ & $93,33 \%$ & $3,33 \%$ & $100,00 \%$ \\
\hline & Terceiro & 7 & 26 & 0 & 33 \\
\hline & $\%$ na linha & $21 \%$ & $79 \%$ & $0 \%$ & $100 \%$ \\
\hline & Total & 9 & 74 & 2 & 85 \\
\hline & Referência para comparações em \% & $10,59 \%$ & $87,06 \%$ & $2,35 \%$ & $100,00 \%$ \\
\hline
\end{tabular}




\begin{tabular}{|c|c|c|c|c|c|}
\hline \multirow{3}{*}{ Sexo } & Sexo feminino & & & \\
\cline { 2 - 6 } & \% na linha & 3 & 37 & 1 & 41 \\
\cline { 2 - 6 } & Sexo masculino & $7,32 \%$ & $90,24 \%$ & $2,44 \%$ & $100,00 \%$ \\
\hline & \% na linha & $13,64 \%$ & $84,09 \%$ & $2,27 \%$ & $100,00 \%$ \\
\hline & Total & 9 & 74 & 2 & 85 \\
\hline & Referência para comparações em \% & $\mathbf{1 0 , 5 9 \%}$ & $\mathbf{8 7 , 0 6 \%}$ & $\mathbf{2 , 3 5 \%}$ & $\mathbf{1 0 0 , 0 0 \%}$ \\
\hline
\end{tabular}

Os engenheiros civis são os que mais discordam sobre a participação de comunicadores sociais no planejamento das obras de drenagem em porcentagem bem acima da referência. Em consequiência, seu nível de concordância com esta participação é o mais baixo frente à referência. Com relação ao nível hierárquico, nota-se que os que situam no quarto escalão se destacam por estar mais acima da referência que os demais grupos, exceção feita aos consultores autônomos que compõem o grupo de nível hierárquico 'outros'. Entende-se por quarto escalão talvez aqueles que, em uma organização estejam mais próximos do trabalho de comunicadores sociais e compreendem seu papel. Também mulheres, mais do que homens, ainda que em pequena diferença, concordam com a importância da participação de comunicadores sociais no planejamento de obras. Será por serem 'comunicadores sociais' em sua maioria mulheres? Em termos de função, os respondentes em cargo de coordenação, gestão e supervisão também concordam com a participação de comunicadores sociais. Uma explicação pode ser a necessidade que veem do bom andamento de projetos que coordenam, gerem e supervisionam, necessitando a interface com a comunidade via os comunicadores sociais. São interpretações da pesquisadora.

\begin{tabular}{|c|c|c|c|c|c|}
\hline \multicolumn{6}{|c|}{ Pergunta 2.5 - 0 bom planejamento de obras de drenagem exige a participação de Lideranças Comunitárias } \\
\hline & & \multirow[b]{2}{*}{ discordo } & \multirow[b]{2}{*}{ concordo } & \multirow{2}{*}{$\begin{array}{c}\text { sem } \\
\text { resposta }\end{array}$} & \multirow[b]{2}{*}{ total } \\
\hline & \multirow[b]{2}{*}{ Atributo } & & & & \\
\hline Variável & & & & & \\
\hline \multirow{10}{*}{ Formação } & Arquitetura & 0 & 22 & 0 & 22 \\
\hline & $\%$ na linha & $0,00 \%$ & $100,00 \%$ & $0,00 \%$ & $100,00 \%$ \\
\hline & Engenharia Civil & 4 & 25 & 1 & 30 \\
\hline & \% na linha & $13,33 \%$ & $83,33 \%$ & $3,33 \%$ & $100,00 \%$ \\
\hline & Outros & 0 & 12 & 0 & 12 \\
\hline & $\%$ na linha & $0,00 \%$ & $100,00 \%$ & $0,00 \%$ & $100,00 \%$ \\
\hline & Sociopolítico & 2 & 18 & 1 & 21 \\
\hline & \% na linha & $9,52 \%$ & $85,71 \%$ & $4,76 \%$ & $100,00 \%$ \\
\hline & Total & 6 & 77 & 2 & 85 \\
\hline & Referência para comparações em \% & $7,06 \%$ & $90,59 \%$ & $2,35 \%$ & $100,00 \%$ \\
\hline \multirow{4}{*}{ Função } & Assessoria - Consultoria - Docência & 3 & 42 & 1 & 46 \\
\hline & $\%$ na linha & $6,52 \%$ & $91,30 \%$ & $2,17 \%$ & $100,00 \%$ \\
\hline & Coordenação - Gestão - Supervisão & 3 & 35 & 1 & 39 \\
\hline & $\%$ na linha & $7,69 \%$ & $89,74 \%$ & $2,56 \%$ & $100,00 \%$ \\
\hline
\end{tabular}




\begin{tabular}{|c|c|c|c|c|c|}
\hline & Total & 6 & 77 & 2 & 85 \\
\hline & Referência para comparações em \% & $7,06 \%$ & $90,59 \%$ & $2,35 \%$ & $100,00 \%$ \\
\hline \multirow{10}{*}{ Idade } & 30a39anos & 0 & 18 & 0 & 18 \\
\hline & $\%$ na linha & $0,00 \%$ & $100,00 \%$ & $0,00 \%$ & $100,00 \%$ \\
\hline & 40a49anos & 1 & 13 & 1 & 15 \\
\hline & $\%$ na linha & $6,67 \%$ & $86,67 \%$ & $6,67 \%$ & $100,00 \%$ \\
\hline & 50a59anos & 4 & 33 & 0 & 37 \\
\hline & $\%$ na linha & $10,81 \%$ & $89,19 \%$ & $0,00 \%$ & $100,00 \%$ \\
\hline & 60anos a mais & 1 & 13 & 1 & 15 \\
\hline & $\%$ na linha & $4,55 \%$ & $59,09 \%$ & $4,55 \%$ & $68,18 \%$ \\
\hline & Total & 6 & 77 & 2 & 85 \\
\hline & Referência para comparações em \% & $7,06 \%$ & $90,59 \%$ & $2,35 \%$ & $100,00 \%$ \\
\hline \multirow{12}{*}{ Nível } & Outro(especifique) & 1 & 3 & 0 & 4 \\
\hline & $\%$ na linha & $25,00 \%$ & $75,00 \%$ & $0,00 \%$ & $100,00 \%$ \\
\hline & Primeiro(mais alto) & 0 & 9 & 1 & 10 \\
\hline & $\%$ na linha & $0,00 \%$ & $90,00 \%$ & $10,00 \%$ & $100,00 \%$ \\
\hline & Quarto & 0 & 8 & 0 & 8 \\
\hline & $\%$ na linha & $0,00 \%$ & $100,00 \%$ & $0,00 \%$ & $100,00 \%$ \\
\hline & Segundo & 2 & 28 & 0 & 30 \\
\hline & $\%$ na linha & $6,67 \%$ & $93,33 \%$ & $0,00 \%$ & $100,00 \%$ \\
\hline & Terceiro & 3 & 29 & 1 & 33 \\
\hline & $\%$ na linha & $9,09 \%$ & $87,88 \%$ & $3,03 \%$ & $100,00 \%$ \\
\hline & Total & 6 & 77 & 2 & 85 \\
\hline & Referência para comparações em \% & $7,06 \%$ & $90,59 \%$ & $2,35 \%$ & $100,00 \%$ \\
\hline \multirow{6}{*}{ Sexo } & Sexo feminino. & 2 & 39 & 0 & 41 \\
\hline & $\%$ na linha & $4,88 \%$ & $95,12 \%$ & $0,00 \%$ & $100,00 \%$ \\
\hline & Sexo masculino & 4 & 38 & 2 & 44 \\
\hline & $\%$ na linha & $9,09 \%$ & $86,36 \%$ & $4,55 \%$ & $100,00 \%$ \\
\hline & Total & 6 & 77 & 2 & 85 \\
\hline & Referência para comparações em \% & $7,06 \%$ & $90,59 \%$ & $2,35 \%$ & $100,00 \%$ \\
\hline
\end{tabular}

Há relativo consenso com relação à concordância frente a esta afirmação. No cômputo geral, o nível de discordância é baixo. O grupo de formação em Engenharia Civil é o que menos concorda com a participação de lideranças comunitárias no planejamento das obras, estando acima da referência quanto a esta discordância, seguido do grupo de formação 'sociopolítica'. A consonância entre esses grupos pode ser fruto da rejeição à participação de lideranças comunitárias em projetos por estarem, muitas vezes, atreladas à política partidaria, prejudicando a transparência das observações feitas e de sua participação. 
Pergunta 2.6- 0 bom planejamento de obras de drenagem exige a participação de Educadores Ambientais

\begin{tabular}{|c|c|c|c|c|c|}
\hline \multirow[b]{2}{*}{ Variável } & \multirow[b]{2}{*}{ Atributo } & \multirow[t]{2}{*}{ discordo } & concordo & $\begin{array}{c}\text { sem } \\
\text { resposta }\end{array}$ & total \\
\hline & & & & & \\
\hline \multirow{10}{*}{ Formação } & Arquitetura & 2 & 20 & 0 & 22 \\
\hline & $\%$ na linha & $9,09 \%$ & $90,91 \%$ & $0,00 \%$ & $100,00 \%$ \\
\hline & Engenharia Civil & 3 & 26 & 1 & 30 \\
\hline & $\%$ na linha & $10,00 \%$ & $86,67 \%$ & $3,33 \%$ & $100,00 \%$ \\
\hline & Outros & 1 & 11 & 0 & 12 \\
\hline & $\%$ na linha & $8,33 \%$ & $91,67 \%$ & $0,00 \%$ & $100,00 \%$ \\
\hline & Sociopolítico & 2 & 17 & 2 & 21 \\
\hline & $\%$ na linha & $9,52 \%$ & $80,95 \%$ & $9,52 \%$ & $100,00 \%$ \\
\hline & Total & 8 & 74 & 3 & 85 \\
\hline & Referência para comparações em \% & $9,41 \%$ & $87,06 \%$ & $3,53 \%$ & $100,00 \%$ \\
\hline \multirow{6}{*}{ Função } & Assessoria - Consultoria - Docência & 6 & 39 & 1 & 46 \\
\hline & $\%$ na linha & $13,04 \%$ & $84,78 \%$ & $2,17 \%$ & $100,00 \%$ \\
\hline & Coordenação - Gestão - Supervisão & 2 & 35 & 2 & 39 \\
\hline & $\%$ na linha & $5,13 \%$ & $89,74 \%$ & $5,13 \%$ & $100,00 \%$ \\
\hline & Total & 8 & 74 & 3 & 85 \\
\hline & Referência para comparações em \% & $9,41 \%$ & $87,06 \%$ & $3,53 \%$ & $100,00 \%$ \\
\hline \multirow{10}{*}{ Idade } & 30a39anos & 0 & 18 & 0 & 18 \\
\hline & $\%$ na linha & $0,00 \%$ & $100,00 \%$ & $0,00 \%$ & $100,00 \%$ \\
\hline & 40a49anos & 2 & 12 & 1 & 15 \\
\hline & $\%$ na linha & $13,33 \%$ & $80,00 \%$ & $6,67 \%$ & $100,00 \%$ \\
\hline & 50a59anos & 5 & 31 & 1 & 37 \\
\hline & $\%$ na linha & $13,51 \%$ & $83,78 \%$ & $2,70 \%$ & $100,00 \%$ \\
\hline & 60anos a mais & 1 & 13 & 1 & 15 \\
\hline & $\%$ na linha & $6,67 \%$ & $86,67 \%$ & $6,67 \%$ & $100,00 \%$ \\
\hline & Total & 8 & 74 & 3 & 85 \\
\hline & Referência para comparações em \% & $9,41 \%$ & $87,06 \%$ & $3,53 \%$ & $100,00 \%$ \\
\hline \multirow{12}{*}{ Nível } & Outro(especifique) & 0 & 4 & 0 & 4 \\
\hline & $\%$ na linha & $0,00 \%$ & $100,00 \%$ & $0,00 \%$ & $100,00 \%$ \\
\hline & Primeiro(mais alto) & 0 & 9 & 1 & 10 \\
\hline & $\%$ na linha & $0,00 \%$ & $90,00 \%$ & $10,00 \%$ & $100,00 \%$ \\
\hline & Quarto & 0 & 7 & 1 & 8 \\
\hline & $\%$ na linha & $0,00 \%$ & $87,50 \%$ & $12,50 \%$ & $100,00 \%$ \\
\hline & Segundo & 3 & 27 & 0 & 30 \\
\hline & $\%$ na linha & $10,00 \%$ & $90,00 \%$ & $0,00 \%$ & $100,00 \%$ \\
\hline & Terceiro & 5 & 27 & 1 & 33 \\
\hline & $\%$ na linha & $15,15 \%$ & $81,82 \%$ & $3,03 \%$ & $100,00 \%$ \\
\hline & Total & 8 & 74 & 3 & 85 \\
\hline & Referência para comparações em \% & $9,41 \%$ & $87,06 \%$ & $3,53 \%$ & $100,00 \%$ \\
\hline Sexo & Sexo feminino. & 2 & 38 & 1 & 41 \\
\hline
\end{tabular}




\begin{tabular}{ccccc} 
\% na linha & $\mathbf{4 , 8 8 \%}$ & $\mathbf{9 2 , 6 8 \%}$ & $2,44 \%$ & \multicolumn{1}{c}{$100,00 \%$} \\
Sexo masculino & 6 & 36 & 2 & 44 \\
\% na linha & $13,64 \%$ & $81,82 \%$ & $4,55 \%$ & $100,00 \%$ \\
\hline Total & 8 & 74 & 3 & 85 \\
Referência para comparações em \% & $\mathbf{9 , 4 1 \%}$ & $\mathbf{8 7 , 0 6 \%}$ & $\mathbf{3 , 5 3 \%}$ & $\mathbf{1 0 0 , 0 0 \%}$ \\
\hline
\end{tabular}

Tal como frente à participação de comunicadores sociais, são as mulheres e os mais jovens que apresentam maior percentual de concordância com a participação de educadores ambientais. Quanto à variável 'sexo', esta pergunta revela maior diferença entre homens e mulheres. Também a função é variável que apresenta diferenças entre a opinião de Assessores - Consultores -Docência e a opinião de Coordenação - Gestão Supervisão, estes concordando mais com a participação de educadores ambientais do que aqueles, tal como em relação à participação de comunicadores sociais. Os grupos de ‘formação' não apresentam discrepâncias marcantes com relação à referência.

Pergunta 2.7- 0 bom planejamento de obras de drenagem exige a participação de Coordenadores de Projeto e Engenheiros

\begin{tabular}{|c|c|c|c|c|c|}
\hline \multirow[b]{2}{*}{ Variável } & \multirow[b]{2}{*}{ Atributo } & \multirow[t]{2}{*}{ discordo } & concordo & $\begin{array}{c}\text { sem } \\
\text { resposta }\end{array}$ & total \\
\hline & & & & & \\
\hline \multirow{10}{*}{ Formação } & Arquitetura & 0 & 22 & 0 & 22 \\
\hline & $\%$ na linha & $0,00 \%$ & $100,00 \%$ & $0,00 \%$ & $100,00 \%$ \\
\hline & Engenharia Civil & 0 & 30 & 0 & 30 \\
\hline & $\%$ na linha & $0 \%$ & $100 \%$ & $0 \%$ & $100 \%$ \\
\hline & Outros & 0 & 12 & 0 & 12 \\
\hline & $\%$ na linha & $0,00 \%$ & $100,00 \%$ & $0,00 \%$ & $100,00 \%$ \\
\hline & Sociopolítico & 0 & 20 & 1 & 21 \\
\hline & $\%$ na linha & $0,00 \%$ & $95,24 \%$ & $4,76 \%$ & $100,00 \%$ \\
\hline & Total & 0 & 84 & 1 & 85 \\
\hline & Referência para comparações em \% & $0,00 \%$ & $98,82 \%$ & $1,18 \%$ & $100,00 \%$ \\
\hline \multirow{6}{*}{ Função } & Assessoria - Consultoria - Docência & 0 & 46 & 0 & 46 \\
\hline & $\%$ na linha & $0,00 \%$ & $100,00 \%$ & $0,00 \%$ & $100,00 \%$ \\
\hline & Coordenação - Gestão - Supervisão & 0 & 38 & 1 & 39 \\
\hline & $\%$ na linha & $0,00 \%$ & $97,44 \%$ & $2,56 \%$ & $100,00 \%$ \\
\hline & Total & 0 & 84 & 1 & 85 \\
\hline & Referência para comparações em \% & $0,00 \%$ & $98,82 \%$ & $1,18 \%$ & $100,00 \%$ \\
\hline \multirow{7}{*}{ Idade } & 30a39anos & 0 & 18 & 0 & 18 \\
\hline & $\%$ na linha & $0,00 \%$ & $100,00 \%$ & $0,00 \%$ & $100,00 \%$ \\
\hline & 40a49anos & 0 & 14 & 1 & 15 \\
\hline & $\%$ na linha & $0,00 \%$ & $93,33 \%$ & $6,67 \%$ & $100,00 \%$ \\
\hline & 50a59anos & 0 & 37 & 0 & 37 \\
\hline & $\%$ na linha & $0,00 \%$ & $100,00 \%$ & $0,00 \%$ & $100,00 \%$ \\
\hline & 60anos a mais & 0 & 15 & 0 & 15 \\
\hline
\end{tabular}




\begin{tabular}{|c|c|c|c|c|c|}
\hline & $\%$ na linha & $0,00 \%$ & $100,00 \%$ & $0,00 \%$ & $100,00 \%$ \\
\hline & Total & 0 & 84 & 1 & 85 \\
\hline & Referência para comparações em \% & $0,00 \%$ & $98,82 \%$ & $1,18 \%$ & $100,00 \%$ \\
\hline \multirow{12}{*}{ Nível } & Outro(especifique) & 0 & 4 & 0 & 4 \\
\hline & $\%$ na linha & $0,00 \%$ & $100,00 \%$ & $0,00 \%$ & $100,00 \%$ \\
\hline & Primeiro(mais alto) & 0 & 10 & 0 & 10 \\
\hline & $\%$ na linha & $0,00 \%$ & $100,00 \%$ & $0,00 \%$ & $100,00 \%$ \\
\hline & Quarto & 0 & 8 & 0 & 8 \\
\hline & $\%$ na linha & $0,00 \%$ & $100,00 \%$ & $0,00 \%$ & $100,00 \%$ \\
\hline & Segundo & 0 & 30 & 0 & 30 \\
\hline & $\%$ na linha & $0,00 \%$ & $100,00 \%$ & $0,00 \%$ & $100,00 \%$ \\
\hline & Terceiro & 0 & 32 & 1 & 33 \\
\hline & $\%$ na linha & $0,00 \%$ & $96,97 \%$ & $3,03 \%$ & $100,00 \%$ \\
\hline & Total & 0 & 84 & 1 & 85 \\
\hline & Referência para comparações em \% & $0,00 \%$ & $98,82 \%$ & $1,18 \%$ & $100,00 \%$ \\
\hline \multirow{6}{*}{ Sexo } & Sexo feminino. & 0 & 41 & 0 & 41 \\
\hline & \% na linha & $0,00 \%$ & $100,00 \%$ & $0,00 \%$ & $100,00 \%$ \\
\hline & Sexo masculino & 0 & 43 & 1 & 44 \\
\hline & \% na linha & $0,00 \%$ & $97,73 \%$ & $2,27 \%$ & $100,00 \%$ \\
\hline & Total & 0 & 84 & 1 & 85 \\
\hline & Referência para comparações em \% & $0,00 \%$ & $98,82 \%$ & $1,18 \%$ & $100,00 \%$ \\
\hline
\end{tabular}

Não há diferenças entre as respostas dadas a esta pergunta já que há um notável consenso com seus termos. Apenas deixaram de ser respondidas perguntas por algum respondente, mas o consenso é geral.

\begin{tabular}{|c|c|c|c|c|c|}
\hline \multirow[b]{2}{*}{ Variável } & \multirow[b]{2}{*}{ Atributo } & \multirow[t]{2}{*}{ discordo } & \multirow[t]{2}{*}{ concordo } & \multirow[t]{2}{*}{$\begin{array}{c}\text { sem } \\
\text { resposta }\end{array}$} & \multirow[t]{2}{*}{ total } \\
\hline & & & & & \\
\hline \multirow{10}{*}{ Formação } & Arquitetura & 1 & 20 & 1 & 22 \\
\hline & $\%$ na linha & $4,55 \%$ & $90,91 \%$ & $4,55 \%$ & $100,00 \%$ \\
\hline & Engenharia Civil & 3 & 26 & 1 & 30 \\
\hline & $\%$ na linha & $10,00 \%$ & $86,67 \%$ & $3,33 \%$ & $100,00 \%$ \\
\hline & Outros & 0 & 12 & 0 & 12 \\
\hline & $\%$ na linha & $0,00 \%$ & $100,00 \%$ & $0,00 \%$ & $100,00 \%$ \\
\hline & Sociopolítico & 0 & 21 & 0 & 21 \\
\hline & $\%$ na linha & $0,00 \%$ & $100,00 \%$ & $0,00 \%$ & $100,00 \%$ \\
\hline & Total & 4 & 79 & 2 & 85 \\
\hline & Referência para comparações em \% & $4,71 \%$ & $92,94 \%$ & $2,35 \%$ & $100,00 \%$ \\
\hline \multirow{2}{*}{ Função } & Assessoria - Consultoria - Docência & 3 & 41 & 2 & 46 \\
\hline & $\%$ na linha & $6,52 \%$ & $89,13 \%$ & $4,35 \%$ & $100,00 \%$ \\
\hline
\end{tabular}




\begin{tabular}{|c|c|c|c|c|c|}
\hline & Coordenação - Gestão - Supervisão & 1 & 38 & 0 & 39 \\
\hline & $\%$ na linha & $2,56 \%$ & $97,44 \%$ & $0,00 \%$ & $100,00 \%$ \\
\hline & Total & 4 & 79 & 2 & 85 \\
\hline & Referência para comparações em \% & $4,71 \%$ & $92,94 \%$ & $2,35 \%$ & $100,00 \%$ \\
\hline \multirow{10}{*}{ Idade } & 30a39anos & 0 & 18 & 0 & 18 \\
\hline & $\%$ na linha & $0,00 \%$ & $100,00 \%$ & $0,00 \%$ & $100,00 \%$ \\
\hline & 40a49anos & 1 & 14 & 0 & 15 \\
\hline & $\%$ na linha & $6,67 \%$ & $93,33 \%$ & $0,00 \%$ & $100,00 \%$ \\
\hline & 50a59anos & 3 & 34 & 0 & 37 \\
\hline & $\%$ na linha & $8,11 \%$ & $91,89 \%$ & $0,00 \%$ & $100,00 \%$ \\
\hline & 60anos a mais & 0 & 13 & 2 & 15 \\
\hline & $\%$ na linha & $0,00 \%$ & $86,67 \%$ & $13,33 \%$ & $100,00 \%$ \\
\hline & Total & 4 & 79 & 2 & 85 \\
\hline & Referência para comparações em \% & $4,71 \%$ & $92,94 \%$ & $2,35 \%$ & $100,00 \%$ \\
\hline \multirow{12}{*}{ Nível } & Outro(especifique) & 0 & 4 & 0 & 4 \\
\hline & $\%$ na linha & $0,00 \%$ & $100,00 \%$ & $0,00 \%$ & $100,00 \%$ \\
\hline & Primeiro(mais alto) & 1 & 8 & 1 & 10 \\
\hline & \% na linha & $10,00 \%$ & $80,00 \%$ & $10,00 \%$ & $100,00 \%$ \\
\hline & Quarto & 0 & 8 & 0 & 8 \\
\hline & $\%$ na linha & $0,00 \%$ & $100,00 \%$ & $0,00 \%$ & $100,00 \%$ \\
\hline & Segundo & 0 & 29 & 1 & 30 \\
\hline & $\%$ na linha & $0,00 \%$ & $96,67 \%$ & $3,33 \%$ & $100,00 \%$ \\
\hline & Terceiro & 3 & 30 & 0 & 33 \\
\hline & $\%$ na linha & $9,09 \%$ & $90,91 \%$ & $0,00 \%$ & $100,00 \%$ \\
\hline & Total & 4 & 79 & 2 & 85 \\
\hline & Referência para comparações em \% & $4,71 \%$ & $92,94 \%$ & $2,35 \%$ & $100,00 \%$ \\
\hline \multirow{6}{*}{ Sexo } & Sexo feminino. & 1 & 39 & 1 & 41 \\
\hline & $\%$ na linha & $2,44 \%$ & $95,12 \%$ & $2,44 \%$ & $100,00 \%$ \\
\hline & Sexo masculino & 3 & 40 & 1 & 44 \\
\hline & $\%$ na linha & $6,82 \%$ & $90,91 \%$ & $2,27 \%$ & $100,00 \%$ \\
\hline & Total & 4 & 79 & 2 & 85 \\
\hline & Referência para comparações em \% & $4,71 \%$ & $92,94 \%$ & $2,35 \%$ & $100,00 \%$ \\
\hline
\end{tabular}

Em geral, existe consenso frente à concordância com a participação de moradores no planejamento de obras. A maior discordância vem da parte de engenheiros civis e de profissionais no primeiro escalão. Dentre os grupos, a maior diferença de opinião está entre homens e mulheres, e entre os grupos de 'função'. No entanto, predomina o consenso entre todos os grupos com relação a esta questão.

Pergunta 2.9- 0 bom planejamento de obras de drenagem exige a participação de políticos da região

Atributo discordo concordo resposta total




\begin{tabular}{|c|c|c|c|c|c|}
\hline \multirow{10}{*}{ Formação } & Arquitetura & 7 & 13 & 2 & 22 \\
\hline & $\%$ na linha & $31,82 \%$ & $59,09 \%$ & $9,09 \%$ & $100,00 \%$ \\
\hline & Engenharia Civil & 12 & 17 & 1 & 30 \\
\hline & $\%$ na linha & $40,00 \%$ & $56,67 \%$ & $3,33 \%$ & $100,00 \%$ \\
\hline & Outros & 5 & 7 & 0 & 12 \\
\hline & $\%$ na linha & $41,67 \%$ & $58,33 \%$ & $0,00 \%$ & $100,00 \%$ \\
\hline & Sociopolítico & 6 & 13 & 2 & 21 \\
\hline & $\%$ na linha & $28,57 \%$ & $61,90 \%$ & $9,52 \%$ & $100,00 \%$ \\
\hline & Total & 30 & 50 & 5 & 85 \\
\hline & Referência para comparações em \% & $35,29 \%$ & $58,82 \%$ & $5,88 \%$ & $100,00 \%$ \\
\hline \multirow{6}{*}{ Função } & Assessoria - Consultoria - Docência & 16 & 28 & 2 & 46 \\
\hline & $\%$ na linha & $34,78 \%$ & $60,87 \%$ & $4,35 \%$ & $100,00 \%$ \\
\hline & Coordenação - Gestão - Supervisão & 14 & 22 & 3 & 39 \\
\hline & $\%$ na linha & $35,90 \%$ & $56,41 \%$ & $7,69 \%$ & $100,00 \%$ \\
\hline & Total & 30 & 50 & 5 & 85 \\
\hline & Referência para comparações em \% & $35,29 \%$ & $58,82 \%$ & $5,88 \%$ & $100,00 \%$ \\
\hline \multirow{10}{*}{ Idade } & 30a39anos & 5 & 13 & 0 & 18 \\
\hline & $\%$ na linha & $27,78 \%$ & $72,22 \%$ & $0,00 \%$ & $100,00 \%$ \\
\hline & 40a49anos & 6 & 8 & 1 & 15 \\
\hline & $\%$ na linha & $40,00 \%$ & $53,33 \%$ & $6,67 \%$ & $100,00 \%$ \\
\hline & 50a59anos & 15 & 20 & 2 & 37 \\
\hline & $\%$ na linha & $40,54 \%$ & $54,05 \%$ & $5,41 \%$ & $100,00 \%$ \\
\hline & 60anos a mais & 4 & 9 & 2 & 15 \\
\hline & $\%$ na linha & $26,67 \%$ & $60,00 \%$ & $13,33 \%$ & $100,00 \%$ \\
\hline & Total & 30 & 50 & 5 & 85 \\
\hline & Referência para comparações em \% & $35,29 \%$ & $58,82 \%$ & $5,88 \%$ & $100,00 \%$ \\
\hline \multirow{10}{*}{ Nível } & Outro(especifique) & 2 & 2 & 0 & 4 \\
\hline & $\%$ na linha & $50,00 \%$ & $50,00 \%$ & $0,00 \%$ & $100,00 \%$ \\
\hline & Primeiro(mais alto) & 4 & 5 & 1 & 10 \\
\hline & $\%$ na linha & $40,00 \%$ & $50,00 \%$ & $10,00 \%$ & $100,00 \%$ \\
\hline & Quarto & 0 & 7 & 1 & 8 \\
\hline & $\%$ na linha & $0,00 \%$ & $87,50 \%$ & $12,50 \%$ & $100,00 \%$ \\
\hline & Segundo & 10 & 19 & 1 & 30 \\
\hline & $\%$ na linha & $33,33 \%$ & $63,33 \%$ & $3,33 \%$ & $100,00 \%$ \\
\hline & Terceiro & 14 & 17 & 2 & 33 \\
\hline & $\%$ na linha & $42,42 \%$ & $51,52 \%$ & $6,06 \%$ & $100,00 \%$ \\
\hline & Total & 30 & 50 & 5 & 85 \\
\hline & Referência para comparações em \% & $35,29 \%$ & $58,82 \%$ & $5,88 \%$ & $100,00 \%$ \\
\hline \multirow{4}{*}{ Sexo } & Sexo feminino. & 11 & 27 & 3 & 41 \\
\hline & $\%$ na linha & $26,83 \%$ & $65,85 \%$ & $7,32 \%$ & $100,00 \%$ \\
\hline & Sexo masculino & 19 & 23 & 2 & 44 \\
\hline & $\%$ na linha & $43,18 \%$ & $52,27 \%$ & $4,55 \%$ & $100,00 \%$ \\
\hline
\end{tabular}


Total

30

50

5

85

Referência para comparações em \%

$35,29 \%$

$58,82 \%$

$5,88 \%$

$100,00 \%$

Esta questão resultou em alta proporção de discordância. Praticamente $36 \%$ discordam da importância da participação de políticos da região no planejamento de obras de drenagem. Engenheiros civis estão entre os que mais rejeitam esta participação. Esta pergunta registrou maior número de 'sem resposta'.

Pergunta 2.10- 0 bom planejamento de obras de drenagem exige a participação de Técnicos de manutenção de obras de drenagem.

\begin{tabular}{|c|c|c|c|c|c|}
\hline \multirow[b]{2}{*}{ Variável } & \multirow[b]{2}{*}{ Atributo } & \multirow[t]{2}{*}{ discordo } & concordo & $\begin{array}{c}\text { sem } \\
\text { resposta }\end{array}$ & total \\
\hline & & & & & \\
\hline \multirow{10}{*}{ Formação } & Arquitetura & 2 & 20 & 0 & 22 \\
\hline & $\%$ na linha & $9,09 \%$ & $90,91 \%$ & $0,00 \%$ & $100,00 \%$ \\
\hline & Engenharia Civil & 1 & 27 & 2 & 30 \\
\hline & $\%$ na linha & $3,33 \%$ & $90,00 \%$ & $6,67 \%$ & $100,00 \%$ \\
\hline & Outros & 0 & 12 & 0 & 12 \\
\hline & $\%$ na linha & $0,00 \%$ & $100,00 \%$ & $0,00 \%$ & $100,00 \%$ \\
\hline & Sociopolítico & 1 & 18 & 2 & 21 \\
\hline & $\%$ na linha & $4,76 \%$ & $85,71 \%$ & $9,52 \%$ & $100,00 \%$ \\
\hline & Total & 4 & 77 & 4 & 85 \\
\hline & Referência para comparações em \% & $4,71 \%$ & $90,59 \%$ & $4,71 \%$ & $100,00 \%$ \\
\hline \multirow{6}{*}{ Função } & Assessoria - Consultoria - Docência & 3 & 41 & 2 & 46 \\
\hline & $\%$ na linha & $6,52 \%$ & $89,13 \%$ & $4,35 \%$ & $100,00 \%$ \\
\hline & Coordenação - Gestão - Supervisão & 1 & 36 & 2 & 39 \\
\hline & $\%$ na linha & $2,56 \%$ & $92,31 \%$ & $5,13 \%$ & $100,00 \%$ \\
\hline & Total & 4 & 77 & 4 & 85 \\
\hline & Referência para comparações em \% & $4,71 \%$ & $90,59 \%$ & $4,71 \%$ & $100,00 \%$ \\
\hline \multirow{10}{*}{ Idade } & 30a39anos & 0 & 18 & 0 & 18 \\
\hline & $\%$ na linha & $0,00 \%$ & $100,00 \%$ & $0,00 \%$ & $100,00 \%$ \\
\hline & 40a49anos & 0 & 14 & 1 & 15 \\
\hline & $\%$ na linha & $0,00 \%$ & $93,33 \%$ & $6,67 \%$ & $100,00 \%$ \\
\hline & 50a59anos & 3 & 33 & 1 & 37 \\
\hline & $\%$ na linha & $8,11 \%$ & $89,19 \%$ & $2,70 \%$ & $100,00 \%$ \\
\hline & 60 anos a mais & 1 & 12 & 2 & 15 \\
\hline & $\%$ na linha & $6,67 \%$ & $80,00 \%$ & $13,33 \%$ & $100,00 \%$ \\
\hline & Total & 4 & 77 & 4 & 85 \\
\hline & Referência para comparações em \% & $4,71 \%$ & $90,59 \%$ & $4,71 \%$ & $100,00 \%$ \\
\hline \multirow{3}{*}{ Nível } & Outro(especifique) & 0 & 4 & 0 & 4 \\
\hline & $\%$ na linha & $0,00 \%$ & $100,00 \%$ & $0,00 \%$ & $100,00 \%$ \\
\hline & Primeiro(mais alto) & 0 & 9 & 1 & 10 \\
\hline
\end{tabular}




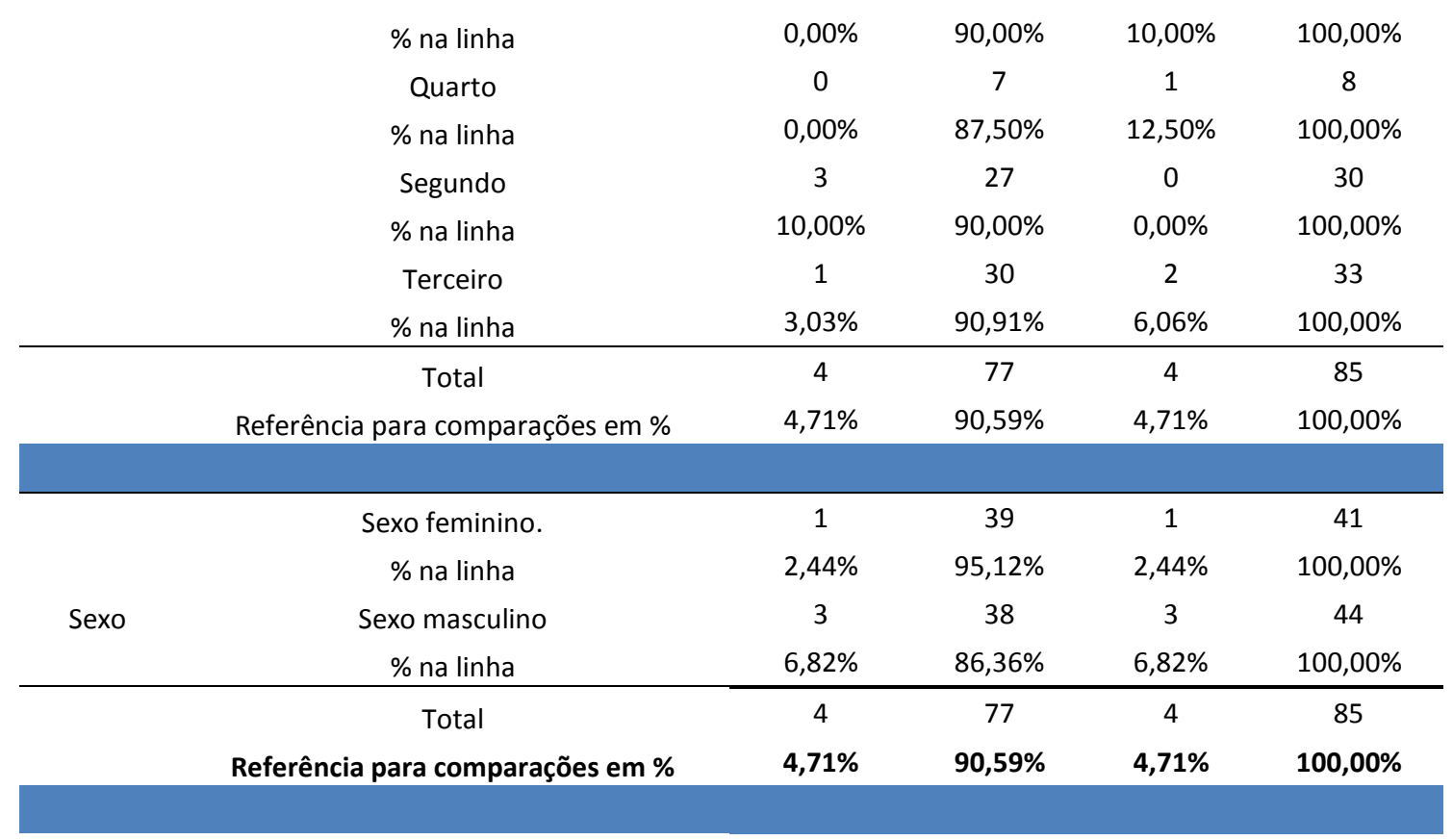

A participação de técnicos de manutenção é aceita por mais de $90 \%$ dos respondentes. Arquitetos e aqueles que compõem o grupo formado por dirigentes do segundo escalão, assim como os grupos que agregam os mais velhos são os que mais discordam desta afirmação. Há um consenso generalizado da importância desta participação. Entretanto, nota-se que entre os Engenheiros Civis e os com formação 'sociopolítica' estão entre os grupos com maior número de 'sem resposta'.

\begin{tabular}{|c|c|c|c|c|c|}
\hline \multirow[b]{2}{*}{ Variável } & \multirow[b]{2}{*}{ Atributo } & \multirow[t]{2}{*}{ discordo } & \multirow[t]{2}{*}{ concordo } & \multirow[t]{2}{*}{$\begin{array}{c}\text { sem } \\
\text { resposta }\end{array}$} & \multirow[t]{2}{*}{ total } \\
\hline & & & & & \\
\hline \multirow{10}{*}{ Formação } & Arquitetura & 5 & 17 & 0 & 22 \\
\hline & $\%$ na linha & $22,73 \%$ & $77,27 \%$ & $0,00 \%$ & $100,00 \%$ \\
\hline & Engenharia Civil & 2 & 28 & 0 & 30 \\
\hline & $\%$ na linha & $6,67 \%$ & $93,33 \%$ & $0,00 \%$ & $100,00 \%$ \\
\hline & Outros & 2 & 10 & 0 & 12 \\
\hline & $\%$ na linha & $16,67 \%$ & $83,33 \%$ & $0,00 \%$ & $100,00 \%$ \\
\hline & Sociopolítico & 2 & 19 & 0 & 21 \\
\hline & $\%$ na linha & $9,52 \%$ & $90,48 \%$ & $0,00 \%$ & $100,00 \%$ \\
\hline & Total & 11 & 74 & 0 & 85 \\
\hline & Referência para comparações em \% & $12,94 \%$ & $87,06 \%$ & $0,00 \%$ & $100,00 \%$ \\
\hline \multirow{6}{*}{ Função } & Assessoria - Consultoria - Docência & 5 & 41 & 0 & 46 \\
\hline & $\%$ na linha & $10,87 \%$ & $89,13 \%$ & $0,00 \%$ & $100,00 \%$ \\
\hline & Coordenação - Gestão - Supervisão & 6 & 33 & 0 & 39 \\
\hline & $\%$ na linha & $15,38 \%$ & $84,62 \%$ & $0,00 \%$ & $100,00 \%$ \\
\hline & Total & 11 & 74 & 0 & 85 \\
\hline & Referência para comparações em \% & $12,94 \%$ & $87,06 \%$ & $0,00 \%$ & $100,00 \%$ \\
\hline
\end{tabular}




\begin{tabular}{|c|c|c|c|c|c|}
\hline \multirow{10}{*}{ Idade } & 30a39anos & 2 & 16 & 0 & 18 \\
\hline & $\%$ na linha & $11,11 \%$ & $88,89 \%$ & $0,00 \%$ & $100,00 \%$ \\
\hline & 40a49anos & 1 & 14 & 0 & 15 \\
\hline & $\%$ na linha & $6,67 \%$ & $93,33 \%$ & $0,00 \%$ & $100,00 \%$ \\
\hline & 50a59anos & 6 & 31 & 0 & 37 \\
\hline & $\%$ na linha & $16,22 \%$ & $83,78 \%$ & $0,00 \%$ & $100,00 \%$ \\
\hline & 60 anos a mais & 2 & 13 & 0 & 15 \\
\hline & $\%$ na linha & $13,33 \%$ & $86,67 \%$ & $0,00 \%$ & $100,00 \%$ \\
\hline & Total & 11 & 74 & 0 & 85 \\
\hline & Referência para comparações em \% & $12,94 \%$ & $87,06 \%$ & $0,00 \%$ & $100,00 \%$ \\
\hline \multirow{12}{*}{ Nível } & Outro(especifique) & 0 & 4 & 0 & 4 \\
\hline & $\%$ na linha & $0,00 \%$ & $100,00 \%$ & $0,00 \%$ & $100,00 \%$ \\
\hline & Primeiro(mais alto) & 2 & 8 & 0 & 10 \\
\hline & \% na linha & $20,00 \%$ & $80,00 \%$ & $0,00 \%$ & $100,00 \%$ \\
\hline & Quarto & 0 & 8 & 0 & 8 \\
\hline & $\%$ na linha & $0,00 \%$ & $100,00 \%$ & $0,00 \%$ & $100,00 \%$ \\
\hline & Segundo & 4 & 26 & 0 & 30 \\
\hline & $\%$ na linha & $13,33 \%$ & $86,67 \%$ & $0,00 \%$ & $100,00 \%$ \\
\hline & Terceiro & 5 & 28 & 0 & 33 \\
\hline & $\%$ na linha & $15,15 \%$ & $84,85 \%$ & $0,00 \%$ & $100,00 \%$ \\
\hline & Total & 11 & 74 & 0 & 85 \\
\hline & Referência para comparações em \% & $12,94 \%$ & $87,06 \%$ & $0,00 \%$ & $100,00 \%$ \\
\hline \multirow{6}{*}{ Sexo } & Sexo feminino. & 6 & 35 & 0 & 41 \\
\hline & \% na linha & $14,63 \%$ & $85,37 \%$ & $0,00 \%$ & $100,00 \%$ \\
\hline & Sexo masculino & 5 & 39 & 0 & 44 \\
\hline & $\%$ na linha & $11,36 \%$ & $88,64 \%$ & $0,00 \%$ & $100,00 \%$ \\
\hline & Total & 11 & 74 & 0 & 85 \\
\hline & Referência para comparações em \% & $12,94 \%$ & $87,06 \%$ & $0,00 \%$ & $100,00 \%$ \\
\hline
\end{tabular}

Os Engenheiros Civis concordam com esta afirmação, situando sua opinião acima da referência. Por outro lado, os que se encontram no primeiro escalão de decisões e os arquitetos tendem a discordar, , ou seja, tendem a não acreditar que gerentes de obras não queiram envolver moradores, situando sua opinião acima da referência em comparação aos demais grupos.

Pergunta 4 - Em geral, moradores das áreas onde obras serão implantadas não têm condição de opinar sobre as mesmas para que atendam sua demanda por melhorias.

\begin{tabular}{lccccc} 
& & & & sem \\
Variável & Atributo & discordo & concordo & resposta & total \\
\hline \multirow{3}{*}{ Formação } & Arquitetura & 13 & 9 & 0 & 22 \\
& $\%$ na linha & $59,09 \%$ & $40,91 \%$ & $0,00 \%$ & $100,00 \%$ \\
& Engenharia Civil & 18 & 12 & 0 & 30
\end{tabular}




\begin{tabular}{|c|c|c|c|c|c|}
\hline & $\%$ na linha & $60,00 \%$ & $40,00 \%$ & $0,00 \%$ & $100,00 \%$ \\
\hline & Outros & 7 & 5 & 0 & 12 \\
\hline & $\%$ na linha & $58,33 \%$ & $41,67 \%$ & $0,00 \%$ & $100,00 \%$ \\
\hline & Sociopolítico & 16 & 5 & 0 & 21 \\
\hline & $\%$ na linha & $76,19 \%$ & $23,81 \%$ & $0,00 \%$ & $100,00 \%$ \\
\hline & Total & 54 & 31 & 0 & 85 \\
\hline & Referência para comparações em \% & $63,53 \%$ & $36,47 \%$ & $0,00 \%$ & $100,00 \%$ \\
\hline & Assessoria - Consultoria - Docência & 28 & 18 & 0 & 46 \\
\hline Funcão & $\%$ na linha & $60,87 \%$ & $39,13 \%$ & $0,00 \%$ & $100,00 \%$ \\
\hline Tuाद̧व & Coordenação - Gestão - Supervisão & 26 & 13 & 0 & 39 \\
\hline & $\%$ na linha & $66,67 \%$ & $33,33 \%$ & $0,00 \%$ & $100,00 \%$ \\
\hline & Total & 54 & 31 & 0 & 85 \\
\hline & Referência para comparações em \% & $63,53 \%$ & $36,47 \%$ & $0,00 \%$ & $100,00 \%$ \\
\hline & 30a39anos & 13 & 5 & 0 & 18 \\
\hline & $\%$ na linha & $72,22 \%$ & $27,78 \%$ & $0,00 \%$ & $100,00 \%$ \\
\hline & 40a49anos & 10 & 5 & 0 & 15 \\
\hline Idade & $\%$ na linha & $66,67 \%$ & $33,33 \%$ & $0,00 \%$ & $100,00 \%$ \\
\hline the & 50a59anos & 21 & 16 & 0 & 37 \\
\hline & $\%$ na linha & $56,76 \%$ & $43,24 \%$ & $0,00 \%$ & $100,00 \%$ \\
\hline & 60 anos a mais & 10 & 5 & 0 & 15 \\
\hline & $\%$ na linha & $66,67 \%$ & $33,33 \%$ & $0,00 \%$ & $100,00 \%$ \\
\hline & Total & 54 & 31 & 0 & 85 \\
\hline & Referência para comparações em \% & $63,53 \%$ & $36,47 \%$ & $0,00 \%$ & $100,00 \%$ \\
\hline & Outro(especifique) & 4 & 0 & 0 & 4 \\
\hline & $\%$ na linha & $100,00 \%$ & $0,00 \%$ & $0,00 \%$ & $100,00 \%$ \\
\hline & Primeiro(mais alto) & 6 & 4 & 0 & 10 \\
\hline & $\%$ na linha & $60,00 \%$ & $40,00 \%$ & $0,00 \%$ & $100,00 \%$ \\
\hline Nível & Quarto & 4 & 4 & 0 & 8 \\
\hline & $\%$ na linha & $50,00 \%$ & $50,00 \%$ & $0,00 \%$ & $100,00 \%$ \\
\hline & Segundo & 21 & 9 & 0 & 30 \\
\hline & $\%$ na linha & $70,00 \%$ & $30,00 \%$ & $0,00 \%$ & $100,00 \%$ \\
\hline & Terceiro & 19 & 14 & 0 & 33 \\
\hline & $\%$ na linha & $57,58 \%$ & $42,42 \%$ & $0,00 \%$ & $100,00 \%$ \\
\hline & Total & 54 & 31 & 0 & 85 \\
\hline & Referência para comparações em \% & $63,53 \%$ & $36,47 \%$ & $0,00 \%$ & $100,00 \%$ \\
\hline & Sexo feminino. & 30 & 11 & 0 & 41 \\
\hline & $\%$ na linha & $73,17 \%$ & $26,83 \%$ & $0,00 \%$ & $100,00 \%$ \\
\hline Sexo & Sexo masculino & 24 & 20 & 0 & 44 \\
\hline & $\%$ na linha & $54,55 \%$ & $45,45 \%$ & $0,00 \%$ & $100,00 \%$ \\
\hline & Total & 54 & 31 & 0 & 85 \\
\hline & Referência para comparações em \% & $63,53 \%$ & $36,47 \%$ & $0,00 \%$ & $100,00 \%$ \\
\hline
\end{tabular}


Esta foi a afirmação que gerou a maior proporção de discordância. Quase $65 \%$ dos entrevistados discordam da afirmação que os moradores das áreas onde obras serão implantadas não têm condição de opinar sobre as mesmas para que atendam sua demanda por melhorias. Os de formação sociopolítica são os que se encontram bem acima desta referência, seguidos pelas mulheres que, mais que os homens, acreditam que os moradores podem opinar, assim como os mais jovens, os de nível hierárquico mais alto.

\section{Pergunta 5 - Em geral, comerciantes instalados nas áreas onde obras serão implantadas não têm condição de opinar sobre as mesmas para que atendam sua demanda por melhorias.}

\begin{tabular}{|c|c|c|c|c|c|}
\hline & & discordo & concordo & $\begin{array}{c}\text { sem } \\
\text { resposta }\end{array}$ & total \\
\hline Variável & Atributo & & & & \\
\hline \multirow{10}{*}{ Formação } & Arquitetura & 12 & 10 & 0 & 22 \\
\hline & $\%$ na linha & $54,55 \%$ & $45,45 \%$ & $0,00 \%$ & $100,00 \%$ \\
\hline & Engenharia Civil & 17 & 13 & 0 & 30 \\
\hline & $\%$ na linha & $56,67 \%$ & $43,33 \%$ & $0,00 \%$ & $100,00 \%$ \\
\hline & Outros & 7 & 5 & 0 & 12 \\
\hline & $\%$ na linha & $58,33 \%$ & $41,67 \%$ & $0,00 \%$ & $100,00 \%$ \\
\hline & Sociopolítico & 14 & 7 & 0 & 21 \\
\hline & $\%$ na linha & $66,67 \%$ & $33,33 \%$ & $0,00 \%$ & $100,00 \%$ \\
\hline & Total & 50 & 35 & 0 & 85 \\
\hline & Referência para comparações em \% & $58,82 \%$ & $41,18 \%$ & $0,00 \%$ & $100,00 \%$ \\
\hline \multirow{6}{*}{ Função } & Assessoria - Consultoria - Docência & 27 & 19 & 0 & 46 \\
\hline & $\%$ na linha & $58,70 \%$ & $41,30 \%$ & $0,00 \%$ & $100,00 \%$ \\
\hline & Coordenação - Gestão - Supervisão & 23 & 16 & 0 & 39 \\
\hline & $\%$ na linha & $58,97 \%$ & $41,03 \%$ & $0,00 \%$ & $100,00 \%$ \\
\hline & Total & 50 & 35 & 0 & 85 \\
\hline & Referência para comparações em \% & $58,82 \%$ & $41,18 \%$ & $0,00 \%$ & $100,00 \%$ \\
\hline \multirow{10}{*}{ Idade } & 30a39anos & 14 & 4 & 0 & 18 \\
\hline & $\%$ na linha & $77,78 \%$ & $22,22 \%$ & $0,00 \%$ & $100,00 \%$ \\
\hline & 40a49anos & 8 & 7 & 0 & 15 \\
\hline & $\%$ na linha & $53,33 \%$ & $46,67 \%$ & $0,00 \%$ & $100,00 \%$ \\
\hline & 50a59anos & 19 & 18 & 0 & 37 \\
\hline & $\%$ na linha & $51,35 \%$ & $48,65 \%$ & $0,00 \%$ & $100,00 \%$ \\
\hline & 60anos a mais & 9 & 6 & 0 & 15 \\
\hline & $\%$ na linha & $60,00 \%$ & $40,00 \%$ & $0,00 \%$ & $100,00 \%$ \\
\hline & Total & 50 & 35 & 0 & 85 \\
\hline & Referência para comparações em \% & $58,82 \%$ & $41,18 \%$ & $0,00 \%$ & $100,00 \%$ \\
\hline \multirow{5}{*}{ Nível } & Outro(especifique) & 3 & 1 & 0 & 4 \\
\hline & $\%$ na linha & $75,00 \%$ & $25,00 \%$ & $0,00 \%$ & $100,00 \%$ \\
\hline & Primeiro(mais alto) & 5 & 5 & 0 & 10 \\
\hline & $\%$ na linha & $50,00 \%$ & $50,00 \%$ & $0,00 \%$ & $100,00 \%$ \\
\hline & Quarto & 5 & 3 & 0 & 8 \\
\hline
\end{tabular}




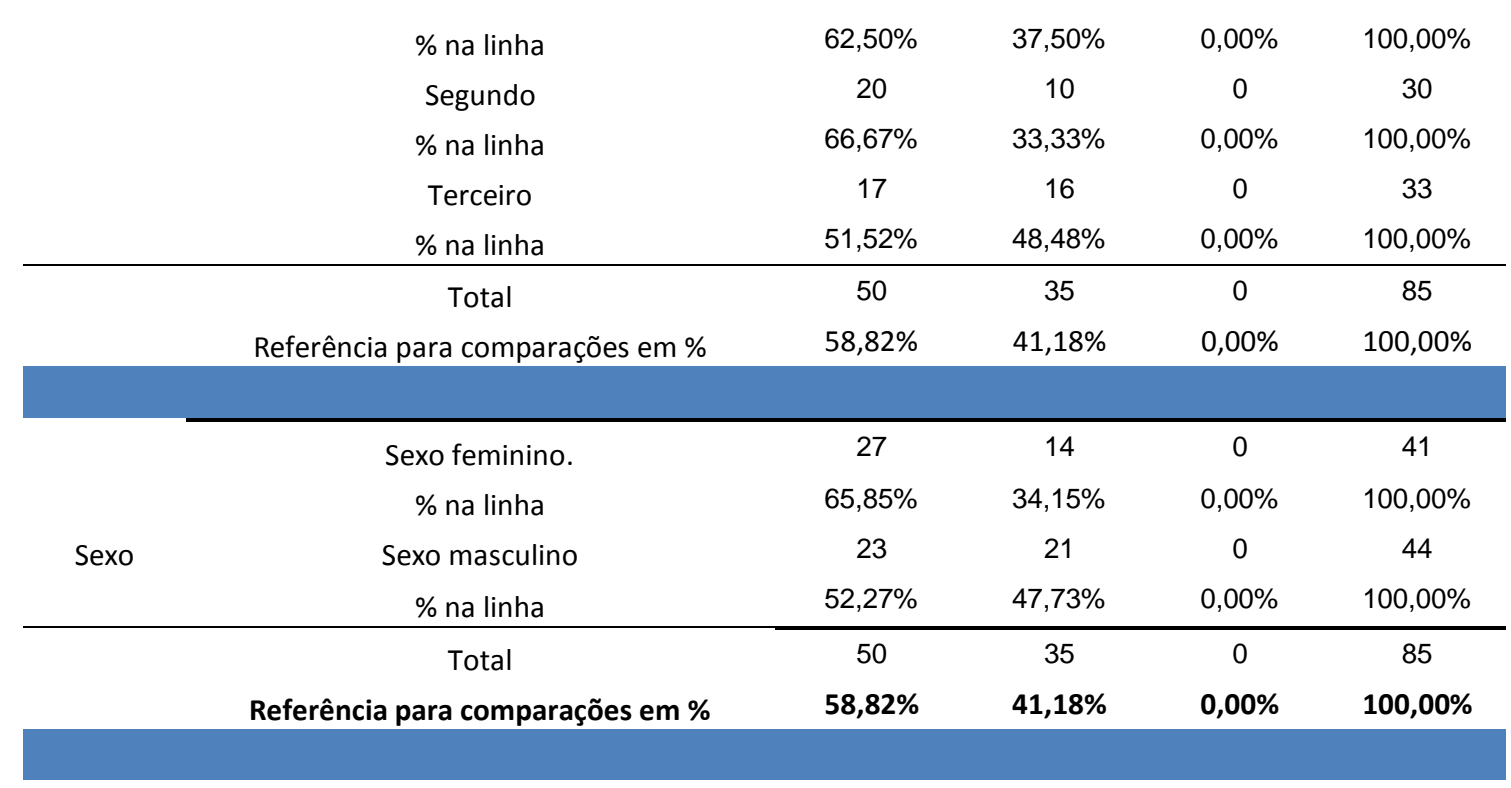

Também com relação a esta afirmação, o grau de discordância é dos mais altos. Isto significa que há uma tendência generalizada em não acreditam que os comerciantes não tenham condição de opinar sobre as obras a serem implantadas para que as mesmas tragam melhorias para o bairro. Os mais jovens são os que mais acreditam que comerciantes podem opinar. As mulheres e aqueles com formação 'sociopolítica' seguem esta tendência. No geral, há um equilíbrio entre todos quanto a rejeitar esta afirmação.

Pergunta 6 - Audiências públicas são suficientes como processo participativo da população.

\begin{tabular}{|c|c|c|c|c|c|}
\hline & & discordo & concordo & $\begin{array}{c}\text { sem } \\
\text { resposta }\end{array}$ & total \\
\hline Variável & Atributo & & & & \\
\hline \multirow{10}{*}{ Formação } & Arquitetura & 16 & 6 & 0 & 22 \\
\hline & $\%$ na linha & $72,73 \%$ & $27,27 \%$ & $0,00 \%$ & $100,00 \%$ \\
\hline & Engenharia Civil & 19 & 11 & 0 & 30 \\
\hline & $\%$ na linha & $63,33 \%$ & $36,67 \%$ & $0,00 \%$ & $100,00 \%$ \\
\hline & Outros & 6 & 6 & 0 & 12 \\
\hline & $\%$ na linha & $50,00 \%$ & $50,00 \%$ & $0,00 \%$ & $100,00 \%$ \\
\hline & Sociopolítico & 14 & 7 & 0 & 21 \\
\hline & $\%$ na linha & $66,67 \%$ & $33,33 \%$ & $0,00 \%$ & $100,00 \%$ \\
\hline & Total & 55 & 30 & 0 & 85 \\
\hline & Referência para comparações em \% & $64,71 \%$ & $35,29 \%$ & $0,00 \%$ & $100,00 \%$ \\
\hline \multirow{6}{*}{ Função } & Assessoria - Consultoria - Docência & 31 & 15 & 0 & 46 \\
\hline & $\%$ na linha & $67,39 \%$ & $32,61 \%$ & $0,00 \%$ & $100,00 \%$ \\
\hline & Coordenação - Gestão - Supervisão & 24 & 15 & 0 & 39 \\
\hline & $\%$ na linha & $61,54 \%$ & $38,46 \%$ & $0,00 \%$ & $100,00 \%$ \\
\hline & Total & 55 & 30 & 0 & 85 \\
\hline & Referência para comparações em \% & $64,71 \%$ & $35,29 \%$ & $0,00 \%$ & $100,00 \%$ \\
\hline
\end{tabular}




\begin{tabular}{|c|c|c|c|c|c|}
\hline \multirow{10}{*}{ Idade } & 30a39anos & 14 & 4 & 0 & 18 \\
\hline & $\%$ na linha & $77,78 \%$ & $22,22 \%$ & $0,00 \%$ & $100,00 \%$ \\
\hline & 40a49anos & 8 & 7 & 0 & 15 \\
\hline & $\%$ na linha & $53,33 \%$ & $46,67 \%$ & $0,00 \%$ & $100,00 \%$ \\
\hline & 50a59anos & 25 & 12 & 0 & 37 \\
\hline & $\%$ na linha & $67,57 \%$ & $32,43 \%$ & $0,00 \%$ & $100,00 \%$ \\
\hline & 60 anos a mais & 8 & 7 & 0 & 15 \\
\hline & $\%$ na linha & $53,33 \%$ & $46,67 \%$ & $0,00 \%$ & $100,00 \%$ \\
\hline & Total & 55 & 30 & 0 & 85 \\
\hline & Referência para comparações em \% & $64,71 \%$ & $35,29 \%$ & $0,00 \%$ & $100,00 \%$ \\
\hline \multirow{12}{*}{ Nível } & Outro(especifique) & 2 & 2 & 0 & 4 \\
\hline & $\%$ na linha & $50,00 \%$ & $50,00 \%$ & $0,00 \%$ & $100,00 \%$ \\
\hline & Primeiro(mais alto) & 6 & 4 & 0 & 10 \\
\hline & $\%$ na linha & $60,00 \%$ & $40,00 \%$ & $0,00 \%$ & $100,00 \%$ \\
\hline & Quarto & 5 & 3 & 0 & 8 \\
\hline & $\%$ na linha & $62,50 \%$ & $37,50 \%$ & $0,00 \%$ & $100,00 \%$ \\
\hline & Segundo & 20 & 10 & 0 & 30 \\
\hline & $\%$ na linha & $66,67 \%$ & $33,33 \%$ & $0,00 \%$ & $100,00 \%$ \\
\hline & Terceiro & 22 & 11 & 0 & 33 \\
\hline & $\%$ na linha & $66,67 \%$ & $33,33 \%$ & $0,00 \%$ & $100,00 \%$ \\
\hline & Total & 55 & 30 & 0 & 85 \\
\hline & Referência para comparações em \% & $64,71 \%$ & $35,29 \%$ & $0,00 \%$ & $100,00 \%$ \\
\hline \multirow{6}{*}{ Sexo } & Sexo feminino. & 29 & 12 & 0 & 41 \\
\hline & $\%$ na linha & $70,73 \%$ & $29,27 \%$ & $0,00 \%$ & $100,00 \%$ \\
\hline & Sexo masculino & 26 & 18 & 0 & 44 \\
\hline & $\%$ na linha & $59,09 \%$ & $40,91 \%$ & $0,00 \%$ & $100,00 \%$ \\
\hline & Total & 55 & 30 & 0 & 85 \\
\hline & Referência para comparações em \% & $64,71 \%$ & $35,29 \%$ & $0,00 \%$ & $100,00 \%$ \\
\hline
\end{tabular}

Dos respondentes, praticamente $65 \%$ discorda da afirmação de que audiências públicas sejam suficientes como processo participativo da população. O grupo formado pelos mais jovens é o que mais discorda dessa afirmação, seguidos das mulheres e do grupo formado por arquitetos.

Pergunta 7.1 - Para a boa implantação de obras de drenagem é necessário que haja o envolvimento de Comunicadores sociais

\begin{tabular}{cccccc} 
& & & & sem & concordo \\
Variável & Atributo & discordo & resposta & total \\
\hline \multirow{2}{*}{ Formação } & Arquitetura & & & 1 & 22 \\
& $\%$ na linha & 2 & 19 & $4,55 \%$ & $100,00 \%$ \\
& Engenharia Civil & $9,09 \%$ & $86,36 \%$ & 0 & 30 \\
& $\%$ na linha & 4 & 26 & $0,00 \%$ & $100,00 \%$
\end{tabular}




\begin{tabular}{|c|c|c|c|c|c|}
\hline & Outros & 1 & 11 & 0 & 12 \\
\hline & $\%$ na linha & $8,33 \%$ & $91,67 \%$ & $0,00 \%$ & $100,00 \%$ \\
\hline & Sociopolítico & 1 & 18 & 2 & 21 \\
\hline & $\%$ na linha & $4,76 \%$ & $85,71 \%$ & $9,52 \%$ & $100,00 \%$ \\
\hline & Total & 8 & 74 & 3 & 85 \\
\hline & Referência para comparações em \% & $9,41 \%$ & $87,06 \%$ & $3,53 \%$ & $100,00 \%$ \\
\hline \multirow{6}{*}{ Função } & Assessoria - Consultoria - Docência & 4 & 42 & 0 & 46 \\
\hline & $\%$ na linha & $8,70 \%$ & $91,30 \%$ & $0,00 \%$ & $100,00 \%$ \\
\hline & Coordenação - Gestão - Supervisão & 4 & 32 & 3 & 39 \\
\hline & $\%$ na linha & $10,26 \%$ & $82,05 \%$ & $7,69 \%$ & $100,00 \%$ \\
\hline & Total & 8 & 74 & 3 & 85 \\
\hline & Referência para comparações em \% & $9,41 \%$ & $87,06 \%$ & $3,53 \%$ & $100,00 \%$ \\
\hline \multirow{10}{*}{ Idade } & 30a39anos & 0 & 18 & 0 & 18 \\
\hline & $\%$ na linha & $0,00 \%$ & $100,00 \%$ & $0,00 \%$ & $100,00 \%$ \\
\hline & 40a49anos & 2 & 12 & 1 & 15 \\
\hline & $\%$ na linha & $13,33 \%$ & $80,00 \%$ & $6,67 \%$ & $100,00 \%$ \\
\hline & 50a59anos & 4 & 31 & 2 & 37 \\
\hline & $\%$ na linha & $10,81 \%$ & $83,78 \%$ & $5,41 \%$ & $100,00 \%$ \\
\hline & 60 anos a mais & 2 & 13 & 0 & 15 \\
\hline & $\%$ na linha & $13,33 \%$ & $86,67 \%$ & $0,00 \%$ & $100,00 \%$ \\
\hline & Total & 8 & 74 & 3 & 85 \\
\hline & Referência para comparações em \% & $9,41 \%$ & $87,06 \%$ & $3,53 \%$ & $100,00 \%$ \\
\hline \multirow{12}{*}{ Nível } & Outro(especifique) & 1 & 3 & 0 & 4 \\
\hline & $\%$ na linha & $25,00 \%$ & $75,00 \%$ & $0,00 \%$ & $100,00 \%$ \\
\hline & Primeiro(mais alto) & 1 & 9 & 0 & 10 \\
\hline & $\%$ na linha & $10,00 \%$ & $90,00 \%$ & $0,00 \%$ & $100,00 \%$ \\
\hline & Quarto & 0 & 7 & 1 & 8 \\
\hline & $\%$ na linha & $0,00 \%$ & $87,50 \%$ & $12,50 \%$ & $100,00 \%$ \\
\hline & Segundo & 1 & 28 & 1 & 30 \\
\hline & $\%$ na linha & $3,33 \%$ & $93,33 \%$ & $3,33 \%$ & $100,00 \%$ \\
\hline & Terceiro & 5 & 27 & 1 & 33 \\
\hline & $\%$ na linha & $15,15 \%$ & $81,82 \%$ & $3,03 \%$ & $100,00 \%$ \\
\hline & Total & 8 & 74 & 3 & 85 \\
\hline & Referência para comparações em \% & $9,41 \%$ & $87,06 \%$ & $3,53 \%$ & $100,00 \%$ \\
\hline \multirow{6}{*}{ Sexo } & Sexo feminino. & 3 & 37 & 1 & 41 \\
\hline & $\%$ na linha & $7,32 \%$ & $90,24 \%$ & $2,44 \%$ & $100,00 \%$ \\
\hline & Sexo masculino & 5 & 37 & 2 & 44 \\
\hline & $\%$ na linha & $11,36 \%$ & $84,09 \%$ & $4,55 \%$ & $100,00 \%$ \\
\hline & Total & 8 & 74 & 3 & 85 \\
\hline & Referência para comparações em \% & $9,41 \%$ & $87,06 \%$ & $3,53 \%$ & $100,00 \%$ \\
\hline
\end{tabular}


Assim como para a questão relativa à participação durante o planejamento de obras de drenagem, mais de $87 \%$ dos respondentes concordam com a importância da participação de comunicadores sociais na implantação de obras. Os mais jovens formam o grupo que mais se destaca frente à referência, seguidos do grupo de Assessores - consultores docentes, estes bem acima da referência do que o grupo formado por Coordenadores Gestores - Supervisores. Há também uma certa diferença entre homens e mulheres, estas bem mais acima da referência que os homens, mostrando que as mulheres estão mais abertas à participação de Comunicadores Sociais. Em comparação com a questão sobre a participação no planejamento (pergunta 2.4), esta teve maior número de vazios.

\begin{tabular}{|c|c|c|c|c|c|}
\hline & & discordo & concordo & $\begin{array}{c}\text { sem } \\
\text { resposta }\end{array}$ & total \\
\hline Variável & Atributo & & & & \\
\hline \multirow{10}{*}{ Formação } & Arquitetura & 4 & 18 & 0 & 22 \\
\hline & $\%$ na linha & $18,18 \%$ & $81,82 \%$ & $0,00 \%$ & $100,00 \%$ \\
\hline & Engenharia Civil & 7 & 23 & 0 & 30 \\
\hline & \% na linha & $23,33 \%$ & $76,67 \%$ & $0,00 \%$ & $100,00 \%$ \\
\hline & Outros & 3 & 9 & 0 & 12 \\
\hline & $\%$ na linha & $25,00 \%$ & $75,00 \%$ & $0,00 \%$ & $100,00 \%$ \\
\hline & Sociopolítico & 4 & 14 & 3 & 21 \\
\hline & \% na linha & $19,05 \%$ & $66,67 \%$ & $14,29 \%$ & $100,00 \%$ \\
\hline & Total & 18 & 64 & 3 & 85 \\
\hline & Referência para comparações em \% & $21,18 \%$ & $75,29 \%$ & $3,53 \%$ & $100,00 \%$ \\
\hline \multirow{6}{*}{ Função } & Assessoria - Consultoria - Docência & 10 & 36 & 0 & 46 \\
\hline & $\%$ na linha & $21,74 \%$ & $78,26 \%$ & $0,00 \%$ & $100,00 \%$ \\
\hline & Coordenação - Gestão - Supervisão & 8 & 28 & 3 & 39 \\
\hline & $\%$ na linha & $20,51 \%$ & $71,79 \%$ & $7,69 \%$ & $100,00 \%$ \\
\hline & Total & 18 & 64 & 3 & 85 \\
\hline & Referência para comparações em \% & $21,18 \%$ & $75,29 \%$ & $3,53 \%$ & $100,00 \%$ \\
\hline \multirow{10}{*}{ Idade } & 30a39anos & 4 & 14 & 0 & 18 \\
\hline & $\%$ na linha & $22,22 \%$ & $77,78 \%$ & $0,00 \%$ & $100,00 \%$ \\
\hline & 40a49anos & 4 & 10 & 1 & 15 \\
\hline & $\%$ na linha & $26,67 \%$ & $66,67 \%$ & $6,67 \%$ & $100,00 \%$ \\
\hline & 50a59anos & 7 & 28 & 2 & 37 \\
\hline & \% na linha & $18,92 \%$ & $75,68 \%$ & $5,41 \%$ & $100,00 \%$ \\
\hline & 60 anos a mais & 3 & 12 & 0 & 15 \\
\hline & \% na linha & $20,00 \%$ & $80,00 \%$ & $0,00 \%$ & $100,00 \%$ \\
\hline & Total & 18 & 64 & 3 & 85 \\
\hline & Referência para comparações em \% & $21,18 \%$ & $75,29 \%$ & $3,53 \%$ & $100,00 \%$ \\
\hline \multirow{3}{*}{ Nível } & Outro(especifique) & 0 & 3 & 1 & 4 \\
\hline & $\%$ na linha & $0,00 \%$ & $75,00 \%$ & $25,00 \%$ & $100,00 \%$ \\
\hline & Primeiro(mais alto) & 3 & 7 & 0 & 10 \\
\hline
\end{tabular}




\begin{tabular}{|c|c|c|c|c|c|}
\hline \multicolumn{2}{|c|}{$\%$ na linha } & \multirow{2}{*}{$\begin{array}{c}30,00 \% \\
0\end{array}$} & \multirow{2}{*}{$\begin{array}{c}70,00 \% \\
7\end{array}$} & \multirow{2}{*}{$\begin{array}{c}0,00 \% \\
1\end{array}$} & \multirow{2}{*}{$\begin{array}{c}100,00 \% \\
8\end{array}$} \\
\hline & Quarto & & & & \\
\hline & $\%$ na linha & $0,00 \%$ & $87,50 \%$ & $12,50 \%$ & $100,00 \%$ \\
\hline & Segundo & 8 & 22 & 0 & 30 \\
\hline & $\%$ na linha & $26,67 \%$ & $73,33 \%$ & $0,00 \%$ & $100,00 \%$ \\
\hline & Terceiro & 7 & 25 & 1 & 33 \\
\hline & $\%$ na linha & $21,21 \%$ & $75,76 \%$ & $3,03 \%$ & $100,00 \%$ \\
\hline & Total & 18 & 64 & 3 & 85 \\
\hline & Referência para comparações em \% & $21,18 \%$ & $75,29 \%$ & $3,53 \%$ & $100,00 \%$ \\
\hline \multirow{6}{*}{ Sexo } & Sexo feminino. & 3 & 37 & 1 & 41 \\
\hline & \% na linha & $7,32 \%$ & $90,24 \%$ & $2,44 \%$ & $100,00 \%$ \\
\hline & Sexo masculino & 15 & 27 & 2 & 44 \\
\hline & $\%$ na linha & $34,09 \%$ & $61,36 \%$ & $4,55 \%$ & $100,00 \%$ \\
\hline & Total & 18 & 64 & 3 & 85 \\
\hline & Referência para comparações em \% & $21,18 \%$ & $75,29 \%$ & $3,53 \%$ & $100,00 \%$ \\
\hline
\end{tabular}

Enquanto a questão 2.1 "o bom planejamento de obras de drenagem exige a participação de cientistas sociais" obteve uma proporção de concordância de quase $70 \%$, a concordância com a participação de cientistas sociais para a boa implantação de obras de drenagem chega a pouco mais de $75 \%$. O grupo de nível hierárquico de primeiro e segundo escalão, sendo que estes são os que se encontram mais acima do percentual de referência, revelando maior rejeição quanto à participação de cientistas sociais na implantação de obras. A grande diferença fica entre homens e mulheres No computo geral, são as mulheres que mais aceitam a participação de cientistas sociais na implantação das obras de drenagem quando seu grau de concordância é comparado com a referência. Chama atenção o número de 'sem resposta', sobretudo entre o grupo de formação 'sociopolítica', onde se encontram cientistas sociais.

\begin{tabular}{|c|c|c|c|c|c|}
\hline \multirow[b]{2}{*}{ Variável } & \multirow[b]{2}{*}{ Atributo } & \multirow[t]{2}{*}{ discordo } & \multirow[t]{2}{*}{ concordo } & \multirow[t]{2}{*}{$\begin{array}{c}\text { sem } \\
\text { resposta }\end{array}$} & \multirow[t]{2}{*}{ total } \\
\hline & & & & & \\
\hline \multirow{10}{*}{ Formação } & Arquitetura & 3 & 19 & 0 & 22 \\
\hline & $\%$ na linha & $13,64 \%$ & $86,36 \%$ & $0,00 \%$ & $100,00 \%$ \\
\hline & Engenharia Civil & 1 & 29 & 0 & 30 \\
\hline & \% na linha & $3,33 \%$ & $96,67 \%$ & $0,00 \%$ & $100,00 \%$ \\
\hline & Outros & 1 & 10 & 1 & 12 \\
\hline & $\%$ na linha & $8,33 \%$ & $83,33 \%$ & $8,33 \%$ & $100,00 \%$ \\
\hline & Sociopolítico & 2 & 18 & 1 & 21 \\
\hline & $\%$ na linha & $9,52 \%$ & $85,71 \%$ & $4,76 \%$ & $100,00 \%$ \\
\hline & Total & 7 & 76 & 2 & 85 \\
\hline & ia para comparações em \% & $8,24 \%$ & $89,41 \%$ & $2,35 \%$ & $100,00 \%$ \\
\hline
\end{tabular}




\begin{tabular}{|c|c|c|c|c|c|}
\hline \multirow{6}{*}{ Função } & Assessoria - Consultoria - Docência & 3 & 42 & 1 & 46 \\
\hline & $\%$ na linha & $6,52 \%$ & $91,30 \%$ & $2,17 \%$ & $100,00 \%$ \\
\hline & Coordenação - Gestão - Supervisão & 4 & 34 & 1 & 39 \\
\hline & $\%$ na linha & $10,26 \%$ & $87,18 \%$ & $2,56 \%$ & $100,00 \%$ \\
\hline & Total & 7 & 76 & 2 & 85 \\
\hline & Referência para comparações em \% & $8,24 \%$ & $89,41 \%$ & $2,35 \%$ & $100,00 \%$ \\
\hline \multirow{10}{*}{ Idade } & 30a39anos & 2 & 16 & 0 & 18 \\
\hline & $\%$ na linha & $11,11 \%$ & $88,89 \%$ & $0,00 \%$ & $100,00 \%$ \\
\hline & 40a49anos & 2 & 12 & 1 & 15 \\
\hline & $\%$ na linha & $13,33 \%$ & $80,00 \%$ & $6,67 \%$ & $100,00 \%$ \\
\hline & 50a59anos & 3 & 34 & 0 & 37 \\
\hline & $\%$ na linha & $8,11 \%$ & $91,89 \%$ & $0,00 \%$ & $100,00 \%$ \\
\hline & 60anos a mais & 0 & 14 & 1 & 15 \\
\hline & $\%$ na linha & $0,00 \%$ & $93,33 \%$ & $6,67 \%$ & $100,00 \%$ \\
\hline & Total & 7 & 76 & 2 & 85 \\
\hline & Referência para comparações em \% & $8,24 \%$ & $89,41 \%$ & $2,35 \%$ & $100,00 \%$ \\
\hline \multirow{12}{*}{ Nível } & Outro(especifique) & 1 & 3 & 0 & 4 \\
\hline & $\%$ na linha & $25,00 \%$ & $75,00 \%$ & $0,00 \%$ & $100,00 \%$ \\
\hline & Primeiro(mais alto) & 0 & 10 & 0 & 10 \\
\hline & $\%$ na linha & $0,00 \%$ & $100,00 \%$ & $0,00 \%$ & $100,00 \%$ \\
\hline & Quarto & 0 & 8 & 0 & 8 \\
\hline & $\%$ na linha & $0,00 \%$ & $100,00 \%$ & $0,00 \%$ & $100,00 \%$ \\
\hline & Segundo & 1 & 29 & 0 & 30 \\
\hline & $\%$ na linha & $3,33 \%$ & $96,67 \%$ & $0,00 \%$ & $100,00 \%$ \\
\hline & Terceiro & 5 & 26 & 2 & 33 \\
\hline & $\%$ na linha & $15,15 \%$ & $78,79 \%$ & $6,06 \%$ & $100,00 \%$ \\
\hline & Total & 7 & 76 & 2 & 85 \\
\hline & Referência para comparações em \% & $8,24 \%$ & $89,41 \%$ & $2,35 \%$ & $100,00 \%$ \\
\hline \multirow{6}{*}{ Sexo } & Sexo feminino. & 1 & 40 & 0 & 41 \\
\hline & $\%$ na linha & $2,44 \%$ & $97,56 \%$ & $0,00 \%$ & $100,00 \%$ \\
\hline & Sexo masculino & 6 & 36 & 2 & 44 \\
\hline & $\%$ na linha & $13,64 \%$ & $81,82 \%$ & $4,55 \%$ & $100,00 \%$ \\
\hline & Total & 7 & 76 & 2 & 85 \\
\hline & Referência para comparações em \% & $8,24 \%$ & $89,41 \%$ & $2,35 \%$ & $100,00 \%$ \\
\hline
\end{tabular}

Já a participação de educadores ambientais para a boa implantação de obras de drenagem é bem mais aceita do que a de cientistas sociais. A referência de concordância frente a esta questão (implantação de obras de drenagem) é ligeiramente mais alta (referência de concordância de quase $89,41 \%$ ) do que a obtida para a participação de educadores ambientais no planejamento das obras (referência de concordância de quase $87,6 \%$ ). No grupo de nível hierárquico de primeiro escalão e de quarto escalão a concordância é a mais alta frente a referência. Também o grupo de mulheres 
(divergindo da opinião dos homens) e os de formação em Engenharia Civil apresentam proporção de concordância bem superior à referência. Parece haver o reconhecimento do papel do educador ambiental tanto no planejamento quanto na implantação das obras, o que significa a valorização deste profissional.

\begin{tabular}{|c|c|c|c|c|c|}
\hline & & discordo & concordo & $\begin{array}{c}\text { sem } \\
\text { resposta }\end{array}$ & total \\
\hline Variável & Atributo & & & & \\
\hline \multirow{10}{*}{ Formação } & Arquitetura & 2 & 19 & 1 & 22 \\
\hline & $\%$ na linha & $9,09 \%$ & $86,36 \%$ & $4,55 \%$ & $100,00 \%$ \\
\hline & Engenharia Civil & 7 & 23 & 0 & 30 \\
\hline & \% na linha & $23,33 \%$ & $76,67 \%$ & $0,00 \%$ & $100,00 \%$ \\
\hline & Outros & 3 & 9 & 0 & 12 \\
\hline & $\%$ na linha & $25,00 \%$ & $75,00 \%$ & $0,00 \%$ & $100,00 \%$ \\
\hline & Sociopolítico & 1 & 18 & 2 & 21 \\
\hline & $\%$ na linha & $4,76 \%$ & $85,71 \%$ & $9,52 \%$ & $100,00 \%$ \\
\hline & Total & 13 & 69 & 3 & 85 \\
\hline & Referência para comparações em \% & $15,29 \%$ & $81,18 \%$ & $3,53 \%$ & $100,00 \%$ \\
\hline \multirow{6}{*}{ Função } & Assessoria - Consultoria - Docência & 7 & 38 & 1 & 46 \\
\hline & $\%$ na linha & $4,76 \%$ & $85,71 \%$ & $9,52 \%$ & $100,00 \%$ \\
\hline & Coordenação - Gestão - Supervisão & 6 & 31 & 2 & 39 \\
\hline & $\%$ na linha & $15,38 \%$ & $79,49 \%$ & $5,13 \%$ & $100,00 \%$ \\
\hline & Total & 13 & 69 & 3 & 85 \\
\hline & Referência para comparações em \% & $15,29 \%$ & $81,18 \%$ & $3,53 \%$ & $100,00 \%$ \\
\hline \multirow{10}{*}{ Idade } & 30a39anos & 1 & 17 & 0 & 18 \\
\hline & $\%$ na linha & $5,56 \%$ & $94,44 \%$ & $0,00 \%$ & $100,00 \%$ \\
\hline & 40a49anos & 3 & 11 & 1 & 15 \\
\hline & $\%$ na linha & $20,00 \%$ & $73,33 \%$ & $6,67 \%$ & $100,00 \%$ \\
\hline & 50a59anos & 6 & 29 & 2 & 37 \\
\hline & $\%$ na linha & $16,22 \%$ & $78,38 \%$ & $5,41 \%$ & $100,00 \%$ \\
\hline & 60anos a mais & 3 & 12 & 0 & 15 \\
\hline & $\%$ na linha & $20,00 \%$ & $80,00 \%$ & $0,00 \%$ & $100,00 \%$ \\
\hline & Total & 13 & 69 & 3 & 85 \\
\hline & Referência para comparações em \% & $15,29 \%$ & $81,18 \%$ & $3,53 \%$ & $100,00 \%$ \\
\hline \multirow{8}{*}{ Nível } & Outro(especifique) & 0 & 4 & 0 & 4 \\
\hline & $\%$ na linha & $0,00 \%$ & $100,00 \%$ & $0,00 \%$ & $100,00 \%$ \\
\hline & Primeiro(mais alto) & 2 & 8 & 0 & 10 \\
\hline & $\%$ na linha & $20,00 \%$ & $80,00 \%$ & $0,00 \%$ & $100,00 \%$ \\
\hline & Quarto & 0 & 7 & 1 & 8 \\
\hline & $\%$ na linha & $0,00 \%$ & $87,50 \%$ & $12,50 \%$ & $100,00 \%$ \\
\hline & Segundo & 4 & 25 & 1 & 30 \\
\hline & $\%$ na linha & $13,33 \%$ & $83,33 \%$ & $3,33 \%$ & $100,00 \%$ \\
\hline
\end{tabular}




\begin{tabular}{|c|c|c|c|c|c|}
\hline & Terceiro & 7 & 25 & 1 & 33 \\
\hline & $\%$ na linha & $21,21 \%$ & $75,76 \%$ & $3,03 \%$ & $100,00 \%$ \\
\hline & Total & 13 & 69 & 3 & 85 \\
\hline & Referência para comparações em \% & $15,29 \%$ & $81,18 \%$ & $3,53 \%$ & $100,00 \%$ \\
\hline \multirow{6}{*}{ Sexo } & Sexo feminino. & 4 & 36 & 1 & 41 \\
\hline & $\%$ na linha & $9,76 \%$ & $87,80 \%$ & $2,44 \%$ & $100,00 \%$ \\
\hline & Sexo masculino & 9 & 33 & 2 & 44 \\
\hline & $\%$ na linha & $20,45 \%$ & $75,00 \%$ & $4,55 \%$ & $100,00 \%$ \\
\hline & Total & 13 & 69 & 3 & 85 \\
\hline & Referência para comparações em \% & $15,29 \%$ & $81,18 \%$ & $3,53 \%$ & $100,00 \%$ \\
\hline
\end{tabular}

Esses dados revelam certo consenso quanto á concordância com a participação de empresários locais ou comerciantes na implantação das obras de drenagem, sobretudo por parte dos engenheiros. Os mais jovens são os que mais concordam, estando bem acima da referência do percentual do grau de concordância. Essa tendência foi também verificada, ainda que em menor grau de concordância, quanto à participação desses atores no planejamenteo de obras, tal como ilustrado para a pergunta 2.2.

Pergunta 7.5 - Para a boa implantação de obras de drenagem é necessário que haja o envolvimento de Engenheiros.

\begin{tabular}{|c|c|c|c|c|c|}
\hline & & discordo & concordo & $\begin{array}{c}\text { sem } \\
\text { resposta }\end{array}$ & total \\
\hline Variável & Atributo & & & & \\
\hline \multirow{10}{*}{ Formação } & Arquitetura & 0 & 22 & 0 & 22 \\
\hline & $\%$ na linha & $0,00 \%$ & $100,00 \%$ & $0,00 \%$ & $100,00 \%$ \\
\hline & Engenharia Civil & 0 & 30 & 0 & 30 \\
\hline & $\%$ na linha & $0,00 \%$ & $100,00 \%$ & $0,00 \%$ & $100,00 \%$ \\
\hline & Outros & 0 & 12 & 0 & 12 \\
\hline & $\%$ na linha & $0,00 \%$ & $100,00 \%$ & $0,00 \%$ & $100,00 \%$ \\
\hline & Sociopolítico & 2 & 18 & 1 & 21 \\
\hline & \% na linha & $9,52 \%$ & $85,71 \%$ & $4,76 \%$ & $100,00 \%$ \\
\hline & Total & 2 & 82 & 1 & 85 \\
\hline & Referência para comparações em \% & $2,35 \%$ & $96,47 \%$ & $1,18 \%$ & $100,00 \%$ \\
\hline \multirow{6}{*}{ Função } & Assessoria - Consultoria - Docência & 0 & 46 & 0 & 46 \\
\hline & $\%$ na linha & $0,00 \%$ & $100,00 \%$ & $0,00 \%$ & $100,00 \%$ \\
\hline & Coordenação - Gestão - Supervisão & 2 & 36 & 1 & 39 \\
\hline & $\%$ na linha & $5,13 \%$ & $92,31 \%$ & $2,56 \%$ & $100,00 \%$ \\
\hline & Total & 2 & 82 & 1 & 85 \\
\hline & Referência para comparações em \% & $2,35 \%$ & $96,47 \%$ & $1,18 \%$ & $100,00 \%$ \\
\hline \multirow{4}{*}{ Idade } & 30a39anos & 1 & 17 & 0 & 18 \\
\hline & $\%$ na linha & $5,56 \%$ & $94,44 \%$ & $0,00 \%$ & $100,00 \%$ \\
\hline & 40a49anos & 0 & 14 & 1 & 15 \\
\hline & $\%$ na linha & $0,00 \%$ & $93,33 \%$ & $6,67 \%$ & $100,00 \%$ \\
\hline
\end{tabular}




\begin{tabular}{|c|c|c|c|c|c|}
\hline & 50a59anos & 1 & 36 & 0 & 37 \\
\hline & $\%$ na linha & $2,70 \%$ & $97,30 \%$ & $0,00 \%$ & $100,00 \%$ \\
\hline & 60 anos a mais & 0 & 15 & 0 & 15 \\
\hline & $\%$ na linha & $0,00 \%$ & $100,00 \%$ & $0,00 \%$ & $100,00 \%$ \\
\hline & Total & 2 & 82 & 1 & 85 \\
\hline & Referência para comparações em \% & $2,35 \%$ & $96,47 \%$ & $1,18 \%$ & $100,00 \%$ \\
\hline \multirow{12}{*}{ Nível } & Outro(especifique) & 1 & 3 & 0 & 4 \\
\hline & $\%$ na linha & $25,00 \%$ & $75,00 \%$ & $0,00 \%$ & $100,00 \%$ \\
\hline & Primeiro(mais alto) & 0 & 10 & 0 & 10 \\
\hline & $\%$ na linha & $0,00 \%$ & $100,00 \%$ & $0,00 \%$ & $100,00 \%$ \\
\hline & Quarto & 0 & 8 & 0 & 8 \\
\hline & $\%$ na linha & $0,00 \%$ & $100,00 \%$ & $0,00 \%$ & $100,00 \%$ \\
\hline & Segundo & 1 & 29 & 0 & 30 \\
\hline & $\%$ na linha & $3,33 \%$ & $96,67 \%$ & $0,00 \%$ & $100,00 \%$ \\
\hline & Terceiro & 0 & 32 & 1 & 33 \\
\hline & $\%$ na linha & $0,00 \%$ & $96,97 \%$ & $3,03 \%$ & $100,00 \%$ \\
\hline & Total & 2 & 82 & 1 & 85 \\
\hline & Referência para comparações em \% & $2,35 \%$ & $96,47 \%$ & $1,18 \%$ & $100,00 \%$ \\
\hline \multirow{6}{*}{ Sexo } & Sexo feminino. & 0 & 41 & 0 & 41 \\
\hline & \% na linha & $0,00 \%$ & $100,00 \%$ & $0,00 \%$ & $100,00 \%$ \\
\hline & Sexo masculino & 2 & 41 & 1 & 44 \\
\hline & $\%$ na linha & $4,55 \%$ & $93,18 \%$ & $2,27 \%$ & $100,00 \%$ \\
\hline & Total & 2 & 82 & 1 & 85 \\
\hline & Referência para comparações em \% & $2,35 \%$ & $96,47 \%$ & $1,18 \%$ & $100,00 \%$ \\
\hline
\end{tabular}

Existe consenso com relação a esta questão, sendo que os grupos de formação em Arquitetura, Engenharia Civil e outras são unânimes quanto à sua concordância, da mesma forma que o grupo de função em Assessoria - Consultoria - Docência e o grupo de mulheres. Essa concordância para a participação de Engenheiros é a maior verificada, o que não é surpresa. O grupo composto pelos de formação sociopolítico foi o grupo que apresentou o maior grau de discordância. Talvez este resultado se explique pelo maior nível de falta de resposta por parte deste grupo. A pergunta que fica: como pode a obra ser implantada sem a presença do engenheiro? Este é um resultado a ser tomado com cuidado.

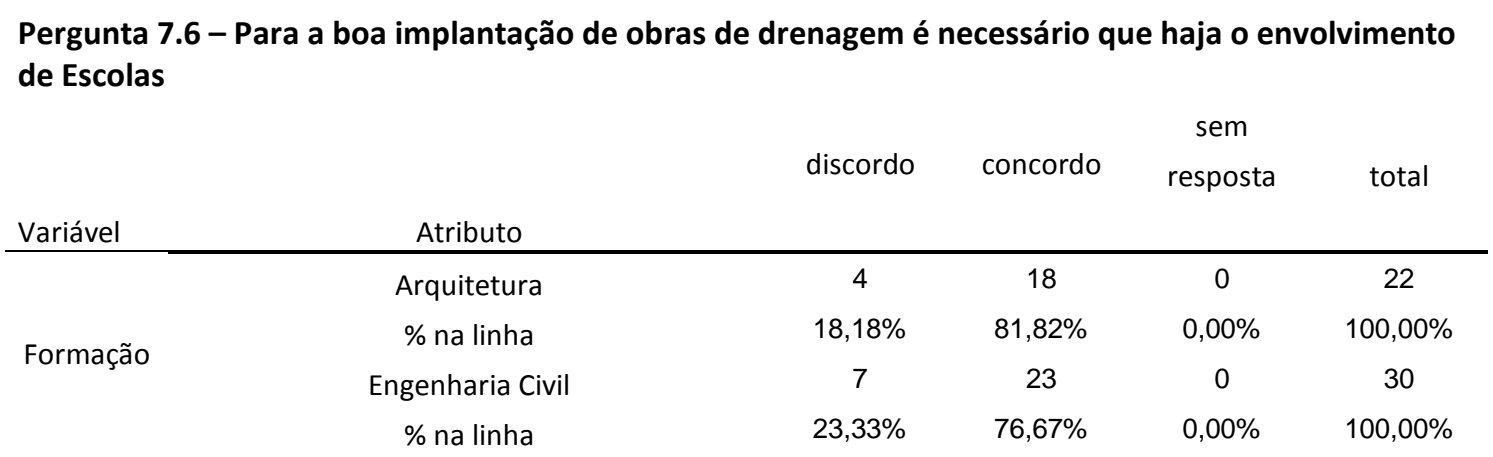




\begin{tabular}{|c|c|c|c|c|c|}
\hline & Outros & 3 & 9 & 0 & 12 \\
\hline & $\%$ na linha & $25,00 \%$ & $75,00 \%$ & $0,00 \%$ & $100,00 \%$ \\
\hline & Sociopolítico & 3 & 16 & 2 & 21 \\
\hline & $\%$ na linha & $14,29 \%$ & $76,19 \%$ & $9,52 \%$ & $100,00 \%$ \\
\hline & Total & 17 & 66 & 2 & 85 \\
\hline & Referência para comparações em \% & $20,00 \%$ & $77,65 \%$ & $2,35 \%$ & $100,00 \%$ \\
\hline \multirow{6}{*}{ Função } & Assessoria - Consultoria - Docência & 9 & 37 & 0 & 46 \\
\hline & $\%$ na linha & $19,57 \%$ & $80,43 \%$ & $0,00 \%$ & $100,00 \%$ \\
\hline & Coordenação - Gestão - Supervisão & 8 & 29 & 2 & 39 \\
\hline & $\%$ na linha & $20,51 \%$ & $74,36 \%$ & $5,13 \%$ & $100,00 \%$ \\
\hline & Total & 17 & 66 & 2 & 85 \\
\hline & Referência para comparações em \% & $20,00 \%$ & $77,65 \%$ & $2,35 \%$ & $100,00 \%$ \\
\hline \multirow{10}{*}{ Idade } & 30a39anos & 4 & 14 & 0 & 18 \\
\hline & $\%$ na linha & $22,22 \%$ & $77,78 \%$ & $0,00 \%$ & $100,00 \%$ \\
\hline & 40a49anos & 3 & 11 & 1 & 15 \\
\hline & $\%$ na linha & $20,00 \%$ & $73,33 \%$ & $6,67 \%$ & $100,00 \%$ \\
\hline & 50a59anos & 7 & 29 & 1 & 37 \\
\hline & $\%$ na linha & $18,92 \%$ & $78,38 \%$ & $2,70 \%$ & $100,00 \%$ \\
\hline & 60 anos a mais & 3 & 12 & 0 & 15 \\
\hline & $\%$ na linha & $20,00 \%$ & $80,00 \%$ & $0,00 \%$ & $100,00 \%$ \\
\hline & Total & 17 & 66 & 2 & 85 \\
\hline & Referência para comparações em \% & $20,00 \%$ & $77,65 \%$ & $2,35 \%$ & $100,00 \%$ \\
\hline \multirow{12}{*}{ Nível } & Outro(especifique) & 1 & 3 & 0 & 4 \\
\hline & $\%$ na linha & $25,00 \%$ & $75,00 \%$ & $0,00 \%$ & $100,00 \%$ \\
\hline & Primeiro(mais alto) & 1 & 9 & 0 & 10 \\
\hline & $\%$ na linha & $10,00 \%$ & $90,00 \%$ & $0,00 \%$ & $100,00 \%$ \\
\hline & Quarto & 0 & 7 & 1 & 8 \\
\hline & $\%$ na linha & $0,00 \%$ & $87,50 \%$ & $12,50 \%$ & $100,00 \%$ \\
\hline & Segundo & 4 & 26 & 0 & 30 \\
\hline & $\%$ na linha & $13,33 \%$ & $86,67 \%$ & $0,00 \%$ & $100,00 \%$ \\
\hline & Terceiro & 11 & 21 & 1 & 33 \\
\hline & $\%$ na linha & $33,33 \%$ & $63,64 \%$ & $3,03 \%$ & $100,00 \%$ \\
\hline & Total & 17 & 66 & 2 & 85 \\
\hline & Referência para comparações em \% & $20,00 \%$ & $77,65 \%$ & $2,35 \%$ & $100,00 \%$ \\
\hline \multirow{6}{*}{ Sexo } & Sexo feminino. & 6 & 34 & 1 & 41 \\
\hline & $\%$ na linha & $14,63 \%$ & $82,93 \%$ & $2,44 \%$ & $100,00 \%$ \\
\hline & Sexo masculino & 11 & 32 & 1 & 44 \\
\hline & $\%$ na linha & $25,00 \%$ & $72,73 \%$ & $2,27 \%$ & $100,00 \%$ \\
\hline & Total & 17 & 66 & 2 & 85 \\
\hline & Referência para comparações em \% & $20,00 \%$ & $77,65 \%$ & $2,35 \%$ & $100,00 \%$ \\
\hline
\end{tabular}


Não há interesse em que escolares ou professores das escolas da região se envolvam na implantação de obras de drenagem. O grupo de respondentes com formação em Engenharia Civil é o que maior grau de discordância apresenta com relação a esta questão, junto com o grupo de outras formações (onde se incluem também engenheiros -químicos, mecânicos, elétricos). O grupo do terceiro escalão tem a maior discordância entre todos.

Pergunta 7.7 - Para a boa implantação de obras de drenagem é necessário que haja o envolvimento de Lideranças Comunitária

\begin{tabular}{|c|c|c|c|c|c|}
\hline & & discordo & concordo & $\begin{array}{c}\text { sem } \\
\text { resposta }\end{array}$ & total \\
\hline Variável & Atributo & & & & \\
\hline \multirow{10}{*}{ Formação } & Arquitetura & 2 & 20 & 0 & 22 \\
\hline & $\%$ na linha & $9,09 \%$ & $90,91 \%$ & $0,00 \%$ & $100,00 \%$ \\
\hline & Engenharia Civil & 1 & 29 & 0 & 30 \\
\hline & $\%$ na linha & $3,33 \%$ & $96,67 \%$ & $0,00 \%$ & $100,00 \%$ \\
\hline & Outros & 1 & 11 & 0 & 12 \\
\hline & $\%$ na linha & $8,33 \%$ & $91,67 \%$ & $0,00 \%$ & $100,00 \%$ \\
\hline & Sociopolítico & 1 & 19 & 1 & 21 \\
\hline & $\%$ na linha & $4,76 \%$ & $90,48 \%$ & $4,76 \%$ & $100,00 \%$ \\
\hline & Total & 5 & 79 & 1 & 85 \\
\hline & Referência para comparações em \% & $5,88 \%$ & $92,94 \%$ & $1,18 \%$ & $100,00 \%$ \\
\hline \multirow{6}{*}{ Função } & Assessoria - Consultoria - Docência & 2 & 44 & 0 & 46 \\
\hline & $\%$ na linha & $4,35 \%$ & $95,65 \%$ & $0,00 \%$ & $100,00 \%$ \\
\hline & Coordenação - Gestão - Supervisão & 3 & 35 & 1 & 39 \\
\hline & $\%$ na linha & $7,69 \%$ & $89,74 \%$ & $2,56 \%$ & $100,00 \%$ \\
\hline & Total & 5 & 79 & 1 & 85 \\
\hline & Referência para comparações em \% & $5,88 \%$ & $92,94 \%$ & $1,18 \%$ & $100,00 \%$ \\
\hline \multirow{10}{*}{ Idade } & 30a39anos & 1 & 17 & 0 & 18 \\
\hline & $\%$ na linha & $5,56 \%$ & $94,44 \%$ & $0,00 \%$ & $100,00 \%$ \\
\hline & 40a49anos & 1 & 13 & 1 & 15 \\
\hline & $\%$ na linha & $6,67 \%$ & $86,67 \%$ & $6,67 \%$ & $100,00 \%$ \\
\hline & 50a59anos & 3 & 34 & 0 & 37 \\
\hline & $\%$ na linha & $8,11 \%$ & $91,89 \%$ & $0,00 \%$ & $100,00 \%$ \\
\hline & 60 anos a mais & 0 & 15 & 0 & 15 \\
\hline & $\%$ na linha & $0,00 \%$ & $100,00 \%$ & $0,00 \%$ & $100,00 \%$ \\
\hline & Total & 5 & 79 & 1 & 85 \\
\hline & Referência para comparações em \% & $5,88 \%$ & $92,94 \%$ & $1,18 \%$ & $100,00 \%$ \\
\hline \multirow{5}{*}{ Nível } & Outro(especifique) & 1 & 3 & 0 & 4 \\
\hline & $\%$ na linha & $25,00 \%$ & $75,00 \%$ & $0,00 \%$ & $100,00 \%$ \\
\hline & Primeiro(mais alto) & 0 & 10 & 0 & 10 \\
\hline & $\%$ na linha & $0,00 \%$ & $100,00 \%$ & $0,00 \%$ & $100,00 \%$ \\
\hline & Quarto & 1 & 7 & 0 & 8 \\
\hline
\end{tabular}




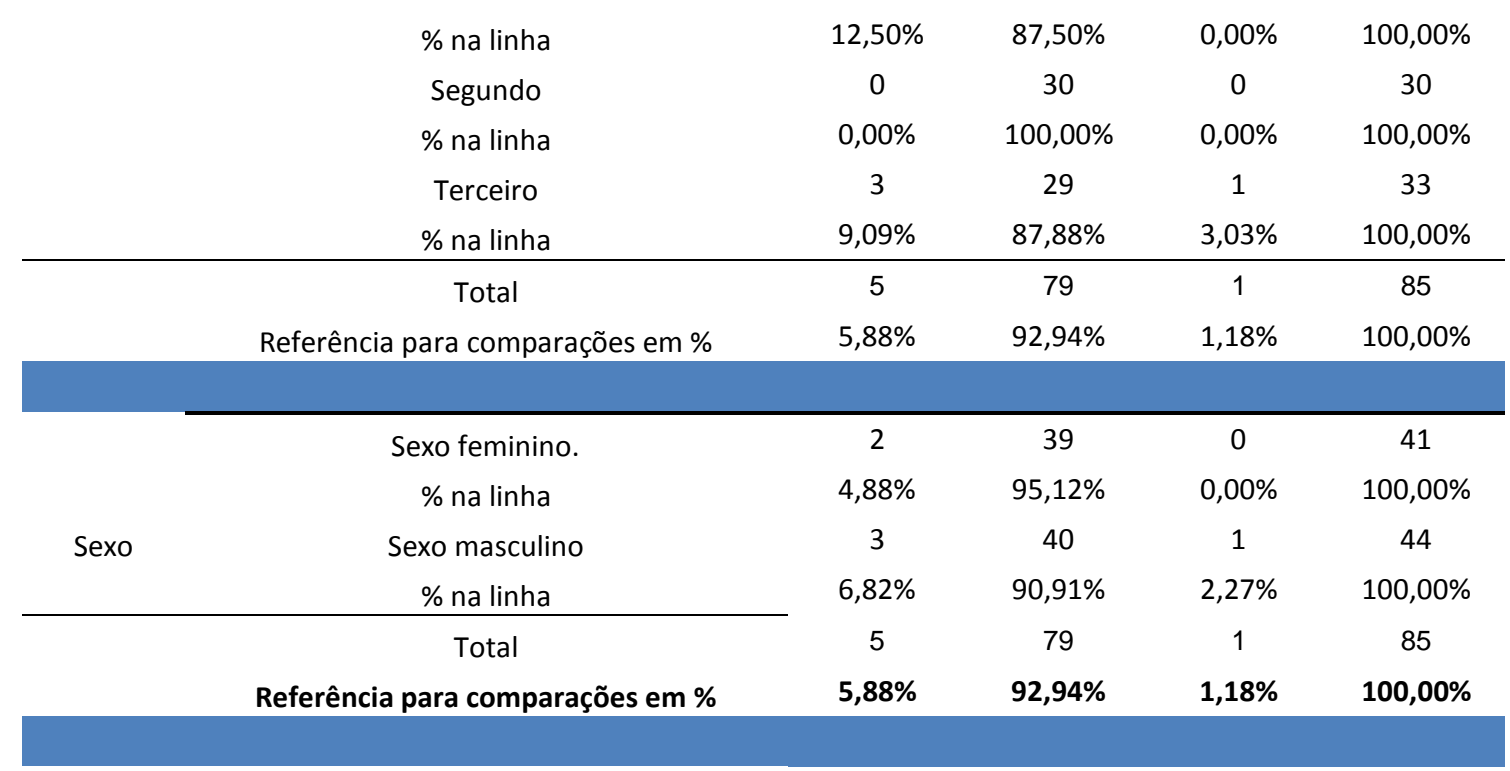

É interessante notar que, enquanto a participação de Lideranças Comunitárias no planejamento das obras contou com grau de concordância dos Engenheiros Civis de 83,33\%, para a implantação das obras, quase $97 \%$ dos Engenheiros Civis concordam com a importância da participação de Lideranças Comunitárias. Esse resultado pode refletir a necessidade de parcerias com as lideranças locais para o sucesso da implantação. Também acima da referência está a concordância de 100\% profissionais de primeiro e de segundo escalões, dado talvez a sua maior responsabilidade com relação ao sucesso das obras e também a necessidade de parcerias.

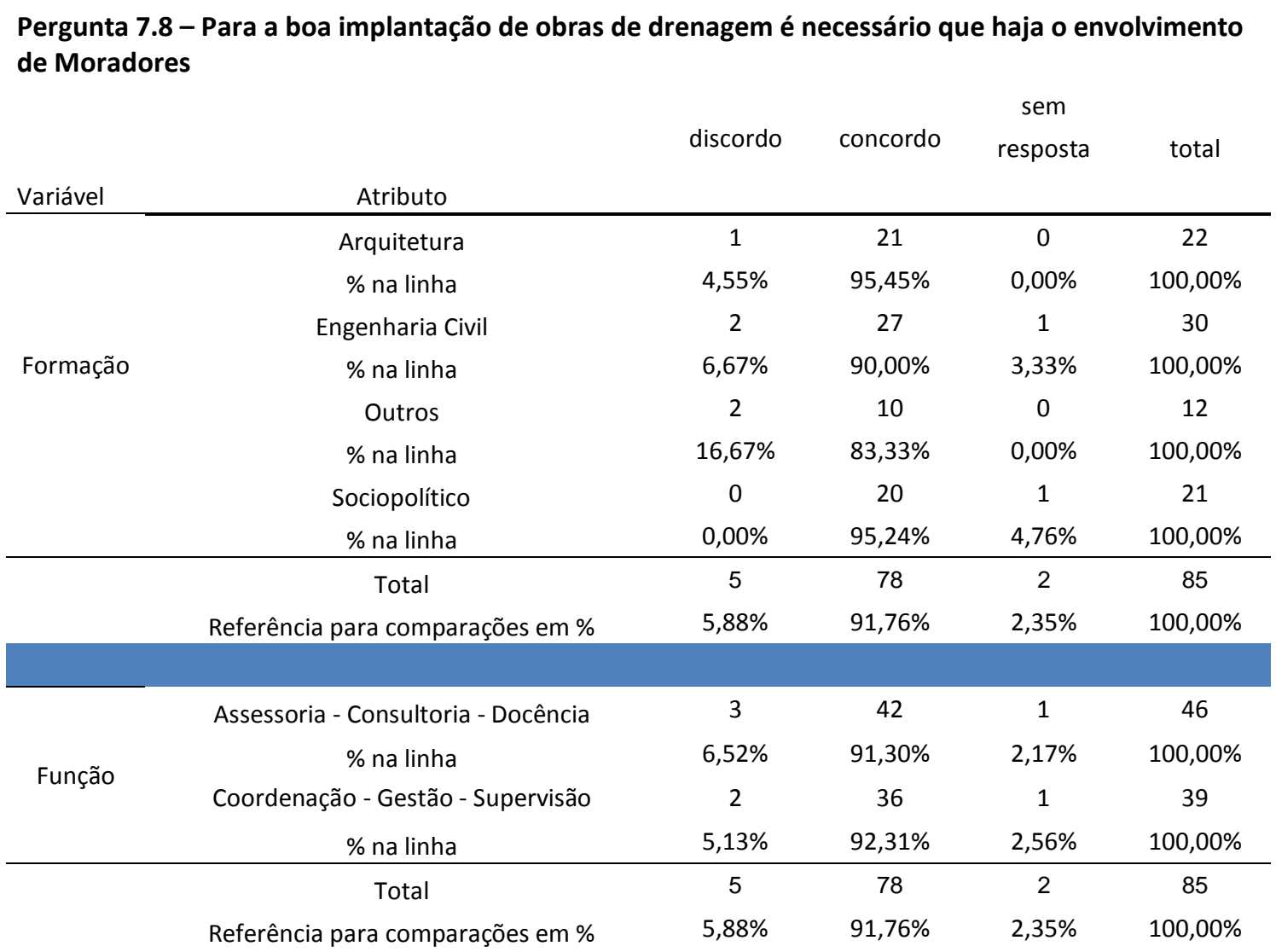




\begin{tabular}{|c|c|c|c|c|c|}
\hline \multirow{10}{*}{ Idade } & 30a39anos & 0 & 18 & 0 & 18 \\
\hline & $\%$ na linha & $0,00 \%$ & $100,00 \%$ & $0,00 \%$ & $100,00 \%$ \\
\hline & 40a49anos & 1 & 13 & 1 & 15 \\
\hline & $\%$ na linha & $6,67 \%$ & $86,67 \%$ & $6,67 \%$ & $100,00 \%$ \\
\hline & 50a59anos & 3 & 34 & 0 & 37 \\
\hline & $\%$ na linha & $8,11 \%$ & $91,89 \%$ & $0,00 \%$ & $100,00 \%$ \\
\hline & 60anos a mais & 1 & 13 & 1 & 15 \\
\hline & $\%$ na linha & $6,67 \%$ & $86,67 \%$ & $6,67 \%$ & $100,00 \%$ \\
\hline & Total & 5 & 78 & 2 & 85 \\
\hline & Referência para comparações em \% & $5,88 \%$ & $91,76 \%$ & $2,35 \%$ & $100,00 \%$ \\
\hline \multirow{12}{*}{ Nível } & Outro(especifique) & 0 & 4 & 0 & 4 \\
\hline & $\%$ na linha & $0,00 \%$ & $100,00 \%$ & $0,00 \%$ & $100,00 \%$ \\
\hline & Primeiro(mais alto) & 1 & 9 & 0 & 10 \\
\hline & $\%$ na linha & $10 \%$ & $90 \%$ & $0 \%$ & $100 \%$ \\
\hline & Quarto & 0 & 8 & 0 & 8 \\
\hline & $\%$ na linha & $0,00 \%$ & $100,00 \%$ & $0,00 \%$ & $100,00 \%$ \\
\hline & Segundo & 0 & 30 & 0 & 30 \\
\hline & $\%$ na linha & $0,00 \%$ & $100,00 \%$ & $0,00 \%$ & $100,00 \%$ \\
\hline & Terceiro & 4 & 27 & 2 & 33 \\
\hline & $\%$ na linha & $12,12 \%$ & $81,82 \%$ & $6,06 \%$ & $100,00 \%$ \\
\hline & Total & 5 & 78 & 2 & 85 \\
\hline & Referência para comparações em \% & $5,88 \%$ & $91,76 \%$ & $2,35 \%$ & $100,00 \%$ \\
\hline \multirow{6}{*}{ Sexo } & Sexo feminino. & 3 & 38 & 0 & 41 \\
\hline & \% na linha & $7,32 \%$ & $92,68 \%$ & $0,00 \%$ & $100,00 \%$ \\
\hline & Sexo masculino & 2 & 40 & 2 & 44 \\
\hline & $\%$ na linha & $4,55 \%$ & $90,91 \%$ & $4,55 \%$ & $100,00 \%$ \\
\hline & Total & 5 & 78 & 2 & 85 \\
\hline & Referência para comparações em \% & $5,88 \%$ & $91,76 \%$ & $2,35 \%$ & $100,00 \%$ \\
\hline
\end{tabular}

Em geral, a referência do percentual de concordância com a participação de moradores no planejamento das obras é de 92,94\% como visto anteriormente, e na implantação de obras de drenagem o percentual de referência é de $91,76 \%$, portanto ligeiramente menor. Este primeiro resultado demonstra que há consenso quanto à participação de moradores. Em ambos casos (participação de moradores no planejamento e na implantação das obras), os Engenheiros Civis e os profissionais do primeiro escalão apresentam os mais baixos graus de concordância com esta participação.

Pergunta 7.9 - Para a boa implantação de obras de drenagem é necessário que haja o envolvimento de Políticos

\begin{tabular}{lccccc} 
& & discordo & concordo & remposta & total \\
Variável & Atributo & & & & \\
\hline Formação & Arquitetura & 6 & 15 & 1 & 22
\end{tabular}




\begin{tabular}{|c|c|c|c|c|c|}
\hline & $\%$ na linha & $27,27 \%$ & $68,18 \%$ & $4,55 \%$ & $100,00 \%$ \\
\hline & Engenharia Civil & 11 & 19 & 0 & 30 \\
\hline & $\%$ na linha & $36,67 \%$ & $63,33 \%$ & $0,00 \%$ & $100,00 \%$ \\
\hline & Outros & 6 & 5 & 1 & 12 \\
\hline & $\%$ na linha & $50,00 \%$ & $41,67 \%$ & $8,33 \%$ & $100,00 \%$ \\
\hline & Sociopolítico & 3 & 16 & 2 & 21 \\
\hline & $\%$ na linha & $14,29 \%$ & $76,19 \%$ & $9,52 \%$ & $100,00 \%$ \\
\hline & Total & 26 & 55 & 4 & 85 \\
\hline & Referência para comparações em \% & $30,59 \%$ & $64,71 \%$ & $4,71 \%$ & $100,00 \%$ \\
\hline \multirow{6}{*}{ Função } & Assessoria - Consultoria - Docência & 14 & 31 & 1 & 46 \\
\hline & $\%$ na linha & $30,43 \%$ & $67,39 \%$ & $2,17 \%$ & $100,00 \%$ \\
\hline & Coordenação - Gestão - Supervisão & 12 & 24 & 3 & 39 \\
\hline & $\%$ na linha & $30,77 \%$ & $61,54 \%$ & $7,69 \%$ & $100,00 \%$ \\
\hline & Total & 26 & 55 & 4 & 85 \\
\hline & Referência para comparações em \% & $30,59 \%$ & $64,71 \%$ & $4,71 \%$ & $100,00 \%$ \\
\hline \multirow{10}{*}{ Idade } & 30a39anos & 6 & 12 & 0 & 18 \\
\hline & $\%$ na linha & $33,33 \%$ & $66,67 \%$ & $0,00 \%$ & $100,00 \%$ \\
\hline & 40a49anos & 5 & 8 & 2 & 15 \\
\hline & $\%$ na linha & $33,33 \%$ & $53,33 \%$ & $13,33 \%$ & $100,00 \%$ \\
\hline & 50a59anos & 11 & 24 & 2 & 37 \\
\hline & $\%$ na linha & $29,73 \%$ & $64,86 \%$ & $5,41 \%$ & $100,00 \%$ \\
\hline & 60 anos a mais & 4 & 11 & 0 & 15 \\
\hline & $\%$ na linha & $26,67 \%$ & $73,33 \%$ & $0,00 \%$ & $100,00 \%$ \\
\hline & Total & 26 & 55 & 4 & 85 \\
\hline & Referência para comparações em \% & $30,59 \%$ & $64,71 \%$ & $4,71 \%$ & $100,00 \%$ \\
\hline \multirow{12}{*}{ Nível } & Outro(especifique) & 0 & 4 & 0 & 4 \\
\hline & $\%$ na linha & $0,00 \%$ & $100,00 \%$ & $0,00 \%$ & $100,00 \%$ \\
\hline & Primeiro(mais alto) & 3 & 6 & 1 & 10 \\
\hline & $\%$ na linha & $30,00 \%$ & $60,00 \%$ & $10,00 \%$ & $100,00 \%$ \\
\hline & Quarto & 2 & 5 & 1 & 8 \\
\hline & $\%$ na linha & $25,00 \%$ & $62,50 \%$ & $12,50 \%$ & $100,00 \%$ \\
\hline & Segundo & 9 & 20 & 1 & 30 \\
\hline & $\%$ na linha & $30,00 \%$ & $66,67 \%$ & $3,33 \%$ & $100,00 \%$ \\
\hline & Terceiro & 12 & 20 & 1 & 33 \\
\hline & $\%$ na linha & $36,36 \%$ & $60,61 \%$ & $3,03 \%$ & $100,00 \%$ \\
\hline & Total & 26 & 55 & 4 & 85 \\
\hline & Referência para comparações em \% & $30,59 \%$ & $64,71 \%$ & $4,71 \%$ & $100,00 \%$ \\
\hline \multirow{6}{*}{ Sexo } & Sexo feminino. & 9 & 29 & 3 & 41 \\
\hline & $\%$ na linha & $21,95 \%$ & $70,73 \%$ & $7,32 \%$ & $100,00 \%$ \\
\hline & Sexo masculino & 17 & 26 & 1 & 44 \\
\hline & $\%$ na linha & $38,64 \%$ & $59,09 \%$ & $2,27 \%$ & $100,00 \%$ \\
\hline & Total & 26 & 55 & 4 & 85 \\
\hline & Referência para comparações em \% & $30,59 \%$ & $64,71 \%$ & $4,71 \%$ & $100,00 \%$ \\
\hline
\end{tabular}


Assim como no planejamento de obras de drenagem, a participação de políticos da região não é bem vinda durante a sua implantação. Ainda que em menor proporção do que para a discordância com a participação de políticos no planejamento das obras (35,29\%), na sua implantação o grau de discordância é ainda alto (30,59\%). É interessante notar que o grupo de formação sociopolítica é o que apresenta maior grau de concordância com a participação de políticos na implantação de obras, seguido dos mais velhos e do grupo formado por mulheres. Já Engenheiros Civis, os do terceiro escalão e o grupo de homens são os que apresentam maior grau de discordância com esta participação. Também quanto a essa participação na implantação de obras, é alto o grau de 'sem resposta'.

\begin{tabular}{|c|c|c|c|c|c|}
\hline & & discordo & concordo & $\begin{array}{c}\text { sem } \\
\text { resposta }\end{array}$ & total \\
\hline Variável & Atributo & & & & \\
\hline \multirow{10}{*}{ Formação } & Arquitetura & 1 & 21 & 0 & 22 \\
\hline & $\%$ na linha & $4,55 \%$ & $95,45 \%$ & $0,00 \%$ & $100,00 \%$ \\
\hline & Engenharia Civil & 1 & 29 & 0 & 30 \\
\hline & $\%$ na linha & $3,33 \%$ & $96,67 \%$ & $0,00 \%$ & $100,00 \%$ \\
\hline & Outros & 0 & 12 & 0 & 12 \\
\hline & $\%$ na linha & $0,00 \%$ & $100,00 \%$ & $0,00 \%$ & $100,00 \%$ \\
\hline & Sociopolítico & 0 & 20 & 1 & 21 \\
\hline & $\%$ na linha & $0,00 \%$ & $95,24 \%$ & $4,76 \%$ & $100,00 \%$ \\
\hline & Total & 2 & 82 & 1 & 85 \\
\hline & Referência para comparações em \% & $2,35 \%$ & $96,47 \%$ & $1,18 \%$ & $100,00 \%$ \\
\hline \multirow{6}{*}{ Função } & Assessoria - Consultoria - Docência & 0 & 46 & 0 & 46 \\
\hline & $\%$ na linha & $0,00 \%$ & $100,00 \%$ & $0,00 \%$ & $100,00 \%$ \\
\hline & Coordenação - Gestão - Supervisão & 2 & 36 & 1 & 39 \\
\hline & $\%$ na linha & $5,13 \%$ & $92,31 \%$ & $2,56 \%$ & $100,00 \%$ \\
\hline & Total & 2 & 82 & 1 & 85 \\
\hline & Referência para comparações em \% & $2,35 \%$ & $96,47 \%$ & $1,18 \%$ & $100,00 \%$ \\
\hline \multirow{8}{*}{ Idade } & 30a39anos & 1 & 17 & 0 & 18 \\
\hline & $\%$ na linha & $5,56 \%$ & $94,44 \%$ & $0,00 \%$ & $100,00 \%$ \\
\hline & 40a49anos & 0 & 14 & 1 & 15 \\
\hline & $\%$ na linha & $0,00 \%$ & $93,33 \%$ & $6,67 \%$ & $100,00 \%$ \\
\hline & 50a59anos & 0 & 37 & 0 & 37 \\
\hline & $\%$ na linha & $0,00 \%$ & $100,00 \%$ & $0,00 \%$ & 100,00 \\
\hline & 60anos a mais & 1 & 14 & 0 & 15 \\
\hline & $\%$ na linha & $6,67 \%$ & $93,33 \%$ & $0,00 \%$ & $100,00 \%$ \\
\hline
\end{tabular}




\begin{tabular}{|c|c|c|c|c|c|}
\hline & Total & 2 & 82 & 1 & 85 \\
\hline & Referência para comparações em \% & $2,35 \%$ & $96,47 \%$ & $1,18 \%$ & $100,00 \%$ \\
\hline \multirow{12}{*}{ Nível } & Outro(especifique) & 0 & 4 & 0 & 4 \\
\hline & $\%$ na linha & $0,00 \%$ & $100,00 \%$ & $0,00 \%$ & $100,00 \%$ \\
\hline & Primeiro(mais alto) & 0 & 10 & 0 & 10 \\
\hline & $\%$ na linha & $0,00 \%$ & $100,00 \%$ & $0,00 \%$ & $100,00 \%$ \\
\hline & Quarto & 0 & 8 & 0 & 8 \\
\hline & $\%$ na linha & $0,00 \%$ & $100,00 \%$ & $0,00 \%$ & $100,00 \%$ \\
\hline & Segundo & 1 & 29 & 0 & 30 \\
\hline & $\%$ na linha & $3,33 \%$ & $96,67 \%$ & $0,00 \%$ & $100,00 \%$ \\
\hline & Terceiro & 1 & 31 & 1 & 33 \\
\hline & $\%$ na linha & $3,03 \%$ & $93,94 \%$ & $3,03 \%$ & $100,00 \%$ \\
\hline & Total & 2 & 82 & 1 & 85 \\
\hline & Referência para comparações em \% & $2,35 \%$ & $96,47 \%$ & $1,18 \%$ & $100,00 \%$ \\
\hline \multirow{6}{*}{ Sexo } & Sexo feminino. & 1 & 40 & 0 & 41 \\
\hline & $\%$ na linha & $2,44 \%$ & $97,56 \%$ & $0,00 \%$ & $100,00 \%$ \\
\hline & Sexo masculino & 1 & 42 & 1 & 44 \\
\hline & $\%$ na linha & $2,27 \%$ & $95,45 \%$ & $2,27 \%$ & $100,00 \%$ \\
\hline & Total & 2 & 82 & 1 & 85 \\
\hline & Referência para comparações em \% & $2,35 \%$ & $96,47 \%$ & $1,18 \%$ & $100,00 \%$ \\
\hline
\end{tabular}

Em geral, há grande concordância com a participação de técnicos de manutenção na implantação das obras de drenagem $(96,47 \%)$, maior do que com a participação no planejamento (90,59\%), o que é razoável do ponto de vista da Engenharia. No detalhe, a maior discordância é apresentada pelos mais velhos.

\begin{tabular}{|c|c|c|c|c|c|}
\hline \multirow[b]{2}{*}{ Variável } & \multirow[b]{2}{*}{ Atributo } & \multirow[t]{2}{*}{ discordo } & \multirow[t]{2}{*}{ concordo } & \multirow[t]{2}{*}{$\begin{array}{c}\text { sem } \\
\text { resposta }\end{array}$} & \multirow[t]{2}{*}{ total } \\
\hline & & & & & \\
\hline \multirow{10}{*}{ Formação } & Arquitetura & 4 & 18 & 0 & 22 \\
\hline & $\%$ na linha & $18,18 \%$ & $81,82 \%$ & $0,00 \%$ & $100,00 \%$ \\
\hline & Engenharia Civil & 9 & 21 & 0 & 30 \\
\hline & \% na linha & $30,00 \%$ & $70,00 \%$ & $0,00 \%$ & $100,00 \%$ \\
\hline & Outros & 1 & 11 & 0 & 12 \\
\hline & $\%$ na linha & $8,33 \%$ & $91,67 \%$ & $0,00 \%$ & $100,00 \%$ \\
\hline & Sociopolítico & 3 & 17 & 1 & 21 \\
\hline & $\%$ na linha & $14,29 \%$ & $80,95 \%$ & $4,76 \%$ & $100,00 \%$ \\
\hline & Total & 17 & 67 & 1 & 85 \\
\hline & Referência para comparações em \% & $20,00 \%$ & $78,82 \%$ & $1,18 \%$ & $100,00 \%$ \\
\hline \multirow{2}{*}{ Função } & Assessoria - Consultoria - Docência & 8 & 38 & 0 & 46 \\
\hline & $\%$ na linha & $17,39 \%$ & $82,61 \%$ & $0,00 \%$ & $100,00 \%$ \\
\hline
\end{tabular}




\begin{tabular}{|c|c|c|c|c|c|}
\hline & Coordenação - Gestão - Supervisão & 9 & 29 & 1 & 39 \\
\hline & $\%$ na linha & $23,08 \%$ & $74,36 \%$ & $2,56 \%$ & $100,00 \%$ \\
\hline & Total & 17 & 67 & 1 & 85 \\
\hline & Referência para comparações em \% & $20,00 \%$ & $78,82 \%$ & $1,18 \%$ & $100,00 \%$ \\
\hline \multirow{10}{*}{ Idade } & 30a39anos & 1 & 17 & 0 & 18 \\
\hline & $\%$ na linha & $5,56 \%$ & $94,44 \%$ & $0,00 \%$ & $100,00 \%$ \\
\hline & 40a49anos & 2 & 13 & 0 & 15 \\
\hline & $\%$ na linha & $13,33 \%$ & $86,67 \%$ & $0,00 \%$ & $100,00 \%$ \\
\hline & 50a59anos & 10 & 26 & 1 & 37 \\
\hline & $\%$ na linha & $27,03 \%$ & $70,27 \%$ & $2,70 \%$ & $100,00 \%$ \\
\hline & 60anos a mais & 4 & 11 & 0 & 15 \\
\hline & $\%$ na linha & $26,67 \%$ & $73,33 \%$ & $0,00 \%$ & $100,00 \%$ \\
\hline & Total & 17 & 67 & 1 & 85 \\
\hline & Referência para comparações em \% & $20,00 \%$ & $78,82 \%$ & $1,18 \%$ & $100,00 \%$ \\
\hline \multirow{12}{*}{ Nível } & Outro(especifique) & 2 & 2 & 0 & 4 \\
\hline & $\%$ na linha & $50,00 \%$ & $50,00 \%$ & $0,00 \%$ & $100,00 \%$ \\
\hline & Primeiro(mais alto) & 2 & 8 & 0 & 10 \\
\hline & $\%$ na linha & $20,00 \%$ & $80,00 \%$ & $0,00 \%$ & $100,00 \%$ \\
\hline & Quarto & 1 & 6 & 1 & 8 \\
\hline & $\%$ na linha & $12,50 \%$ & $75,00 \%$ & $12,50 \%$ & $100,00 \%$ \\
\hline & Segundo & 7 & 23 & 0 & 30 \\
\hline & $\%$ na linha & $23,33 \%$ & $76,67 \%$ & $0,00 \%$ & $100,00 \%$ \\
\hline & Terceiro & 5 & 28 & 0 & 33 \\
\hline & $\%$ na linha & $15,15 \%$ & $84,85 \%$ & $0,00 \%$ & $100,00 \%$ \\
\hline & Total & 17 & 67 & 1 & 85 \\
\hline & Referência para comparações em \% & $20,00 \%$ & $78,82 \%$ & $1,18 \%$ & $100,00 \%$ \\
\hline \multirow{6}{*}{ Sexo } & Sexo feminino. & 6 & 34 & 1 & 41 \\
\hline & $\%$ na linha & $14,63 \%$ & $82,93 \%$ & $2,44 \%$ & $100,00 \%$ \\
\hline & Sexo masculino & 11 & 33 & 0 & 44 \\
\hline & $\%$ na linha & $25,00 \%$ & $75,00 \%$ & $0,00 \%$ & $100,00 \%$ \\
\hline & Total & 17 & 67 & 1 & 85 \\
\hline & Referência para comparações em \% & $20,00 \%$ & $78,82 \%$ & $1,18 \%$ & $100,00 \%$ \\
\hline
\end{tabular}

O grau de concordância com esta afirmação não está entre os mais altos. Inclusive, os Engenheiros Civis não são unânimes em considerar que devam ter mais autonomia frente às interferências políticas e de arranjos institucionais para implantar obras já planejadas. É este grupo que apresenta o mais baixo grau de concordância com esta afirmação. Os mais jovens são os que apresentam o maior grau de concordância, bem acima do percentual de referência.

Pergunta 8.2 - Na implantação de obras de drenagem, é necessário que Engenheiros Civis compreendam as interferências sociopolíticas que podem ocorrer durante a implantação das obras. 


\begin{tabular}{|c|c|c|c|c|c|}
\hline & & discordo & concordo & resposta & total \\
\hline Variável & Atributo & & & & \\
\hline \multirow{10}{*}{ Formação } & Arquitetura & 0 & 21 & 1 & 22 \\
\hline & $\%$ na linha & $0,00 \%$ & $95,45 \%$ & $4,55 \%$ & $100,00 \%$ \\
\hline & Engenharia Civil & 0 & 30 & 0 & 30 \\
\hline & $\%$ na linha & $0,00 \%$ & $100,00 \%$ & $0,00 \%$ & $100,00 \%$ \\
\hline & Outros & 0 & 12 & 0 & 12 \\
\hline & $\%$ na linha & $0,00 \%$ & $100,00 \%$ & $0,00 \%$ & $100,00 \%$ \\
\hline & Sociopolítico & 2 & 19 & 0 & 21 \\
\hline & $\%$ na linha & $9,52 \%$ & $90,48 \%$ & $0,00 \%$ & $100,00 \%$ \\
\hline & Total & 2 & 82 & 1 & 85 \\
\hline & Referência para comparações em \% & $2,35 \%$ & $96,47 \%$ & $1,18 \%$ & $100,00 \%$ \\
\hline \multirow{6}{*}{ Função } & Assessoria - Consultoria - Docência & 1 & 44 & 1 & 46 \\
\hline & $\%$ na linha & $2,17 \%$ & $95,65 \%$ & $2,17 \%$ & $100,00 \%$ \\
\hline & Coordenação - Gestão - Supervisão & 1 & 38 & 0 & 39 \\
\hline & $\%$ na linha & $2,56 \%$ & $97,44 \%$ & $0,00 \%$ & $100,00 \%$ \\
\hline & Total & 2 & 82 & 1 & 85 \\
\hline & Referência para comparações em \% & $2,35 \%$ & $96,47 \%$ & $1,18 \%$ & $100,00 \%$ \\
\hline \multirow{10}{*}{ Idade } & 30a39anos & 0 & 18 & 0 & 18 \\
\hline & $\%$ na linha & $0,00 \%$ & $100,00 \%$ & $0,00 \%$ & $100,00 \%$ \\
\hline & 40a49anos & 0 & 15 & 0 & 15 \\
\hline & $\%$ na linha & $0,00 \%$ & $100,00 \%$ & $0,00 \%$ & $100,00 \%$ \\
\hline & 50a59anos & 2 & 35 & 0 & 37 \\
\hline & $\%$ na linha & $5,41 \%$ & $94,59 \%$ & $0,00 \%$ & $100,00 \%$ \\
\hline & 60 anos a mais & 0 & 14 & 1 & 15 \\
\hline & $\%$ na linha & $0,00 \%$ & $93,33 \%$ & $6,67 \%$ & $100,00 \%$ \\
\hline & Total & 2 & 82 & 1 & 85 \\
\hline & Referência para comparações em \% & $2,35 \%$ & $96,47 \%$ & $1,18 \%$ & $100,00 \%$ \\
\hline \multirow{12}{*}{ Nível } & Outro(especifique) & 1 & 3 & 0 & 4 \\
\hline & $\%$ na linha & $25,00 \%$ & $75,00 \%$ & $0,00 \%$ & $100,00 \%$ \\
\hline & Primeiro(mais alto) & 0 & 10 & 0 & 10 \\
\hline & $\%$ na linha & $0,00 \%$ & $100,00 \%$ & $0,00 \%$ & $100,00 \%$ \\
\hline & Quarto & 0 & 8 & 0 & 8 \\
\hline & $\%$ na linha & $0,00 \%$ & $100,00 \%$ & $0,00 \%$ & $100,00 \%$ \\
\hline & Segundo & 1 & 28 & 1 & 30 \\
\hline & $\%$ na linha & $3,33 \%$ & $93,33 \%$ & $3,33 \%$ & $100,00 \%$ \\
\hline & Terceiro & 0 & 33 & 0 & 33 \\
\hline & $\%$ na linha & $0,00 \%$ & $100,00 \%$ & $0,00 \%$ & $100,00 \%$ \\
\hline & Total & 2 & 82 & 1 & 85 \\
\hline & Referência para comparações em \% & $2,35 \%$ & $96,47 \%$ & $1,18 \%$ & $100,00 \%$ \\
\hline \multirow[b]{3}{*}{ Sexo } & Sexo feminino. & 0 & 40 & 1 & 41 \\
\hline & $\%$ na linha & $0,00 \%$ & $97,56 \%$ & $2,44 \%$ & $100,00 \%$ \\
\hline & Sexo masculino & 2 & 42 & 0 & 44 \\
\hline
\end{tabular}




\begin{tabular}{ccccc} 
\% na linha & $4,55 \%$ & $95,45 \%$ & $0,00 \%$ & $100,00 \%$ \\
\hline Total & 2 & 82 & 1 & 85 \\
Referência para comparações em \% & $2,35 \%$ & $96,47 \%$ & $1,18 \%$ & $100,00 \%$
\end{tabular}

Os Engenheiros Civis formam o grupo de concordância total com a afirmação quanto a importância para compreender as interferências sociopolíticas que podem ocorrer durante a implantação das obras. É essa a visão de praticamente todos os níveis hierárquicos. Pode-se dizer que este resultado é importante para os fins da pesquisa, sobretudo quando o foco recai sobre a formação do Engenheiro Civil em aspectos da organização social e políticas das comunidades onde implantam obras.

\section{Pergunta 8.3 - Na implantação de obras de drenagem, é necessário que Engenheiros Civis tenham} sensibilidade para aspectos da organização sociopolítica das comunidades onde implantam obras.

\begin{tabular}{|c|c|c|c|c|c|}
\hline & & discordo & concordo & $\begin{array}{c}\text { sem } \\
\text { resposta }\end{array}$ & total \\
\hline Variável & Atributo & & & & \\
\hline \multirow{10}{*}{ Formação } & Arquitetura & 1 & 21 & 0 & 22 \\
\hline & $\%$ na linha & $4,55 \%$ & $95,45 \%$ & $0,00 \%$ & $100,00 \%$ \\
\hline & Engenharia Civil & 3 & 27 & 0 & 30 \\
\hline & $\%$ na linha & $10,00 \%$ & $90,00 \%$ & $0,00 \%$ & $100,00 \%$ \\
\hline & Outros & 1 & 11 & 0 & 12 \\
\hline & $\%$ na linha & $8,33 \%$ & $91,67 \%$ & $0,00 \%$ & $100,00 \%$ \\
\hline & Sociopolítico & 3 & 18 & 0 & 21 \\
\hline & $\%$ na linha & $14,29 \%$ & $85,71 \%$ & $0,00 \%$ & $100,00 \%$ \\
\hline & Total & 8 & 77 & 0 & 85 \\
\hline & Referência para comparações em \% & $9,41 \%$ & $90,59 \%$ & $0,00 \%$ & $100,00 \%$ \\
\hline \multirow{6}{*}{ Função } & Assessoria - Consultoria - Docência & 4 & 42 & 0 & 46 \\
\hline & $\%$ na linha & $8,70 \%$ & $91,30 \%$ & $0,00 \%$ & $100,00 \%$ \\
\hline & Coordenação - Gestão - Supervisão & 4 & 35 & 0 & 39 \\
\hline & $\%$ na linha & $10,26 \%$ & $89,74 \%$ & $0,00 \%$ & $100,00 \%$ \\
\hline & Total & 8 & 77 & 0 & 85 \\
\hline & Referência para comparações em \% & $9,41 \%$ & $90,59 \%$ & $0,00 \%$ & $100,00 \%$ \\
\hline \multirow{10}{*}{ Idade } & 30a39anos & 3 & 15 & 0 & 18 \\
\hline & $\%$ na linha & $16,67 \%$ & $83,33 \%$ & $0,00 \%$ & $100,00 \%$ \\
\hline & 40a49anos & 1 & 14 & 0 & 15 \\
\hline & $\%$ na linha & $6,67 \%$ & $93,33 \%$ & $0,00 \%$ & $100,00 \%$ \\
\hline & 50a59anos & 3 & 34 & 0 & 37 \\
\hline & $\%$ na linha & $8,11 \%$ & $91,89 \%$ & $0,00 \%$ & $100,00 \%$ \\
\hline & 60anos a mais & 1 & 14 & 0 & 15 \\
\hline & $\%$ na linha & $6,67 \%$ & $93,33 \%$ & $0,00 \%$ & $100,00 \%$ \\
\hline & Total & 8 & 77 & 0 & 85 \\
\hline & Referência para comparações em \% & $9,41 \%$ & $90,59 \%$ & $0,00 \%$ & $100,00 \%$ \\
\hline
\end{tabular}




\begin{tabular}{|c|c|c|c|c|c|}
\hline & Outro(especifique) & 0 & 4 & 0 & 4 \\
\hline & $\%$ na linha & $0,00 \%$ & $100,00 \%$ & $0,00 \%$ & $100,00 \%$ \\
\hline & Primeiro(mais alto) & 0 & 10 & 0 & 10 \\
\hline & $\%$ na linha & $0,00 \%$ & $100,00 \%$ & $0,00 \%$ & $100,00 \%$ \\
\hline \multirow[t]{10}{*}{ Nível } & Quarto & 0 & 8 & 0 & 8 \\
\hline & $\%$ na linha & $0,00 \%$ & $100,00 \%$ & $0,00 \%$ & $100,00 \%$ \\
\hline & Segundo & 4 & 26 & 0 & 30 \\
\hline & $\%$ na linha & $13,33 \%$ & $86,67 \%$ & $0,00 \%$ & $100,00 \%$ \\
\hline & Terceiro & 4 & 29 & 0 & 33 \\
\hline & $\%$ na linha & $12,12 \%$ & $87,88 \%$ & $0,00 \%$ & $100,00 \%$ \\
\hline & Total & 8 & 77 & 0 & 85 \\
\hline & Referência para comparações em \% & $9,41 \%$ & $90,59 \%$ & $0,00 \%$ & $100,00 \%$ \\
\hline & Sexo feminino. & 2 & 39 & 0 & 41 \\
\hline & $\%$ na linha & $4,88 \%$ & $95,12 \%$ & $0,00 \%$ & $100,00 \%$ \\
\hline \multirow[t]{4}{*}{ Sexo } & Sexo masculino & 6 & 38 & 0 & 44 \\
\hline & $\%$ na linha & $13,64 \%$ & $86,36 \%$ & $0,00 \%$ & $100,00 \%$ \\
\hline & Total & 8 & 77 & 0 & 85 \\
\hline & Referência para comparações em \% & $9,41 \%$ & $90,59 \%$ & $0,00 \%$ & $100,00 \%$ \\
\hline
\end{tabular}

Há consenso quanto à necessária sensibilidade por parte do Engenheiro Civil para os aspectos sociopolíticos, já que o grau geral de concordância com esta afirmação é de 90,59\%. No detalhe, os de primeiro escalão (e os de quarto escalão) são unânimes em concordar com esta afirmação. Os arquitetos e as mulheres também apresentam grau de concordância bem acima do percentual de referência, e bem acima daquele apresentado por Engenheiros Civis.

Pergunta 8.4 - Na implantação de obras de drenagem, é necessário que Engenheiros Civis tenham tempo para ocupar-se com aspectos da organização sociopolítica nas comunidades onde obras são implantadas.

\begin{tabular}{|c|c|c|c|c|c|}
\hline & & discordo & concordo & $\begin{array}{c}\text { sem } \\
\text { resposta }\end{array}$ & total \\
\hline Variável & Atributo & & & & \\
\hline \multirow{10}{*}{ Formação } & Arquitetura & 4 & 18 & 0 & 22 \\
\hline & $\%$ na linha & $18,18 \%$ & $81,82 \%$ & $0,00 \%$ & $100,00 \%$ \\
\hline & Engenharia Civil & 6 & 24 & 0 & 30 \\
\hline & $\%$ na linha & $20,00 \%$ & $80,00 \%$ & $0,00 \%$ & $100,00 \%$ \\
\hline & Outros & 5 & 7 & 0 & 12 \\
\hline & $\%$ na linha & $41,67 \%$ & $58,33 \%$ & $0,00 \%$ & $100,00 \%$ \\
\hline & Sociopolítico & 3 & 18 & 0 & 21 \\
\hline & $\%$ na linha & $14,29 \%$ & $85,71 \%$ & $0,00 \%$ & $100,00 \%$ \\
\hline & Total & 18 & 67 & 0 & 85 \\
\hline & Referência para comparações em \% & $21,18 \%$ & $78,82 \%$ & $0,00 \%$ & $100,00 \%$ \\
\hline \multirow{2}{*}{ Função } & Assessoria - Consultoria - Docência & 11 & 35 & 0 & 46 \\
\hline & $\%$ na linha & $23,91 \%$ & $76,09 \%$ & $0,00 \%$ & $100,00 \%$ \\
\hline
\end{tabular}




\begin{tabular}{|c|c|c|c|c|c|}
\hline & Coordenação - Gestão - Supervisão & 7 & 32 & 0 & 39 \\
\hline & $\%$ na linha & $17,95 \%$ & $82,05 \%$ & $0,00 \%$ & $100,00 \%$ \\
\hline & Total & 18 & 67 & 0 & 85 \\
\hline & Referência para comparações em \% & $21,18 \%$ & $78,82 \%$ & $0,00 \%$ & $100,00 \%$ \\
\hline \multirow{10}{*}{ Idade } & 30a39anos & 4 & 14 & 0 & 18 \\
\hline & $\%$ na linha & $22,22 \%$ & $77,78 \%$ & $0,00 \%$ & $100,00 \%$ \\
\hline & 40a49anos & 4 & 11 & 0 & 15 \\
\hline & $\%$ na linha & $26,67 \%$ & $73,33 \%$ & $0,00 \%$ & $100,00 \%$ \\
\hline & 50a59anos & 8 & 29 & 0 & 37 \\
\hline & $\%$ na linha & $21,62 \%$ & $78,38 \%$ & $0,00 \%$ & $100,00 \%$ \\
\hline & 60anos a mais & 2 & 13 & 0 & 15 \\
\hline & $\%$ na linha & $13,33 \%$ & $86,67 \%$ & $0,00 \%$ & $100,00 \%$ \\
\hline & Total & 18 & 67 & 0 & 85 \\
\hline & Referência para comparações em \% & $21,18 \%$ & $78,82 \%$ & $0,00 \%$ & $100,00 \%$ \\
\hline \multirow{12}{*}{ Nível } & Outro(especifique) & 1 & 3 & 0 & 4 \\
\hline & $\%$ na linha & $25,00 \%$ & $75,00 \%$ & $0,00 \%$ & $100,00 \%$ \\
\hline & Primeiro(mais alto) & 1 & 9 & 0 & 10 \\
\hline & $\%$ na linha & $10,00 \%$ & $90,00 \%$ & $0,00 \%$ & $100,00 \%$ \\
\hline & Quarto & 0 & 8 & 0 & 8 \\
\hline & $\%$ na linha & $0,00 \%$ & $100,00 \%$ & $0,00 \%$ & $100,00 \%$ \\
\hline & Segundo & 6 & 24 & 0 & 30 \\
\hline & $\%$ na linha & $20,00 \%$ & $80,00 \%$ & $0,00 \%$ & $100,00 \%$ \\
\hline & Terceiro & 10 & 23 & 0 & 33 \\
\hline & $\%$ na linha & $30,30 \%$ & $69,70 \%$ & $0,00 \%$ & $100,00 \%$ \\
\hline & Total & 18 & 67 & 0 & 85 \\
\hline & Referência para comparações em \% & $21,18 \%$ & $78,82 \%$ & $0,00 \%$ & $100,00 \%$ \\
\hline \multirow{6}{*}{ Sexo } & Sexo feminino. & 8 & 33 & 0 & 41 \\
\hline & $\%$ na linha & $19,51 \%$ & $80,49 \%$ & $0,00 \%$ & $100,00 \%$ \\
\hline & Sexo masculino & 10 & 34 & 0 & 44 \\
\hline & $\%$ na linha & $22,73 \%$ & $77,27 \%$ & $0,00 \%$ & $100,00 \%$ \\
\hline & Total & 18 & 67 & 0 & 85 \\
\hline & Referência para comparações em \% & $21,18 \%$ & $78,82 \%$ & $0,00 \%$ & $100,00 \%$ \\
\hline
\end{tabular}

A necessidade de ter tempo para ocupar-se de aspectos sociopolíticos não parece ser unanimidade entre os respondentes. O maior grau de concordância com esta afirmação vem de profissionais do primeiro escalão e do quarto escalão. Os de 40 a 49 anos, e os do terceiro escalão, seguidos pelo grupo formado por homens são os grupos que mais rejeitam esta afirmação, ficando bem acima do percentual de referência para discordância. Entre os formados em Engenharia Civil não há unanimidade com relação à necessidade de tempo para ocupar-se de aspectos sociopolíticos.

Pergunta 8.5 - Na implantação de obras de drenagem, é necessário que Engenheiros Civis tenham vontade de lidar com aspectos sociopolíticos nas comunidades onde implantam obras. 


\begin{tabular}{|c|c|c|c|c|c|}
\hline & & discordo & concordo & $\begin{array}{c}\text { sem } \\
\text { resposta }\end{array}$ & total \\
\hline Variável & Atributo & & & & \\
\hline \multirow{10}{*}{ Formação } & Arquitetura & 1 & 21 & 0 & 22 \\
\hline & $\%$ na linha & $4,55 \%$ & $95,45 \%$ & $0,00 \%$ & $100,00 \%$ \\
\hline & Engenharia Civil & 5 & 25 & 0 & 30 \\
\hline & $\%$ na linha & $16,67 \%$ & $83,33 \%$ & $0,00 \%$ & $100,00 \%$ \\
\hline & Outros & 1 & 11 & 0 & 12 \\
\hline & $\%$ na linha & $8,33 \%$ & $91,67 \%$ & $0,00 \%$ & $100,00 \%$ \\
\hline & Sociopolítico & 1 & 19 & 1 & 21 \\
\hline & $\%$ na linha & $4,76 \%$ & $90,48 \%$ & $4,76 \%$ & $100,00 \%$ \\
\hline & Total & 8 & 76 & 1 & 85 \\
\hline & Referência para comparações em \% & $9,41 \%$ & $89,41 \%$ & $1,18 \%$ & $100,00 \%$ \\
\hline \multirow{6}{*}{ Função } & Assessoria - Consultoria - Docência & 5 & 41 & 0 & 46 \\
\hline & $\%$ na linha & $10,87 \%$ & $89,13 \%$ & $0,00 \%$ & $100,00 \%$ \\
\hline & Coordenação - Gestão - Supervisão & 3 & 35 & 1 & 39 \\
\hline & $\%$ na linha & $7,69 \%$ & $89,74 \%$ & $2,56 \%$ & $100,00 \%$ \\
\hline & Total & 8 & 76 & 1 & 85 \\
\hline & Referência para comparações em \% & $9,41 \%$ & $89,41 \%$ & $1,18 \%$ & $100,00 \%$ \\
\hline \multirow{10}{*}{ Idade } & 30a39anos & 1 & 17 & 0 & 18 \\
\hline & $\%$ na linha & $5,56 \%$ & $94,44 \%$ & $0,00 \%$ & $100,00 \%$ \\
\hline & 40a49anos & 0 & 15 & 0 & 15 \\
\hline & $\%$ na linha & $0,00 \%$ & $100,00 \%$ & $0,00 \%$ & $100,00 \%$ \\
\hline & 50a59anos & 6 & 30 & 1 & 37 \\
\hline & $\%$ na linha & $16,22 \%$ & $81,08 \%$ & $2,70 \%$ & $100,00 \%$ \\
\hline & 60 anos a mais & 1 & 14 & 0 & 15 \\
\hline & $\%$ na linha & $6,67 \%$ & $93,33 \%$ & $0,00 \%$ & $100,00 \%$ \\
\hline & Total & 8 & 76 & 1 & 85 \\
\hline & Referência para comparações em \% & $9,41 \%$ & $89,41 \%$ & $1,18 \%$ & $100,00 \%$ \\
\hline \multirow{12}{*}{ Nível } & Outro(especifique) & 1 & 3 & 0 & 4 \\
\hline & $\%$ na linha & $25,00 \%$ & $75,00 \%$ & $0,00 \%$ & $100,00 \%$ \\
\hline & Primeiro(mais alto) & 0 & 10 & 0 & 10 \\
\hline & $\%$ na linha & $0,00 \%$ & $100,00 \%$ & $0,00 \%$ & $100,00 \%$ \\
\hline & Quarto & 0 & 7 & 1 & 8 \\
\hline & $\%$ na linha & $0,00 \%$ & $87,50 \%$ & $12,50 \%$ & $100,00 \%$ \\
\hline & Segundo & 3 & 27 & 0 & 30 \\
\hline & $\%$ na linha & $10,00 \%$ & $90,00 \%$ & $0,00 \%$ & $100,00 \%$ \\
\hline & Terceiro & 4 & 29 & 0 & 33 \\
\hline & $\%$ na linha & $12,12 \%$ & $87,88 \%$ & $0,00 \%$ & $100,00 \%$ \\
\hline & Total & 8 & 76 & 1 & 85 \\
\hline & Referência para comparações em \% & $9,41 \%$ & $89,41 \%$ & $1,18 \%$ & $100,00 \%$ \\
\hline \multirow[b]{2}{*}{ Sexo } & Sexo feminino. & 4 & 36 & 1 & 41 \\
\hline & \% na linha & $9,76 \%$ & $87,80 \%$ & $2,44 \%$ & $100,00 \%$ \\
\hline
\end{tabular}




\begin{tabular}{ccccc}
$\begin{array}{c}\text { Sexo masculino } \\
\text { \% na linha }\end{array}$ & 4 & 40 & 0 & 44 \\
Total & $9,09 \%$ & $90,91 \%$ & $0,00 \%$ & $100,00 \%$ \\
\hline Referência para comparações em \% & 8 & 76 & 1 & 85 \\
\end{tabular}

Os de primeiro escalão são unânimes em concordar com a afirmação de que Engenheiros devem ter vontade de lidar com os aspectos sociopolíticos das comunidades onde implantam obras. Isso é importante dada a sua autoridade em influenciar políticas públicas e estratégias, assim como os arranjos institucionais que facilitem a operacionalização de canais para a incorporação de aspectos sociopolíticos. O grupo formado por aqueles com formação em Arquitetura apresenta alto grau de concordância frente ao percentual de referência. O grupo de formação em Engenharia Civil é o que apresenta menor grau de concordância com essa afirmação: é necessário ter vontade para lidar com aspectos sociopolíticos.

\section{Pergunta 9 - A graduação em Engenharia Civil capacita suficientemente para a boa execução de} obras de drenagem.

\begin{tabular}{|c|c|c|c|c|c|}
\hline \multirow[b]{2}{*}{ Variável } & \multirow[b]{2}{*}{ Atributo } & \multirow[t]{2}{*}{ discordo } & concordo & $\begin{array}{c}\text { sem } \\
\text { resposta }\end{array}$ & total \\
\hline & & & & & \\
\hline \multirow{10}{*}{ Formação } & Arquitetura & 9 & 13 & 0 & 22 \\
\hline & $\%$ na linha & $40,91 \%$ & $59,09 \%$ & $0,00 \%$ & $100,00 \%$ \\
\hline & Engenharia Civil & 13 & 17 & 0 & 30 \\
\hline & \% na linha & $43,33 \%$ & $56,67 \%$ & $0,00 \%$ & $100,00 \%$ \\
\hline & Outros & 6 & 6 & 0 & 12 \\
\hline & $\%$ na linha & $50,00 \%$ & $50,00 \%$ & $0,00 \%$ & $100,00 \%$ \\
\hline & Sociopolítico & 9 & 12 & 0 & 21 \\
\hline & $\%$ na linha & $42,86 \%$ & $57,14 \%$ & $0,00 \%$ & $100,00 \%$ \\
\hline & Total & 37 & 48 & 0 & 85 \\
\hline & Referência para comparações em \% & $43,53 \%$ & $56,47 \%$ & $0,00 \%$ & $100,00 \%$ \\
\hline \multirow{6}{*}{ Função } & Assessoria - Consultoria - Docência & 22 & 24 & 0 & 46 \\
\hline & $\%$ na linha & $47,83 \%$ & $52,17 \%$ & $0,00 \%$ & $100,00 \%$ \\
\hline & Coordenação - Gestão - Supervisão & 15 & 24 & 0 & 39 \\
\hline & $\%$ na linha & $38,46 \%$ & $61,54 \%$ & $0,00 \%$ & $100,00 \%$ \\
\hline & Total & 37 & 48 & 0 & 85 \\
\hline & Referência para comparações em \% & $43,53 \%$ & $56,47 \%$ & $0,00 \%$ & $100,00 \%$ \\
\hline \multirow{8}{*}{ Idade } & 30a39anos & 9 & 9 & 0 & 18 \\
\hline & $\%$ na linha & $50,00 \%$ & $50,00 \%$ & $0,00 \%$ & $100,00 \%$ \\
\hline & 40a49anos & 6 & 9 & 0 & 15 \\
\hline & $\%$ na linha & $40,00 \%$ & $60,00 \%$ & $0,00 \%$ & $100,00 \%$ \\
\hline & 50a59anos & 16 & 21 & 0 & 37 \\
\hline & $\%$ na linha & $43,24 \%$ & $56,76 \%$ & $0,00 \%$ & $100,00 \%$ \\
\hline & 60 anos a mais & 6 & 9 & 0 & 15 \\
\hline & \% na linha & $40,00 \%$ & $60,00 \%$ & $0,00 \%$ & $100,00 \%$ \\
\hline
\end{tabular}




\begin{tabular}{|c|c|c|c|c|c|}
\hline & Total & 37 & 48 & 0 & 85 \\
\hline & Referência para comparações em \% & $43,53 \%$ & $56,47 \%$ & $0,00 \%$ & $100,00 \%$ \\
\hline \multirow{12}{*}{ Nível } & Outro(especifique) & 0 & 4 & 0 & 4 \\
\hline & $\%$ na linha & $0,00 \%$ & $100,00 \%$ & $0,00 \%$ & $100,00 \%$ \\
\hline & Primeiro(mais alto) & 6 & 4 & 0 & 10 \\
\hline & $\%$ na linha & $60,00 \%$ & $40,00 \%$ & $0,00 \%$ & $100,00 \%$ \\
\hline & Quarto & 4 & 4 & 0 & 8 \\
\hline & $\%$ na linha & $50,00 \%$ & $50,00 \%$ & $0,00 \%$ & $100,00 \%$ \\
\hline & Segundo & 14 & 16 & 0 & 30 \\
\hline & $\%$ na linha & $46,67 \%$ & $53,33 \%$ & $0,00 \%$ & $100,00 \%$ \\
\hline & Terceiro & 13 & 20 & 0 & 33 \\
\hline & $\%$ na linha & $39,39 \%$ & $60,61 \%$ & $0,00 \%$ & $100,00 \%$ \\
\hline & Total & 37 & 48 & 0 & 85 \\
\hline & Referência para comparações em \% & $43,53 \%$ & $56,47 \%$ & $0,00 \%$ & $100,00 \%$ \\
\hline \multirow{6}{*}{ Sexo } & Sexo feminino. & 13 & 28 & 0 & 41 \\
\hline & $\%$ na linha & $31,71 \%$ & $68,29 \%$ & $0,00 \%$ & $100,00 \%$ \\
\hline & Sexo masculino & 24 & 20 & 0 & 44 \\
\hline & $\%$ na linha & $54,55 \%$ & $45,45 \%$ & $0,00 \%$ & $100,00 \%$ \\
\hline & Total & 37 & 48 & 0 & 85 \\
\hline & Referência para comparações em \% & $43,53 \%$ & $56,47 \%$ & $0,00 \%$ & $100,00 \%$ \\
\hline
\end{tabular}

Essa afirmação traz um elemento importante para os fins desta pesquisa: como vêm os Engenheiros Civis e os demais incluídos na amostra da pesquisa a formação em Engenharia Civil para a boa execução de obras de drenagem. É interessante verificar que esta pergunta, simplesmente formulada, foi a que resultou no maior grau de discordância de todo este survey. Não há consenso, pois a opinião dos grupos converge para $56,47 \%$ de concordância e 43,53\% de discordância, havendo um equilíbrio de opiniões opostas. Entre aqueles formados em Engenharia Civil, o grau de nãoconcordância com a suficiência da formação em Engenharia Civil para a boa execução de obras de drenagem corresponde à referência percentual. $\mathrm{O}$ grupo formado por aqueles que se situam em nível hierárquico de primeiro escalão registrou a maior rejeição a esta afirmação.

Pergunta 10 - A graduação em Engenharia Civil deveria ter disciplinas obrigatórias sobre aspectos sociopolíticos.

\begin{tabular}{cccccc} 
& & & & sem \\
Variável & Atributo & discordo & concordo & resposta & total \\
\hline \multirow{3}{*}{ Formação } & Arquitetura & & & & 22 \\
& $\%$ na linha & $13,64 \%$ & $86,36 \%$ & $0,00 \%$ & $100,00 \%$ \\
& Engenharia Civil & 2 & 27 & 1 & 30
\end{tabular}




\begin{tabular}{|c|c|c|c|c|c|}
\hline & $\%$ na linha & $6,67 \%$ & $90,00 \%$ & $3,33 \%$ & $100,00 \%$ \\
\hline & Outros & 0 & 12 & 0 & 12 \\
\hline & $\%$ na linha & $0,00 \%$ & $100,00 \%$ & $0,00 \%$ & $100,00 \%$ \\
\hline & Sociopolítico & 3 & 18 & 0 & 21 \\
\hline & $\%$ na linha & $14,29 \%$ & $85,71 \%$ & $0,00 \%$ & $100,00 \%$ \\
\hline & Total & 8 & 76 & 1 & 85 \\
\hline & Referência para comparações em \% & $9,41 \%$ & $89,41 \%$ & $1,18 \%$ & $100,00 \%$ \\
\hline \multirow{6}{*}{ Função } & Assessoria - Consultoria - Docência & 7 & 38 & 1 & 46 \\
\hline & $\%$ na linha & $15,22 \%$ & $82,61 \%$ & $2,17 \%$ & $100,00 \%$ \\
\hline & Coordenação - Gestão - Supervisão & 1 & 38 & 0 & 39 \\
\hline & $\%$ na linha & $2,56 \%$ & $97,44 \%$ & $0,00 \%$ & $100,00 \%$ \\
\hline & Total & 8 & 76 & 1 & 85 \\
\hline & Referência para comparações em \% & $9,41 \%$ & $89,41 \%$ & $1,18 \%$ & $100,00 \%$ \\
\hline \multirow{10}{*}{ Idade } & 30a39anos & 1 & 17 & 0 & 18 \\
\hline & $\%$ na linha & $5,56 \%$ & $94,44 \%$ & $0,00 \%$ & $100,00 \%$ \\
\hline & 40a49anos & 2 & 13 & 0 & 15 \\
\hline & $\%$ na linha & $13,33 \%$ & $86,67 \%$ & $0,00 \%$ & $100,00 \%$ \\
\hline & 50a59anos & 5 & 32 & 0 & 37 \\
\hline & $\%$ na linha & $13,51 \%$ & $86,49 \%$ & $0,00 \%$ & $100,00 \%$ \\
\hline & 60 anos a mais & 0 & 14 & 1 & 15 \\
\hline & $\%$ na linha & $0,00 \%$ & $93,33 \%$ & $6,67 \%$ & $100,00 \%$ \\
\hline & Total & 8 & 76 & 1 & 85 \\
\hline & Referência para comparações em \% & $9,41 \%$ & $89,41 \%$ & $1,18 \%$ & $100,00 \%$ \\
\hline \multirow{12}{*}{ Nível } & Outro(especifique) & 0 & 4 & 0 & 4 \\
\hline & $\%$ na linha & $0,00 \%$ & $100,00 \%$ & $0,00 \%$ & $100,00 \%$ \\
\hline & Primeiro(mais alto) & 2 & 8 & 0 & 10 \\
\hline & $\%$ na linha & $20,00 \%$ & $80,00 \%$ & $0,00 \%$ & $100,00 \%$ \\
\hline & Quarto & 1 & 7 & 0 & 8 \\
\hline & $\%$ na linha & $12,50 \%$ & $87,50 \%$ & $0,00 \%$ & $100,00 \%$ \\
\hline & Segundo & 2 & 28 & 0 & 30 \\
\hline & $\%$ na linha & $6,67 \%$ & $93,33 \%$ & $0,00 \%$ & $100,00 \%$ \\
\hline & Terceiro & 3 & 29 & 1 & 33 \\
\hline & $\%$ na linha & $9,09 \%$ & $87,88 \%$ & $3,03 \%$ & $100,00 \%$ \\
\hline & Total & 8 & 76 & 1 & 85 \\
\hline & Referência para comparações em \% & $9,41 \%$ & $89,41 \%$ & $1,18 \%$ & $100,00 \%$ \\
\hline \multirow{6}{*}{ Sexo } & Sexo feminino. & 3 & 38 & 0 & 41 \\
\hline & $\%$ na linha & $7,32 \%$ & $92,68 \%$ & $0,00 \%$ & $100,00 \%$ \\
\hline & Sexo masculino & 5 & 38 & 1 & 44 \\
\hline & $\%$ na linha & $11,36 \%$ & $86,36 \%$ & $2,27 \%$ & $100,00 \%$ \\
\hline & Total & 8 & 76 & 1 & 85 \\
\hline & Referência para comparações em \% & $9,41 \%$ & $89,41 \%$ & $1,18 \%$ & $100,00 \%$ \\
\hline
\end{tabular}


O exame das respostas à afirmação de que graduação em Engenharia Civil deve incluir disciplinas obrigatórias sobre aspectos sociopolíticos revela que a maior discrepância com relação ao percentual de referência vem do grupo de profissionais que declararam ocupar cargos de primeiro escalão. Seu grau de discordância com esta afirmação é de 20\%. Entretanto, o grupo formado por aqueles que ocupam cargo de Coordenação Gestão - Supervisão registra o mais alto grau de concordância com a obrigatoriedade de disciplinas relativas ao sociopolítico na graduação em Engenharia Civil. Trata-se de resultado a ser tomado com cautela.

\begin{tabular}{|c|c|c|c|c|c|}
\hline & & discordo & concordo & $\begin{array}{c}\text { sem } \\
\text { resposta }\end{array}$ & total \\
\hline Variável & Atributo & & & & \\
\hline \multirow{10}{*}{ Formação } & Arquitetura & 1 & 20 & 1 & 22 \\
\hline & $\%$ na linha & $4,55 \%$ & $90,91 \%$ & $4,55 \%$ & $100,00 \%$ \\
\hline & Engenharia Civil & 6 & 24 & 0 & 30 \\
\hline & $\%$ na linha & $20,00 \%$ & $80,00 \%$ & $0,00 \%$ & $100,00 \%$ \\
\hline & Outros & 3 & 9 & 0 & 12 \\
\hline & $\%$ na linha & $25,00 \%$ & $75,00 \%$ & $0,00 \%$ & $100,00 \%$ \\
\hline & Sociopolítico & 4 & 17 & 0 & 21 \\
\hline & $\%$ na linha & $19,05 \%$ & $80,95 \%$ & $0,00 \%$ & $100,00 \%$ \\
\hline & Total & 14 & 70 & 1 & 85 \\
\hline & Referência para comparações em \% & $16,47 \%$ & $82,35 \%$ & $1,18 \%$ & $100,00 \%$ \\
\hline \multirow{6}{*}{ Função } & Assessoria - Consultoria - Docência & 9 & 37 & 0 & 46 \\
\hline & $\%$ na linha & $19,57 \%$ & $80,43 \%$ & $0,00 \%$ & $100,00 \%$ \\
\hline & Coordenação - Gestão - Supervisão & 5 & 33 & 1 & 39 \\
\hline & $\%$ na linha & $12,82 \%$ & $84,62 \%$ & $2,56 \%$ & $100,00 \%$ \\
\hline & Total & 14 & 70 & 1 & 85 \\
\hline & Referência para comparações em \% & $16,47 \%$ & $82,35 \%$ & $1,18 \%$ & $100,00 \%$ \\
\hline \multirow{10}{*}{ Idade } & 30a39anos & 4 & 14 & 0 & 18 \\
\hline & $\%$ na linha & $22,22 \%$ & $77,78 \%$ & $0,00 \%$ & $100,00 \%$ \\
\hline & 40a49anos & 3 & 12 & 0 & 15 \\
\hline & $\%$ na linha & $20,00 \%$ & $80,00 \%$ & $0,00 \%$ & $100,00 \%$ \\
\hline & 50a59anos & 5 & 31 & 1 & 37 \\
\hline & $\%$ na linha & $13,51 \%$ & $83,78 \%$ & $2,70 \%$ & $100,00 \%$ \\
\hline & 60 anos a mais & 2 & 13 & 0 & 15 \\
\hline & $\%$ na linha & $13,33 \%$ & $86,67 \%$ & $0,00 \%$ & $100,00 \%$ \\
\hline & Total & 14 & 70 & 1 & 85 \\
\hline & Referência para comparações em \% & $16,47 \%$ & $82,35 \%$ & $1,18 \%$ & $100,00 \%$ \\
\hline \multirow{4}{*}{ Nível } & Outro(especifique) & 0 & 4 & 0 & 4 \\
\hline & $\%$ na linha & $0,00 \%$ & $100,00 \%$ & $0,00 \%$ & $100,00 \%$ \\
\hline & Primeiro(mais alto) & 2 & 8 & 0 & 10 \\
\hline & $\%$ na linha & $20,00 \%$ & $80,00 \%$ & $0,00 \%$ & $100,00 \%$ \\
\hline
\end{tabular}




\begin{tabular}{|c|c|c|c|c|c|}
\hline & Quarto & 0 & 8 & 0 & 8 \\
\hline & $\%$ na linha & $0,00 \%$ & $100,00 \%$ & $0,00 \%$ & $100,00 \%$ \\
\hline & Segundo & 4 & 26 & 0 & 30 \\
\hline & $\%$ na linha & $13,33 \%$ & $86,67 \%$ & $0,00 \%$ & $100,00 \%$ \\
\hline & Terceiro & 8 & 24 & 1 & 33 \\
\hline & $\%$ na linha & $24,24 \%$ & $72,73 \%$ & $3,03 \%$ & $100,00 \%$ \\
\hline & Total & 14 & 70 & 1 & 85 \\
\hline & Referência para comparações em \% & $16,47 \%$ & $82,35 \%$ & $1,18 \%$ & $100,00 \%$ \\
\hline \multirow{6}{*}{ Sexo } & Sexo feminino. & 5 & 35 & 1 & 41 \\
\hline & $\%$ na linha & $12,20 \%$ & $85,37 \%$ & $2,44 \%$ & $100,00 \%$ \\
\hline & Sexo masculino & 9 & 35 & 0 & 44 \\
\hline & $\%$ na linha & $20,45 \%$ & $79,55 \%$ & $0,00 \%$ & $100,00 \%$ \\
\hline & Total & 14 & 70 & 1 & 85 \\
\hline & Referência para comparações em \% & $16,47 \%$ & $82,35 \%$ & $1,18 \%$ & $100,00 \%$ \\
\hline
\end{tabular}

Em geral, é alto o grau de discordância com a afirmação de que cientistas sociais são bem vindos para atuar em projetos de intervenções em drenagem. Arquitetos e o grupo formado pelo primeiro escalão são os que apresentam maior grau de concordância com relação a esta afirmação. Jovens e o terceiro escalão apresentam a maior discordância com relação ao percentual de referência.

Pergunta 12.1 - As principais causas das inundações no Município de São Paulo são: a capacitação de profissionais de formação humanista e social para envolver moradores e comerciantes de maneira que se sintam capazes de contribuir para a redução de alagamentos e inundações.

\begin{tabular}{|c|c|c|c|c|c|}
\hline & & discordo & concordo & $\begin{array}{c}\text { sem } \\
\text { resposta }\end{array}$ & total \\
\hline Variável & Atributo & & & & \\
\hline \multirow{10}{*}{ Formação } & Arquitetura & 7 & 15 & 0 & 22 \\
\hline & $\%$ na linha & $31,82 \%$ & $68,18 \%$ & $0,00 \%$ & $100,00 \%$ \\
\hline & Engenharia Civil & 12 & 18 & 0 & 30 \\
\hline & $\%$ na linha & $40,00 \%$ & $60,00 \%$ & $0,00 \%$ & $100,00 \%$ \\
\hline & Outros & 8 & 4 & 0 & 12 \\
\hline & $\%$ na linha & $66,67 \%$ & $33,33 \%$ & $0,00 \%$ & $100,00 \%$ \\
\hline & Sociopolítico & 9 & 11 & 1 & 21 \\
\hline & $\%$ na linha & $42,86 \%$ & $52,38 \%$ & $4,76 \%$ & $100,00 \%$ \\
\hline & Total & 36 & 48 & 1 & 85 \\
\hline & Referência para comparações em \% & $42,35 \%$ & $56,47 \%$ & $1,18 \%$ & $100,00 \%$ \\
\hline \multirow{6}{*}{ Função } & Assessoria - Consultoria - Docência & 20 & 26 & 0 & 46 \\
\hline & $\%$ na linha & $43,48 \%$ & $56,52 \%$ & $0,00 \%$ & $100,00 \%$ \\
\hline & Coordenação - Gestão - Supervisão & 16 & 22 & 1 & 39 \\
\hline & $\%$ na linha & $41,03 \%$ & $56,41 \%$ & $2,56 \%$ & $100,00 \%$ \\
\hline & Total & 36 & 48 & 1 & 85 \\
\hline & Referência para comparações em \% & $42,35 \%$ & $56,47 \%$ & $1,18 \%$ & $100,00 \%$ \\
\hline
\end{tabular}




\begin{tabular}{|c|c|c|c|c|c|}
\hline \multirow{10}{*}{ Idade } & 30a39anos & 10 & 8 & 0 & 18 \\
\hline & $\%$ na linha & $55,56 \%$ & $44,44 \%$ & $0,00 \%$ & $100,00 \%$ \\
\hline & 40a49anos & 7 & 8 & 0 & 15 \\
\hline & $\%$ na linha & $46,67 \%$ & $53,33 \%$ & $0,00 \%$ & $100,00 \%$ \\
\hline & 50a59anos & 14 & 22 & 1 & 37 \\
\hline & $\%$ na linha & $37,84 \%$ & $59,46 \%$ & $2,70 \%$ & $100,00 \%$ \\
\hline & 60 anos a mais & 5 & 10 & 0 & 15 \\
\hline & $\%$ na linha & $33,33 \%$ & $66,67 \%$ & $0,00 \%$ & $100,00 \%$ \\
\hline & Total & 36 & 48 & 1 & 85 \\
\hline & Referência para comparações em \% & $42,35 \%$ & $56,47 \%$ & $1,18 \%$ & $100,00 \%$ \\
\hline \multirow{12}{*}{ Nível } & Outro(especifique) & 1 & 3 & 0 & 4 \\
\hline & $\%$ na linha & $25,00 \%$ & $75,00 \%$ & $0,00 \%$ & $100,00 \%$ \\
\hline & Primeiro(mais alto) & 6 & 3 & 1 & 10 \\
\hline & $\%$ na linha & $60,00 \%$ & $30,00 \%$ & $10,00 \%$ & $100,00 \%$ \\
\hline & Quarto & 2 & 6 & 0 & 8 \\
\hline & $\%$ na linha & $25,00 \%$ & $75,00 \%$ & $0,00 \%$ & $100,00 \%$ \\
\hline & Segundo & 16 & 14 & 0 & 30 \\
\hline & $\%$ na linha & $53,33 \%$ & $46,67 \%$ & $0,00 \%$ & $100,00 \%$ \\
\hline & Terceiro & 11 & 22 & 0 & 33 \\
\hline & $\%$ na linha & $33,33 \%$ & $66,67 \%$ & $0,00 \%$ & $100,00 \%$ \\
\hline & Total & 36 & 48 & 1 & 85 \\
\hline & Referência para comparações em \% & $42,35 \%$ & $56,47 \%$ & $1,18 \%$ & $100,00 \%$ \\
\hline \multirow{6}{*}{ Sexo } & Sexo feminino. & 17 & 24 & 0 & 41 \\
\hline & $\%$ na linha & $41,46 \%$ & $58,54 \%$ & $0,00 \%$ & $100,00 \%$ \\
\hline & Sexo masculino & 19 & 24 & 1 & 44 \\
\hline & $\%$ na linha & $43,18 \%$ & $54,55 \%$ & $2,27 \%$ & $100,00 \%$ \\
\hline & Total & 36 & 48 & 1 & 85 \\
\hline & Referência para comparações em \% & $42,35 \%$ & $56,47 \%$ & $1,18 \%$ & $100,00 \%$ \\
\hline
\end{tabular}

Esta questão apresenta também um baixo grau de concordância quanto à relação entre a capacitação de profissionais com formação humanista e social e seu trabalho com moradores e comerciantes no sentido de contribuírem para atenuar o problema de inundações no município de São Paulo. O percentual de referência da discordância é de $42,35 \%$, situando-se entre os mais altos. No detalhe, o grupo com maior grau de discordância é aquele formado por profissionais do primeiro escalão. Apenas $30 \%$ deles concorda com esta relação e $10 \%$ dentre eles não respondeu à pergunta, sendo este o maior percentual de não respostas. Ao comparar a posição deste grupo com a sua concordância com afirmações em favor da incorporação do sociopolítico vê-se uma certa contradição: consideram importante o papel do morador e do comerciante mas não no sentido da questão atual, ou seja, não veem relação entre a capacitação de profissionais com formação humanista e social e o trabalho com os atores sociais com vistas a reduzir as inundações. 
Pergunta 12.2 - As principais causas das inundações no Município de São Paulo são: variações climáticas e o consequente aumento das chuvas.

\begin{tabular}{|c|c|c|c|c|c|}
\hline & & discordo & concordo & $\begin{array}{c}\text { sem } \\
\text { resposta }\end{array}$ & total \\
\hline Variável & Atributo & & & & \\
\hline \multirow{10}{*}{ Formação } & Arquitetura & 13 & 8 & 1 & 22 \\
\hline & $\%$ na linha & $59,09 \%$ & $36,36 \%$ & $4,55 \%$ & $100,00 \%$ \\
\hline & Engenharia Civil & 14 & 16 & 0 & 30 \\
\hline & $\%$ na linha & $46,67 \%$ & $53,33 \%$ & $0,00 \%$ & $100,00 \%$ \\
\hline & Outros & 5 & 6 & 1 & 12 \\
\hline & $\%$ na linha & $41,67 \%$ & $50,00 \%$ & $8,33 \%$ & $100,00 \%$ \\
\hline & Sociopolítico & 5 & 15 & 1 & 21 \\
\hline & \% na linha & $23,81 \%$ & $71,43 \%$ & $4,76 \%$ & $100,00 \%$ \\
\hline & Total & 37 & 45 & 3 & 85 \\
\hline & Referência para comparações em \% & $43,53 \%$ & $52,94 \%$ & $3,53 \%$ & $100,00 \%$ \\
\hline \multirow{6}{*}{ Função } & Assessoria - Consultoria - Docência & 22 & 23 & 1 & 46 \\
\hline & $\%$ na linha & $47,83 \%$ & $50,00 \%$ & $2,17 \%$ & $100,00 \%$ \\
\hline & Coordenação - Gestão - Supervisão & 15 & 22 & 2 & 39 \\
\hline & $\%$ na linha & $38,46 \%$ & $56,41 \%$ & $5,13 \%$ & $100,00 \%$ \\
\hline & Total & 37 & 45 & 3 & 85 \\
\hline & Referência para comparações em \% & $43,53 \%$ & $52,94 \%$ & $3,53 \%$ & $100,00 \%$ \\
\hline \multirow{10}{*}{ Idade } & 30a39anos & 10 & 7 & 1 & 18 \\
\hline & $\%$ na linha & $55,56 \%$ & $38,89 \%$ & $5,56 \%$ & $100,00 \%$ \\
\hline & 40a49anos & 5 & 9 & 1 & 15 \\
\hline & $\%$ na linha & $33,33 \%$ & $60,00 \%$ & $6,67 \%$ & $100,00 \%$ \\
\hline & 50a59anos & 16 & 20 & 1 & 37 \\
\hline & $\%$ na linha & $43,24 \%$ & $54,05 \%$ & $2,70 \%$ & $100,00 \%$ \\
\hline & 60anos a mais & 6 & 9 & 0 & 15 \\
\hline & $\%$ na linha & $40,00 \%$ & $60,00 \%$ & $0,00 \%$ & $100,00 \%$ \\
\hline & Total & 37 & 45 & 3 & 85 \\
\hline & Referência para comparações em \% & $43,53 \%$ & $52,94 \%$ & $3,53 \%$ & $100,00 \%$ \\
\hline \multirow{12}{*}{ Nível } & Outro(especifique) & 0 & 4 & 0 & 4 \\
\hline & $\%$ na linha & $0,00 \%$ & $100,00 \%$ & $0,00 \%$ & $100,00 \%$ \\
\hline & Primeiro(mais alto) & 2 & 8 & 0 & 10 \\
\hline & $\%$ na linha & $20,00 \%$ & $80,00 \%$ & $0,00 \%$ & $100,00 \%$ \\
\hline & Quarto & 3 & 3 & 2 & 8 \\
\hline & $\%$ na linha & $37,50 \%$ & $37,50 \%$ & $25,00 \%$ & $100,00 \%$ \\
\hline & Segundo & 14 & 16 & 0 & 30 \\
\hline & $\%$ na linha & $46,67 \%$ & $53,33 \%$ & $0,00 \%$ & $100,00 \%$ \\
\hline & Terceiro & 18 & 14 & 1 & 33 \\
\hline & $\%$ na linha & $54,55 \%$ & $42,42 \%$ & $3,03 \%$ & $100,00 \%$ \\
\hline & Total & 37 & 45 & 3 & 85 \\
\hline & Referência para comparações em \% & $43,53 \%$ & $52,94 \%$ & $3,53 \%$ & $100,00 \%$ \\
\hline
\end{tabular}




\begin{tabular}{cccccc} 
& & & & & \\
& Sexo feminino. & 18 & 20 & 3 & 41 \\
\% na linha & $43,90 \%$ & $48,78 \%$ & $7,32 \%$ & $100,00 \%$ \\
Sexo masculino & 19 & 25 & 0 & 44 & $100,00 \%$ \\
\hline \% na linha & $43,18 \%$ & $56,82 \%$ & $0,00 \%$ & 35 & $100,00 \%$
\end{tabular}

É digno de nota o fato de haver um alto grau de discordância com a afirmação de que as variações climáticas e o conseqüente aumento das chuvas estão entre as causas das inundações em São Paulo, inclusive por parte daqueles que formam o grupo dos formados em Engenharia Civil. O primeiro escalão e o grupo de formação sociopolítica apresentam os maiores graus de concordância e, portanto, bastante acima do percentual de referência.

Pergunta 12.3 - As principais causas das inundações no Município de São Paulo são: envolvimento de moradores e comerciantes no planejamento das obras a fim de se obter consenso sobre as mesmas $e$ praticar seu uso racional.

\begin{tabular}{|c|c|c|c|c|c|}
\hline & & discordo & concordo & $\begin{array}{c}\text { sem } \\
\text { resposta }\end{array}$ & total \\
\hline Variável & Atributo & & & & \\
\hline \multirow{10}{*}{ Formação } & Arquitetura & 9 & 13 & 0 & 22 \\
\hline & $\%$ na linha & $40,91 \%$ & $59,09 \%$ & $0,00 \%$ & $100,00 \%$ \\
\hline & Engenharia Civil & 13 & 17 & 0 & 30 \\
\hline & $\%$ na linha & $43,33 \%$ & $56,67 \%$ & $0,00 \%$ & $100,00 \%$ \\
\hline & Outros & 7 & 4 & 1 & 12 \\
\hline & $\%$ na linha & $58,33 \%$ & $33,33 \%$ & $8,33 \%$ & $100,00 \%$ \\
\hline & Sociopolítico & 8 & 13 & 0 & 21 \\
\hline & $\%$ na linha & $38,10 \%$ & $61,90 \%$ & $0,00 \%$ & $100,00 \%$ \\
\hline & Total & 37 & 47 & 1 & 85 \\
\hline & Referência para comparações em \% & $43,53 \%$ & $55,29 \%$ & $1,18 \%$ & $100,00 \%$ \\
\hline \multirow{6}{*}{ Função } & Assessoria - Consultoria - Docência & 21 & 24 & 1 & 46 \\
\hline & $\%$ na linha & $45,65 \%$ & $52,17 \%$ & $2,17 \%$ & $100,00 \%$ \\
\hline & Coordenação - Gestão - Supervisão & 16 & 23 & 0 & 39 \\
\hline & $\%$ na linha & $41,03 \%$ & $58,97 \%$ & $0,00 \%$ & $100,00 \%$ \\
\hline & Total & 37 & 47 & 1 & 85 \\
\hline & Referência para comparações em \% & $43,53 \%$ & $55,29 \%$ & $1,18 \%$ & $100,00 \%$ \\
\hline \multirow{7}{*}{ Idade } & 30a39anos & 5 & 13 & 0 & 18 \\
\hline & $\%$ na linha & $27,78 \%$ & $72,22 \%$ & $0,00 \%$ & $100,00 \%$ \\
\hline & 40a49anos & 6 & 8 & 1 & 15 \\
\hline & $\%$ na linha & $40,00 \%$ & $53,33 \%$ & $6,67 \%$ & $100,00 \%$ \\
\hline & 50a59anos & 18 & 19 & 0 & 37 \\
\hline & \% na linha & $48,65 \%$ & $51,35 \%$ & $0,00 \%$ & $100,00 \%$ \\
\hline & 60 anos a mais & 8 & 7 & 0 & 15 \\
\hline
\end{tabular}




\begin{tabular}{|c|c|c|c|c|c|}
\hline & $\%$ na linha & $53,33 \%$ & $46,67 \%$ & $0,00 \%$ & $100,00 \%$ \\
\hline & Total & 37 & 47 & 1 & 85 \\
\hline & Referência para comparações em \% & $43,53 \%$ & $55,29 \%$ & $1,18 \%$ & $100,00 \%$ \\
\hline \multirow{12}{*}{ Nível } & Outro(especifique) & 1 & 3 & 0 & 4 \\
\hline & \% na linha & $25,00 \%$ & $75,00 \%$ & $0,00 \%$ & $100,00 \%$ \\
\hline & Primeiro(mais alto) & 5 & 5 & 0 & 10 \\
\hline & $\%$ na linha & $50,00 \%$ & $50,00 \%$ & $0,00 \%$ & $100,00 \%$ \\
\hline & Quarto & 1 & 6 & 1 & 8 \\
\hline & $\%$ na linha & $12,50 \%$ & $75,00 \%$ & $12,50 \%$ & $100,00 \%$ \\
\hline & Segundo & 14 & 16 & 0 & 30 \\
\hline & $\%$ na linha & $46,67 \%$ & $53,33 \%$ & $0,00 \%$ & $100,00 \%$ \\
\hline & Terceiro & 16 & 17 & 0 & 33 \\
\hline & $\%$ na linha & $48,48 \%$ & $51,52 \%$ & $0,00 \%$ & $100,00 \%$ \\
\hline & Total & 37 & 47 & 1 & 85 \\
\hline & Referência para comparações em \% & $43,53 \%$ & $55,29 \%$ & $1,18 \%$ & $100,00 \%$ \\
\hline \multirow{6}{*}{ Sexo } & Sexo feminino. & 17 & 23 & 1 & 41 \\
\hline & $\%$ na linha & $41,46 \%$ & $56,10 \%$ & $2,44 \%$ & $100,00 \%$ \\
\hline & Sexo masculino & 20 & 24 & 0 & 44 \\
\hline & $\%$ na linha & $45,45 \%$ & $54,55 \%$ & $0,00 \%$ & $100,00 \%$ \\
\hline & Total & 37 & 47 & 1 & 85 \\
\hline & Referência para comparações em \% & $43,53 \%$ & $55,29 \%$ & $1,18 \%$ & $100,00 \%$ \\
\hline
\end{tabular}

O consenso revelado sobre importância do envolvimento de comerciantes e moradores tanto no planejamento quanto na implantação de obras de drenagem (perguntas 2.2, 2.8 7.4 e 7.8 respectivamente) não se repete no que se refere à importância da relação entre o envolvimento desses atores sociais e a redução dos impactos das inundações. Dentre os grupos que apresentam maior grau de concordância com esta afirmação estão aqueles em nível hierárquico mais baixo, os mais jovens e os de formação sociopolítica.

Pergunta 12.4 - As principais causas das inundações no Município de São Paulo são: a fiscalização do uso e ocupação do solo em áreas de proteção de mananciais e de preservação permanente.

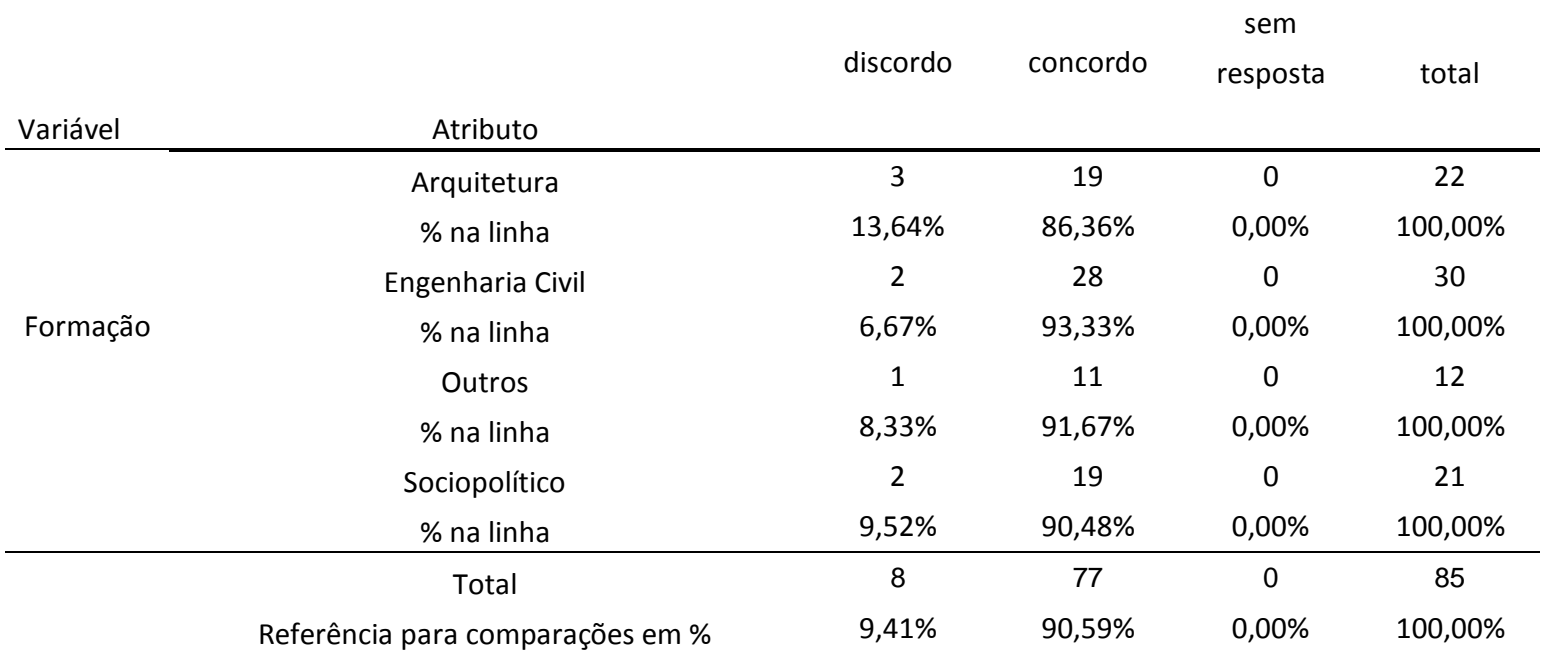




\begin{tabular}{|c|c|c|c|c|c|}
\hline \multirow{6}{*}{ Função } & Assessoria - Consultoria - Docência & 4 & 42 & 0 & 46 \\
\hline & $\%$ na linha & $8,70 \%$ & $91,30 \%$ & $0,00 \%$ & $100,00 \%$ \\
\hline & Coordenação - Gestão - Supervisão & 4 & 35 & 0 & 39 \\
\hline & $\%$ na linha & $10,26 \%$ & $89,74 \%$ & $0,00 \%$ & $100,00 \%$ \\
\hline & Total & 8 & 77 & 0 & 85 \\
\hline & Referência para comparações em \% & $9,41 \%$ & $90,59 \%$ & $0,00 \%$ & $100,00 \%$ \\
\hline \multirow{10}{*}{ Idade } & 30a39anos & 2 & 16 & 0 & 18 \\
\hline & $\%$ na linha & $11,11 \%$ & $88,89 \%$ & $0,00 \%$ & $100,00 \%$ \\
\hline & 40a49anos & 3 & 12 & 0 & 15 \\
\hline & $\%$ na linha & $20,00 \%$ & $80,00 \%$ & $0,00 \%$ & $100,00 \%$ \\
\hline & 50a59anos & 2 & 35 & 0 & 37 \\
\hline & $\%$ na linha & $5,41 \%$ & $94,59 \%$ & $0,00 \%$ & $100,00 \%$ \\
\hline & 60 anos a mais & 1 & 14 & 0 & 15 \\
\hline & $\%$ na linha & $6,67 \%$ & $93,33 \%$ & $0,00 \%$ & $100,00 \%$ \\
\hline & Total & 8 & 77 & 0 & 85 \\
\hline & Referência para comparações em \% & $9,41 \%$ & $90,59 \%$ & $0,00 \%$ & $100,00 \%$ \\
\hline \multirow{12}{*}{ Nível } & Outro(especifique) & 0 & 4 & 0 & 4 \\
\hline & $\%$ na linha & $0,00 \%$ & $100,00 \%$ & $0,00 \%$ & $100,00 \%$ \\
\hline & Primeiro(mais alto) & 1 & 9 & 0 & 10 \\
\hline & $\%$ na linha & $10,00 \%$ & $90,00 \%$ & $0,00 \%$ & $100,00 \%$ \\
\hline & Quarto & 1 & 7 & 0 & 8 \\
\hline & $\%$ na linha & $12,50 \%$ & $87,50 \%$ & $0,00 \%$ & $100,00 \%$ \\
\hline & Segundo & 4 & 26 & 0 & 30 \\
\hline & $\%$ na linha & $13,33 \%$ & $86,67 \%$ & $0,00 \%$ & $100,00 \%$ \\
\hline & Terceiro & 2 & 31 & 0 & 33 \\
\hline & $\%$ na linha & $6,06 \%$ & $93,94 \%$ & $0,00 \%$ & $100,00 \%$ \\
\hline & Total & 8 & 77 & 0 & 85 \\
\hline & Referência para comparações em \% & $9,41 \%$ & $90,59 \%$ & $0,00 \%$ & $100,00 \%$ \\
\hline \multirow{6}{*}{ Sexo } & Sexo feminino. & 2 & 39 & 0 & 41 \\
\hline & $\%$ na linha & $4,88 \%$ & $95,12 \%$ & $0,00 \%$ & $100,00 \%$ \\
\hline & Sexo masculino & 6 & 38 & 0 & 44 \\
\hline & $\%$ na linha & $13,64 \%$ & $86,36 \%$ & $0,00 \%$ & $100,00 \%$ \\
\hline & Total & 8 & 77 & 0 & 85 \\
\hline & Referência para comparações em \% & $9,41 \%$ & $90,59 \%$ & $0,00 \%$ & $100,00 \%$ \\
\hline
\end{tabular}

Há consenso com relação ao grau de concordância sobre esta questão. Uma diferença notória é mostrada pelo grau de concordância entre homens e mulheres. Estas apresentam o grau mais elevado de concordância com esta afirmação, e os homens um dos mais baixos, juntamente com o grupo daqueles formados em arquitetura. 


\begin{tabular}{|c|c|c|c|c|c|}
\hline \multirow[b]{2}{*}{ Variável } & \multirow[b]{2}{*}{ Atributo } & \multirow[t]{2}{*}{ discordo } & concordo & $\begin{array}{c}\text { sem } \\
\text { resposta }\end{array}$ & total \\
\hline & & & & & \\
\hline \multirow{10}{*}{ Formação } & Arquitetura & 14 & 7 & 1 & 22 \\
\hline & $\%$ na linha & $63,64 \%$ & $31,82 \%$ & $4,55 \%$ & $100,00 \%$ \\
\hline & Engenharia Civil & 22 & 7 & 1 & 30 \\
\hline & $\%$ na linha & $73,33 \%$ & $23,33 \%$ & $3,33 \%$ & $100,00 \%$ \\
\hline & Outros & 9 & 3 & 0 & 12 \\
\hline & $\%$ na linha & $75,00 \%$ & $25,00 \%$ & $0,00 \%$ & $100,00 \%$ \\
\hline & Sociopolítico & 13 & 6 & 2 & 21 \\
\hline & $\%$ na linha & $61,90 \%$ & $28,57 \%$ & $9,52 \%$ & $100,00 \%$ \\
\hline & Total & 58 & 23 & 4 & 85 \\
\hline & Referência para comparações em \% & $68,24 \%$ & $27,06 \%$ & $4,71 \%$ & $100,00 \%$ \\
\hline \multirow{6}{*}{ Função } & Assessoria - Consultoria - Docência & 34 & 11 & 1 & 46 \\
\hline & $\%$ na linha & $73,91 \%$ & $23,91 \%$ & $2,17 \%$ & $100,00 \%$ \\
\hline & Coordenação - Gestão - Supervisão & 24 & 12 & 3 & 39 \\
\hline & $\%$ na linha & $61,54 \%$ & $30,77 \%$ & $7,69 \%$ & $100,00 \%$ \\
\hline & Total & 58 & 23 & 4 & 85 \\
\hline & Referência para comparações em \% & $68,24 \%$ & $27,06 \%$ & $4,71 \%$ & $100,00 \%$ \\
\hline \multirow{10}{*}{ Idade } & 30a39anos & 15 & 3 & 0 & 18 \\
\hline & $\%$ na linha & $83,33 \%$ & $16,67 \%$ & $0,00 \%$ & $100,00 \%$ \\
\hline & 40a49anos & 10 & 5 & 0 & 15 \\
\hline & $\%$ na linha & $66,67 \%$ & $33,33 \%$ & $0,00 \%$ & $100,00 \%$ \\
\hline & 50a59anos & 25 & 9 & 3 & 37 \\
\hline & $\%$ na linha & $67,57 \%$ & $24,32 \%$ & $8,11 \%$ & $100,00 \%$ \\
\hline & 60 anos a mais & 8 & 6 & 1 & 15 \\
\hline & $\%$ na linha & $53,33 \%$ & $40,00 \%$ & $6,67 \%$ & $100,00 \%$ \\
\hline & Total & 58 & 23 & 4 & 85 \\
\hline & Referência para comparações em \% & $68,24 \%$ & $27,06 \%$ & $4,71 \%$ & $100,00 \%$ \\
\hline \multirow{12}{*}{ Nível } & Outro(especifique) & 3 & 1 & 0 & 4 \\
\hline & $\%$ na linha & $75,00 \%$ & $25,00 \%$ & $0,00 \%$ & $100,00 \%$ \\
\hline & Primeiro(mais alto) & 6 & 3 & 1 & 10 \\
\hline & $\%$ na linha & $60,00 \%$ & $30,00 \%$ & $10,00 \%$ & $100,00 \%$ \\
\hline & Quarto & 3 & 4 & 1 & 8 \\
\hline & $\%$ na linha & $37,50 \%$ & $50,00 \%$ & $12,50 \%$ & $100,00 \%$ \\
\hline & Segundo & 21 & 8 & 1 & 30 \\
\hline & $\%$ na linha & $70,00 \%$ & $26,67 \%$ & $3,33 \%$ & $100,00 \%$ \\
\hline & Terceiro & 25 & 7 & 1 & 33 \\
\hline & $\%$ na linha & $75,76 \%$ & $21,21 \%$ & $3,03 \%$ & $100,00 \%$ \\
\hline & Total & 58 & 23 & 4 & 85 \\
\hline & Referência para comparações em \% & $68,24 \%$ & $27,06 \%$ & $4,71 \%$ & $100,00 \%$ \\
\hline
\end{tabular}




\begin{tabular}{|c|c|c|c|c|}
\hline$\%$ na linha & $68,29 \%$ & $26,83 \%$ & $4,88 \%$ & $100,00 \%$ \\
\hline Sexo masculino & 30 & 12 & 2 & 44 \\
\hline$\%$ na linha & $68,18 \%$ & $27,27 \%$ & $4,55 \%$ & $100,00 \%$ \\
\hline Total & 58 & 23 & 4 & 85 \\
\hline Referência para comparações em \% & $68,24 \%$ & $27,06 \%$ & $4,71 \%$ & $100,00 \%$ \\
\hline
\end{tabular}

Esta questão resultou no mais baixo grau de concordância entre todas as perguntas Todos se situam bem próximo ao percentual de referência para discordância, $68 \%$, e a concordância ficou em $27,06 \%$, o que revela que os respondentes não acreditam que as inundações estejam relacionadas com a formação do Engenheiro Civil em aspectos sociopolíticos. Quando da questão 9 sobre o fato da Engenharia Civil capacitar suficientemente para a boa execução de obras de drenagem, somente $56,47 \%$ dos respondentes concordaram.

\section{Pergunta 12.6 - As principais causas das inundações no Município de São Paulo são: a} impermeabilização do solo.

\begin{tabular}{|c|c|c|c|c|c|}
\hline \multirow[b]{2}{*}{ Variável } & \multirow[b]{2}{*}{ Atributo } & \multirow[t]{2}{*}{ discordo } & concordo & $\begin{array}{c}\text { sem } \\
\text { resposta }\end{array}$ & total \\
\hline & & & & & \\
\hline \multirow{10}{*}{ Formação } & Arquitetura & 2 & 20 & 0 & 22 \\
\hline & $\%$ na linha & $9,09 \%$ & $90,91 \%$ & $0,00 \%$ & $100,00 \%$ \\
\hline & Engenharia Civil & 1 & 29 & 0 & 30 \\
\hline & $\%$ na linha & $3,33 \%$ & $96,67 \%$ & $0,00 \%$ & $100,00 \%$ \\
\hline & Outros & 0 & 12 & 0 & 12 \\
\hline & $\%$ na linha & $0,00 \%$ & $100,00 \%$ & $0,00 \%$ & $100,00 \%$ \\
\hline & Sociopolítico & 1 & 18 & 2 & 21 \\
\hline & $\%$ na linha & $4,76 \%$ & $85,71 \%$ & $9,52 \%$ & $100,00 \%$ \\
\hline & Total & 4 & 79 & 2 & 85 \\
\hline & Referência para comparações em \% & $4,71 \%$ & $92,94 \%$ & $2,35 \%$ & $100,00 \%$ \\
\hline \multirow{6}{*}{ Função } & Assessoria - Consultoria - Docência & 1 & 45 & 0 & 46 \\
\hline & $\%$ na linha & $2,17 \%$ & $97,83 \%$ & $0,00 \%$ & $100,00 \%$ \\
\hline & Coordenação - Gestão - Supervisão & 3 & 34 & 2 & 39 \\
\hline & $\%$ na linha & $7,69 \%$ & $87,18 \%$ & $5,13 \%$ & $100,00 \%$ \\
\hline & Total & 4 & 79 & 2 & 85 \\
\hline & Referência para comparações em \% & $4,71 \%$ & $92,94 \%$ & $2,35 \%$ & $100,00 \%$ \\
\hline \multirow{9}{*}{ Idade } & 30a39anos & 2 & 16 & 0 & 18 \\
\hline & $\%$ na linha & $11,11 \%$ & $88,89 \%$ & $0,00 \%$ & $100,00 \%$ \\
\hline & 40a49anos & 0 & 15 & 0 & 15 \\
\hline & $\%$ na linha & $0,00 \%$ & $100,00 \%$ & $0,00 \%$ & $100,00 \%$ \\
\hline & 50a59anos & 1 & 34 & 2 & 37 \\
\hline & $\%$ na linha & $2,70 \%$ & $91,89 \%$ & $5,41 \%$ & $100,00 \%$ \\
\hline & 60 anos a mais & 1 & 14 & 0 & 15 \\
\hline & $\%$ na linha & $6,67 \%$ & $93,33 \%$ & $0,00 \%$ & $100,00 \%$ \\
\hline & Total & 4 & 79 & 2 & 85 \\
\hline
\end{tabular}




\begin{tabular}{|c|c|c|c|c|c|}
\hline & Referência para comparações em \% & $4,71 \%$ & $92,94 \%$ & $2,35 \%$ & $100,00 \%$ \\
\hline \multirow{12}{*}{ Nível } & Outro(especifique) & 0 & 3 & 1 & 4 \\
\hline & $\%$ na linha & $0,00 \%$ & $75,00 \%$ & $25,00 \%$ & $100,00 \%$ \\
\hline & Primeiro(mais alto) & 2 & 8 & 0 & 10 \\
\hline & \% na linha & $20,00 \%$ & $80,00 \%$ & $0,00 \%$ & $100,00 \%$ \\
\hline & Quarto & 0 & 7 & 1 & 8 \\
\hline & $\%$ na linha & $0,00 \%$ & $87,50 \%$ & $12,50 \%$ & $100,00 \%$ \\
\hline & Segundo & 1 & 29 & 0 & 30 \\
\hline & $\%$ na linha & $3,33 \%$ & $96,67 \%$ & $0,00 \%$ & $100,00 \%$ \\
\hline & Terceiro & 1 & 32 & 0 & 33 \\
\hline & $\%$ na linha & $3,03 \%$ & $96,97 \%$ & $0,00 \%$ & $100,00 \%$ \\
\hline & Total & 4 & 79 & 2 & 85 \\
\hline & Referência para comparações em \% & $4,71 \%$ & $92,94 \%$ & $2,35 \%$ & $100,00 \%$ \\
\hline \multirow{6}{*}{ Sexo } & Sexo feminino. & 1 & 39 & 1 & 41 \\
\hline & $\%$ na linha & $2,44 \%$ & $95,12 \%$ & $2,44 \%$ & $100,00 \%$ \\
\hline & Sexo masculino & 3 & 40 & 1 & 44 \\
\hline & $\%$ na linha & $6,82 \%$ & $90,91 \%$ & $2,27 \%$ & $100,00 \%$ \\
\hline & Total & 4 & 79 & 2 & 85 \\
\hline & Referência para comparações em \% & $4,71 \%$ & $92,94 \%$ & $2,35 \%$ & $100,00 \%$ \\
\hline
\end{tabular}

Houve consenso entre os grupos com relação ao grau de concordância com esta questão. É interessante notar que a maior discordância foi registrada entre o grupo de nível hierárquico em primeiro escalão.

\section{Pergunta 12.7 - As principais causas das inundações no Município de São Paulo são: insuficientes recursos financeiros por parte do Poder Público.}

\begin{tabular}{|c|c|c|c|c|c|}
\hline \multirow[b]{2}{*}{ Variável } & \multirow[b]{2}{*}{ Atributo } & \multirow[t]{2}{*}{ discordo } & concordo & $\begin{array}{c}\text { sem } \\
\text { resposta }\end{array}$ & total \\
\hline & & & & & \\
\hline \multirow{10}{*}{ Formação } & Arquitetura & 14 & 8 & 0 & 22 \\
\hline & $\%$ na linha & $63,64 \%$ & $36,36 \%$ & $0,00 \%$ & $100,00 \%$ \\
\hline & Engenharia Civil & 11 & 19 & 0 & 30 \\
\hline & $\%$ na linha & $36,67 \%$ & $63,33 \%$ & $0,00 \%$ & $100,00 \%$ \\
\hline & Outros & 7 & 5 & 0 & 12 \\
\hline & $\%$ na linha & $58,33 \%$ & $41,67 \%$ & $0,00 \%$ & $100,00 \%$ \\
\hline & Sociopolítico & 8 & 12 & 1 & 21 \\
\hline & $\%$ na linha & $38,10 \%$ & $57,14 \%$ & $4,76 \%$ & $100,00 \%$ \\
\hline & Total & 40 & 44 & 1 & 85 \\
\hline & Referência para comparações em \% & $47,06 \%$ & $51,76 \%$ & $1,18 \%$ & $100,00 \%$ \\
\hline \multirow{4}{*}{ Função } & Assessoria - Consultoria - Docência & 26 & 20 & 0 & 46 \\
\hline & $\%$ na linha & $56,52 \%$ & $43,48 \%$ & $0,00 \%$ & $100,00 \%$ \\
\hline & Coordenação - Gestão - Supervisão & 14 & 24 & 1 & 39 \\
\hline & $\%$ na linha & $35,90 \%$ & $61,54 \%$ & $2,56 \%$ & $100,00 \%$ \\
\hline
\end{tabular}




\begin{tabular}{|c|c|c|c|c|c|}
\hline & Total & 40 & 44 & 1 & 85 \\
\hline & Referência para comparações em \% & $47,06 \%$ & $51,76 \%$ & $1,18 \%$ & $100,00 \%$ \\
\hline \multirow{10}{*}{ Idade } & 30a39anos & 10 & 8 & 0 & 18 \\
\hline & $\%$ na linha & $55,56 \%$ & $44,44 \%$ & $0,00 \%$ & $100,00 \%$ \\
\hline & 40a49anos & 6 & 9 & 0 & 15 \\
\hline & $\%$ na linha & $40,00 \%$ & $60,00 \%$ & $0,00 \%$ & $100,00 \%$ \\
\hline & 50a59anos & 18 & 18 & 1 & 37 \\
\hline & $\%$ na linha & $48,65 \%$ & $48,65 \%$ & $2,70 \%$ & $100,00 \%$ \\
\hline & 60 anos a mais & 6 & 9 & 0 & 15 \\
\hline & $\%$ na linha & $40,00 \%$ & $60,00 \%$ & $0,00 \%$ & $100,00 \%$ \\
\hline & Total & 40 & 44 & 1 & 85 \\
\hline & Referência para comparações em \% & $47,06 \%$ & $51,76 \%$ & $1,18 \%$ & $100,00 \%$ \\
\hline \multirow{12}{*}{ Nível } & Outro(especifique) & 2 & 2 & 0 & 4 \\
\hline & $\%$ na linha & $50,00 \%$ & $50,00 \%$ & $0,00 \%$ & $100,00 \%$ \\
\hline & Primeiro(mais alto) & 2 & 8 & 0 & 10 \\
\hline & \% na linha & $20,00 \%$ & $80,00 \%$ & $0,00 \%$ & $100,00 \%$ \\
\hline & Quarto & 0 & 7 & 1 & 8 \\
\hline & $\%$ na linha & $0,00 \%$ & $87,50 \%$ & $12,50 \%$ & $100,00 \%$ \\
\hline & Segundo & 15 & 15 & 0 & 30 \\
\hline & $\%$ na linha & $50,00 \%$ & $50,00 \%$ & $0,00 \%$ & $100,00 \%$ \\
\hline & Terceiro & 21 & 12 & 0 & 33 \\
\hline & $\%$ na linha & $63,64 \%$ & $36,36 \%$ & $0,00 \%$ & $100,00 \%$ \\
\hline & Total & 40 & 44 & 1 & 85 \\
\hline & Referência para comparações em \% & $47,06 \%$ & $51,76 \%$ & $1,18 \%$ & $100,00 \%$ \\
\hline \multirow{6}{*}{ Sexo } & Sexo feminino. & 22 & 18 & 1 & 41 \\
\hline & $\%$ na linha & $53,66 \%$ & $43,90 \%$ & $2,44 \%$ & $100,00 \%$ \\
\hline & Sexo masculino & 18 & 26 & 0 & 44 \\
\hline & $\%$ na linha & $40,91 \%$ & $59,09 \%$ & $0,00 \%$ & $100,00 \%$ \\
\hline & Total & 40 & 44 & 1 & 85 \\
\hline & Referência para comparações em \% & $47,06 \%$ & $51,76 \%$ & $1,18 \%$ & $100,00 \%$ \\
\hline
\end{tabular}

Outra questão em que as opiniões estão divididas: $47,06 \%$ dos respondentes não concordam em que uma das causas das inundações seja a falta de investimentos públicos. Os profissionais de nível hierárquico em terceiro escalão e os arquitetos são os grupos que mais discordam desta afirmação. É interessante que aqueles que se situam em primeiro escalão apresentam o maior grau de concordância com esta afirmação, Em geral, as respostas se situam ao redor do percentual de referência.

Pergunta 12.8 - As principais causas das inundações no Município de São Paulo são: a manutenção das obras de drenagem pelo Poder Público.

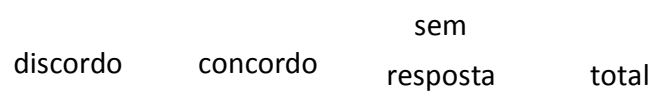




\begin{tabular}{|c|c|c|c|c|c|}
\hline & Arquitetura & 2 & 19 & 1 & 22 \\
\hline & $\%$ na linha & $9,09 \%$ & $86,36 \%$ & $4,55 \%$ & $100,00 \%$ \\
\hline & Engenharia Civil & 1 & 29 & 0 & 30 \\
\hline \multirow[t]{7}{*}{ Formação } & $\%$ na linha & $3,33 \%$ & $96,67 \%$ & $0,00 \%$ & $100,00 \%$ \\
\hline & Outros & 1 & 10 & 1 & 12 \\
\hline & $\%$ na linha & $8,33 \%$ & $83,33 \%$ & $8,33 \%$ & $100,00 \%$ \\
\hline & Sociopolítico & 4 & 16 & 1 & 21 \\
\hline & $\%$ na linha & $19,05 \%$ & $76,19 \%$ & $4,76 \%$ & $100,00 \%$ \\
\hline & Total & 8 & 74 & 3 & 85 \\
\hline & Referência para comparações em \% & $9,41 \%$ & $87,06 \%$ & $3,53 \%$ & $100,00 \%$ \\
\hline \multirow{6}{*}{ Função } & Assessoria - Consultoria - Docência & 3 & 41 & 2 & 46 \\
\hline & $\%$ na linha & $6,52 \%$ & $89,13 \%$ & $4,35 \%$ & $100,00 \%$ \\
\hline & Coordenação - Gestão - Supervisão & 5 & 33 & 1 & 39 \\
\hline & $\%$ na linha & $12,82 \%$ & $84,62 \%$ & $2,56 \%$ & $100,00 \%$ \\
\hline & Total & 8 & 74 & 3 & 85 \\
\hline & Referência para comparações em \% & $9,41 \%$ & $87,06 \%$ & $3,53 \%$ & $100,00 \%$ \\
\hline \multirow{10}{*}{ Idade } & 30a39anos & 1 & 17 & 0 & 18 \\
\hline & $\%$ na linha & $5,56 \%$ & $94,44 \%$ & $0,00 \%$ & $100,00 \%$ \\
\hline & 40a49anos & 3 & 12 & 0 & 15 \\
\hline & $\%$ na linha & $20,00 \%$ & $80,00 \%$ & $0,00 \%$ & $100,00 \%$ \\
\hline & 50a59anos & 3 & 31 & 3 & 37 \\
\hline & $\%$ na linha & $8,11 \%$ & $83,78 \%$ & $8,11 \%$ & $100,00 \%$ \\
\hline & 60 anos a mais & 1 & 14 & 0 & 15 \\
\hline & $\%$ na linha & $6,67 \%$ & $93,33 \%$ & $0,00 \%$ & $100,00 \%$ \\
\hline & Total & 8 & 74 & 3 & 85 \\
\hline & Referência para comparações em \% & $9,41 \%$ & $87,06 \%$ & $3,53 \%$ & $100,00 \%$ \\
\hline \multirow{12}{*}{ Nível } & Outro(especifique) & 0 & 4 & 0 & 4 \\
\hline & $\%$ na linha & $0,00 \%$ & $100,00 \%$ & $0,00 \%$ & $100,00 \%$ \\
\hline & Primeiro(mais alto) & 1 & 9 & 0 & 10 \\
\hline & $\%$ na linha & $10,00 \%$ & $90,00 \%$ & $0,00 \%$ & $100,00 \%$ \\
\hline & Quarto & 0 & 7 & 1 & 8 \\
\hline & $\%$ na linha & $0,00 \%$ & $87,50 \%$ & $12,50 \%$ & $100,00 \%$ \\
\hline & Segundo & 4 & 26 & 0 & 30 \\
\hline & $\%$ na linha & $13,33 \%$ & $86,67 \%$ & $0,00 \%$ & $100,00 \%$ \\
\hline & Terceiro & 3 & 28 & 2 & 33 \\
\hline & $\%$ na linha & $9,09 \%$ & $84,85 \%$ & $6,06 \%$ & $100,00 \%$ \\
\hline & Total & 8 & 74 & 3 & 85 \\
\hline & Referência para comparações em \% & $9,41 \%$ & $87,06 \%$ & $3,53 \%$ & $100,00 \%$ \\
\hline \multirow{5}{*}{ Sexo } & Sexo feminino. & 3 & 35 & 3 & 41 \\
\hline & $\%$ na linha & $7,32 \%$ & $85,37 \%$ & $7,32 \%$ & $100,00 \%$ \\
\hline & Sexo masculino & 5 & 39 & 0 & 44 \\
\hline & $\%$ na linha & $11,36 \%$ & $88,64 \%$ & $0,00 \%$ & $100,00 \%$ \\
\hline & Total & 8 & 74 & 3 & 85 \\
\hline
\end{tabular}


Há consenso com relação ao grau de concordância com esta afirmação. O mais elevado grau de concordância é apresentado pelo grupo de formação em Engenharia Civil.

\section{Pergunta 12.9 - As principais causas das inundações no Município de São Paulo são: a resíduos sólidos depositados nas vias públicas e cursos de água.}

\begin{tabular}{|c|c|c|c|c|c|}
\hline \multirow[b]{2}{*}{ Variável } & \multirow[b]{2}{*}{ Atributo } & \multirow[t]{2}{*}{ discordo } & concordo & $\begin{array}{c}\text { sem } \\
\text { resposta }\end{array}$ & total \\
\hline & & & & & \\
\hline \multirow{10}{*}{ Formação } & Arquitetura & 2 & 20 & 0 & 22 \\
\hline & $\%$ na linha & $9,09 \%$ & $90,91 \%$ & $0,00 \%$ & $100,00 \%$ \\
\hline & Engenharia Civil & 2 & 28 & 0 & 30 \\
\hline & $\%$ na linha & $6,67 \%$ & $93,33 \%$ & $0,00 \%$ & $100,00 \%$ \\
\hline & Outros & 0 & 12 & 0 & 12 \\
\hline & $\%$ na linha & $0,00 \%$ & $100,00 \%$ & $0,00 \%$ & $100,00 \%$ \\
\hline & Sociopolítico & 0 & 21 & 0 & 21 \\
\hline & $\%$ na linha & $0,00 \%$ & $100,00 \%$ & $0,00 \%$ & $100,00 \%$ \\
\hline & Total & 4 & 81 & 0 & 85 \\
\hline & Referência para comparações em \% & $4,71 \%$ & $95,29 \%$ & $0,00 \%$ & $100,00 \%$ \\
\hline \multirow{6}{*}{ Função } & Assessoria - Consultoria - Docência & 4 & 42 & 0 & 46 \\
\hline & $\%$ na linha & $8,70 \%$ & $91,30 \%$ & $0,00 \%$ & $100,00 \%$ \\
\hline & Coordenação - Gestão - Supervisão & 0 & 39 & 0 & 39 \\
\hline & $\%$ na linha & $0,00 \%$ & $100,00 \%$ & $0,00 \%$ & $100,00 \%$ \\
\hline & Total & 4 & 81 & 0 & 85 \\
\hline & Referência para comparações em \% & $4,71 \%$ & $95,29 \%$ & $0,00 \%$ & $100,00 \%$ \\
\hline \multirow{10}{*}{ Idade } & 30a39anos & 0 & 18 & 0 & 18 \\
\hline & $\%$ na linha & $0,00 \%$ & $100,00 \%$ & $0,00 \%$ & $100,00 \%$ \\
\hline & 40a49anos & 1 & 14 & 0 & 15 \\
\hline & $\%$ na linha & $6,67 \%$ & $93,33 \%$ & $0,00 \%$ & $100,00 \%$ \\
\hline & 50a59anos & 3 & 34 & 0 & 37 \\
\hline & \% na linha & $8,11 \%$ & $91,89 \%$ & $0,00 \%$ & $100,00 \%$ \\
\hline & 60 anos a mais & 0 & 15 & 0 & 15 \\
\hline & $\%$ na linha & $0,00 \%$ & $100,00 \%$ & $0,00 \%$ & $100,00 \%$ \\
\hline & Total & 4 & 81 & 0 & 85 \\
\hline & Referência para comparações em \% & $4,71 \%$ & $95,29 \%$ & $0,00 \%$ & $100,00 \%$ \\
\hline \multirow{7}{*}{ Nível } & Outro(especifique) & 0 & 4 & 0 & 4 \\
\hline & $\%$ na linha & $0,00 \%$ & $100,00 \%$ & $0,00 \%$ & $100,00 \%$ \\
\hline & Primeiro(mais alto) & 0 & 10 & 0 & 10 \\
\hline & $\%$ na linha & $0,00 \%$ & $100,00 \%$ & $0,00 \%$ & $100,00 \%$ \\
\hline & Quarto & 1 & 7 & 0 & 8 \\
\hline & $\%$ na linha & $12,50 \%$ & $87,50 \%$ & $0,00 \%$ & $100,00 \%$ \\
\hline & Segundo & 0 & 30 & 0 & 30 \\
\hline
\end{tabular}




\begin{tabular}{|c|c|c|c|c|c|}
\hline & $\%$ na linha & $0,00 \%$ & $100,00 \%$ & $0,00 \%$ & $100,00 \%$ \\
\hline & Terceiro & 3 & 30 & 0 & 33 \\
\hline & $\%$ na linha & $9,09 \%$ & $90,91 \%$ & $0,00 \%$ & $100,00 \%$ \\
\hline & Total & 4 & 81 & 0 & 85 \\
\hline & Referência para comparações em \% & $4,71 \%$ & $95,29 \%$ & $0,00 \%$ & $100,00 \%$ \\
\hline \multirow{6}{*}{ Sexo } & Sexo feminino. & 2 & 39 & 0 & 41 \\
\hline & \% na linha & $4,88 \%$ & $95,12 \%$ & $0,00 \%$ & $100,00 \%$ \\
\hline & Sexo masculino & 2 & 42 & 0 & 44 \\
\hline & \% na linha & $4,55 \%$ & $95,45 \%$ & $0,00 \%$ & $100,00 \%$ \\
\hline & Total & 4 & 81 & 0 & 85 \\
\hline & Referência para comparações em \% & $4,71 \%$ & $95,29 \%$ & $0,00 \%$ & $100,00 \%$ \\
\hline
\end{tabular}

Há consenso com relação ao fato de que uma das causas de inundações é a deposição de resíduos sólidos em vias públicas e cursos de água. Apesar deste consenso, o maior grau de discordância com esta afirmação é registrado pelo grupo formado por pessoas em nível hierárquico do quarto escalão.

14 - Relação mais estreita entre o técnico-científico (o campo de atuação e a formação do Engenheiro Civil) e o sociopolítico (a organização social e política) é fundamental para a durabilidade das obras e a sustentabilidade do serviço que oferece.

\begin{tabular}{|c|c|c|c|c|c|}
\hline & & discordo & concordo & $\begin{array}{c}\text { sem } \\
\text { resposta }\end{array}$ & total \\
\hline Variável & Atributo & & & & \\
\hline \multirow{10}{*}{ Formação } & Arquitetura & 2 & 20 & 0 & 22 \\
\hline & $\%$ na linha & $9,09 \%$ & $90,91 \%$ & $0,00 \%$ & $100,00 \%$ \\
\hline & Engenharia Civil & 3 & 26 & 1 & 30 \\
\hline & $\%$ na linha & $10,00 \%$ & $86,67 \%$ & $3,33 \%$ & $100,00 \%$ \\
\hline & Outros & 1 & 11 & 0 & 12 \\
\hline & $\%$ na linha & $8,33 \%$ & $91,67 \%$ & $0,00 \%$ & $100,00 \%$ \\
\hline & Sociopolítico & 0 & 20 & 1 & 21 \\
\hline & $\%$ na linha & $0,00 \%$ & $95,24 \%$ & $4,76 \%$ & $100,00 \%$ \\
\hline & Total & 6 & 77 & 2 & 85 \\
\hline & Referência para comparações em \% & $7,06 \%$ & $90,59 \%$ & $2,35 \%$ & $100,00 \%$ \\
\hline \multirow{6}{*}{ Função } & Assessoria - Consultoria - Docência & 4 & 41 & 1 & 46 \\
\hline & $\%$ na linha & $8,70 \%$ & $89,13 \%$ & $2,17 \%$ & $100,00 \%$ \\
\hline & Coordenação - Gestão - Supervisão & 2 & 36 & 1 & 39 \\
\hline & $\%$ na linha & $5,13 \%$ & $92,31 \%$ & $2,56 \%$ & $100,00 \%$ \\
\hline & Total & 6 & 77 & 2 & 85 \\
\hline & Referência para comparações em \% & $7,06 \%$ & $90,59 \%$ & $2,35 \%$ & $100,00 \%$ \\
\hline \multirow{4}{*}{ Idade } & 30a39anos & 2 & 16 & 0 & 18 \\
\hline & $\%$ na linha & $11,11 \%$ & $88,89 \%$ & $0,00 \%$ & $100,00 \%$ \\
\hline & 40a49anos & 0 & 14 & 1 & 15 \\
\hline & $\%$ na linha & $0,00 \%$ & $93,33 \%$ & $6,67 \%$ & $100,00 \%$ \\
\hline
\end{tabular}




\begin{tabular}{|c|c|c|c|c|c|}
\hline & 50a59anos & 4 & 33 & 0 & 37 \\
\hline & $\%$ na linha & $10,81 \%$ & $89,19 \%$ & $0,00 \%$ & $100,00 \%$ \\
\hline & 60anos a mais & 0 & 14 & 1 & 15 \\
\hline & $\%$ na linha & $0,00 \%$ & $93,33 \%$ & $6,67 \%$ & $100,00 \%$ \\
\hline & Total & 6 & 77 & 2 & 85 \\
\hline & Referência para comparações em \% & $7,06 \%$ & $90,59 \%$ & $2,35 \%$ & $100,00 \%$ \\
\hline \multirow{12}{*}{ Nível } & Outro(especifique) & 0 & 4 & 0 & 4 \\
\hline & $\%$ na linha & $0,00 \%$ & $100,00 \%$ & $0,00 \%$ & $100,00 \%$ \\
\hline & Primeiro(mais alto) & 0 & 9 & 1 & 10 \\
\hline & $\%$ na linha & $0,00 \%$ & $90,00 \%$ & $10,00 \%$ & $100,00 \%$ \\
\hline & Quarto & 0 & 8 & 0 & 8 \\
\hline & $\%$ na linha & $0,00 \%$ & $100,00 \%$ & $0,00 \%$ & $100,00 \%$ \\
\hline & Segundo & 1 & 29 & 0 & 30 \\
\hline & $\%$ na linha & $3,33 \%$ & $96,67 \%$ & $0,00 \%$ & $100,00 \%$ \\
\hline & Terceiro & 5 & 27 & 1 & 33 \\
\hline & $\%$ na linha & $15,15 \%$ & $81,82 \%$ & $3,03 \%$ & $100,00 \%$ \\
\hline & Total & 6 & 77 & 2 & 85 \\
\hline & Referência para comparações em \% & $7,06 \%$ & $90,59 \%$ & $2,35 \%$ & $100,00 \%$ \\
\hline \multirow{6}{*}{ Sexo } & Sexo feminino. & 3 & 38 & 0 & 41 \\
\hline & $\%$ na linha & $7,32 \%$ & $92,68 \%$ & $0,00 \%$ & $100,00 \%$ \\
\hline & Sexo masculino & 3 & 39 & 2 & 44 \\
\hline & $\%$ na linha & $6,82 \%$ & $88,64 \%$ & $4,55 \%$ & $100,00 \%$ \\
\hline & Total & 6 & 77 & 2 & 85 \\
\hline & Referência para comparações em \% & $7,06 \%$ & $90,59 \%$ & $2,35 \%$ & $100,00 \%$ \\
\hline
\end{tabular}

Houve consenso com relação ao grau de concordância frente a esta questão, a que seria a mais importante para os fins desta pesquisa. Entretanto, é interessante notar que as situadas acima da referência foram registradas entre o grupo de formação em Engenharia Civil, os mais jovens, aqueles com idade entre 50 e 59 anos e o grupo situado em nível hierárquico do terceiro escalão. 


\section{ANEXO 8 - MORADORES E COMERCIANTES : CONJUNTO DE TABELAS GERADAS.}

\begin{tabular}{ccccc} 
& Não Proprietário & Proprietário & Sem resposta & Total \\
\hline \multirow{2}{*}{ Comerciante } & 53 & 23 & 13 & 89 \\
& $59,6 \%$ & $25,8 \%$ & $14,6 \%$ & $100 \%$ \\
Morador & 59 & 151 & 2 & 212 \\
& $27,8 \%$ & $71,2 \%$ & $0,9 \%$ & $100 \%$ \\
\hline \multirow{2}{*}{ Total } & 112 & 174 & 15 & 301
\end{tabular}

Tabela 1 - Distribuição de frequências para moradores e comerciantes e ser ou não proprietários do lote onde se instalam.

\begin{tabular}{ccccc} 
& Não & & & \\
& proprietário & Proprietário & Vazios & Total \\
\hline \multirow{2}{*}{ Reg1 } & 45 & 86 & 15 & 146 \\
& $31 \%$ & $59 \%$ & $10 \%$ & $100 \%$ \\
Reg2 & 32 & 40 & & 72 \\
& $44 \%$ & $56 \%$ & $0 \%$ & $100 \%$ \\
Reg3 & 35 & 48 & & 83 \\
& $42 \%$ & $58 \%$ & $0 \%$ & $100 \%$ \\
\hline \multirow{2}{*}{ Total } & 112 & 174 & 15 & 301 \\
& $37 \%$ & $58 \%$ & $5 \%$ & $100 \%$
\end{tabular}

Tabela 2 - Proprietários e não-proprietários x região.

\begin{tabular}{|c|c|c|c|c|c|c|}
\hline & Mulheres & Homens & Total & & & \\
\hline \multirow{2}{*}{ Reg1 } & 78 & 68 & 146 & \multirow[b]{2}{*}{146} & & \\
\hline & $53 \%$ & $47 \%$ & $100 \%$ & & & \\
\hline \multirow{2}{*}{ Reg2 } & 32 & 40 & 72 & \multirow{2}{*}{$\begin{array}{l}68 \\
78\end{array}$} & 72 & 83 \\
\hline & $44 \%$ & $56 \%$ & $100 \%$ & & $\begin{array}{l}40 \\
32\end{array}$ & $\begin{array}{l}45 \\
38\end{array}$ \\
\hline Reg3 & $\begin{array}{c}38 \\
46 \%\end{array}$ & $\begin{array}{c}45 \\
54 \%\end{array}$ & $\begin{array}{c}83 \\
100 \%\end{array}$ & Reg 1 & $\operatorname{Reg} 2$ & $\operatorname{Reg} 3$ \\
\hline \multirow[t]{2}{*}{ Total } & 148 & 153 & 301 & \multirow[t]{2}{*}{ Mulheres } & - Homens & - Total \\
\hline & $49 \%$ & $\begin{array}{r}51 \% \\
\text { bela } 3-\end{array}$ & $\begin{array}{l}100 \% \\
\text { x Regi }\end{array}$ & & & \\
\hline
\end{tabular}




\begin{tabular}{|c|c|c|c|c|c|c|c|c|c|}
\hline & $<20$ & $20-24$ & $25-34$ & $35-44$ & $45-54$ & $55-64$ & $>=65$ & Vazios & Total \\
\hline \multirow{2}{*}{ Reg1 } & 6 & 29 & 22 & 15 & 33 & 21 & 18 & 2 & 146 \\
\hline & $4 \%$ & $20 \%$ & $15 \%$ & $10 \%$ & $23 \%$ & $14 \%$ & $12 \%$ & $1 \%$ & $100 \%$ \\
\hline \multirow{2}{*}{ Reg2 } & 4 & 8 & 13 & 12 & 9 & 14 & 12 & & 72 \\
\hline & $6 \%$ & $11 \%$ & $18 \%$ & $17 \%$ & $13 \%$ & $19 \%$ & $17 \%$ & $0 \%$ & $100 \%$ \\
\hline \multirow{2}{*}{ Reg3 } & 2 & 4 & 12 & 16 & 19 & 21 & 9 & & 83 \\
\hline & $2 \%$ & $5 \%$ & $14 \%$ & $19 \%$ & $23 \%$ & $25 \%$ & $11 \%$ & $0 \%$ & $100 \%$ \\
\hline \multirow{2}{*}{ Total } & 12 & 41 & 47 & 43 & 61 & 56 & 39 & 2 & 301 \\
\hline & $4 \%$ & $14 \%$ & $16 \%$ & $14 \%$ & $20 \%$ & $19 \%$ & $13 \%$ & $1 \%$ & $100 \%$ \\
\hline
\end{tabular}

\begin{tabular}{cccccccccc} 
& $\begin{array}{c}\text { Analfabeto ou } \\
\text { primeiro grau } \\
\text { incompleto }\end{array}$ & $\begin{array}{c}\text { Primeiro } \\
\text { grau } \\
\text { completo }\end{array}$ & $\begin{array}{c}\text { Segundo } \\
\text { grau } \\
\text { incompleto }\end{array}$ & $\begin{array}{c}\text { Segundo } \\
\text { grau } \\
\text { completo }\end{array}$ & $\begin{array}{c}\text { Curso } \\
\text { técnico }\end{array}$ & $\begin{array}{c}\text { Curso } \\
\text { Universitário }\end{array}$ & Vazios & Total \\
\hline \multirow{2}{*}{ Comerciante } & 8 & 7 & 8 & 26 & 1 & 38 & 1 & 89 \\
& $9 \%$ & $8 \%$ & $9 \%$ & $29 \%$ & $1 \%$ & $43 \%$ & $1 \%$ & $100 \%$ \\
Morador & 58 & 14 & 18 & 53 & 3 & 60 & 6 & 212 \\
& $27 \%$ & $7 \%$ & $8 \%$ & $25 \%$ & $1 \%$ & $28 \%$ & $3 \%$ & $100 \%$ \\
\hline \multirow{2}{*}{ Total Geral } & 66 & 21 & 26 & 79 & 4 & 98 & 7 & 301 \\
& $22 \%$ & $7 \%$ & $9 \%$ & $26 \%$ & $1 \%$ & $33 \%$ & $2 \%$ & $100 \%$
\end{tabular}

Tabela 5 - Distribuição de frequências para moradores e comerciantes, de acordo o grau de instrução.

\begin{tabular}{|c|c|c|c|c|c|c|c|c|}
\hline & $\begin{array}{c}\text { Analfabeto } \\
\text { ou primeiro } \\
\text { grau } \\
\text { incompleto }\end{array}$ & $\begin{array}{l}\text { Primeiro } \\
\text { grau } \\
\text { completo }\end{array}$ & $\begin{array}{c}\text { Segundo } \\
\text { grau } \\
\text { incompleto }\end{array}$ & $\begin{array}{l}\text { Segundo grau } \\
\text { completo }\end{array}$ & $\begin{array}{l}\text { Curso técnico, } \\
\text { completo ou } \\
\text { não }\end{array}$ & $\begin{array}{c}\text { Curso } \\
\text { Universitário, } \\
\text { completo ou } \\
\text { não }\end{array}$ & Vazios & Total \\
\hline \multirow[t]{2}{*}{ Reg1 } & 44 & 17 & 19 & 42 & 1 & 19 & 4 & 146 \\
\hline & $30 \%$ & $12 \%$ & $13 \%$ & $29 \%$ & $1 \%$ & $13 \%$ & $3 \%$ & $100 \%$ \\
\hline \multirow[t]{2}{*}{ Reg2 } & 16 & 3 & 6 & 18 & 2 & 26 & 1 & 72 \\
\hline & $22 \%$ & $4 \%$ & $8 \%$ & $25 \%$ & $3 \%$ & $36 \%$ & $1 \%$ & $100 \%$ \\
\hline \multirow[t]{2}{*}{ Reg3 } & 6 & 1 & 1 & 19 & 1 & 53 & 2 & 83 \\
\hline & $7 \%$ & $1 \%$ & $1 \%$ & $23 \%$ & $1 \%$ & $64 \%$ & $2 \%$ & $100 \%$ \\
\hline Total & 66 & 21 & 26 & 79 & 4 & 98 & 7 & 301 \\
\hline geral & $22 \%$ & $7 \%$ & $\begin{array}{c}9 \% \\
\text { Tabela } 6\end{array}$ & $\begin{array}{c}26 \% \\
\text { Escolaridade } x\end{array}$ & gião & $33 \%$ & $2 \%$ & $100 \%$ \\
\hline
\end{tabular}


Até 1 ano De2a5anos De6a10anos De 11a20anos De 21a30anos De 31a40anos De 41a 50 anos Mais que 50 Vazios Total

\begin{tabular}{ccccccccccc}
\hline \multirow{2}{*}{ Comerciante } & 13 & 41 & 15 & 13 & 7 & & & & 89 \\
& $14,6 \%$ & $46 \%$ & $17 \%$ & $15 \%$ & $8 \%$ & $0 \%$ & $0 \%$ & $0 \%$ & $0 \%$ & $30 \%$ \\
Morador & 8 & 35 & 19 & 48 & 36 & 45 & 16 & 4 & 1 & 212 \\
& $3,8 \%$ & $17 \%$ & $9 \%$ & $23 \%$ & $17 \%$ & $21 \%$ & $8 \%$ & $2 \%$ & $0 \%$ & $70 \%$ \\
\hline \multirow{2}{*}{ TOTAL GERAL } & 21 & 76 & 34 & 61 & 43 & 45 & 16 & 4 & 1 & 301 \\
& $7,0 \%$ & $25 \%$ & $11 \%$ & $20 \%$ & $14 \%$ & $15 \%$ & $5 \%$ & $1 \%$ & $0 \%$ & $100 \%$
\end{tabular}

Tabela 7 - Distribuição de frequências para o tempo em que se encontra instalado na região.

\begin{tabular}{|c|c|c|c|c|c|c|c|c|c|c|}
\hline & Até 1 & De 2 a 5 & De 6 a 10 & De 11 a 20 & De 21 a 30 & De 31 a 40 & De 41 a 50 & Mais que 50 & Vazios & Total \\
\hline \multirow{2}{*}{ Reg1 } & 6 & 35 & 13 & 26 & 25 & 27 & 12 & 1 & 1 & 146 \\
\hline & $4 \%$ & $24 \%$ & $9 \%$ & $18 \%$ & $17 \%$ & $18 \%$ & $8 \%$ & $1 \%$ & $1 \%$ & $100 \%$ \\
\hline \multirow{2}{*}{ Reg2 } & 9 & 14 & 9 & 22 & 8 & 9 & 1 & & & 72 \\
\hline & $13 \%$ & $19 \%$ & $13 \%$ & $31 \%$ & $11 \%$ & $13 \%$ & $1 \%$ & $0 \%$ & $0 \%$ & $100 \%$ \\
\hline \multirow{2}{*}{ Reg3 } & 6 & 27 & 12 & 13 & 10 & 9 & 3 & 3 & & 83 \\
\hline & $7 \%$ & $33 \%$ & $14 \%$ & $16 \%$ & $12 \%$ & $11 \%$ & $4 \%$ & $4 \%$ & $0 \%$ & $100 \%$ \\
\hline \multirow{2}{*}{ Total } & 21 & 76 & 34 & 61 & 43 & 45 & 16 & 4 & 1 & 301 \\
\hline & $7 \%$ & $25 \%$ & $11 \%$ & $20 \%$ & $14 \%$ & $15 \%$ & $5 \%$ & $1 \%$ & $0 \%$ & $100 \%$ \\
\hline
\end{tabular}

Tabela 8 - Moradores e comerciantes: tempo na área x região.

\begin{tabular}{|c|c|c|c|c|c|c|c|c|c|}
\hline $\begin{array}{l}\text { Tempo na } \\
\text { área em } \longrightarrow \\
\text { períodos } \\
\text { de } 10 \text { anos }\end{array}$ & Até 1 & De 2 a 10 & $\begin{array}{c}\text { De } 11 \text { a } \\
20\end{array}$ & $\begin{array}{c}\text { De } 21 \text { a } \\
30\end{array}$ & $\begin{array}{c}\text { De } 31 \text { a } \\
40\end{array}$ & $\begin{array}{c}\text { De } 41 \text { a } \\
50\end{array}$ & $\begin{array}{c}\text { Mais que } \\
50\end{array}$ & Vazios & Total \\
\hline \multirow{2}{*}{ Região 1} & 6 & 48 & 26 & 25 & 27 & 12 & 1 & 1 & 146 \\
\hline & $4 \%$ & $33 \%$ & $18 \%$ & $17 \%$ & $18 \%$ & $8 \%$ & $1 \%$ & $1 \%$ & $100,0 \%$ \\
\hline \multirow{2}{*}{ Região 2} & 9 & 23 & 22 & 8 & 9 & 1 & & & 72 \\
\hline & $13 \%$ & $32 \%$ & $31 \%$ & $11 \%$ & $13 \%$ & $1 \%$ & $0 \%$ & $0 \%$ & $100 \%$ \\
\hline \multirow{2}{*}{ Região 3} & 6 & 39 & 13 & 10 & 9 & 3 & 3 & & 83 \\
\hline & $7 \%$ & $47 \%$ & $16 \%$ & $12 \%$ & $11 \%$ & $4 \%$ & $4 \%$ & $0 \%$ & $100 \%$ \\
\hline \multirow{2}{*}{ Total } & 21 & 111 & 61 & 43 & 45 & 16 & 4 & 1 & 301 \\
\hline & $7 \%$ & $37 \%$ & $20 \%$ & $14 \%$ & $15 \%$ & $5 \%$ & $1 \%$ & $0 \%$ & $100 \%$ \\
\hline
\end{tabular}

Tabela 9 - Moradores e Comerciantes: Tempo na área contados a cada 10 anos x Região. 


\begin{tabular}{ccccccc} 
& Melhorou & Mesma Coisa & Não sabe & Piorou & Vazio & Total \\
\hline \multirow{2}{*}{ Comerciante } & 5 & 11 & 3 & 26 & 1 & 46 \\
& $11 \%$ & $24 \%$ & $7 \%$ & $57 \%$ & $2 \%$ & $100 \%$ \\
Morador & 26 & 30 & 1 & 51 & 1 & 109 \\
& $24 \%$ & $28 \%$ & $1 \%$ & $47 \%$ & $1 \%$ & $100 \%$ \\
\hline \multirow{2}{*}{ Total } & 31 & 41 & 4 & 77 & 2 & 155 \\
& $20 \%$ & $26 \%$ & $3 \%$ & $50 \%$ & $1 \%$ & $100 \%$
\end{tabular}

Tabela 10 - Distribuição de frequências para moradores e comerciantes de acordo com sua visão sobre a situação das inundações.

\begin{tabular}{ccccccc} 
Tempo no local & Melhorou & Mesma Coisa & Não sabe & Piorou & $\begin{array}{c}\text { Sem } \\
\text { resposta }\end{array}$ & Total \\
\hline Até 1 ano & 2 & 1 & 1 & 3 & 1 & 8 \\
De 2 a 5 anos & 9 & 12 & 3 & 13 & 1 & 38 \\
De 6 a 10 anos & 5 & 2 & & 9 & & 16 \\
De 11 a 20 anos & 6 & 11 & & 16 & & 33 \\
De 21 a 30 anos & 4 & 8 & & 10 & & 22 \\
de 31 a 40 anos & 4 & 5 & & 18 & & 27 \\
De 41 a 50 anos & 1 & 2 & & 6 & & 9 \\
Mais que 50 & & 41 & 4 & 77 & 2 & 155
\end{tabular}

Tabela 11 - Dados para o teste qui-quadrado de associação entre as variáveis 'tempo no local' e 'opinião sobre a situação das inundações'.

\begin{tabular}{|c|c|c|c|c|c|c|}
\hline & Melhorou & Mesma Coisa & Não Sabe & Piorou & Vazios & Total \\
\hline \multirow{2}{*}{ Reg1 } & 21 & 23 & & 34 & 2 & 80 \\
\hline & $26 \%$ & $29 \%$ & $0 \%$ & $43 \%$ & $3 \%$ & $100 \%$ \\
\hline \multirow{2}{*}{ Reg2 } & 10 & 11 & 1 & 7 & & 29 \\
\hline & $34 \%$ & $38 \%$ & $3 \%$ & $24 \%$ & $0 \%$ & $100 \%$ \\
\hline \multirow{2}{*}{ Reg3 } & & 7 & 3 & 36 & & 46 \\
\hline & $0 \%$ & $15 \%$ & $7 \%$ & $78 \%$ & $0 \%$ & $100 \%$ \\
\hline \multirow{2}{*}{ Total } & 31 & 41 & 4 & 77 & 2 & 155 \\
\hline & $20 \%$ & $26 \%$ & $3 \%$ & $50 \%$ & $1 \%$ & $100 \%$ \\
\hline
\end{tabular}

Tabela 12 - Moradores e comerciantes que passaram por inundação: melhorou - piorou - mesma coisa x região. 


\begin{tabular}{cccccc} 
Número de vezes & Até 3 & Entre 4 e 6 & 7 ou mais & Vazios & Total \\
\hline Reg1 & 50 & 15 & 3 & 12 & 80 \\
& $63 \%$ & $19 \%$ & $4 \%$ & $15 \%$ & $100 \%$ \\
Reg2 & 22 & 6 & & 1 & 29 \\
& $76 \%$ & $21 \%$ & $0 \%$ & $3 \%$ & $100 \%$ \\
Reg3 & 30 & 8 & 8 & & 46 \\
& $65 \%$ & $17 \%$ & $17 \%$ & $0 \%$ & $100 \%$ \\
\hline Total & 102 & 29 & 11 & 13 & 155 \\
& $66 \%$ & $19 \%$ & $7 \%$ & $8 \%$ & $100 \%$
\end{tabular}

Tabela 13 - Moradores e comerciantes que já passaram ou ainda passam por inundação x região.

\begin{tabular}{ccccc} 
& $\begin{array}{c}\text { Não construíram obras de } \\
\text { contenção }\end{array}$ & $\begin{array}{c}\text { Sim, construíram obras } \\
\text { de contenção }\end{array}$ & Vazios & Total \\
\hline \multirow{2}{*}{ Comerciante } & 20 & 26 & & 46 \\
\multirow{2}{*}{ Morador } & $43 \%$ & $57 \%$ & $0 \%$ & $100 \%$ \\
& 40 & 68 & 1 & 109 \\
\multirow{2}{*}{ Total } & $37 \%$ & $62 \%$ & $1 \%$ & $100 \%$ \\
\hline & 60 & 94 & 1 & 155 \\
& $39 \%$ & $61 \%$ & $1 \%$ & $100 \%$
\end{tabular}

\begin{tabular}{ccccc} 
& Não & Sim & Vazios & Total \\
\hline \multirow{2}{*}{ Reg1 } & 29 & 50 & 1 & 80 \\
& $36 \%$ & $63 \%$ & $1 \%$ & $100 \%$ \\
Reg2 & 10 & 19 & & 29 \\
& $34 \%$ & $66 \%$ & $0 \%$ & $100 \%$ \\
Reg3 & 21 & 25 & & 46 \\
& $46 \%$ & $54 \%$ & $0 \%$ & $100 \%$ \\
\hline \multirow{2}{*}{ Total geral } & 60 & 94 & 1 & 155 \\
& $39 \%$ & $61 \%$ & $1 \%$ & $100 \%$
\end{tabular}

Tabela 15 - Moradores e comerciantes que passaram por inundação: construção ou não de obras de contenção x região 


\begin{tabular}{|c|c|c|c|c|c|c|c|c|c|c|c|c|}
\hline & $\begin{array}{l}\text { Ocupa- } \\
\text { ção } \\
\text { E }\end{array}$ & $\begin{array}{l}\text { Lixo + } \\
\text { Obra } \\
\quad F\end{array}$ & $\begin{array}{c}\text { Governo } \\
\text { ou } \\
\text { Poder } \\
\text { Público } \\
\text { G }\end{array}$ & $\begin{array}{c}\text { Topogra- } \\
\text { fia }+ \\
\text { falta de } \\
\text { Obra } \\
\text { H }\end{array}$ & $\begin{array}{c}\text { Poder } \\
\text { Público + } \\
\text { Lixo } \\
\text { I }\end{array}$ & $\begin{array}{c}\text { Lixo ou } \\
\text { sujeira } \\
\text { depositados } \\
\text { L }\end{array}$ & $\begin{array}{l}\text { Não } \\
\text { Sabe }\end{array}$ & $\begin{array}{c}\text { Obras ou } \\
\text { infra- } \\
\text { estrutura } \\
0\end{array}$ & $\begin{array}{c}\text { Lixo+ } \\
\text { Ocupação } \\
\text { + topogra- } \\
\text { Fia } \\
\text { Q } \\
\end{array}$ & $\begin{array}{c}\text { Topo- } \\
\text { grafia } \\
\text { T }\end{array}$ & Vazio & Total \\
\hline \multirow{2}{*}{ Comerciante } & 8 & 6 & 6 & 1 & 8 & 33 & 0 & 10 & 8 & 9 & 0 & 89 \\
\hline & $9 \%$ & $7 \%$ & $6 \%$ & $1 \%$ & $9 \%$ & $37 \%$ & $0 \%$ & $11 \%$ & $9 \%$ & $10 \%$ & $0 \%$ & $100 \%$ \\
\hline \multirow{2}{*}{ Morador } & 13 & 15 & 8 & 0 & 11 & 111 & 1 & 28 & 12 & 13 & 0 & 212 \\
\hline & $6 \%$ & $7 \%$ & $4 \%$ & $0 \%$ & $5 \%$ & $52 \%$ & $0 \%$ & $13 \%$ & $6 \%$ & $6 \%$ & $0 \%$ & $100 \%$ \\
\hline \multirow{2}{*}{ Total } & 21 & 21 & 13 & 1 & 19 & 144 & 1 & 38 & 20 & 22 & 0 & 301 \\
\hline & $7 \%$ & $7 \%$ & $4 \%$ & $0 \%$ & $6 \%$ & $48 \%$ & $0 \%$ & $13 \%$ & $7 \%$ & $7 \%$ & $0 \%$ & $100 \%$ \\
\hline
\end{tabular}

Legenda:

$\mathrm{E}=$ Falta de espaço, muita construção, inclusive irregular, urbanização, pavimentação, impermeabilização, água não tem para onde escoar, falta vazão.

$\mathbf{F}=$ Lixo + Obra.

$\mathrm{G}=$ Falta de planejamento, má administração, falta de manutenção, falta de atenção pelo poder público.

$\mathrm{H}=$ Topografia + falta de Obra.

$I=\mathbf{G}+$ Lixo.

$L=$ Lixo ou Sujeira depositados.

$\mathrm{O}=$ Problema de obra, infraestrutura.

$\mathrm{Q}=$ Lixo $+\mathrm{E}+\mathrm{T}$.

$\mathrm{T}=$ Baixada ou várzea ou topografia ou excesso de chuva.

Tabela 16 - A opinião de moradores e comerciantes quanto à principal causa de inundação.

Lixo como causa combinada com outros fatores.

$\begin{array}{ccc}\text { Geral } & \mathrm{L}+\mathrm{F}+\mathrm{l}+\mathrm{Q} & 68 \% \\ \text { Comerciante } & \mathrm{L}+\mathrm{F}+\mathrm{l}+\mathrm{Q} & 62 \% \\ \text { Morador } & \mathrm{L}+\mathrm{F}+\mathrm{l}+\mathrm{Q} & 70 \%\end{array}$

Tabela 17: 'Lixo' ou 'sujeira' depositados em locais públicos como principal causa inundações em várias combinações.

\begin{tabular}{|c|c|c|c|c|c|c|c|c|c|c|c|}
\hline & $\begin{array}{l}\text { Ocupa- } \\
\text { ção } \\
\text { E }\end{array}$ & $\begin{array}{c}\text { Lixo } \\
+ \\
\text { Obra } \\
\text { F } \\
\end{array}$ & $\begin{array}{l}\text { Governo } \\
\text { ou Poder } \\
\text { Público G }\end{array}$ & $\begin{array}{c}\text { Topogra- } \\
\text { fia + falta de } \\
\text { Obra } \\
\text { H } \\
\end{array}$ & $\begin{array}{c}\text { Poder } \\
\text { Público + } \\
\text { Lixo } \\
\text { I }\end{array}$ & $\begin{array}{c}\text { Lixo ou } \\
\text { sujeira } \\
\text { depositada } \\
\text { L } \\
\end{array}$ & $\begin{array}{l}\text { Não } \\
\text { Sabe }\end{array}$ & $\begin{array}{c}\text { Obras ou } \\
\text { infra-estrutura } \\
\mathrm{O} \\
\end{array}$ & $\begin{array}{c}\text { Lixo+ } \\
\text { Ocupação } \\
+ \\
\text { topogra- } \\
\text { Fia } \\
\text { Q } \\
\end{array}$ & $\begin{array}{l}\text { Topo- } \\
\text { grafia } \\
\mathrm{T} \\
\end{array}$ & Total \\
\hline \multirow{2}{*}{ Reg1 } & 4 & 9 & 5 & 1 & 7 & 83 & 1 & 16 & 10 & 10 & 146 \\
\hline & $3 \%$ & $6 \%$ & $3 \%$ & $1 \%$ & $5 \%$ & $57 \%$ & $1 \%$ & $11 \%$ & $7 \%$ & $7 \%$ & $100 \%$ \\
\hline \multirow{2}{*}{ Reg2 } & 7 & 8 & 3 & 0 & 2 & 28 & 0 & 10 & 6 & 8 & 72 \\
\hline & $10 \%$ & $11 \%$ & $4 \%$ & $0 \%$ & $3 \%$ & $39 \%$ & $0 \%$ & $14 \%$ & $8 \%$ & $11 \%$ & $100 \%$ \\
\hline \multirow{2}{*}{ Reg3 } & 10 & 4 & 5 & 0 & 10 & 34 & 0 & 12 & 4 & 4 & 83 \\
\hline & $12 \%$ & $5 \%$ & $6 \%$ & $0 \%$ & $12 \%$ & $41 \%$ & $0 \%$ & $14 \%$ & $5 \%$ & $5 \%$ & $100 \%$ \\
\hline \multirow{2}{*}{ Total } & 21 & 21 & 13 & 1 & 19 & 146 & 1 & 38 & 20 & 22 & 301 \\
\hline & $7 \%$ & $7 \%$ & $4 \%$ & $0 \%$ & $6 \%$ & $48 \%$ & $0 \%$ & $13 \%$ & $7 \%$ & $7 \%$ & $100 \%$ \\
\hline
\end{tabular}


Legenda:

$\mathrm{E}=$ Falta de espaço, muita construção, inclusive irregular, urbanização, pavimentação, impermeabilização, água não tem para onde escoar, falta vazão.

$\mathrm{F}=\mathrm{Lixo}+$ Obra.

G = Falta de planejamento, má administração, falta de manutenção, falta de atenção pelo poder público.

$\mathrm{H}=$ Topografia + falta de Obra.

$\mathrm{I}=\mathrm{G}+$ Lixo.

$\mathrm{L}=$ Lixo ou Sujeira depositada.

$\mathrm{O}=$ Problema de obra, infraestrutura.

$\mathrm{Q}=\mathrm{Lixo}+\mathrm{E}+\mathrm{T}$.

$\mathrm{T}=$ Baixada ou várzea ou topografia ou excesso de chuva

Tabela 18 - As causas da inundação em cada uma das regiões.

\begin{tabular}{|c|c|c|c|c|c|c|c|c|c|c|}
\hline Responsáveis & $\begin{array}{c}\text { Moradores } \\
\text { que } \\
\text { constroem e } \\
\text { geram } \\
\text { Asfalto, } \\
\text { cimento, } \\
\text { concreto } \\
\text { A }\end{array}$ & $\begin{array}{c}\text { Políticos } \\
\text { e } \\
\text { Moradores } \\
\text { C } \\
\end{array}$ & $\begin{array}{c}\text { Engenheiros } \\
\text { E }\end{array}$ & $\begin{array}{c}\text { Topografia e } \\
\text { Moradores } \\
\mathrm{H}\end{array}$ & $\begin{array}{l}\text { Moradores, } \\
\text { povo, } \\
\text { população, } \\
\text { pessoal, } \\
\text { humanos } \\
\text { M }\end{array}$ & $\begin{array}{c}\text { Natureza } \\
\text { ou Deus } \\
\mathrm{N}\end{array}$ & $\begin{array}{c}\text { Não } \\
\text { sabe } \\
\text { NS } \\
\end{array}$ & $\begin{array}{c}\text { Poder } \\
\text { Público e } \\
\text { Políticos } \\
\text { P }\end{array}$ & $\begin{array}{l}\text { Sem } \\
\text { resposta }\end{array}$ & Total \\
\hline \multirow{2}{*}{ Ocupação E } & 2 & 2 & 0 & 0 & 1 & 1 & 0 & 15 & 0 & \multirow{2}{*}{21} \\
\hline & $10 \%$ & $10 \%$ & $0 \%$ & $0 \%$ & $5 \%$ & $5 \%$ & $0 \%$ & $71 \%$ & $0 \%$ & \\
\hline \multirow{2}{*}{$\begin{array}{c}\text { Lixo + Obras } \\
\text { F }\end{array}$} & 0 & 19 & 0 & 0 & 2 & 0 & 0 & 0 & 0 & \multirow{2}{*}{21} \\
\hline & $0 \%$ & $90 \%$ & $0 \%$ & $0 \%$ & $10 \%$ & $0 \%$ & $0 \%$ & $0 \%$ & $0 \%$ & \\
\hline $\begin{array}{l}\text { Governo ou } \\
\text { Poder }\end{array}$ & 0 & 0 & 1 & 0 & 0 & 0 & 0 & 12 & 0 & \multirow{2}{*}{13} \\
\hline Público G & $0 \%$ & $0 \%$ & $8 \%$ & $0 \%$ & $0 \%$ & $0 \%$ & $0 \%$ & $92 \%$ & $0 \%$ & \\
\hline \multirow{2}{*}{$\begin{array}{c}\text { Topografia }+ \\
\text { falta de Obra } \\
\mathrm{H}\end{array}$} & 0 & 0 & 0 & 0 & 0 & 0 & 0 & 1 & 0 & \multirow{2}{*}{1} \\
\hline & $0 \%$ & $0 \%$ & $0 \%$ & $0 \%$ & $0 \%$ & $0 \%$ & $0 \%$ & $100 \%$ & $0 \%$ & \\
\hline \multirow{2}{*}{$\begin{array}{c}\text { Poder } \\
\text { Público + } \\
\text { Lixo I }\end{array}$} & 0 & 18 & 0 & 0 & 0 & 0 & 0 & 1 & 0 & \multirow{2}{*}{19} \\
\hline & $0 \%$ & $95 \%$ & $0 \%$ & $0 \%$ & $0 \%$ & $0 \%$ & $0 \%$ & $5 \%$ & $0 \%$ & \\
\hline \multirow{2}{*}{$\begin{array}{l}\text { Lixo ou } \\
\text { Sujeira } \\
\text { depositados } \\
\text { em locais } \\
\text { públicos L }\end{array}$} & 0 & 8 & 0 & 0 & 130 & 0 & 0 & 7 & 0 & \multirow[b]{2}{*}{145} \\
\hline & $0 \%$ & $6 \%$ & $0 \%$ & $0 \%$ & $90 \%$ & $0 \%$ & $0 \%$ & $4 \%$ & $0 \%$ & \\
\hline \multirow{2}{*}{ Não Sabe NS } & 0 & 0 & 0 & 0 & 0 & 0 & 1 & 0 & 0 & \multirow{2}{*}{1} \\
\hline & $0 \%$ & $0 \%$ & $0 \%$ & $0 \%$ & $0 \%$ & $0 \%$ & $100 \%$ & $0 \%$ & $0 \%$ & \\
\hline \multirow{2}{*}{$\begin{array}{c}\text { Obras ou } \\
\text { Infraestrutura } \\
\text { O }\end{array}$} & 0 & 2 & 0 & 0 & 1 & 0 & 1 & 34 & 0 & \multirow{2}{*}{38} \\
\hline & $0 \%$ & $5 \%$ & $0 \%$ & $0 \%$ & $3 \%$ & $0 \%$ & $3 \%$ & $89 \%$ & $0 \%$ & \\
\hline \multirow{2}{*}{$\begin{array}{c}\text { Lixo + } \\
\text { Ocupação + } \\
\text { Topografia Q }\end{array}$} & 0 & 11 & 0 & 2 & 3 & 0 & 0 & 4 & 0 & \multirow{2}{*}{20} \\
\hline & $0 \%$ & $55 \%$ & $0 \%$ & $10 \%$ & $15 \%$ & $0 \%$ & $0 \%$ & $20 \%$ & $0 \%$ & \\
\hline \multirow{2}{*}{ Topografia $\mathrm{T}$} & 0 & 0 & 0 & 0 & 1 & 11 & 0 & 9 & 1 & \multirow{2}{*}{22} \\
\hline & $0 \%$ & $0 \%$ & $0 \%$ & $0 \%$ & $5 \%$ & $50 \%$ & $0 \%$ & $41 \%$ & $5 \%$ & \\
\hline \multirow{2}{*}{ Total } & 2 & 60 & 1 & 2 & 138 & 12 & 2 & 83 & 1 & \multirow{2}{*}{301} \\
\hline & $1 \%$ & $20 \%$ & $0 \%$ & $1 \%$ & $46 \%$ & $4 \%$ & $1 \%$ & $28 \%$ & $0 \%$ & \\
\hline
\end{tabular}

Tabela 19 - Principais causas de inundação e seus maiores responsáveis, por região. 


\begin{tabular}{|c|c|c|c|c|c|c|c|c|c|c|}
\hline & $\begin{array}{c}\text { Asfalto, } \\
\text { cimento, } \\
\text { concreto e } \\
\text { construção } \\
\text { por } \\
\text { moradores } \\
\text { A } \\
\end{array}$ & $\begin{array}{c}\text { Políticos } \\
\text { e } \\
\text { Moradores } \\
\text { C } \\
\end{array}$ & $\begin{array}{c}\text { Engenheiros } \\
\text { E }\end{array}$ & $\begin{array}{c}\text { Topografia } \\
\text { e } \\
\text { Moradores } \\
\text { H } \\
\end{array}$ & $\begin{array}{l}\text { Moradores, } \\
\text { povo, } \\
\text { população, } \\
\text { pessoal, } \\
\text { humanos } \\
\text { M }\end{array}$ & $\begin{array}{c}\text { Natureza } \\
\text { ou Deus } \\
N\end{array}$ & $\begin{array}{c}\text { Não } \\
\text { sabe } \\
\text { NS }\end{array}$ & $\begin{array}{c}\text { Poder } \\
\text { Público } \\
\text { e } \\
\text { Políticos } \\
\text { P } \\
\end{array}$ & $\begin{array}{c}\text { Sem } \\
\text { resposta }\end{array}$ & Total \\
\hline \multirow{2}{*}{ REG1 } & 0 & 21 & 1 & 2 & 82 & 6 & 1 & 32 & 1 & \multirow{2}{*}{146} \\
\hline & $0 \%$ & $14 \%$ & $1 \%$ & $1 \%$ & $56 \%$ & $4 \%$ & $1 \%$ & $22 \%$ & $1 \%$ & \\
\hline \multirow{2}{*}{ REG2 } & 1 & 17 & 0 & 0 & 26 & 4 & 0 & 24 & 0 & \multirow{2}{*}{72} \\
\hline & $1 \%$ & $24 \%$ & $0 \%$ & $0 \%$ & $36 \%$ & $6 \%$ & $0 \%$ & $33 \%$ & $0 \%$ & \\
\hline \multirow{2}{*}{ REG3 } & 1 & 22 & 0 & 0 & 30 & 2 & 1 & 27 & 0 & \multirow{2}{*}{83} \\
\hline & $1 \%$ & $27 \%$ & $0 \%$ & $0 \%$ & $36 \%$ & $2 \%$ & $1 \%$ & $33 \%$ & $0 \%$ & \\
\hline \multirow{2}{*}{ Total } & 2 & 60 & 1 & 2 & 138 & 12 & 2 & 83 & 1 & \multirow{2}{*}{301} \\
\hline & $1 \%$ & $20 \%$ & $0 \%$ & $1 \%$ & $46 \%$ & $4 \%$ & $1 \%$ & $28 \%$ & $0 \%$ & \\
\hline
\end{tabular}

Tabela 20 - Responsáveis pelas causas de inundação em cada região.

\begin{tabular}{|c|c|c|c|c|c|c|c|c|c|c|}
\hline & Amigos & $\begin{array}{c}\text { Cada um } \\
\text { por si }\end{array}$ & Família & $\begin{array}{l}\text { Não } \\
\text { Sabe }\end{array}$ & Outro & $\begin{array}{c}\text { Prefeitura, } \\
\text { Defesa } \\
\text { Civil, } \\
\text { Bombeiro }\end{array}$ & Associação & Vizinhos & $\begin{array}{c}\text { Sem } \\
\text { resposta }\end{array}$ & Total \\
\hline \multirow{2}{*}{ Comerciantes } & 0 & 33 & 0 & 1 & 1 & 13 & 1 & 38 & 2 & \multirow{2}{*}{89} \\
\hline & $0 \%$ & $37 \%$ & $0 \%$ & $1 \%$ & $1 \%$ & $15 \%$ & $1 \%$ & $43 \%$ & $2 \%$ & \\
\hline \multirow{2}{*}{ Moradores } & 2 & 49 & 3 & 8 & 1 & 28 & 2 & 119 & 0 & \multirow{2}{*}{212} \\
\hline & $1 \%$ & $23 \%$ & $1 \%$ & $4 \%$ & $0 \%$ & $13 \%$ & $1 \%$ & $56 \%$ & $0 \%$ & \\
\hline \multirow{2}{*}{ Total } & 2 & 82 & 3 & 9 & 2 & 41 & 3 & 157 & 2 & \multirow{2}{*}{301} \\
\hline & $1 \%$ & $27 \%$ & $1 \%$ & $3 \%$ & $1 \%$ & $14 \%$ & $1 \%$ & $52 \%$ & $1 \%$ & \\
\hline
\end{tabular}

Tabela 21 - Distribuição de frequências de quem, em primeiro lugar, presta socorro a moradores e comerciantes em caso de inundação.

\begin{tabular}{|c|c|c|c|c|c|c|c|c|c|c|}
\hline & Amigos & $\begin{array}{c}\text { Cada um } \\
\text { por si }\end{array}$ & Família & $\begin{array}{l}\text { Não } \\
\text { Sabe }\end{array}$ & Outro & $\begin{array}{c}\text { Prefeitura, } \\
\text { Defesa } \\
\text { Civil, } \\
\text { Bombeiro }\end{array}$ & Associação & Vizinhos & $\begin{array}{c}\text { Sem } \\
\text { resposta }\end{array}$ & Total \\
\hline \multirow{2}{*}{ Comerciantes } & 0 & 33 & 0 & 1 & 1 & 13 & 1 & 38 & 2 & \multirow{2}{*}{89} \\
\hline & $0 \%$ & $37 \%$ & $0 \%$ & $1 \%$ & $1 \%$ & $15 \%$ & $1 \%$ & $43 \%$ & $2 \%$ & \\
\hline \multirow{2}{*}{ Moradores } & 2 & 49 & 3 & 8 & 1 & 28 & 2 & 119 & 0 & \multirow{2}{*}{212} \\
\hline & $1 \%$ & $23 \%$ & $1 \%$ & $4 \%$ & $0 \%$ & $13 \%$ & $1 \%$ & $56 \%$ & $0 \%$ & \\
\hline \multirow{2}{*}{ Total } & 2 & 82 & 3 & 9 & 2 & 41 & 3 & 157 & 2 & \multirow{2}{*}{301} \\
\hline & $1 \%$ & $27 \%$ & $1 \%$ & $3 \%$ & $1 \%$ & $14 \%$ & $1 \%$ & $52 \%$ & $1 \%$ & \\
\hline
\end{tabular}

Tabela 22 - Distribuição de frequências de quem, em primeiro lugar, presta socorro a moradores e comerciantes em caso de inundação. 


\begin{tabular}{|c|c|c|c|c|c|c|c|c|c|c|}
\hline & $\begin{array}{c}\text { Amigos } \\
\text { A }\end{array}$ & $\begin{array}{l}\text { Cada } \\
\text { um por } \\
\text { si } \\
\text { C }\end{array}$ & $\begin{array}{c}\text { Família } \\
\text { F }\end{array}$ & $\begin{array}{c}\text { Não } \\
\text { Sabe } \\
\text { NS }\end{array}$ & $\begin{array}{c}\text { Outro } \\
\text { O }\end{array}$ & $\begin{array}{c}\text { Prefeitura, } \\
\text { Defesa } \\
\text { Civil, } \\
\text { Bombeiro } \\
\text { P }\end{array}$ & $\begin{array}{c}\text { Associação } \\
\text { S }\end{array}$ & $\begin{array}{c}\text { Vizinhos } \\
\text { V }\end{array}$ & $\begin{array}{l}\text { Sem } \\
\text { resposta } \\
\text { SR }\end{array}$ & Total \\
\hline & 2 & 33 & 0 & 8 & 1 & 33 & 2 & 65 & 2 & \multirow[b]{2}{*}{146} \\
\hline $\begin{array}{l}\text { Nunca } \\
\text { Passou }\end{array}$ & $1 \%$ & $23 \%$ & $0 \%$ & $5 \%$ & $1 \%$ & $23 \%$ & $1 \%$ & $45 \%$ & $1 \%$ & \\
\hline & - & 49 & 3 & 1 & 1 & 8 & 1 & 92 & - & \multirow[b]{2}{*}{155} \\
\hline $\begin{array}{c}\text { Já } \\
\text { passou }\end{array}$ & $0 \%$ & $32 \%$ & $2 \%$ & $1 \%$ & $1 \%$ & $5 \%$ & $1 \%$ & $59 \%$ & $0 \%$ & \\
\hline Total & 2 & 82 & 3 & 9 & 2 & 41 & 3 & 157 & 2 & 301 \\
\hline
\end{tabular}

Analisando esses dados no SPSS temos a seguinte saída

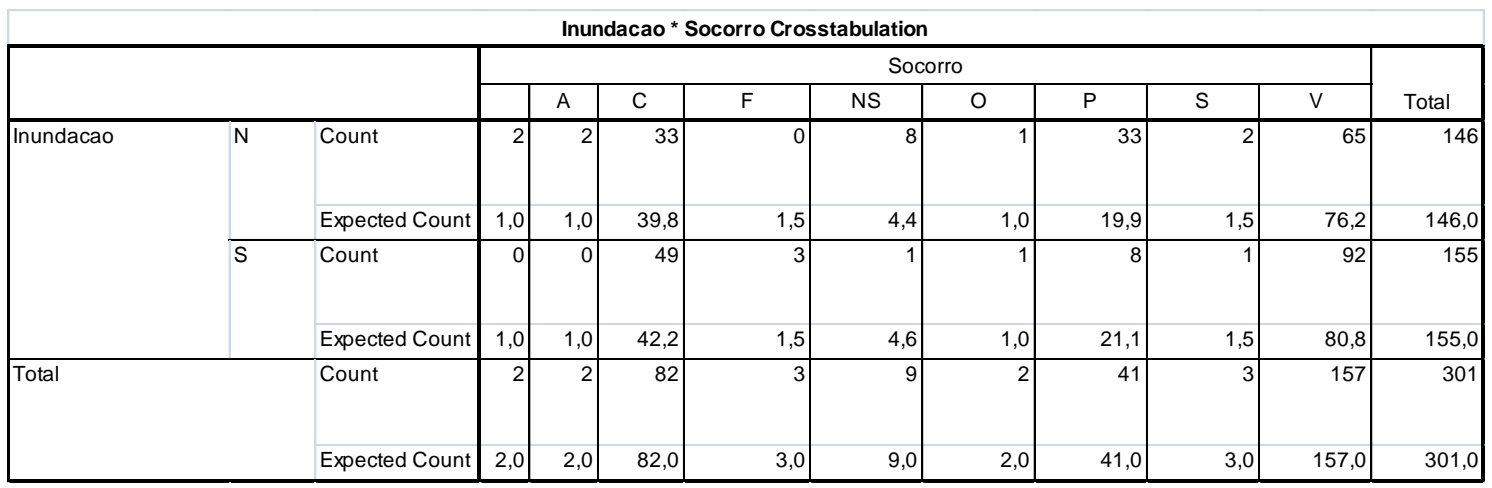

Tabela 24 - Tabela resultante do SPSS para a variável 'passou ou não por inundação'.

Linha Count = quantas observações se tem na realidade. Ex. 33 pessoas que NÃO passaram por inundação acham que o socorro é CADA UM POR SI (C) Linha Expected Count = cálculo do SPSS para quantas observações seriam esperadas caso não houvesse associação entre as variáveis. Entretanto, o teste qui-quadrado para que seja adequado não pode ter muitas observações esperadas menores do que 5 . Neste caso 12 células estão com valor esperado menor do que 5 e por isso esse teste de associação não pode ser aplicado.

\begin{tabular}{cccc} 
& Cat. 1 & Cat. 2 & Cat. 3 \\
\cline { 2 - 4 } Nunca Passou & 33 & 67 & 33 \\
& $25 \%$ & $50 \%$ & $25 \%$ \\
Já passou & 49 & 95 & 8 \\
\hline Total & $32 \%$ & $63 \%$ & $5 \%$ \\
\hline & 82 & 162 & 41
\end{tabular}

Tabela 25 - Evidência de associação entre quem passou por inundação x quem ajuda em primeiro lugar após re-categorização. 


\begin{tabular}{ccccccccccc} 
& \multicolumn{3}{c}{$\begin{array}{c}\text { um por } \\
\text { si }\end{array}$} & & Sabe & \multicolumn{3}{c}{$\begin{array}{c}\text { Defesa } \\
\text { Civil, } \\
\text { Bombeiro }\end{array}$} \\
\cline { 2 - 11 } REG1 & 1 & 35 & 1 & 5 & 1 & 17 & 2 & 82 & 2 & 146 \\
& $1 \%$ & $24 \%$ & $1 \%$ & $3 \%$ & $1 \%$ & $12 \%$ & $1 \%$ & $56 \%$ & $1 \%$ & \\
REG2 & 1 & 18 & 2 & 4 & 0 & 11 & 1 & 35 & 0 & 72 \\
& $1 \%$ & $25 \%$ & $3 \%$ & $6 \%$ & $0 \%$ & $15 \%$ & $1 \%$ & $49 \%$ & $0 \%$ & \\
\multirow{2}{*}{ REG3 } & 0 & 29 & 0 & 0 & 1 & 13 & 0 & 40 & 0 & 83 \\
& $0 \%$ & $35 \%$ & $0 \%$ & $0 \%$ & $1 \%$ & $16 \%$ & $0 \%$ & $48 \%$ & $0 \%$ & \\
\hline \multirow{2}{*}{ Total } & 2 & 82 & 3 & 9 & 2 & 41 & 3 & 157 & 2 & \multirow{2}{*}{301} \\
& $1 \%$ & $27 \%$ & $1 \%$ & $3 \%$ & $1 \%$ & $14 \%$ & $1 \%$ & $52 \%$ & $1 \%$ & \\
\hline
\end{tabular}

Tabela 26 - Quem socorre primeiro em caso de inundação em cada uma das regiões.

\begin{tabular}{ccccc} 
& Não sabe se proteger & Sabe se proteger & Sem resposta & Total \\
\cline { 2 - 5 } Comerciantes & 60 & 29 & 0 & \multirow{2}{*}{89} \\
& $67 \%$ & $33 \%$ & $0 \%$ & \\
\multirow{3}{*}{ Moradores } & 135 & 75 & 2 & 212 \\
& $64 \%$ & $35 \%$ & $1 \%$ & \\
\hline \multirow{2}{*}{ Total } & 195 & 104 & 2 & \multirow{2}{*}{301}
\end{tabular}

Tabela 27 - Saber ou não se proteger de inundações e alagamentos.

\begin{tabular}{ccccc} 
& Não & Sim & Sem resposta & Total geral \\
\cline { 2 - 5 } REG1 & 94 & 50 & 2 & \multirow{2}{*}{146} \\
& $64 \%$ & $34 \%$ & $1 \%$ & \\
REG2 & 47 & 25 & 0 & 72 \\
& $65 \%$ & $35 \%$ & $0 \%$ & \multirow{2}{*}{83} \\
\multirow{2}{*}{ REG3 } & 54 & 29 & 0 & \multirow{2}{*}{301} \\
& $65 \%$ & $35 \%$ & $0 \%$ & 2 \\
\hline \multirow{2}{*}{ Total } & 195 & 104 & $1 \%$ & \\
\hline
\end{tabular}

Tabela 28 - Saber ou não se proteger de inundações e alagamentos em cada uma das regiões. 


\begin{tabular}{|c|c|c|c|c|c|c|c|c|c|c|}
\hline & $\begin{array}{l}\text { Conjunto de } \\
\text { poder } \\
\text { público, } \\
\text { moradores e } \\
\text { engenheiros }\end{array}$ & $\begin{array}{c}\begin{array}{c}\text { Associação } \\
\text { de }\end{array} \\
\text { Moradores } \\
\text { e Poder } \\
\text { Público } \\
\end{array}$ & $\begin{array}{c}\text { Engenheiros } \\
\text { e técnicos } \\
\text { preparados }\end{array}$ & $\begin{array}{c}\text { Moradores, } \\
\text { sociedade, } \\
\text { população, } \\
\text { eleitores }\end{array}$ & $\begin{array}{l}\text { Não } \\
\text { sei }\end{array}$ & $\begin{array}{c}\text { Outro } \\
\text { membro }\end{array}$ & $\begin{array}{l}\text { Poder } \\
\text { Público }\end{array}$ & $\begin{array}{l}\text { Associação } \\
\text { de } \\
\text { Moradores }\end{array}$ & $\begin{array}{c}\text { Sem } \\
\text { resposta }\end{array}$ & Total \\
\hline \multirow{2}{*}{ Com. } & 14 & 0 & 4 & 22 & 4 & 0 & 43 & 2 & 0 & \multirow{2}{*}{89} \\
\hline & $16 \%$ & $0 \%$ & $4 \%$ & $25 \%$ & $4 \%$ & $0 \%$ & $48 \%$ & $2 \%$ & $0 \%$ & \\
\hline \multirow{2}{*}{ Mor. } & 36 & 1 & 12 & 51 & 12 & 2 & 93 & 2 & 3 & \multirow{2}{*}{212} \\
\hline & $17 \%$ & $0 \%$ & $6 \%$ & $24 \%$ & $6 \%$ & $1 \%$ & $44 \%$ & $1 \%$ & $1 \%$ & \\
\hline \multirow{2}{*}{ Total } & 50 & 1 & 16 & 73 & 16 & 2 & 136 & 4 & 3 & \multirow{2}{*}{301} \\
\hline & $17 \%$ & $0 \%$ & $5 \%$ & $24 \%$ & $5 \%$ & $1 \%$ & $45 \%$ & $1 \%$ & $1 \%$ & \\
\hline
\end{tabular}

Tabela 29 - Quem deve decidir sobre as obras que serão construídas na área.

\begin{tabular}{|c|c|c|c|c|c|c|c|c|c|c|}
\hline & $\begin{array}{c}\text { Conjunto } \\
\text { de poder } \\
\text { público, } \\
\text { moradores } \\
\text { e } \\
\text { engenheiros } \\
\text { C }\end{array}$ & $\begin{array}{c}\text { Associação de } \\
\text { Moradores e } \\
\text { Poder Público } \\
\text { D }\end{array}$ & $\begin{array}{c}\text { Engenheiros } \\
\text { e técnicos } \\
\text { preparados } \\
\text { E }\end{array}$ & $\begin{array}{c}\text { Moradores, } \\
\text { sociedade, } \\
\text { população, } \\
\text { eleitores } \\
\text { M }\end{array}$ & $\begin{array}{c}\text { Não } \\
\text { sabe } \\
\text { NS }\end{array}$ & $\begin{array}{c}\text { Outro } \\
\text { membro } \\
\mathrm{O}\end{array}$ & $\begin{array}{c}\text { Poder Público } \\
\text { P }\end{array}$ & $\begin{array}{c}\text { Associação } \\
\text { de } \\
\text { Moradores } \\
\text { S }\end{array}$ & $\begin{array}{l}\text { Sem } \\
\text { resposta }\end{array}$ & Total \\
\hline \multirow{2}{*}{ REG1 } & 19 & 1 & 6 & 29 & 11 & 1 & 74 & 3 & 2 & \multirow{2}{*}{146} \\
\hline & $13 \%$ & $1 \%$ & $4 \%$ & $20 \%$ & $8 \%$ & $1 \%$ & $51 \%$ & $2 \%$ & $1 \%$ & \\
\hline \multirow{2}{*}{ REG2 } & 10 & 0 & 6 & 19 & 1 & 1 & 34 & 0 & 1 & \multirow{2}{*}{72} \\
\hline & $14 \%$ & $0 \%$ & $8 \%$ & $26 \%$ & $1 \%$ & $1 \%$ & $47 \%$ & $0 \%$ & $1 \%$ & \\
\hline \multirow{2}{*}{ REG3 } & 21 & 0 & 4 & 25 & 4 & 0 & 28 & 1 & 0 & \multirow{2}{*}{83} \\
\hline & $25 \%$ & $0 \%$ & $5 \%$ & $30 \%$ & $5 \%$ & $0 \%$ & $34 \%$ & $1 \%$ & $0 \%$ & \\
\hline \multirow{2}{*}{ Total } & 50 & 1 & 16 & 73 & 16 & 2 & 136 & 4 & 3 & \multirow{2}{*}{301} \\
\hline & $17 \%$ & $0 \%$ & $5 \%$ & $24 \%$ & $5 \%$ & $1 \%$ & $45 \%$ & $1 \%$ & $1 \%$ & \\
\hline
\end{tabular}

Tabela 30 - Quem deve tomar decidir sobre as obras, segundo cada região.

\begin{tabular}{ccccc} 
& Não seriam capazes & Não sabem & Sim, seriam capazes & Total \\
\cline { 2 - 5 } Comerciante & 53 & 0 & 36 & 89 \\
& $60 \%$ & $0 \%$ & $40 \%$ & \\
\multirow{2}{*}{ Morador } & 70 & 1 & 141 & 212 \\
& $33 \%$ & $0 \%$ & $67 \%$ & 301
\end{tabular}

Tabela 31 - Distribuição de frequências de ser ou não capaz de dar sua opinião sobre as obras. 


\begin{tabular}{cccc} 
& Não se sente capaz & Se sente capaz & Total \\
\hline \multirow{2}{*}{ Já passou } & 61 & 85 & 146 \\
\multirow{2}{*}{ Não passou } & $42 \%$ & $58 \%$ & $100 \%$ \\
& 62 & 92 & 154 \\
Total & $40 \%$ & $60 \%$ & $100 \%$ \\
& 123 & 177 & $300 *$ \\
& $41 \%$ & $59 \%$ & $100 \%$
\end{tabular}

Tabela 32 - Ter passado ou não por inundação e sentir-se capaz de dar opinião.

*excluída a observação 'não sei'.

\begin{tabular}{cccc} 
& Não se sente capaz & Se sente capaz & Total \\
\hline \multirow{2}{*}{ Já passou } & 61 & 85 & 146 \\
& $42 \%$ & $58 \%$ & $100 \%$ \\
Não passou & 63 & 92 & 154 \\
& $41 \%$ & $59 \%$ & $100 \%$ \\
\hline \multirow{2}{*}{ Total } & $124^{*}$ & 177 & 301 \\
& $41 \%$ & $59 \%$ & $100 \%$
\end{tabular}

Tabela 33 - Ter passado ou não por inundação x sentir-se capaz de dar opinião.

*agregada a observação 'não sei' à observação 'não se sente capaz'.

\begin{tabular}{ccccc} 
& Não & Não Sabe & Sim & Total geral \\
\cline { 2 - 5 } REG1 & 58 & 0 & 88 & \multirow{2}{*}{146} \\
& $40 \%$ & $0 \%$ & $60 \%$ & 72 \\
\multirow{2}{*}{ REG2 } & 30 & 0 & 42 & \\
& $42 \%$ & $0 \%$ & $58 \%$ & 83 \\
\multirow{2}{*}{ REG3 } & 35 & 1 & 47 & 301 \\
& $42 \%$ & $1 \%$ & $57 \%$ & \multirow{2}{*}{ Total } \\
\multirow{2}{*}{ Tot } & 123 & 1 & 177 & $59 \%$ \\
\end{tabular}

Tabela 34 - Sentir-se ou não capaz de tomar decisões em cada região.

\begin{tabular}{cccc} 
& Não estiveram & Sim, já estiveram & Total \\
\cline { 2 - 4 } Comerciante & 85 & 4 & 89 \\
& $96 \%$ & $4 \%$ & \\
\multirow{3}{*}{ Morador } & 198 & 14 & 212 \\
\hline \multirow{2}{*}{ Total } & $93 \%$ & $7 \%$ & \multirow{2}{*}{301}
\end{tabular}

Tabela 35 -Conhecimento da presença de engenheiros ou técnicos por moradores e comerciantes. 


\begin{tabular}{cccc} 
& Não & Sim & Total \\
\hline \multirow{2}{*}{ REG1 } & 132 & 14 & 146 \\
& $90 \%$ & $10 \%$ & \\
REG2 & 68 & 4 & 72 \\
& $94 \%$ & $6 \%$ & 83 \\
REG3 & 83 & 0 & \multirow{2}{*}{301} \\
& $100 \%$ & $0 \%$ &
\end{tabular}

Tabela 36 - Conhecimento da presença de engenheiros ou técnicos por moradores e comerciantes em cada uma das regiões.

\begin{tabular}{cccc} 
& Não estiveram & Sim, já estiveram & Total \\
\cline { 2 - 4 } Comerciante & 88 & 1 & 89 \\
\multirow{2}{*}{ Morador } & $99 \%$ & $1 \%$ & \\
& 201 & 11 & 212 \\
Total & $95 \%$ & $5 \%$ & 301
\end{tabular}

Tabela 37 - Presença ou não de educadores ambientais, comunicadores sociais ou lideranças comunitárias

\begin{tabular}{cccc} 
& Não & Sim & Total \\
\hline \multirow{2}{*}{ REG1 } & 141 & 5 & 146 \\
& $97 \%$ & $3 \%$ & \\
REG2 & 72 & 0 & 72 \\
& $100 \%$ & $0 \%$ & \\
\multirow{2}{*}{ REG3 } & 76 & 7 & 83 \\
& $92 \%$ & $8 \%$ & \\
\hline \multirow{2}{*}{ Total } & 289 & 12 & 301
\end{tabular}

Tabela 38 - Presença ou não de educadores ambientais, comunicadores sociais ou lideranças comunitárias em cada uma das regiões.

\begin{tabular}{cccc} 
& Nunca conversaram & Sim, já conversaram & Total \\
\cline { 2 - 4 } Comerciante & 72 & 17 & 89 \\
& $81 \%$ & $19 \%$ & \\
\multirow{3}{*}{ Morador } & 155 & 57 & 212 \\
\hline \multirow{2}{*}{ Total } & $73 \%$ & $27 \%$ & \\
& 227 & 74 & 301
\end{tabular}

Tabela 39 - Houve ou não conversas sobre as obras dos piscinões para moradores e comerciantes*. *a pergunta sobre obras de piscinões incluía o tema das inundações. 


\begin{tabular}{cccc} 
& Não & Sim & Total \\
\cline { 2 - 4 } REG1 & 98 & 48 & \multirow{2}{*}{146} \\
& $67 \%$ & $33 \%$ & \\
REG2 & 57 & 15 & 72 \\
& $79 \%$ & $21 \%$ & \\
\multirow{2}{*}{ REG3 } & 72 & 11 & \multirow{2}{*}{83} \\
& $87 \%$ & $13 \%$ & \\
\hline \multirow{2}{*}{ Total } & 227 & 74 & \multirow{2}{*}{301} \\
\hline
\end{tabular}

Tabela 40 - Conversa com vizinhos ou outras pessoas sobre as obras, por região

\begin{tabular}{cccccc} 
& Não & Não Sabe & Sim & Vazio & Total \\
\hline Comerciante & 70 & 2 & 17 & 0 & 89 \\
& $79 \%$ & $2 \%$ & $19 \%$ & $0 \%$ & $100 \%$ \\
Morador & 161 & 16 & 34 & 1 & 212 \\
& $76 \%$ & $8 \%$ & $16 \%$ & $0 \%$ & $100 \%$ \\
\hline \multirow{2}{*}{ Total } & 231 & 18 & 51 & 1 & 301 \\
& $77 \%$ & $6 \%$ & $17 \%$ & $0 \%$ & $100 \%$
\end{tabular}

Tabela 41 - Moradores e Comerciantes x Acreditar que são levados a sério

\begin{tabular}{cccccc} 
& Não & Não Sabe & Sim & Sem resposta & Total \\
\hline \multirow{2}{*}{ REG1 } & 109 & 11 & 25 & 1 & \multirow{2}{*}{146} \\
& $75 \%$ & $8 \%$ & $17 \%$ & $1 \%$ & \\
\multirow{2}{*}{ REG2 } & 58 & 4 & 10 & 0 & 72 \\
\multirow{2}{*}{ REG3 } & $81 \%$ & $6 \%$ & $14 \%$ & $0 \%$ & \\
& 64 & 3 & 16 & 0 & \multirow{2}{*}{83} \\
\hline \multirow{2}{*}{ Total } & $77 \%$ & $4 \%$ & $19 \%$ & $0 \%$ & 301 \\
& 231 & 18 & 51 & 1 & \multirow{2}{*}{$0 \%$}
\end{tabular}

Tabela 42 - A opinião dos moradores e comerciantes é levada a sério pelos técnicos ou engenheiros das obras, segundo as regiões.

\begin{tabular}{ccccc} 
& Não & \multicolumn{3}{l}{ Sim, } \\
& gostaria & Não Sabe & gostaria & Total \\
\hline \multirow{3}{*}{ Comerciante } & 30 & 1 & 58 & 89 \\
& $34 \%$ & $1 \%$ & $65 \%$ & $100 \%$ \\
Morador & 46 & 0 & 166 & 212 \\
& $22 \%$ & $0 \%$ & $78 \%$ & $100 \%$ \\
\hline \multirow{2}{*}{ Total } & 76 & 1 & 224 & 301 \\
& $25 \%$ & $0 \%$ & $74 \%$ & 100
\end{tabular}

Tabela 43 - Gostaria ou não gostaria de participar de conversas com técnicos e engenheiros 


\begin{tabular}{cccccc} 
& Não & Não Sabe & Sim & Sem resposta & Total \\
\hline \multirow{2}{*}{ REG1 } & 41 & 0 & 105 & 0 & \multirow{2}{*}{146} \\
& $28 \%$ & $0 \%$ & $72 \%$ & $0 \%$ & \\
REG2 & 18 & 1 & 53 & 0 & 72 \\
& $25 \%$ & $1 \%$ & $74 \%$ & $0 \%$ & \\
\multirow{2}{*}{ REG3 } & 17 & 0 & 66 & 0 & 83 \\
& $20 \%$ & $0 \%$ & $80 \%$ & $0 \%$ & 301 \\
\hline \multirow{2}{*}{ Total } & 76 & 1 & 224 & 0 & \multirow{2}{*}{. } \\
& $25 \%$ & $0 \%$ & $74 \%$ & $0 \%$ & 301
\end{tabular}

Tabela 44 - O desejo de participar de conversas com técnicos ou engenheiros, em cada uma das regiões.

\begin{tabular}{ccccc} 
Região & $\begin{array}{c}\text { Valorizam o } \\
\text { Conjunto } \\
\text { C }\end{array}$ & Percentual & Outros & Total \\
\hline REG1 & 19 & $38 \%$ & 127 & 146 \\
REG2 & 10 & $20 \%$ & 62 & 72 \\
REG3 & 21 & $42 \%$ & 62 & 83 \\
\hline Total & 50 & $100 \%$ & 251 & 301
\end{tabular}

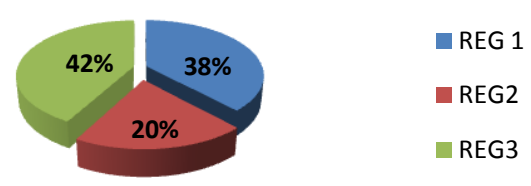

Tabela 45 - Moradores e comerciantes que valorizam as decisões compartilhadas entre Poder Público Moradores - engenheiros (conjunto C) e cada uma das regiões.

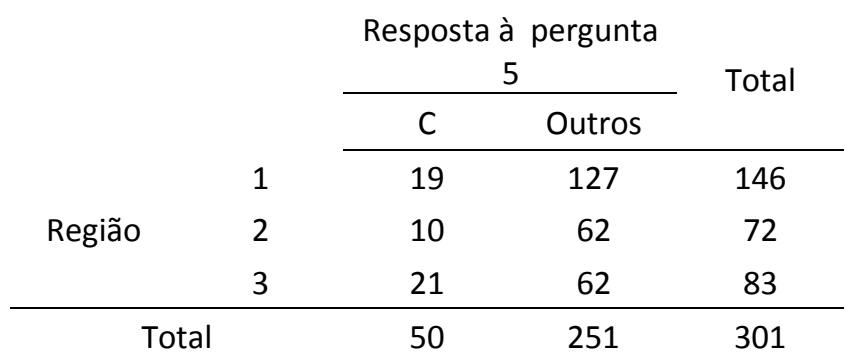

Tabela 46 - Dados para teste de associação qui-quadrado entre valorizar o conjunto $\mathrm{C}$ na tomada de decisão sobre as obras e região.

\begin{tabular}{ccccc} 
Já passou por inundação & $\begin{array}{c}\text { Valorizam o } \\
\text { Conjunto C }\end{array}$ & Percentual & Outros & Total \\
\hline Não & 25 & $50 \%$ & 121 & 146 \\
Sim & 25 & $50 \%$ & 130 & 155 \\
\hline Total & 50 & & 251 & 301 \\
\hline
\end{tabular}

Tabela 47 - Distribuição de frequência de respondentes que declararam já ter passado por inundação e a valorização do conjunto $\mathrm{C}$ na decisão sobre as obras. 


\begin{tabular}{|cc|c|c|c|}
\hline \multirow{2}{*}{} & & \multicolumn{2}{|c|}{ Resposta à pergunta 5 } & \multirow{2}{*}{ Total } \\
\cline { 2 - 4 } & $\begin{array}{c}\text { Valorizam o } \\
\text { conjunto C }\end{array}$ & Outros & \\
\hline \multirow{2}{*}{ Inundação } & Não & 25 & 121 & 146 \\
& Sim & 25 & 130 & 155 \\
Total & & 50 & 251 & 301 \\
\hline
\end{tabular}

Tabela 48 - Dados para teste de associação qui-quadrado entre valorizar o conjunto C na tomada de decisão sobre as obras e ter passado por inundação.

\begin{tabular}{ccc} 
Formação & $\begin{array}{c}\text { Valorizam o } \\
\text { conjunto C }\end{array}$ & Percentual \\
\hline Analfabeto ou primeiro grau & 2 & $4 \%$ \\
incompleto & 2 & $4 \%$ \\
Primeiro grau completo & 3 & $6 \%$ \\
Segundo grau incompleto & 11 & $22 \%$ \\
Segundo grau completo & 1 & $2 \%$ \\
Curso técnico & 31 & $62 \%$ \\
Curso Universitário & 50 & $100 \%$
\end{tabular}

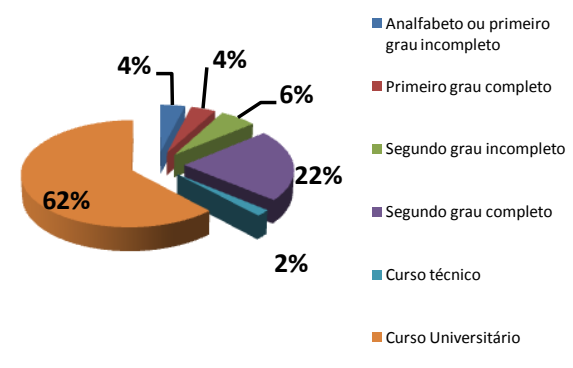

Tabela 49 - Moradores e comerciantes que valorizam o conjunto $\mathrm{C}$ na tomada de decisões sobre as obras e seu grau de escolaridade.

\begin{tabular}{|c|c|c|c|c|c|}
\hline Faixa Etária & $\begin{array}{l}\text { Valorizam o } \\
\text { conjunto C }\end{array}$ & Percentual & Outros & Total & \\
\hline Menos que 20 anos & 1 & $2 \%$ & 11 & 12 & Menos que 20 anos \\
\hline 20 a 24 anos & 10 & $20 \%$ & 31 & 41 & $=20$ a 24 anos \\
\hline 25 a 34 anos & 9 & $18 \%$ & 38 & 47 & $=25$ a 34 anos \\
\hline 35 a 44 anos & 6 & $12 \%$ & 37 & 43 & $\begin{array}{l}-15 \text { a } 44 \text { anos } \\
-45 \text { a } 54 \text { anos }\end{array}$ \\
\hline 45 a 54 anos & 12 & $24 \%$ & 49 & 61 & $=55$ a 64 anos \\
\hline 55 a 64 anos & 8 & $16 \%$ & 48 & 56 & - Mais que 65 anos \\
\hline Mais que 65 anos & 4 & $8 \%$ & 35 & 39 & \\
\hline Total & 50 & $100 \%$ & 249 & 299 & \\
\hline
\end{tabular}
as obras e sua idade. 


\begin{tabular}{|cc|c|c|c|}
\hline & & \multicolumn{2}{|c|}{ Resposta à pergunta 5 } & \multirow{2}{*}{ Total } \\
\cline { 3 - 4 } & 1 & $\begin{array}{c}\text { Valorizam o conjunto } \\
\text { C }\end{array}$ & Outros & \\
\hline \multirow{3}{*}{ Faixa etária } & 2 & 1 & 11 & 12 \\
& 3 & 10 & 31 & 41 \\
& 5 & 9 & 38 & 47 \\
& 5 & 6 & 37 & 43 \\
& 7 & 12 & 49 & 61 \\
& 7 & 4 & 48 & 56 \\
Total & & 50 & 35 & 39 \\
\hline
\end{tabular}

51 - Dados para teste de associação qui-quadrado entre valorizar o conjunto C na tomada de decisão sobre as obras e idade.

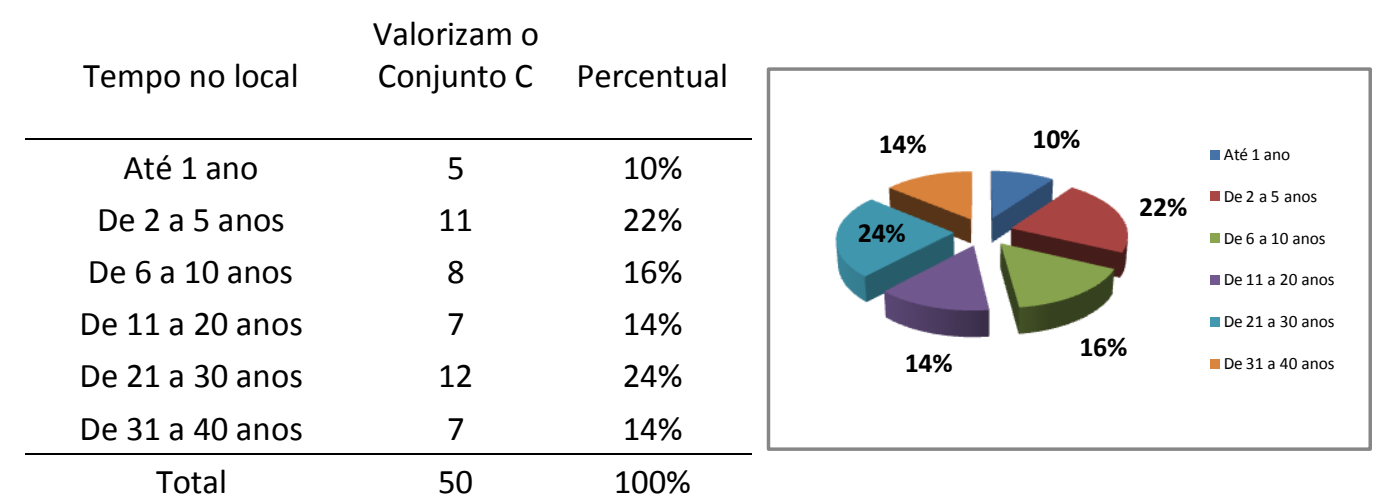

Tabela 52 - Moradores e comerciantes que valorizam o conjunto $\mathrm{C}$ na tomada de decisão sobre as obras e o tempo em que se encontram no local.

\begin{tabular}{ccccc} 
Sexo & $\begin{array}{c}\text { Valorizam o } \\
\text { conjunto C }\end{array}$ & Percentual & Outros & Total \\
\hline Feminino & 27 & $54 \%$ & 121 & 148 \\
asculino & 23 & $46 \%$ & 130 & 153 \\
\hline Total & 50 & $100 \%$ & 251 & 301
\end{tabular}

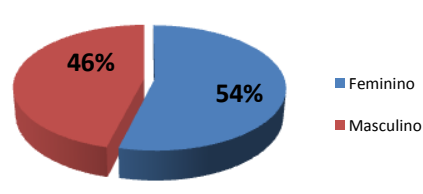

Tabela 53 - Moradores e comerciantes que valorizam o conjunto $\mathrm{C}$ na tomada decisão sobre as obras e seu sexo. 


\begin{tabular}{|cc|c|c|c|}
\hline \multirow{4}{*}{} & & \multicolumn{2}{|c|}{ Resposta à pergunta } & \multirow{2}{*}{ Total } \\
\cline { 3 - 4 } & & C & Outros & \\
\hline \multirow{3}{*}{ Sexo } & Feminino & 27 & 121 & 148 \\
& Masculino & 23 & 130 & 153 \\
& Total & 50 & 251 & 301 \\
\hline
\end{tabular}

Tabela 54 - Dados para teste de associação qui-quadrado entre valorizar o conjunto C na tomada de decisão sobre as obras e sexo.

\begin{tabular}{ccc} 
Palorizam o & Percentual \\
Proprietário & conjunto C & $36 \%$ \\
\hline Não & 18 & $60 \%$ \\
Sim & 30 & $4 \%$ \\
Vazio & 2 & $100 \%$
\end{tabular}

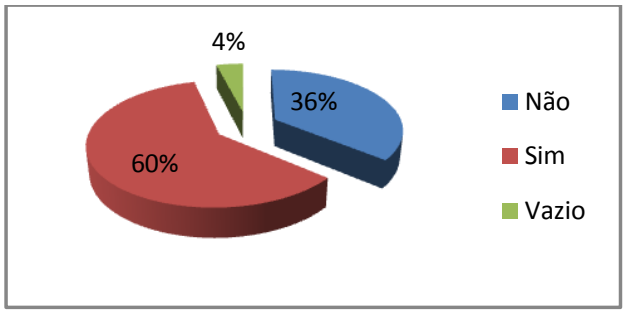

Tabela 55 - Moradores e comerciantes que valorizam o conjunto C na tomada de decisão sobre as obras e ser ou não proprietário.

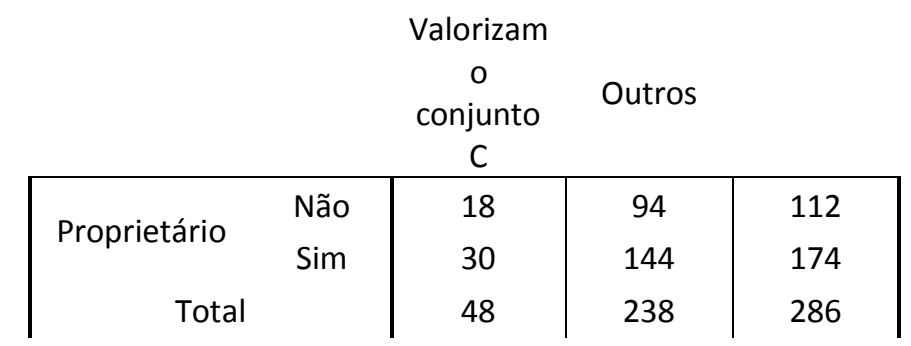

Tabela 56 - Dados para teste de associação qui-quadrado entre valorizar o conjunto $\mathrm{C}$ na tomada de decisão sobre as obras e ser proprietário ou não proprietários, excluídos os vazios.

\begin{tabular}{ccc} 
Região & $\begin{array}{c}\text { Seriam } \\
\text { capazes de } \\
\text { dar opinião }\end{array}$ & Percentual \\
\hline REG1 & 88 & $49 \%$ \\
REG2 & 42 & $24 \%$ \\
REG3 & 47 & $27 \%$ \\
\hline Total & 177 & $100 \%$
\end{tabular}

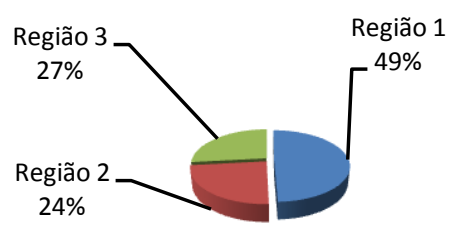

Tabela 57 - Moradores e comerciantes que seriam capazes de dar opinião sobre as obras contra inundação no bairro, por região. 


\begin{tabular}{|c|c|c|c|c|}
\hline & & \multicolumn{2}{|c|}{$\begin{array}{c}\text { Resposta à pergunta } \\
6 \\
\end{array}$} & \multirow{2}{*}{ Total } \\
\hline & & Sim & Não & \\
\hline \multirow{3}{*}{ Região } & REG1 & 88 & 58 & 146 \\
\hline & REG2 & 42 & 30 & 72 \\
\hline & REG3 & 47 & 36 & 83 \\
\hline \multicolumn{2}{|c|}{ Total } & 177 & 124 & 301 \\
\hline
\end{tabular}

Tabela 58 - Dados para teste de associação qui-quadrado entre ser capaz de dar opinião sobre as obras e região.

\begin{tabular}{ccc} 
Passaram por inundação & $\begin{array}{c}\text { Seriam capazes } \\
\text { de dar opinião }\end{array}$ & Percentual \\
\hline Não & 85 & $48 \%$ \\
Sim & 92 & $52 \%$ \\
\hline Total & 177 & $100 \%$
\end{tabular}

Tabela 59 - Moradores e comerciantes que seriam capazes de dar opinião sobre as obras contra inundação no bairro e ter ou não passado por inundação.

\begin{tabular}{|c|c|c|c|c|}
\hline & & \multicolumn{2}{|c|}{ Resposta à pergunta 6} & \multirow{2}{*}{ Total } \\
\hline & & Sim & Não & \\
\hline \multirow{2}{*}{ Inundação } & Nãp & 85 & 61 & 146 \\
\hline & Sim & 92 & 63 & 155 \\
\hline \multicolumn{2}{|c|}{ Total } & 177 & 124 & 301 \\
\hline
\end{tabular}

Tabela 60 - Dados para teste de associação qui-quadrado entre ser capaz de dar opinião sobre as obras e ter ou não passado por inundação.

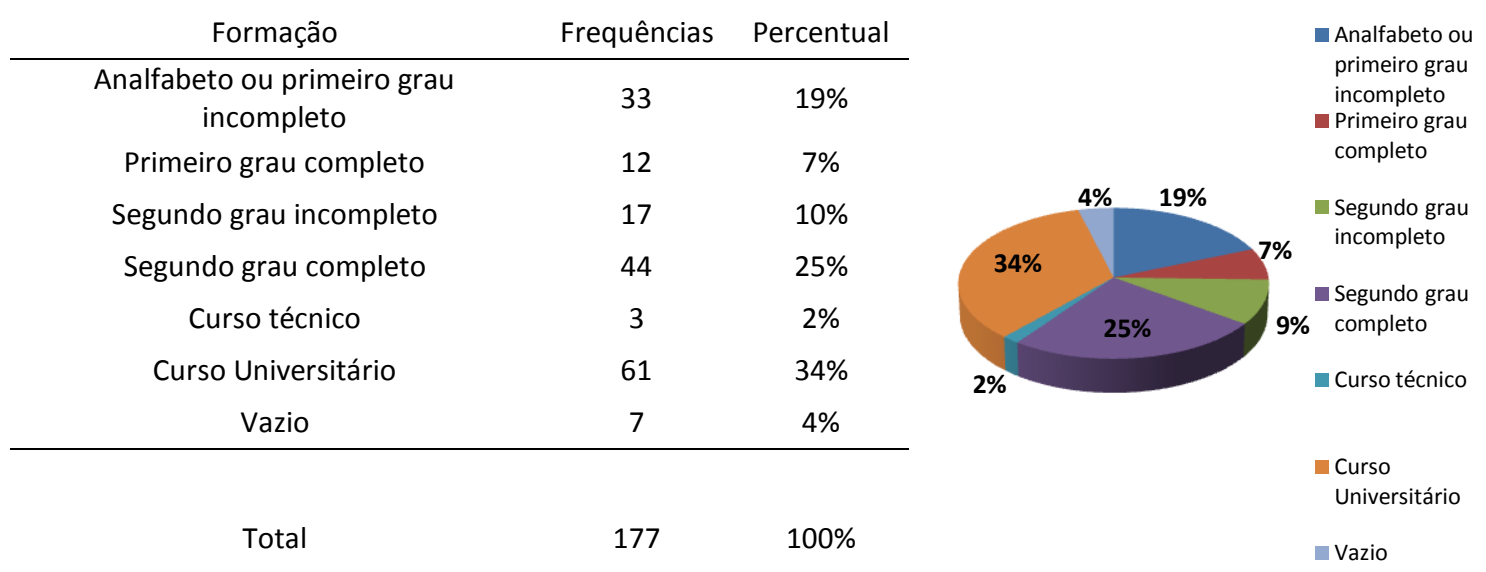

Tabela 61 - Moradores e comerciantes que seriam capazes de dar opinião sobre as obras contra inundação no bairro e formação. 


\begin{tabular}{|ll|c|c|c|}
\hline \multirow{2}{*}{} & & \multicolumn{2}{|c|}{ Resposta à pergunta 6 } & \multirow{2}{*}{ Total } \\
\cline { 3 - 4 } & 1 & Sim & Não & \\
\hline \multirow{4}{*}{ Formação } & 2 & 33 & 33 & 66 \\
& 3 & 12 & 9 & 21 \\
& 4 & 44 & 9 & 26 \\
& 5 & 3 & 1 & 79 \\
& 6 & 61 & 37 & 98 \\
Total & & 170 & 124 & 294 \\
\hline
\end{tabular}

Tabela 62 - Dados para teste de associação qui-quadrado entre ser capaz de dar opinião sobre as obras e formação.

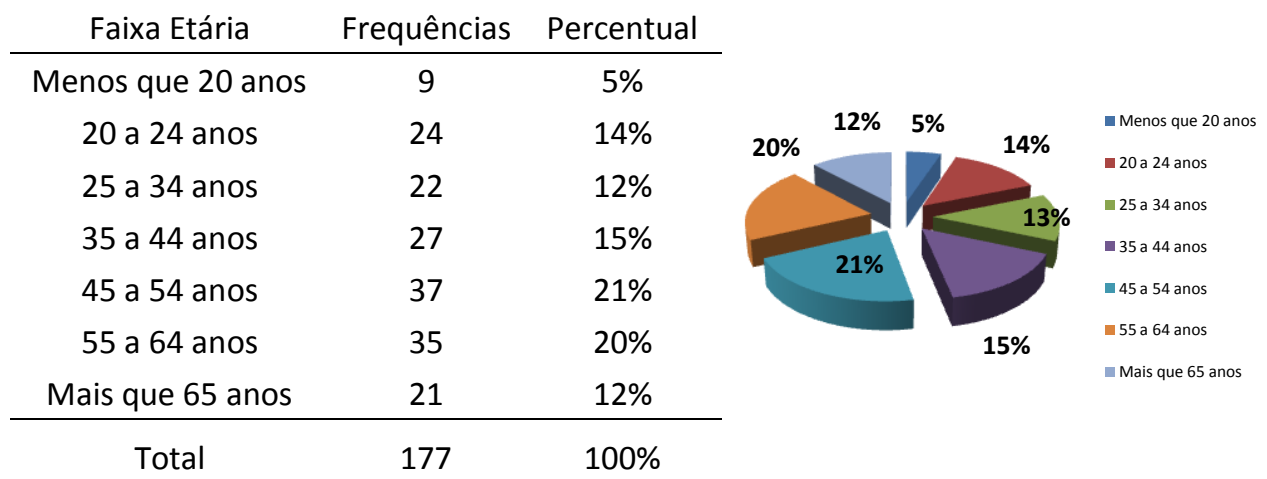

Tabela 63 - Moradores e Comerciantes que seriam capazes de dar opinião sobre as obras e faixa etária.

\begin{tabular}{|cc|c|c|c|}
\hline & & \multicolumn{2}{|c|}{ Resposta à pergunta 6 } & \multirow{2}{*}{ Total } \\
\cline { 3 - 4 } & 1 & Sim & Não & \\
\hline \multirow{5}{*}{ Faixa etária } & 2 & 9 & 3 & 12 \\
& 3 & 24 & 17 & 41 \\
& 5 & 22 & 25 & 47 \\
& 6 & 37 & 16 & 43 \\
& 7 & 35 & 24 & 61 \\
& & 21 & 21 & 56 \\
Total & & 175 & 124 & 299 \\
\hline
\end{tabular}

Tabela 64 - Dados para teste de associação qui-quadrado entre ser capaz de dar opinião sobre as obras e faixa etária. 


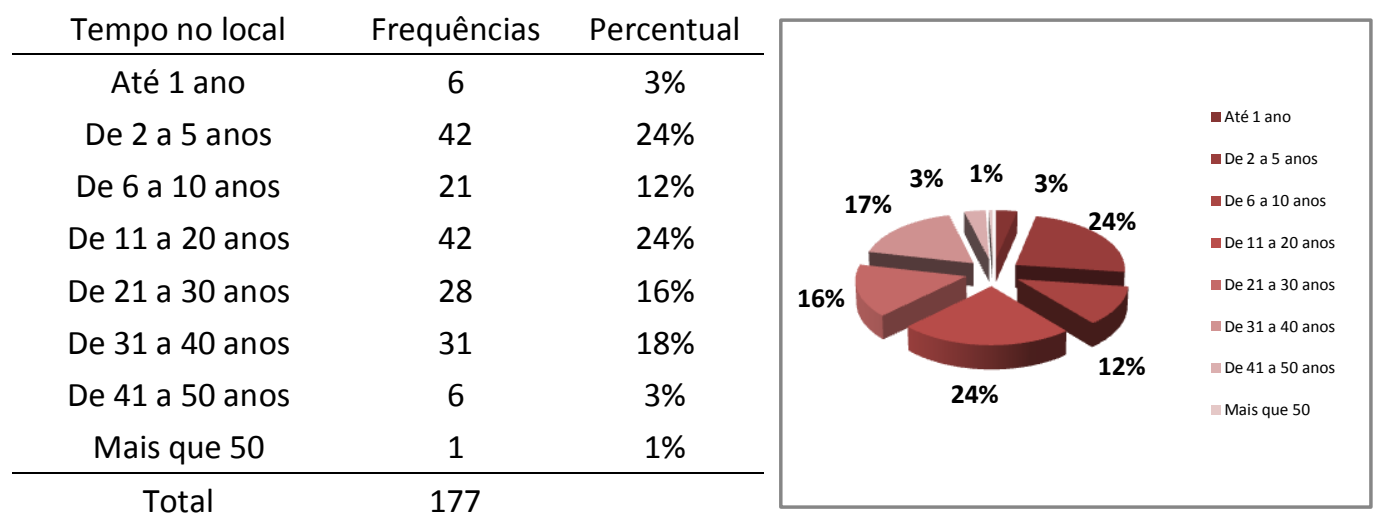

Tabela 65 - Moradores e comerciantes que seriam capazes de dar opinião sobre as obras e o tempo em que se encontram instalados no local.

\begin{tabular}{cccc} 
& \multicolumn{2}{c}{ Resposta à pergunta } & \multirow{2}{*}{ Total } \\
\cline { 1 - 3 } Tempo no local & Sim & Não & \\
Até 1 ano & 6 & 15 & 21 \\
De 2 a 5 anos & 42 & 34 & 76 \\
De 6 a 10 anos & 21 & 13 & 34 \\
De 11 a 20 anos & 42 & 19 & 61 \\
De 21 a 30 anos & 28 & 15 & 43 \\
De 31 a 40 anos & 31 & 14 & 45 \\
De 41 a 50 anos & 6 & 10 & 16 \\
Mais que 50 & 1 & 3 & 4 \\
\hline & 177 & 123 & 300
\end{tabular}

Tabela 66 - Dados para o teste de associação entre ser capaz de dar opinião sobre as obras e o tempo em que se encontra instalado no local.

\begin{tabular}{ccc} 
Sexo & $\begin{array}{c}\text { São capazes } \\
\text { de dar } \\
\text { opinião }\end{array}$ & Percentual \\
\hline Feminino & 84 & $47 \%$ \\
Masculino & 93 & $53 \%$ \\
\hline Total & 177 &
\end{tabular}

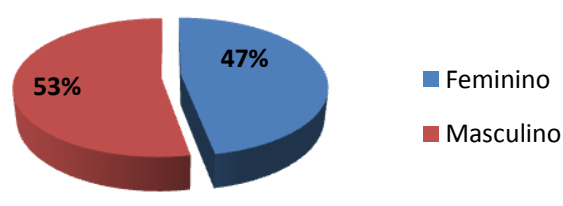

Tabela 67 - Ser capaz de dar opinião sobre as obras contra inundação no bairro e sexo.

\begin{tabular}{ccccc} 
& & \multicolumn{2}{c}{ Resposta à pergunta 6 } & Total \\
& & Sim & Não & \\
\hline \multirow{2}{*}{ Sexo } & Feminino & 84 & 64 & 148 \\
& Masculino & 93 & 60 & 153 \\
\hline \multirow{2}{*}{ Total } & 177 & 124 & 301
\end{tabular}

Tabela 68 - Dados para o teste de associação entre ser capaz de dar opinião e sexo. 


\begin{tabular}{ccc} 
Proprietário & Frequência & Percentual \\
\hline Não & 55 & $31 \%$ \\
Sim & 116 & $66 \%$ \\
Vazio & 6 & $3 \%$ \\
\hline Total & 177 &
\end{tabular}

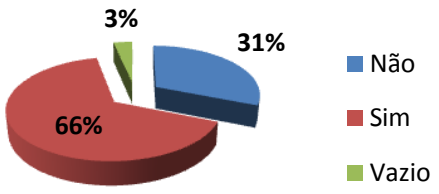

Tabela 69 - Moradores e comerciantes que seriam capazes de dar opinião sobre as obras contra inundação no bairro e serem ou não proprietários.

\begin{tabular}{ccccc} 
& & \multicolumn{2}{c}{ Ser capaz de dar opinião } & Total \\
& & Sim & Não & \\
\hline \multirow{2}{*}{ Proprietário } & Não & 55 & 57 & 112 \\
& Sim & 116 & 58 & 174 \\
\multicolumn{1}{c}{ Total } & & 171 & 115 & 286
\end{tabular}

Tabela 70 - Dados para o teste de associação entre ser capaz de dar opinião e ser ou não proprietário.

\begin{tabular}{|c|c|c|c|}
\hline Região & $\begin{array}{c}\text { Frequências } \\
\text { Conversa no } \\
\text { bairro }\end{array}$ & Percentual & $15 \%$ \\
\hline REG1 & 48 & $65 \%$ & \\
\hline REG2 & 15 & $20 \%$ & \\
\hline REG3 & 11 & $15 \%$ & \\
\hline Total & 74 & $100 \%$ & \\
\hline
\end{tabular}

Tabela 71 - Moradores e comerciantes que já conversaram com pessoas do bairro sobre as obras dos piscinões em cada uma das regiões.

\begin{tabular}{|c|c|c|c|c|}
\hline & \multicolumn{4}{|c|}{$\begin{array}{l}\text { Conversou com pessoas } \\
\text { no bairro }\end{array}$} \\
\hline & & Não & Sim & Total \\
\hline \multirow[t]{3}{*}{ Região } & REG1 & 98 & 48 & 146 \\
\hline & REG2 & 57 & 15 & 72 \\
\hline & REG3 & 72 & 11 & 83 \\
\hline \multicolumn{2}{|c|}{ Total } & 227 & 74 & 301 \\
\hline
\end{tabular}

Tabela 72 - Dados para o teste de associação ter conversado com pessoas do bairro e região. 


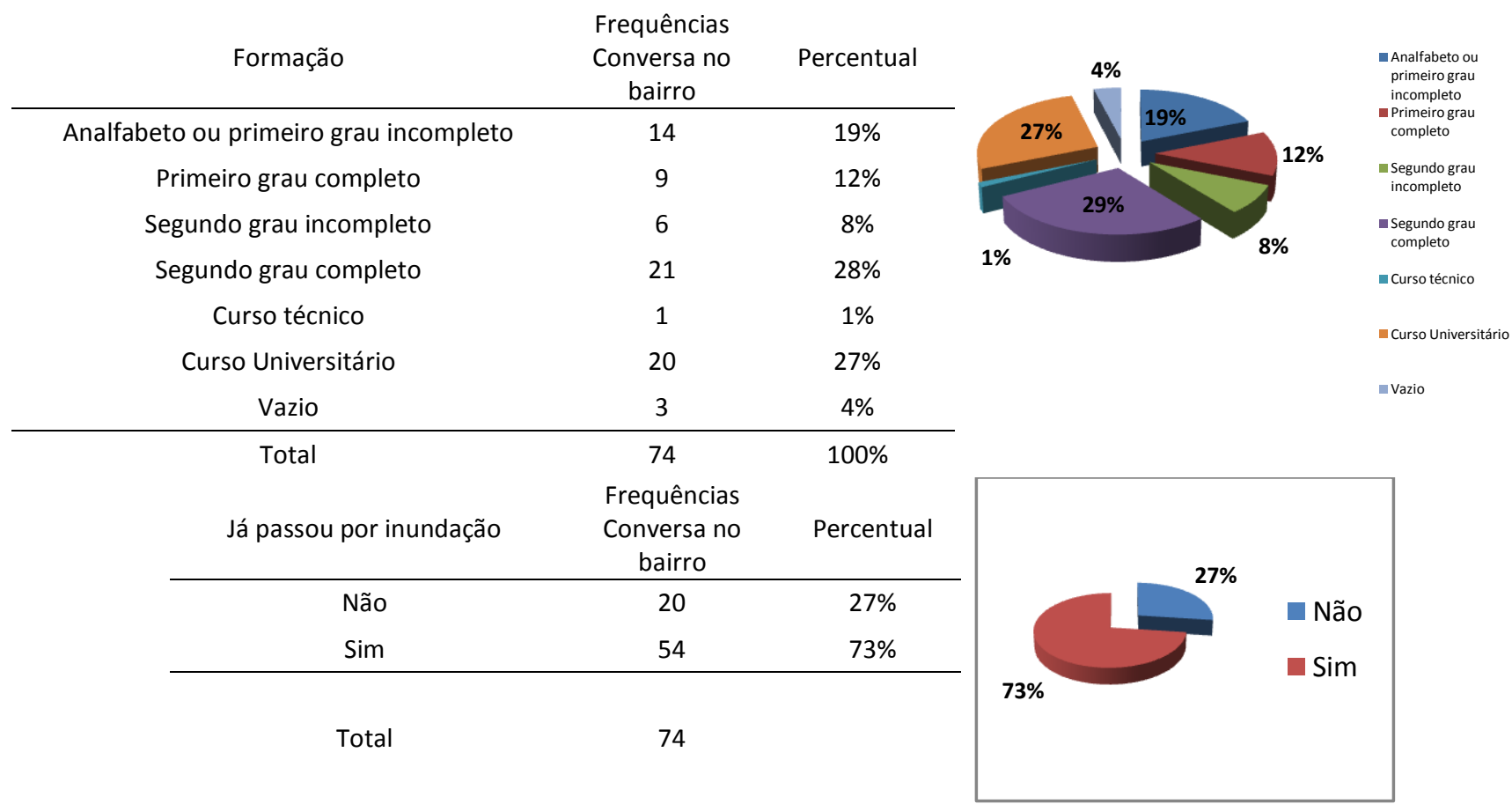

Tabela 73 - Moradores e comerciantes que já conversaram com gente do bairro sobre as obras dos piscinões e ter ou não passado por inundação.

\begin{tabular}{lcccc}
\multicolumn{5}{c}{$\begin{array}{c}\text { Conversou com gente } \\
\text { do bairro }\end{array}$} \\
& Não & Sim & Total \\
\hline Inundação & $\mathrm{N}$ & 126 & 20 & 146 \\
& $\mathrm{~S}$ & 101 & 54 & 155 \\
\hline Total & & 227 & 74 & 301
\end{tabular}

Tabela 74 - Dados para o teste de associação entre já ter conversado com pessoas do bairro ter ou não passado por inundação. 


\begin{tabular}{ccc} 
Formação & $\begin{array}{c}\text { Conversou com } \\
\text { gente do bairro }\end{array}$ & Percentual \\
\hline Analfabeto ou primeiro grau incompleto & 14 & $19 \%$ \\
Primeiro grau completo & 9 & $12 \%$ \\
Segundo grau incompleto & 6 & $8 \%$ \\
Segundo grau completo & 21 & $28 \%$ \\
Curso técnico & 1 & $1 \%$ \\
Curso Universitário & 20 & $27 \%$ \\
Vazio & 3 & $4 \%$ \\
\hline Total & 74 & $100 \%$
\end{tabular}

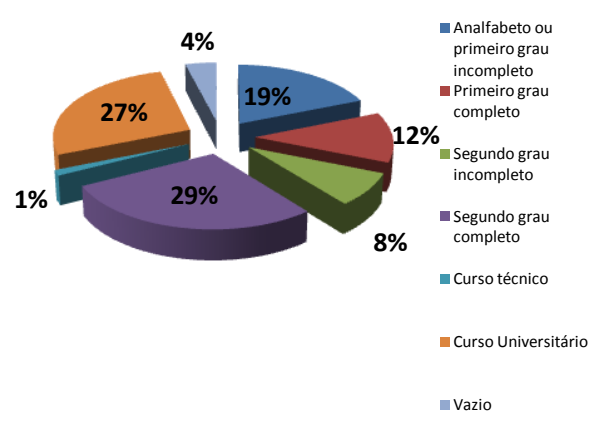

Tabela 75 - Moradores e comerciantes que já conversaram com pessoas no bairro sobre as obras dos piscinões e formação.

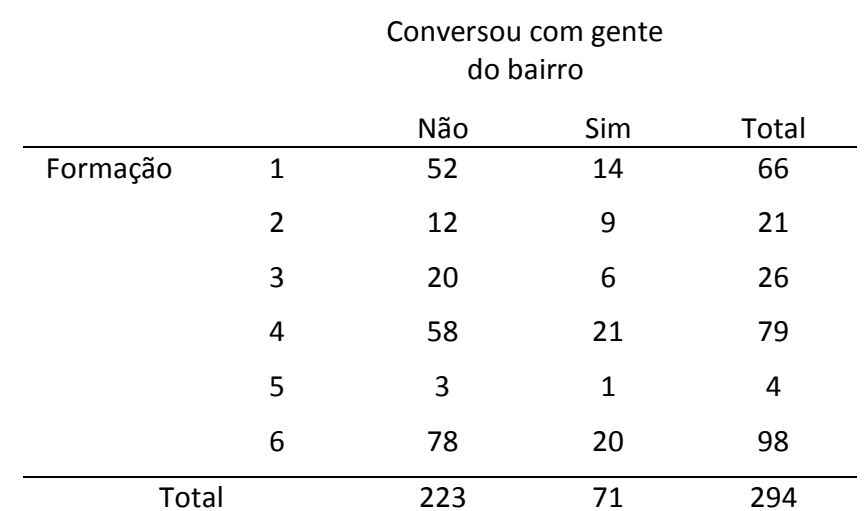

Tabela 76 - Dados para o teste de associação entre já ter conversado com pessoas do bairro e formação.

\begin{tabular}{|c|c|c|c|c|}
\hline Faixa Etária & $\begin{array}{c}\text { Conversou } \\
\text { com gente do } \\
\text { bairro }\end{array}$ & Percentual & & \\
\hline Menos que 20 anos & 2 & $3 \%$ & & $\begin{array}{l}\text { - Analfabeto ou primeiro } \\
\text { grau incompleto }\end{array}$ \\
\hline 20 a 24 anos & 14 & $19 \%$ & $19 \%$ & - Primeiro grau completo \\
\hline 25 a 34 anos & 11 & $15 \%$ & & - Segundo grau incompleto \\
\hline 35 a 44 anos & 4 & $5 \%$ & & - Segundo grau completto \\
\hline 45 a 54 anos & 16 & $22 \%$ & $1 \%$ & Curso técnico \\
\hline 55 a 64 anos & 17 & $23 \%$ & & 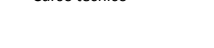 \\
\hline Mais que 65 anos & 8 & $11 \%$ & & E Curso Universitário \\
\hline Vazio & 2 & $3 \%$ & & \\
\hline Total & 74 & $100 \%$ & & \\
\hline
\end{tabular}

Tabela 77 - Moradores e comerciantes que já conversaram com gente do bairro sobre as obras dos piscinões e faixa etária. 


\begin{tabular}{|c|c|c|c|}
\hline \multirow[t]{2}{*}{ Faixa Etária } & \multicolumn{2}{|c|}{$\begin{array}{l}\text { Conversou com gente } \\
\text { do bairro }\end{array}$} & \multirow[t]{2}{*}{ Total } \\
\hline & Não & $\operatorname{Sim}$ & \\
\hline Menos que 20 anos & 10 & 2 & 12 \\
\hline 20 a 24 anos & 27 & 14 & 41 \\
\hline 25 a 34 anos & 36 & 11 & 47 \\
\hline 35 a 44 anos & 39 & 4 & 43 \\
\hline 45 a 54 anos & 45 & 16 & 61 \\
\hline 55 a 64 anos & 39 & 17 & 56 \\
\hline Mais que 65 anos & 31 & 8 & 39 \\
\hline Total & 227 & 72 & 299 \\
\hline
\end{tabular}

Tabela 78 - Dados para o teste de associação entre já ter conversado com pessoas do bairro e faixa etária.

\begin{tabular}{|c|c|c|c|c|}
\hline Tempo no local & $\begin{array}{c}\text { Conversou } \\
\text { com gente } \\
\text { do bairro }\end{array}$ & Percentual & & \\
\hline Até 1 ano & 7 & $9 \%$ & $11 \% \quad 3 \%$ & - Menos que 20 anos \\
\hline De 2 a 5 anos & 14 & $19 \%$ & & - 20 a 24 anos \\
\hline De 6 a 10 anos & 5 & $7 \%$ & & $\nabla 25$ a 34 anos \\
\hline De 11 a 20 anos & 14 & $19 \%$ & & = 45 a 54 anos \\
\hline De 21 a 30 anos & 14 & $19 \%$ & & $=55 \mathrm{a} 64$ anos \\
\hline De 31 a 40 anos & 16 & $22 \%$ & & — Mais que 65 anos \\
\hline De 41 a 50 anos & 4 & $5 \%$ & & \\
\hline Total & 74 & $100 \%$ & & \\
\hline
\end{tabular}

Tabela 79 - Moradores e comerciantes que já conversaram com gente do bairro sobre obras dos piscinões e tempo no local.

\begin{tabular}{|c|c|c|c|c|}
\hline & & \multicolumn{2}{|c|}{$\begin{array}{l}\text { Conversou com } \\
\text { gente do bairro }\end{array}$} & \multirow{2}{*}{ Total } \\
\hline & & Não & Sim & \\
\hline \multirow{8}{*}{$\begin{array}{l}\text { Tempo } \\
\text { no local }\end{array}$} & Até 1 ano & 14 & 7 & 21 \\
\hline & De 2 a 5 anos & 62 & 14 & 76 \\
\hline & De 6 a 10 anos & 29 & 5 & 34 \\
\hline & De 11 a 20 anos & 47 & 14 & 61 \\
\hline & De 21 a 30 anos & 29 & 14 & 43 \\
\hline & De 31 a 40 anos & 29 & 16 & 45 \\
\hline & De 41 a 50 anos & 12 & 4 & 16 \\
\hline & Mais que 50 & 4 & 0 & 4 \\
\hline Total & & 226 & 74 & 300 \\
\hline
\end{tabular}

Tabela 80 - Dados para o teste de associação entre já ter conversado com pessoas do bairro e tempo no local. 


\begin{tabular}{ccc} 
Sexo & $\begin{array}{c}\text { Conversou } \\
\text { com gente do } \\
\text { bairro }\end{array}$ & Percentual \\
\hline Feminino & 39 & $53 \%$ \\
Masculino & 35 & $47 \%$ \\
\hline Total & 74 &
\end{tabular}

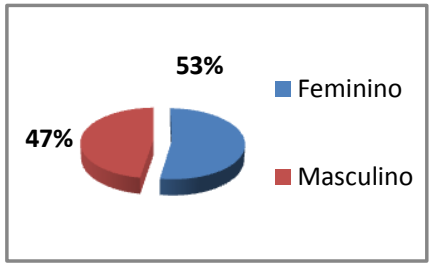

Tabela 81 - Moradores e comerciantes que já conversaram com gente do bairro sobre as obras dos piscinões e sexo.

\begin{tabular}{llllll} 
& \multicolumn{5}{c}{$\begin{array}{c}\text { Conversou com gente } \\
\text { do bairro }\end{array}$} \\
& Não & \multicolumn{2}{c}{ Sim } & Total & \\
\hline \multirow{2}{*}{ Sexo } & Feminino & 109 & 39 & 148 \\
& Masculino & 118 & 35 & 153 \\
\hline \multirow{2}{*}{ Total } & & 227 & 74 & 301
\end{tabular}

Tabela 82 - Dados para a realização do teste de associação entre já ter conversado com gente do bairro sobre as obras dos piscinões e sexo.

\begin{tabular}{ccc} 
Proprietário & $\begin{array}{c}\text { Conversou } \\
\text { com gente do } \\
\text { bairro }\end{array}$ & Percentual \\
\hline Não & 20 & $27 \%$ \\
Sim & 48 & $65 \%$ \\
Vazio & 6 & $8 \%$ \\
\hline Total & 74 &
\end{tabular}

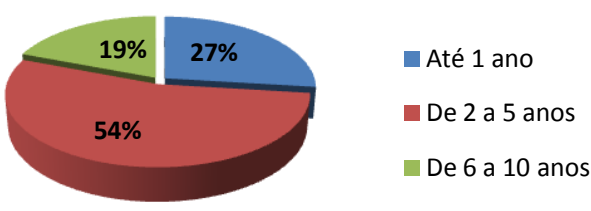

Tabela 83 - Moradores e comerciantes que já conversaram no bairro sobre as obras dos piscinões e ser ou não proprietários.

\begin{tabular}{lcrrrr} 
& \multicolumn{5}{c}{$\begin{array}{c}\text { Conversou com gente } \\
\text { do bairro }\end{array}$} \\
& \multicolumn{1}{c}{$\begin{array}{c}\text { Tão } \\
\text { Sim }\end{array}$} & \multicolumn{2}{c}{ Total } \\
\hline \multirow{2}{*}{ Proprietário } & $\mathrm{N}$ & 92 & 20 & 112 \\
& $\mathrm{~S}$ & 126 & 48 & 174 \\
\hline Total & & 218 & 68 & 286
\end{tabular}

Tabela 84 - Dados para o teste de associação entre já ter conversado com pessoas do bairro sobre as obras dos piscinções e ser ou não proprietário. 


\begin{tabular}{lcc} 
Região & $\begin{array}{c}\text { Levar a sério a } \\
\text { opinião }\end{array}$ & Percentual \\
\hline REG1 & 25 & $49 \%$ \\
REG2 & 10 & $20 \%$ \\
REG3 & 16 & $31 \%$ \\
\hline Total & 51 & $100 \%$
\end{tabular}
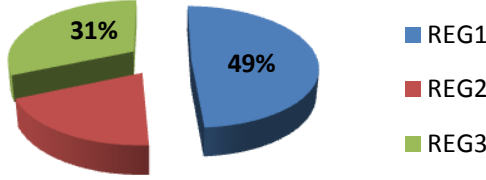

$20 \%$

Tabela 85 - Moradores e comerciantes que acreditam que os técnicos /engenheiros levam a sério sua opinião em cada uma das regiões.

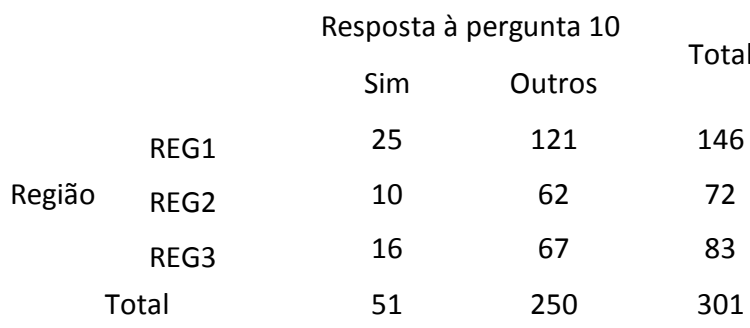

Tabela 86 - Dados para o teste de associação entre técnicos e engenheiros levam a sério a opinião e região.

\begin{tabular}{ccc} 
Já passou por inundação & $\begin{array}{c}\text { Levar a sério a } \\
\text { opinião }\end{array}$ & Percentual \\
\hline Não & 23 & $45 \%$ \\
Sim & 28 & $55 \%$ \\
\hline Total & 51 & $100 \%$
\end{tabular}

Tabela 87 - Moradores e comerciantes que acreditam que os técnicos /engenheiros levam a sério sua opinião e ter ou não passado por inundação.

\begin{tabular}{|c|c|c|c|c|}
\hline & & \multicolumn{2}{|c|}{$\begin{array}{c}\text { Resposta à pergunta } \\
10 .\end{array}$} & \multirow[t]{2}{*}{ Tota } \\
\hline & & Sim & Outros & \\
\hline \multirow{2}{*}{ Inundação } & $\mathrm{N}$ & 23 & 123 & 146 \\
\hline & $S$ & 28 & 127 & 155 \\
\hline \multicolumn{2}{|c|}{ Total } & 51 & 250 & 301 \\
\hline
\end{tabular}

Tabela 88 - Dados para o teste de associação entre técnicos e engenheiros levam a sério a opinião e ter ou não passado por inundação. 


\begin{tabular}{ccc} 
Formação & $\begin{array}{c}\text { Levar a sério } \\
\text { a opinião }\end{array}$ & Percentual \\
\hline Analfabeto ou primeiro grau incompleto & 9 & $18 \%$ \\
Primeiro grau completo & 4 & $8 \%$ \\
Segundo grau incompleto & 9 & $18 \%$ \\
Segundo grau completo & 11 & $22 \%$ \\
Curso Universitário & 16 & $31 \%$ \\
Vazio & 2 & $4 \%$ \\
\hline Total & 51 &
\end{tabular}

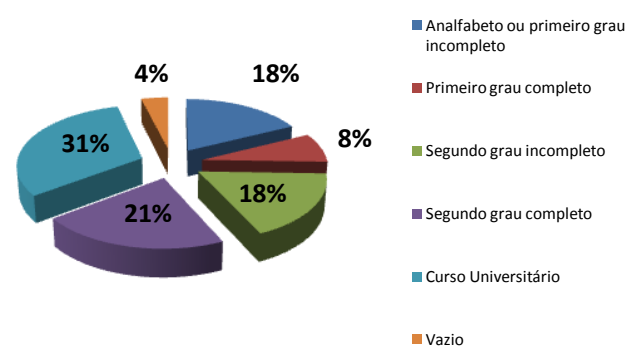

Tabela 89 - Moradores e comerciantes que acreditam que os técnicos /engenheiros levam a sério sua opinião e grau de escolaridade.

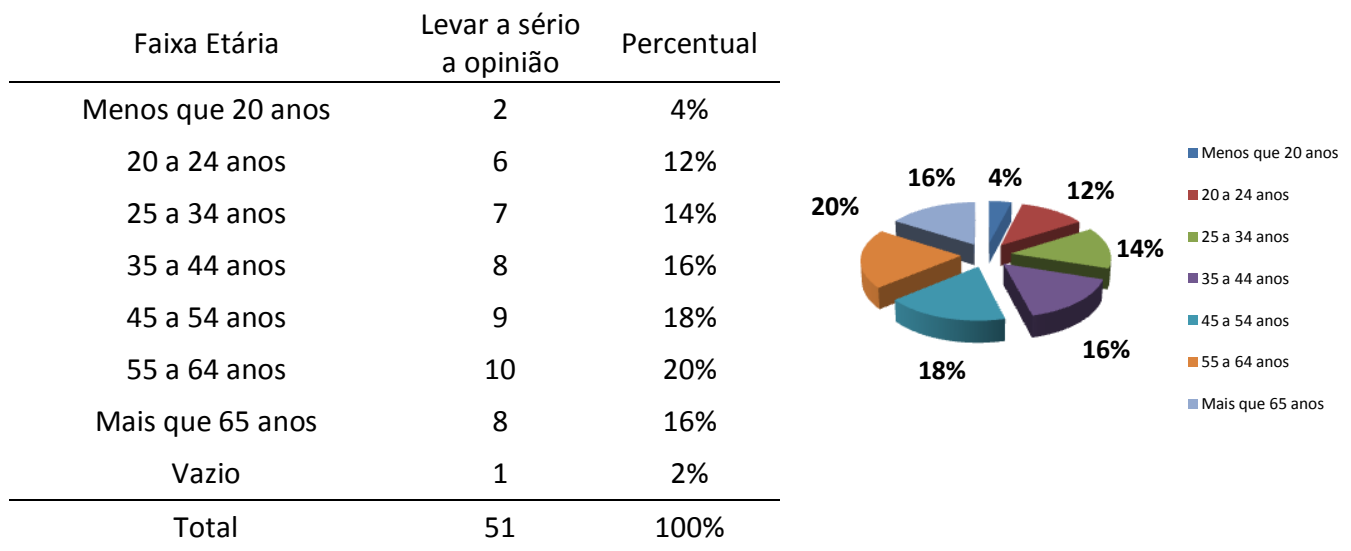

Tabela 90 - Moradores e comerciantes que acreditam que os técnicos /engenheiros levam a sério sua opinião e faixa etária.

\begin{tabular}{ccccc} 
& & \multicolumn{2}{c}{ Resposta à pergunta 10} & Total \\
& Menos que 20 anos & Sim & Outros & \\
\hline \multirow{2}{*}{$\begin{array}{c}\text { Faixa } \\
\text { etária }\end{array}$} & 25 a 24 anos & 6 & 10 & 12 \\
& 25 a 34 anos & 7 & 40 & 41 \\
& 35 a 44 anos & 8 & 35 & 43 \\
& 45 a 54 anos & 9 & 52 & 61 \\
& 55 a 64 anos & 10 & 46 & 56 \\
& Mais que 65 anos & 8 & 31 & 39 \\
\hline
\end{tabular}

Tabela 91 - Dados para o teste de associação entre acreditar que técnicos e engenheiros levam a sério a opinião e faixa etária. 


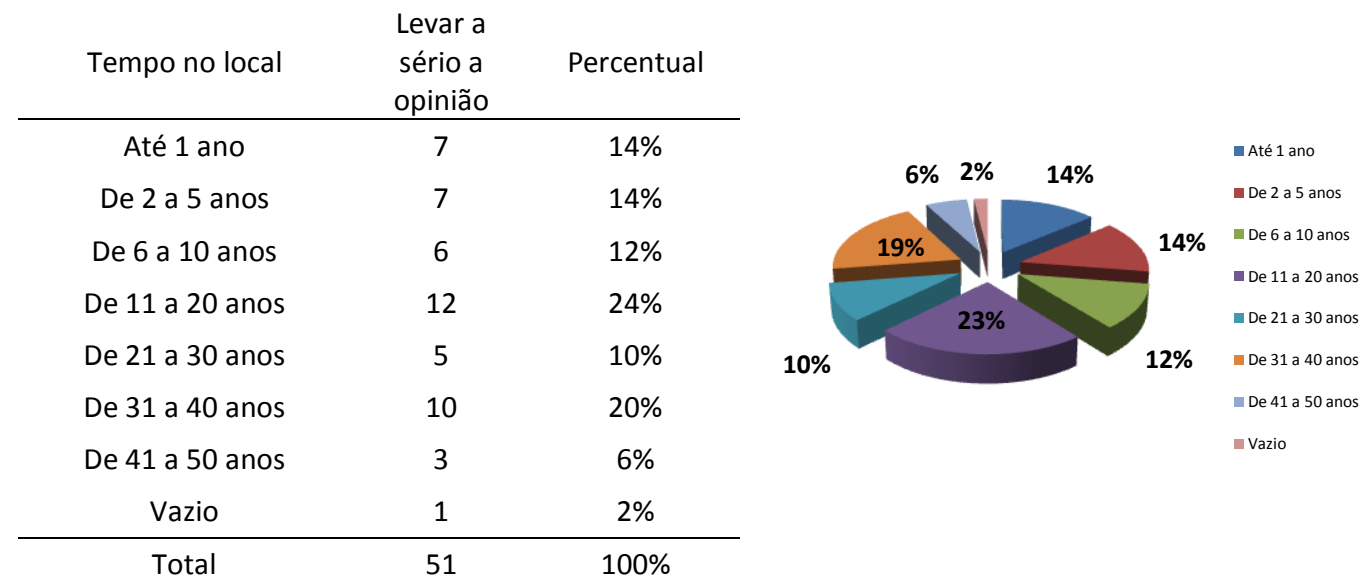

Tabela 92 - Moradores e comerciantes que acreditam que os técnicos /engenheiros levam a sério sua opinião e tempo no local.

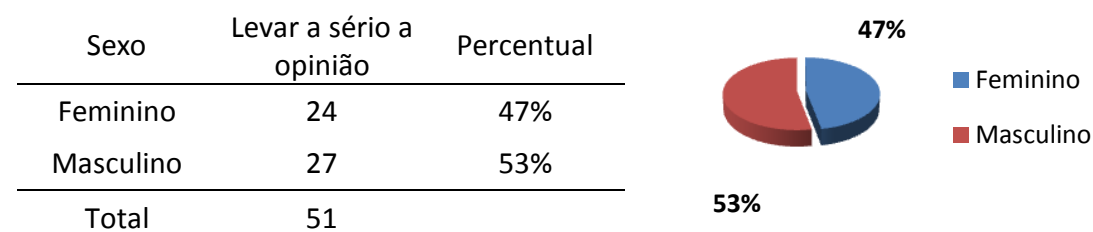

Tabela 93 - Moradores e comerciantes que acreditam que os técnicos /engenheiros levam a sério sua opinião e sexo.

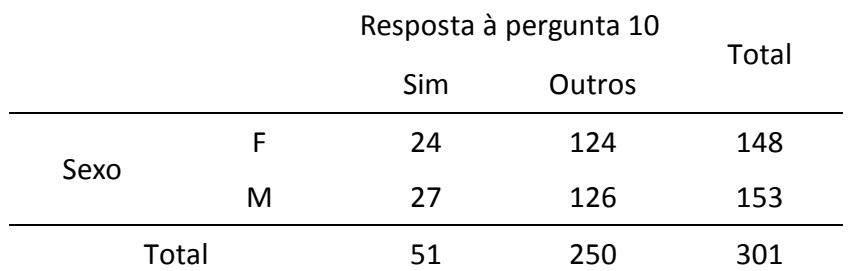

Tabela 94 - Dados para o teste de associação entre acreditar que técnicos e engenheiros levam a sério a opinião e sexo. 


\begin{tabular}{ccc} 
Proprietário & Frequências & Percentual \\
\hline Não & 19 & $37 \%$ \\
Sim & 29 & $57 \%$ \\
Vazio & 3 & $6 \%$ \\
\hline Total & 51 &
\end{tabular}

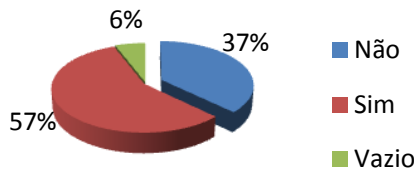

Tabela 95 - Moradores e comerciantes que acreditam que os técnicos /engenheiros levam a sério sua opinião e ser ou não proprietário.

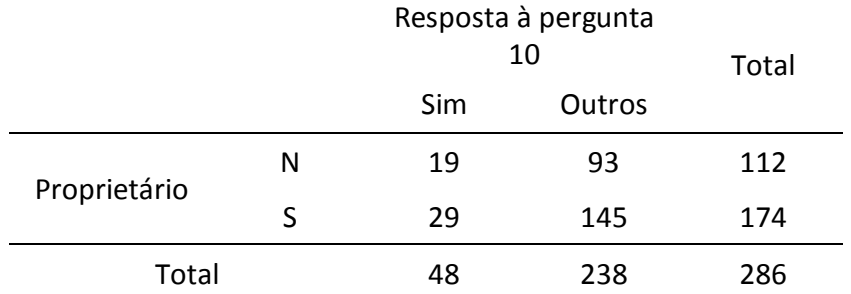

Tabela 96 - Dados para o teste de associação entre acreditar que técnicos e engenheiros levam a sério a opinião e ser ou não proprietário.

\begin{tabular}{lcc} 
Região & Frequências & Percentual \\
\hline REG1 & 105 & $47 \%$ \\
REG2 & 53 & $24 \%$ \\
REG3 & 66 & $29 \%$ \\
\hline Total & 224 & $100 \%$
\end{tabular}

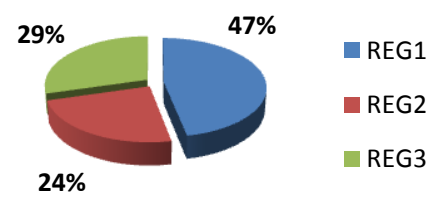

Tabela 97 - Moradores e comerciantes que gostariam de participar de conversas com os técnicos e engenheiros das obras e a região.

\begin{tabular}{|c|c|c|c|c|}
\hline & \multicolumn{3}{|c|}{ Resposta à questão 11} & \multirow{2}{*}{ Total } \\
\hline & & Sim & Outros & \\
\hline \multirow{3}{*}{ Região } & REG1 & 105 & 41 & 146 \\
\hline & REG2 & 53 & 19 & 72 \\
\hline & REG3 & 66 & 17 & 83 \\
\hline \multicolumn{2}{|c|}{ Total } & 224 & 77 & 301 \\
\hline
\end{tabular}

Tabela 98 - Dados para o teste de associação entre gostaria de participar de conversas com os técnicos e engenheiros das obras e a região. 


\begin{tabular}{ccc} 
Já passou por inundação & $\begin{array}{c}\text { Gostariam de } \\
\text { participar }\end{array}$ & Percentual \\
\hline Não & 108 & $48 \%$ \\
Sim & 116 & $52 \%$ \\
\hline Total & 224 &
\end{tabular}

Tabela 99 - Moradores e comerciantes que gostariam de participar de conversas com os técnicos e engenheiros das obras e ter ou não passado por inundação.

\begin{tabular}{ccccc} 
& & \multicolumn{2}{c}{ Resposta à questão 11} & Total \\
& & Sim & Outros & \\
\hline \multirow{2}{*}{ Inundação } & N & 108 & 38 & 146 \\
& S & 116 & 39 & 155 \\
Total & & 224 & 77 & 301
\end{tabular}

Tabela 100 - Dados para o teste de associação entre gostaria de participar de conversas com os técnicos e engenheiros das obras e ter ou não passado por inundação.

\begin{tabular}{ccc} 
& $\begin{array}{c}\text { Sim, deseja } \\
\text { participar }\end{array}$ & Percentual \\
\hline Não fez obras & 42 & $19 \%$ \\
Já fez obras & 74 & $33 \%$ \\
Nunca passou por inundação & 107 & $48 \%$ \\
Vazio & 1 & $0 \%$ \\
\hline Total & 224 & $100 \%$
\end{tabular}

Tabela 101 - Moradores e comerciantes que gostariam de participar de conversas com técnicos e engenheiros das obras dos piscinões, ter ou não passado por inundação e ter ou não feito obras de contenção em seu imóvel.

\begin{tabular}{|c|c|c|c|c|}
\hline & \multicolumn{3}{|c|}{ Resposta à questão 11} & \multirow{2}{*}{ Tota } \\
\hline & & Sim & Outros & \\
\hline \multirow{3}{*}{ Obras } & Não & 42 & 20 & 62 \\
\hline & \multirow{3}{*}{ Sim } & & & \\
\hline & & 74 & 20 & 94 \\
\hline & & 116 & 40 & 156 \\
\hline
\end{tabular}

Tabela 102 - Dados para o teste de associação entre gostar de participar de conversas com técnicos e engenheiros das obras dos piscinões, ter ou não feito obras (na resposta recodificada). 


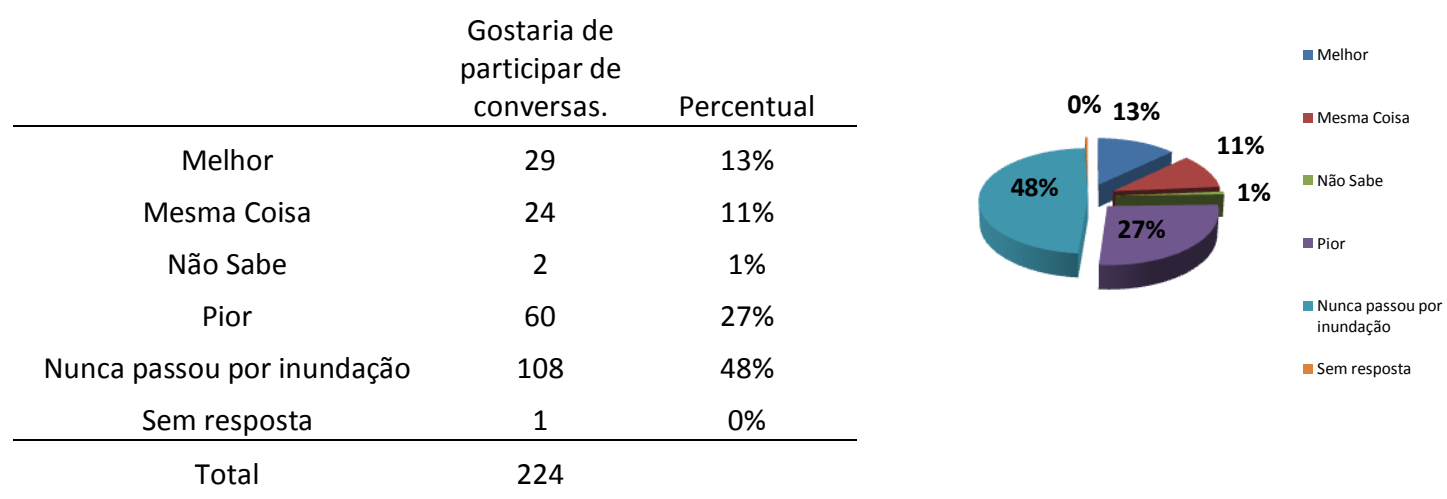

Tabela 103 - Moradores e comerciantes que gostariam de participar de conversas com técnicos e engenheiros das obras dos piscinões, e acreditar que está pior ou melhor que antes, mesmo sem ter passado por inundação.

\begin{tabular}{|c|c|c|c|c|c|}
\hline & & & spost & nta 11 & \\
\hline & & & Sim & Não & \\
\hline & & Quantidade & 29 & 2 & 31 \\
\hline & Melhor & $\%$ & $26 \%$ & $6 \%$ & $21 \%$ \\
\hline Jitudçdo & Mesma & Quantidade & 24 & 17 & 41 \\
\hline & Coisa & $\%$ & $21 \%$ & $47 \%$ & $28 \%$ \\
\hline & & Quantidade & 60 & 17 & 77 \\
\hline & PIor & $\%$ & $56 \%$ & $47 \%$ & $52 \%$ \\
\hline & & Quantidade & 113 & 36 & 149 \\
\hline
\end{tabular}

Tabela 104 - Dados para o teste de associação entre situação das inundações e desejo de participar de conversas com técnicos e engenheiros.

\begin{tabular}{ccc} 
Formação & $\begin{array}{c}\text { Frequências } \\
\text { desejo de } \\
\text { participar }\end{array}$ & Percentual \\
\hline $\begin{array}{c}\text { Analfabeto ou primeiro grau } \\
\text { incompleto }\end{array}$ & 46 & $21 \%$ \\
Primeiro grau completo & 16 & $7 \%$ \\
Segundo grau incompleto & 18 & $8 \%$ \\
Segundo grau completo & 54 & $24 \%$ \\
Curso Universitário & 81 & $36 \%$ \\
Curso Técnico & 4 & $2 \%$ \\
Vazio & 5 & $2 \%$ \\
\hline Total & 224 &
\end{tabular}

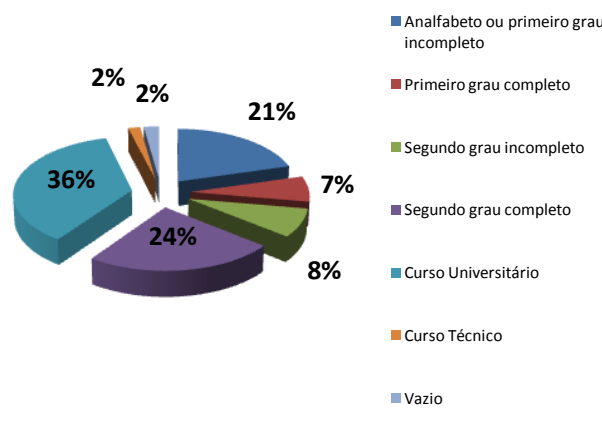

Tabela 105 - Moradores e comerciantes que gostariam de participar de conversas com os técnicos e engenheiros das obras e grau de escolaridade. 


\begin{tabular}{ccccc} 
& & \multicolumn{2}{c}{ Resposta à questão 11} & Total \\
& Analfabeto ou primeiro grau incompleto & 46 & Outros & \\
\hline \multirow{2}{*}{ Formação } & Sim & 20 & 66 \\
& Segundo grau incompleto & 16 & 5 & 21 \\
& Segundo grau completo & 18 & 8 & 26 \\
Curso Universitário & 54 & 25 & 79 \\
Curso Técnico & 4 & 0 & 4 \\
\hline & Total & 81 & 17 & 98 \\
\hline
\end{tabular}

Tabela 106 - Dados para o teste de associação entre gostaria de participar de conversas com os técnicos e engenheiros das obras e grau de escolaridade.

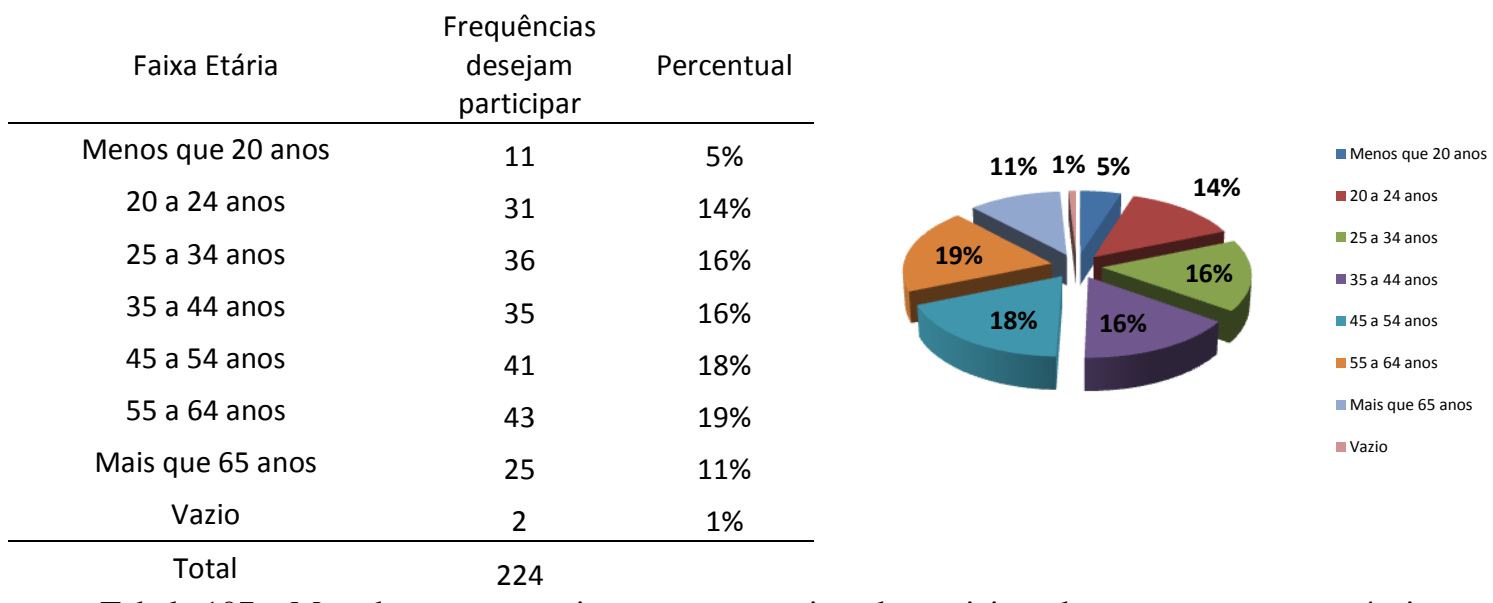

Tabela 107 - Moradores e comerciantes que gostariam de participar de conversas com os técnicos e engenheiros das obras e faixa etária.

\begin{tabular}{ccccc} 
& & \multicolumn{2}{c}{ Resposta a questão 11} & Total \\
& & Sim & Outros & \\
\hline \multirow{5}{*}{ Faixa etária } & 1 & 11 & 1 & 12 \\
& 2 & 31 & 10 & 41 \\
& 3 & 36 & 11 & 47 \\
& 5 & 35 & 8 & 43 \\
& 6 & 41 & 20 & 61 \\
& 7 & 43 & 13 & 56 \\
\hline Total & & 222 & 14 & 39 \\
\hline
\end{tabular}

Tabela 108 - Dados para o teste de associação entre gostaria de participar de conversas com os técnicos e engenheiros das obras e faixa etária. 


\begin{tabular}{ccccc} 
Tempo no local & Frequências & Percentual & \\
\hline Até 1 ano & 16 & $7 \%$ & $24 \%$ &
\end{tabular}

Tabela 109 - Moradores e comerciantes que gostariam de participar de conversas com os técnicos e engenheiros das obras e tempo no local.

\begin{tabular}{llccc} 
& & \multicolumn{3}{c}{ Resposta à questão } \\
& & Sim & Outros & Total \\
\hline \multirow{4}{*}{ Tempo } & Até 1 ano & 16 & 5 & 21 \\
& De 2 a 5 anos & 54 & 22 & 76 \\
& De 6 a 10 anos & 24 & 10 & 34 \\
& De 11 a 20 anos & 47 & 14 & 61 \\
& De 21 a 30 anos & 30 & 13 & 43 \\
& De 31 a 40 anos & 34 & 11 & 45 \\
& De 41 a 50 anos & 14 & 2 & 16 \\
& Mais que 50 & 4 & 0 & 4 \\
\hline & Total & 223 & 77 & 300
\end{tabular}

Tabela 110 - Dados para o teste de associação entre gostaria de participar de conversas com os técnicos e engenheiros das obras e tempo no local.

\begin{tabular}{ccc} 
Sexo & Frequências & Percentual \\
\hline Feminino & 113 & $50 \%$ \\
Masculino & 111 & $50 \%$ \\
\hline Total & 224 &
\end{tabular}

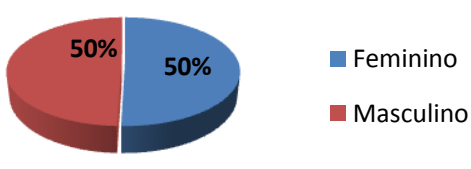

Tabela 111 - Moradores e comerciantes que gostariam de participar de conversas com os técnicos e engenheiros das obras e sexo. 


\begin{tabular}{ccccc} 
& & \multicolumn{2}{c}{ Resposta à questão 11} & Total \\
& & Sim & Outros & \\
\hline \multirow{2}{*}{ Sexo } & Feminino & 113 & 35 & 148 \\
& Masculino & 111 & 42 & 153 \\
\cline { 3 - 5 } & Total & 224 & 77 & 301
\end{tabular}

Tabela 112 - Dados para o teste de associação entre gostaria de participar de conversas com os técnicos e engenheiros das obras e sexo.

\begin{tabular}{ccc} 
Proprietário & $\begin{array}{c}\text { Sim, deseja } \\
\text { participar }\end{array}$ & Percentual \\
\hline Não & 77 & $34 \%$ \\
Sim & 138 & $62 \%$ \\
Vazio & 9 & $4 \%$ \\
\hline Total & 224 & $100 \%$
\end{tabular}

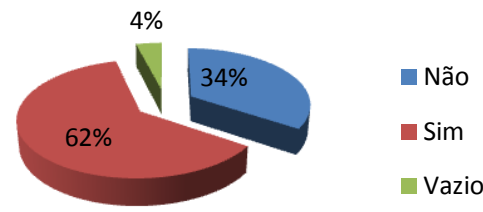

Tabela 113 - Moradores e comerciantes que gostariam de participar de conversas com os técnicos e engenheiros das obras e ser ou não proprietário.

\begin{tabular}{|c|c|c|c|c|}
\hline & \multicolumn{3}{|c|}{ Resposta à questão 11} & \multirow{2}{*}{ Total } \\
\hline & & Sim & Outros & \\
\hline \multirow{2}{*}{ Proprietário } & $\mathrm{N}$ & 77 & 35 & 112 \\
\hline & $S$ & 138 & 36 & 174 \\
\hline Tot & & 215 & 71 & 286 \\
\hline
\end{tabular}

Tabela 114 - Dados para o teste de associação entre gostaria de participar de conversas com os técnicos e engenheiros das obras e ser ou não proprietários. 


\section{ANEXO 9 - ANÁLISE ESTATÍSTICA: CATEGORIZAÇÃO DE VARIÁ VEIS E REGRESSÃO LOGÍSTICA}

Categorização de Variáveis

A tabela a seguir apresenta as frequências da questão 5 (Quem você acha que deve decidir sobre as obras contra inundação?) e a questão 11 (Você gostaria de participar de conversas com os técnicos / Engenheiros das obras?).

Gostaria de Participar * QuemDeveDecidir

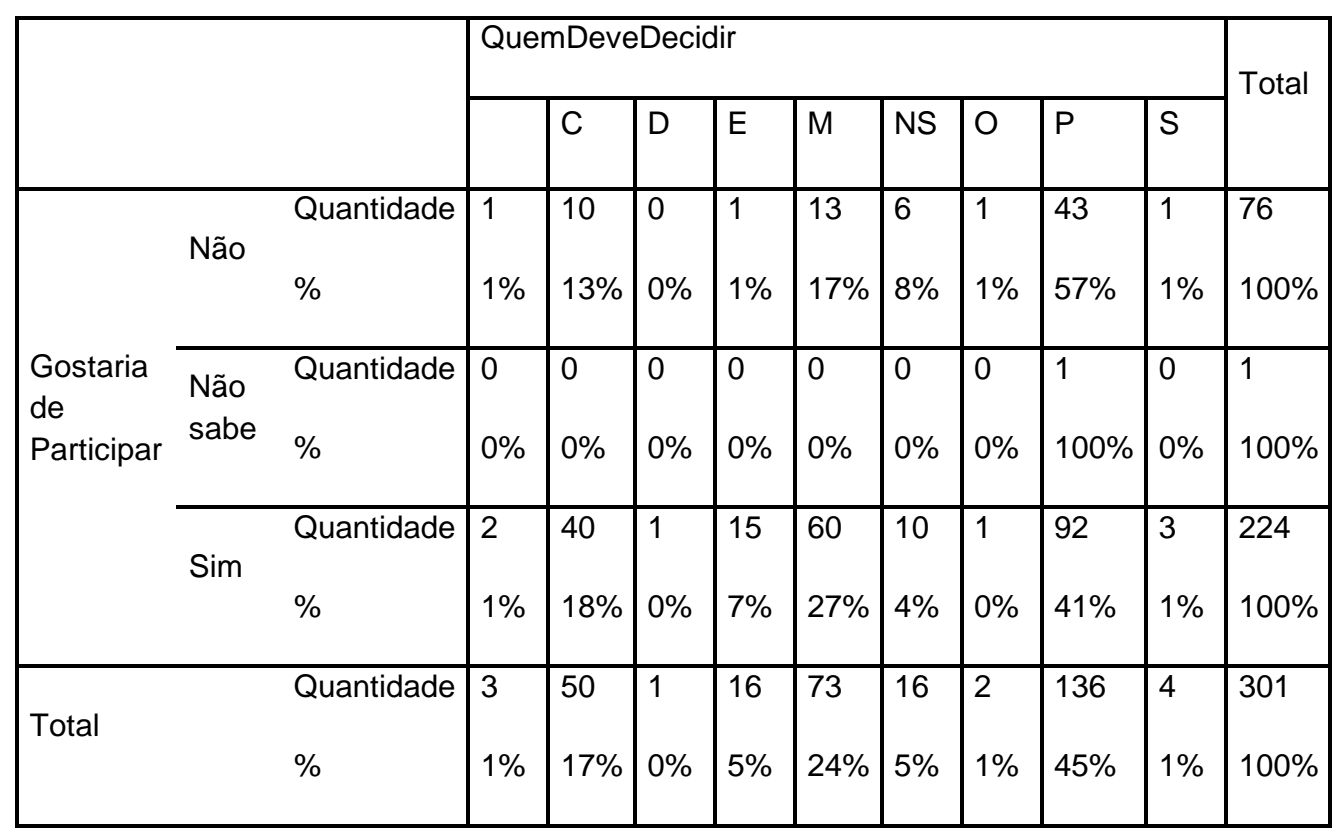

A partir desta informação, será construído um modelo de regressão logística para identificar os fatores que influenciam o fato do entrevistado acreditar que quem deve decidir sobre as obras contra inundação são os moradores $(\mathrm{M})$ ou o conjunto de moradores, técnicos e poder público (C) e querer participar das decisões sobre as obras. Para isto foi construída uma variável resposta binária, em que $\mathrm{Y}_{\mathrm{i}}=1$ para casos em que o entrevistado respondeu $\mathrm{M}$ ou $\mathrm{C}$ na questão 5 e $S$ na questão 11 e $Y_{i}=0$ para todos os outros casos.

Variáveis nominais que possuem muitas categorias ou categorias com poucos casos podem ser categorizadas, pois o peso atribuído no modelo a estas variáveis pode distorcer o modelo final. Variáveis contínuas também podem ser categorizadas por conveniência de análise (SICSÚ, 2010). As categorias já existentes nas variáveis foram agrupadas de forma a maximizar a sua capacidade de diferenciar a variável resposta binária já construída. 
A seguir são apresentadas as variáveis categorizadas, assim como a distribuição de frequências de cada categoria relacionadas à resposta binária do modelo. A fim de visualização, somente as variáveis que permaneceram no modelo final são apresentadas.

Tabela 1: Variável Formação

\begin{tabular}{|c|c|c|c|c|}
\hline \multirow[b]{2}{*}{ Formação } & \multicolumn{3}{|c|}{ Variável resposta binária } & \multirow[b]{2}{*}{$\begin{array}{l}\text { Percentual } \\
\text { na linha }\end{array}$} \\
\hline & Outros & $\begin{array}{l}\text { C e M (questão 5) } \\
\text { e S (questão 11) }\end{array}$ & Total & \\
\hline $\begin{array}{l}\text { Sem escolarização ou 10 grau } \\
\text { incompleto }\end{array}$ & 57 & 9 & 66 & $14 \%$ \\
\hline Até $2^{\circ}$ grau completo & 34 & 13 & 47 & $28 \%$ \\
\hline $\begin{array}{l}\text { Curso técnico, até universitário } \\
\text { completo e sem resposta }\end{array}$ & 110 & 78 & 188 & $41 \%$ \\
\hline Total & 201 & 100 & 301 & \\
\hline
\end{tabular}

Tabela 2: Pergunta 4

\begin{tabular}{|c|c|c|c|c|}
\hline \multirow[b]{2}{*}{$\begin{array}{l}\text { Sabe se } \\
\text { proteger }\end{array}$} & \multicolumn{2}{|c|}{ Variável resposta binária } & \multirow[b]{2}{*}{ Total } & \multirow[b]{2}{*}{$\begin{array}{l}\text { Percentual } \\
\text { na linha }\end{array}$} \\
\hline & Outros & $\begin{array}{l}\text { C e M (questão 5) } \\
\text { e S (questão 11) }\end{array}$ & & \\
\hline Sim & 137 & 60 & 197 & $30 \%$ \\
\hline $\begin{array}{l}\text { Não e sem } \\
\text { resposta }\end{array}$ & 64 & 40 & 104 & $38 \%$ \\
\hline Total & 201 & 100 & 301 & \\
\hline
\end{tabular}

Tabela 3: Pergunta 6

\begin{tabular}{|c|c|c|c|c|}
\hline \multirow[b]{2}{*}{$\begin{array}{l}\text { Seria capaz de } \\
\text { dar sua opinião }\end{array}$} & \multicolumn{2}{|c|}{ Variável resposta binária } & \multirow[b]{2}{*}{ Total } & \multirow[b]{2}{*}{$\begin{array}{l}\text { Percentual } \\
\text { na linha }\end{array}$} \\
\hline & Outros & $\begin{array}{l}\text { C e M (questão 5) } \\
\text { e S (questão 11) }\end{array}$ & & \\
\hline Sim & 106 & 18 & 124 & $15 \%$ \\
\hline Não e não sabe & 95 & 82 & 177 & $46 \%$ \\
\hline Total & 201 & 100 & 301 & \\
\hline
\end{tabular}

Tabela 4: Pergunta 8

\begin{tabular}{lllll} 
& \multicolumn{2}{l}{ Variável resposta binária } & \\
\cline { 2 - 4 } $\begin{array}{l}\text { Já estiveram } \\
\begin{array}{l}\text { Educadores } \\
\text { Ambientais para } \\
\text { explicar sobre }\end{array}\end{array}$ & & & \\
Os piscinões & Outros & $\begin{array}{l}\text { C e M (questão 5) } \\
\text { e S (questão 11) }\end{array}$ & Total & $\begin{array}{l}\text { Percentual } \\
\text { na linha }\end{array}$ \\
\hline Sim & 193 & 96 & 289 & $33 \%$ \\
Não & 8 & 4 & 12 & $33 \%$ \\
\hline Total & 201 & 100 & 301 & \\
\hline
\end{tabular}




\section{Modelo de Regressão Logística}

A regressão logística é uma técnica estatística utilizada para descrever o comportamento entre uma variável dependente binária e variáveis independentes. Identifica o efeito destas variáveis independentes sobre a probabilidade da ocorrência do evento de interesse.

Variáveis correlacionadas não podem ser utilizadas juntas no modelo, pois geram problemas de estimação. Para verificar se as variáveis finais possuem associação, foi realizado um teste qui-quadrado de associação para todas as variáveis explicativas selecionadas duas a duas. As variáveis, a estatística, os graus de liberdade e o nível descritivo de cada teste das variáveis com associação, utilizando uma confiança de $99 \%$, são apresentadas na tabela 5.

Tabela 5 - Testes qui-quadrado de associação

\begin{tabular}{|c|c|c|c|c|}
\hline & & Estatística & & \\
\hline Variável 1 & Variável 2 & $\begin{array}{l}\text { Qui- } \\
\text { quadrado }\end{array}$ & $\begin{array}{l}\text { Graus de } \\
\text { Liberdade }\end{array}$ & $\begin{array}{l}\text { Nível } \\
\text { Descritivo }\end{array}$ \\
\hline Estragos & ForaDent & 426,5671528 & 4 & $5,04787 \mathrm{E}-91$ \\
\hline Estragos & Obras & 326,4194258 & 4 & 2,15934E-69 \\
\hline Perg7 & Perg7 & 301 & 1 & $1,99483 \mathrm{E}-67$ \\
\hline ForaDent & Inundacao & 301 & 2 & $4,35192 \mathrm{E}-66$ \\
\hline Estragos & Inundacao & 293,2689503 & 2 & 2,0771E-64 \\
\hline ForaDent & Sabia & 309,6717706 & 6 & $6,91755 \mathrm{E}-64$ \\
\hline ForaDent & Obras & 300,6452803 & 4 & 7,86341E-64 \\
\hline Estragos & Sabia & 305,3061188 & 6 & $5,96609 \mathrm{E}-63$ \\
\hline Obras & Sabia & 297,8261215 & 6 & $2,39082 \mathrm{E}-61$ \\
\hline Estragos & PiorMelhor & 305,4300839 & 8 & 2,87576E-61 \\
\hline ForaDent & PiorMelhor & 304,5985152 & 8 & $4,32312 \mathrm{E}-61$ \\
\hline Obras & PiorMelhor & 296,1872534 & 8 & 2,6671E-59 \\
\hline PiorMelhor & Sabia & 305,1877217 & 12 & $3,82123 \mathrm{E}-58$ \\
\hline Perg1_CatNat & Perg2_MACH & 216,8603527 & 1 & 4,37767E-49 \\
\hline Obras & Perg4_Orig & 64,87795777 & 2 & $8,16452 \mathrm{E}-15$ \\
\hline AnosLocalOrig & MoradorComer & 58,19549383 & 1 & $2,37322 \mathrm{E}-14$ \\
\hline AnosLocalOrig & Proprietario & 49,23349754 & 1 & $2,27237 \mathrm{E}-12$ \\
\hline MoradorComer & Proprietario & 40,61500855 & 1 & $1,85377 \mathrm{E}-10$ \\
\hline FormacaoOrig & Local3 & 47,42671238 & 4 & $1,24266 \mathrm{E}-09$ \\
\hline
\end{tabular}




\begin{tabular}{|c|c|c|c|c|}
\hline Estragos & Perg4_Orig & 35,74958132 & 2 & $1,72614 \mathrm{E}-08$ \\
\hline Sabia & VezesAnoOrig & 38,82360289 & 3 & $1,89162 \mathrm{E}-08$ \\
\hline Local3 & MoradorComer & 34,94084279 & 2 & $2,58638 \mathrm{E}-08$ \\
\hline ForaDent & Perg4_Orig & 31,7708413 & 2 & $1,26197 \mathrm{E}-07$ \\
\hline ForaDent & VezesAnoOrig & 30,29190856 & 2 & $2,6436 \mathrm{E}-07$ \\
\hline Obras & VezesAnoOrig & 29,93946206 & 2 & $3,15303 \mathrm{E}-07$ \\
\hline Estragos & VezesAnoOrig & 28,90087993 & 2 & $5,29973 \mathrm{E}-07$ \\
\hline Obras & Perg9 & 28,35075392 & 2 & $6,9777 \mathrm{E}-07$ \\
\hline Perg9 & PiorMelhor & 33,80484868 & 4 & $8,17113 \mathrm{E}-07$ \\
\hline PiorMelhor & VezesAnoOrig & 33,55920086 & 4 & $9,17559 \mathrm{E}-07$ \\
\hline Perg4_Orig & Sabia & 30,61352618 & 3 & $1,02519 \mathrm{E}-06$ \\
\hline Perg4_Orig & PiorMelhor & 32,59948133 & 4 & $1,44262 \mathrm{E}-06$ \\
\hline FaixaEtariaOrig & Perg2_MACH & 26,29308567 & 2 & $1,95222 \mathrm{E}-06$ \\
\hline AnosLocalOrig & FaixaEtariaOrig & 26,12561512 & 2 & $2,12273 \mathrm{E}-06$ \\
\hline Local3 & PiorMelhor & 39,19925158 & 8 & $4,51415 \mathrm{E}-06$ \\
\hline Estragos & Perg3_catNat & 34,14970077 & 6 & $6,2941 \mathrm{E}-06$ \\
\hline Perg10 & Perg8 & 25,4749099 & 3 & $1,22838 \mathrm{E}-05$ \\
\hline FaixaEtariaOrig & FormacaoOrig & 27,24325926 & 4 & $1,775 \mathrm{E}-05$ \\
\hline MoradorComer & Perg6_SimNao & 17,57300745 & 1 & $2,76485 \mathrm{E}-05$ \\
\hline ForaDent & Perg3_catNat & 29,28885793 & 6 & 5,36371E-05 \\
\hline ForaDent & Perg9 & 19,63996797 & 2 & $5,43545 \mathrm{E}-05$ \\
\hline Obras & Perg3_catNat & 28,45883131 & 6 & 7,69925E-05 \\
\hline Perg6_SimNao & Perg9 & 15,5198295 & 1 & $8,16443 \mathrm{E}-05$ \\
\hline Estragos & Perg9 & 18,31721698 & 2 & 0,000105309 \\
\hline Perg4_Orig & Perg9 & 14,29607559 & 1 & 0,00015619 \\
\hline Perg3_catNat & PiorMelhor & 37,86146447 & 12 & 0,000161776 \\
\hline Perg3_catNat & Sabia & 32,14620774 & 9 & 0,000187866 \\
\hline FaixaEtariaOrig & Perg1_CatNat & 16,90409098 & 2 & 0,000213463 \\
\hline Perg10 & Perg7 & 19,01139038 & 3 & 0,00027192 \\
\hline Perg9 & Sabia & 17,4159912 & 3 & 0,000580304 \\
\hline
\end{tabular}




\begin{tabular}{lllll} 
AltAgua & Perg8 & 52,60347324 & 24 & 0,000652325 \\
FaixaEtariaOrig & MoradorComer & 14,39684059 & 2 & 0,000747766 \\
Perg9 & VezesAnoOrig & 10,75541502 & 1 & 0,001039746 \\
FaixaEtariaOrig & Perg3_catNat & 21,89063402 & 6 & 0,001267382 \\
FormacaoOrig & MoradorComer & 12,54012897 & 2 & 0,001892107 \\
Local3 & Perg9 & 11,70921226 & 2 & 0,002866664 \\
Perg3_catNat & Perg4_Orig & 13,90216022 & 3 & 0,0030414 \\
Perg6_SimNao & Perg8 & 8,755850097 & 1 & 0,003086105 \\
Perg6_SimNao & Proprietario & 8,739062027 & 1 & 0,003114647 \\
FaixaEtariaOrig & Perg4_Orig & 11,43980455 & 2 & 0,003280031 \\
Perg7 & Perg8 & 8,041590249 & 1 & 0,004571539 \\
FormacaoOrig & VezesAnoOrig & 10,16130825 & 2 & 0,006215842 \\
Sabia & Sexo & 11,94919804 & 3 & 0,007559228 \\
AltAgua & VezesAnoOrig & 43,70153084 & 24 & 0,008262568 \\
FaixaEtariaOrig & Inundacao & 9,315444808 & 2 & 0,009488048 \\
Perg7 & Perg9 & 6,669877514 & 1 & 0,009805593 \\
\hline
\end{tabular}

Serão retiradas do modelo as variáveis com associação. Para escolher qual, foi realizado um teste qui-quadrado das variáveis com a variável resposta. Os campos com menor maior nível descritivo foram excluídos, um a um, até não restar nenhuma combinação de variáveis com associação. As variáveis restantes foram FORMACAOORIG, PERG10, PERG3_CATNAT, PERG6_SIMNAO e TPOBAIXAR.

Foi aplicado o modelo de regressão logística binária no software SAS 9.2 utilizando o método de seleção de variáveis Backward. Assim, todas as variáveis se iniciam no modelo e, em cada passo, é retirada a variável com o maior nível descritivo.

Após 2 passos o modelo selecionou 2 variáveis significativas. As variáveis categóricas, para construção do modelo, são recodificadas como variáveis binárias, criadas da forma apresentada na tabela 6 .

Tabela 6 - Variáveis finais recodificadas

Variável Categoria

Binária 1 Binária 2

\begin{tabular}{llll}
\hline FORMACAOORIG & Até primeiro grau incompleto & 1 & 0 \\
& Até segundo grau incompleto & 0 & 1
\end{tabular}




\begin{tabular}{llll} 
& Até universitário & 0 & 0 \\
PERG6_SIMNAO & Sim & 1 \\
& Não e não sabe & 0 \\
\hline
\end{tabular}

A tabela 7 apresenta os resultados do modelo logístico, contendo a variável, a categoria, o coeficiente, o erro padrão do coeficiente, a estatística Wald e o nível descritivo. As variáveis selecionadas foram: formação e o fato do respondente acreditar que é capaz de dar sua opinião sobre as obras. O respondente que está na primeira categoria de formação, ou seja, até o primeiro grau incompleto tem menor chance de querer participar que os respondentes que tem até o segundo grau incompleto que, por sua vez, tem menor chance de querer participar que os respondentes que tem até universitário superior. Em outras palavras, quanto maior a escolaridade mais ele quer participar. Quem acredita que é capaz de dar opinião tem mais chance de querer participar das decisões sobre obras.

Tabela 7- Modelo de regressão logística

\begin{tabular}{|c|c|c|c|c|c|}
\hline Variável & Categoria & Coeficiente & $\begin{array}{l}\text { Erro } \\
\text { padrão }\end{array}$ & $\begin{array}{l}\text { Estatística } \\
\text { Wald }\end{array}$ & $\begin{array}{l}\text { Nível } \\
\text { Descritivo }\end{array}$ \\
\hline Intercepto & & $-1,4105$ & 0,2678 & 277.363 & $<, 0001$ \\
\hline FORMACAOORIG & $\begin{array}{l}\text { Até primeiro grau } \\
\text { incompleto }\end{array}$ & - 1,4807 & 0,4028 & 135.150 & 0,0002 \\
\hline FORMACAOORIG & $\begin{array}{l}\text { Até segundo grau } \\
\text { incompleto }\end{array}$ & $-0,7002$ & 0,3773 & 34.450 & 0,0634 \\
\hline FORMACAOORIG & $\begin{array}{l}\text { Até universitário } \\
\text { superior }\end{array}$ & 0 & & & \\
\hline PERG6_SIMNAO & Sim & 1,6263 & 0,3036 & 286.982 & $<, 0001$ \\
\hline PERG6_SIMNAO & Não e não sabe & 0 & & & \\
\hline
\end{tabular}

A tabela de classificação resultante do modelo é utilizada para verificar sua capacidade de previsão. $O$ ponto de corte utilizado foi de 0,33 , escolhido com base no percentual de respostas $Y_{i}=1$ verdadeiro da base. 0 modelo classifica bem $67,4 \%$ do total de respondentes, sendo classifica corretamente $73 \%$ das observações $Y_{i}=1$ e $64,7 \%$ das observações $Y_{i}=0$. A tabela 8 apresenta essa matriz de classificação.

Tabela 8 - Matriz de classificação 


\begin{tabular}{|ll|l|l|l|}
\hline \multirow{2}{*}{ Observados } & \multicolumn{2}{l|}{ Previstos } \\
\cline { 3 - 5 } & & \multicolumn{2}{l|}{ Perg5e11_CatNat } & \multicolumn{2}{l|}{$\begin{array}{l}\text { Percentual de } \\
\text { Acerto (\%) }\end{array}$} \\
\cline { 3 - 5 } & & 0 & 1 & \\
\hline Perg5e11_CatNat & 0 & 130 & 71 & $64,7 \%$ \\
& 1 & 27 & 73 & $73,0 \%$ \\
Percentual de Acerto Geral & & & $67,4 \%$ \\
\hline
\end{tabular}

SICSÚ, A. L. Credit Scoring: desenvolvimento, implantação, acompanhamento. São Paulo: Blucher, 2010. 


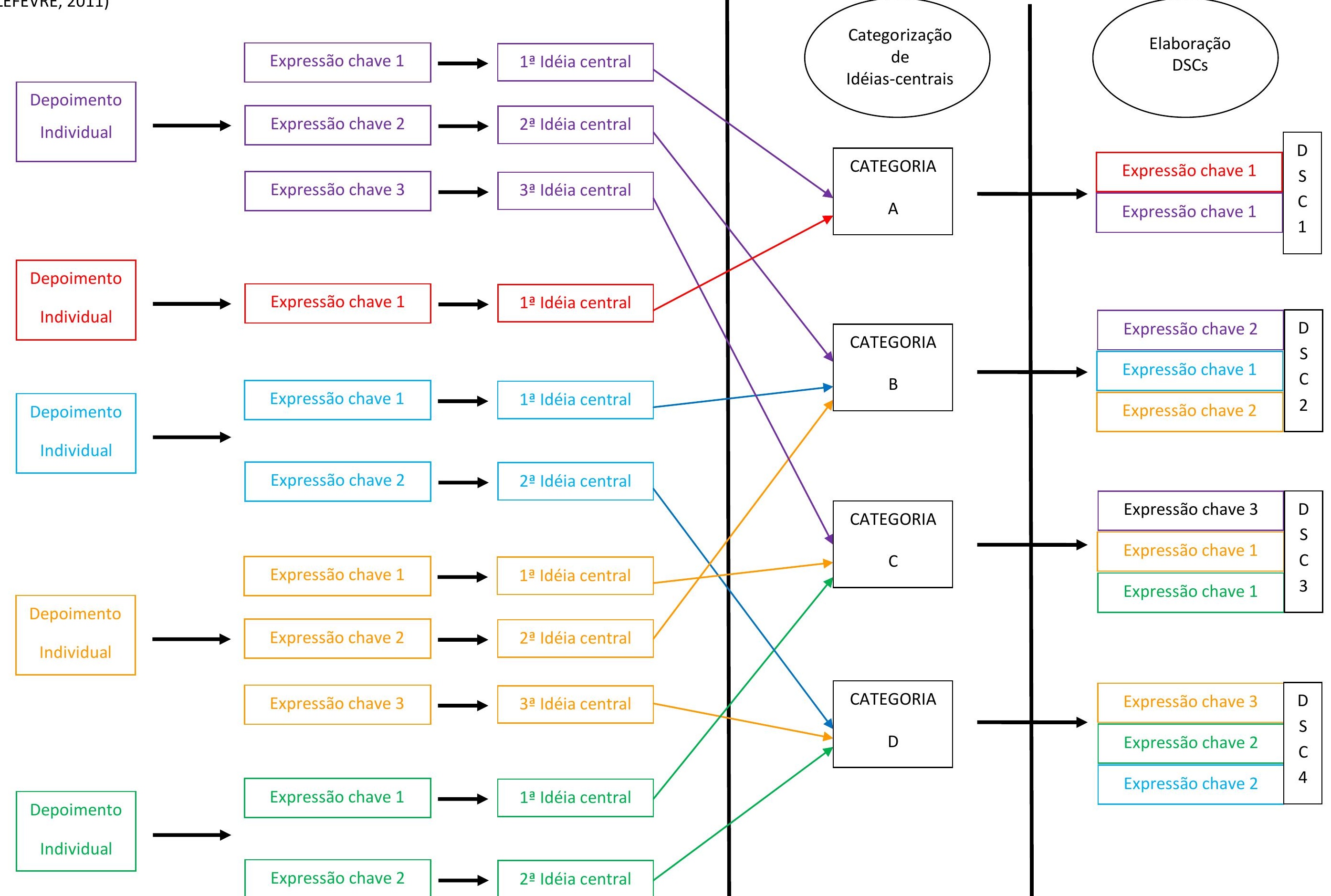





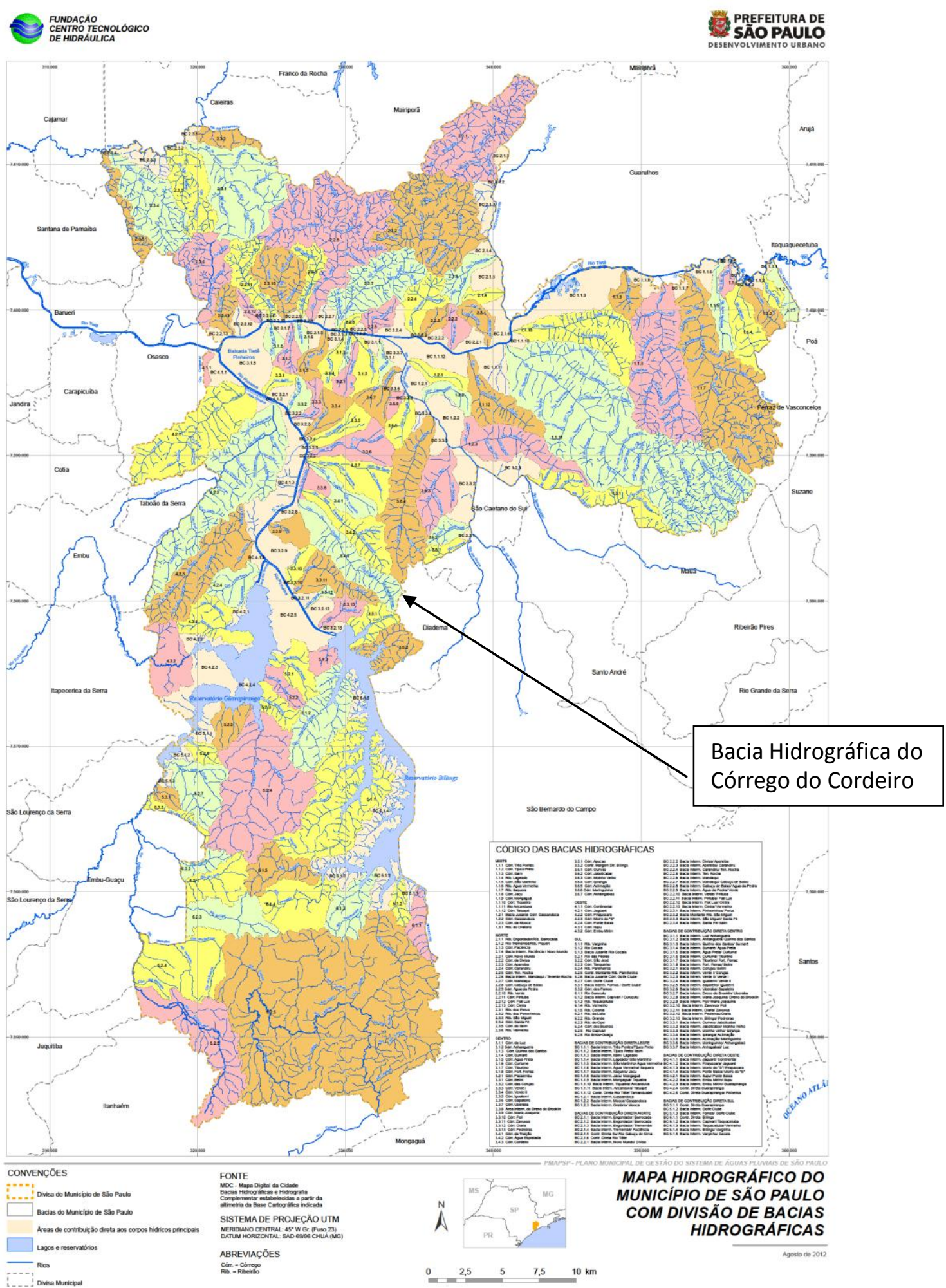

ANEXO 11

Mapa 1 - Mapa Hidrográfico do Município de São Paulo com divisão de Bacias Hidrográficas, indicando a Bacia Hidrográfica do Córrego do Cordeiro.

Fonte: Fundação Centro de Tecnologia Hidráulica - FCTH (2012) 